\title{
FLEXURE STRENGTH PREDICTION OF CLOSURE STRIP BETWEEN PREFABRICATED DECK SLABS SUPPORTED OVER BRIDGE GIRDERS INCORPORATING GFRP BARS AND UHPFRC
}

\author{
By \\ Mohtady Moataz Sherif \\ B.Eng., The British University in Egypt, Egypt, 2011
}

\author{
A thesis \\ presented to Ryerson University \\ in partial fulfillment of the \\ requirements for the degree of \\ Master of Applied Science \\ in the Program of \\ Civil Engineering
}




\section{Author's Declaration}

I hereby declare that I am the sole author of this thesis. This is a true copy of the thesis, including any required final revisions, as accepted by my examiners. I authorize Ryerson University to lend this thesis to other institutions or individuals for the purpose of scholarly research. I further authorize Ryerson University to reproduce this thesis by photocopying or by other means, in total or in part, at the request of other institutions or individuals for the purpose of scholarly research. I understand that my thesis may be made electronically available to the public. 


\title{
FLEXURE STRENGTH PREDICTION OF CLOSURE STRIP BETWEEN PREFABRICATED DECK SLABS SUPPORTED OVER BRIDGE GIRDERS INCORPORATING GFRP BARS AND UHPFRC
}

\author{
Mohtady Moataz Sherif \\ Ryerson University \\ Master of Applied Science \\ Civil Engineering, 2017
}

\begin{abstract}
Glass fiber reinforced polymer (GFRP) bars are used in bridge decks to overcome the problem of corrosion of steel bars and concrete spalling. However, design guidelines for joints between GFRPreinforced precast deck panels supported over girders for accelerated bridge replacement is as yet unavailable. The proposed research investigates the use of GFRP bars in the closure strip between jointed precast deck panels, which is filled with ultra-high performance fiber-reinforced concrete (UHPFRC). Four different bar splice lengths in the joint were considered in this study, namely: 75, 105, 135 and $165 \mathrm{~mm}$, with bar splice spacing taken as 0, 75 and $100 \mathrm{~mm} .27$ specimens were constructed and tested to-collapse to determine their structural behavior and load carrying capacity. Correlation between experimental findings and available design equations for moment and shear capacities was conducted, leading to recommendations for the use of the proposed joints between precast deck panels in slab-on-girder bridges.
\end{abstract}




\section{Acknowledgements}

The author would like to express his appreciation to his supervisor Dr. Khaled Sennah, for his advice, guidance and encouragement throughout the execution of this research program.

The author would also like to express his deepest appreciation to his parents for all the support, patience, encouragement, and guidance, throughout every stage of his life including this research. The author would like to express his sincerely thanks to the Civil Engineering Department, the technical staff, and the undergraduate research assistants for their help throughout the execution of this research program.

The author also would like to thank and acknowledge Fiberline Composites Canada Inc., Lafarge Canada Inc. and CRH Canada Group Inc. for providing the material for this research.

Finally, the author is grateful to his family, colleagues, and friends for their support and encouragement throughout this work. 


\section{Table of Contents}

Author's Declaration ................................................................................................................................. ii

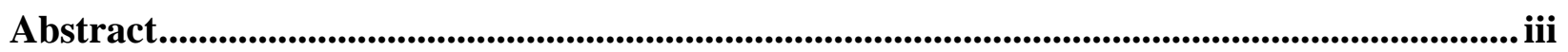

Acknowledgements ........................................................................................................................... iv

List of Tables ......................................................................................................................... vii

List of Figures........................................................................................................................................ viii

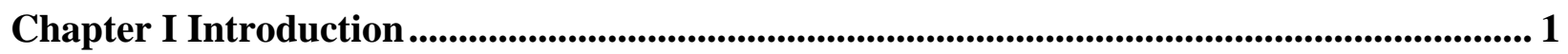

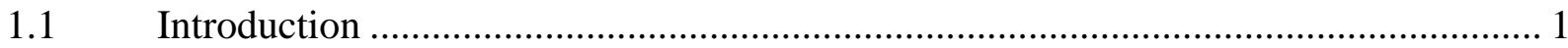

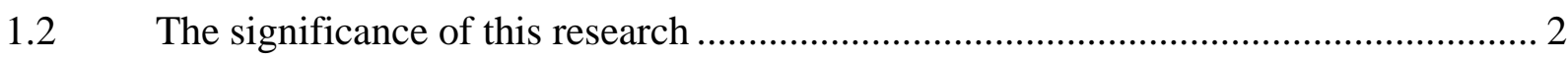

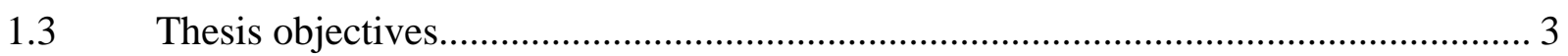

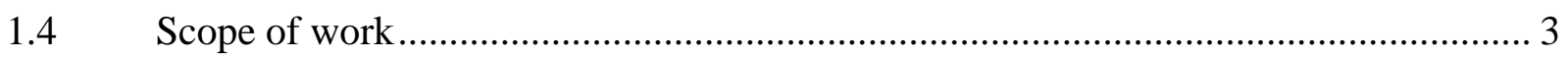

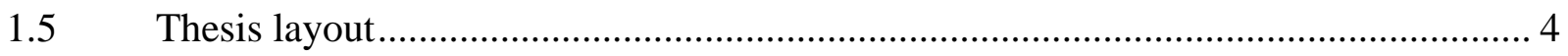

Chapter II Literature Review .......................................................................................................................... 5

2.1 FRP technology and its use in structural engineering ............................................ 5

2.2 Capacity of GFRP bars reinforced concrete ……...................................................... 6

2.2.1 Flexural capacity of GFRP reinforced concrete ………........................................... 7

2.2.2 Shear capacity of GFRP bars reinforced concrete.................................................. 9

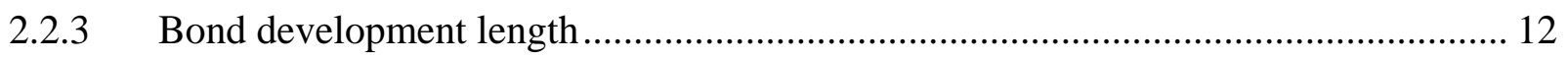

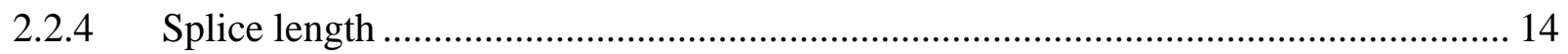

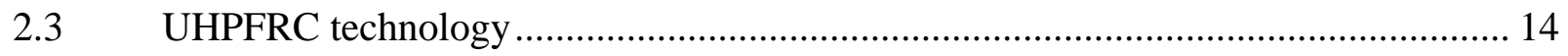

2.4 Flexural capacity of UHPFRC section …………........................................... 15

2.5 Development length of GFRP bars in UHPFRC .................................................. 17

2.6 Static analysis of concrete deck slabs ................................................................... 17

2.7 Joints between prefabricated deck Slabs ............................................................. 19

Chapter III Experimental Program ....................................................................................................... 25

3.1 Experimental program and test matrix ………................................................... 25

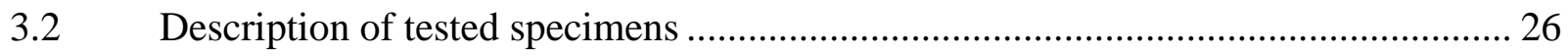

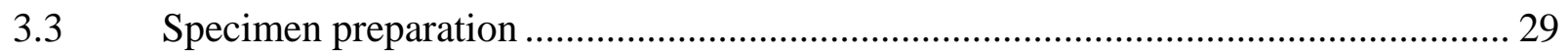

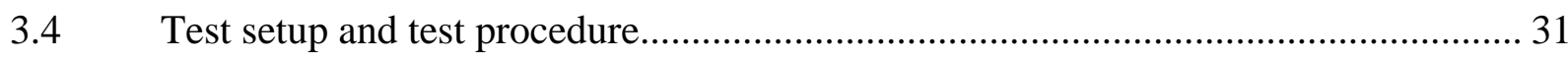

Chapter IV Experimental Results ...................................................................................................... 33

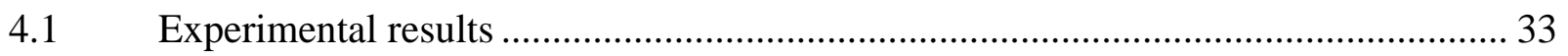

4.1.1 Cracking pattern, ultimate capacity, and failure modes ............................................. 33

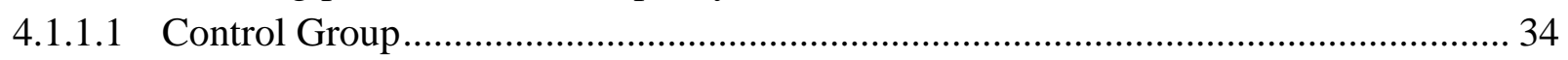

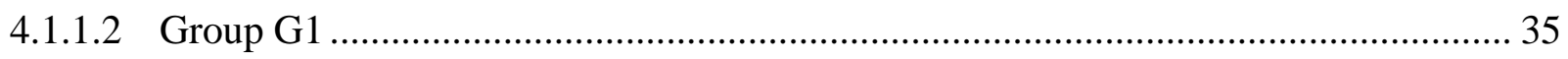

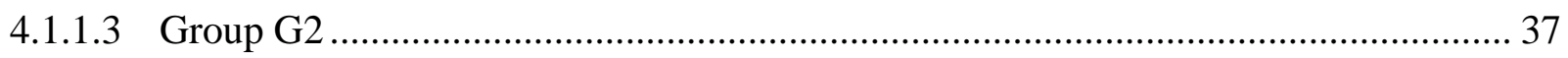




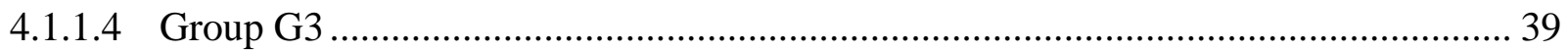

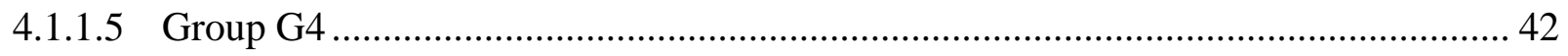

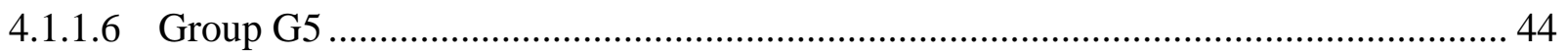

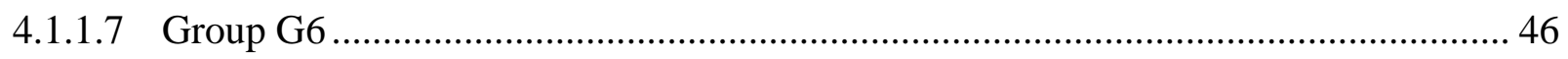

4.1.2 Deflection patterns and ultimate strain ............................................................ 48

E.2 Effect of lap splice spacing and joint width ................................................... 49

4.3 Theoretical moment and shear capacities ..................................................... 50

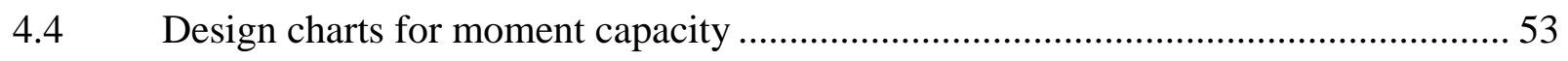

Chapter V Conclusion and Recommendations for Future Research..................................... 55

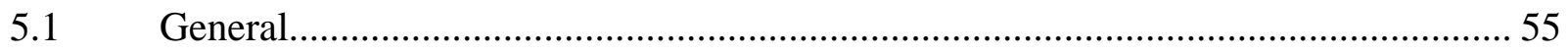

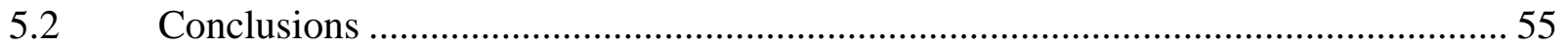

5.3 Recommendation for future research ......................................................... 57

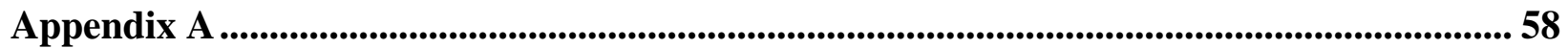

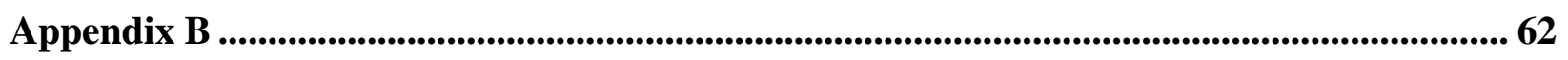

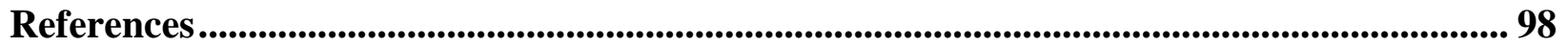

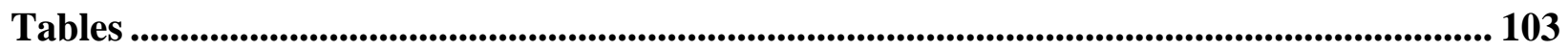

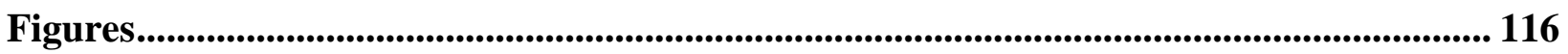




\section{List of Tables}

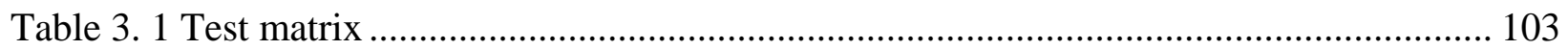

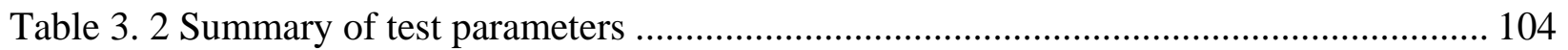

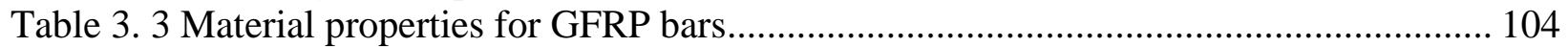

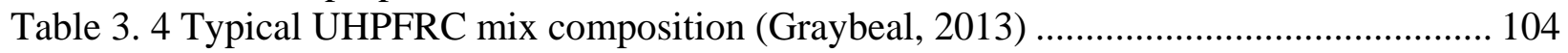

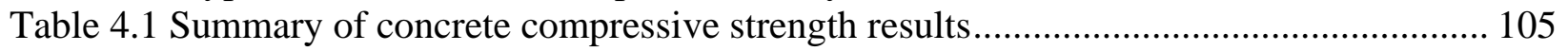

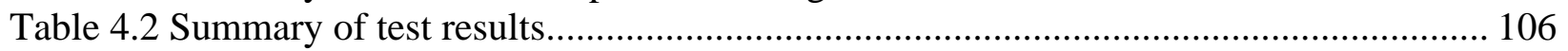

Table 4.3 Summary of experimental bar strains and their correlation with GFRP manufacturer

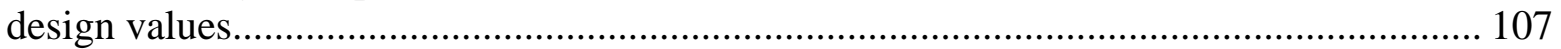

Table 4.4 Summary of experimental ultimate moment, shear and failure modes ....................... 108

Table 4.5 Summary of the concrete and bar strains for group CG, G1 and G2 ........................ 109

Table 4.6 Summary of the top concrete strains and bar strains for group G3 and G4 ................ 110

Table 4.7 Summary of the top concrete strains and bar strains for group G5 and G6............... 111

Table 4.8 Summary of the ultimate load for groups G1, G2 and G3 vs slabs S1 and S3 ........... 112

Table 4.9 Summary of the deflection at $50 \mathrm{kN}$ for groups G1, G2 and G3 vs slabs S1 and S3. 112

Table 4.10 Summary of the maximum bottom bar strains for groups G1, G2 and G3 vs slab S3

Table 4.11 Summary of the maximum concrete top strains for group G1, G2 and G3 vs slab S1

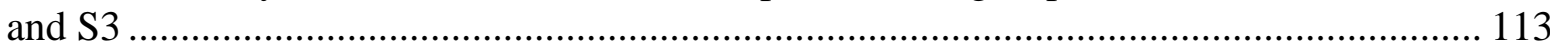

Table 4.12 Summary of experimental moment and shear compared to theoritical values .......... 114

Table 4.13 Specified maximum spacing between girders for jointed slabs............................... 115 


\section{List of Figures}

Figure. 1.1 Views of two types of prefabricated bridge systems to accelerate bridge construction

Figure 2.1 Stress-strain behavior and internal forces of UHPC Section (Aalet et al., 2013) .... 116

Figure 2.2 Stress strain behavior and internal forces of UHPC section: (a) beam section, (b) .. 117 strain distribution, (c) concrete stress, (d) equivalent stress blocks (Hussein, 2015) ................ 117

Figure 3.1 Geometry and dimensions of the shear key................................................... 118

Figure 3.2 Dimensions, joint configuration and GFRP bar arrangement for Slab $S_{1}$ and $S_{2}$ in

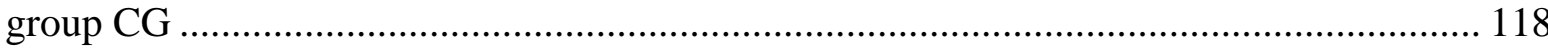

Figure 3.3 Dimensions, joint configuration and GFRP bar arrangement for $\mathrm{Slab}_{3}$ in group CG

Figure 3.4 Dimensions, joint configuration and GFRP bar arrangement for slab in group G1.. 120 Figure 3.5 Dimensions, joint configuration and GFRP bar arrangement for slabs in group G2 121 Figure 3.6 Dimensions, joint configuration and GFRP bar arrangement for slabs in group G3 122 Figure 3.7 Dimensions, joint configuration and bar arrangement for slabs in groups G4 and G6

Figure 3.8 Dimensions, joint configuration and GFRP bar arrangement for slabs in groups G5124 Figure 3.9 Location of strain gauges on bottom GFRP bars............................124 Figure 3.10 3D view of a typical jointed slab showing the locations of Concrete strain gauges 125 Figure 3.11 locations of Concrete strain gauges across the slab thickness............................ 125

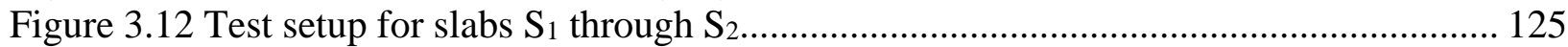

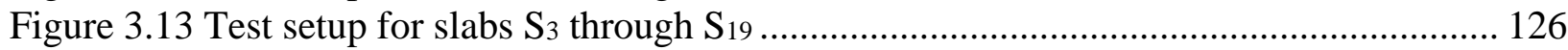

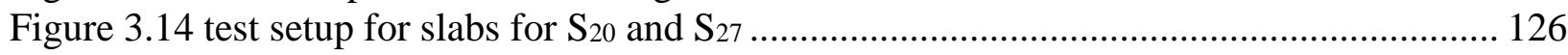

Figure 3.15 GFRP view of bars delivered by the manufacturer cut to size and tagged............. 127 Figure 3.16 View of the GFRP bars tied with zip ties, tagged and ready to be placed in the forms

Figure 3.17 View of the inner form for slab $\mathrm{S}_{1}$ during the assembly of GFRP bars over the seats

Figure 3.18 View of the inner form for slab $\mathrm{S}_{3}$ showing GFRP bars assembled and placed over

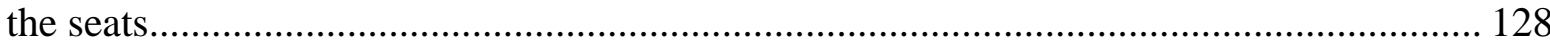

Figure 3.19 View of the inner form for slab $\mathrm{S}_{1}$ showing GFRP bars assembled and placed over

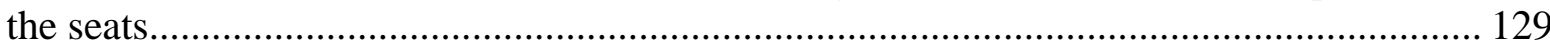

Figure 3.20 View of the inner form for the slab with $50 \mathrm{~mm}$ spliced bar offset at the joint ...... 129

Figure 3.21 View of the inner form for the slab with equally spaced spliced bars .................. 130 Figure 3.22 View of styrofoam boards cut to the dimensions of the joint and ready to be shaped

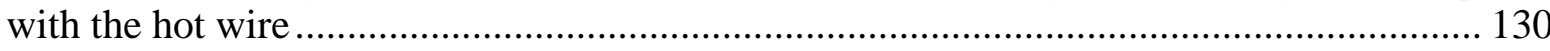

Figure 3.23 3D view of the joint foam cut to size and grooved for the GFRP bars locations ...131

Figure 3.24 Close-up view of a strain gauge attached to the bar ........................................ 131

Figure 3.25 View of a strain gauge attached to the bar .................................................. 132

Figure 3.26 View of the joint foam and bars for the slab with $50 \mathrm{~mm}$ spliced bar offset ......... 132

Figure 3.27 View of the joint foam and bars for the slab with $50 \mathrm{~mm}$ spliced bar offset ......... 133

Figure 3.28 View of the joint foam and bars for the slab with $50 \mathrm{~mm}$ spliced bar offset ......... 133

Figure 3.29 View of the bottom layer of the joint foam for slab $\mathrm{S}_{3}$ with GFRP bars................ 134

Figure 3.30 View of the bottom layer of the joint foam for slab with equal spliced bars ......... 134

Figure 3.31 View of the bottom layer of the joint foam with the slab equally spliced.............. 135 
Figure 3.32 View of the bottom layer of the joint foam for slab with equally spliced bar........ 135

Figure 3.33 View of the joint foam for the slab with equally spliced bars ............................. 136 Figure 3.34 View of the joint foam where all layers of foam were placed and weight placed on

top of the joint to fix it in position till the glue hardened............................................... 136

Figure 3.35 View of slabs $\mathrm{S}_{4}$ and $\mathrm{S}_{5}$ with bar-contacted splice connection before casting ........ 137

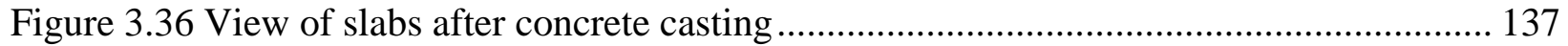

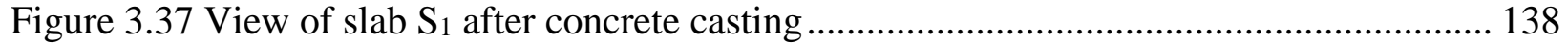

Figure 3.38 View of slab after concrete casting showing the foam for the joint at the mid-span

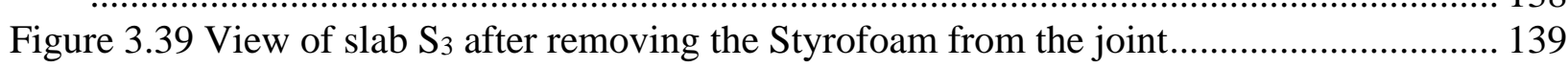

Figure 3.40 View of a cleaned joint after removing the Styrofoam in the joint ...................... 139

Figure 3.41 view of slab $S_{11}$ with $50 \mathrm{~mm}$ bar offset after removing the Styrofoam in the joint 140

Figure 3.42 View of the joint with $50 \mathrm{~mm}$ bar offset after removing the Styrofoam ............... 140

Figure 3.43 View of the shear key with projecting bars .................................................... 141

Figure 3.44 Front view of the shear key with projected GFRP bars..................................... 141

Figure 3.45 View of the joint in slab $\mathrm{S}_{5}$ with contact lap splice during casting the UHPFRC... 142

Figure 3.46 View of a joint during casting the UHPFRC ................................................... 142

Figure 3.47 View of slab $S_{2}$ during casting the UHPFRC ............................................... 143

Figure 3.48 View of a $50 \mathrm{~mm}$ offset spliced joint during casting the UHPFRC ..................... 143

Figure 3.49 View of a $50 \mathrm{~mm}$ offset spliced joint during casting the UHPFRC ..................... 144

Figure 3.50 View of the joint of slab $\mathrm{S}_{3}$ during casting the UHPFRC.................................... 144

Figure 3.51 View of the joint of slab $S_{3}$ during casting the UHPFRC .................................. 145

Figure 3.52 View of the joint of slab $\mathrm{S}_{3}$ during casting the UHPFRC .................................. 145

Figure 3.53 View of demolded slabs ready to be painted and for the application of concrete strain

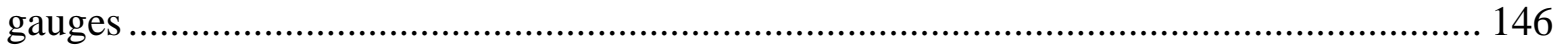

Figure 4.1 View of crack pattern of slab $\mathrm{S}_{1}$ after failure .............................................. 147

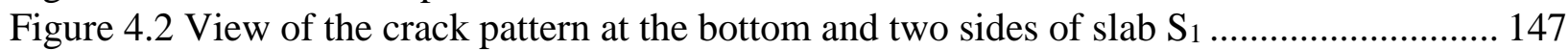

Figure 4.3 Test setup of slab S2 before testing ................................................................ 148

Figure 4.4 View of crack pattern of slab $\mathrm{S}_{2}$ after failure .................................................. 148

Figure 4.5 View of the crack pattern at the bottom and two sides of slab $\mathrm{S}_{2}$...................... 149

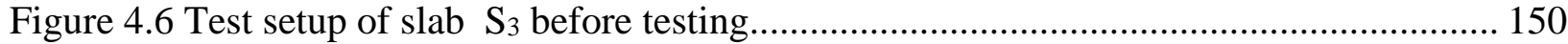

Figure 4.7 View of crack pattern of slab $\mathrm{S}_{3}$ after failure ................................................ 150

Figure 4.8 Close-up view of the flexural cracks at the joint of slab S3 ................................ 151

Figure 4.9 View of the crack pattern at the bottom and two sides of slab $\mathrm{S}_{3}$........................ 151

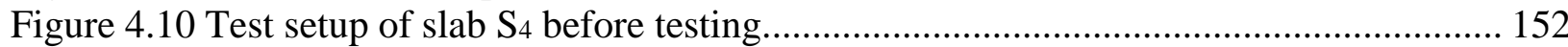

Figure 4.11 View of crack pattern of slab $S_{4}$ after failure ............................................. 152

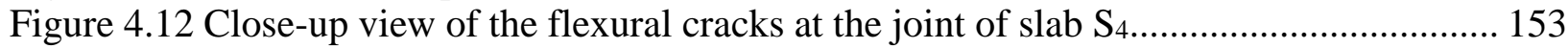

Figure 4.13 View of the crack pattern at the bottom and two sides of slab $\mathrm{S}_{4} \ldots \ldots \ldots \ldots \ldots \ldots \ldots . . \ldots \ldots 3$

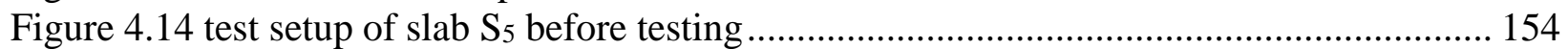

Figure 4.15 View of crack pattern of slab $\mathrm{S}_{5}$ after failure ................................................ 154

Figure 4.16 Close-up view of flexural cracks at the joint of slab $\mathrm{S}_{5}$.................................... 155

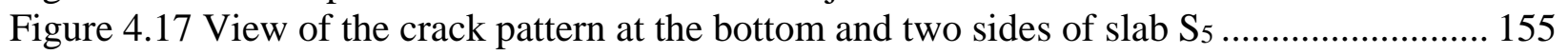

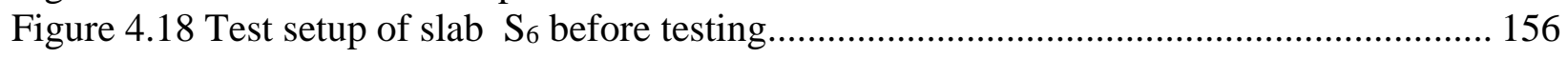

Figure 4.19 View of crack pattern of slab $\mathrm{S}_{6}$ after failure ................................................ 156

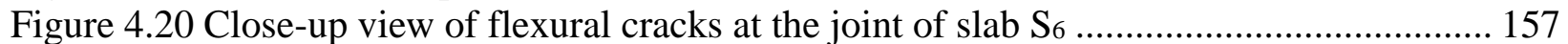

Figure 4.21 View of the crack pattern at the bottom and two sides of slab $\mathrm{S}_{6} \ldots \ldots \ldots \ldots \ldots \ldots \ldots . . . . . . . . . .157$ 


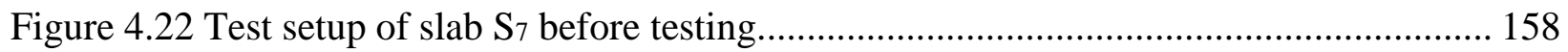

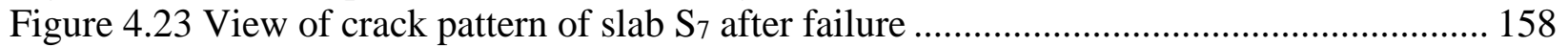

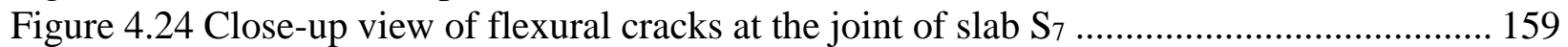

Figure 4.25 View of the crack pattern at the bottom and two sides of slab $\mathrm{S}_{7} \ldots \ldots \ldots \ldots \ldots \ldots \ldots \ldots . . . . . . . . . . .159$

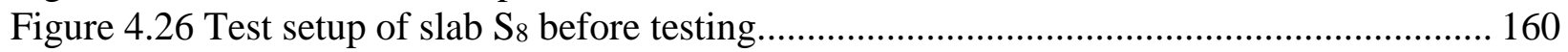

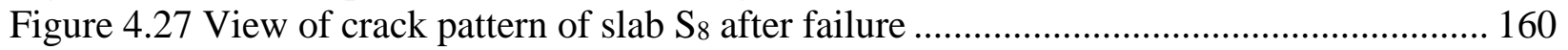

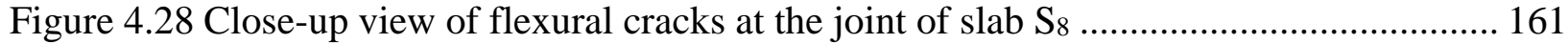

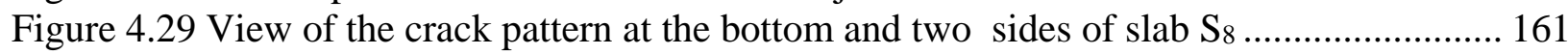

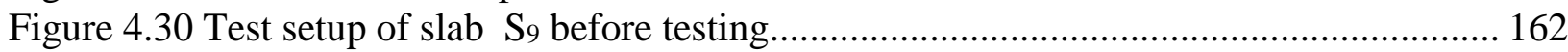

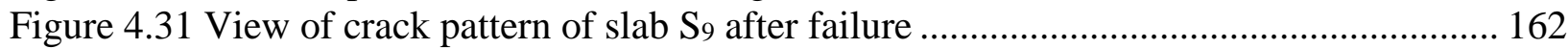

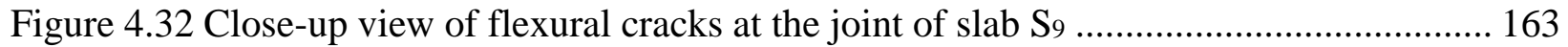

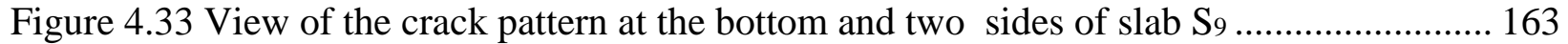

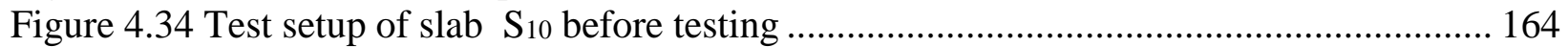

Figure 4.35 View of crack pattern of slab $S_{10}$ after failure .................................................... 164

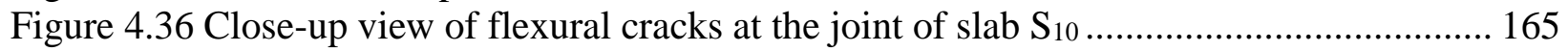

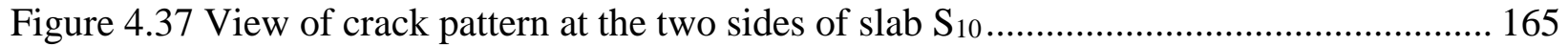

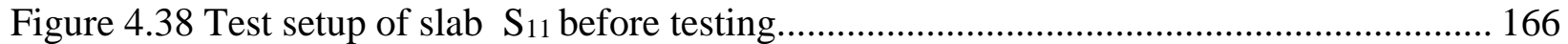

Figure 4.39 View of crack pattern of slab $S_{11}$ after failure..................................................... 166

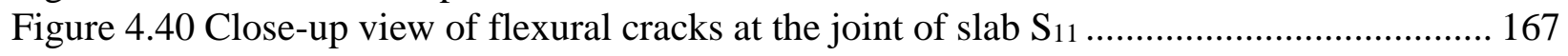

Figure 4.41 View of the crack pattern at the bottom and two sides of slab $S_{11} \ldots \ldots \ldots \ldots . . . \ldots \ldots \ldots . . . . .167$

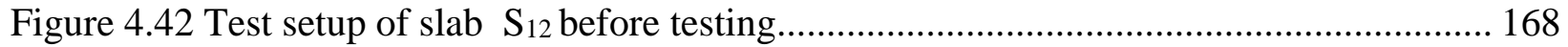

Figure 4.43 View of crack pattern of slab $S_{12}$ after failure ...................................................... 168

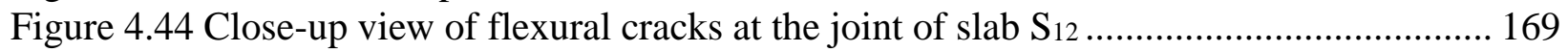

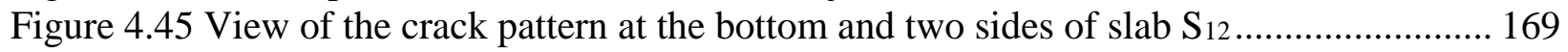

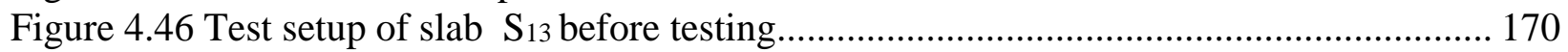

Figure 4.47 View of crack pattern of slab $S_{13}$ after failure .................................................... 170

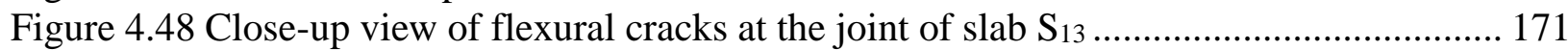

Figure 4.49 View of the crack pattern at the bottom and two sides of slab $S_{13} \ldots \ldots \ldots \ldots \ldots \ldots \ldots \ldots . . . . . .171$

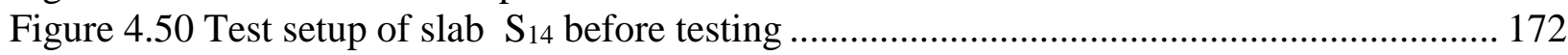

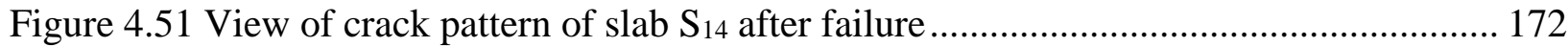

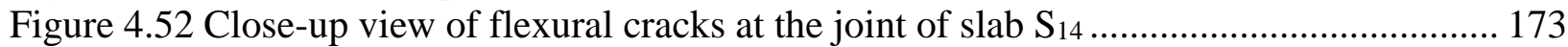

Figure 4.53 View of the crack pattern at the bottom and two sides of slab $S_{14} \ldots \ldots \ldots \ldots \ldots \ldots \ldots \ldots \ldots . . . \ldots 173$

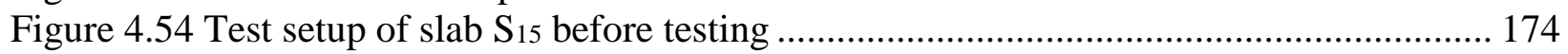

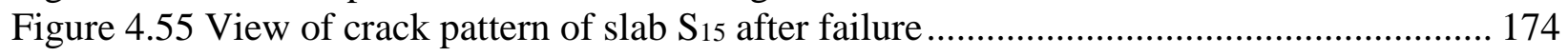

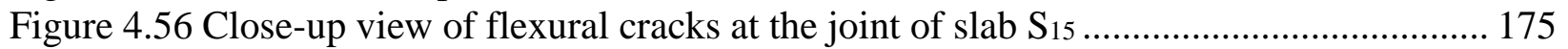

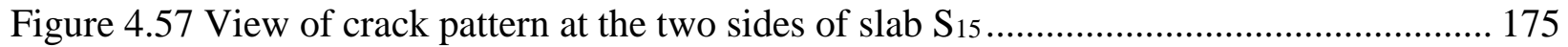

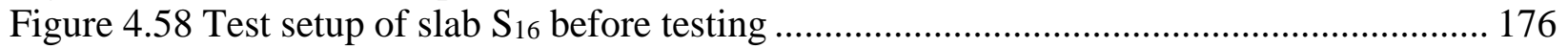

Figure 4.59 View of crack pattern of slab $S_{16}$ after failure ........................................................ 176

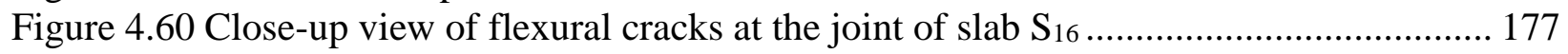

Figure 4.61 View of the crack pattern at the bottom and two sides of slab S16 ........................ 177

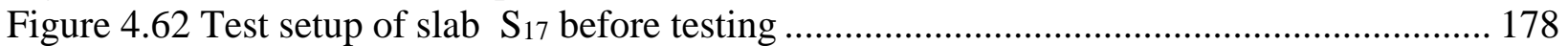

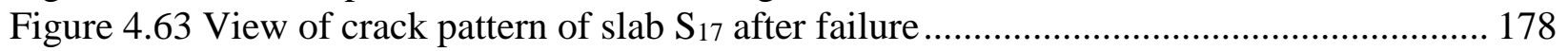

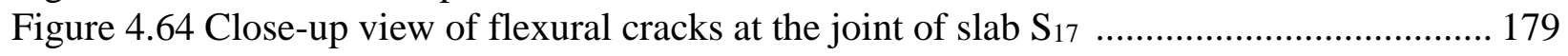

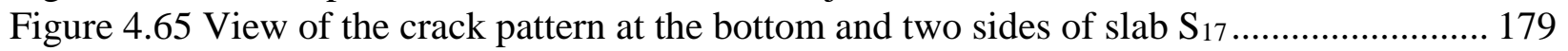

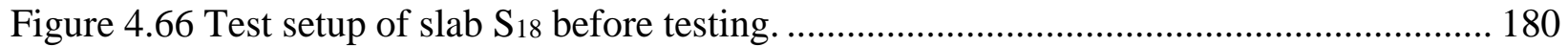

Figure 4.67 View of crack pattern of slab $\mathrm{S}_{18}$ after failure ........................................................ 180 


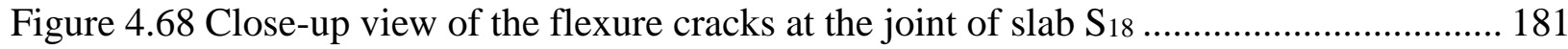

Figure 4.69 View of the crack pattern at the bottom and two sides of slab $\mathrm{S}_{18} \ldots \ldots \ldots \ldots \ldots \ldots \ldots . . . . . . . .181$

Figure 4.70 Test setup of slab $S_{19}$ before testing ........................................................ 182

Figure 4.71 View of crack pattern of slab $S_{19}$ after failure .................................................. 182

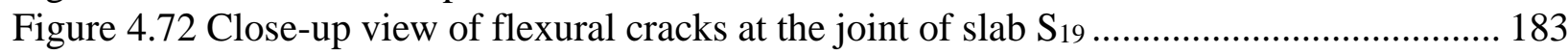

Figure 4.73 View of the crack pattern at the bottom and two sides of slab $\mathrm{S}_{19} \ldots \ldots \ldots \ldots \ldots \ldots \ldots . . . . . . . . .183$

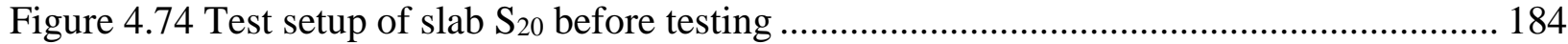

Figure 4.75 View of crack pattern of slab $S_{20}$ after failure ................................................ 184

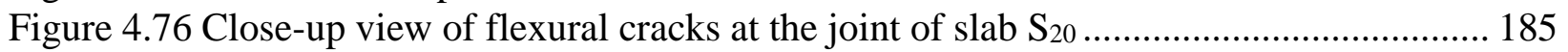

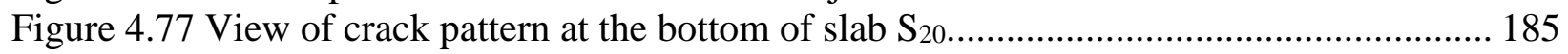

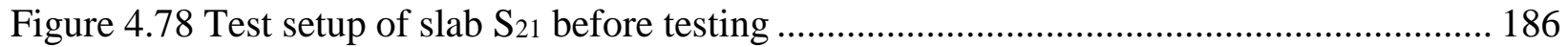

Figure 4.79 View of crack pattern of slab $S_{21}$ after failure .................................................. 186

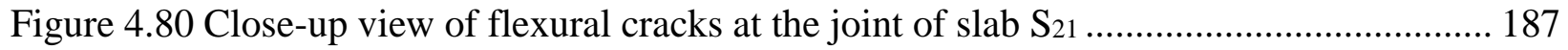

Figure 4.81 View of the crack pattern at the bottom and two sides of slab $S_{21} \ldots \ldots \ldots \ldots \ldots \ldots \ldots . . . . . . . .187$

Figure 4.82 Test setup of slab $\mathrm{S}_{22}$ before testing ......................................................... 188

Figure 4.83 View of crack pattern of slab $S_{22}$ after failure ................................................ 188

Figure 4.84 Close-up view of the flexure cracks at the joint of slab $S_{22}$.............................. 189

Figure 4.85 View of the crack pattern at the bottom and two sides of slab $\mathrm{S}_{22}$...................... 189

Figure 4.86 Test setup of slab $S_{23}$ before testing .............................................................. 190

Figure 4.87 View of crack pattern of slab $S_{23}$ after failure ............................................... 190

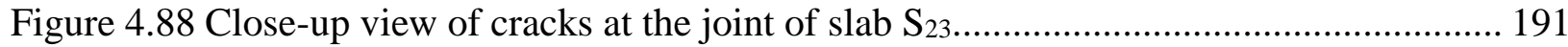

Figure 4.89 View of the crack pattern at the bottom and two sides of slab $\mathrm{S}_{23} \ldots \ldots \ldots \ldots \ldots \ldots \ldots . . . . . . . . .191$

Figure 4.90 Test setup of slab $\mathrm{S}_{24}$ before testing ............................................................. 192

Figure $4.91 \mathrm{View}$ of crack pattern of slab $\mathrm{S}_{24}$ after failure ............................................... 192

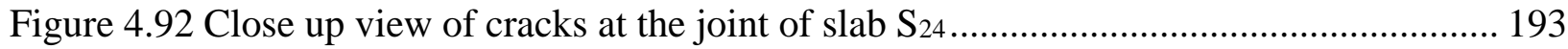

Figure 4.93 View of the crack pattern at the bottom and two sides of slab $\mathrm{S}_{24} \ldots \ldots \ldots \ldots \ldots \ldots \ldots . . . \ldots 193$

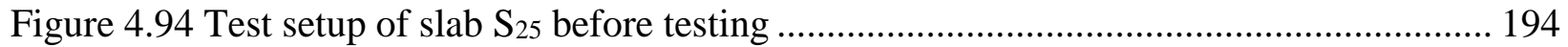

Figure 4.95 View of crack pattern of slab $S_{25}$ after failure .................................................. 194

Figure 4.96 View of the crack pattern at the bottom and two sides of slab $\mathrm{S}_{25} \ldots \ldots \ldots \ldots \ldots \ldots \ldots . . . . . . . . .195$

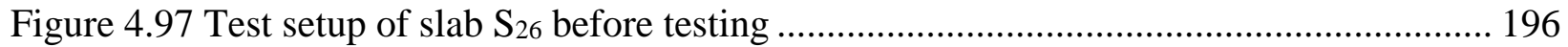

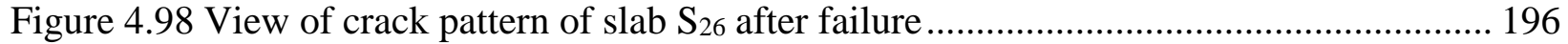

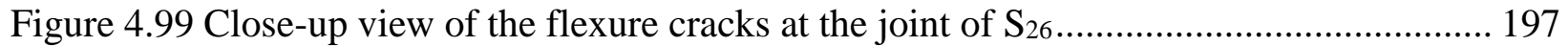

Figure 4.100 View of the crack pattern at the bottom and two sides of slab $\mathrm{S}_{26 \ldots \ldots \ldots \ldots \ldots \ldots \ldots . . . . . . . . . .197}$

Figure 4.101 Test setup of slab $S_{27}$ before testing ........................................................... 198

Figure 4.102 View of crack pattern of slab $S_{27}$ after failure ............................................ 198

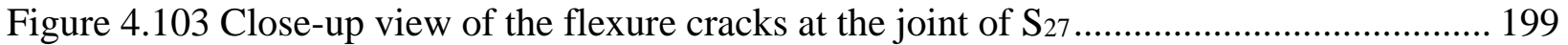

Figure 4.104 View of the crack pattern at the bottom and two sides of slab $\mathrm{S}_{27} \ldots \ldots \ldots \ldots \ldots \ldots . . . . . . . . .199$

Figure 4.105 View of failure modes of slabs from side 1 in group G ................................. 200

Figure 4.106 View of failure modes of slabs from side 2 in group G ................................. 200

Figure 4.107 View of failure modes of slabs from side 1 in group G1 ............................... 201

Figure 4.108 View of failure modes of slabs from side 2 in group G1 ................................. 201

Figure 4.109 View of failure modes of slabs from side 1 in group G2 ................................ 202

Figure 4.110 View of failure modes of slabs from side 2 in group G2 ............................... 202

Figure 4.111 View of failure modes of slabs from side 1 in group G3 ................................ 203

Figure 4.112 View of failure modes of slabs from side 2 in group G3 …........................... 203

Figure 4.113 View of failure modes of slabs from side 1 in group G4 ............................... 204 
Figure 4.114 View of failure modes of slabs from side 2 in group G4 ................................. 204

Figure 4.115 View of failure modes of slabs from side 1 in group G5 ................................ 205

Figure 4.116 View of failure modes of slabs from side 2 in group G5 ................................. 205

Figure 4.117 View of failure modes of slabs from side 1 in group G6 .................................. 206

Figure 4.118 View of failure modes of slabs from side 2 in group G6 ................................ 206

Figure 4.119 View of bar slippage in the UHPFRC joint after taking a core sample and slicing it

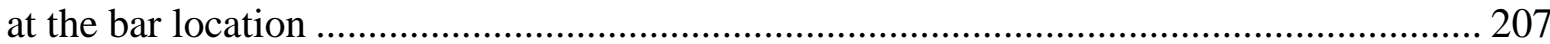

Figure 4.120 View of bar slippage failure due to shearing of the bar ribs ............................ 207

Figure 4.121 Moment vs deflection relationship for slabs in group CG ............................... 208

Figure 4.122 Moment vs deflection relationship for slabs in group G1 .............................. 208

Figure 4.123 Moment vs deflection relationship for slabs in group G2 .............................. 209

Figure 4.124 Moment vs deflection relationship for slabs in group G3 .............................. 209

Figure 4.125 Moment vs deflection relationship for slabs in group G4 .............................. 210

Figure 4.126 Moment vs deflection relationship for slabs in group G5 .............................. 210

Figure 4.127 Moment vs deflection relationship for slabs in group G6 .............................. 211

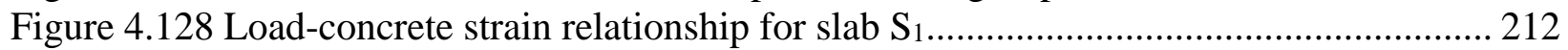

Figure 4.129 Load-bar strain relationship for slab $\mathrm{S}_{1}$................................................... 212

(Note: the strain gauge did not work to the ultimate load) ................................................ 212

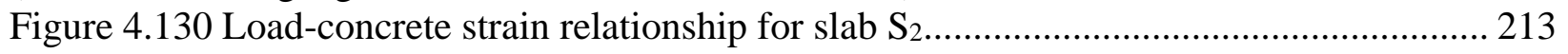

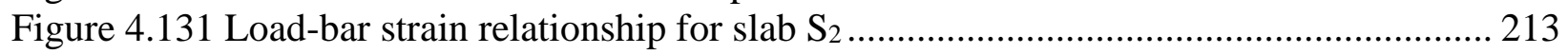

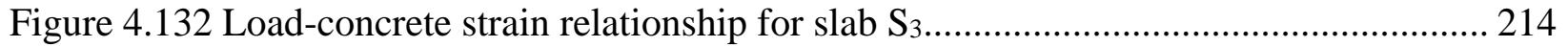

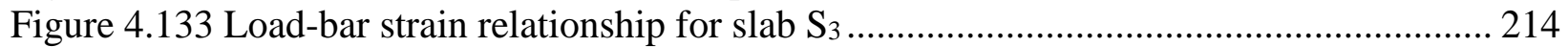

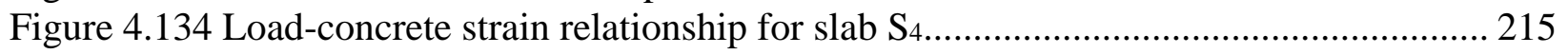

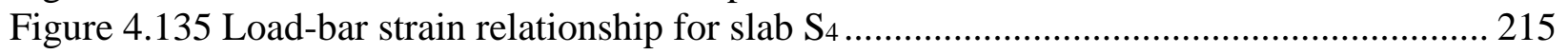

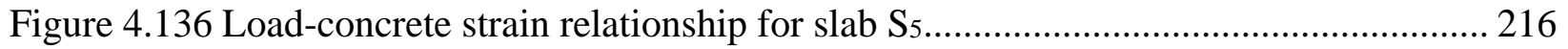

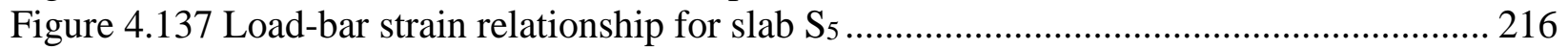

Figure 4.138 Load-concrete strain relationship for slab S6............................................. 217

Figure 4.139 Load-bar strain relationship for slab S6 .................................................... 217

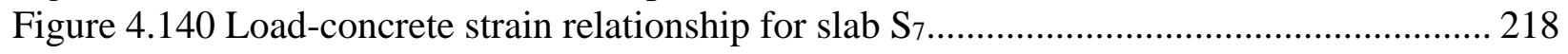

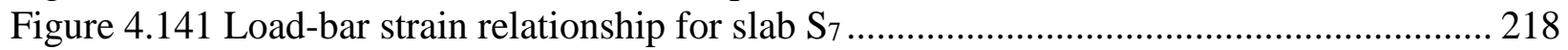

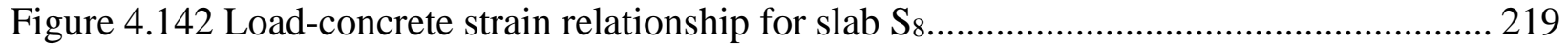

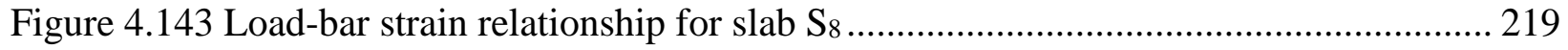

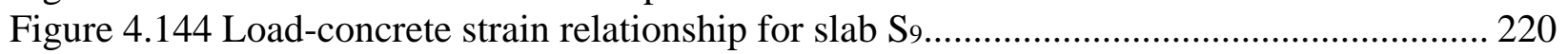

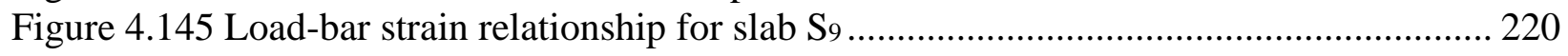

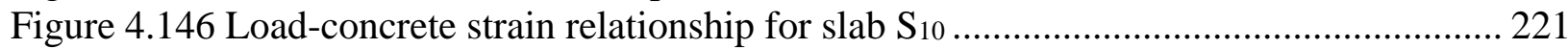

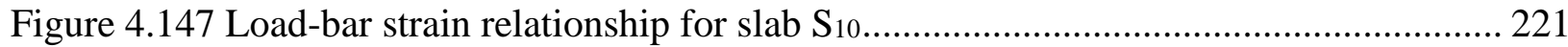

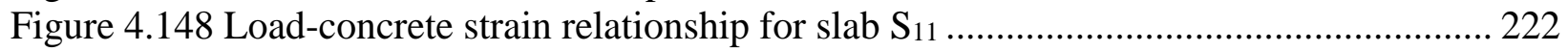

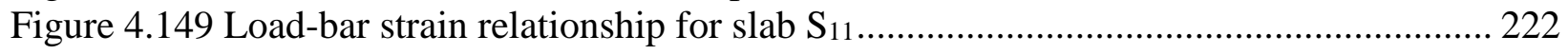

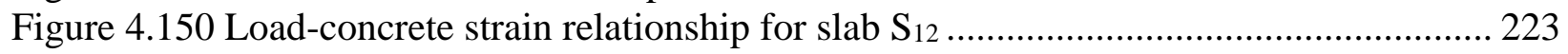

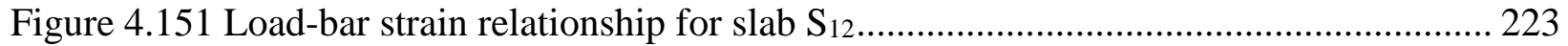

Figure 4.152 Load-concrete strain relationship for slab $\mathrm{S}_{13}$.............................................. 224

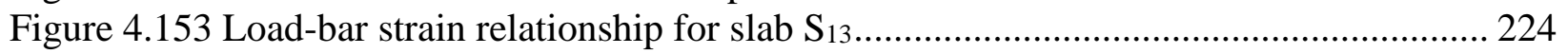

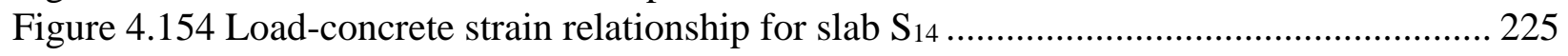

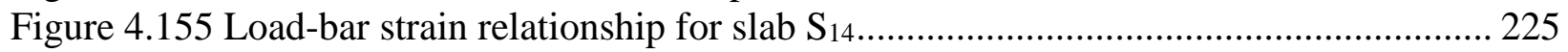

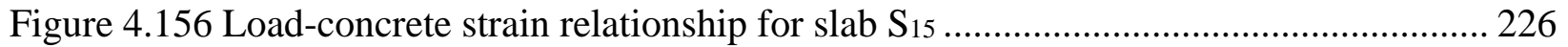

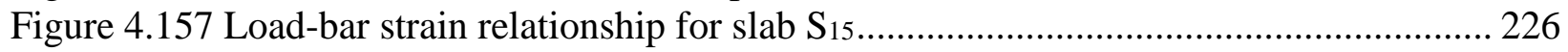




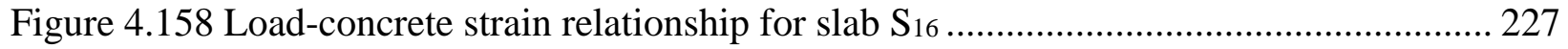

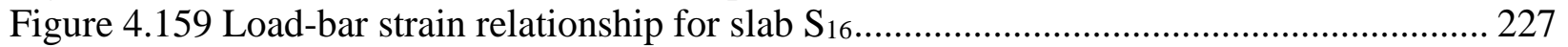

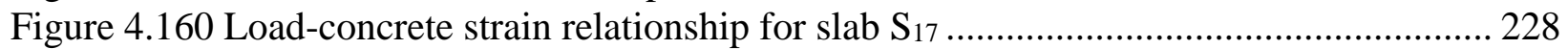

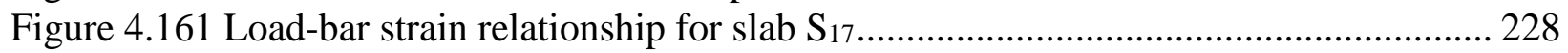

Figure 4.162 Load-concrete strain relationship for slab $\mathrm{S}_{18}$............................................... 229

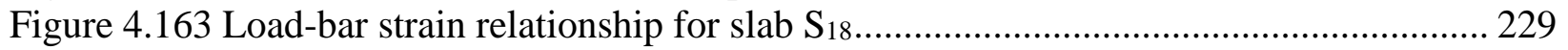

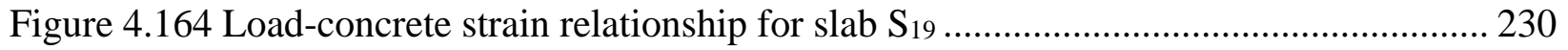

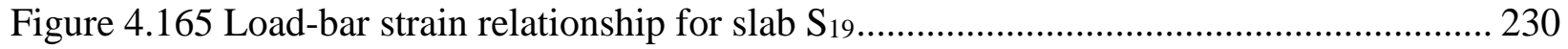

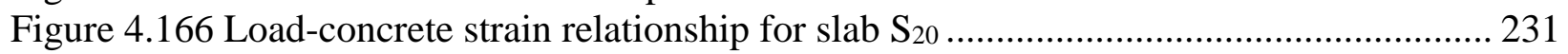

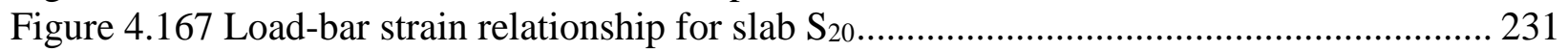

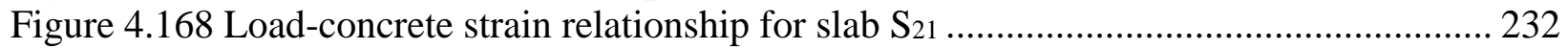

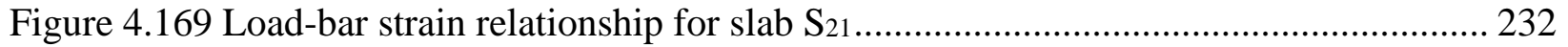

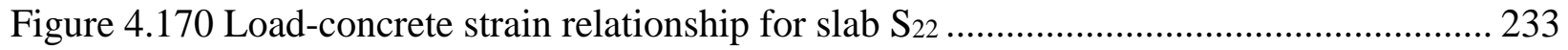

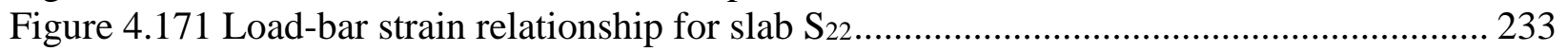

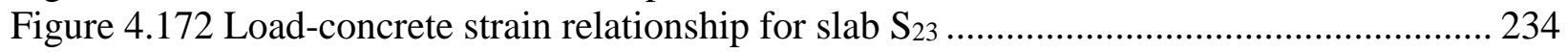

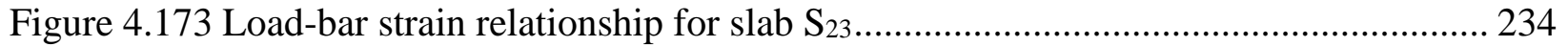

Figure 4.174 Load-concrete strain relationship for slab $\mathrm{S}_{24}$.......................................... 235

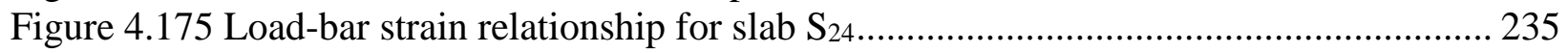

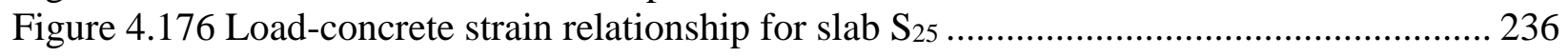

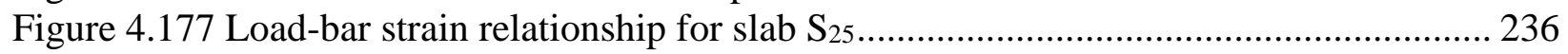

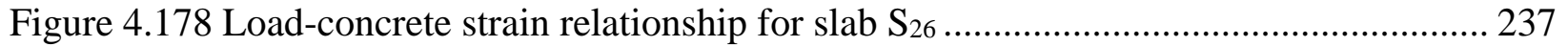

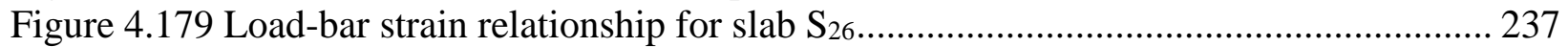

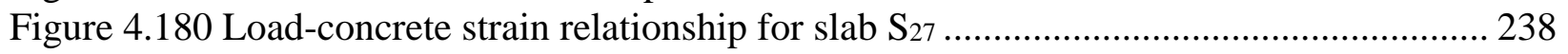

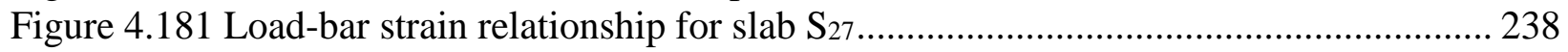

Figure 4.182 Effect of lap splice spacing and joint width on the capacity ............................ 239

Figure 4.183 Effect of main bar spacing and joint width on the capacity ............................... 239

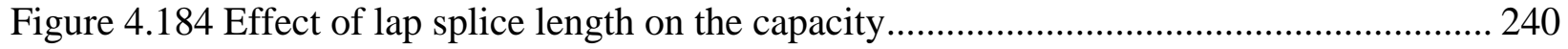

Figure 4.185 Effect of the development length on the capacity .......................................... 240

Figure 4.186 Specified maximum spacing between girders for jointed slabs in group G1 with full

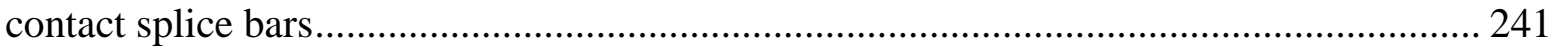

Figure 4.187 Specified maximum spacing between girders for jointed slabs in group G2 with 50

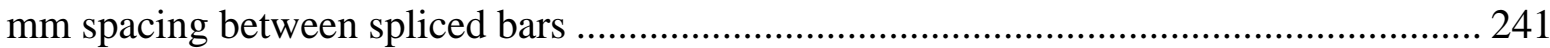

Figure 4.188 Specified maximum spacing between girders for jointed slabs in group G3 with 100 $\mathrm{mm}$ spacing between spliced bar ............................................................................ 242

Figure 4.189 Specified maximum spacing between girders for jointed slabs in group G4 with 75 mm spacing between spliced bars ..................................................................... 242

Figure 4.190 Specified maximum spacing between girders for jointed slabs in group G5 with 50 mm spacing between spliced bars ................................................................. 243

Figure 4.191 Specified maximum spacing between girders for jointed slabs in group G6 with 75

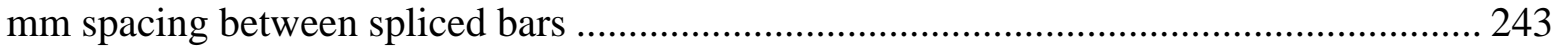




\section{Chapter I}

\section{Introduction}

\subsection{Introduction}

Bridges are a major component of any infrastructure, acting as critical links in most of the road networks and railways, connecting cities and countries and securing a critical mean of transportation of goods and people from place to another. Such vital asset requires routine inspection, maintenance and as problems arise, the demand for research, innovation and development of new materials, structural components, applications, and construction methods increase. In Canada, severe weather fluctuations in winter times result in freezing and thawing of structural members and the use of deicing salts makes the expansive corrosion of steel reinforcement in bridge deck slabs a major issue. This leads to reduction in the capacity and the life expectancy of bridges, costly routine maintenance and in some cases replacement of the bridge or the severely deteriorated components.

From engineering and economic perspectives, for the process of replacing the deteriorated bridge or some of its components to be effective, it should have a minimal impact on the traffic. Also, it should incorporate innovative materials and construction techniques that will limit or minimize the effect of deicing salt used in winter times in Canada. The federal highway administration (FHWA) defines accelerated bridge construction (ABC) as making use of innovative planning, design, materials, and construction methods in a safe and cost-effective manner to reduce the onsite construction time that occurs when building new bridges or replacing and rehabilitating existing bridges. $\mathrm{ABC}$ results in improved site constructability, total project delivery time and work zone safety for travelling public. It also reduces the impact on traffic, and the weather-related time delays, maintaining and/or improving construction quality, and reducing the life cycle costs and 
environmental impacts. Prefabricated components can be delivered to site and quickly assembled, and thus they can reduce design and constriction time and cost, minimize forming, minimize lane closure time and/or possibly eliminate the need for a temporary bridge. (Culmo 2009).

One of the $\mathrm{ABC}$ techniques is the use of prefabricated systems, to minimize the use of the conventional cast in place techniques; a major component of such system which is the focus of this research is the jointed prefabricated deck panels that are supported over either steel or prefabricated precast concrete girders. Figure 1.1(a) depicts a schematic diagram of precast fulldepth deck panels placed transversally over girders. While Fig. 1.1(b) presented the bulb-tee pretentioned girders placed side-by-side over abutments and/or piers and jointed together at the level of the deck slab.

\subsection{The significance of this research}

Several research studies have been conducted on the behavior of the joint between the precast prefabricated deck panels considering conventional steel reinforcement, epoxy-coated steel bars and GFRP bars. These studies investigated the reinforcement details in the joint such as bent bars, bars with hooked ends, headed- and straight-end bars, combined with different shear key shapes and different joint filling materials, such as non-shrinking grout, high performance concrete (HPC) and ultra-high performance fiber reinforced concrete (UHPFRC).

Among the materials being proposed and investigated in the jointed precast deck panels, the ribbed-surface GFRP bars and UHPFRC are of a growing interest and focus. The outstanding properties of each of these materials eliminate the durability issues that existed when using steel reinforcement and allow for expansion on accelerated bridge construction practice. However literature survey showed that neither the CHBDC (2014), nor the AASHTO-LRFD (2012), provide guidance of the design of the joints of prefabricated deck slabs reinforced with GFRP and 
UHPFRC. The significance of the is research is that it addresses the problem of the lack of guidance in design manuals and design standards due to the lack of research data in literature for the behavior of the joints incorporating straight-end, ribbed-surface, GFRP bars and UHPFRC joints. Specifically, the change in joint width and associated bar splice length in the joint and the spacing between spliced bar in the joint has not been investigated before. The proposed experimental program will provide data to assist in obtaining the precast deck slab capacity based on the joint details as affected by (i) joint width and associated bar splice length, and (ii) spacing between spliced bars in the joint.

\subsection{Thesis objectives}

The objective of this research are:

1- to conduct a parametric study using experimental testing to investigate the behavior of ribbed-surface glass fiber reinforced polymer GFRP bars in the closure strip between jointed precast deck slabs resting over steel or concrete girders.

2- to correlate the experimental findings with the available theoretical capacities of the slab section in moment and shear to examine their applicability.

3- to determine the maximum spacing between girders to be considered to use the developed joints in practice.

\subsection{Scope of work}

The Jointed deck slabs investigated in this study are one-way slabs utilizing two vertical shear keys, one on each side of the closure strip. GFRP bars in the precast deck slabs are proposed to project with straight ends into the closure strip, which will then be filled with ultra-high performance fiber-reinforced concrete (UHPFRC). The behavior of GFRP reinforcement in the UHPFRC joint is studied using full-scale tests. The key parameters considered in this study were 
bar spacing, splice length in the joint and splice bar spacing within the joint. Four different bar splice length were considered, namely: 75, 105, 135 and $165 \mathrm{~mm}$ for closure strip widths of 125 , 155, 185 and $215 \mathrm{~mm}$, respectively. The splice bars were considered (i) lapped with direct contract and non-contacted with spacing of 50,75 and $100 \mathrm{~mm}$. The mechanics of the anchorage behavior were observed and recorded to evaluate the manner in which the capacity of a straight-end GFRP bars was developed for different splice length and bar spacing. Observations from these tests provided information on the mechanism of stress transfer between lapped bars in the closure strip.

\subsection{Thesis layout}

The content of this thesis is presented in five chapters. Chapter 1 presents the introduction, research significance, objectives and scope of work. Chapter 2 presented the literature review pertained to the research topic. Chapter 3 presented the experimental program designed to fulfill the objectives of this research. It includes description of test specimens, test setup and test procedure. Chapter 4 presents the experimental findings and test results. Chapter 4 presents the conclusions of this research and recommendations for further investigations. 


\section{Chapter II \\ Literature Review}

\subsection{FRP technology and its use in structural engineering}

The use of FRP material in structural applications where first investigated in the 1950s but it was finally considered for structural application in the 1970s, according to the ISIS Manual No. 3 (ISIS Canada 2007). Early works in FRP used in construction and retrofitting of concrete structures in USA, Japan, Canada and Europe was between 1980 and 1990 (Bank, 2006). Starting from the year 1993, the initiation of a series of biannual international symposium with the use of FRP in construction started to take place. And from that time, a dramatic increase in the international interests of the area of FRP in the construction and retrofitting. Since the early 1980's ASCE is publishing a collection of papers about FRP profile sections. Later the ASCE founded "the journal of composites for construction"; which represents the main international archive for reporting on research and development on the FRP in the construction field (Bank, 2006).

FRP or Fiber Reinforced Polymer is a composite material composed of a polymer matrix reinforced with Microfibers whether Carbon, Glass or Aramid fibers, with the Carbon and Glass fibers being used more often in structural applications with the latter being widely used for concrete reinforcement as a replacement for conventional and stainless steel reinforcement. CFRP can be found in three four main types A-Glass, E-Glass, C-Glass, S-Glass. The most common in structural applications and least expensive is the E-Glass, having a tensile strength of around 3400 $\mathrm{MPa}$, a density of $2.75 \mathrm{~kg} / \mathrm{cm}^{3}$ and a Modulus of elasticity of $75.2 \mathrm{GPa}$ (Bank,2006). The main source of strength in the FRP composite are the fibers having high tensile strength, and so having the fibers in the FRP composite oriented in the same plane of the tensile component of any straining action will better utilize the capacity of the fiber. 
In general, FRP technology can be applied in the structural engineering field in rehabilitation and retrofitting of existing RC structures as Externally Bonded Reinforcement or as a Near Surface Mounted Reinforcement. In addition to its use as an alternative to conventional and stainless steel reinforcement in reinforcing new reinforced concrete structural members (AASHTO, 2009).

With the growing need for the use of innovative materials in bridge construction that combines both strength and durability to eliminate the durability problems resulting from the use of steel reinforcement, the FRP and specifically the GFRP reinforcement bars have emerged as an alternative to the steel reinforcement, due to their non-corrosive nature (AASHTO, 2009). Moreover they have better advantage over the conventional and stainless steel as the GFRP is lighter in weight in addition to its higher strength relative to the steel. Although the initial cost of the GFRP reinforcement is higher than steel reinforcement, the long-term cost should be less than that of steel throughout the life span of the structure or the bridge given the higher durability and strength properties that GFRP has over the steel.

\subsection{Capacity of GFRP bars reinforced concrete}

Several design manuals and guidelines have been developed to aid in the design of GFRP reinforced concrete Sections and predict their capacity flexural and shear capacity (ISIS Canada,2007; AASHTO, 2009; CHBDC, 2014). 


\subsubsection{Flexural capacity of GFRP reinforced concrete}

For the flexural Capacity of FRP reinforced concrete Sections, Chapter 6 of the ISIS manual No. 3 (ISIS, 2007) presents the design guidelines for reinforcing with FRP, it describes three distinct modes of failure in flexure, Balanced failure, Compression failure and tension failure and it states that the compression failure is more desirable and less violent when compared to the tension failure mode due to the sudden rupture of FRP reinforcement in the tension failure mode

For the compression failure mode, the ISIS manual No. 3 presents the following equations for predicting the ultimate moment capacity from the equilibrium of compressive and tensile forces in the concrete compression block and the FRP reinforcement respectively,

The equilibrium of forces $\mathrm{C}$ and $\mathrm{T}$, should be satisfied yielding the following term

$$
\mathrm{C}=\mathrm{T}
$$

$\mathrm{C}=\alpha_{1} \emptyset_{\mathrm{c}} \mathrm{f}^{\prime} \beta_{1} \mathrm{cb}$

$\mathrm{T}=\mathrm{A}_{\mathrm{FRP}} \emptyset_{\mathrm{FRP}} \varepsilon_{\mathrm{FRP}} \mathrm{E}_{\mathrm{FRP}}$

$$
\alpha_{1} \emptyset_{\mathrm{c}} \mathrm{f}^{\prime}{ }_{\mathrm{c}} \beta_{1} \mathrm{cb}=\mathrm{A}_{\mathrm{FRP}} \emptyset_{\mathrm{FRP}} \varepsilon_{\mathrm{FRP}} \mathrm{E}_{\mathrm{FRP}}
$$

Where,

$\mathrm{T}=$ internal force due to tension in FRP reinforcement, $\mathrm{N}$,

$\mathrm{C}=$ resultant of compressive stresses in concrete, $\mathrm{N}$,

AFRP $=$ area of cross-section of an FRP bar, plate, sheet, or tendon, $\mathrm{mm}^{2}$,

$\mathrm{EFRP}_{\mathrm{F}}=$ mean modulus of elasticity of FRP bars, plates, sheets, and tendons, MPa,

$\phi_{\mathrm{c}}=$ resistance factor for concrete,

$\emptyset_{\mathrm{FRP}}=$ resistance factor for FRP reinforcement,

$\mathrm{f}_{\mathrm{c}}=$ compressive strength of concrete, $\mathrm{MPa}$, 
$\varepsilon_{\mathrm{FRP}}=$ strain in FRP reinforcement,

$c=$ depth of the neutral axis,mm,

$\alpha_{1}, \beta_{1}=$ stress-block factors for concrete based on CSA A23.3-94,

ffrp reinforcement ratio

$\rho_{\text {frpb balanced reinforcement ratio }}$

This is achieved through series of iterations, using an assumed value for the depth of the neutral axis $\mathrm{c}$ and it's corresponding $\varepsilon_{F R P}$, the forces $\mathrm{C}$ and $\mathrm{T}$ are calculated, and by changing the value of c for each new iteration till equilibrium is satisfied, then the moment capacity $\mathrm{Mr}$ can be calculated as equation 2.5 .

An alternative approach is to achieve equilibrium condition through calculating the force $\mathrm{T}$ as equation 2.2 then the depth of the neutral axis $\mathrm{c}$ and the compressive force $\mathrm{C}$ can be achieved thus $\mathrm{M}_{\mathrm{r}}$ can be calculated by substituting values $\mathrm{c}$ and $\mathrm{C}$ in equation 2.5 ,

$$
\mathrm{T}=\mathrm{A}_{\mathrm{FRP}} \emptyset_{\mathrm{FRP}} \mathrm{f}_{\mathrm{FRP}}
$$

Where,

$$
\begin{aligned}
& \mathrm{f}_{\mathrm{FRP}}=0.5 \mathrm{E}_{\mathrm{FRP}} \varepsilon_{c u}\left[\left(1+\frac{4 \alpha_{1} \beta_{1} f^{\prime}{ }_{c}}{\rho_{f} \emptyset_{\mathrm{FRP}} \varepsilon_{c u} E_{F R P}}\right)^{1 / 2}-1\right] \\
& \rho_{f r p}=\frac{A_{f r p}}{b d} \\
& \mathrm{M}_{\mathrm{r}}=\mathrm{C}\left(\mathrm{d}-\frac{\beta_{1} \mathrm{c}}{2}\right)
\end{aligned}
$$

Moreover, the AASHTO Design Guides on the design of GFRP Reinforced Decks (2009) presents in Section 2 guidelines for predicting and designing for the flexural capacity of GFRP reinforced concrete deck, and it describes the same three modes of failure however it accepts both the tension 
and the compression modes of failure provided that the strength and serviceability requirements are satisfied.

For the compression failure mode the AASHTO provides the following term for predicting the moment capacity,

$$
\mathrm{M}_{\mathrm{r}}=\mathrm{A}_{\mathrm{f}} \mathrm{f}_{\mathrm{f}}\left(\mathrm{d}-\frac{\mathrm{a}}{2}\right)
$$

Where,

$\mathrm{a}=$ the depth of the equivalent stress block given by

$$
\mathrm{a}=\frac{\mathrm{A}_{\mathrm{f}} \mathrm{f}_{\mathrm{f}}}{0.85 \mathrm{f}^{\prime}{ }_{\mathrm{c}} \mathrm{b}}
$$

$\mathrm{f}_{\mathrm{f}}=$ effective strength in GFRP given by

$$
\begin{aligned}
\mathrm{f}_{\mathrm{f}} & =\sqrt{\frac{\left(E_{f} \varepsilon_{c u}\right)^{2}}{4}+\frac{0.85 \beta_{1} f^{\prime}{ }_{c}}{\rho_{f}} E_{f} \varepsilon_{c u}}-0.5 E_{f} \varepsilon_{c u} \leq f_{f d} \\
\mathrm{f}_{\mathrm{fd}} & =\text { design force of GFRP bars }
\end{aligned}
$$

Both ISIS Canada manula No. 3 and AASHTO guidelines assume the contribution of the compression reinforcement to be negligible. CHBDC of 2014 in Section 16accepts the two prementioned two failure modes however it requires the factored flexural capacity $\mathrm{M}_{\mathrm{r}}$ to be atleast $50 \%$ greater than the cracking moment $\mathrm{M}_{\mathrm{cr}}$ unless $\mathrm{M}_{\mathrm{r}}$ is $50 \%$ greater than the factored applied moment $\mathrm{M}_{\mathrm{f}}$ and in case of failure governed by FRP rupture $\mathrm{M}_{\mathrm{r}}$ shall be greater than $1.5 \mathrm{M}_{\mathrm{f}}$.

\subsubsection{Shear capacity of GFRP bars reinforced concrete}

The CHBDC presents in Section 16.8 guidelines for predicting the contribution of the concrete component in the shear capacity shear capacity of the Section as follows 


$$
\mathrm{Vc}=2.5 \beta \emptyset_{\mathrm{c}} \mathrm{f}_{\mathrm{cr}} \mathrm{b}_{\mathrm{v}} \mathrm{d}_{\text {long }}
$$

Where $\beta$ is a factor used to account for the shear resistance of cracked concrete and to be calculated in accordance with Clause 8.9.3.7 using $\varepsilon_{\mathrm{x}}$ in accordance with Clause 16.8.7 as follows.

$$
\begin{aligned}
& \beta=\left[\frac{0.4}{\left(1+1500 \varepsilon_{\mathrm{x}}\right)}\right]+\left[\frac{1300}{\left(1000+\mathrm{S}_{\mathrm{ze}}\right)}\right] \\
& \varepsilon_{\mathrm{x}}=\frac{\frac{\mathrm{M}_{\mathrm{f}}}{\mathrm{d}_{\text {long }}}+\mathrm{V}_{\mathrm{f}}-\mathrm{V}_{\mathrm{p}}+0.5 \mathrm{~N}_{\mathrm{f}}-\left(\mathrm{A}_{\mathrm{FRP}} \mathrm{f}_{\mathrm{po}}\right)}{2\left(\mathrm{E}_{\mathrm{s}} \mathrm{A}_{\mathrm{s}}+\mathrm{E}_{\mathrm{FRP}} \mathrm{A}_{\mathrm{FRP}}\right)} \leq 0.003
\end{aligned}
$$

Where,

$\mathrm{A}_{\mathrm{FRP}}=$ area of cross-section of an FRP bar, plate, sheet, or tendon, $\mathrm{mm}^{2}$

$\mathrm{EFRP}_{\mathrm{F}}=$ mean modulus of elasticity of FRP bars, plates, sheets, and tendons, $\mathrm{MPa}$

$A_{s}=$ area of cross-section of steel or FRP reinforcing bars used in edge stiffening of deck slabs

$E s=$ modulus of elasticity of steel, $\mathrm{MPa}$

$\mathrm{f}_{\mathrm{cr}}=$ cracking strength of concrete, $\mathrm{MPa}$

$\mathrm{f}_{\mathrm{po}}=$ stress in tendons when the stress in the surrounding concrete is zero, $\mathrm{MPa}$

$b_{v}=$ effective web width within depth $d_{v}, m m$

$\mathrm{M}_{\mathrm{f}}=$ factored moment at a section, N.mm

$\varepsilon_{\mathrm{x}}=$ longitudinal strain

$\phi_{\mathrm{c}}=$ resistance factor for concrete

$V_{f}=$ factored shear force at a section, $\mathrm{N}$

$\mathrm{V}_{\mathrm{p}}=$ component in the direction of the applied shear of all of the effective prestressing force crossing the critical section factored by $\phi_{p}$ (taken as positive if resisting the applied shear), $\mathrm{N}$ 
$\mathrm{N}_{\mathrm{f}}=$ factored axial load normal to the cross-section occurring simultaneously with $\mathrm{V}_{\mathrm{f}}$, including the effects of tension due to creep and shrinkage, $\mathrm{N}$

$\mathrm{Sze}_{\mathrm{e}}=$ equivalent value of $\mathrm{sz}_{\mathrm{z}}$ that accounts for influence of aggregate size, $\mathrm{mm}$

$\mathrm{sz}=$ crack spacing parameter dependent on crack control characteristics of longitudinal reinforcement, $\mathrm{mm}$

On the other hand, the ISIS Manual No. 3 provides an equation for predicting the shear capacity of slabs and members with no shear reinforcement and an effective depth of less than $300 \mathrm{~mm}$ as follows

$$
\mathrm{Vc}=0.2 \lambda \emptyset_{\mathrm{c}} \sqrt{\mathrm{f}^{\prime}{ }_{\mathrm{c}}} \mathrm{b}_{\mathrm{w}} \mathrm{d} \sqrt{\frac{\mathrm{E}_{\mathrm{FRP}}}{\mathrm{E}_{\mathrm{s}}}}
$$

Where,

$$
\sqrt{\frac{\mathrm{E}_{\mathrm{FRP}}}{\mathrm{E}_{\mathrm{S}}}} \leq 1.0 \text { and } \mathrm{E}_{\mathrm{s}}=200 \times 10^{3} \mathrm{MPa}
$$

The AASHTO Bridge Design Guide Specifications for GFRP-Reinforced Concrete Bridge Decks and Traffic Railings (2009) provides in Section 2.10.3.2 an equation for calculating the nominal shear capacity provided by the concrete component of a singly reinforced rectangular cross Section bent in uniaxial bending, the AASHTO guidelines also requires that the shear capacity Vc shall not exceed the punching shear capacity, the $\mathrm{V}_{\mathrm{c}}$ equation is presented as:

$$
\mathrm{Vc}=0.16 \sqrt{\mathrm{f}^{\prime}{ }_{\mathrm{c}}} \mathrm{b}_{\mathrm{w}} \mathrm{c} \leq 0.32 \sqrt{\mathrm{f}^{\prime}{ }_{\mathrm{c}}} \mathrm{b}_{\mathrm{o}} \mathrm{c}
$$

Where $\mathrm{c}=\mathrm{kd}$

$\mathrm{K}=$ ratio of depth of neutral axis to reinforcement depth as in equation 2.13

$$
\mathrm{k}=\sqrt{2 \rho_{\mathrm{f}} \mathrm{n}_{\mathrm{f}}+\left(\rho_{\mathrm{f}} \mathrm{n}_{\mathrm{f}}\right)^{2}}-\rho_{\mathrm{f}} \mathrm{n}_{\mathrm{f}}
$$


$\mathrm{n}_{\mathrm{f}}=\frac{\mathrm{E}_{\mathrm{f}}}{\mathrm{E}_{\mathrm{c}}}$ and $\rho_{\mathrm{f}}=\frac{\mathrm{A}_{\mathrm{f}}}{\mathrm{bd}}$,

$\mathrm{b}_{\mathrm{o}}=$ perimeter of the critical Section at $0.5 \mathrm{~d}$ from the concentrated load.

\subsubsection{Bond development length}

Behavior of GFRP bars in normal strength concrete, high strength concrete and fiber reinforced concrete have been investigated by many researchers (among them: Benmokrane, et al.,1996 Hanus et al., 2000; Achillides, 2004; Hossain et al,2012; Vint, 2012; Islam et al., 2015). Research showed that GFRP bars develop a non-linear behavior along its length, the bond strength between GFRP bars and concrete is influenced by the bar diameter compressive strength of concrete, properties of the resin matrix of the bar material and the end anchorage mechanism. (Vin, 2012).

CHBDC presents in Section 16.8.4 the following equation for the development length of FRP reinforcement.

$$
\mathrm{l}_{\mathrm{d}}=0.45 \frac{\mathrm{k}_{1} \mathrm{k}_{4}}{\left[\mathrm{~d}_{\mathrm{cs}}+\mathrm{k}_{\mathrm{tr}} \frac{\mathrm{E}_{\mathrm{FRP}}}{\mathrm{E}_{\mathrm{S}}}\right]}\left[\frac{\mathrm{f}_{\mathrm{FRPU}}}{\mathrm{f}_{\mathrm{cr}}}\right] \mathrm{A} \geq 250
$$

Where $\left(\mathrm{d}_{\mathrm{cS}}+\mathrm{k}_{\mathrm{tr}} \frac{\mathrm{E}_{\mathrm{FRP}}}{\mathrm{E}_{\mathrm{S}}}\right) \leq 2.5 \mathrm{~d}_{\mathrm{b}}$

$$
\mathrm{k}_{4}=\frac{\text { bond strength of FRP bar }}{\text { bond strength of steel bar }} \leq 1, \quad \text { in case of no experimental data } \mathrm{k}_{4}=0.8
$$

On the other hand, the AASHTO GFRP Bridge Design Guide Specifications for GFRP-Reinforced Concrete Bridge Decks and Traffic Railings (2009) provides in Section 2.12 more detailed guide lines and specifications on the requirement of development and splice lengths of GFRP bars imbedded in concrete, it allows the use of hooks and end anchors provided that the performance is approved after being verified by tests equivalent to ASTM D 3916 it also allows the use of 
mechanical anchors provided that the performance is verified by tests and that the anchor is ensured not to cause any damage to the concrete or the bar. For straight deformed bars the AASHTO guidelines presents in Section 2.12.2.1 the following equation for determining the tension development length $l_{d}$ in inches this equation takes into consideration the bar location in the factor $\alpha$ and the ratio of the bar tributary area to bar diameter.

$$
\mathrm{l}_{\mathrm{d}}=\frac{3.16 \alpha \frac{\mathrm{f}_{\mathrm{f}}}{\sqrt{\mathrm{f}_{\mathrm{c}}^{\prime}}}-340}{\left[13.6+\frac{\mathrm{C}}{\mathrm{d}_{\mathrm{b}}}\right]} \mathrm{d}_{\mathrm{b}} \geq 20 \mathrm{~d}_{\mathrm{b}}
$$

Where,

$\alpha=$ bar location modification factor

$\mathrm{d}_{\mathrm{b}}=$ GFRP bar diameter, in

$\mathrm{C}=$ lesser of the cover to the center of the bar or one-half of the center-to-center spacing of the bars being developed, in

$f_{\mathrm{f}}=$ effective strength in reinforcement as follows,

$\mathrm{f}_{\mathrm{f}}=\sqrt{\frac{\left(\mathrm{E}_{\mathrm{f}} \varepsilon_{\mathrm{cu}}\right)^{2}}{4}+\frac{0.85 \beta_{1} \mathrm{f}_{\mathrm{c}}^{\prime}}{\rho_{\mathrm{f}}} \mathrm{E}_{\mathrm{f}} \varepsilon_{\mathrm{cu}}-0.5 \mathrm{E}_{\mathrm{f}} \varepsilon_{\mathrm{cu}} \leq \mathrm{f}_{\mathrm{fd}}}$

$\beta_{1}=$ factor taken as 0.85 for concrete strength $\leq 4 \mathrm{ksi}$, for concrete strength $\geq 4 \mathrm{ksi} \beta_{1}$ shall be reduced at a rate of 0.05 for each extra $1 \mathrm{ksi}$ but $\beta_{1}$ should not be less than 0.65 .

For bars with standard hooks in tension, the AASHTO guidelines presents in Section 2.12.2.3 three equations to predict the tension development length in bars with standard hook $\mathrm{l}_{\mathrm{dh}}$ based on the range of the design tensile strength of GFRP bars $f_{f}$. the guideline states that $l_{d h}$ should be greater 
than or equal to $12 \mathrm{~d}_{\mathrm{b}}$ or ( 9 in) moreover it sets limitations on the tail length and the bend radius to avoid shear failure at the bend.

\subsubsection{Splice length}

CHBDC specifies the splice length of FRP bars in tension to be at least $1.3 l_{d}$ and the spacing of the spliced bars shall not exceed $150 \mathrm{~mm}$. On the other hand, the AASHTO guidelines specifies the splice length of FRP bars in tension to be at least $1.3 \mathrm{l}_{\mathrm{d}}$ or $300 \mathrm{~mm}(12 \mathrm{in})$ and the spacing of the spliced bars shall not exceed $150 \mathrm{~mm}$ (6 in).

\subsection{UHPFRC technology}

Ultra-High Performance Fiber Reinforced Concrete UHPFRC, also known as Reactive Powder concrete is the latest generation of structural concrete that was first introduced by a French concrete produces in the 1990's having an outstanding fresh and hardened concrete properties, this includes the ease of placement and consolidation with ultra-high early and long term mechanical properties, as well as toughness volume stability, durability, higher flexural and tensile strength and ductility (Graybeal, 2006; Kosmata et al., 2003; Graybeal, 2013; Russell et al., 2013).

Its high compressive capacity and high flow-ability as well as low porosity is achieved by optimizing the particle packing and the minimal water content and the use of chemical and mineral admixtures. The durability of the UHPFRC is enhanced by the low porosity which makes it suitable for a wide array of applications especially in the field of precast prefabricated bridge construction.

To achieve these properties coarse aggregate is eliminated and only fine particles are used; the grain size distribution should be optimized to densify the mix and improve rheology, moreover a superplasticizer or high range water reducer should be used to improve rheology while maintaining 
the $\mathrm{W} / \mathrm{C}$ as low as 0.2 , fibres usually steel or synthetic fibers should be added as a volumetric ratio up to $2 \%$ to improve ductility and achieve higher tensile and flexural strength. Further detailed literature survey on the UHPFRC properties is presented in the state of the art report published by FHWA (Russell, 2013).

\subsection{Flexural capacity of UHPFRC section}

Several models have been developed to predict the capacity of fiber reinforced concrete, however all models available are obtained based on fiber reinforced concrete Section with steel bars as the main flexural reinforcement not with GFRP, most of the model are based on the strain compatibility and equilibrium equations. Among these models are the models presented in the ACI report No. ACI 544.4R-88 and the FHWA report number FHWA-HIF-13-032.

Sriram et al. (2013) presents a model for predicting the ultimate capacity of UHPC for rectangular members and T-members reinforced with mild steel reinforcing bars Figure 2.1. It assumes a linear stress strain relationship, and recommends the use of a conservative value of fiber pullout strain in design as 0.007 and a corresponding limiting tensile strength of the UHPC to be $\cong 8.25 \mathrm{MPa}$, (1.2 ksi) it also mentions that the ultimate compressive strain at the extreme top compression fibers to be 0.0032 having a corresponding compressive strength to be $\cong 165 \mathrm{MPa}$ (24 ksi). The model approximates the compression stress block to be triangular, and till the neutral axis and the tensile stress of the HPC uniform from and acting approximately from the neutral axis to the extreme tensile fibers. The proposed design procedure uses the equilibrium of the internal forces and the strain compatibility at the ultimate limit state to determine the governing failure mode and from that failure mode, and based on the governing failure mode the neutral axis and moment capacity obtained, the design procedure can be summarized as:

1- Determining the failure mode from equations 


$\begin{array}{lllr}\frac{\rho_{s} f_{y}+f_{t u}}{f_{t u}+0.5 f_{c u}} & >0.314 & \text { Compression failure } & 2.16 \\ \frac{\rho_{s} f_{y}+f_{t u}}{f_{t u}+0.5 f_{c u}} & =0.314 & \text { Balanced condition } & 2.17 \\ \frac{\rho_{s} f_{y}+f_{t u}}{f_{t u}+0.5 f_{c u}} & <0.314 & \text { Tensile failure } & 2.18\end{array}$

2- Depth of neutral axis

$$
\begin{array}{ll}
\text { For compression failure, } & c=\left(\frac{\rho_{s} f_{y}+f_{t u}}{f_{t u}+0.5 f_{c u}}\right) h \\
\text { For tension failure, } & c=\left(\frac{\rho_{s} f_{y}+f_{t u}}{f_{t u}+0.0035 E_{U H P C}\left(\frac{c}{h-c}\right)}\right) h
\end{array}
$$

3- Moment capacity

$$
\mathrm{M}_{n}=f_{t u} b(h-c)\left(\frac{3 h-c}{6}\right)+\rho_{s} f_{y} b h\left(d-\frac{c}{3}\right)
$$

Where

$\mathrm{c}=$ neutral axis depth

$\mathrm{b}=$ width of the beam,

$\mathrm{h}=$ height of the beam,

$\varepsilon_{\mathrm{cu}}=$ the compressive strain at the ultimate limit state taken as 0.0035 ,

$\mathrm{f}_{\mathrm{cu}}=$ compressive stress of UHPFRC,

$\varepsilon_{\mathrm{tu}}=$ tensile strain at which fiber pullout occurs conservatively taken as 0.007 ,

$\mathrm{f}_{\mathrm{tu}}=$ tensile stress corresponding to $\varepsilon_{\mathrm{tu}}$,

these parameters are also illustrated on the schematic diagram in Figure 2.1

Literature survey conducted elsewhere (Hussein, 2015) presented a model for predicting the capacity of UHPFRC beams Figure 2.2, according to (Hussein, 2015) the accuracy of this model 
has been verified experimentally by studies conducted elsewhere (Hussain, 2015; Wahba et al., 2012; Yang et al, 2010), the ratio between the capacity predicted by the model to that obtained experimentally, ranged from 0.817 to 1.022 , thus the model is showing good agreement with the experimental results. The moment capacity is given by:

$$
M_{u}=A_{s t} * f_{y} *\left(d-\frac{\beta_{1} c}{2}\right)+f_{f t} * \frac{(h-c)^{2}}{2} * b+\alpha_{1} \alpha_{2} f_{c}^{\prime} \beta_{1} c b *\left(c-\frac{\beta_{1} c}{2}\right)
$$

Where;

$$
\xi=\left(\frac{f_{c}^{\prime}}{10}\right)^{1.5} \quad, \quad \alpha_{2}=0.96 * \exp (-0.0039 \xi) \quad, \quad \beta=0.925 * \xi^{-075} \leq 1
$$

\subsection{Development length of GFRP bars in UHPFRC}

Bond strength of UHPFRC and high strength fiber reinforced concrete have been studied by several researchers, (among them Nielsen et al, 1996; Aarup and Jensen, 1998).

The behavior of GFRP bars in UHPFRC started to gain more attention more recently, studies were conducted on various GFRP bar types (among them Ametrano, 2011; Graybeal, 2011; Khederzadeh and Sennah, 2013) A more recent study (Sayed Ahmed, 2016) investigated pullout strength of straight-end and headed-end GFRP bars embedded into UHPFRC to determine the required closure strip width to develop bar full strength, the study recommends a bond development length of the straight bars not to be less than $9.5 \mathrm{db}$ or $150 \mathrm{~mm}$, whichever is greater.

\subsection{Static analysis of concrete deck slabs}

Section 5 in the CHBDC (2014), states that concrete deck slabs should be designed for both positive and negative moments in the transverse direction and the induced moment in the longitudinal direction shall also be considered in the analysis and design, it provides a simplified 
method of analysis to predict the transverses and longitudinal live load moment for concrete deck slabs supported over longitudinal concrete or steel girders, as summarized as follows:

For transverse moment per one meter strip for inner portion of simple span:

$$
\text { Moment }=\frac{(\mathrm{Se}+0.6) \mathrm{P}}{10} \quad \mathrm{kN} \cdot \mathrm{m} / \mathrm{m}
$$

For transverse moment per one meter strip for inner portion of continuous span:

$$
\text { Moment }=0.8 \times \frac{(\mathrm{Se}+0.6) \mathrm{P}}{10} \quad \mathrm{kN} . \mathrm{m} / \mathrm{m}
$$

Where, $\mathrm{P}=87.5 \mathrm{kN}$ and $\mathrm{S}_{\mathrm{e}}$ is the effective span between girders web to web.

For longitudinal moment, it should be taken as $120 /\left(\mathrm{Se}^{0.5}\right) \%$ (but not to exceed $67 \%$ of the maximum transverse moment intensity) and shall be applied as a positive moment that produces tension in the bottom portion of the deck slab.

The AASHTO-LFRD Bridge design specifications (2014) present an approach for determining the moment in kip-in/in due to live load on bridge deck slab in transverse and longitudinal directions as follows.

In the transverse direction,

For $\mathrm{L} \leq 120$ in

$$
\mathrm{M}_{\text {transverse }}=1.28 \mathrm{D}^{0.197} \mathrm{~L}^{0.459} \mathrm{C}
$$

For $\mathrm{L}>120$ in

$$
\mathrm{M}_{\text {transverse }}=\frac{\mathrm{D}^{0.188}\left(3.7 \mathrm{~L}^{1.35}-956.3\right)}{\mathrm{L}}(\mathrm{C})
$$

In the longitudinal direction, 
For $\mathrm{L} \leq 120$ in

$$
\mathrm{M}_{\text {prallel }}=0.73 \mathrm{D}^{0.188} \mathrm{~L}^{0.64} \mathrm{C}
$$

For $\mathrm{L}>120$ in

$$
\mathrm{M}_{\text {parallel }}=\frac{\mathrm{D}^{0.138}\left(3.1 \mathrm{~L}^{1.429}-1088.5\right)}{\mathrm{L}}(\mathrm{C})
$$

Where,

$\mathrm{L}=$ span length from center-to-center of supports (in),

$\mathrm{C}=$ continuity factor; 1.0 for simply supported and 0.8 for continuous spans,

$\mathrm{D}=\mathrm{D}_{\mathrm{x}} / \mathrm{D}_{\mathrm{y}}$

$\mathrm{D}_{\mathrm{x}}=\mathrm{EI}_{\mathrm{x}}$ flexural rigidity of deck in main bar direction (kip-in.2/in.),

$\mathrm{D}_{\mathrm{y}}=\mathrm{EI}_{\mathrm{y}}$ flexural rigidity of deck in main bar direction (kip-in.2/in.),

$\mathrm{E}=$ the modulus of elasticity,

$\mathrm{I}_{\mathrm{x}}$ and $\mathrm{I}_{\mathrm{y}}=$ the moments of inertia per unit width of deck,

\subsection{Joints between prefabricated deck Slabs}

As the use of prefabricated precast elements is one of the major practices in the accelerated bridge construction, the connections between these prefabricated element is a critical component especially in deck slab panels, not only because it should ensure the continuity within the system and the transfer of forces and moments from one panel to the other but also as the quality of the joint is one of major factors affecting the durability of both the super and substructure Figure 2.3 shows a schematic diagram of prefabricated bulb-tee girders system. 
Several research studies have been conducted on the behavior of the joint between the prefabricated deck slabs, the studies included various types of steel reinforcement, various types of end anchorages of steel reinforcement like straight bars, bet bars u-shaped end bars, in addition to various shear key shapes and geometry, joint width and bar embedment length and splice connection details as well as different types of joint fill materials such as UHPFRC, Cementous grout, epoxy, magnesium ammonium phosphate grout and post tensioning cable grout (NCHRP 2008; Li et al., 2010; NCHRP, 2011). However, fewer studies have been conducted on the joints incorporating UHPFRC and GFRP reinforcement.

Culmo (2009) produced a state of the practice report for the FHWA on the Connection Details for Prefabricated Bridge Elements and Systems, the document focuses on the connection details and design considerations up to the date it was written, it includes an introduction on the $\mathrm{ABC}$ and connection details and design consideration for the connections of prefabricated elements, Section 2.2 contains the state of practice information on connections between the full depth precast deck slabs. Further literature survey and state of the practice survey could be found elsewhere (PCINER Technical Committee, 2002; Hieber and Wacker, 2005; Badie et al., 2006; Badie and Tadros, 2008; UDOT, 2010; PCI. 2011; Roddenberry, 2012).

Li et al. (2010) conducted a study aiming to promote the use of bulb-tee girder system by improving the joint connection details used with this system at the time of the study by proposing and investigating an alternate joint detail to the longitudinal joints with welded steel connectors and grouted shear keys. The proposed joint details were lapped headed reinforcement or lapped welded wire reinforcement. Seven reinforced concrete beam specimens incorporating the proposed joints were evaluated based on flexural capacity, curvature at failure, cracking, deflection, and steel strain. The study resulted in a conclusion that headed bar detail with a $152 \mathrm{~mm}$ lap length 
was recommended for replacing the current welded steel connector detail as this lap length provided full development of the bars to produce full load capacity and significant ductility.

To further improve the joint detail for bulb-tee girders, and facilitate the accelerated bridge construction, and as a continuation to the research conducted by Li et al. (2010), Ma et al. (2012) investigated the performance of the tight bend diameter U-bars as potential alternate reinforcing materials and joint details compared to the headed bar joint proposed by Li et al. (2010). In this study headed bar and U-bar specimens made of stainless steel (SS) and deformed wire reinforcement (DWR) with the same joint detail configurations were tested and compared, then the effect of concrete strengths, bar spacings, and overlap lengths of U-bars (DWR) were also investigated, for moment capacity, cracking at service and failure load, and steel strains. The study found that a $16 \mathrm{~mm}$ U-bar detail with a minimum bend diameter of three times the diameter of the bar (3db) can be used to facilitate accelerated bridge construction, as is the U-bar detail using DWR performed better than the headed bar detail in terms of moment capacity and service-level crack widths, moreover, it was observed that the U-bar joint zone is less congested than the headed bar detail, the study recommended that in order to provide adequate ductility without significant loss of strength at the ultimate conditions, the joint overlap length should not be less than $152 \mathrm{~mm}$ when using $16 \mathrm{~mm}$ joint reinforcement, moreover it recommends the use $13 \mathrm{~mm}$ lacer bars in the joint detail and be located at the bearing face of the U-bar as the $13 \mathrm{~mm}$ lacer bars were observed to provide restraint to help facilitate anchorage of the U-bar details for the joint zones in flexure. 
He et al. (2013) conducted a study to develop a strut-and-tie model (STM) that can be used in the design of previously developed longitudinal joint incorporating tight bend diameter Ubars by Ma et al. (2012). Four joint specimens reinforced with tight bend diameter U-bars that were previously tested under bending were used to validate the proposed STM . the study yielded the development of an STM model that provided conservative and consistent strength predictions for the U-bar joints.

Lee and Lee (2015) studied the flexural behavior of precast concrete moment connections incorporating steel bars embedded in UHPFRC, their experimental program consisted of two phases. The first phase was focused on the bonding performance of steel reinforcing bars embedded in the UHPFRC, the performance was evaluated using lap-spliced beam specimens with three different volumes of steel fibers. The second phase, was to study the flexural behavior of the UHPFRC moment connections, the study was conducted on 14 precast concrete beam specimens. The precast connections had a joint width ranging from 250 to $100 \mathrm{~mm}$ and included three noncontact splice details: straight bars, 90-degree hooked bars, and U-loop bars. The study showed the remarkable bonding characteristics of UHPFRC, it was also noted that the precast specimens with a joint width larger than $150 \mathrm{~mm}$ exhibited flexural behavior equivalent to that of a monolithic concrete beam specimen, moreover the anchorage provided by the hooked bars and Uloop bars did not contribute significantly to the bonding strength.

Khalafalla (2014) developed and studied the behavior of Six precast slab joint details between flanges of precast bulb-tee girders incorporating GFRP bars with straight ends, headed ends and L-shaped ends embedded in a non-shrink cement grout or ultra-high-performance concrete (UHPC) filled closure strip. In this study, 11 actual-size specimens representing the one-way slab system with the proposed joint details, in addition to 5 cast-in-place control specimens tested to 
failure to examine the structural adequacy of the proposed joint detail. Moreover, the study included 8 actual-size, GFRP reinforced concrete deck slabs under fatigue load to examine its fatigue life using different schemes of fatigue loading. Khalafalla (2014) found that for deck slab reinforced with the same reinforcement ratio specified in CHBDC, the ultimate load capacity of GFRP-reinforced cast-in-place slabs is about $75 \%$ greater than that of a similar slab reinforced with steel bars. It was also observed that closure strip with 125 -mm width with projecting headedend or L-shaped GFRP bars filled with UHPC and the closure strip with 200-mm wide joints with projecting L-shaped GFRP bars, filled with non-shrink grout showed about 27\% greater load carrying capacity than that of a similar slab reinforced with steel bars. It was also found that headed ends GFRP bars can provide a continuous force transfer in the longitudinal joint for deck bulb-tee bridge systems thus allowing for a reduced closure strip width. Moreover the static and fatigue loading tests for the GFRP reinforced restrained deck slabs with the proposed joints showed a punching shear failure mode. It also concluded that reinforcement ratio specified by CHBDC is adequate to meet the ultimate and fatigue limit state requirements for concrete bridge deck slabs. Moreover, the study compared the experimental results with the available equation in CSA S80612 (2012) and El-Gamal et al. (2005) the comparison showed that these models can predict the punching shear strength of the cast-in-place as well as precast jointed bridge deck slabs reinforced with GFRP-bars with good accuracy.

Sayed Ahmed (2016) studied the effect of the joint detail on the capacity of the joint incorporating GFRP bars and UHPFRC joint fill material between deck slab panels made of normal strength concrete and high performance concrete, in this study three joint details were proposed and investigated namely: angle-shape joint, C-shape joint, and zigzag-shape joint. In this study one way slabs were tested by applying concentric and eccentric wheel loading at the joint to expose it 
to pure bending and combined bending and shear respectively. The study showed GFRP-reinforced cast-in-place slab showed an ultimate load capacity of was about $15 \%$ less than the capacity of a similar slab reinforced with steel bars in accordance with the CHBDC and having the same crosssectional area as the GFRP bars. It also shows that GFRP-reinforced jointed slab with a $200 \mathrm{~mm}$ wide joint width with a zigzag-shaped showed a flexural strength that was about $1.4 \%$ less than that for a similar cast-in-place slab. Moreover, it was observed that the ultimate load of the jointed slab with a vertical shear key increased by $15 \%$ as a result of using eccentric loading rather than the concentric loading at the closure strip. The failure mode in all tested one-way slab specimens was either pure flexural of combined flexural and shear in the NSC panel rather than in the UHPFRC-filled joint or bond failure of GFRP bars embedded into the joint. 


\section{Chapter III \\ Experimental Program}

\subsection{Experimental program and test matrix}

The proposed experimental program of this research was designed to conduct a parametric study on the joints between prefabricated deck panels incorporating ribbed GFRP straight-end bars imbedded into the joint. The parameters being considered in this study were the bar embedment length and associated joint width, spliced bar spacing, and main bar spacing. This experimental study is composed of 27 one-way slabs in seven groups, namely: a control group of three slabs and 6 groups of four slabs each. The slabs in one group had a fixed spacing of bars in the lap splice and main bar spacing with bar splice length of 75, 105, 135 and $165 \mathrm{~mm}$ for closure strip widths of $125,155,185$ and $215 \mathrm{~mm}$, respectively.

The slabs were tested under static loading in a four-point loading scenario to-collapse. The target data to be collected from these tests were the maximum load reached at failure, load-vertical deflection relationship, load-concrete strain relationship along the depth of the slab, the loadtensile reinforcement strain relationship for the bottom bars, and the failure mode of each specimen. These results were then be correlated to the theoretical moment and shear capacity using available equations in the literature. A summary of the test matrix is presented in Table 3.1.

Each of the seven groups composing the test matrix investigates certain set of parameters as summarized in Table 3.2, The aim of the first three groups (G1, G2 and G3) was to study the behavior and capacity of the spliced bar configuration (i.e. contact vs non-contact configuration) at the joint with respect to the four proposed closer strip width and their corresponding lap splice length. While Groups G3, G4, and G5 were designed to study the effect of varying the main bar spacing on the capacity of the connection at the joint with respect to the four proposed closer strip 
width and their corresponding lap splice length. Finally groups G4 and G6 are designed to study the effect of the compressive strength of the joint-filled material which is in this study is UHPFRC.

\subsection{Description of tested specimens}

All slabs in this study except slab $S_{1}$ and $S_{2}$ had a shear key on the left and right side of the joint. The dimensions and shape of the shear key were identical for all the jointed slabs as presented in Figure 3.1. The description of each group is shown as follow.

\subsubsection{Control Group (CG)}

Three control slabs were considered in this group, namely: $\mathrm{S}_{1}, \mathrm{~S}_{2}$, and $\mathrm{S}_{3}$. Each slab was 2800 $\mathrm{mm}$ long, $600 \mathrm{~mm}$ wide and of $200 \mathrm{~mm}$ depth. All the slabs have continuous (non-spliced) bars with main bar spacing of $200 \mathrm{~mm}$. Slabs $\mathrm{S}_{1}$ and $\mathrm{S}_{2}$ were considered cast-in-place slabs using normal strength concrete and UHPFRC, respectively. Figure 3.2 shows details of slabs $\mathrm{S}_{1}$ and $\mathrm{S}_{2}$ made of normal strength concrete and UHPFRC, respectively. Figure 3.3 shows dimensioning, joint configuration and GFRP arrangement of precast slab $\mathrm{S}_{3}$. This jointed slab is intended to study the effect of using UHPFRC in the joint in a precast slab build with normal strength concrete compared to slab $S_{1}$ which was built entirely from normal strength concrete. It should be noted that the GFRP bars in the slab were continuous through the joint to limit the difference between the two slabs in the strength of concrete at the joint location.

\subsubsection{Group G1}

This group considered contact lap splice where the spacing between the lap splice is zero (i.e. contact or overlapped splice). The size and bar arrangement in this slab were identical to those in slab $\mathrm{S}_{3}$ except that the joint had spliced bars. Slabs in this group were designated as $\mathrm{S}_{4}, \mathrm{~S}_{5}, \mathrm{~S}_{6}$, and 
$\mathrm{S}_{7}$, with bar splice lengths into the joint of 75, 105, 135 and $165 \mathrm{~mm}$, respectively. This made the joint widths of $125,155,185$ and $215 \mathrm{~m}$ for slabs $\mathrm{S}_{4}, \mathrm{~S}_{5}, \mathrm{~S}_{6}$, and $\mathrm{S}_{7}$, respectively. This made the development length of the bars in the joint of $25 \mathrm{~mm}$ short from the joint width to allow for construction tolerance. Figure 3.4 depicts the dimensioning, joint details and GFRP bar arrangement in the slabs of group G1.

\subsubsection{Group G2}

Group G2 was identical to group G1 except that the spacing between the spliced bar in the joint was taken as $50 \mathrm{~mm}$ (i.e. non-contact lap splice). Slabs in this group were designated as $\mathrm{S}_{8}, \mathrm{~S}_{9}, \mathrm{~S}_{10}$, and $\mathrm{S}_{11}$, with bar splice lengths into the joint of 75, 105, 135 and $165 \mathrm{~mm}$, respectively. This made the joint widths of $125,155,185$ and $215 \mathrm{~m}$ for slabs $\mathrm{S}_{8}, \mathrm{~S}_{9}, \mathrm{~S}_{10}$, and $\mathrm{S}_{11}$, respectively. This made the development length of the bars in the joint of $25 \mathrm{~mm}$ short from the joint width to allow for construction tolerance. Figure 3.5 depicts the dimensioning, joint details and GFRP bar arrangement in the slabs of group G2.

\subsubsection{Group G3}

Group G3 was identical to group G1 except that the spacing between the spliced bar in the joint was taken as $100 \mathrm{~mm}$ (i.e. non-contact lap splice). Slabs in this group were designated as $\mathrm{S}_{12}, \mathrm{~S}_{13}$, $\mathrm{S}_{14}$, and $\mathrm{S}_{15}$, with bar splice lengths into the joint of $75,105,135$ and $165 \mathrm{~mm}$, respectively. This made the joint widths of $125,155,185$ and $215 \mathrm{~m}$ for slabs $\mathrm{S}_{8}, \mathrm{~S}_{9}, \mathrm{~S}_{10}$, and $\mathrm{S}_{11}$, respectively. This made the development length of the bars in the joint of $25 \mathrm{~mm}$ short from the joint width to allow for construction tolerance. Figure 3.6 depicts the dimensioning, joint details and GFRP bar arrangement in the slabs of group G3.

\subsubsection{Group G4}


Groups G4 and G5 were considered to study the effect of joint width with different spacing between main bars in the slab, with maintaining the spacing between spliced bars as half the spacing between main bars in the precast slab. This makes the GFRP ratio in the slab different from those in groups G1 through 3. Each slab in groups G4 and G5 was $2800 \mathrm{~mm}$ long, $475 \mathrm{~mm}$ wide and of $200 \mathrm{~mm}$ depth. All the slabs in Group G4 had main bar spacing of $150 \mathrm{~mm}$ and spacing between the spliced bar in the joint $75 \mathrm{~mm}$. Slabs in this group were designated as $\mathrm{S}_{16}, \mathrm{~S}_{17}, \mathrm{~S}_{18}$, and $\mathrm{S}_{19}$, with bar splice lengths into the joint of 75, 105, 135 and $165 \mathrm{~mm}$, respectively. This made the joint widths of $125,155,185$ and $215 \mathrm{~m}$ for slabs $\mathrm{S}_{16}, \mathrm{~S}_{17}, \mathrm{~S}_{18}$, and $\mathrm{S}_{19}$, respectively. Figure 3.7 depicts the dimensioning, joint details and GFRP bar arrangement in the slabs of group G4.

\subsubsection{Group G5}

Groups G5 was identical to group G4 except that the spacing of main bars was taken as $100 \mathrm{~mm}$ and the spacing between the spliced bar in the joint $50 \mathrm{~mm}$. Slabs in this group were designated as $\mathrm{S}_{20}, \mathrm{~S}_{21}, \mathrm{~S}_{22}$, and $\mathrm{S}_{23}$, with bar splice lengths into the joint of 75, 105, 135 and $165 \mathrm{~mm}$, respectively. This made the joint widths of $125,155,185$ and $215 \mathrm{~m}$ for slabs $\mathrm{S}_{20}, \mathrm{~S}_{21}, \mathrm{~S}_{22}$, and $\mathrm{S}_{23}$, respectively. Figure 3.8 depicts the dimensioning, joint details and GFRP bar arrangement in the slabs of group G5.

\subsubsection{Group G6}

Groups G6 was identical to group G4 except that the target compressive strength of UHPFRC was $120 \mathrm{MPa}$ in the former and $160 \mathrm{MPa}$ in the later to examine whether the reduction in UHPFRC strength to $120 \mathrm{MPa}$ would make a difference in the structural behavior, crack pattern and ultimate load carrying capacity of the slab. Slabs in this group were designated as $\mathrm{S}_{24}, \mathrm{~S}_{25}, \mathrm{~S}_{26}$, and $\mathrm{S}_{27}$, with 
bar splice lengths into the joint of 75, 105, 135 and $165 \mathrm{~mm}$, respectively. This made the joint widths of $125,155,185$ and $215 \mathrm{~m}$ for slabs $\mathrm{S}_{24}, \mathrm{~S}_{25}, \mathrm{~S}_{26}$, and $\mathrm{S}_{27}$, respectively.

\subsection{Specimen preparation}

\subsubsection{Form work}

To construct the specimens, timber forms were constructed using plywood sheets and $2 \times 4$ lumber cut to size, strengthened, oiled and sealed and made ready for the placement of the reinforcement ad depicted in Figures 3.17 through 3.34.

\subsubsection{Joint forming}

Joints were formed using layers of Styrofoam cut to the exact joint shape, size, and dimensions using a hotwire and grooved to the exact dimensions to let GFRP bars go though as depicted Figures 3.22 through 3.35. The layers of Styrofoam forming the joint were glued together using waterproof special type glue to ensure the layers were bonded together to withstand the pressure resulting from concrete placement.

\subsubsection{Reinforcement assembly}

The longitudinal GFRP bars considered in this study were ordered from the manufacturer as it was cut to the exact bar size required to form the main top and bottom reinforcement as well as the top and bottom transverse reinforcement. The bar meshes were assembled using plastic zip ties and placed in location in the formwork using concrete cover seats as depicted in Figures 3.15 through 3.21. Material properties of the GFRP bare are listed in Table 3.3 as obtained from the GFRP manufacturer. The tensile strength and modulus of elasticity of the bars were $1188 \mathrm{MPa}$ and 64 $\mathrm{GPa}$, respectively. While the tensile strain at rupture was $2.6 \%$. Two bar sizes were considered in 
this study, namely: $12 \mathrm{M}$ and $16 \mathrm{M}$ bars with nominal cross-sectional area of 113 and $201 \mathrm{~mm}^{2}$, respectively. The main tension reinforcement and bottom transverse reinforcement the slabs were considered of M16 bar, while top mesh was considered of M12 bars.

\subsubsection{Bar strain gauge Instrumentation}

GFRP bar strain gauges were used to record strain history during the test. Bar strain-gauges were attached to bottom reinforcing bars as depicted in Figure 3.9. The gauges were installed by marking the location of the gauge on the bar then grinding the surface of the bar using handheld rotating head grinder to remove the GFRP bar ribs at the gauge location and to ensure an even surface for the gauge to be attached and ensure the best bond was achieved. The surface of the bar was cleaned from dust and residues and cleaned with a conditioner and surface neutralizer, then the surface of the gauge and the bar were coated with the glue hardener and a layer of glue was applied to the bar and the gauge was applied to the bar and held in place for a few seconds to ensure the glue was hardened. Figures 3.24 through 3.35 show views of bar stain gauges in different slabs.

\subsubsection{Casting}

The finished forms of the slabs were secured to a flat-leveled ground to ensure perfect level of concrete was achieved when casting. Each slab was cast on two stages. The first stage included casting the cast-in-place slabs and jointed precast slab with target normal strength concrete of 35 $\mathrm{MPa}$, except that cast-in-place slab $\mathrm{S}_{2}$ was cast with target compressive strength of $160 \mathrm{MPa}$ for UHPFRC. Table 3.4 shows typical composition of UHPFRC. However, each supplier provided the dry mix bags without details about the mix design. Vibrators were used to ensure better concrete compaction and to prevent honey combing and air pockets from forming. Then, the top surface of concrete was leveled flush, then left to cure for 28 days while being covered with plastic 
sheets and sprayed with water. After the curing period was over, the joint foam was removed and the joint surface and the GFRP bars were cleaned from any residue and the joint was sprayed with water to prepare it for casting as directed by the UHPFRC supplier. UHPFRC of the joint was mixed in the structures laboratory and cast into the joint as shown Figures 3.39 through 3.52. Then, the joint was covered with a plywood sheet as instructed by the UHPFRC supplier. Concrete cylinder specimens were collected from every batch so that they can be tested on the day of testing of the slabs. Figure 3.53 showed view of the jointed slabs before preparation for the testing. Before the start of each test, the surface of the joint was prepared at specified locations to glue concrete strain gauges. Figures 3.10 and 3.11 depict the locations of concrete strain gauges at the top surface and on the side of the slab at the mid-span location. The slab was then painted in white for the precast panels and light yellow for the UHPFRC joint.

\subsection{Test setup and test procedure}

A four-point loading setup was used in the testing in order to expose the joint to pure flexure. Figure 3.12 shows the test setup for slabs $\mathrm{S}_{1}$ and $\mathrm{S}_{2}$, while Figure 3.13 shows the test setup for slabs $\mathrm{S}_{3}$ through $\mathrm{S}_{19}$. The slab was supported over steel pedestals and on top of the left pedestals. A hinged support was utilized at the left support line using a steel rod sandwiched between two grooved steel plates while at the right support line, a roller support was formed on top of the pedestal using a steel rod sandwiched between two flat steel plates. In slabs S20 to S27, the fourpoint loading was adjusted as shown in Figure 3.14 so that the middle point loads were located just over the joint to increase the tendency for flexural failure mode. Two linear variable displacement transducers (LVDTs) were installed at the mid-span to measure the deflection as depicted in Figures 3.12 through 3.14. The load was applied gradually in increments of $10 \mathrm{kN}$ till 
failure so that initiation of cracks and crack propagations were recorded. A data acquisition system was used to collect data from sensors during the test. After each test, data collected from sensors were analyzed and presented in graphical format for further discussions. 


\section{Chapter IV \\ Experimental Results}

\subsection{Experimental results}

The proposed research investigates the use of GFRP bars in the closure strip between jointed precast deck panels, which is filled with ultra-high performance fiber-reinforced concrete (UHPFRC). Four different bar splice lengths in the joint were considered in this study, namely: $75,105,135$ and $165 \mathrm{~mm}$, with bar splice spacing taken as 0,75 and $100 \mathrm{~mm} .27$ specimens were constructed and tested to-collapse to determine their structural behavior and load carrying capacity.

Different spacing between spliced bars into the joint were considered, namely, 0, 50, 75 and 100 $\mathrm{mm}$. Correlation between experimental findings and available design equations for moment and shear capacities was conducted, leading to recommendations for the use of the proposed joints between precast deck panels in slab-on-girder bridges. This chapter discusses the behavior of the tested cast-in-place and jointed slabs as obtained from experimental findings in the form of cracking patterns, ultimate capacity, deflection pattern, ultimate deflection and load-strain relationships. Concrete cylinder specimens were tested to-collapse at the time of each test to determine the average compressive strength of normal-strength concrete as well as UHPFRC. Table 4.1 summaries the results from these tests for each slab.

\subsubsection{Cracking pattern, ultimate capacity, and failure modes}

The following section discusses the failure modes, cracking patterns and ultimate load carrying capacity of the tested slabs. 


\subsubsection{Control Group}

Figures 4.1 through 4.2 show views of cracks in the control cast-in-place slab $\mathrm{S}_{1}$. It was observed that the first flexural crack appeared at $23.25 \mathrm{kN}$ at the mid-span location, followed by other flexural cracks appearing within the quarter points of the slab and propagating vertically upwards the top of the slab. As the load increased, some cracks started to deviate diagonally around the slab quarter points, leading to sudden flexural-shear failure between the point load the support at an ultimate load of 137.08 kN.m.

Slab $\mathrm{S}_{2}$ which was made entirely from UHPFRC had the test setup before and after testing as depicted in Figures 4.3 and 4.4, respectively. The slab had the first flexural crack visually observed at the mid-span region at a load increment of $88.15 \mathrm{kN}$. In contrast to the flexural crack in slab $\mathrm{S}_{1}$, steel fibers appeared bridging the flexural crack. With increase in the applied load, other flexural cracks appeared between the two loading points as shown in Figures 4.5. Cracks continued widening and propagating to the top surface of the slab till a sudden compression failure occurred at the top of the slab at about $150 \mathrm{~mm}$ from the mid-span point. The slab failed in pure flexural mode at an ultimate load of $236.72 \mathrm{kN}$.

Slab $\mathrm{S}_{3}$ which was identical to slab $\mathrm{S}_{1}$ with continuous GFRP bars between supports but with UHPFRC-filled joint at the mid-span was with UHPFRC joint. Figures 4.6 and 4.7 show views of the slab test setup before and after failure. The first flexural crack was observed at the interface between the precast concrete and the UHPFRC-filled joint at $21.05 \mathrm{kN}$. This crack continued propagating upward along the interface of the joint and the precast slab till almost half the depth of the shear key, then it deviated diagonally away from the shear key and into the precast slab as depicted in Figure 4.9. Other flexural cracks within the precast slab started to appear at a load increment of $30 \mathrm{kN}$ between the loading point and the mid-span. Other diagonal cracks appeared 
between the point load and the supports at higher loads till a sudden flexural-shear failure took place at an ultimate load of $149.68 \mathrm{kN}$ as shown in Figures 4.11 and 4.12. Figures 4.129 4.130 show the cracking pattern from the two sides of slabs $S_{1}, S_{2}$ and $S_{3}$ when stacked on top of each other. One may observe that the use of UHPFRC in slab $\mathrm{S}_{2}$ in lieu of normal strength concrete in slab $S_{1}$ changed the failure mode from flexural-shear to pure flexural mode and increased the slab ultimate load carrying capacity by $73 \%$. When comparing results for slabs $S_{1}$ and $S_{3}$, it can be observed that the increase of material strength within 185 width at the mid-span using UHPFRC increased the load carrying capacity of the slab by $9 \%$ while the failure more remained unchanged.

\subsubsection{Group G1}

Slabs in Group G1 had contact spliced bars with different splice length and associated joint width. The jointed slab $\mathrm{S}_{4}$ with splice length of $75 \mathrm{~mm}$ and joint width of $125 \mathrm{~mm}$ was tested to-collapse with setup before and after failure as depicted in Figures 4.10 and 4.11. The first flexural crack was observed at the interface between the precast concrete and the UHPFRC-filled joint at 21.35 $\mathrm{kN}$. This crack continued propagating upward along the interface of the joint and the precast slab with increase in applied load as depicted in Figure 4.14. Other flexural cracks within the precast slab started to appear between the quarter points of the slab and continued propagating towards the top of the slab causing flexural failure at an ultimate load of $99.34 \mathrm{kN}$ as shown in Figures 4.12 and 4.13 .

The jointed slab $\mathrm{S}_{5}$ with splice length of $105 \mathrm{~mm}$ and joint width of $155 \mathrm{~mm}$ was tested to-collapse with setup before and after failure as depicted in Figures 4.14 and 4.15. The first flexural crack was observed at the interface between the precast concrete and the UHPFRC-filled joint at 23.65 $\mathrm{kN}$. This crack continued propagating upward along the interface of the joint and the precast slab with increase in applied load as depicted in Figure 4.17. Other flexural cracks within the precast 
slab started to appear between the quarter points of the slab and continued propagating towards the top of the slab causing flexural failure at an ultimate load of $120.32 \mathrm{kN}$ as shown in Figures 4.16 and 4.17 .

The jointed slab $\mathrm{S}_{6}$ with splice length of $135 \mathrm{~mm}$ and joint width of $185 \mathrm{~mm}$ was tested to-collapse with setup before and after failure as depicted in Figures 4.18 and 4.19. The first flexural crack was observed at the interface between the precast concrete and the UHPFRC-filled joint at 22.80 $\mathrm{kN}$. This crack continued propagating upward along the interface of the joint and the precast slab with increase in applied load as depicted in Figure 4.21. Other flexural cracks within the precast slab started to appear between the quarter points of the slab and continued propagating towards the top of the slab with increase of applied load. Also, other diagonal cracks appeared just beside the point load on the support side and propagated further in the slab thickness till reaching a sudden flexural-shear failure at an ultimate load of $135.74 \mathrm{kN}$ as shown in Figures 4.20 and 4.21.

The jointed slab $\mathrm{S}_{7}$ with splice length of $165 \mathrm{~mm}$ and joint width of $215 \mathrm{~mm}$ was tested to-collapse with setup before and after failure as depicted in Figures 4.22 and 4.23. The first flexural crack was observed at the interface between the precast concrete and the UHPFRC-filled joint at 23.55 $\mathrm{kN}$. This crack continued propagating upward along the interface of the joint and the precast slab with increase in applied load as depicted in Figure 4.25. Other flexural cracks within the precast slab started to appear between the quarter points of the slab and continued propagating towards the top of the slab with increase of applied load. Also, other diagonal cracks appeared just beside the point load on the support side and propagated further in the slab thickness till reaching a sudden flexural-shear failure at an ultimate load of $131.82 \mathrm{kN}$ as shown in Figures 4.24 and 4.25. 
Figures 4.107 and 4.108 show the cracking pattern from the two sides of slabs $\mathrm{S}_{4}, \mathrm{~S}_{5}, \mathrm{~S}_{6}$ and $\mathrm{S}_{7}$ when stacked on top of each other. One may observe that with increase in bar splice length and hence the joint width, the failure mode changed from pure flexural to combined flexural and shear. When comparing results for slabs $\mathrm{S}_{4}$ and $\mathrm{S}_{5}$ of the same failure mode, it can be observed that the increase of splice length from 75 to $105 \mathrm{~mm}$ increased the slab capacity by $21 \%$. Also, when comparing results for slabs $\mathrm{S}_{5}$ and $\mathrm{S}_{6}$, it can be observed that the increase of splice length from 105 to $135 \mathrm{~mm}$ increased the slab capacity by $13 \%$ and changed the failure mode from flexural to combined-flexure and shear. Moreover, when comparing results for slabs $\mathrm{S}_{6}$ and $\mathrm{S}_{7}$, it can be observed that the increase of splice length from 135 to $165 \mathrm{~mm}$ showed slight change in the load carrying capacity of 3\% while the failure mode remained unchanged. The slight difference of 3\% may be attributed to the slight difference in compressive strength of the concrete materials as depicted in Table 4.1. So, it can be concluded that the load carrying capacity of the slab may remain unchanged increase in splice length beyond $135 \mathrm{~mm}$ and hence the joint width beyond $185 \mathrm{~mm}$. In slabs $\mathrm{S}_{4}$ and $\mathrm{S}_{5}$, one may observe that the flexural crack at the interface between the UHPFRC and the precast slab was too wide to the extent that bar slip from the UHPFRC occurred. To investigate this possibility, a core sample was taken from each slab and then sliced at the bar location to examine whether the bar slipped from concrete. Figure 4.119 and 4.120 show views of the sliced core sample showing the end of the GFRP bar slipped from concrete at its end as well as shearing of bar ribs, respectively.

\subsubsection{Group G2}

Slabs in Group G2 had non-contact spliced bars with spacing between spliced bars of $50 \mathrm{~mm}$ but with different splice lengths and associated joint widths. The jointed slab $\mathrm{S}_{8}$ with splice length of $75 \mathrm{~mm}$ and joint width of $125 \mathrm{~mm}$ was tested to-collapse with setup before and after failure as 
depicted in Figures 4.26 and 4.27. The first flexural crack was observed at the interface between the precast concrete and the UHPFRC-filled joint at $22.05 \mathrm{kN}$. This crack continued propagating upward along the interface of the joint and the precast slab with increase in applied load as depicted in Figure 4.29. Other flexural cracks within the precast slab started to appear between the quarter points of the slab and continued propagating towards the top of the slab. However, the flexural crack at the joint-precast slab interface continued to widen till slip occurred in the bar from UHPFRC causing no increase in the applied load that reached 88.74. Figures 4.28 and 4.29 show view of the flexural failure mode of this jointed slab.

The jointed slab $\mathrm{S}_{9}$ with splice length of $105 \mathrm{~mm}$ and joint width of $155 \mathrm{~mm}$ was tested to-collapse with setup before and after failure as depicted in Figures 4.30 and 4.31. The first flexural crack was observed at the interface between the precast concrete and the UHPFRC-filled joint at 20.40 $\mathrm{kN}$. This crack continued propagating upward along the interface of the joint and the precast slab with increase in applied load as depicted in Figure 4.33. Other flexural cracks within the precast slab started to appear between the quarter points of the slab and continued propagating towards the top of the slab causing flexural failure at an ultimate load of $110.24 \mathrm{kN}$ as shown in Figures 4.32 and 4.33. Similar observation regarding bar slip from UHPFRC at failure was noted through the very wide flexural crack at through the wide flexural crack at the joint-precast slab interface.

The jointed slab $\mathrm{S}_{10}$ with splice length of $135 \mathrm{~mm}$ and joint width of $185 \mathrm{~mm}$ was tested to-collapse with setup before and after failure as depicted in Figures 4.34 and 4.35 . The first flexural crack was observed at the interface between the precast concrete and the UHPFRC-filled joint at 22.1 $\mathrm{kN}$. This crack continued propagating upward along the interface of the joint and the precast slab with increase in applied load as depicted in Figure 4.37. Other flexural cracks within the precast slab started to appear between the quarter points of the slab and continued propagating towards 
the top of the slab causing flexural failure at an ultimate load of $128.41 \mathrm{kN}$ as shown in Figures 4.36 and 4.37. Similar observation regarding bar slip from UHPFRC at failure was noted through the very wide flexural crack at through the wide flexural crack at the joint-precast slab interface but it was not as wide as those in slabs $\mathrm{S}_{8}$ and $\mathrm{S}_{9}$.

The jointed slab $\mathrm{S}_{11}$ with splice length of $165 \mathrm{~mm}$ and joint width of $215 \mathrm{~mm}$ was tested to-collapse with setup before and after failure as depicted in Figures 4.38 and 4.39. The first flexural crack was observed at the interface between the precast concrete and the UHPFRC-filled joint at 19.55 $\mathrm{kN}$. This crack continued propagating upward along the interface of the joint and the precast slab with increase in applied load as depicted in Figure 4.40. Other flexural cracks within the precast slab started to appear between the quarter points of the slab and continued propagating towards the top of the slab causing flexural failure at an ultimate load of $128.41 \mathrm{kN}$ as shown in Figures 4.41 and 4.42. Similar observation regarding bar slip from UHPFRC at failure was noted through the very wide flexural crack at through the wide flexural crack at the joint-precast slab interface.

Figures 4.109 and 4.110 show the cracking pattern from the two sides of slabs $\mathrm{S}_{8}, \mathrm{~S}_{9}, \mathrm{~S}_{10}$ and $\mathrm{S}_{11}$ when stacked on top of each other. One may observe that with increase in bar splice length and hence the joint width, the failure mode remained unchanged. When comparing results for slabs $\mathrm{S}_{8}, \mathrm{~S}_{9}, \mathrm{~S}_{10}$ and $\mathrm{S}_{11}$ of the same failure mode, it can be observed that the slab capacity increased by $24 \%, 24 \%$ and $45 \%$ with increase of splice length from 75 to 105,135 and $165 \mathrm{~mm}$, respectively.

\subsubsection{Group G3}

Slabs in Group G3 had contact spliced bars at spacing of $100 \mathrm{~mm}$ but with different splice length and associated joint width. The jointed slab $\mathrm{S}_{12}$ with splice length of $75 \mathrm{~mm}$ and joint width of 125 $\mathrm{mm}$ was tested to-collapse with setup before and after failure as depicted in Figures 4.42 and 4.43. The first flexural crack was observed at the interface between the precast concrete and the 
UHPFRC-filled joint at $18.30 \mathrm{kN}$. This crack continued propagating upward along the interface of the joint and the precast slab with increase in applied load as depicted in Figure 4.44. Other flexural cracks within the precast slab started to appear between the quarter points of the slab and continued propagating towards the top of the slab causing flexural failure at an ultimate load of $97.71 \mathrm{kN}$ as shown in Figures 4.44 and 4.45. Indication of bar slip from UHPFRC at failure was noted through the very wide flexural crack at through the wide flexural crack at the joint-precast slab interface.

The jointed slab $\mathrm{S}_{13}$ with splice length of $105 \mathrm{~mm}$ and joint width of $155 \mathrm{~mm}$ was tested to-collapse with setup before and after failure as depicted in Figures 4.46 and 4.47. The first flexural crack was observed at the interface between the precast concrete and the UHPFRC-filled joint at 18.68 $\mathrm{kN}$. This crack continued propagating upward along the interface of the joint and the precast slab with increase in applied load as depicted in Figure 4.48. Other flexural cracks within the precast slab started to appear between the quarter points of the slab and continued propagating towards the top of the slab causing flexural failure at an ultimate load of $117.51 \mathrm{kN}$ as shown in Figure 4.49. Similar observation to slab $S_{12}$ was noted regarding bar slip from UHPFRC at failure through the very wide flexural crack at through the wide flexural crack at the joint-precast slab interface

The jointed slab $\mathrm{S}_{14}$ with splice length of $135 \mathrm{~mm}$ and joint width of $185 \mathrm{~mm}$ was tested to-collapse with setup before and after failure as depicted in Figures 4.50 and 4.51. The first flexural crack was observed at the interface between the precast concrete and the UHPFRC-filled joint at 18.68 $\mathrm{kN}$. This crack continued propagating upward along the interface of the joint and the precast slab with increase in applied load as depicted in Figure 4.52. Other flexural cracks within the precast slab started to appear between the quarter points of the slab and continued propagating towards the top of the slab with increase of applied load. Failure appeared to occurs due to bar slip from 
UHPFRC resulting in wide flexural cracking at the joint-precast slab interface at an ultimate load of $133.74 \mathrm{kN}$ as shown in Figures 4.52 and 4.53.

The jointed slab $\mathrm{S}_{15}$ with splice length of $165 \mathrm{~mm}$ and joint width of $215 \mathrm{~mm}$ was tested to-collapse with setup before and after failure as depicted in Figures 4.54 and 4.55. The first flexural crack was observed at the interface between the precast concrete and the UHPFRC-filled joint at 18.90 $\mathrm{kN}$. This crack continued propagating upward along the interface of the joint and the precast slab with increase in applied load as depicted in Figure 4.56. Other flexural cracks within the precast slab started to appear between the quarter points of the slab and continued propagating towards the top of the slab with increase of applied load. Also, other diagonal cracks appeared just beside the point load on the support side and propagated further in the slab thickness till reaching a sudden flexural-shear failure at an ultimate load of $136.86 \mathrm{kN}$ as shown in Figures 4.56 and 4.75.

Figures 4.111 and 4.112 show the cracking pattern from the two sides of slabs $\mathrm{S}_{12}, \mathrm{~S}_{13}, \mathrm{~S}_{14}$ and $\mathrm{S}_{15}$ when stacked on top of each other. One may observe that with increase in bar splice length and hence the joint width, the failure mode changed from pure flexural to combined flexural and shear. When comparing results for slabs $\mathrm{S}_{12}, \mathrm{~S}_{13}$ and $\mathrm{S}_{14}$ of the same failure mode, it can be observed that the slab capacity increased by $20 \%$ and $37 \%$ with increase in splice length from 75 to 105 and $135 \mathrm{~mm}$, respectively. Also, when comparing results for slabs $\mathrm{S}_{14}$ and $\mathrm{S}_{15}$, it can be observed that the increase of splice length from 135 to $165 \mathrm{~mm}$ increased the slab capacity by only $2.3 \%$ while the failure mode changed from flexural to combined-flexure and shear. The slight difference of 3\% may be attributed to the slight difference in compressive strength of the concrete materials as depicted in Table 4.1. So, it can be concluded that the load carrying capacity of the slab may remain unchanged increase in splice length beyond $135 \mathrm{~mm}$ and hence the joint width beyond $185 \mathrm{~mm}$. 


\subsubsection{Group G4}

The Slabs in Group G4 had contact spliced bars of spacing $75 \mathrm{~mm}$ with different splice length and associated joint width. The jointed slab $\mathrm{S}_{16}$ with splice length of $75 \mathrm{~mm}$ and joint width of $125 \mathrm{~mm}$ was tested to-collapse with setup before and after failure as depicted in Figures 4.58 and 4.59. The first flexural crack was observed at the interface between the precast concrete and the UHPFRCfilled joint at $9.26 \mathrm{kN}$. This crack continued propagating upward along the interface of the joint and the precast slab with increase in applied load as depicted in Figure 4.60. Other flexural cracks within the precast slab started to appear between the quarter points of the slab and continued propagating towards the top of the slab causing flexural failure at an ultimate load of $105.79 \mathrm{kN}$ as shown in Figures 4.60 and 4.61. Observations regarding very wide flexural crack at the jointprecast interface was noted as an indication of bar slip from UHPFRC.

The jointed slab $\mathrm{S}_{17}$ with splice length of $105 \mathrm{~mm}$ and joint width of $155 \mathrm{~mm}$ was tested to-collapse with setup before and after failure as depicted in Figures 4.62 and 4.63. The first flexural crack was observed at the interface between the precast concrete and the UHPFRC-filled joint at 12.60 $\mathrm{kN}$. This crack continued propagating upward along the interface of the joint and the precast slab with increase in applied load as depicted in Figure 4.64. Other flexural cracks within the precast slab started to appear between the quarter points of the slab and continued propagating towards the top of the slab. While sudden diagonal crack occurred between the point load and the support leading to flexural-shear failure at an ultimate load of $109.06 \mathrm{kN}$ as shown in Figures 4.64 and 4.65 .

The jointed slab $\mathrm{S}_{18}$ with splice length of $135 \mathrm{~mm}$ and joint width of $185 \mathrm{~mm}$ was tested to-collapse with setup before and after failure as depicted in Figures 4.66 and 4.67. The first flexural crack was observed at the interface between the precast concrete and the UHPFRC-filled joint at 12.53 
$\mathrm{kN}$. This crack continued propagating upward along the interface of the joint and the precast slab with increase in applied load as depicted in Figure 4.68. Other flexural cracks within the precast slab started to appear between the quarter points of the slab and continued propagating towards the top of the slab with increase of applied load. Also, a few diagonal cracks appeared just beside the point load on the support side and propagated further in the slab thickness till reaching a sudden flexural-shear failure at an ultimate load of $110.02 \mathrm{kN}$ as shown in Figure 4.69.

The jointed slab $\mathrm{S}_{19}$ with splice length of $165 \mathrm{~mm}$ and joint width of $215 \mathrm{~mm}$ was tested to-collapse with setup before and after failure as depicted in Figures 4.70 and 4.71. The first flexural crack was observed at the interface between the precast concrete and the UHPFRC-filled joint at 19.50 $\mathrm{kN}$. This crack continued propagating upward along the interface of the joint and the precast slab with increase in applied load as depicted in Figure 4.72. Other flexural cracks within the precast slab started to appear between the quarter points of the slab and continued propagating towards the top of the slab with increase of applied load till a sudden diagonal shear crack failure occurred between the point load and the support at an ultimate load of $120.70 \mathrm{kN}$ as shown in Figures 4.72 and 4.73 .

Figures 4.113 and 4.114 show the cracking pattern from the two sides of slabs $\mathrm{S}_{16}, \mathrm{~S}_{17}, \mathrm{~S}_{18}$ and $\mathrm{S}_{19}$ when stacked on top of each other. One may observe that with increase in bar splice length and hence the joint width, the failure mode changed from pure flexural to combined flexural and shear. When comparing results for slabs $\mathrm{S}_{16}$ and $\mathrm{S}_{17}$ of the same failure mode, it can be observed that the increase of splice length from 75 to $105 \mathrm{~mm}$ increased the slab capacity by only $3 \%$ while the failure mode changed from flexural to combined flexural and shear. Also, when comparing results for slabs $\mathrm{S}_{17} \mathrm{~S}_{18}$ and $\mathrm{S}_{19}$, it can be observed that slab capacity increased by $0.9 \%$ and $11 \%$ when 
splice length changes from 105 to 135 and $165 \mathrm{~mm}$, respectively, with failure more remained unchanged.

\subsubsection{Group G5}

Slabs in Group G5 had contact spliced bars with spacing of $50 \mathrm{~mm}$ but with different splice length and associated joint width. The jointed slab $S_{20}$ with splice length of $75 \mathrm{~mm}$ and joint width of 125 mm was tested to-collapse with setup before and after failure as depicted in Figures 4.74 and 4.75. The first flexural crack was observed at the interface between the precast concrete and the UHPFRC-filled joint at $7.71 \mathrm{kN}$. This crack continued propagating upward along the interface of the joint and the precast slab with increase in applied load as depicted in Figure 4.76. Other flexural cracks within the precast slab started to appear between the quarter points of the slab and continued propagating towards the top of the slab causing flexural failure at an ultimate load of $60.57 \mathrm{kN}$ as shown in Figures 4.76 and 4.77.

The jointed slab $\mathrm{S}_{21}$ with splice length of $105 \mathrm{~mm}$ and joint width of $155 \mathrm{~mm}$ was tested to-collapse with setup before and after failure as depicted in Figures 4.78 and 4.79. The first flexural crack was observed at the interface between the precast concrete and the UHPFRC-filled joint at 7.55 $\mathrm{kN}$. This crack continued propagating upward along the interface of the joint and the precast slab with increase in applied load as depicted in Figure 4.80. Other flexural cracks within the precast slab started to appear between the quarter points of the slab and continued propagating towards the top of the slab causing flexural failure at an ultimate load of $77.40 \mathrm{kN}$ as shown in Figures 4.80 and 4.81 .

The jointed slab $\mathrm{S}_{22}$ with splice length of $135 \mathrm{~mm}$ and joint width of $185 \mathrm{~mm}$ was tested to-collapse with setup before and after failure as depicted in Figures 4.82 and 4.83 . The first flexural crack was observed at the interface between the precast concrete and the UHPFRC-filled joint at 10.16 
$\mathrm{kN}$. This crack continued propagating upward along the interface of the joint and the precast slab with increase in applied load as depicted in Figure 4.84. Other flexural cracks within the precast slab started to appear between the quarter points of the slab and continued propagating towards the top of the slab with increase of applied load. Also, other diagonal cracks appeared just beside the point load on the support side and propagated further in the slab thickness till reaching a sudden flexural-shear failure at an ultimate load of $79.25 \mathrm{kN}$ as shown in Figures 4.84 and 4.85.

The jointed slab $\mathrm{S}_{23}$ with splice length of $165 \mathrm{~mm}$ and joint width of $215 \mathrm{~mm}$ was tested to-collapse with setup before and after failure as depicted in Figures 4.86 and 4.87. The first flexural crack was observed at the interface between the precast concrete and the UHPFRC-filled joint at 10.53 $\mathrm{kN}$. This crack continued propagating upward along the interface of the joint and the precast slab with increase in applied load as depicted in Figure 4.88. Other flexural cracks within the precast slab started to appear between the quarter points of the slab and continued propagating towards the top of the slab with increase of applied load. Also, other diagonal cracks appeared just beside the point load on the support side and propagated further in the slab thickness till reaching a sudden flexural-shear failure at an ultimate load of $79.25 \mathrm{kN}$ as shown in Figures 4.88 and 4.89.

Figures 4.117 and 4.115 show the cracking pattern from the two sides of slabs $\mathrm{S}_{20}, \mathrm{~S}_{21}, \mathrm{~S}_{22}$ and $\mathrm{S}_{23}$ when stacked on top of each other. One may observe that with increase in bar splice length and hence the joint width, the failure mode changed from pure flexural to combined flexural and shear. When comparing results for slabs $\mathrm{S}_{20}$ and $\mathrm{S}_{21}$ of the same failure mode, it can be observed that the increase of splice length from 75 to $105 \mathrm{~mm}$ increased the slab capacity by $28 \%$. Also, when comparing results for slabs $S_{21}$ and $S_{22}$, it can be observed that the increase of splice length from 105 to $135 \mathrm{~mm}$ increased the slab capacity by only $2.4 \%$ while the failure mode changed from flexural to combined-flexure and shear. Moreover, when comparing results for slabs $\mathrm{S}_{22}$ and $\mathrm{S}_{23}$, 
it can be observed that the increase of splice length from 135 to $165 \mathrm{~mm}$ showed slight change in the load carrying capacity of $3 \%$ while the failure mode remained unchanged. The slight difference of 3\% may be attributed to the slight difference in compressive strength of the concrete materials as depicted in Table 4.1. So, it can be concluded that the load carrying capacity of the slab may remain unchanged increase in splice length beyond $135 \mathrm{~mm}$ and hence the joint width beyond 185 $\mathrm{mm}$.

\subsubsection{Group G6}

Slabs in Group G6 were identical to those in group G4 but the later has UHPFRC target compressive strength of $120 \mathrm{MPa}$. The jointed slab $\mathrm{S}_{24}$ with splice length of $75 \mathrm{~mm}$ and joint width of $125 \mathrm{~mm}$ was tested to-collapse with setup before and after failure as depicted in Figures 4.90 and 4.91. The first flexural crack was observed at the interface between the precast concrete and the UHPFRC-filled joint at $6.75 \mathrm{kN}$. This crack continued propagating upward along the interface of the joint and the precast slab with increase in applied load as depicted in Figure 4.92. Other flexural cracks within the precast slab started to appear between the quarter points of the slab and continued propagating towards the top of the slab causing flexural failure at an ultimate load of $73.25 \mathrm{kN}$ as shown in Figures 4.92 and 4.93.

The jointed slab $\mathrm{S}_{25}$ with splice length of $105 \mathrm{~mm}$ and joint width of $155 \mathrm{~mm}$ was tested to-collapse with setup before and after failure as depicted in Figures 4.94 and 4.95. The first flexural crack was observed at the interface between the precast concrete and the UHPFRC-filled joint at 5.33 $\mathrm{kN}$. This crack continued propagating upward along the interface of the joint and the precast slab with increase in applied load as depicted in Figure 4.96. Other flexural cracks within the precast slab started to appear between the quarter points of the slab and continued propagating towards the top of the slab causing flexural failure at an ultimate load of $89.19 \mathrm{kN}$ as shown in Figure 4.97. 
The jointed slab $\mathrm{S}_{26}$ with splice length of $135 \mathrm{~mm}$ and joint width of $185 \mathrm{~mm}$ was tested to-collapse with setup before and after failure as depicted in Figures 4. 97 and 4.98. The first flexural crack was observed at the interface between the precast concrete and the UHPFRC-filled joint at 5.49 $\mathrm{kN}$. This crack continued propagating upward along the interface of the joint and the precast slab with increase in applied load as depicted in Figure 4.99. Other flexural cracks within the precast slab started to appear between the quarter points of the slab and continued propagating towards the top of the slab with increase of applied load. Also, other diagonal cracks appeared just beside the point load on the support side and propagated further in the slab thickness till reaching a sudden flexural-shear failure at an ultimate load of $105.35 \mathrm{kN}$ as shown in Figures 4.99 and 4.100. One may observe that wide flexural crack occurred at the joint-precast slab interface indicating bar slip from concrete at failure. So, two types of failure appeared in this specimen at failure, namely: flexural failure at the joint-precast slab interface due to bar slippage and flexural-shear failure just beside the point load towards the support.

The jointed slab $\mathrm{S}_{27}$ with splice length of $165 \mathrm{~mm}$ and joint width of $215 \mathrm{~mm}$ was tested to-collapse with setup before and after failure as depicted in Figures 4.101 and 4.102. The first flexural crack was observed at the interface between the precast concrete and the UHPFRC-filled joint at 4.30 $\mathrm{kN}$. This crack continued propagating upward along the interface of the joint and the precast slab with increase in applied load as depicted in Figure 4.103. Other flexural cracks within the precast slab started to appear between the quarter points of the slab and continued propagating towards the top of the slab with increase of applied load. Also, other diagonal cracks appeared just beside the point load on the support side and propagated further in the slab thickness till reaching an ultimate load of $100.3125 \mathrm{kN}$. This slab showed signs of wide flexural crack at the joint-precast slab interface indicating bar slippage from UHPFRC as shown in Figures 4.103 and 4.104. 
Figures 4.117 and 4.118 show the cracking pattern from the two sides of slabs $\mathrm{S}_{24}, \mathrm{~S}_{25}, \mathrm{~S}_{26}$ and $\mathrm{S}_{27}$ when stacked on top of each other. One may observe that with increase in bar splice length and hence the joint width, the failure mode remained generally unchanged as flexural mode with an exception of slab $\mathrm{S}_{26}$ that showed flexural crack at joint-precast slab interface combined with flexural-shear crack almost at the quarter point. When comparing results for slabs $\mathrm{S}_{24}, \mathrm{~S}_{25}$ and $\mathrm{S}_{26}$, it can be observed that the slab capacity increased by $22 \%$ and $44 \%$ when increasing the splice length from 75 to 105 and $135 \mathrm{~mm}$, respectively. Also, when comparing results for slabs $\mathrm{S}_{26}$ and $\mathrm{S}_{27}$, it can be observed that the increase of splice length from 135 to $165 \mathrm{~mm}$ changed the slab capacity by only $5 \%$.

\subsubsection{Deflection patterns and ultimate strain}

Figures 4.121 through 4.127 present the load-deflection relationships for each test group, this relationship could be used to indicate the change in slab flexural stiffness due to cracking.

Figure 4.121 shows incremental load-deflection relationship of slabs $\mathrm{S}_{1}, \mathrm{~S}_{2}$ and $\mathrm{S}_{3}$ in the control group. It can be observed that slab $\mathrm{S}_{1}$ with normal strength concrete and $\mathrm{S}_{3}$, both with continuous bars had identical load-deflection relationships irrespective of the presence of the $185 \mathrm{~mm}$ wide UHPFRC joint. The load-deflection relationship for both slabs followed an elastic pattern up to the cracking load. The cracking load of $\mathrm{S}_{1}$ was slightly but non-significantly higher than that of $\mathrm{S}_{3}$ due to the presence of a cold joint at the interface of the shear key. The failure of slabs $\mathrm{S}_{1}$ and $\mathrm{S}_{3}$ exhibited similar deflection change in response to increasing the load, reaching an ultimate deflection of 51.57 and $68.94 \mathrm{~mm}$, respectively. Slab $\mathrm{S}_{2}$ being entirely from UHPFRC exhibited a more ductile behavior with linearly elastic load-deflection relationship up to $88.15 \mathrm{kN}$. Then, flexural stiffness started to decrease as cracks started to develop and the load-deflection relationship stated to experience a non-linear behavior up to about $216.6 \mathrm{kN}$ then the load dropped 
as the curve proceeded in a negative slope to reach $206 \mathrm{kN}$ reaching a point of zero slope. Then, the slab picked up the load and hence the load-deflection relationship continued in a positive slope in a linear manner till failure at $236.72 \mathrm{kN}$. Slabs in groups G1 to G6 followed the same behavior of the control Slabs $S_{1}$ and $S_{3}$. A comparison of the deflection values of slabs in groups G1, G2, and $\mathrm{G} 3$ to the deflection of $\mathrm{S}_{1}$ and $\mathrm{S}_{3}$ is presented in Table 4.9.

Figure 4.128 through 4.181 presents the load-concrete strain relationship load-bar strain relationship for slabs $\mathrm{S}_{1}$ through $\mathrm{S}_{27}$. Summary of the ultimate concrete strain gauges, and bars strain gauges are presented in Tables 4.2 through Table 4.7. Comparisons have been conducted between the control slabs and slabs in group G1, G2, and G3, in terms of ultimate load, ultimate deflection, ultimate bottom reinforcement strain, and the ultimate concrete top compression fibers strain respectively.

Table 4.3 presents a comparison of the bar stress at failure resulting from multiplying ultimate bar strain by bar modulus of elasticity. Then, the bar stress was compared to the bar tensile strength as obtained from the manufacturer. This gives an indication of the level of bar stress at failure. One may notice that bar tensile stresses at slab failure were generally less than the guaranteed tensile strength of the bar except for a few specimens with greatest joint width. On the other hand, when comparing experimental ultimate strain values with the ultimate tensile strain of the bar of $2.6 \%$ as provided by the manufacturers, one may observe that all bars remained in the elastic range at slab failure.

\subsection{Effect of lap splice spacing and joint width}

Figure 4.206 shows the change in the experimental ultimate load with the change in the lap splice spacing. One may observe that the change of lap splice spacing as 0,50 and $100 \mathrm{~mm}$ 
appears to have insignificant change in general if the change was considered for contact splice bars and the $100 \mathrm{~mm}$ spaced slice bars. The data in the graph for $50 \mathrm{~mm}$ lap splice spacing is considered relatively scattered with other data for the joint width of $185 \mathrm{~mm}$. Figure 4.207 depicts the change in the resisting moment per meter width of the tested slab with the change in bar spacing from 100 to $200 \mathrm{~mm}$ with increment of $50 \mathrm{~mm}$. It can be observed that the moment capacity per meter width decreases with increase bar spacing, as expected. Figures 4.208 and 4.209 present the change of the experimental failure moment per meter width with the increase in bar splice length and bar development length into the joint, respectively. It can be observed that the slab resisting moment generally increases with increase in bar lap splice length as well as the development length.

\subsection{Theoretical moment and shear capacities}

Theoretical moment and shear capacities for the precast slabs were calculated based on ISIS Canada manual No. 3 (ISIS, 2007) and CHBDC of 2014. Sample calculations of the moment and shear capacity of a typical slab is shown in Appendix A. The capacities were calculated using spreadsheets programed based on the equations and procedures presented in the above-mentioned references. These capacities were obtained considering resistance factors for concrete and GFRP bars of 0.75 and 0.55 , respectively. However, the experimental capacity requires a matching resistance factor for the sake of comparison.

Chapter 2 of CHBDC (2014) specifies that the designer shall consider the environmental conditions and deterioration mechanisms for the FRP reinforcement. Clause 16.4 in Chapter 16 of CHBDC refer to durability of GFRP without considering a value for the durability factor to be taken in design. On the other hand, Clause 16.5.3 specifies resistance factors to be considered in design calculations. Such resistance factors are generally associated with uncertainty in material's 
mechanical properties obtained from standard mechanical test method (i.e. tensile strength test method for example). On the other hand, since the publication of the previous edition of the CHBDC, it is now recognized that the variability of the strength of FRPs is affected more by environmental exposure than by geometric properties and stress levels. It is for this reason that experts in the structural use of FRP are now suggesting that the resistance factors for FRPs should be specified as products of a "material" factor and an "environmental" factor (ACI 440, 2002; Karbhari, 2000). However, Clause 16.4 in CHBDC commentaries states that findings from analyses of available data in the literature have confirmed that the concerns about the durability of GFRP in alkaline concrete, based on simulated laboratory studies in alkaline solutions, are unfounded. Thus, the resistance factor for design calculations of GFRP in CHBDC was 0.75, as given in CHBDC Commentaries, which was mainly drawn from the Japanese document (JSCE, 1997).

It is common practice that structural members shall be designed by one of the following methods:

(a) standard design procedures and practices provided by the design code and any standards and specifications referred to in this code, or

(b) one of the following three bases of design,

(i) analysis based on generally established theory,

(ii) evaluation of a given full-scale structure or a prototype by a loading tester,

(iii) or studies of model analogues,

provided the design ensures a level of safety and performance at least equivalent to that provided for or implicit in the design carried out by the methods referred to in Clause (a) above. 
Since the scope of this research is to provide experimental findings to qualify the proposed GFRPreinforced closure strip connecting precast deck slab panels, the experimental factor of safety is considered at least equivalent to 1 to ensure that the experimental capacity is at least equal the factored applied moment in the deck slab specified in CHBDC. In case of using experimental findings to qualify the proposed joint details, the resistance factor for design calculation in nonexistence. However, the author believes that a generic durability factor of 0.75 should apply to the experimental data. Table 4.12 present the factors of safety in design of the proposed joint details in the tested slabs as the ratio between the experimental moment resistance and the theoretical resistance moment as well as the ratio between the experimental shear resistance and the theoretical shear resistance GFRP when a durability factor of 0.75 is introduced to the experimental findings and the code resistance factors are applied to code theoretical equations for resisting moment and shear forces. One may observe that the factors of safety in pure shear capacity in the right column in the table is always more than 1 . However, the factors of safety for moment is less than 1 for the jointed slabs. This may be attributed to the fact that the moment capacity was calculated for the GFRP-reinforced concrete section just outside the joint considering full bond between the GFRP bars and concrete. This criteria of full bond between the bar and concrete may not be applicable herein since the jointed slabs with pure flexural failure exhibited very wide flexural crack at the joint-precast slab interface, indicating bar slip from UHPFRC at slab failure. Also, the factor of safety for only pure moment capacity may not apply to slabs failed in combined flexure and shear. Thus, for design purposes, the experimental findings can directly be compared to the applied factored moment in the deck slab due to dead and live loads to obtain the maximum span between girders so that Design Engineers can implement one of the developed joint details in their projects. The follows section presents the procedure to achieve this task. 


\subsection{Design charts for moment capacity}

Table 4.8 provides a summary of correlation between the jointed slab capacities with respect to that for cast-in-place slab S1 as well as slab S3 with UHPFRC-filled joint but with continuous reinforcement through the joint. It can be observed that the capacities of the jointed slab are smaller than those for slabs S1 and S3. Also, it can be observed that the slab capacity increases with increase in joint width. As such, it was decided to be calculated the maximum served span between longitudinal girders in slab-on-girder bridges by comparing the applied factored moment in deck slab due to dead and live load with the experimental values.

The applied transverse moments were calculated based according to Section 5 of CHBDC and using equations 2.23 and 2.24 mentioned in Chapter 2 for live load moment for simple slab and continuous slabs, respectively. Thus, the factored applied moment, $\mathrm{M}_{\mathrm{f}}$, is then given by,

$\mathrm{M}_{\mathrm{f}}=\mathrm{M}_{\mathrm{fD}}+\mathrm{M}_{\mathrm{fL}}$

And

$\mathrm{M}_{\mathrm{fD}}=\mathrm{M}_{\mathrm{slab}}+\mathrm{M}_{\mathrm{asphalt}}$

Where $\mathrm{M}_{\text {slab }}=$ factored moment due to self-weight of the slab, $\mathrm{M}_{\text {asphalt }}=$ factored moment due to weight of asphalt.

Spreadsheet output for transverse moment calculations are presented in appendix A. The slab thickness considered in this study was $200 \mathrm{~mm}$ with unit weight of concrete of $24 \mathrm{kN} / \mathrm{m}^{3}$ and dead load factor of 1.2. The asphalt layer was assumed of $90 \mathrm{~mm}$ thickness and unit weight of 23.5 $\mathrm{kN} / \mathrm{m}^{3}$ with dead load factor of 1.5 . The wheel load for live load moment calculations was 87.5 $\mathrm{kN}$ with dynamic load allowance of 0.4 and live load factor of 1.7 . The applied factored moment in deck slab was calculated for slab spans ranging from 1 to $4.5 \mathrm{~m}$ with 0.5 increments. Two deck slab conditions were considered in this study, namely: simple span deck span supported over two 
girders and deck slab continuous over 3 of more supports. A reduction factor of 0.8 was applied to the live load moment for continuous span deck slab per CHBDC. On the other hand a durability/resistance factor of 0.75 was applied to the experimental resisting moment that was normalized to be per meter width rather than the actual slab width considered in the tested slab.

Figures 4.210 through 4.215 show comparison between the applied factored moments for simple span and continuous span deck slabs against the modified experimental findings for girder spacing ranging from 1 to $4.5 \mathrm{~m}$. From these figures, limiting girder spacing was determined for each joint configuration as the point of intersection of the factored applied moment and the resisting moment obtained experimentally. This data was then summarized in Table 4.13 to assist engineers in selecting the proper joint type per the girder spacing in their bridge project. The use of this data is limited to the materials and geometric conditions in this research. Also, some potential factors of interest could not be addressed in this study. So, bridge designers are expected to include these factors in their design. 


\section{Chapter V Conclusion and Recommendations for Future Research}

\subsection{General}

Glass fiber reinforced polymer (GFRP) bars are used in bridge decks to overcome the problem of corrosion of steel bars and concrete spalling. However, design guidelines for joints between GFRPreinforced precast deck panels supported over girders for accelerated bridge replacement is as yet unavailable. The proposed research investigates the use of GFRP bars in the closure strip between jointed precast deck panels, which is filled with ultra-high performance fiber-reinforced concrete (UHPFRC). Four different bar splice lengths in the joint were considered in this study, namely: $75,105,135$ and $165 \mathrm{~mm}$, with bar splice spacing taken as 0,75 and $100 \mathrm{~mm} .27$ specimens were constructed and tested to-collapse to determine their structural behavior and load carrying capacity. Correlation between experimental findings and available design equations for moment and shear capacities was conducted, leading to recommendations for the use of the proposed joints between precast deck panels in slab-on-girder bridges.

\subsection{Conclusions}

Based on experimental findings and theoretical analysis, the following conclusions can be drawn:

1. The ultimate load capacity of UHPFRC slab reinforced with GFRP bars is higher than the capacity of an identical slab but made from normal strength concrete, as expected. The capacity of precast jointed slab with UHPFRC as filling material in the closure strip and continuous reinforced is slightly higher (about 9\%) than that for cast-in-place slab with identical material and geometric properties. 
2. The capacities of slabs with UHPFRC joints having spliced bars were less than the capacity of cast-in-place slab with made of normal strength concrete and similar GFRP properties.

3. The capacity of the jointed slabs increase as a result of increasing the bar splice length in the joint. Similar conclusion can apply to the bar development length into the joint as well as the joint width.

4. Slabs with joint width of $185 \mathrm{~mm}$ and $215 \mathrm{~mm}$ with contact spliced bars and slab with joint width of $215 \mathrm{~mm}$ with non-contact 100-mm-offset spliced bar spacing experienced flexural-shear failure mode away from the joint. Other slabs experienced flexural failure at the joint-precast slab interface, primarily due to bar slip from UHPFRC.

5. The slab with non-contact configuration of $50 \mathrm{~mm}$ offset yields the lowest capacity for any of the four given joint width, compared to the contact splice and the non-contact equally-spaced splice of $100 \mathrm{~mm}$ spacing which falls almost within the same range of the ultimate capacity for any of the four given joint widths.

6. Design tables and charts specifying the girder spacing limits for each joint configuration were developed based on the moment capacity of each tested jointed slab and the applied factored moment in bridge deck due to dead and live loads. This would assist engineers in selecting the proper joint type per the girder spacing in their bridge project. The use of this data is limited to the materials and geometric conditions in this research. Also, some potential factors of interest could not be addressed in this study. So, bridge designers are expected to include these factors in their design. 


\subsection{Recommendation for future research}

Based on the outcome of this research, the following recommendations for future research can be made:

1. Study of long term effects (creep, shrinkage, freeze/thaw cycles, fatigue loading) that may compromise the developed joints.

2. Investigation of the capacity of joints slabs at the negative moment region when they are subjected to local moment from wheel load and tensile force from the global bending moment on the composite girder.

3. Study the load carrying capacity of deck slabs made of fiber-reinforced concrete.

4. Study the load carrying capacity of the ribs of the ribbed-surface GFRP bars and its effect on the development length. 


\section{Appendix A}

\section{Capacity calculations}

$\underline{\text { Flexural design of GFRP-reinforced concrete section }}$

$\underline{\text { Section dimensions and properties: }}$

$\mathrm{b}=1000 \mathrm{~mm}$

$\mathrm{h}=200 \mathrm{~mm}$

$\mathrm{d}=154 \mathrm{~mm}$

reinforcement type and spacing \#16@200 mm 》》 $\mathrm{A}_{\text {frp }}=1005 \mathrm{~mm}^{2}$

Reinforcement ratio $\rho=\mathrm{A}_{\mathrm{frp}} / \mathrm{bd}=0.00653$

Concrete properties:

$\mathrm{f}_{\mathrm{c}}^{\prime}=44.58 \mathrm{MPa}$

$\mathrm{E}_{\mathrm{c}}=4500 \sqrt{44.58} \mathrm{GPa}$

$\varepsilon_{\mathrm{cu}}=0.0035$

$\varepsilon_{\mathrm{o}}=0.0021 \ldots \ldots \ldots \ldots \ldots . .($ Table 5.7$)$

$\emptyset_{c}=0.75$ 
FRP properties:

$\mathrm{F}_{\mathrm{FRP} \mathrm{u}}=1188 \mathrm{MPa}$

$\mathrm{E}_{\mathrm{FRP}}=64 \mathrm{GPa}$

$\varepsilon_{\mathrm{FRPu}}=0.018562$

$\emptyset_{\mathrm{FRP}}=0.55$

Balanced section properties:

$\alpha 1=0.85-0.0015 f c^{\prime} \geq 0.67 ;=0.85-0.0015(44.58)=0.783$

$\beta 1=0.97-0.0025 f c^{\prime} \geq 0.67 ;=0.97-0.0025(44.58)=0.859$

$\mathrm{c}_{\mathrm{b}}=\frac{\mathrm{d} * \varepsilon_{\mathrm{cu}}}{\varepsilon_{\mathrm{cu}}+\varepsilon_{\mathrm{frpu}}}=24.431 \mathrm{~mm}$

Balanced reinforcement ratio $\rho_{\mathrm{b}}=\alpha 1 \beta 1 \frac{\emptyset_{\mathrm{c}}}{\emptyset_{\mathrm{FRP}}} \frac{\mathrm{f}_{\mathrm{c}}^{\prime}}{\mathrm{f}_{\text {frpu }}}\left(\frac{\varepsilon_{\mathrm{cu}}}{\varepsilon_{\mathrm{cu}}+\varepsilon_{\mathrm{frpu}}}\right)=0.005458$

$\rho_{\text {frp }}>\rho_{\mathrm{b}} \ldots \ldots$ over reinforced section $\gg \gg \gg$ compression failure governs

Over reinforced section properties

$\mathrm{C}=\alpha 1 \beta 1 \emptyset_{\mathrm{c}} \mathrm{f}_{\mathrm{c}}^{\prime} \mathrm{cb}$

$\mathrm{T}=\mathrm{A}_{\mathrm{frp}} \emptyset_{\text {frp }} \varepsilon_{\mathrm{FRP}} \times \mathrm{E}_{\mathrm{FRP}}$

$\varepsilon_{\mathrm{FRP}}=\frac{\mathrm{f}_{\mathrm{FRP}}}{\mathrm{E}_{\mathrm{FRP}}}$, where

$f_{\text {frp }}=0.5 E_{f r p} \varepsilon_{c u}\left[\left(1+\frac{4 \alpha_{1} \beta_{1} \phi_{c} f_{c}^{\prime}}{\rho_{f r p} \phi_{f r p} E_{f r p} \varepsilon_{c u}}\right)^{1 / 2}-1\right]$ 
$\mathrm{f}_{\mathrm{FRP}}=1117.12 \mathrm{MPa}$

Depth of neutral axis after several iterations to satisfy the equilibrium condition $\mathrm{C}=\mathrm{T}$ is:

$\mathrm{c}=26.50 \mathrm{~mm}$

making $\mathrm{C}=\mathrm{T}=608270.666 \mathrm{kN}$

$\operatorname{Mr}=\mathrm{c}\left(\mathrm{d}-\frac{\beta_{1} \mathrm{c}}{2}\right)=84.96 \mathrm{kN} . \mathrm{m}$

$\underline{\text { Minimum flexural resistance should also satisfy this condition }}$

$M_{r} \geq 1.5 M_{c r}$, where $M_{c r}=\frac{f_{r} I_{t}}{y_{t}}$

$f r=0.6 \sqrt{f c^{\prime}}=4.002 \mathrm{MPa}$

$I_{t}=\frac{b h 3}{12}+b h\left(\bar{y}-y_{t}\right)^{2}+(n-1) A_{f r p}(d-\bar{y})^{2}$

$\bar{y}=\frac{(b h) \frac{h}{2}+(n-1) A_{\text {frp }} d}{A_{\text {tr }}}$

$A t r=b h+(n-1) r p$

$n=E_{f r p} / E_{c}$

$E_{c}=\left(3300 \sqrt{f} c^{\prime}+6900\right)=28913.74 \mathrm{MPa}$

$n=E_{f r p} / E_{c}=2.2134$

$A_{t r}=b h+(n-1)=201407.905 \mathrm{~mm}^{2}$

$\overline{\mathrm{y}}=100.4334 \mathrm{~mm}$

$\mathrm{I}_{\mathrm{t}}=6.7 \times 10^{-8} \mathrm{~mm}^{4}$

thus, $\mathrm{M}_{\mathrm{cr}}=23.855 \mathrm{kN} . \mathrm{m} . \gg \gg \gg \gg>1.5 \mathrm{M}_{\mathrm{cr}}=35.78 \mathrm{kN} . \mathrm{m}$

since $M_{r}>1.5 M_{c r} \ldots \ldots$ min. flexural reinforcement is satisfied 


\section{$\underline{\text { Resisting shear force }}$}

Manual calculations for the shear capacity of slab S1

$\mathrm{V}_{\mathrm{c}}=2.5 \beta \emptyset_{\mathrm{c}} \mathrm{f}_{\mathrm{cr}} \mathrm{b}_{\mathrm{v}} \mathrm{d}_{\text {long }}$

$\beta=\left[\frac{0.4}{\left(1+1500 \varepsilon_{\mathrm{x}}\right)}\right] \times\left[\frac{1300}{\left(1000+\mathrm{S}_{\mathrm{ze}}\right)}\right]$

$\varepsilon_{x}=\frac{\frac{M_{f}}{d_{\text {long }}}+V_{f}-V_{p}+0.5 N_{f}-\left(A_{F R P} f_{p o}\right)}{2\left(E_{s} A_{s}+E_{F R P} A_{F R P}\right)} \leq 0.003$

$d_{\text {long }}=$ greater of $\left\{\begin{array}{c}0.75 \mathrm{~h}=0.75(200)=150 \mathrm{~mm} \\ 0.9 \mathrm{~d}=0.9(200-38-8)=138.6 \mathrm{~mm}\end{array}\right.$

$\varepsilon_{\mathrm{x}}=\frac{\frac{91.39 \times 10^{6}}{150}+114.23 \times 10^{3}-0+0.5(0)-(0)}{2(0+64000 \times 1005)}=0.0056>0.003$ then $\varepsilon_{\mathrm{x}}=0.003$

$\beta=\left[\frac{0.4}{(1+1500(0.003))}\right] \times\left[\frac{1300}{(1000+0)}\right]=0.095$

$\mathrm{V}_{\mathrm{c}}=2.5(0.095) \times 0.75 \times(0.4 \times \sqrt{44.58}) \times 1000 \times 150=71.02 \mathrm{kN}$ 


\section{Appendix B}

\section{Spreadsheet output for capacity calculations}

\begin{tabular}{|c|c|c|c|c|c|c|c|c|c|c|c|}
\hline \multirow{3}{*}{ Slab } & \multirow{2}{*}{\multicolumn{4}{|c|}{ Ultimate loads }} & \multicolumn{6}{|c|}{ CHBDC 2014} & \multirow{3}{*}{$\begin{array}{c}\begin{array}{c}\text { Min } \\
\mathrm{V}_{\mathrm{r}}\end{array} \\
\mathrm{kN}\end{array}$} \\
\hline & & & & & \multicolumn{3}{|c|}{ Clause 8.9.3.4 and 8.9.3.6 } & \multicolumn{3}{|c|}{ Clause 16.8.7 } & \\
\hline & $\mathrm{M}_{\mathrm{EXp}}$ & $\mathrm{V}_{\mathrm{EXp}}$ & $\mathrm{d}_{\mathrm{v}}$ & $f_{c}^{\prime}$ & $\beta$ & $\mathrm{kN}$ & $A_{\text {frp }}$ & $e_{x}$ & $\beta$ & $\mathrm{kN}$ & \\
\hline $\mathrm{S}_{1}$ & 91.39 & 114.23 & 150.00 & 44.58 & 0.20 & 150.2 & 1005 & 0.003 & 0.095 & 71.02 & 71.02 \\
\hline $\mathrm{S}_{2}$ & 157.81 & 197.27 & - & & - & - & - & - & - & - & - \\
\hline $\mathrm{S}_{3}$ & 99.79 & 124.73 & 150.00 & 43.10 & 0.20 & 147.7 & 1005 & 0.003 & 0.095 & 69.83 & 69.83 \\
\hline $\mathrm{S}_{4}$ & 66.23 & 82.78 & 150.00 & 44.60 & 0.20 & 150.3 & 1005 & 0.003 & 0.095 & 71.03 & 71.03 \\
\hline $\mathrm{S}_{5}$ & 80.21 & 100.27 & 150.00 & 47.40 & 0.20 & 154.9 & 1005 & 0.003 & 0.095 & 73.23 & 73.23 \\
\hline $\mathrm{S}_{6}$ & 90.49 & 113.12 & 150.00 & 45.63 & 0.20 & 152.0 & 1005 & 0.003 & 0.095 & 71.85 & 71.85 \\
\hline $\mathrm{S}_{7}$ & 87.88 & 109.85 & 150.00 & 44.60 & 0.20 & 150.3 & 1005 & 0.003 & 0.095 & 71.03 & 71.03 \\
\hline $\mathrm{S}_{8}$ & 59.16 & 73.95 & 150.00 & 44.88 & 0.20 & 150.7 & 1005 & 0.003 & 0.095 & 71.26 & 71.26 \\
\hline $\mathrm{S}_{9}$ & 73.49 & 91.87 & 150.00 & 41.30 & 0.20 & 144.6 & 1005 & 0.003 & 0.095 & 68.35 & 68.35 \\
\hline $\mathrm{S}_{10}$ & 73.35 & 91.68 & 150.00 & 44.20 & 0.20 & 149.6 & 1005 & 0.003 & 0.095 & 70.71 & 70.71 \\
\hline $\mathrm{S}_{11}$ & 85.61 & 107.01 & 150.00 & 44.05 & 0.20 & 149.3 & 1005 & 0.003 & 0.095 & 70.59 & 70.59 \\
\hline $\mathrm{S}_{12}$ & 65.14 & 81.43 & 150.00 & 43.10 & 0.20 & 147.7 & 1005 & 0.003 & 0.095 & 69.83 & 69.83 \\
\hline $\mathrm{S}_{13}$ & 78.34 & 97.93 & 150.00 & 43.10 & 0.20 & 147.7 & 1005 & 0.003 & 0.095 & 69.83 & 69.83 \\
\hline $\mathrm{S}_{14}$ & 89.16 & 111.45 & 150.00 & 43.10 & 0.20 & 147.7 & 1005 & 0.003 & 0.095 & 69.83 & 69.83 \\
\hline $\mathrm{S}_{15}$ & 91.24 & 114.05 & 150.00 & 43.10 & 0.20 & 147.7 & 1005 & 0.003 & 0.095 & 69.83 & 69.83 \\
\hline $\mathrm{S} 16$ & 89.09 & 111.36 & 150.00 & 43.10 & 0.20 & 147.7 & 1407 & 0.003 & 0.095 & 69.83 & 69.83 \\
\hline $\mathrm{S}_{17}$ & 91.84 & 114.80 & 150.00 & 43.10 & 0.20 & 147.7 & 1407 & 0.003 & 0.095 & 69.83 & 69.83 \\
\hline $\mathrm{S}_{18}$ & 92.65 & 115.81 & 150.00 & 43.10 & 0.20 & 147.7 & 1407 & 0.003 & 0.095 & 69.83 & 69.83 \\
\hline S19 & 101.64 & 127.05 & 150.00 & 43.10 & 0.20 & 147.7 & 1407 & 0.003 & 0.095 & 69.83 & 69.83 \\
\hline $\mathrm{S}_{20}$ & 70.13 & 63.76 & 150.00 & 46.45 & 0.20 & 153.3 & 2010 & 0.003 & 0.095 & 72.49 & 72.49 \\
\hline $\mathrm{S}_{21}$ & 89.62 & 81.47 & 150.00 & 46.45 & 0.20 & 153.3 & 2010 & 0.003 & 0.095 & 72.49 & 72.49 \\
\hline $\mathrm{S}_{22}$ & 91.76 & 83.42 & 150.00 & 47.03 & 0.20 & 154.3 & 2010 & 0.003 & 0.095 & 72.94 & 72.94 \\
\hline $\mathrm{S}_{23}$ & 88.76 & 80.69 & 150.00 & 49.48 & 0.20 & 158.3 & 2010 & 0.003 & 0.095 & 74.82 & 74.82 \\
\hline S24 & 84.82 & 77.11 & 150.00 & 47.40 & 0.20 & 154.9 & 1407 & 0.003 & 0.095 & 73.23 & 73.23 \\
\hline $\mathrm{S}_{25}$ & 103.27 & 93.88 & 150.00 & 47.51 & 0.20 & 155.1 & 1407 & 0.003 & 0.095 & 73.31 & 73.31 \\
\hline $\mathrm{S}_{26}$ & 121.98 & 110.89 & 150.00 & 42.30 & 0.20 & 146.3 & 1407 & 0.003 & 0.095 & 69.18 & 69.18 \\
\hline $\mathrm{S}_{27}$ & 116.15 & 105.59 & 150.00 & 46.10 & 0.20 & 152.8 & 1407 & 0.003 & 0.095 & 72.22 & 72.22 \\
\hline
\end{tabular}




\section{$\underline{\text { Spreadsheet output for transverse moment calculations }}$}

Transverse moment for simple span deck slab:

$(\mathrm{Se}+0.6) \mathrm{P} / 10 \quad \mathrm{kN} . \mathrm{m} / \mathrm{m} \quad$ Clause (5.7.1.2(a))

Transverse moment for deck slab continuous over 3 or more supports:

$0.8[(\mathrm{Se}+0.6) \mathrm{P} / 10] \quad \mathrm{kN} . \mathrm{m} / \mathrm{m} \quad$ clause (5.7.1.2(b)) $\underline{\text { Loads }}$

$\mathrm{W}_{\text {slab }}(\mathrm{kN} / \mathrm{m})$

$0.2 \times 24 \mathrm{kN} / \mathrm{m}^{3}=4.8$

$\mathrm{W}_{\text {asphlalt }}(\mathrm{kN} / \mathrm{m})$

$0.09 \times 23.5 \mathrm{kN} / \mathrm{m}^{3}=2.12$

$\mathrm{P}(\mathrm{kN})=87.2$ $\underline{\text { Load factors }}$

$\alpha_{1}=1.2$

$\alpha_{2}=1.5$

Live load factor $=1.7$

DLA for single wheel $=0.4$

\begin{tabular}{|c|c|c|c|c|c|}
\hline Span type & $\mathrm{S}_{\mathrm{e}}(\mathrm{m})$ & $\begin{array}{c}\text { Live load } \\
\text { transverse moment } \\
(\mathrm{kN} . \mathrm{m} / \mathrm{m})\end{array}$ & $\begin{array}{c}\text { Live load transverse } \\
\text { moment }+ \text { DLA }+ \\
\text { live load factor } \\
(\mathrm{kN} \cdot \mathrm{m} / \mathrm{m})\end{array}$ & $\begin{array}{l}\text { Factored dead } \\
\text { load transverse } \\
\text { moment } \\
(\mathrm{kN} \cdot \mathrm{m} / \mathrm{m})\end{array}$ & $\begin{array}{c}\text { Total factored } \\
\text { transverse moment } \\
\quad(\mathrm{kN} . \mathrm{m} / \mathrm{m})\end{array}$ \\
\hline Simple span & 1.00 & 13.95 & 33.21 & 1.12 & 34.32 \\
\hline Simple span & 1.50 & 18.31 & 43.58 & 2.51 & 46.09 \\
\hline Simple span & 2.00 & 22.67 & 53.96 & 4.47 & 58.43 \\
\hline Simple span & 2.50 & 27.03 & 64.34 & 6.98 & 71.31 \\
\hline Simple span & 3.00 & 31.39 & 74.71 & 10.05 & 84.76 \\
\hline Simple span & 3.50 & 35.75 & 85.09 & 13.68 & 98.77 \\
\hline Simple span & 4.00 & 40.11 & 95.47 & 17.87 & 113.33 \\
\hline Simple span & 4.50 & 44.47 & 105.84 & 22.61 & 128.45 \\
\hline Continuous span & 1.00 & 11.16 & 26.56 & 1.12 & 27.68 \\
\hline Continuous span & 1.50 & 14.65 & 34.87 & 2.51 & 37.38 \\
\hline Continuous span & 2.00 & 18.14 & 43.17 & 4.47 & 47.63 \\
\hline Continuous span & 2.50 & 21.63 & 51.47 & 6.98 & 58.45 \\
\hline Continuous span & 3.00 & 25.11 & 59.77 & 10.05 & 69.82 \\
\hline Continuous span & 3.50 & 28.60 & 68.07 & 13.68 & 81.75 \\
\hline Continuous span & 4.00 & 32.09 & 76.37 & 17.87 & 94.24 \\
\hline Continuous span & 4.50 & 35.58 & 84.67 & 22.61 & 107.29 \\
\hline
\end{tabular}



according to ISIS Manual No. 3

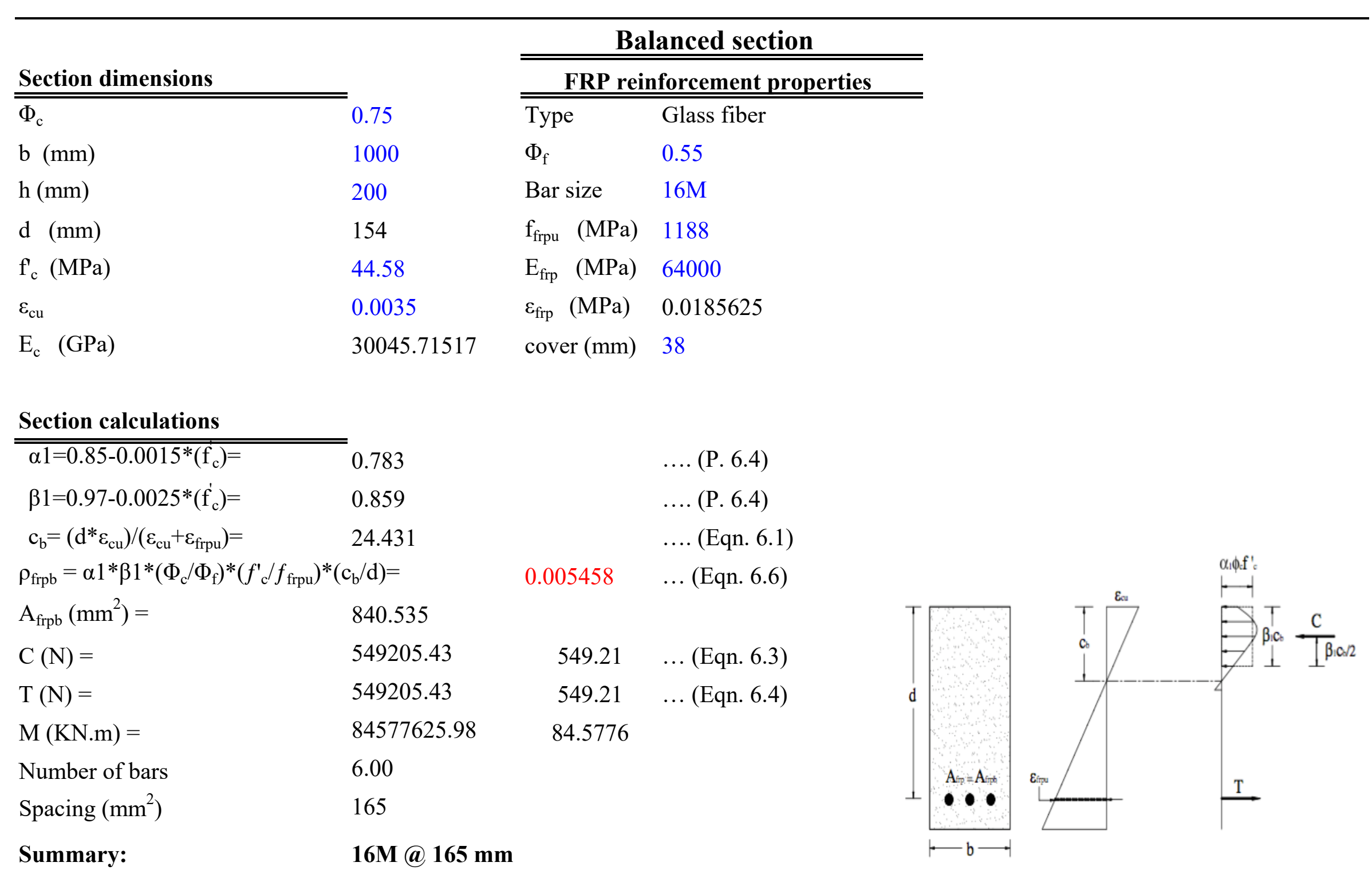


Flexural Design of FRP Reinforced Concrete according to ISIS Manual No. 3

\begin{tabular}{|c|c|c|c|c|c|c|c|c|}
\hline \multirow{2}{*}{$\frac{\text { Section dimensions }}{\text { b }(\mathrm{mm})}$} & \multirow[b]{2}{*}{1000} & \multicolumn{4}{|c|}{ FRP reinforcement properties } & & & \\
\hline & & Type & Glass fiber & & & & & \\
\hline $\mathrm{h}(\mathrm{mm})$ & 200 & $\Phi_{\mathrm{f}}$ & 0.55 & & & & & \\
\hline $\mathrm{d}(\mathrm{mm})$ & 154 & Bar size & $16 \mathrm{M}$ & & & & & \\
\hline Concrete properties & & $\mathrm{A}_{\text {frp }}\left(\mathrm{mm}^{2}\right)$ & 1005 & & & & & \\
\hline $\mathrm{f}_{\mathrm{c}}(\mathrm{MPa})$ & 44.58 & bar spacing $(\mathrm{mm})$ & 200 & $5-161$ & & & & \\
\hline$\varepsilon_{\mathrm{cu}}$ & 0.0035 & $\rho_{\text {frp }}=$ & $\mathrm{A}_{\mathrm{frp}} / \mathrm{bd}=$ & 0.006 & 653 & & & \\
\hline$\varepsilon_{0}$ & 0.0021 & $\rho_{\text {frp }}$ & $>$ & $\rho_{\text {frpb }}$ & & over reinforced & & \\
\hline$\alpha=$ & 0 & $\mathrm{f}_{\text {frpu }}(\mathrm{MPa})$ & 1188 & $\varepsilon_{\text {frpu }}$ & $(\mathrm{MPa})$ & 0.0185625 & & \\
\hline$\beta=$ & 0 & $\mathrm{f}_{\text {frp }}(\mathrm{MPa})$ & 1077.74 & $\varepsilon_{\text {frp }}$ & $(\mathrm{MPa})$ & 0.016839741 & & \\
\hline$\Phi_{\mathrm{c}}$ & 0.75 & $\mathrm{E}_{\text {frp }}(\mathrm{MPa})$ & 64000 & & & & & \\
\hline Section calculations & & & & & & & & \\
\hline$\overline{\mathrm{C}_{\text {assumed }}}=$ & 26.50 & & & & & & & \\
\hline $\mathrm{c} / \mathrm{d}$ & 0.172 & & & & & & & \\
\hline$\varepsilon_{\mathrm{c}}=$ & 0.00386 & & & & & & $\alpha \phi f_{f}^{\prime}$ & \\
\hline$\varepsilon_{\mathrm{c}} / \varepsilon_{\mathrm{o}}=$ & 1.83717 & & & & & & & \\
\hline$\alpha=$ & 0.783 & & & & & & $\Rightarrow \beta_{i}$ & $T_{B}: 12$ \\
\hline$\beta=$ & 0.859 & & & d & & & & \\
\hline $\mathrm{C}(\mathrm{N}>>\mathrm{kN})=$ & 595722.674 & 595.723 & $\ldots($ Eqn.6.7) & & & & & \\
\hline $\mathrm{T}(\mathrm{N}>>\mathrm{kN})=$ & 595722.674 & 595.723 & $\ldots($ Eqn.6.8) & & $A_{i n}>A_{i n t}$ & & $T$ & \\
\hline $\operatorname{Mr}(\mathrm{N} \cdot \mathrm{mm})=$ & 84964516.640 & & $\ldots($ Eqn.6.10) & & $\bullet \bullet$ & & & \\
\hline $\operatorname{Mr}(\mathbf{k N} . \mathbf{m})=$ & 84.96 & & & & $\vdash b-$ & & & \\
\hline
\end{tabular}



according to ISIS Manual No. 3

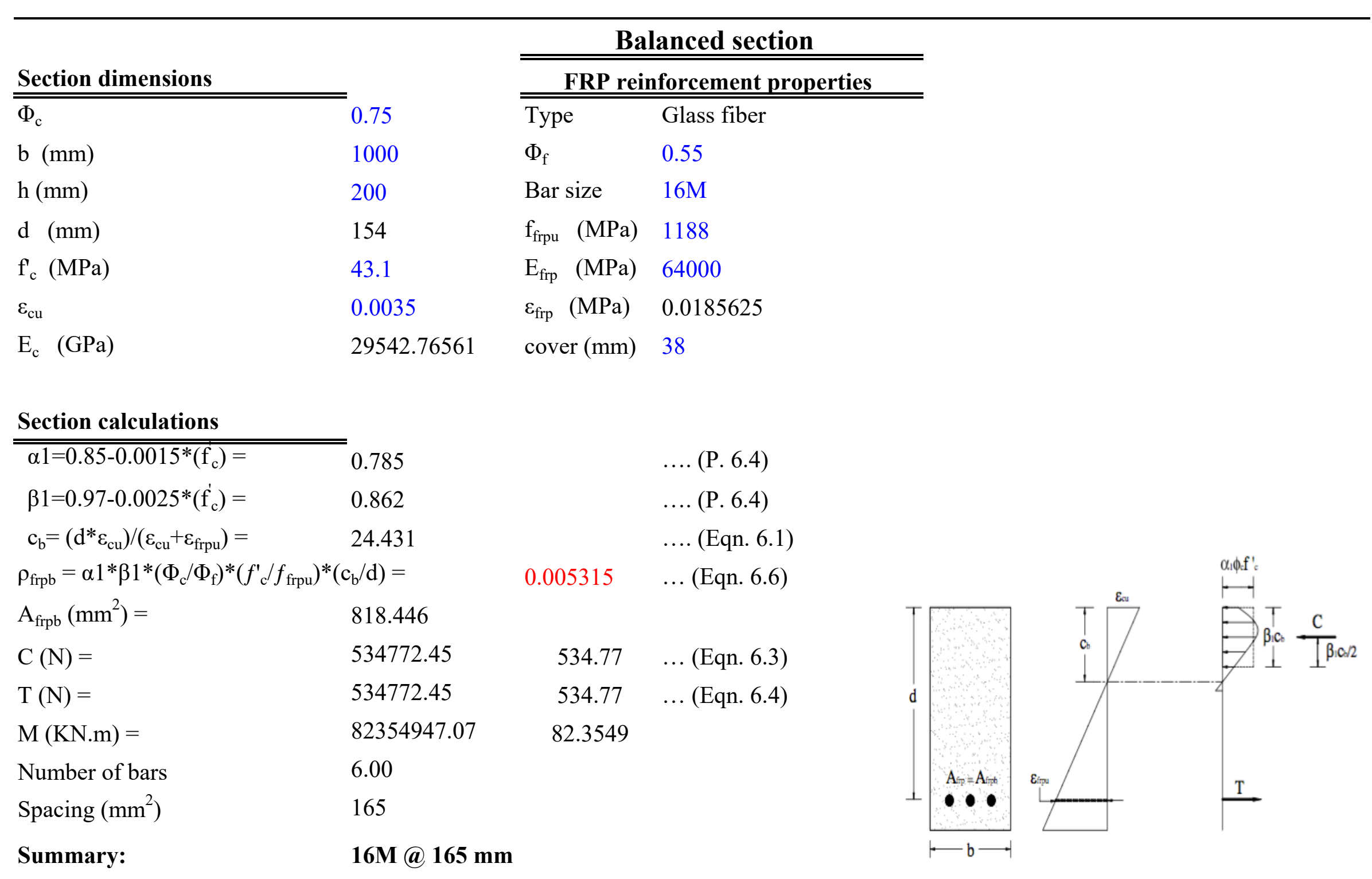


Flexural Design of FRP Reinforced Concrete according to ISIS Manual No. 3

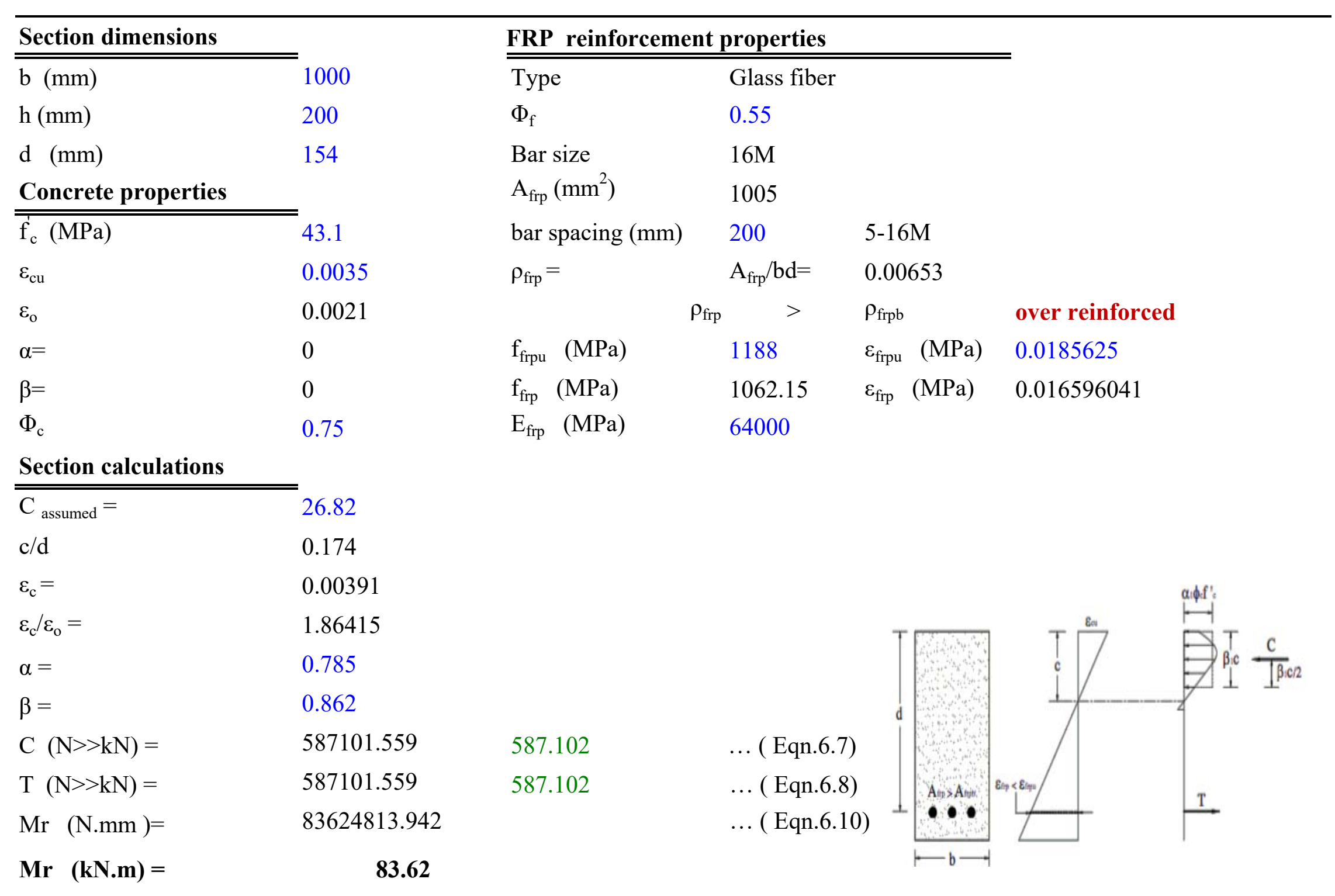



according to ISIS Manual No. 3

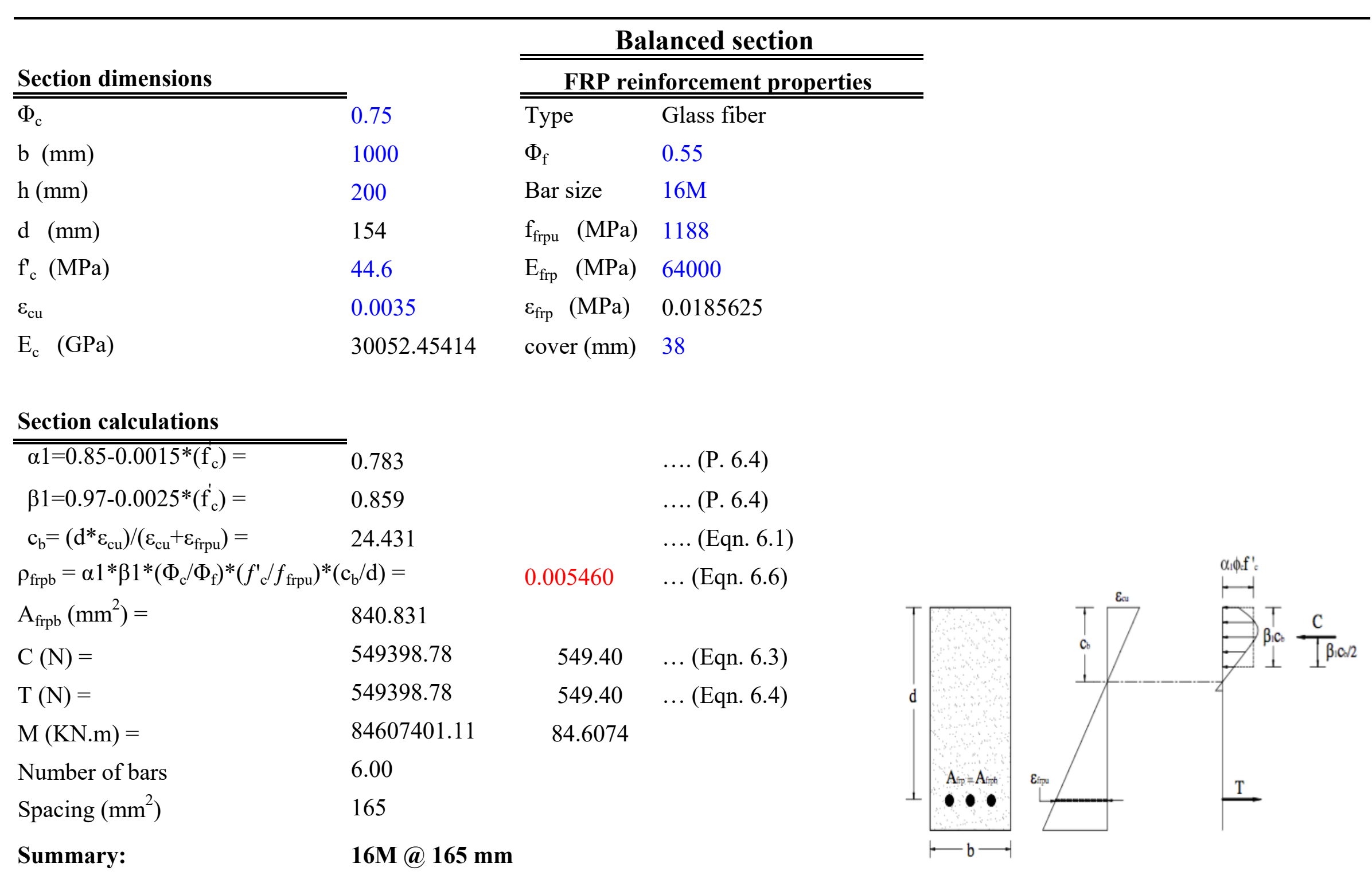


Flexural Design of FRP Reinforced Concrete according to ISIS Manual No. 3

\begin{tabular}{|c|c|c|c|c|c|c|c|c|}
\hline \multirow{2}{*}{$\frac{\text { Section dimensions }}{\text { b }(\mathrm{mm})}$} & \multirow[b]{2}{*}{1000} & \multicolumn{4}{|c|}{ FRP reinforcement properties } & & & \\
\hline & & Type & Glass fiber & & & & & \\
\hline $\mathrm{h}(\mathrm{mm})$ & 200 & $\Phi_{\mathrm{f}}$ & 0.55 & & & & & \\
\hline $\mathrm{d}(\mathrm{mm})$ & 154 & Bar size & $16 \mathrm{M}$ & & & & & \\
\hline Concrete properties & & $\mathrm{A}_{\text {frp }}\left(\mathrm{mm}^{2}\right)$ & 1005 & & & & & \\
\hline $\mathrm{f}_{\mathrm{c}}(\mathrm{MPa})$ & 44.6 & bar spacing $(\mathrm{mm})$ & 200 & $5-161$ & & & & \\
\hline$\varepsilon_{\mathrm{cu}}$ & 0.0035 & $\rho_{\text {frp }}=$ & $\mathrm{A}_{\mathrm{frp}} / \mathrm{bd}=$ & 0.006 & 653 & & & \\
\hline$\varepsilon_{0}$ & 0.0021 & $\rho_{\text {frp }}$ & $>$ & $\rho_{\text {frpb }}$ & & over reinforced & & \\
\hline$\alpha=$ & 0 & $\mathrm{f}_{\text {frpu }}(\mathrm{MPa})$ & 1188 & $\varepsilon_{\text {frpu }}$ & $(\mathrm{MPa})$ & 0.0185625 & & \\
\hline$\beta=$ & 0 & $\mathrm{f}_{\text {frp }}(\mathrm{MPa})$ & 1077.95 & $\varepsilon_{\text {frp }}$ & $(\mathrm{MPa})$ & 0.016842984 & & \\
\hline$\Phi_{\mathrm{c}}$ & 0.75 & $\mathrm{E}_{\text {frp }}(\mathrm{MPa})$ & 64000 & & & & & \\
\hline Section calculations & & & & & & & & \\
\hline$\overline{\mathrm{C}_{\text {assumed }}}=$ & 26.50 & & & & & & & \\
\hline $\mathrm{c} / \mathrm{d}$ & 0.172 & & & & & & & \\
\hline$\varepsilon_{\mathrm{c}}=$ & 0.00386 & & & & & & $\alpha \phi f_{f}^{\prime}$ & \\
\hline$\varepsilon_{\mathrm{c}} / \varepsilon_{\mathrm{o}}=$ & 1.83682 & & & & & & & \\
\hline$\alpha=$ & 0.783 & & & & & & $\Rightarrow \beta_{i}$ & $T_{\beta C / 2}$ \\
\hline$\beta=$ & 0.859 & & & d & & & & \\
\hline $\mathrm{C}(\mathrm{N}>>\mathrm{kN})=$ & 595837.396 & 595.837 & $\ldots($ Eqn.6.7) & & & & & \\
\hline $\mathrm{T}(\mathrm{N}>>\mathrm{kN})=$ & 595837.396 & 595.837 & $\ldots($ Eqn.6.8) & & $A_{i n}>A_{i n t}$ & & $T$ & \\
\hline $\operatorname{Mr}(\mathrm{N} . \mathrm{mm})=$ & 84982353.967 & & $\ldots($ Eqn.6.10) & & $\bullet \bullet$ & & & \\
\hline $\operatorname{Mr}(k N . m)=$ & 84.98 & & & & $\vdash b-$ & & & \\
\hline
\end{tabular}



according to ISIS Manual No. 3

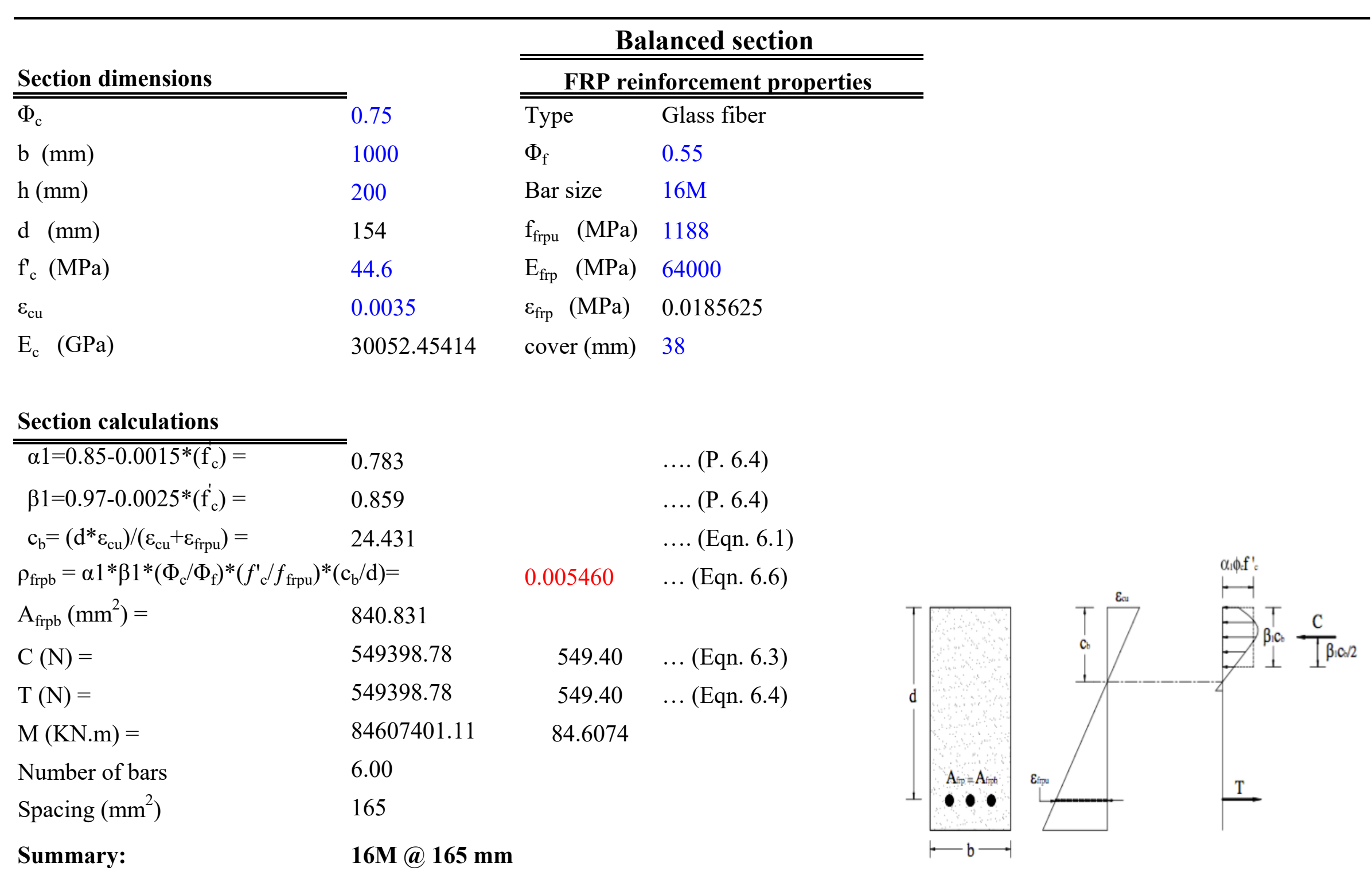


Flexural Design of FRP Reinforced Concrete according to ISIS Manual No. 3

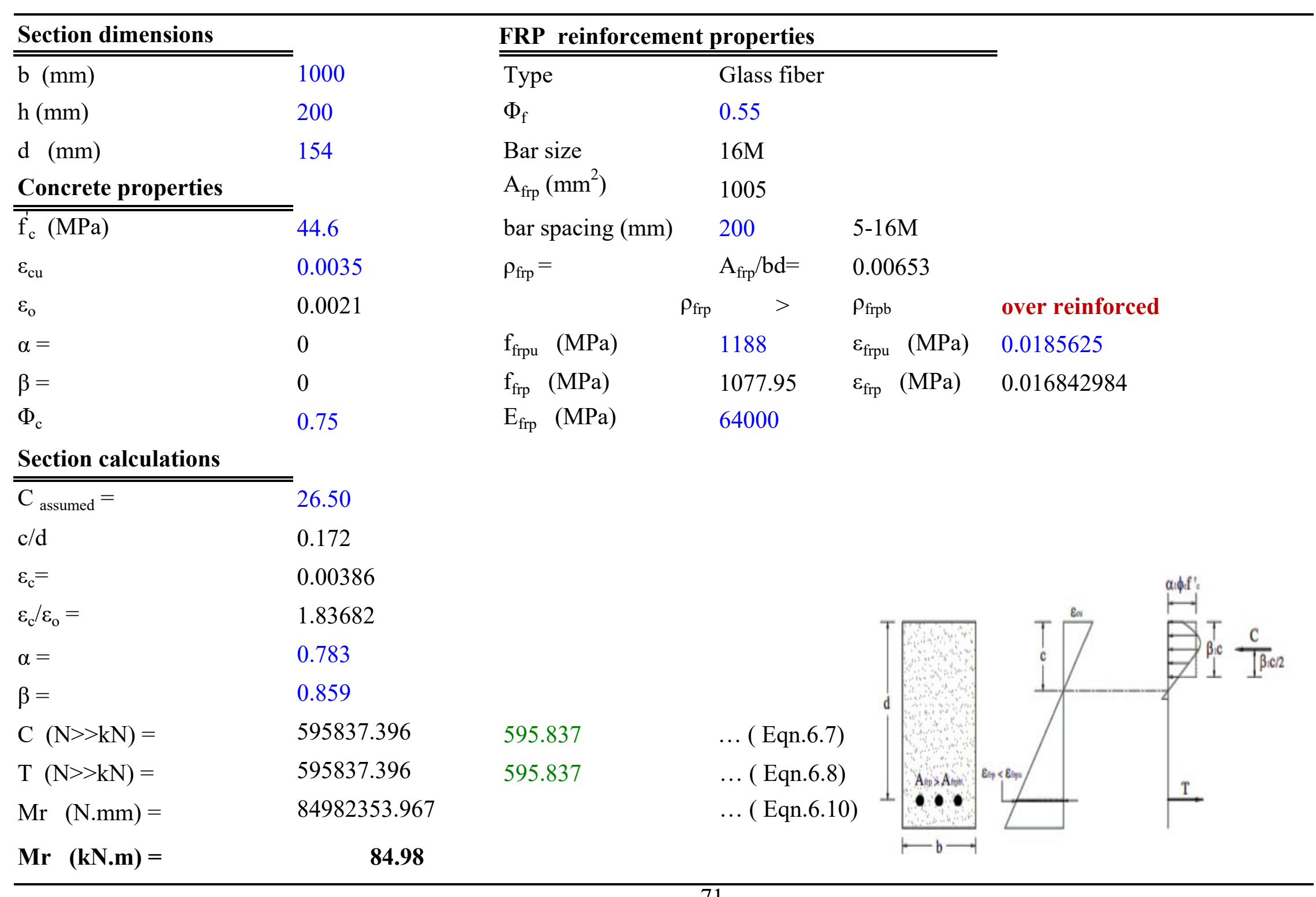



according to ISIS Manual No. 3

\section{Balanced section}

\section{Section dimensions}

$\overline{\overline{\Phi_{\mathrm{c}}}} 0.75$

b (mm) 1000

h $(\mathrm{mm}) \quad 200$

d (mm) 154

$\mathrm{f}_{\mathrm{c}}(\mathrm{MPa}) \quad 45.63$

$\varepsilon_{\mathrm{cu}}$

$\mathrm{E}_{\mathrm{c}}(\mathrm{GPa})$

\begin{tabular}{ll}
\hline \hline \multicolumn{2}{c}{ FRP reinforcement properties } \\
\hline \hline Type & Glass fiber \\
$\Phi_{\mathrm{f}}$ & 0.55 \\
Bar size & $16 \mathrm{M}$ \\
$\mathrm{f}_{\text {frpu }}(\mathrm{MPa})$ & 1188 \\
$\mathrm{E}_{\text {frp }}(\mathrm{MPa})$ & 64000 \\
$\varepsilon_{\text {frp }}(\mathrm{MPa})$ & 0.0185625 \\
cover $(\mathrm{mm})$ & 38
\end{tabular}

\section{Section calculations}

\begin{tabular}{|c|c|c|c|}
\hline$\alpha 1=0.85-0.0015^{*}\left(\mathrm{f}_{\mathrm{c}}\right)=$ & 0.782 & & $\ldots .($ P. 6.4) \\
\hline$\beta 1=0.97-0.0025 *\left(\mathrm{f}_{\mathrm{c}}^{\prime}\right)=$ & 0.856 & & $\ldots .($ P. 6.4) \\
\hline $\mathrm{c}_{\mathrm{b}}=\left(\mathrm{d}^{*} \varepsilon_{\mathrm{cu}}\right) /\left(\varepsilon_{\mathrm{cu}}+\varepsilon_{\mathrm{frpu}}\right)=$ & 24.431 & & $\ldots .($ Eqn. 6.1$)$ \\
\hline \multicolumn{2}{|c|}{$\rho_{\text {frpb }}=\alpha 1 * \beta 1 *\left(\Phi_{\mathrm{c}} / \Phi_{\mathrm{f}}\right) *\left(f_{\mathrm{c}}^{\prime} / f_{\text {frpu }}\right) *\left(\mathrm{c}_{\mathrm{b}} / \mathrm{d}\right)=$} & 0.005558 & $\ldots($ Eqn. 6.6) \\
\hline$A_{\text {frpb }}\left(\mathrm{mm}^{2}\right)=$ & 855.977 & & \\
\hline $\mathrm{C}(\mathrm{N})=$ & 559295.12 & 559.30 & $\ldots($ Eqn. 6.3$)$ \\
\hline $\mathrm{T}(\mathrm{N})=$ & 559295.12 & 559.30 & $\ldots$ (Eqn. 6.4) \\
\hline $\mathrm{M}(\mathrm{KN} . \mathrm{m})=$ & 86131438.41 & 86.1314 & \\
\hline Number of bars & 6.00 & & \\
\hline Spacing $\left(\mathrm{mm}^{2}\right)$ & 165 & & \\
\hline
\end{tabular}

Summary:

16M@165 mm

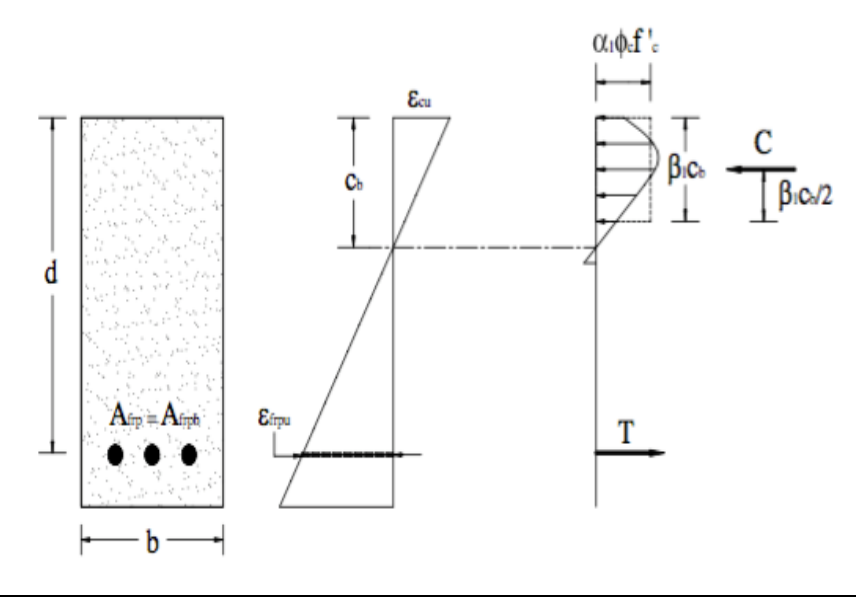


Flexural Design of FRP Reinforced Concrete according to ISIS Manual No. 3

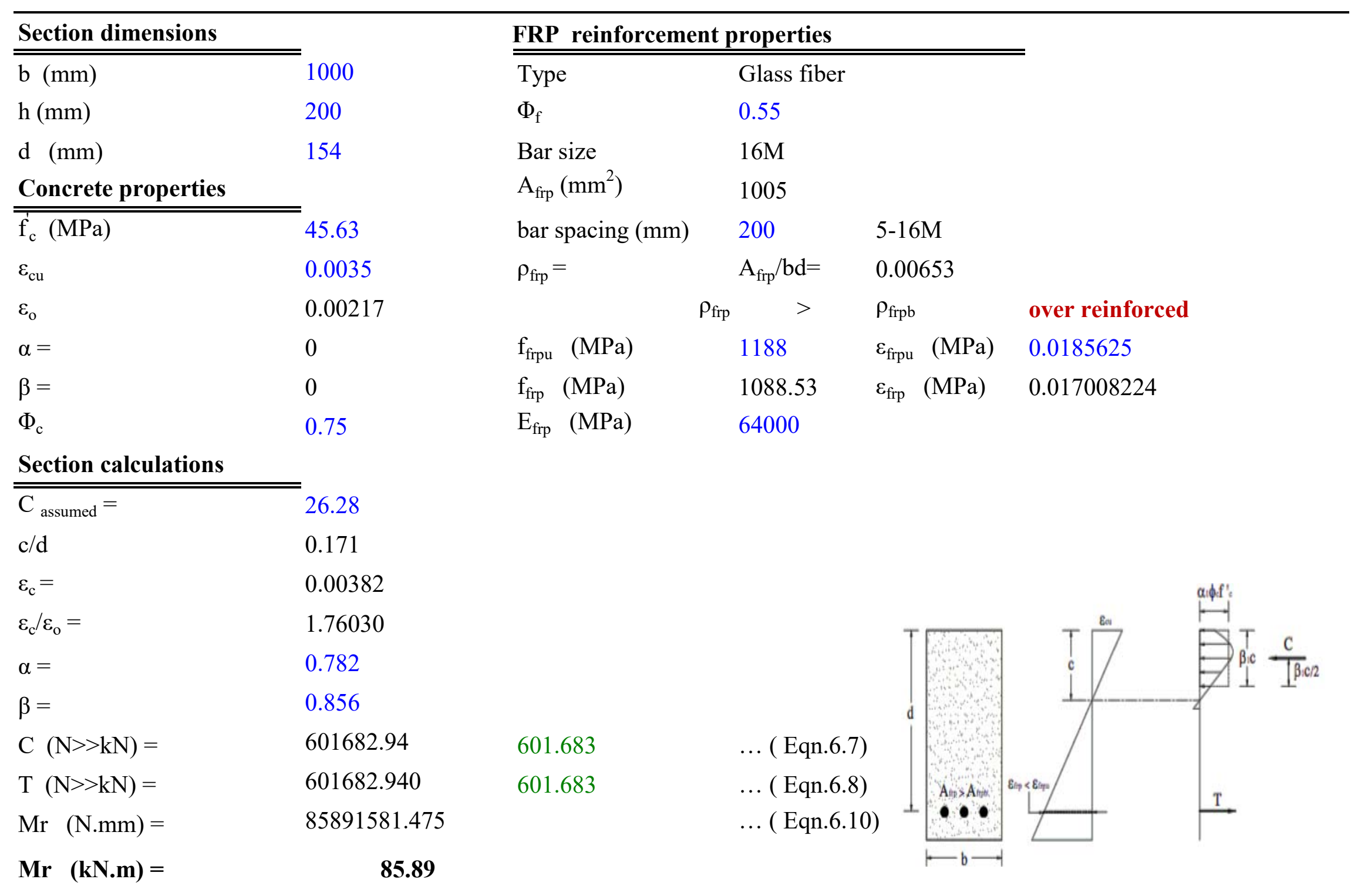


Flexural Design of FRP Reinforced Concrete according to ISIS Manual No. 3

\section{Balanced section}

\section{Section dimensions}

$\overline{\overline{\Phi_{\mathrm{c}}}} 0.75$

b (mm) 1000

h $(\mathrm{mm}) \quad 200$

d $(\mathrm{mm}) \quad 154$

$\mathrm{f}_{\mathrm{c}}(\mathrm{MPa}) \quad 44.88$

$\varepsilon_{\mathrm{cu}}$

$\mathrm{E}_{\mathrm{c}}(\mathrm{GPa})$

\begin{tabular}{ll}
\hline \hline \multicolumn{2}{c}{ FRP reinforcement properties } \\
\hline \hline Type & Glass fiber \\
$\Phi_{\mathrm{f}}$ & 0.55 \\
Bar size & $16 \mathrm{M}$ \\
$\mathrm{f}_{\text {frpu }}(\mathrm{MPa})$ & 1188 \\
$\mathrm{E}_{\text {frp }}(\mathrm{MPa})$ & 64000 \\
$\varepsilon_{\text {frp }}(\mathrm{MPa})$ & 0.0185625 \\
cover $(\mathrm{mm})$ & 38
\end{tabular}

\section{Section calculations}

\begin{tabular}{|c|c|c|c|}
\hline$\alpha 1=0.85-0.0015^{*}\left(f_{c}\right)=$ & 0.783 & & $\ldots .($ P. 6.4) \\
\hline$\beta 1=0.97-0.0025 *\left(f_{c}^{\prime}\right)=$ & 0.858 & & $\ldots .($ P. 6.4) \\
\hline$c_{b}=\left(d^{*} \varepsilon_{\mathrm{cu}}\right) /\left(\varepsilon_{\mathrm{cu}}+\varepsilon_{\mathrm{frpu}}\right)=$ & 24.431 & & $\ldots .($ Eqn. 6.1$)$ \\
\hline \multicolumn{2}{|c|}{$\rho_{\mathrm{frpb}}=\alpha 1 * \beta 1 *\left(\Phi_{\mathrm{c}} / \Phi_{\mathrm{f}}\right) *\left(f_{\mathrm{c}}^{\prime} / f_{\mathrm{frpu}}\right) *\left(\mathrm{c}_{\mathrm{b}} / \mathrm{d}\right)=$} & 0.005487 & $\ldots($ Eqn. 6.6$)$ \\
\hline $\mathrm{A}_{\mathrm{frpb}}\left(\mathrm{mm}^{2}\right)=$ & 844.966 & & \\
\hline $\mathrm{C}(\mathrm{N})=$ & 552100.87 & 552.10 & $\ldots$ (Eqn. 6.3$)$ \\
\hline $\mathrm{T}(\mathrm{N})=$ & 552100.87 & 552.10 & $\ldots($ Eqn. 6.4) \\
\hline $\mathrm{M}(\mathrm{KN} \cdot \mathrm{m})=$ & 85023523.66 & 85.0235 & \\
\hline Number of bars & 6.00 & & \\
\hline Spacing $\left(\mathrm{mm}^{2}\right)$ & 165 & & \\
\hline
\end{tabular}

Summary:

16M@165 mm $\square$

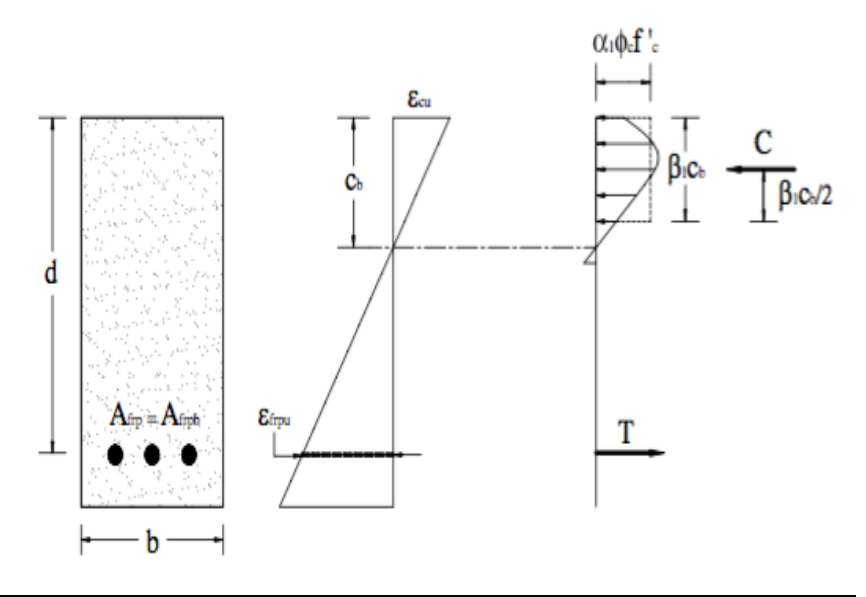


Flexural Design of FRP Reinforced Concrete according to ISIS Manual No. 3

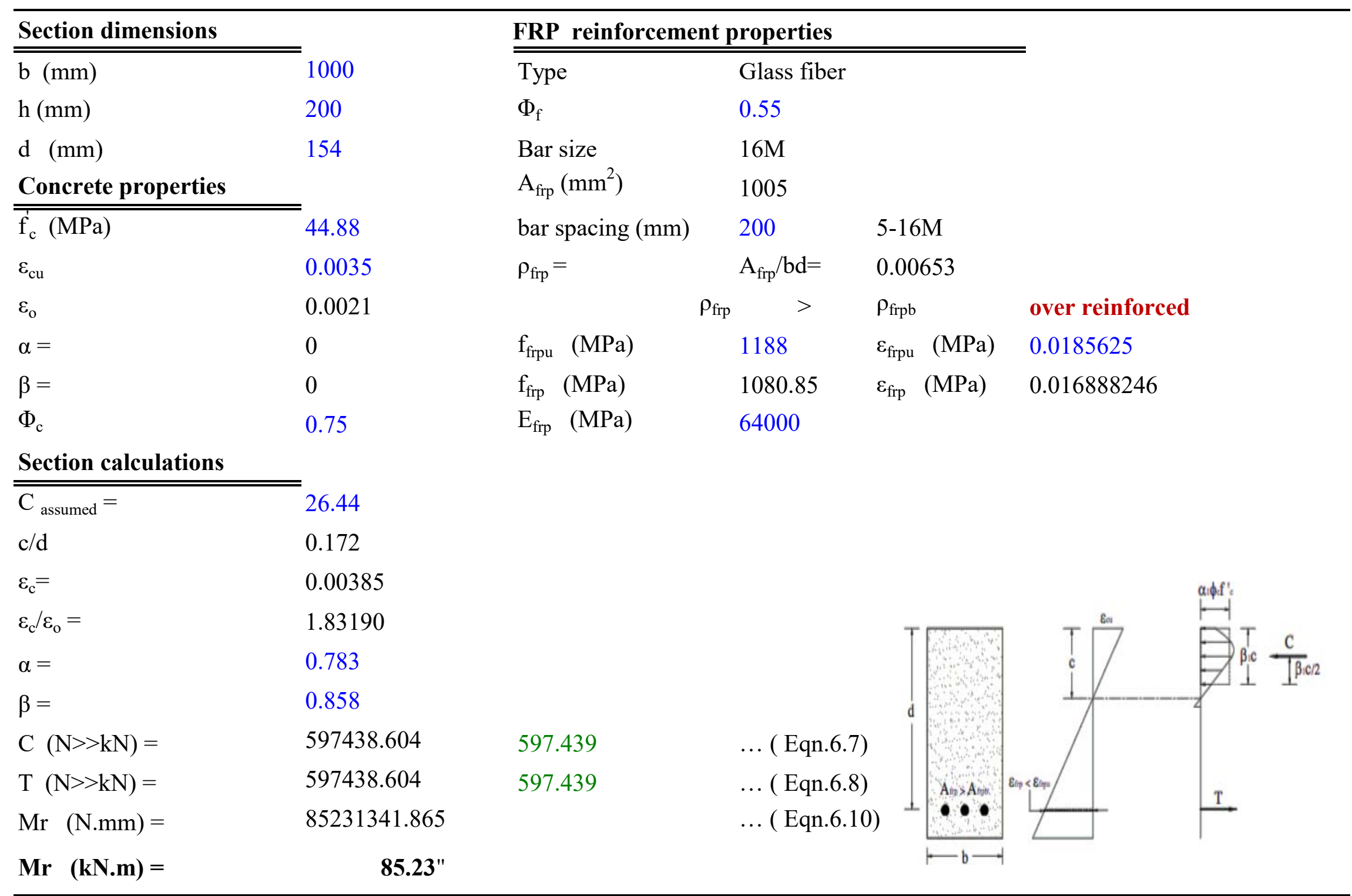


Flexural Design of FRP Reinforced Concrete according to ISIS Manual No. 3

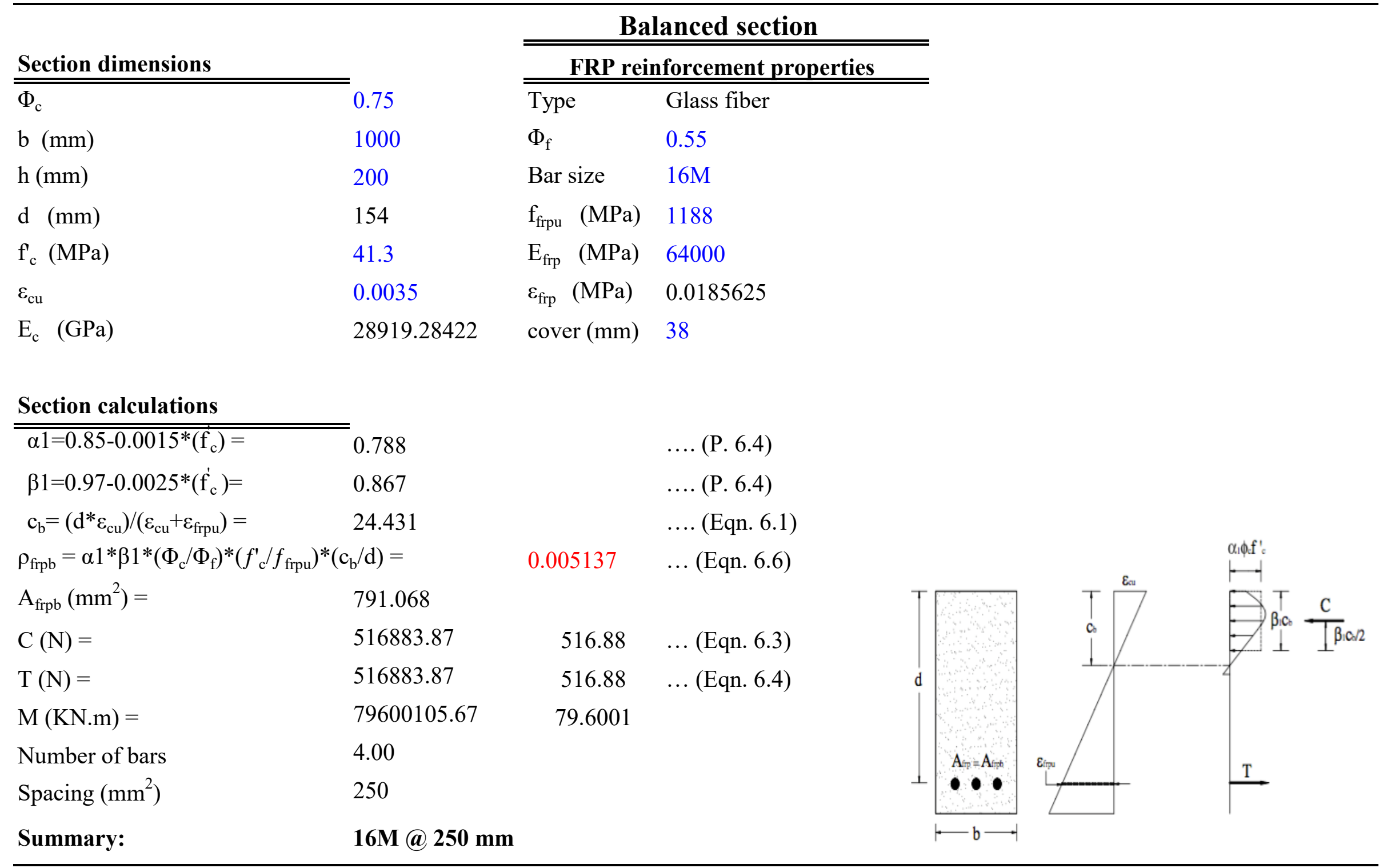


Flexural Design of FRP Reinforced Concrete according to ISIS Manual No. 3

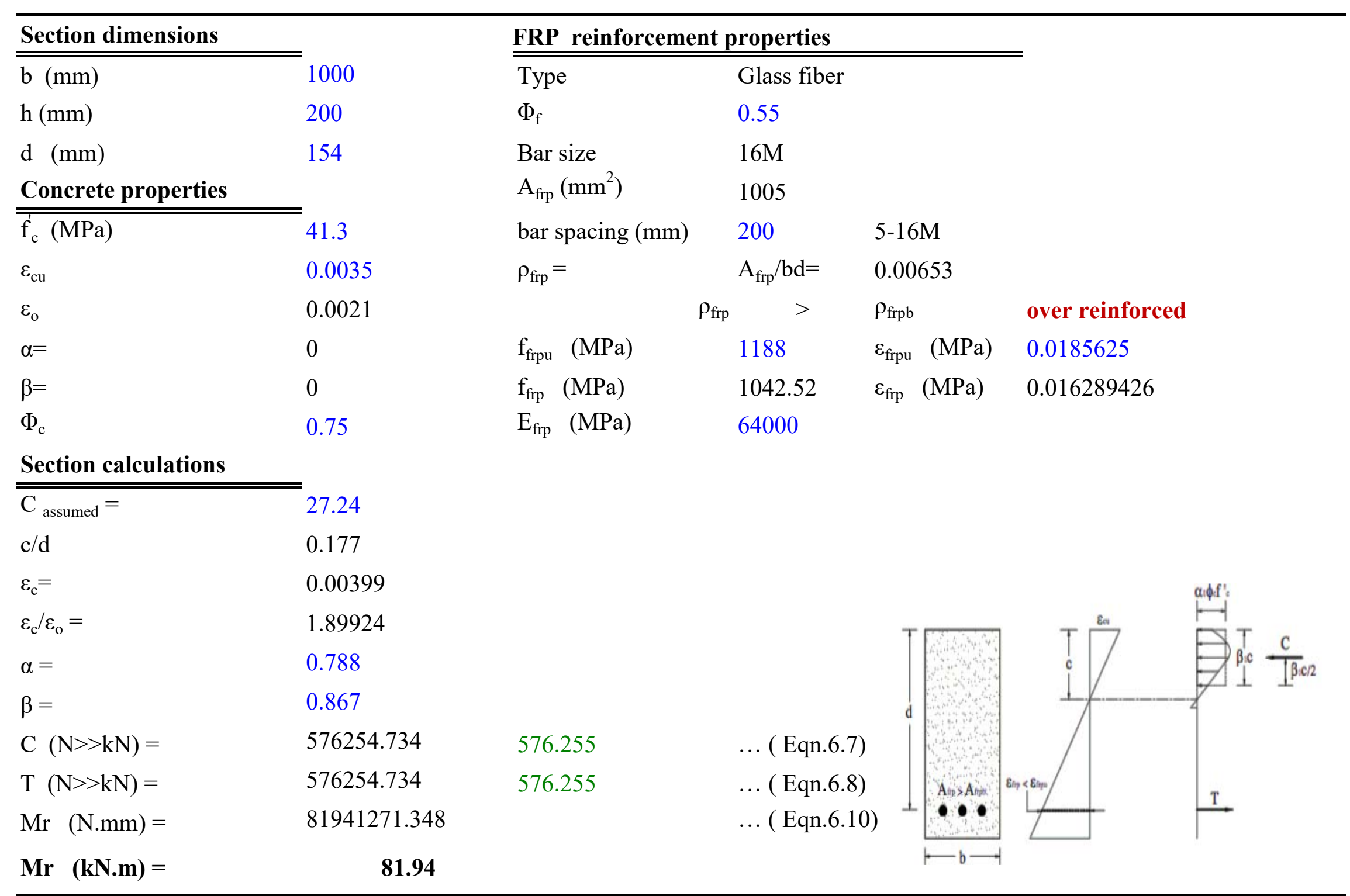


Flexural Design of FRP Reinforced Concrete according to ISIS Manual No. 3

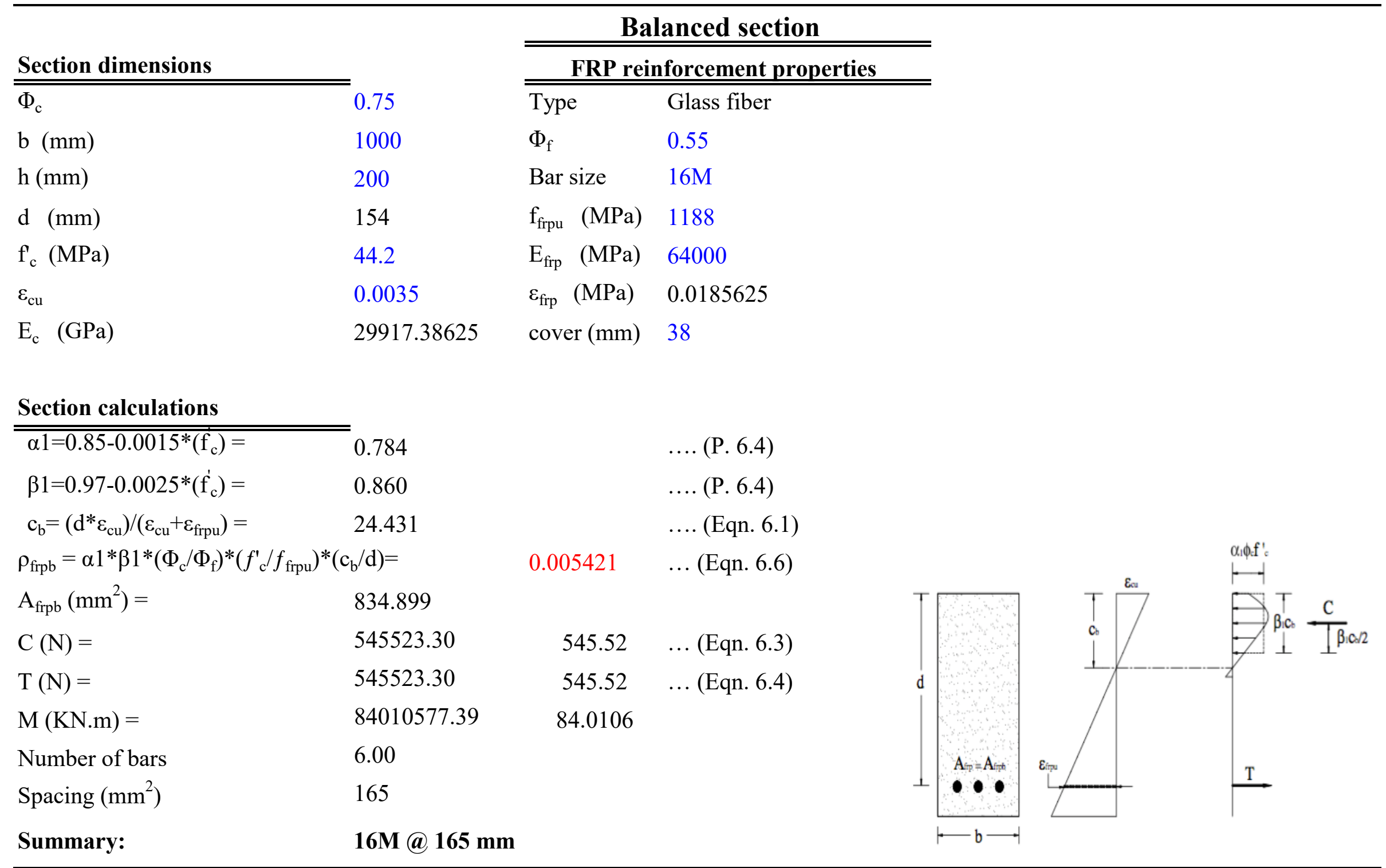


Flexural Design of FRP Reinforced Concrete according to ISIS Manual No. 3

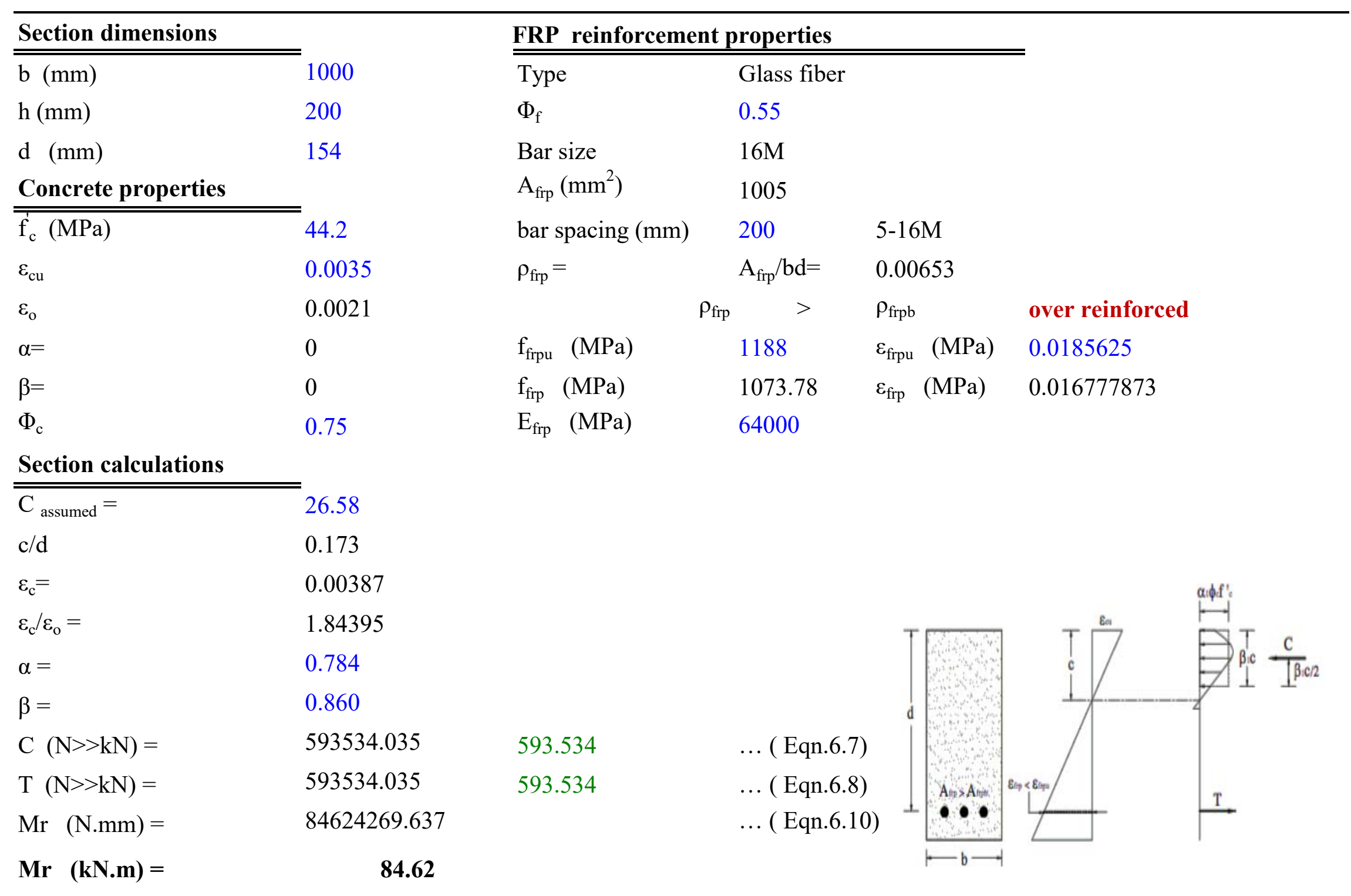


Flexural Design of FRP Reinforced Concrete according to ISIS Manual No. 3

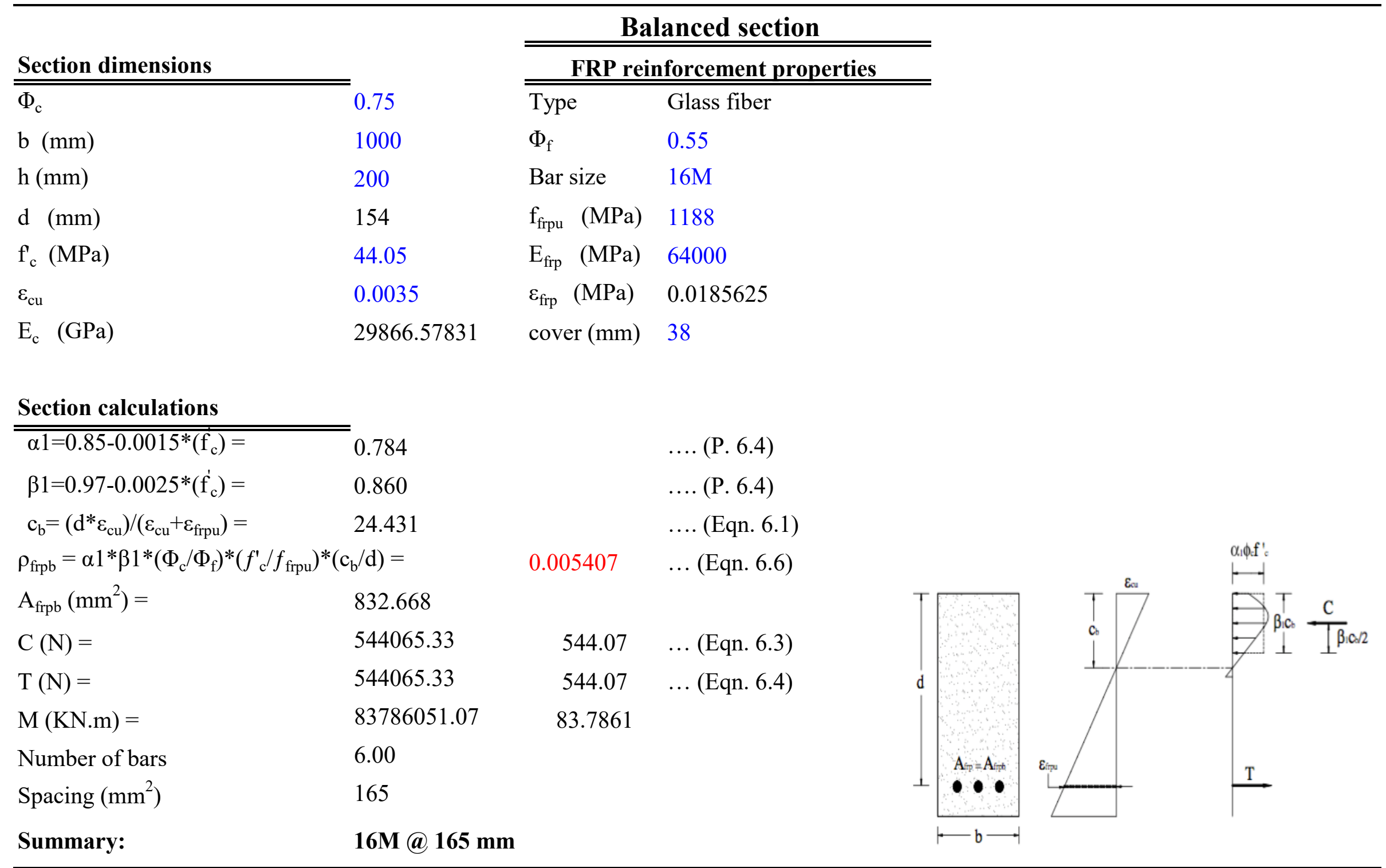


Flexural Design of FRP Reinforced Concrete according to ISIS Manual No. 3

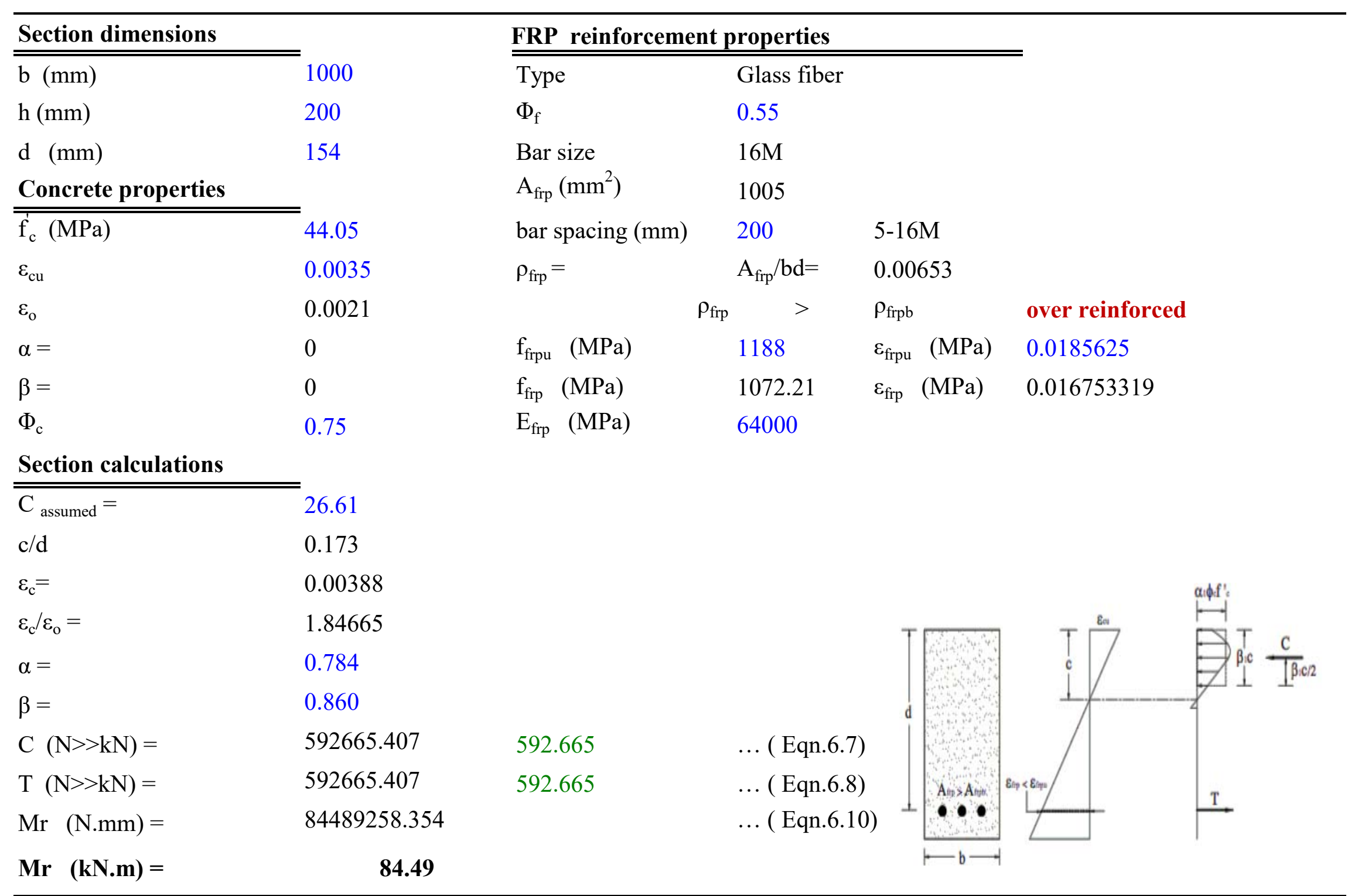


Flexural Design of FRP Reinforced Concrete according to ISIS Manual No. 3

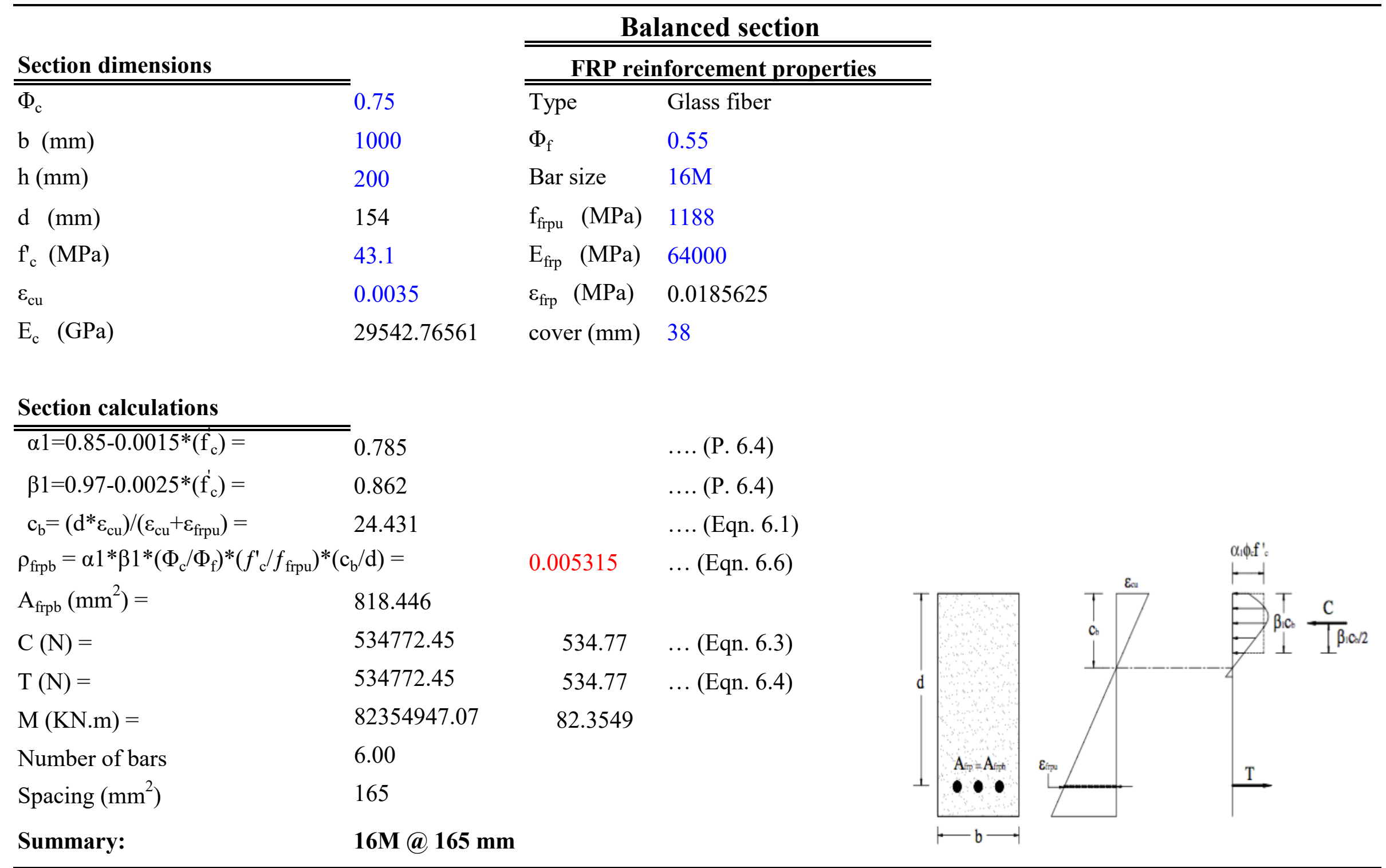


Flexural Design of FRP Reinforced Concrete according to ISIS Manual No. 3

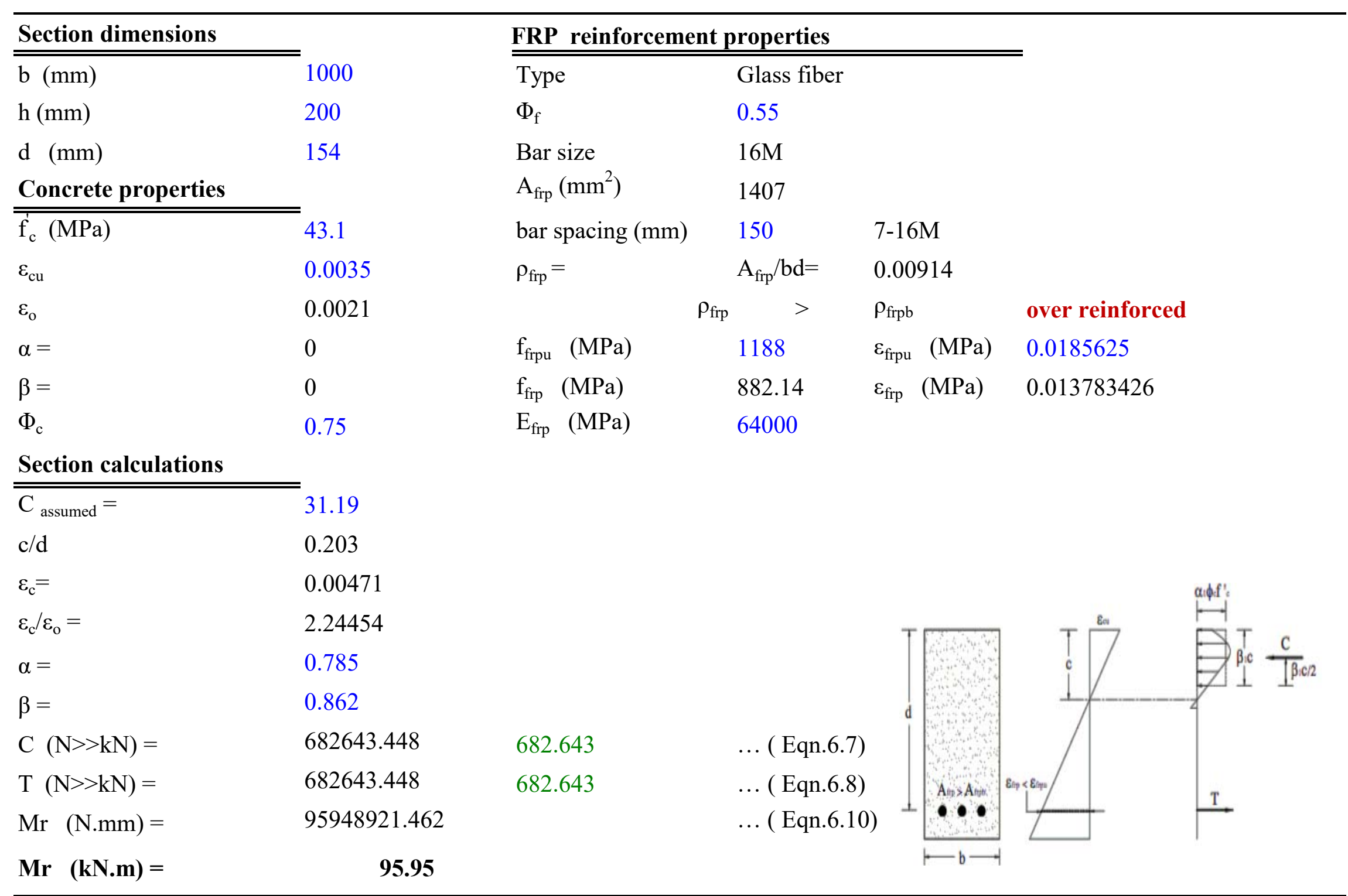



according to ISIS Manual No. 3

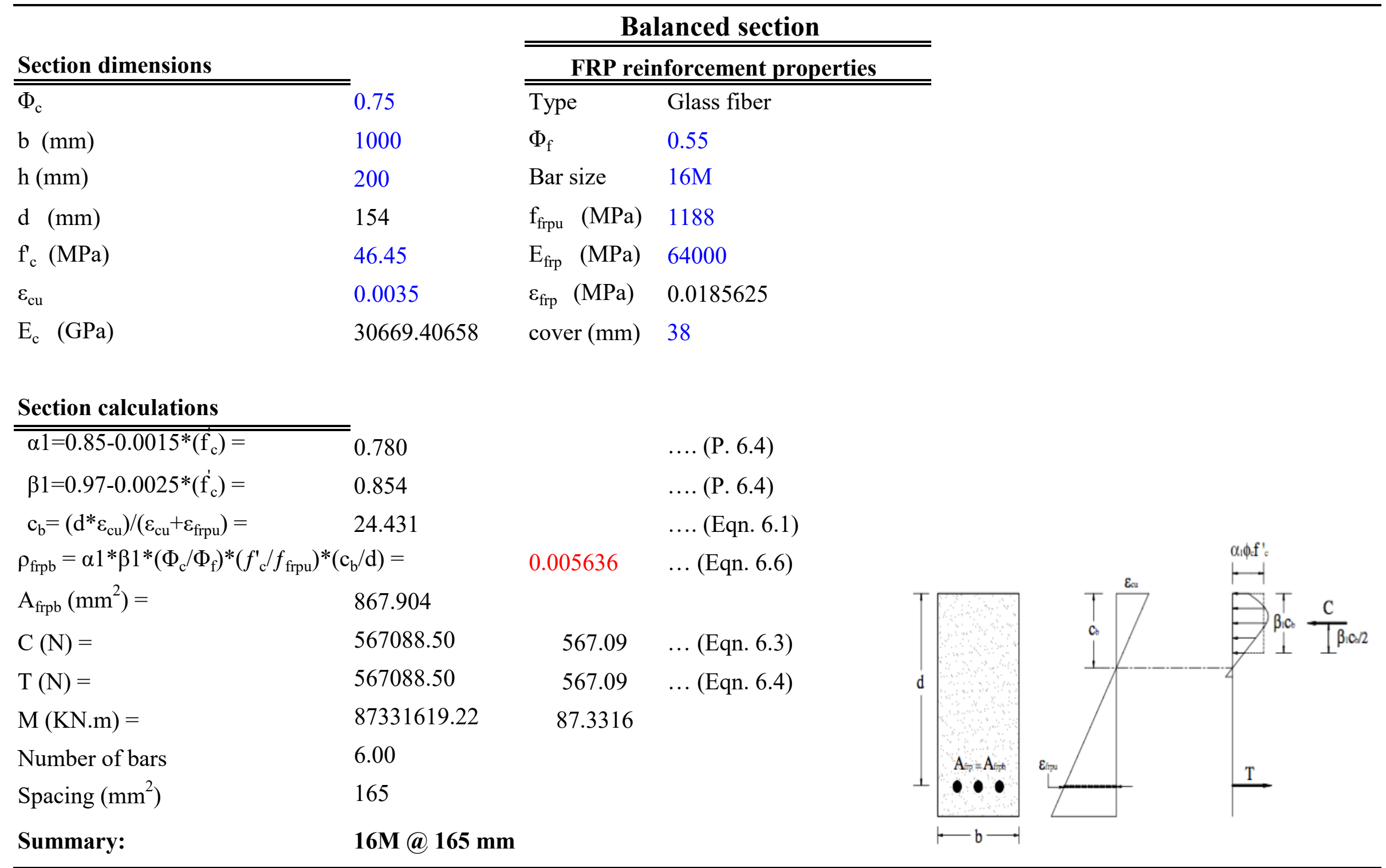


Flexural Design of FRP Reinforced Concrete according to ISIS Manual No. 3

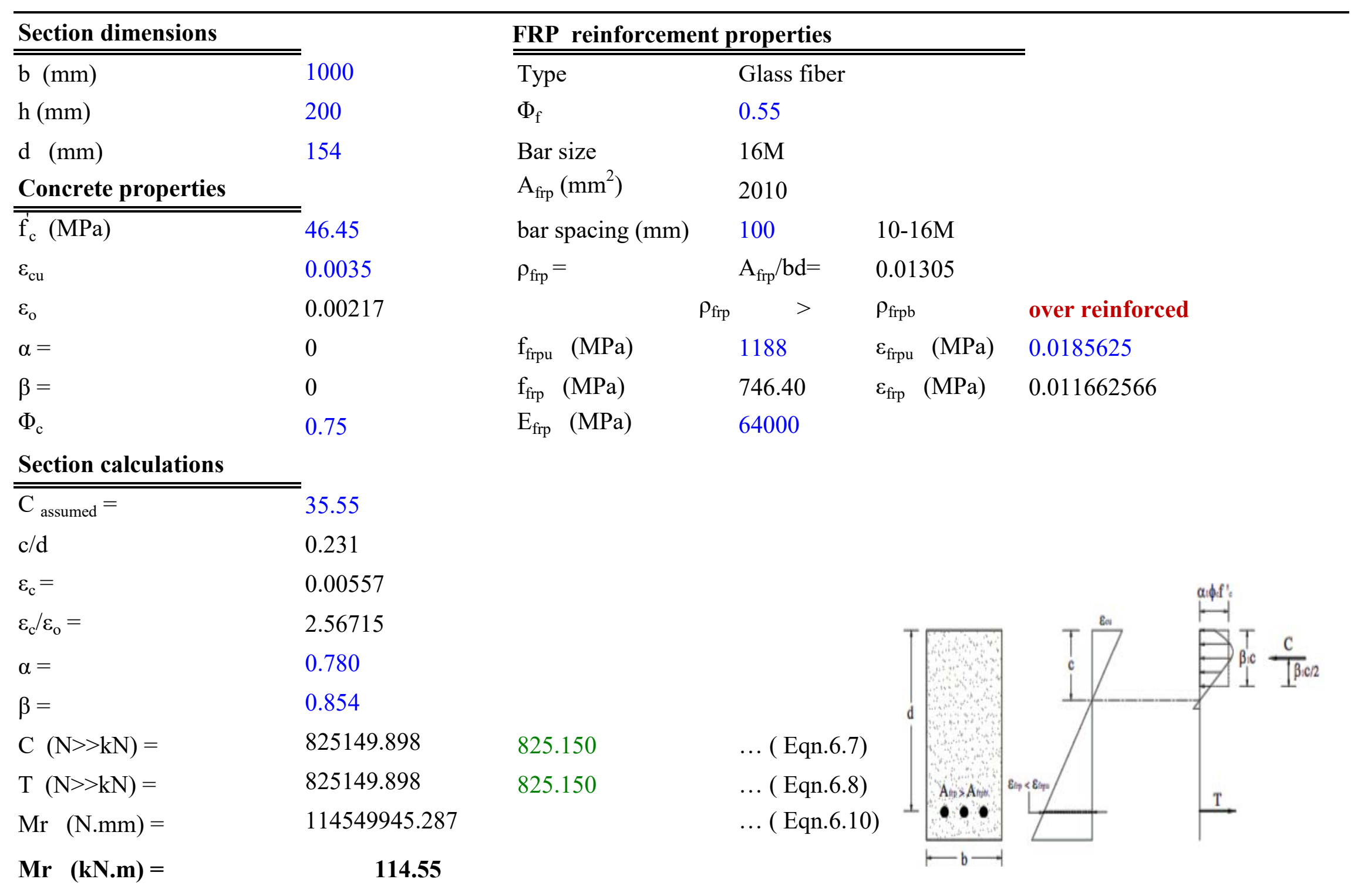



according to ISIS Manual No. 3

\begin{tabular}{|c|c|c|c|c|c|}
\hline \multirow[b]{2}{*}{ Section dimensions } & \multicolumn{3}{|c|}{ Balanced section } & & \\
\hline & & \multicolumn{2}{|c|}{ FRP reinforcement properties } & & \\
\hline$\overline{\Phi_{\mathrm{c}}}$ & 0.75 & Type & Glass fiber & & \\
\hline $\mathrm{b}(\mathrm{mm})$ & 1000 & $\Phi_{\mathrm{f}}$ & 0.55 & & \\
\hline $\mathrm{h}(\mathrm{mm})$ & 200 & Bar size & $16 \mathrm{M}$ & & \\
\hline $\mathrm{d}(\mathrm{mm})$ & 154 & $\mathrm{f}_{\mathrm{frpu}}(\mathrm{MPa})$ & 1188 & & \\
\hline $\mathrm{f}_{\mathrm{c}}^{\prime}(\mathrm{MPa})$ & 47.03 & $\mathrm{E}_{\mathrm{frp}}(\mathrm{MPa})$ & 64000 & & \\
\hline$\varepsilon_{\mathrm{cu}}$ & 0.0035 & $\varepsilon_{\text {frp }}(\mathrm{MPa})$ & 0.0185625 & & \\
\hline $\mathrm{E}_{\mathrm{c}}(\mathrm{GPa})$ & 30860.29002 & cover $(\mathrm{mm})$ & 38 & & \\
\hline \multicolumn{6}{|l|}{ Section calculations } \\
\hline$\alpha 1=0.85-0.0015^{*}\left(\mathrm{f}_{\mathrm{c}}\right)=$ & 0.779 & & $\ldots .($ P. 6.4) & & \\
\hline$\beta 1=0.97-0.0025 *\left(\mathrm{f}_{\mathrm{c}}^{\prime}\right)=$ & 0.852 & & $\ldots .($ P. 6.4) & & \\
\hline $\mathrm{c}_{\mathrm{b}}=\left(\mathrm{d}^{*} \varepsilon_{\mathrm{cu}}\right) /\left(\varepsilon_{\mathrm{cu}}+\varepsilon_{\mathrm{frpu}}\right)=$ & 24.431 & & $\ldots($ Eqn. 6.1$)$ & & \\
\hline \multicolumn{2}{|c|}{$\rho_{\mathrm{frpb}}=\alpha 1 * \beta 1 *\left(\Phi_{\mathrm{c}} / \Phi_{\mathrm{f}}\right)^{*}\left(f_{\mathrm{c}}^{\prime} / f_{\mathrm{frpu}}\right) *\left(\mathrm{c}_{\mathrm{b}} / \mathrm{d}\right)=$} & 0.005690 & $\ldots($ Eqn. 6.6) & & \\
\hline$A_{\text {frpb }}\left(\mathrm{mm}^{2}\right)=$ & 876.271 & & & & $\mathrm{C}$ \\
\hline $\mathrm{C}(\mathrm{N})=$ & 572555.39 & 572.56 & $\ldots($ Eqn. 6.3) & & $\perp_{1} / 2 / 2$ \\
\hline $\mathrm{T}(\mathrm{N})=$ & 572555.39 & 572.56 & $\ldots($ Eqn. 6.4$)$ & d & \\
\hline $\mathrm{M}(\mathrm{KN} . \mathrm{m})=$ & 88173520.19 & 88.1735 & & & \\
\hline Number of bars & 6.00 & & & $A_{p}=A_{p h}$ & \\
\hline Spacing $\left(\mathrm{mm}^{2}\right)$ & 165 & & & 100 & \\
\hline Summary: & 16M@165 n & & & $\vdash b-$ & \\
\hline
\end{tabular}


Flexural Design of FRP Reinforced Concrete according to ISIS Manual No. 3

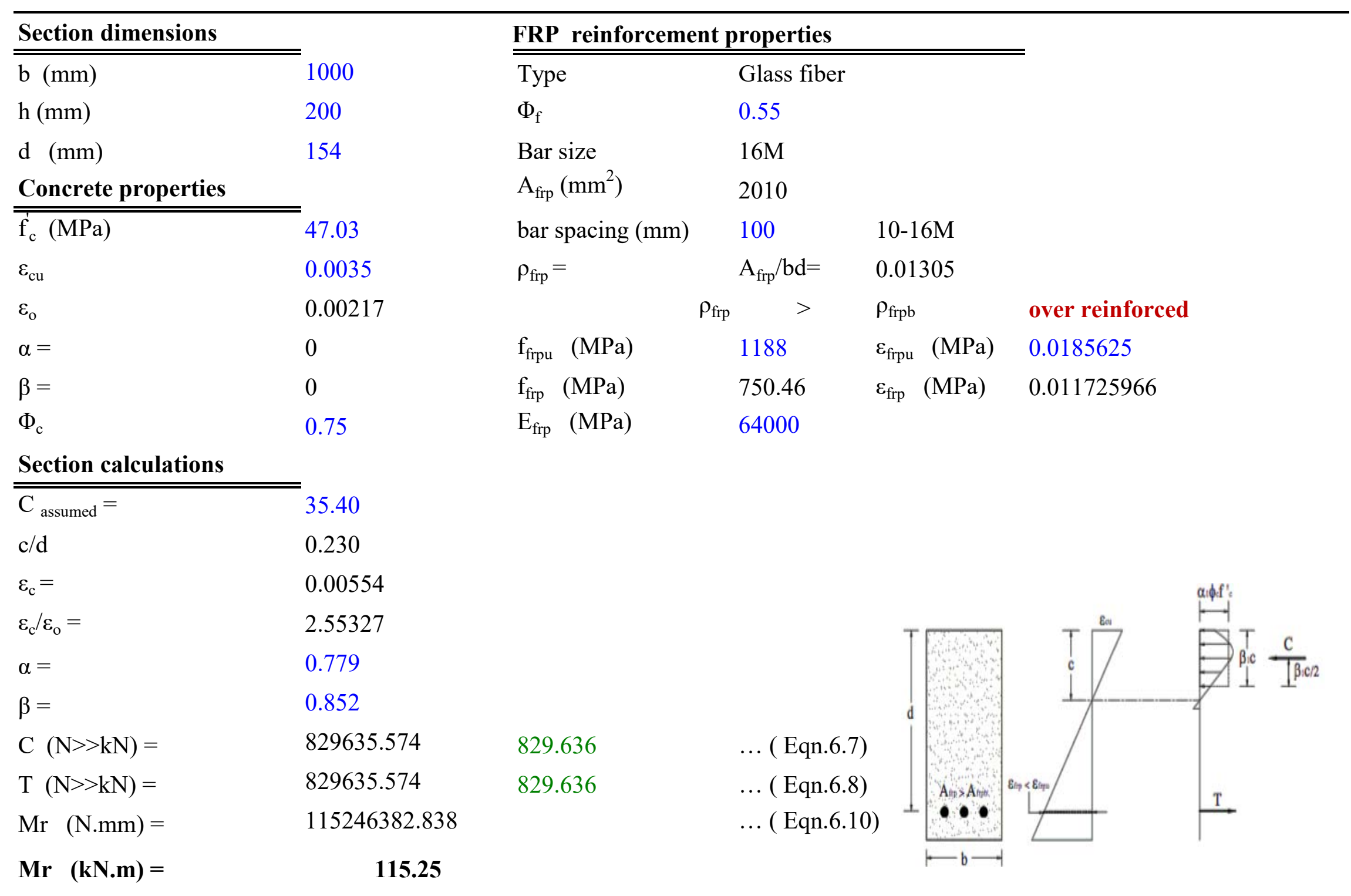



according to ISIS Manual No. 3

\section{Balanced section}

\section{Section dimensions}

$\overline{\overline{\Phi_{\mathrm{c}}}} 0.75$

b (mm) 1000

$\mathrm{h}(\mathrm{mm}) \quad 200$

d $(\mathrm{mm})$

$\mathrm{f}_{\mathrm{c}}(\mathrm{MPa})$

$\varepsilon_{\mathrm{cu}}$

$\mathrm{E}_{\mathrm{c}}(\mathrm{GPa})$

\begin{tabular}{ll}
\multicolumn{2}{c}{ Balanced section } \\
\hline \hline \multicolumn{2}{c}{ FRP reinforcement properties } \\
\hline \hline Type & Glass fiber \\
$\Phi_{\mathrm{f}}$ & 0.55 \\
Bar size & $16 \mathrm{M}$ \\
$\mathrm{f}_{\text {frpu }}(\mathrm{MPa})$ & 1188 \\
$\mathrm{E}_{\text {frp }}(\mathrm{MPa})$ & 64000 \\
$\varepsilon_{\text {frp }}(\mathrm{MPa})$ & 0.0185625 \\
cover $(\mathrm{mm})$ & 38
\end{tabular}

\section{Section calculations}

\begin{tabular}{|c|c|c|c|}
\hline$\alpha 1=0.85-0.0015^{*}\left(f_{c}\right)=$ & 0.776 & & $\ldots .($ P. 6.4) \\
\hline$\beta 1=0.97-0.0025 *\left(\mathrm{f}_{\mathrm{c}}^{\prime}\right)=$ & 0.846 & & $\ldots .($ P. 6.4) \\
\hline$c_{b}=\left(d^{*} \varepsilon_{\mathrm{cu}}\right) /\left(\varepsilon_{\mathrm{cu}}+\varepsilon_{\mathrm{frpu}}\right)=$ & 24.431 & & .... (Eqn. 6.1) \\
\hline \multicolumn{2}{|c|}{$\rho_{\mathrm{frpb}}=\alpha 1 * \beta 1 *\left(\Phi_{\mathrm{c}} / \Phi_{\mathrm{f}}\right) *\left(f_{\mathrm{c}}^{\prime} / f_{\mathrm{frpu}}\right) *\left(\mathrm{c}_{\mathrm{b}} / \mathrm{d}\right)=$} & 0.005915 & $\ldots($ Eqn. 6.6) \\
\hline $\mathrm{A}_{\mathrm{frpb}}\left(\mathrm{mm}^{2}\right)=$ & 910.980 & & \\
\hline $\mathrm{C}(\mathrm{N})=$ & 595234.26 & 595.23 & $\ldots($ Eqn. 6.3$)$ \\
\hline $\mathrm{T}(\mathrm{N})=$ & 595234.26 & 595.23 & $\ldots($ Eqn. 6.4$)$ \\
\hline $\mathrm{M}(\mathrm{KN} \cdot \mathrm{m})=$ & 91666065.01 & 91.6661 & \\
\hline Number of bars & 6.00 & & \\
\hline Spacing $\left(\mathrm{mm}^{2}\right)$ & 165 & & \\
\hline
\end{tabular}

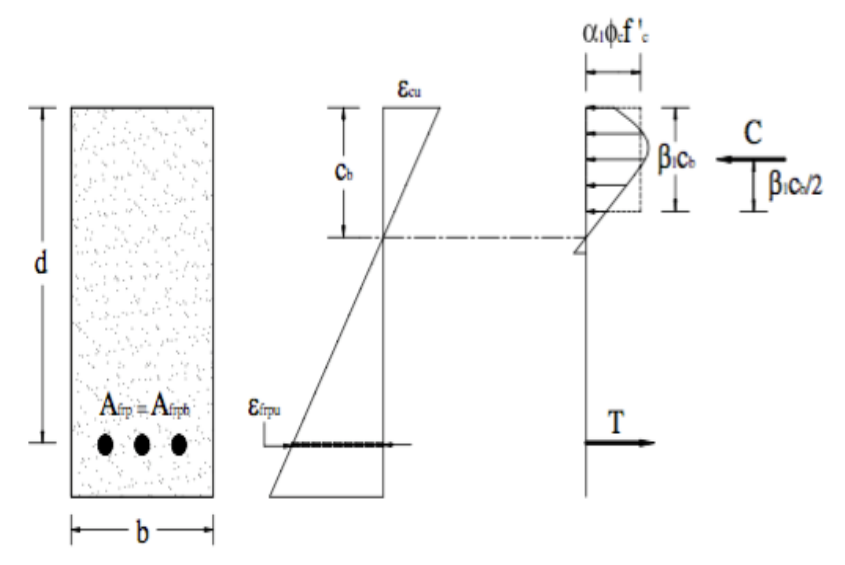

Summary:

16M@165 mm 
Flexural Design of FRP Reinforced Concrete according to ISIS Manual No. 3

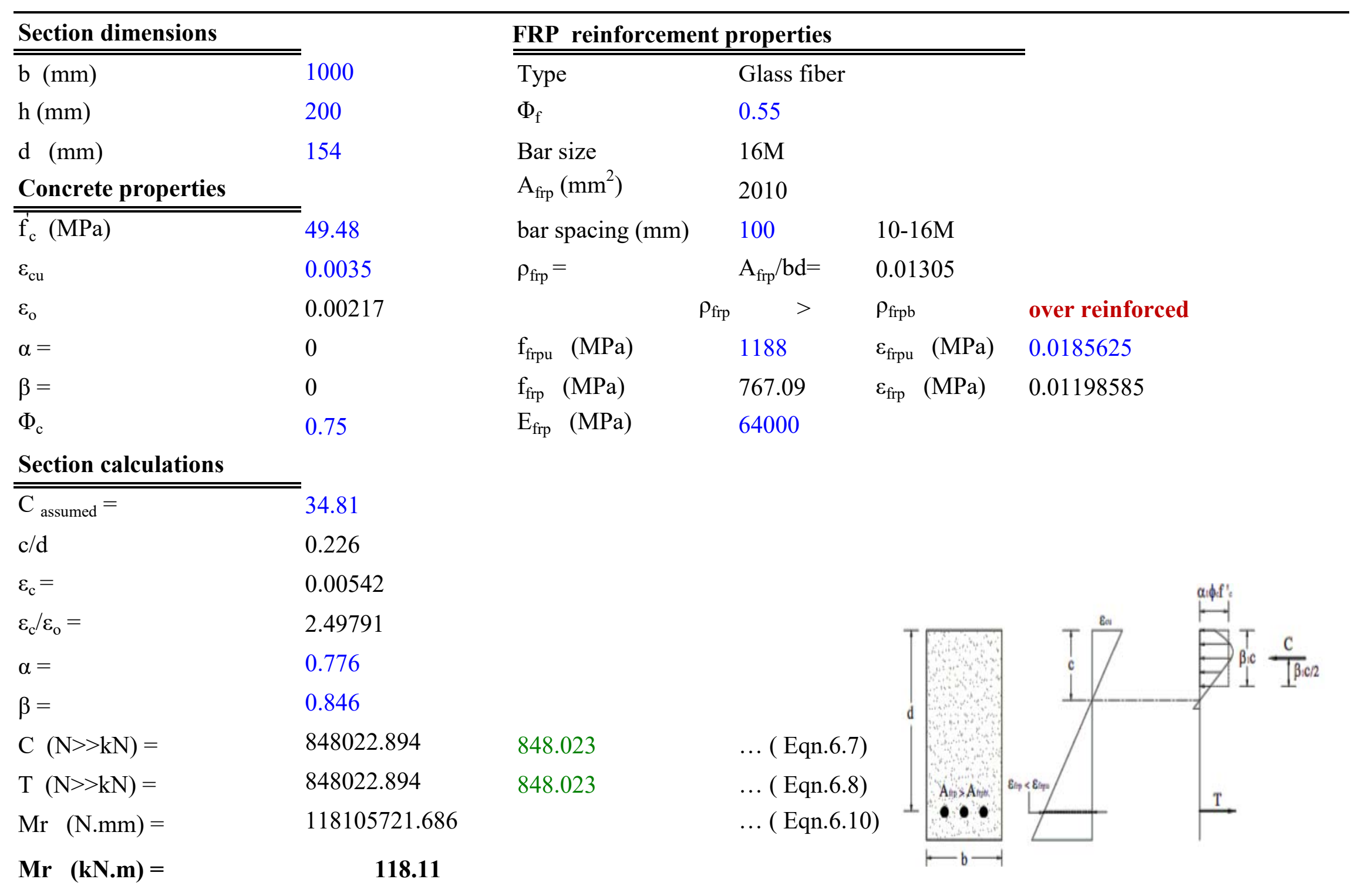



according to ISIS Manual No. 3

\section{Balanced section}

\section{Section dimensions}

$\overline{\overline{\Phi_{\mathrm{c}}}} 0.75$

b (mm) 1000

h (mm) 200

d $(\mathrm{mm})$

$\mathrm{f}_{\mathrm{c}}(\mathrm{MPa})$

$\varepsilon_{\mathrm{cu}}$

$\mathrm{E}_{\mathrm{c}}(\mathrm{GPa})$

\begin{tabular}{ll}
\multicolumn{2}{c}{ Balanced section } \\
\hline \hline \multicolumn{2}{c}{ FRP reinforcement properties } \\
\hline \hline Type & Glass fiber \\
$\Phi_{\mathrm{f}}$ & 0.55 \\
Bar size & $16 \mathrm{M}$ \\
$\mathrm{f}_{\text {frpu }}(\mathrm{MPa})$ & 1188 \\
$\mathrm{E}_{\text {frp }}(\mathrm{MPa})$ & 64000 \\
$\varepsilon_{\text {frp }}(\mathrm{MPa})$ & 0.0185625 \\
cover $(\mathrm{mm})$ & 38
\end{tabular}

\section{Section calculations}

\begin{tabular}{|c|c|c|c|}
\hline$\alpha 1=0.85-0.0015 *\left(f_{c}\right)=$ & 0.779 & & $\ldots .($ P. 6.4) \\
\hline$\beta 1=0.97-0.0025 *\left(\mathrm{f}_{\mathrm{c}}^{\prime}\right)=$ & 0.851 & & $\ldots .($ P. 6.4) \\
\hline $\mathrm{c}_{\mathrm{b}}=\left(\mathrm{d}^{*} \varepsilon_{\mathrm{cu}}\right) /\left(\varepsilon_{\mathrm{cu}}+\varepsilon_{\mathrm{frpu}}\right)=$ & 24.431 & & $\ldots($ Eqn. 6.1$)$ \\
\hline \multicolumn{2}{|c|}{$\rho_{\mathrm{frpb}}=\alpha 1 * \beta 1 *\left(\Phi_{\mathrm{c}} / \Phi_{\mathrm{f}}\right) *\left(f_{\mathrm{c}}^{\prime} / f_{\mathrm{frpu}}\right) *\left(\mathrm{c}_{\mathrm{b}} / \mathrm{d}\right)=$} & 0.005735 & $\ldots($ Eqn. 6.6$)$ \\
\hline $\mathrm{A}_{\mathrm{frpb}}\left(\mathrm{mm}^{2}\right)=$ & 883.152 & & \\
\hline $\mathrm{C}(\mathrm{N})=$ & 577051.27 & 577.05 & $\ldots($ Eqn. 6.3$)$ \\
\hline $\mathrm{T}(\mathrm{N})=$ & 577051.27 & 577.05 & $\ldots($ Eqn. 6.4$)$ \\
\hline $\mathrm{M}(\mathrm{KN} . \mathrm{m})=$ & 88865885.10 & 88.8659 & \\
\hline Number of bars & 6.00 & & \\
\hline Spacing $\left(\mathrm{mm}^{2}\right)$ & 165 & & \\
\hline
\end{tabular}

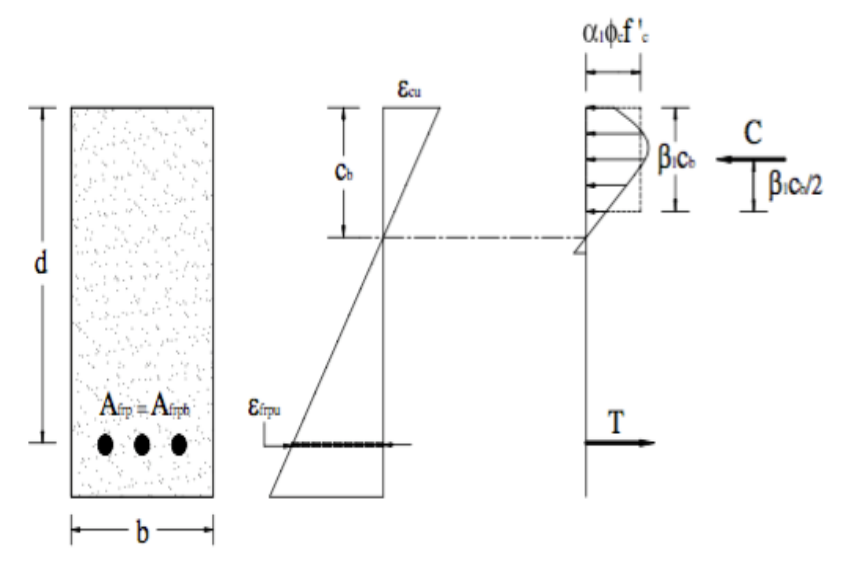

Summary:

16M@165 mm 
Flexural Design of FRP Reinforced Concrete according to ISIS Manual No. 3

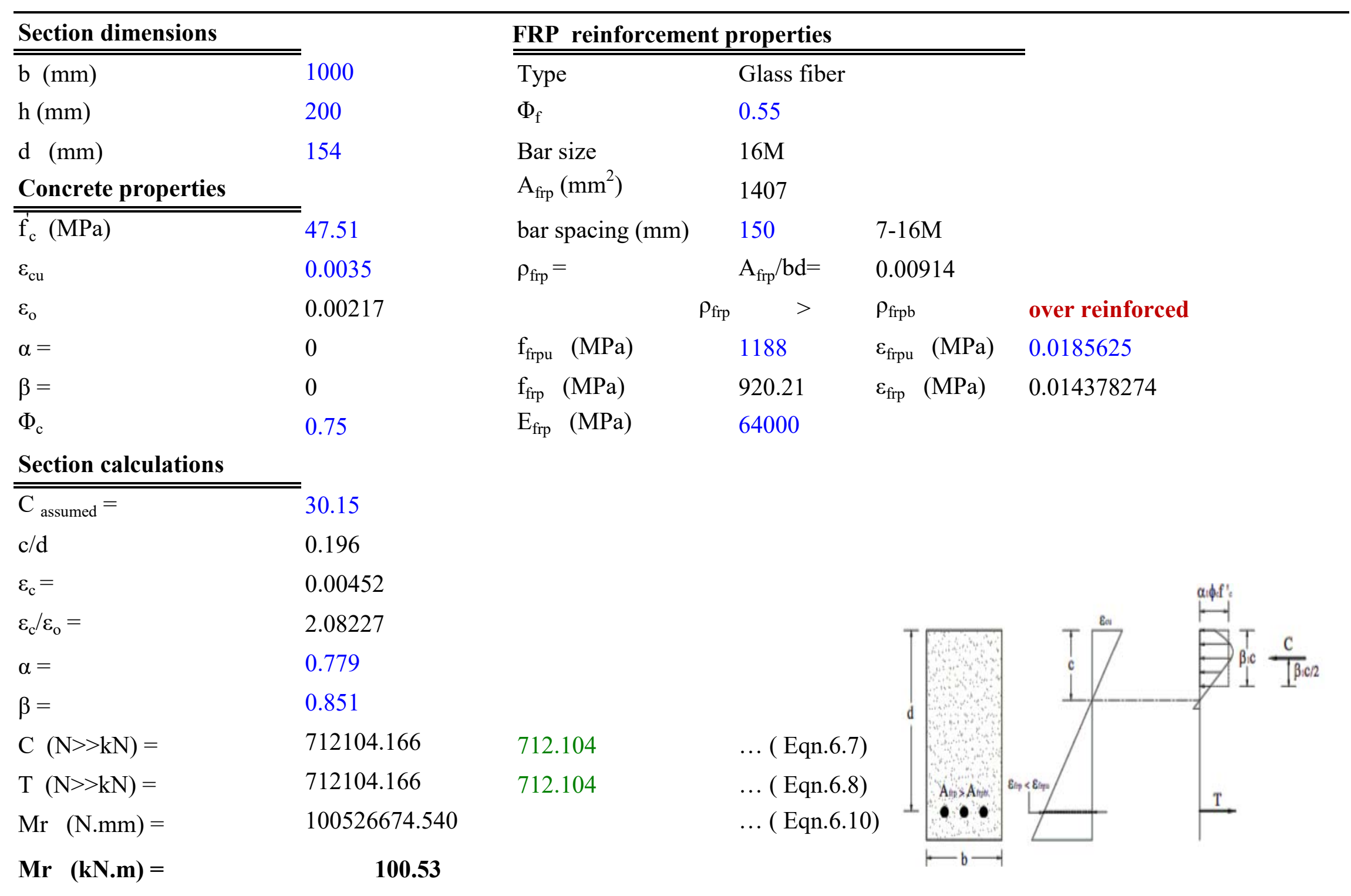



according to ISIS Manual No. 3

\begin{tabular}{|c|c|c|c|c|c|}
\hline \multirow[b]{2}{*}{ Section dimensions } & \multicolumn{3}{|c|}{ Balanced section } & & \\
\hline & & \multicolumn{2}{|c|}{ FRP reinforcement properties } & & \\
\hline$\overline{\Phi_{\mathrm{c}}}$ & 0.75 & Type & Glass fiber & & \\
\hline $\mathrm{b}(\mathrm{mm})$ & 1000 & $\Phi_{\mathrm{f}}$ & 0.55 & & \\
\hline $\mathrm{h}(\mathrm{mm})$ & 200 & Bar size & $16 \mathrm{M}$ & & \\
\hline $\mathrm{d} \quad(\mathrm{mm})$ & 154 & $\mathrm{f}_{\text {frpu }}(\mathrm{MPa})$ & 1188 & & \\
\hline $\mathrm{f}_{\mathrm{c}}^{\prime}(\mathrm{MPa})$ & 42.3 & $\mathrm{E}_{\text {frp }}(\mathrm{MPa})$ & 64000 & & \\
\hline$\varepsilon_{\mathrm{cu}}$ & 0.0035 & $\varepsilon_{\text {frp }}(\mathrm{MPa})$ & 0.0185625 & & \\
\hline $\mathrm{E}_{\mathrm{c}}(\mathrm{GPa})$ & 29267.30257 & cover $(\mathrm{mm})$ & 38 & & \\
\hline \multicolumn{6}{|l|}{ Section calculations } \\
\hline$\alpha 1=0.85-0.0015^{*}\left(\mathrm{f}_{\mathrm{c}}\right)=$ & $=0.787$ & & $\ldots .($ P. 6.4) & & \\
\hline$\beta 1=0.97-0.0025 *\left(\mathrm{f}_{\mathrm{c}}^{\prime}\right)=$ & 0.864 & & $\ldots .($ P. 6.4) & & \\
\hline $\mathrm{c}_{\mathrm{b}}=\left(\mathrm{d}^{*} \varepsilon_{\mathrm{cu}}\right) /\left(\varepsilon_{\mathrm{cu}}+\varepsilon_{\mathrm{frpu}}\right)=$ & 24.431 & & $\ldots($ Eqn. 6.1$)$ & & \\
\hline \multicolumn{2}{|c|}{$\rho_{\mathrm{frpb}}=\alpha 1 * \beta 1 *\left(\Phi_{\mathrm{c}} / \Phi_{\mathrm{f}}\right)^{*}\left(f_{\mathrm{c}}^{\prime} / f_{\mathrm{frpu}}\right) *\left(\mathrm{c}_{\mathrm{b}} / \mathrm{d}\right)=$} & 0.005236 & $\ldots($ Eqn. 6.6) & & \\
\hline$A_{\text {frpb }}\left(\mathrm{mm}^{2}\right)=$ & 806.348 & & & & $\mathrm{C}$ \\
\hline $\mathrm{C}(\mathrm{N})=$ & 526867.48 & 526.87 & $\ldots($ Eqn. 6.3) & & $\perp_{1} / 2 / 2$ \\
\hline $\mathrm{T}(\mathrm{N})=$ & 526867.48 & 526.87 & $\ldots($ Eqn. 6.4$)$ & d & \\
\hline $\mathrm{M}(\mathrm{KN} . \mathrm{m})=$ & 81137582.02 & 81.1376 & & & \\
\hline Number of bars & 6.00 & & & $A_{p}=A_{p h}$ & \\
\hline Spacing $\left(\mathrm{mm}^{2}\right)$ & 165 & & & $10 \bullet$ & \\
\hline Summary: & 16M@165 n & & & $\vdash b-$ & \\
\hline
\end{tabular}


Flexural Design of FRP Reinforced Concrete according to ISIS Manual No. 3

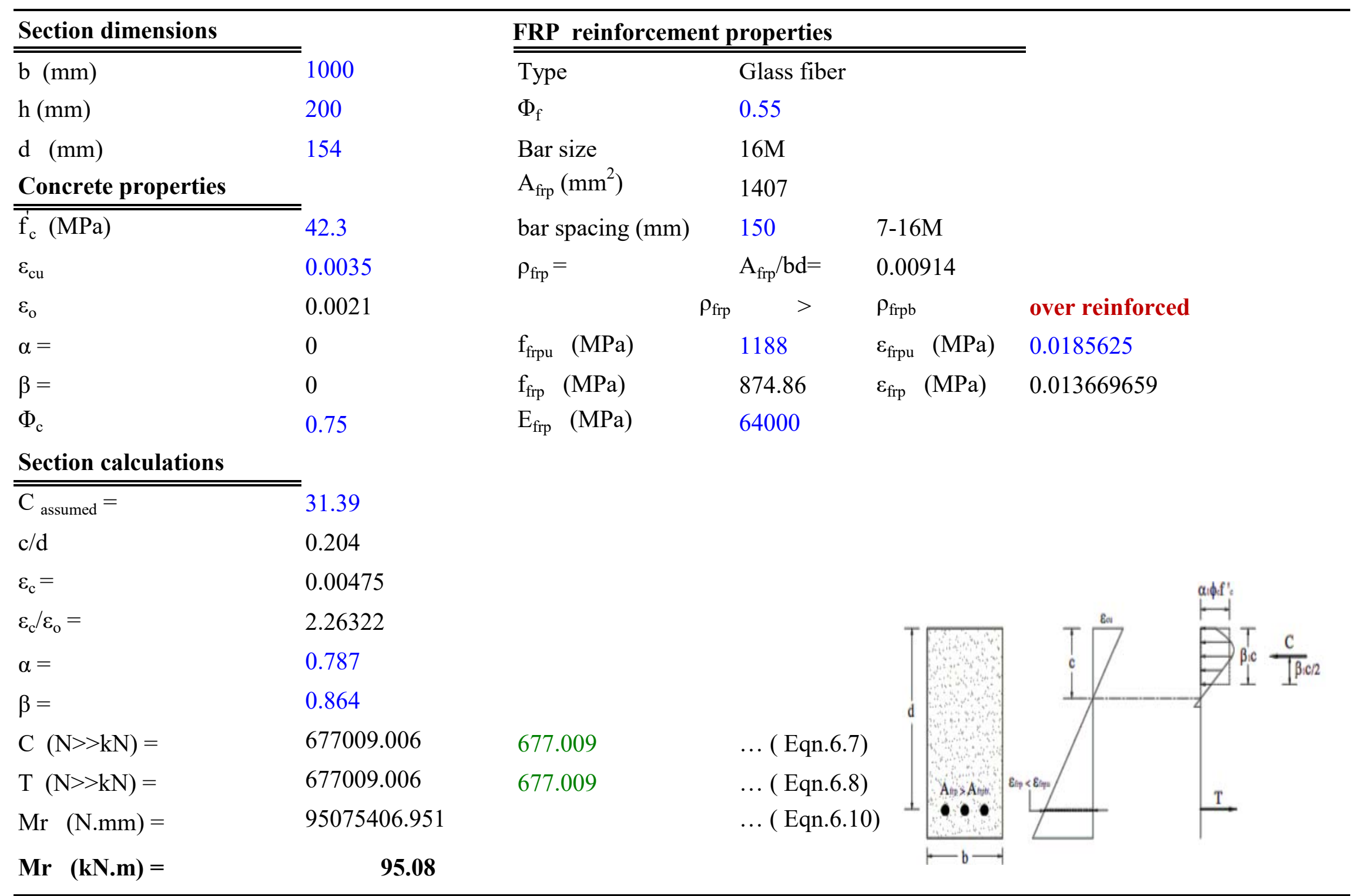



according to ISIS Manual No. 3

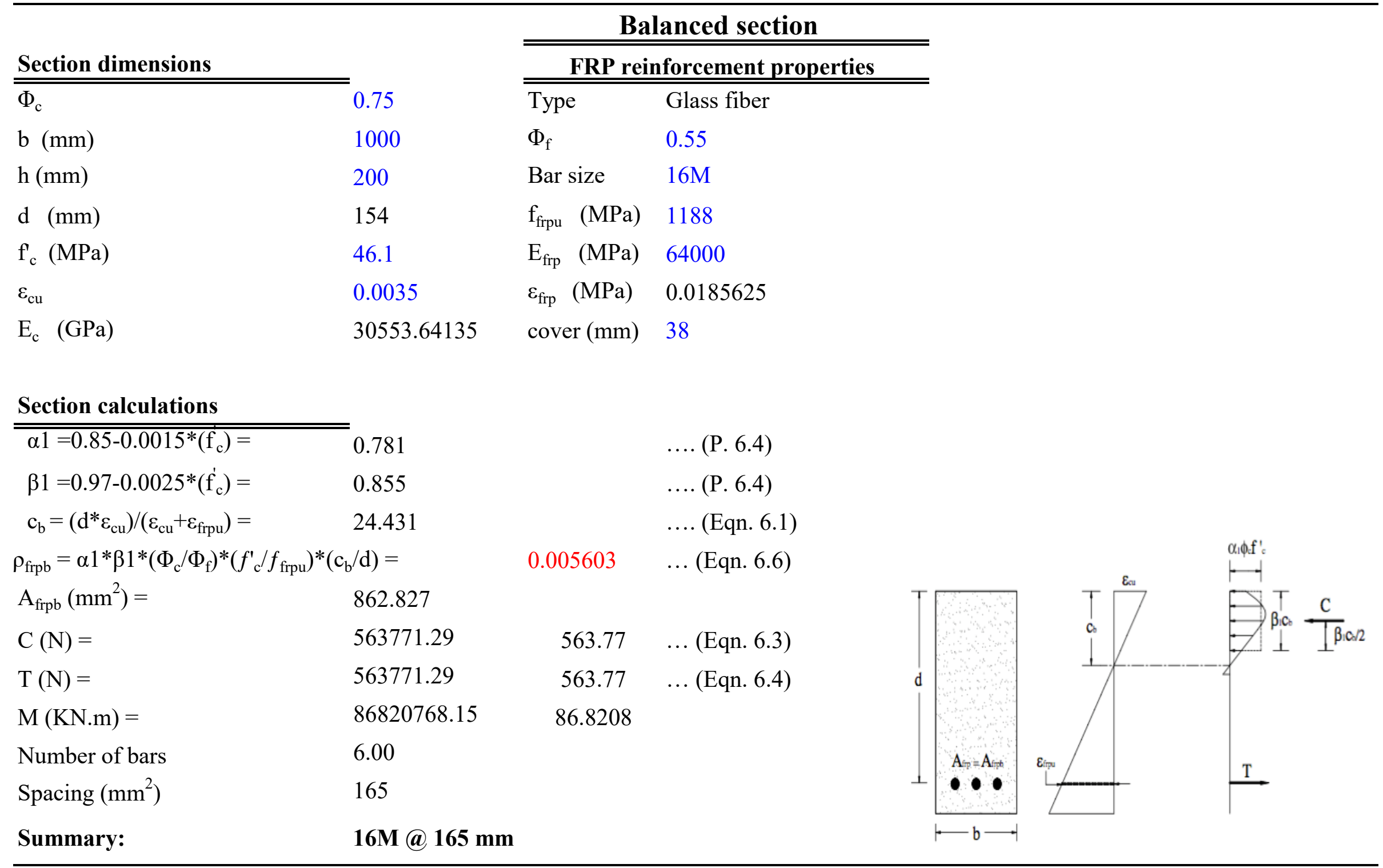


Flexural Design of FRP Reinforced Concrete according to ISIS Manual No. 3

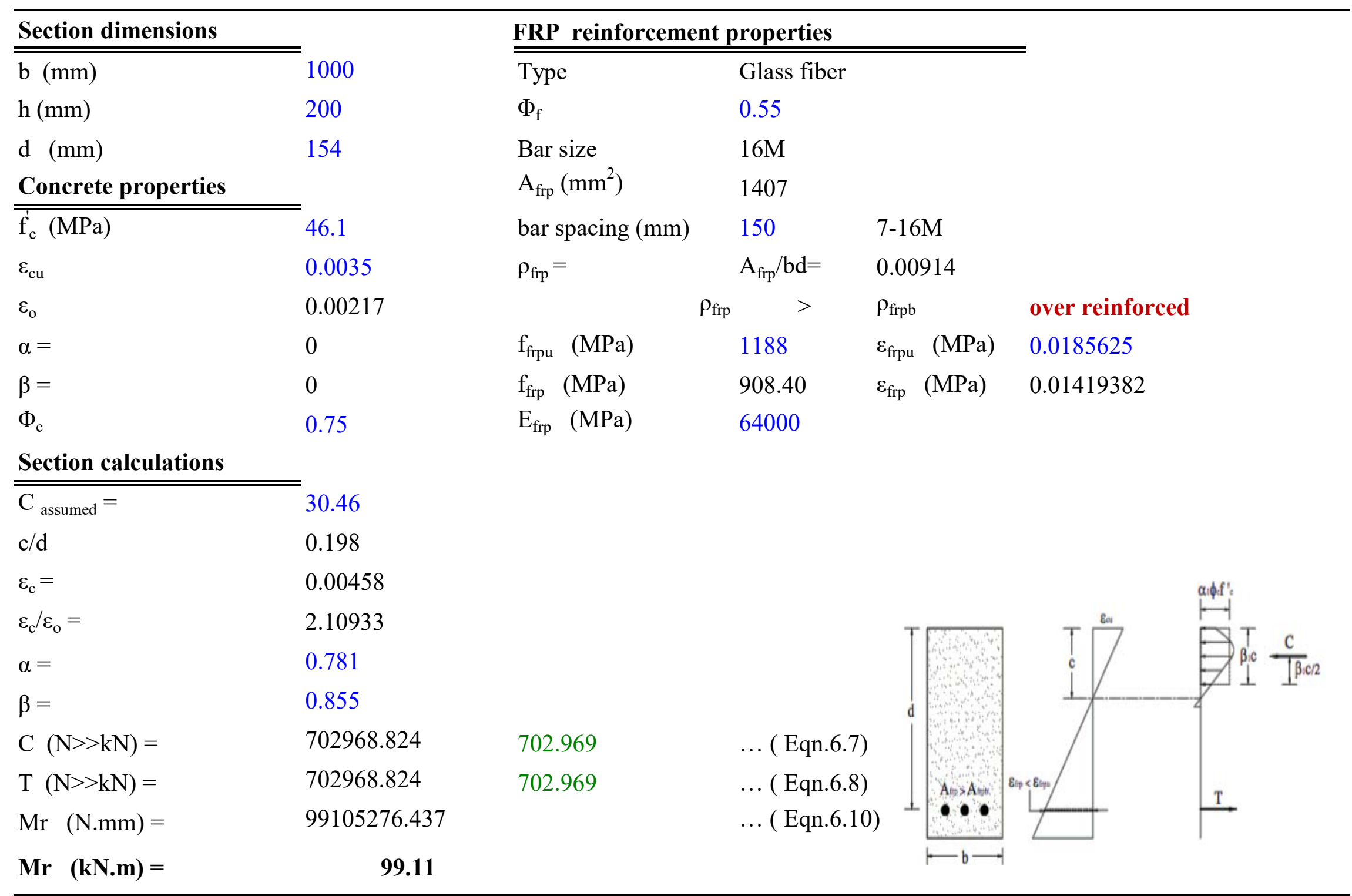



according to ISIS Manual No. 3

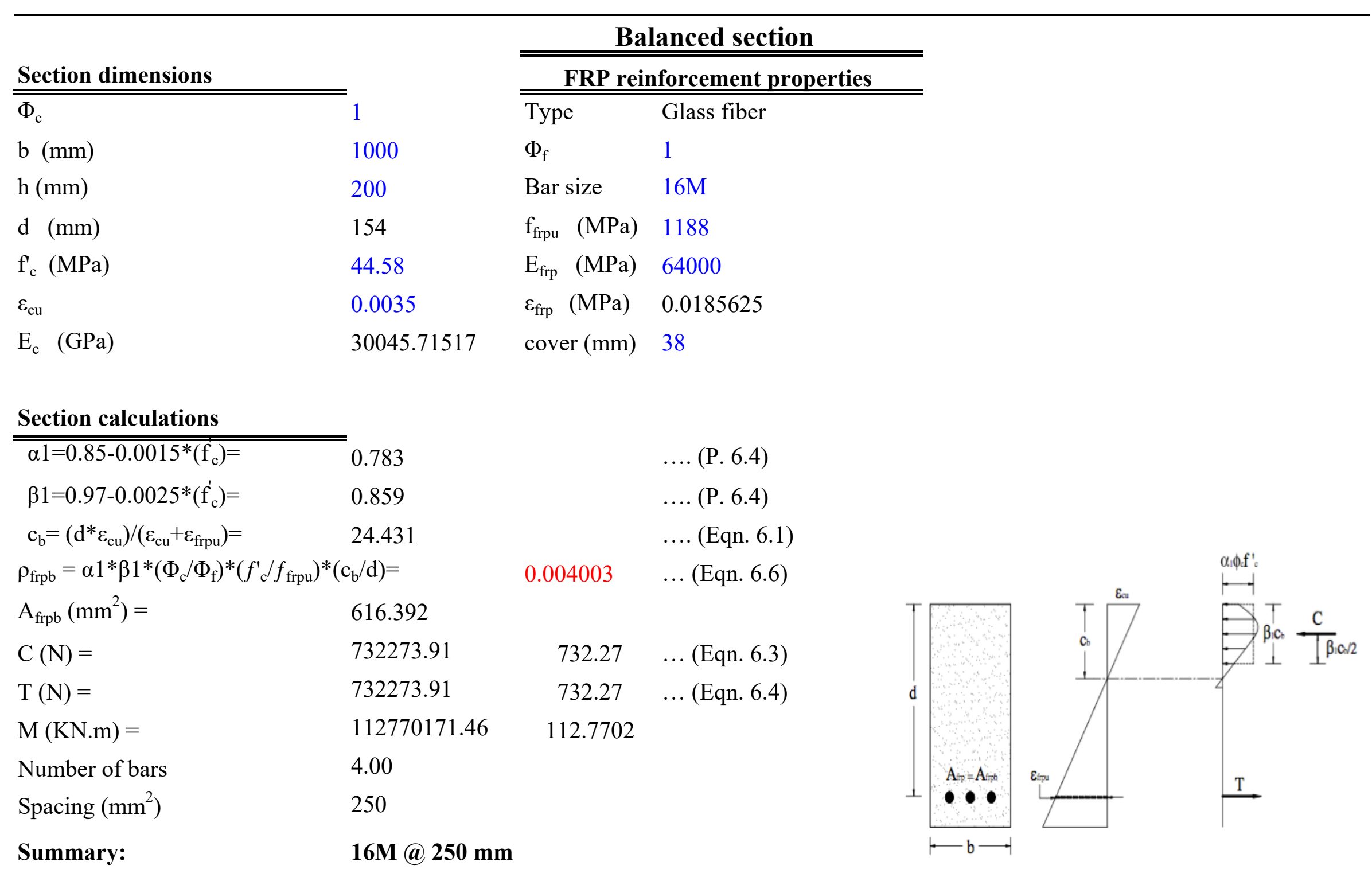


$\underline{M_{\Perp}}$ unfactored for slab S1

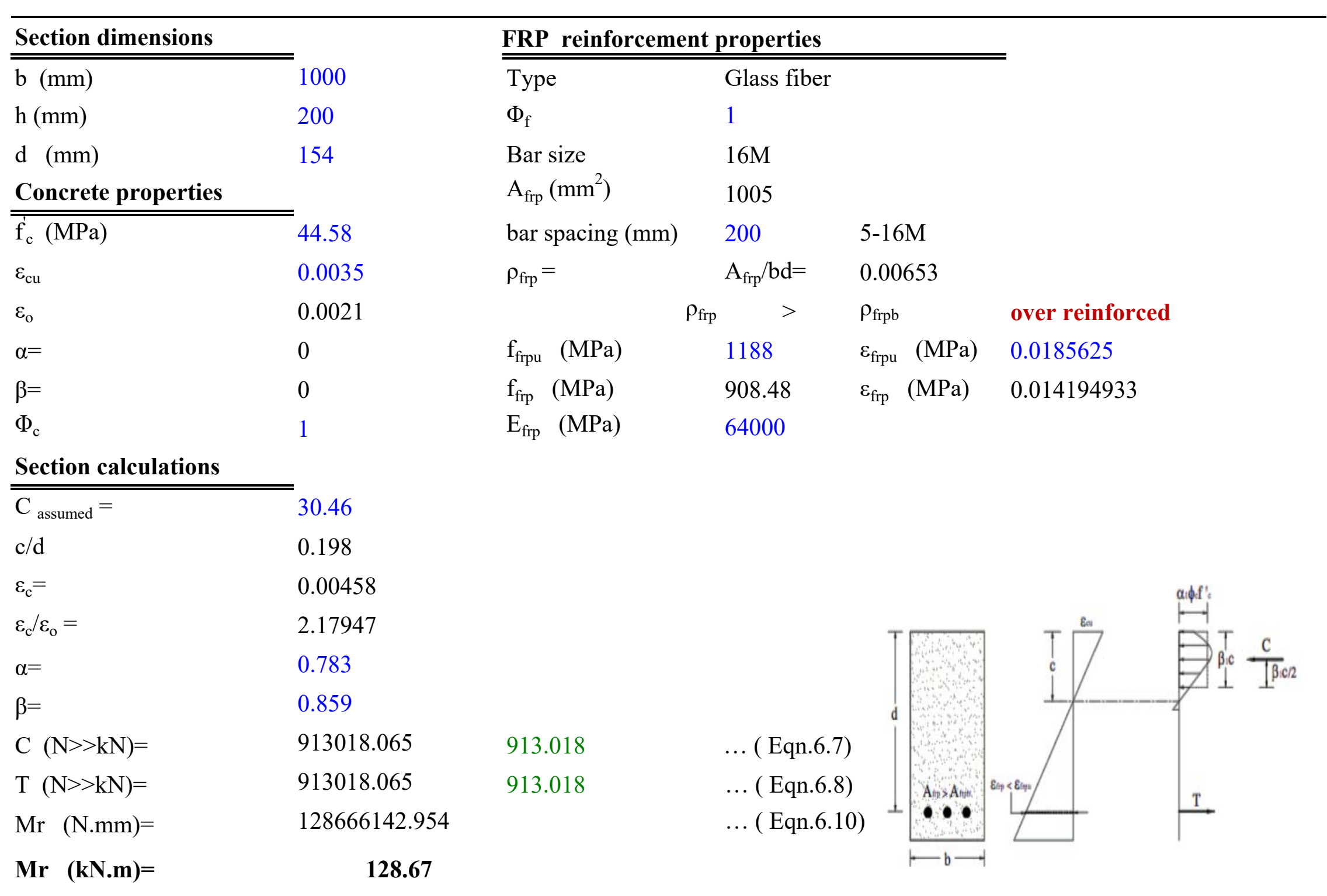
according to ISIS Manual No. 3

Flexural Design of FRP Reinforced Concrete 


\section{References}

AASHTO. 2009. AASHTO-LRFD Bridge Design Guide Spesifications for GFRP-Reinforced

Concrete Bridge Decks and Traffic Railings. American Association of State Highway and Transportation Officials. Washington D.C

AASHTO. 2014. AASHTO LRFD Bridge Design Specifications. American Association of State Highway and Transportation Officials. Washington D.C

Aarup, B., and Jensen, B. 1998. Bond Properties of High Strength Fiber Reinforced Concrete. Bond and Development of Reinforcement, ACI Publication SP-180, pp. 459-472.

Achillides, Z., and Pilakoutas, K. 2004. Bond Behavior of Fiber Reinforced Polymer Bars under Direct Pullout Conditions. ASCE Journal for Composites in Construction, 8(2): 173-181.

ACI 544.4R-88. 1999. Design Considerations for Steel Fiber Reinforced Concrete. American Concrete Institute. Farmington Hills, Michigan.

Ametrano, D. 2011. Bond Characteristics of Glass Fibre Reinforced Polymer Bars Embedded in High Performance and Ultra-High Performance Concrete. M.A.SC. Thesis, Civil Engineering Department, Ryerson University, Toronto, Ontario, Canada.

Bank Lawrence C. 2006. Composites for Construction: Structural Design with FRP Materials. John Wily \& Sons, Inc. 560 pages.

Badie, S., and Tadros, M. 2008. NCHRP Report 584: Full-Depth Precast Concrete Bridge Deck Panel Systems. Transportation Research Board, Washington D.C.

Badie, S., Tadros, M., and Girgis, A. 2006. Full-Depth Precast-Concrete Bridge Deck Panel Systems, Final Report NCHRP-12-65, s.1, National Cooperative Highway Research Program.

Benmokrane, B., Tighiouart, B., and Chaallal, O. 1996. Bond Strength and Load Distribution of Composite GFRP Reinforcing Bars in Concrete. ACI Materials Journal, pp. 246-253. 
CHBDC. 2014. Canadian Highway Bridge Design Code, CAN/CSA-S6-14. Canadian Standard Association, Toronto, Ontario, Canada.

Culmo, M. P. 2011. Accelerated Bridge Construction - Experience in Design, Fabrication and Erection of Prefabricated Bridge Elements and Systems. Report No. FHWA-HIF-12-013, Federal Highway Administration, 347 pages.

Culmo, M. P. 2009. Connection Details for Prefabricated Bridge Elements and Systems. Report No. FHWA-IF-09-010., Federal Highway Administration, 568 pages.

El-Gamal, S., El-Salakawy, E., and Benmokrane, B. 2005. Behavior of Concrete Bridge Deck Slabs Reinforced with Fiber-Reinforced Polymer Bars under Concentrated Loads. ACI Structural Journal, 102(5): 727-735.

Garcia, H. 2007. Analysis of an Ultra-High Performance Concrete Two-Way Ribbed Bridge Deck Slab. Report No. FHWA-HRT-07-056, Federal Highway Administration, McLean, VA.

Graybeal, B. 2006. Material Property Characterization of Ultra-High Performance Concrete. Report No. FHWA-HRT-06-103, Federal Highway Administration, 186 pages.

Graybeal, B., 2011. Ultra-High Performance Concrete. Report No. FHWA-HRT-11-038, Federal Highway Administration, U.S. Department of Transportation.

Graybeal, B., 2013. Ultra-High Performance Concrete: A State-of-the-Art Report for the Bridge Community. Report No. FHWA-HRT-13-060, Federal Highway Administration, U.S. Department of Transportation, 171 pages.

Hanus, J., Shield, C. and French, C. W. 2000. Development Length of GFRP Reinforcement in Concrete Bridge Decks, University of Minnesota. Minneapolis, MN. 
Hossain, K. M., Ametrano, D., and Lachemi, M. 2012. Bond Strength of Standard and High Modulus GFRP Bars in High Strength Concrete. Journal of Materials in Civil Engineering, 26(3): 449-456.

He, Z., Ma, Z., Chapman, C., and Liu, Z. 2013. Longitudinal Joints with Accelerated Construction Features in Decked Bulb-Tee Girder Bridges: Strut-and-Tie Model and Design Guidelines. ASCE Journal of Bridge Engineering, 18(5): 372-379.

Hieber, D., and Wacker, J. 2005. State-of-the-Art Report on Precast Concrete Systems for Rapid Construction of Bridges. Report No. WA-RD 594.1, Washington State Department of Transportation, 112 pages.

Hussein, L. 2015. Structural Behaviour of Ultra High Performance Fiber Reinforced Concrete Composite Members, Ph.D. Thesis, Ryerson University, Toronto, Ontario, Canada.

ISIS. 2007. Reinforcing Concrete Structures with Fibre Reinforced Polymers, Design Manual No. 3., Intelligent Sensing for Innovative Structures, ISIS Canada. University of Manitoba, Winnipeg, Manitoba, Canada.

Islam, S., Afefy, H. M., Sennah, K., and Azimi, H. 2015. Bond Characteristics of Straight and Headed-End, Ribbed-surface, GFRP Bars Embedded in High-Strength Concrete. Construction and Building Materials, 83: 283-298.

Khalafalla, I. 2013. Development of sustainable concrete bridge deck slab systems using corrosion resistant GFRP bars. Ph.D. Thesis, Ryerson University, Toronto, Ontario, Canada.

Kosmata, S., Kerkhoff, B., Hooton, R., McGarth, R. 2003. Design and Control of Concrete Mixture. Cement association of Canada,. Eighth Canadian Edition. 
Khederzadeh, H. R., and Sennah, K. 2013. Pullout Strength of Pre-installed GFRP Bars in Concrete.

Proceedings of the 2013 CSCE Annual General Conference, Canadian Society for Civil Engineering, Montreal, Quebec, pp. 1-10.

Lee, J., and Lee S. 2015. Flexural Behavior of Ultra-High Performance Fibre-Reinforced Concrete Moment Connection for Precast Concrete Decks. ACI Structural Journal, 112(4): 451-638.

Li, L., Ma, Z., Griffey, M., Oesterle, R. 2010. Improved Longitudinal Joint Details in Decked Bulb Tees for Accelerated Bridge Construction: Concept Development. Journal of Bridge Engineering, 15(3): 327-336.

Li, L., Ma, J., and Oesterle, R. 2010. Improved Longitudinal Joint Details in Decked For Accelerated Bridge Construction: Fatigue Evaluation. ASCE Journal of Bridge Engineering, 15(5): 511522.

Ma, Z., Cao, Q., Chapman, C., Burdette, E., and French, C. 2012. Longitudinal Joint Details with Tight Bend Diameter U-Bars. ACI Structural Journal, 109(6): 815- 824.

NCHRP. 2008. Full-Depth Precast Concrete Bridge Deck Panel Systems. NCHRP Report 584, Transportation Research Board, Washington D.C.

NCHRP. 2011. Summary of Cast-In-Place Concrete Connections for Precast Deck Systems. Research Results Digest 355, Transportation Research Board, pp. 1-33.

Nielsen, C., Olesen, J. and Aarup, B. 1996. Effects of Fibres on the Bond Strength of High Strength Concrete. BHP96 Fourth International Symposium on Utilization of High Strength/HighPerformance Concrete, Paris, France.

PCI. 2011. State-of-the-art Report on Full-Depth Precast Concrete Bridge Deck Panels. Prepared by PCI Committee on Bridges and PCI Bridge Producers Committee. Precast/prestressed Concrete Institute, PCI, 141 Pages. 
PCINER Technical Committee, 2002. Full Depth Precast Concrete Deck Slabs. Report No. PCINER-02-FDPCDS, Precast/Prestressed Concrete Institute, New England Region.

Roddenberry, M. 2012. Prefabricated/Precast Bridge Elements and Systems (PBES) for Off System Bridges. Final Report submitted to Florida Department of Transportation and prepared by Florida A\&M University, Florida, 85 pages.

Russell, H. G. and Graybeal, B. A. 2013. Ultra-High Performance Concrete: A State-of-the-Art Report for the Bridge Community. Office of Infrastructure Research \& Development, Federal Highway Administration, McLean, VA.

Sayed-Ahmed, M. 2016. Development and Study of Closure Strip Between Precast Deck Panels in Accelerated Bridge Construction, Ph.D. Thesis, Ryerson University, Toronto, Ontario, Canada.

Sriram, A., Bradley P. and Sri, S. 2013. Design Guide for Precast UHPC Waffle Deck Panel System, including Connections. Report No. FHWA-HIF-13-032, U.S. Department of transportation, Federal Highway Administration, 125pages.

UDOT. 2010. Full Depth Precast Concrete Deck Panel Manual. Utah Department of Transportation, 24 pages.

Vint, L. M. 2012. Investigation of Bond Properties of Glass Fiber Reinforced Polymer Bars in Concrete Under Direct Tension. M.A.Sc Thesis, Graduate Department of Civil Engineering, University of Toronto.

Wahba, K., Marzouk, H., and Dawood, N., 2012. Structural Behaviour of UHPFRC Beams without Stirrups, 3rd International Structural Specialty Conference, Edmonton, Alberta, pp. 1-10.

Yang, I., Joh, C., and Kim, B. 2010. Structural Behaviour of Ultra-high Performance Concrete Beams Subjected to Bending. Engineering Structures, 32: 3478-3487. 


\section{Tables}

Table 3. 1 Test matrix

\begin{tabular}{|c|c|c|c|c|c|c|c|c|c|}
\hline \multirow{2}{*}{ Group } & \multirow{2}{*}{$\begin{array}{l}\text { Slab dimensions } \\
\qquad(\mathrm{mm})\end{array}$} & \multirow{2}{*}{$\begin{array}{l}\text { Slab } \\
\text { No. }\end{array}$} & \multirow{2}{*}{$\begin{array}{l}\text { Joint } \\
\text { width }\end{array}$} & \multirow{2}{*}{$\begin{array}{l}\text { Splice } \\
\text { length }\end{array}$} & \multicolumn{2}{|c|}{$\mathrm{f}_{\mathrm{c}}(\mathrm{MPa})$} & \multicolumn{2}{|c|}{ Splice configuration } & \multirow{2}{*}{$\begin{array}{c}\text { Bar } \\
\text { spacing }\end{array}$} \\
\hline & & & & & precast & Joint & Type & Offset (mm) & \\
\hline \multirow{3}{*}{$\mathrm{CG}$} & \multirow{3}{*}{$2800 \times 600 \times 200$} & $\mathrm{~S}_{1}$ & - & - & 35 & - & \multirow{3}{*}{-} & \multirow{3}{*}{ N/A } & \multirow{3}{*}{200} \\
\hline & & $\mathrm{S}_{2}$ & - & - & 160 & - & & & \\
\hline & & $\mathrm{S}_{3}$ & 185 & - & 35 & 160 & & & \\
\hline \multirow{4}{*}{ G1 } & \multirow{4}{*}{$2800 \times 600 \times 200$} & $\mathrm{~S}_{4}$ & 125 & 75 & \multirow{4}{*}{35} & \multirow{4}{*}{160} & \multirow{4}{*}{ Contact } & \multirow{4}{*}{0} & \multirow{4}{*}{200} \\
\hline & & $\mathrm{S}_{5}$ & 155 & 105 & & & & & \\
\hline & & $\mathrm{S}_{6}$ & 185 & 135 & & & & & \\
\hline & & $\mathrm{S}_{7}$ & 215 & 165 & & & & & \\
\hline \multirow{4}{*}{ G2 } & \multirow{4}{*}{$2800 \times 600 \times 200$} & $\mathrm{~S}_{8}$ & 125 & 75 & \multirow{4}{*}{35} & \multirow{4}{*}{160} & \multirow{4}{*}{$\begin{array}{l}\text { Non- } \\
\text { contact }\end{array}$} & \multirow{4}{*}{50} & \multirow{4}{*}{200} \\
\hline & & $\mathrm{S}_{9}$ & 155 & 105 & & & & & \\
\hline & & $\mathrm{S}_{10}$ & 185 & 135 & & & & & \\
\hline & & $\mathrm{S}_{11}$ & 215 & 165 & & & & & \\
\hline \multirow{4}{*}{ G3 } & \multirow{4}{*}{$2800 \times 600 \times 200$} & $\mathrm{~S}_{12}$ & 125 & 75 & \multirow{4}{*}{35} & & & & \\
\hline & & $\mathrm{S}_{13}$ & 155 & 105 & & 160 & Non- & 100 & 200 \\
\hline & & $\mathrm{S}_{14}$ & 185 & 135 & & 100 & contact & 100 & 200 \\
\hline & & $\mathrm{S}_{15}$ & 215 & 165 & & & & & \\
\hline & & $\mathrm{S}_{16}$ & 125 & 75 & & & & & \\
\hline$G A$ & $2800 \times 475 \times 200$ & $\mathrm{~S}_{17}$ & 155 & 105 & 35 & 160 & Non- & 75 & 150 \\
\hline & & $\mathrm{S}_{18}$ & 185 & 135 & & & contact & & \\
\hline & & $\mathrm{S}_{19}$ & 215 & 165 & & & & & \\
\hline & & $\mathrm{S}_{20}$ & 125 & 75 & & & & & \\
\hline G5 & $2800 \times 350 \times 200$ & $\mathrm{~S}_{21}$ & 155 & 105 & 35 & 160 & Non- & 50 & 100 \\
\hline & & $\mathrm{S}_{22}$ & 185 & 135 & & & contact & & \\
\hline & & $\mathrm{S}_{23}$ & 215 & 165 & & & & & \\
\hline & & $\mathrm{S}_{24}$ & 125 & 75 & & & & & \\
\hline$C 6$ & $2000 \times 175 \times 200$ & $\mathrm{~S}_{25}$ & 155 & 105 & 25 & 120 & Non- & 75 & 150 \\
\hline & & $\mathrm{S}_{26}$ & 185 & 135 & Jנ & 120 & contact & 10 & 100 \\
\hline & & $\mathrm{S}_{27}$ & 215 & 165 & & & & & \\
\hline
\end{tabular}


Table 3. 2 Summary of test parameters

\begin{tabular}{|c|c|c|c|}
\hline Main objectives & $\begin{array}{l}\text { Group } \\
\text { No. }\end{array}$ & Fixed variable/group & Variable/slab \\
\hline $\begin{array}{l}\text { Control group to set a fixed } \\
\text { datum for comparison }\end{array}$ & $\mathrm{CG}$ & - & - \\
\hline \multirow{3}{*}{$\begin{array}{l}\text { The effect of the splice bar } \\
\text { spacing, in different joint } \\
\text { splice configuration }\end{array}$} & G1 & Full contact splice & \multirow{3}{*}{$\begin{array}{l}\text { Joint width and } \\
\text { lap splice length }\end{array}$} \\
\hline & $\mathrm{G} 2$ & Non-contact splice with $50 \mathrm{~mm}$ offset & \\
\hline & G3 & $\begin{array}{l}\text { Non-contact equal with spliced bar with spacing of } \\
100 \mathrm{~mm}\end{array}$ & \\
\hline \multirow{3}{*}{$\begin{array}{l}\text { The effect of the main bar } \\
\text { spacing, in different joint } \\
\text { splice configuration }\end{array}$} & G3 & Main bar spacing of $200 \mathrm{~mm}$ & \multirow{3}{*}{$\begin{array}{l}\text { Joint width and } \\
\text { lap splice length }\end{array}$} \\
\hline & G4 & Main bar spacing of $150 \mathrm{~mm}$ & \\
\hline & G5 & Main bar spacing of $100 \mathrm{~mm}$ & \\
\hline \multirow{2}{*}{$\begin{array}{l}\text { The effect of UHPFRC } \\
\text { joint strength }\end{array}$} & G4 & UHPFRC $\mathrm{f}_{\mathrm{c}}=160 \mathrm{MPa}$ & \multirow{2}{*}{$\begin{array}{l}\text { Joint width and } \\
\text { lap splice length }\end{array}$} \\
\hline & G6 & UHPFRC $\mathrm{f}_{\mathrm{c}}=120 \mathrm{MPa}$ & \\
\hline
\end{tabular}

Table 3. 3 Material properties for GFRP bars

\begin{tabular}{ccccc}
\hline Bar size & Bar area & Guaranteed tensile strength & $\begin{array}{c}\text { Modulus of } \\
\text { elasticity }\end{array}$ & Strain at failure \\
\hline $\mathrm{mm}^{2}$ & $\mathrm{MPa}$ & $\mathrm{GPa}$ & $2.6 \%$ \\
\hline $12 \mathrm{M}$ & 113 & 1188 & 64 & $2 \mathrm{M}$ \\
\hline
\end{tabular}

Table 3. 4 Typical UHPFRC mix composition (Graybeal, 2013)

\begin{tabular}{lcc}
\hline Material & $\mathrm{kg} / \mathrm{m}^{3}$ & Percentage by weight \\
\hline Portland cement & 712 & 28.5 \\
Fine sand & 1020 & 40.8 \\
Silica fume & 231 & 9.3 \\
Ground quartz & 211 & 8.4 \\
HRWRA & 30.7 & 1.2 \\
Accelerator & 30 & 1.2 \\
Steel fibers & 156 & 6.2 \\
water & 109 & 4.4 \\
\hline
\end{tabular}


Table 4.1 Summary of concrete compressive strength results

\begin{tabular}{|c|c|c|c|}
\hline \multirow{2}{*}{ Group } & \multirow{2}{*}{ Slab } & Precast panels & UHPFRC joint \\
\hline & & $\mathrm{MPa}$ & $\mathrm{MPa}$ \\
\hline \multirow{3}{*}{$\mathrm{CG}$} & $\mathrm{S}_{1}$ & 44.58 & - \\
\hline & $\mathrm{S}_{2}$ & - & 139.35 \\
\hline & $\mathrm{S}_{3}$ & 43.10 & 166.45 \\
\hline \multirow{4}{*}{ G1 } & $\mathrm{S}_{4}$ & 44.60 & 122.30 \\
\hline & $\mathrm{S}_{5}$ & 47.40 & 179.90 \\
\hline & $\mathrm{S}_{6}$ & 45.63 & 164.63 \\
\hline & $\mathrm{S}_{7}$ & 44.60 & 160.90 \\
\hline \multirow{4}{*}{$\mathrm{G} 2$} & $\mathrm{~S}_{8}$ & 44.88 & 161.40 \\
\hline & $\mathrm{S}_{9}$ & 41.30 & 180.80 \\
\hline & $\mathrm{S}_{10}$ & 44.20 & 180.83 \\
\hline & $\mathrm{S}_{11}$ & 44.05 & 145.23 \\
\hline \multirow{4}{*}{ G3 } & $\mathrm{S}_{12}$ & 43.10 & 163.00 \\
\hline & $\mathrm{S}_{13}$ & 43.10 & 180.80 \\
\hline & $\mathrm{S}_{14}$ & 43.10 & 180.80 \\
\hline & $\mathrm{S}_{15}$ & 43.10 & 160.90 \\
\hline \multirow{4}{*}{ G4 } & $\mathrm{S}_{16}$ & 43.10 & 163.00 \\
\hline & $\mathrm{S}_{17}$ & 43.10 & 163.00 \\
\hline & $\mathrm{S}_{18}$ & 43.10 & 163.00 \\
\hline & $\mathrm{S}_{19}$ & 43.10 & 160.86 \\
\hline \multirow{4}{*}{ G5 } & $\mathrm{S}_{20}$ & 46.45 & 156.72 \\
\hline & $\mathrm{S}_{21}$ & 46.45 & 156.72 \\
\hline & $\mathrm{S}_{22}$ & 47.03 & 153.60 \\
\hline & $\mathrm{S}_{23}$ & 49.48 & 163.71 \\
\hline \multirow{4}{*}{ G6 } & $\mathrm{S}_{24}$ & 47.40 & 122.40 \\
\hline & $\mathrm{S}_{25}$ & 47.51 & 121.72 \\
\hline & $\mathrm{S}_{26}$ & 42.30 & 121.73 \\
\hline & $\mathrm{S}_{27}$ & 46.10 & 120.30 \\
\hline
\end{tabular}


Table 4.2 Summary of test results

\begin{tabular}{|c|c|c|c|c|c|c|c|c|}
\hline \multirow{2}{*}{ Group } & \multirow{2}{*}{ Slab } & \multirow{2}{*}{$\begin{array}{c}\begin{array}{c}\text { Cracking } \\
\text { moment }\end{array} \\
\text { kN.m }\end{array}$} & \multirow{2}{*}{$\begin{array}{c}\begin{array}{r}\text { Ultimate } \\
\text { moment }\end{array} \\
\text { kN.m }\end{array}$} & \multirow{2}{*}{$\begin{array}{c}\begin{array}{c}\text { Ultimate } \\
\text { deflection }\end{array} \\
\text { mm }\end{array}$} & \multirow{2}{*}{$\begin{array}{c}\text { Max. side } \\
\text { concrete } \\
\text { strain } \\
\begin{array}{c}\text { Micro- } \\
\text { strain }\end{array}\end{array}$} & \multicolumn{2}{|c|}{ Max. bar strain } & \multirow{2}{*}{$\begin{array}{c}\text { Corresponding } \\
\text { bar stress }\end{array}$} \\
\hline & & & & & & $\begin{array}{l}\text { Micro- } \\
\text { strain }\end{array}$ & Strain & \\
\hline \multirow{3}{*}{$\mathrm{CG}$} & $\mathrm{S}_{1}^{*}$ & 9.30 & 54.832 & 51.57 & -542.00 & - & - & - \\
\hline & $\mathrm{S}_{2}$ & 35.26 & 94.69 & 67.56 & $-1,072.00$ & $10,406.00$ & 0.010 & 665.98 \\
\hline & $\mathrm{S}_{3}$ & 8.42 & 59.22 & 68.94 & -881.00 & $15,543.00$ & 0.016 & 994.75 \\
\hline \multirow{4}{*}{ G1 } & $\mathrm{S}_{4}$ & 8.54 & 39.74 & 38.89 & -258.00 & $16,161.00$ & 0.016 & $1,034.30$ \\
\hline & $\mathrm{S}_{5}$ & 9.56 & 48.13 & 45.36 & -457.00 & $17,833.00$ & 0.018 & $1,141.31$ \\
\hline & $\mathrm{S}_{6}$ & 9.12 & 54.30 & 57.50 & -407.00 & $23,048.00$ & 0.023 & $1,475.07$ \\
\hline & $\mathrm{S}_{7}$ & 9.42 & 52.73 & 50.73 & -607.00 & $21,982.00$ & 0.022 & $1,406.85$ \\
\hline \multirow{4}{*}{$\mathrm{G} 2$} & $\mathrm{~S}_{8}$ & 8.82 & 35.50 & 34.82 & -496.59 & $15,440.87$ & 0.015 & 988.22 \\
\hline & $\mathrm{S}_{9}$ & 8.16 & 44.10 & 39.67 & $-1,506.57$ & $16,461.28$ & 0.016 & $1,053.52$ \\
\hline & $\mathrm{S}_{10}$ & 8.85 & 44.01 & 48.08 & -850.76 & $13,256.21$ & 0.013 & 848.40 \\
\hline & $\mathrm{S}_{11}$ & 7.82 & 51.36 & 56.25 & -350.00 & $19,739.00$ & 0.020 & $1,263.30$ \\
\hline \multirow{4}{*}{ G3 } & $\mathrm{S}_{12}$ & 7.32 & 39.08 & 32.54 & -301.00 & $14,241.00$ & 0.014 & 911.42 \\
\hline & $\mathrm{S}_{13}$ & 7.56 & 47.00 & 38.10 & -409.85 & $18,920.07$ & 0.019 & $1,210.88$ \\
\hline & $\mathrm{S}_{14}$ & 7.47 & 53.50 & 48.90 & -627.62 & $11,787.24$ & 0.012 & 754.38 \\
\hline & $\mathrm{S}_{15}$ & 7.56 & 54.74 & 49.08 & -519.00 & $22,278.00$ & 0.022 & $1,425.79$ \\
\hline \multirow{4}{*}{ G4 } & $\mathrm{S}_{16}$ & 3.70 & 42.32 & 32.41 & -290.00 & $16,492.00$ & 0.016 & $1,055.49$ \\
\hline & $\mathrm{S}_{17}$ & 5.04 & 43.62 & 33.51 & -277.23 & $12,464.55$ & 0.012 & 797.73 \\
\hline & $\mathrm{S}_{18}$ & 5.01 & 44.01 & 33.51 & -277.23 & $12,464.55$ & 0.012 & 797.73 \\
\hline & $\mathrm{S}_{19}$ & 7.80 & 48.28 & 41.59 & -565.00 & $8,856.00$ & 0.009 & 566.78 \\
\hline \multirow{4}{*}{ G5 } & $\mathrm{S}_{20}$ & 4.24 & 33.31 & 31.31 & -279.00 & $7,636.00$ & 0.008 & 488.70 \\
\hline & $\mathrm{S}_{21}$ & 4.15 & 42.57 & 39.51 & $-1,306.00$ & $9,500.00$ & 0.010 & 608.00 \\
\hline & $\mathrm{S}_{22}$ & 5.58 & 43.59 & 38.33 & -673.00 & $9,337.00$ & 0.009 & 597.57 \\
\hline & $\mathrm{S}_{23}$ & 5.79 & 42.16 & 44.27 & -850.00 & $9,105.00$ & 0.009 & 582.72 \\
\hline \multirow{4}{*}{ G6 } & $\mathrm{S}_{24}$ & 3.71 & 40.29 & 30.23 & -291.00 & $11,338.00$ & 0.011 & 725.63 \\
\hline & $\mathrm{S}_{25}$ & 2.93 & 49.05 & 33.53 & -294.00 & $8,918.00$ & 0.009 & 570.75 \\
\hline & $\mathrm{S}_{26}$ & 3.02 & 57.94 & 50.77 & -405.00 & $11,074.00$ & 0.011 & 708.74 \\
\hline & $\mathrm{S}_{27}$ & 2.37 & 55.17 & 46.23 & -618.00 & $11,352.00$ & 0.011 & 726.53 \\
\hline
\end{tabular}

*Bar strain gauge did not work to the ultimate load (see Figure 4.129) 
Table 4.3 Summary of experimental bar strains and their correlation with GFRP manufacturer design values

\begin{tabular}{|c|c|c|c|c|c|}
\hline \multirow[t]{2}{*}{ Group } & \multirow[t]{2}{*}{ Slab } & Max. bar strain & $\begin{array}{l}\text { Corresponding } \\
\text { bar stress }\end{array}$ & \multirow{2}{*}{$\begin{array}{c}\text { Bar stress compared } \\
\text { to guaranteed design } \\
\text { stress } * *\end{array}$} & \multirow[t]{2}{*}{$\begin{array}{l}\text { Bar strain compared } \\
\text { to that at failure** }\end{array}$} \\
\hline & & Micro-strain & $\mathrm{MPa}$ & & \\
\hline \multirow{3}{*}{$\mathrm{CG}$} & $\mathrm{S}_{1}{ }^{*}$ & - & - & - & - \\
\hline & $\mathrm{S}_{2}$ & 10406.00 & 665.98 & 0.56 & 0.40 \\
\hline & $\mathrm{S}_{3}$ & 15543.00 & 994.75 & 0.84 & 0.60 \\
\hline \multirow{4}{*}{ G1 } & $\mathrm{S}_{4}$ & 16161.00 & 1034.30 & 0.87 & 0.62 \\
\hline & $\mathrm{S}_{5}$ & 17833.00 & 1141.31 & 0.96 & 0.69 \\
\hline & $\mathrm{S}_{6}$ & 23048.00 & 1475.07 & 1.24 & 0.89 \\
\hline & $\mathrm{S}_{7}$ & 21982.00 & 1406.85 & 1.18 & 0.85 \\
\hline \multirow{4}{*}{ G2 } & $\mathrm{S}_{8}$ & 15440.87 & 988.22 & 0.83 & 0.59 \\
\hline & $\mathrm{S}_{9}$ & 16461.28 & 1053.52 & 0.89 & 0.63 \\
\hline & $\mathrm{S}_{10}$ & 13256.21 & 848.40 & 0.71 & 0.51 \\
\hline & $\mathrm{S}_{11}$ & 19739.00 & 1263.30 & 1.06 & 0.76 \\
\hline \multirow{4}{*}{ G3 } & $\mathrm{S}_{12}$ & 14241.00 & 911.42 & 0.77 & 0.55 \\
\hline & $\mathrm{S}_{13}$ & 18920.07 & 1210.88 & 1.02 & 0.73 \\
\hline & $\mathrm{S}_{14}$ & 11787.24 & 754.38 & 0.64 & 0.45 \\
\hline & $\mathrm{S}_{15}$ & 22278.00 & 1425.79 & 1.20 & 0.86 \\
\hline \multirow{4}{*}{ G4 } & $\mathrm{S}_{16}$ & 16492.00 & 1055.49 & 0.89 & 0.63 \\
\hline & $\mathrm{S}_{17}$ & 12464.55 & 797.73 & 0.67 & 0.48 \\
\hline & $\mathrm{S}_{18}$ & 12464.55 & 797.73 & 0.67 & 0.48 \\
\hline & $\mathrm{S}_{19}$ & 8856.00 & 566.78 & 0.48 & 0.34 \\
\hline \multirow{4}{*}{ G5 } & $\mathrm{S}_{20}$ & 7636.00 & 488.70 & 0.41 & 0.29 \\
\hline & $\mathrm{S}_{21}$ & 9500.00 & 608.00 & 0.51 & 0.37 \\
\hline & $\mathrm{S}_{22}$ & 9337.00 & 597.57 & 0.50 & 0.36 \\
\hline & $\mathrm{S}_{23}$ & 9105.00 & 582.72 & 0.49 & 0.35 \\
\hline \multirow{4}{*}{ G6 } & $\mathrm{S}_{24}$ & 11338.00 & 725.63 & 0.61 & 0.44 \\
\hline & $\mathrm{S}_{25}$ & 8918.00 & 570.75 & 0.48 & 0.34 \\
\hline & $\mathrm{S}_{26}$ & 11074.00 & 708.74 & 0.60 & 0.43 \\
\hline & $\mathrm{S}_{27}$ & 11352.00 & 726.53 & 0.61 & 0.44 \\
\hline
\end{tabular}

*Bar strain gauge did not work to the ultimate load (see Figure 4.129)

** Based on the manufacturer's values (see Table 3.3) 
Table 4.4 Summary of experimental ultimate moment, shear and failure modes

\begin{tabular}{|c|c|c|c|c|c|c|c|}
\hline \multirow[t]{2}{*}{ Group } & \multirow[t]{2}{*}{ Slab } & $\begin{array}{l}\text { Cracking } \\
\text { Load }\end{array}$ & $\begin{array}{l}\text { Cracking } \\
\text { moment }\end{array}$ & $\begin{array}{l}\text { Ultimate } \\
\text { load }\end{array}$ & $\begin{array}{l}\text { Ultimate } \\
\text { moment }\end{array}$ & $\begin{array}{l}\text { Ultimate } \\
\text { shear }\end{array}$ & \multirow[t]{2}{*}{ Failure Mode } \\
\hline & & $\mathrm{kN}$ & kN.m & $\mathrm{kN}$ & kN.m & $\mathrm{kN}$ & \\
\hline \multirow{3}{*}{$\mathrm{CG}$} & $\mathrm{S}_{1}{ }^{*}$ & 23.25 & 9.30 & 137.08 & 54.83 & 68.54 & Flexural-shear \\
\hline & $\mathrm{S}_{2}$ & 88.15 & 35.26 & 236.72 & 94.69 & 118.36 & Flexure \\
\hline & $\mathrm{S}_{3}$ & 21.05 & 8.42 & 149.68 & 59.87 & 74.84 & Flexural-shear \\
\hline \multirow{4}{*}{ G1 } & $\mathrm{S}_{4}$ & 21.35 & 8.54 & 99.34 & 39.74 & 49.67 & Flexure \\
\hline & $\mathrm{S}_{5}$ & 23.65 & 9.46 & 120.32 & 48.13 & 60.16 & Flexure \\
\hline & $\mathrm{S}_{6}$ & 22.80 & 9.12 & 135.74 & 54.30 & 67.87 & Flexural-shear \\
\hline & $\mathrm{S}_{7}$ & 23.55 & 9.42 & 131.82 & 52.73 & 65.91 & Flexural-shear \\
\hline \multirow{4}{*}{$\mathrm{G} 2$} & $\mathrm{~S}_{8}$ & 22.05 & 8.82 & 88.74 & 35.50 & 44.37 & Flexure \\
\hline & $\mathrm{S}_{9}$ & 20.40 & 8.16 & 110.24 & 44.10 & 55.12 & Flexure \\
\hline & $\mathrm{S}_{10}$ & 22.1 & 8.85 & 110.02 & 44.01 & 55.01 & Flexure \\
\hline & $\mathrm{S}_{11}$ & 19.55 & 7.82 & 128.41 & 51.36 & 64.21 & Flexure \\
\hline \multirow{4}{*}{ G3 } & $\mathrm{S}_{12}$ & 18.30 & 7.32 & 97.71 & 39.08 & 48.86 & Flexure \\
\hline & $\mathrm{S}_{13}$ & 18.90 & 7.56 & 117.51 & 47.00 & 58.76 & Flexure \\
\hline & $\mathrm{S}_{14}$ & 18.68 & 7.47 & 133.74 & 53.50 & 66.87 & Flexure \\
\hline & $\mathrm{S}_{15}$ & 18.90 & 7.56 & 136.86 & 54.74 & 68.43 & Flexural-shear \\
\hline \multirow{4}{*}{ G4 } & $\mathrm{S}_{16}$ & 9.26 & 3.70 & 105.79 & 42.32 & 52.90 & Flexure \\
\hline & $\mathrm{S}_{17}$ & 12.60 & 5.04 & 109.06 & 43.62 & 54.53 & Flexural-shear \\
\hline & $\mathrm{S}_{18}$ & 12.53 & 5.01 & 110.02 & 44.01 & 55.01 & Flexural-shear \\
\hline & $\mathrm{S}_{19}$ & 19.50 & 7.80 & 120.70 & 48.28 & 60.35 & Flexural-shear \\
\hline \multirow{4}{*}{ G5 } & $\mathrm{S}_{20}$ & 7.71 & 4.24 & 60.57 & 33.31 & 30.29 & Flexure \\
\hline & $\mathrm{S}_{21}$ & 7.55 & 4.15 & 77.40 & 42.57 & 38.70 & Flexure \\
\hline & $\mathrm{S}_{22}$ & 10.16 & 5.59 & 79.25 & 43.59 & 39.63 & Flexural-shear \\
\hline & $\mathrm{S}_{23}$ & 10.53 & 5.79 & 76.66 & 42.16 & 38.33 & Flexural-shear \\
\hline \multirow{4}{*}{ G6 } & $\mathrm{S}_{24}$ & 6.75 & 3.71 & 73.25 & 40.29 & 36.63 & Flexure \\
\hline & $\mathrm{S}_{25}$ & 5.33 & 2.93 & 89.19 & 49.05 & 44.60 & Flexure \\
\hline & $\mathrm{S}_{26}$ & 5.49 & 3.02 & 105.35 & 57.94 & 52.68 & $\begin{array}{c}\text { *Flexural-shear } \\
\text { /Flexure }\end{array}$ \\
\hline & $\mathrm{S}_{27}$ & 4.30 & 2.37 & 100.31 & 55.17 & 50.16 & Flexure \\
\hline
\end{tabular}

* Flexure failure at the joint combined with flexural-shear outside of the joint 
Table 4.5 Summary of the concrete and bar strains for group CG, G1 and G2

\begin{tabular}{|c|c|c|c|c|c|c|c|c|c|}
\hline \multirow{2}{*}{ Group } & \multirow{2}{*}{ Slab } & \multirow{2}{*}{$\begin{array}{c}\text { Ultimate moment } \\
\text { kN.m }\end{array}$} & \multirow{2}{*}{ Strain location } & \multirow{2}{*}{$\begin{array}{c}\text { Depth } \\
\mathrm{mm}\end{array}$} & \multicolumn{5}{|c|}{ Micro-strain at ultimate moment } \\
\hline & & & & & 1 & 2 & 3 & 4 & Average \\
\hline \multirow{6}{*}{ CG } & \multirow{2}{*}{$\mathrm{S}_{1}$} & \multirow{2}{*}{54.83} & Concrete top & 0.00 & $-1,429.00$ & $-1,907.00$ & - & - & $-1,668.00$ \\
\hline & & & Bottom bar & 162.00 & - & - & - & - & \\
\hline & \multirow{2}{*}{$\mathrm{S}_{2}$} & \multirow{2}{*}{86.92} & Concrete top & 0.00 & $-1,552.00$ & $-1,879.00$ & - & - & $-1,715.50$ \\
\hline & & & Bottom bar & 162.00 & $8,817.00$ & $11,995.00$ & - & - & $10,406.00$ \\
\hline & \multirow{2}{*}{$\mathrm{S}_{3}$} & \multirow{2}{*}{59.22} & Concrete top & 0.00 & $-2,169.00$ & $-1,129.00$ & - & - & $-1,649.00$ \\
\hline & & & Bottom bar & 162.00 & $11,365.00$ & $15,543.00$ & - & - & $13,454.00$ \\
\hline \multirow{7}{*}{ G1 } & \multirow{2}{*}{$\mathrm{S}_{4}$} & \multirow{2}{*}{39.74} & Concrete top & 0.00 & -832.00 & -897.00 & - & - & -864.50 \\
\hline & & & Bottom bar & 162.00 & $16,161.00$ & $15,588.00$ & - & - & $15,874.50$ \\
\hline & $\mathrm{S}_{5}$ & 48.13 & Bottom bar & 162.00 & $14,676.00$ & $17,833.00$ & - & - & $16,254.50$ \\
\hline & \multirow{2}{*}{$\mathrm{S}_{6}$} & \multirow{2}{*}{54.30} & Concrete top & 0.00 & -521.00 & -727.00 & - & - & -624.00 \\
\hline & & & Bottom bar & 162.00 & $23,048.00$ & - & - & - & $23,048.00$ \\
\hline & \multirow{2}{*}{$\mathrm{S}_{7}$} & \multirow{2}{*}{52.73} & Concrete top & 0.00 & -567.00 & -320.00 & - & - & -443.50 \\
\hline & & & Bottom bar & 162.00 & $21,982.00$ & $18,545.00$ & - & - & $20,263.50$ \\
\hline \multirow{7}{*}{$\mathrm{G} 2$} & \multirow{2}{*}{$\mathrm{S}_{8}$} & \multirow{2}{*}{70.99} & Concrete top & 0.00 & -821.48 & -496.59 & - & - & -659.04 \\
\hline & & & Bottom bar & 162.00 & $10,061.35$ & $15,440.87$ & - & - & $12,751.11$ \\
\hline & \multirow{2}{*}{$\mathrm{S}_{9}$} & \multirow{2}{*}{88.19} & Concrete top & 0.00 & $-1,371.34$ & $-1,506.57$ & - & - & $-1,438.96$ \\
\hline & & & Bottom bar & 162.00 & $14,263.74$ & $16,461.28$ & - & - & $15,362.51$ \\
\hline & \multirow{2}{*}{$\mathrm{S}_{10}$} & \multirow{2}{*}{44.01} & Concrete top & 0.00 & $-1,108.36$ & $-1,042.29$ & - & - & $-1,075.33$ \\
\hline & & & Bottom bar & 162.00 & $13,256.21$ & $11,223.19$ & - & - & $12,239.70$ \\
\hline & $\mathrm{S}_{11}$ & 51.36 & Bottom bar & 162.00 & $19,739.00$ & - & - & - & $19,739.00$ \\
\hline
\end{tabular}


Table 4.6 Summary of the top concrete strains and bar strains for group G3 and G4

\begin{tabular}{|c|c|c|c|c|c|c|c|c|c|}
\hline \multirow{2}{*}{ Group } & \multirow{2}{*}{ Slab } & \multirow{2}{*}{$\begin{array}{c}\begin{array}{r}\text { Ultimate } \\
\text { moment }\end{array} \\
\text { kN.m }\end{array}$} & \multirow{2}{*}{ Strain location } & \multirow{2}{*}{$\begin{array}{c}\text { Depth } \\
\mathrm{mm}\end{array}$} & \multicolumn{5}{|c|}{ Micro-strain at ultimate moment } \\
\hline & & & & & 1 & 2 & 3 & 4 & Average \\
\hline \multirow{8}{*}{ G3 } & \multirow{2}{*}{$\mathrm{S}_{12}$} & \multirow{2}{*}{39.08} & Concrete top & 0.00 & -226.00 & -682.00 & & & -454.00 \\
\hline & & & Bottom bar & 162.00 & $14,241.00$ & - & & & $14,241.00$ \\
\hline & \multirow{2}{*}{$\mathrm{S}_{13}$} & \multirow{2}{*}{47.00} & Concrete top & 0.00 & -585.94 & -716.91 & - & - & -651.43 \\
\hline & & & Bottom bar & 162.00 & $17,540.62$ & $18,920.07$ & - & - & $18,230.35$ \\
\hline & \multirow{2}{*}{$\mathrm{S}_{14}$} & \multirow{2}{*}{53.50} & Concrete top & 0.00 & -956.80 & -482.99 & - & - & -719.90 \\
\hline & & & Bottom bar & 162.00 & $10,493.17$ & $10,803.64$ & $11,787.24$ & $9,615.03$ & $10,648.41$ \\
\hline & \multirow{2}{*}{$\mathrm{S}_{15}$} & \multirow{2}{*}{54.74} & Concrete top & 0.00 & -527.00 & -592.00 & - & - & -559.50 \\
\hline & & & Bottom bar & 162.00 & $17,980.00$ & - & $20,744.00$ & $22,278.00$ & $17,980.00$ \\
\hline \multirow{8}{*}{ G4 } & \multirow{2}{*}{$\mathrm{S}_{16}$} & \multirow{2}{*}{42.32} & Concrete top & 0.00 & -775.00 & -561.00 & - & - & -668.00 \\
\hline & & & Bottom bar & 162.00 & 0.00 & $16,040.00$ & $16,492.00$ & $11,067.00$ & $8,020.00$ \\
\hline & \multirow{2}{*}{$\mathrm{S}_{17}$} & \multirow{2}{*}{43.62} & Concrete top & 0.00 & -389.88 & -509.79 & - & - & -449.84 \\
\hline & & & Bottom bar & 162.00 & $11,982.04$ & $12,464.55$ & 0.00 & $9,784.13$ & $12,223.30$ \\
\hline & \multirow{2}{*}{$\mathrm{S}_{18}$} & \multirow{2}{*}{44.01} & Concrete top & 0.00 & -389.88 & -509.79 & - & - & -449.84 \\
\hline & & & Bottom bar & 162.00 & $11,982.04$ & $12,464.55$ & 0.00 & $9,784.13$ & $12,223.30$ \\
\hline & \multirow{2}{*}{$\mathrm{S}_{19}$} & \multirow{2}{*}{48.28} & Concrete top & 0.00 & -724.00 & -865.00 & - & - & -794.50 \\
\hline & & & Bottom bar & 162.00 & $7,483.00$ & $8,856.00$ & $7,386.00$ & $7,174.00$ & $8,169.50$ \\
\hline
\end{tabular}


Table 4.7 Summary of the top concrete strains and bar strains for group G5 and G6

\begin{tabular}{|c|c|c|c|c|c|c|c|c|c|}
\hline \multirow{2}{*}{ Group } & \multirow{2}{*}{ Slab } & \multirow{2}{*}{$\begin{array}{c}\text { Ultimate } \\
\text { moment }\end{array}$} & \multirow{2}{*}{$\begin{array}{c}\text { Strain } \\
\text { location }\end{array}$} & \multirow{2}{*}{$\begin{array}{c}\text { Depth } \\
\mathrm{mm}\end{array}$} & \multicolumn{5}{|c|}{ Micro-strain at ultimate moment } \\
\hline & & & & & 1 & 2 & 3 & 4 & Average \\
\hline \multirow{8}{*}{ G5 } & \multirow{2}{*}{$\mathrm{S}_{20}$} & \multirow{2}{*}{33.31} & Concrete top & 0.00 & $-1,553.00$ & $-2,118.00$ & - & - & $-1,835.50$ \\
\hline & & & Bottom bar & 162.00 & $7,636.00$ & 0.00 & $7,462.00$ & $5,983.00$ & $3,818.00$ \\
\hline & \multirow{2}{*}{$\mathrm{S}_{21}$} & \multirow{2}{*}{42.57} & Concrete top & 0.00 & $-1,684.00$ & $-1,444.00$ & - & - & $-1,564.00$ \\
\hline & & & Bottom bar & 162.00 & $8,554.00$ & $7,847.00$ & $9,500.00$ & $6,220.00$ & $8,200.50$ \\
\hline & \multirow{2}{*}{$\mathrm{S}_{22}$} & \multirow{2}{*}{43.59} & Concrete top & 0.00 & $-1,133.00$ & $-1,275.00$ & - & - & $-1,204.00$ \\
\hline & & & Bottom bar & 162.00 & $6,573.00$ & $7,369.00$ & $9,337.00$ & $9,094.00$ & $6,971.00$ \\
\hline & \multirow{2}{*}{$\mathrm{S}_{23}$} & \multirow{2}{*}{42.16} & Concrete top & 0.00 & -882.00 & -692.00 & - & - & -787.00 \\
\hline & & & Bottom bar & 162.00 & $7,163.00$ & $9,105.00$ & $7,933.00$ & 0.00 & $6,050.25$ \\
\hline \multirow{8}{*}{ G6 } & \multirow{2}{*}{$\mathrm{S}_{24}$} & \multirow{2}{*}{40.29} & Concrete top & 0.00 & -689.00 & -765.00 & - & - & -727.00 \\
\hline & & & Bottom bar & 162.00 & $11,338.00$ & $8,177.00$ & $6,647.00$ & $9,670.00$ & $9,757.50$ \\
\hline & \multirow{2}{*}{$\mathrm{S}_{25}$} & \multirow{2}{*}{49.05} & Concrete top & 0.00 & -704.00 & -774.00 & - & - & -739.00 \\
\hline & & & Bottom bar & 162.00 & 0.00 & $8,918.00$ & $8,706.00$ & $8,471.00$ & $6,523.75$ \\
\hline & \multirow{2}{*}{$\mathrm{S}_{26}$} & \multirow{2}{*}{57.94} & Concrete top & 0.00 & -643.00 & -689.00 & - & - & -666.00 \\
\hline & & & Bottom bar & 162.00 & $9,251.00$ & 0.00 & $11,074.00$ & $8,309.00$ & $4,625.50$ \\
\hline & \multirow{2}{*}{$\mathrm{S}_{27}$} & \multirow{2}{*}{55.17} & Concrete top & 0.00 & $-1,075.00$ & -956.00 & - & - & $-1,015.50$ \\
\hline & & & Bottom bar & 162.00 & 0.00 & $11,352.00$ & 0.00 & 0.00 & $5,676.00$ \\
\hline
\end{tabular}


Table 4.8 Summary of the ultimate load for groups G1, G2 and G3 vs slabs $\mathrm{S}_{1}$ and $\mathrm{S}_{3}$

\begin{tabular}{ccccc}
\hline Group & Slab & Ultimate load $(\mathrm{kN})$ & Load compared to $\mathrm{S}_{1}$ & Load compared to $\mathrm{S}_{3}$ \\
\hline \multirow{3}{*}{$\mathrm{CG}$} & $\mathrm{S}_{1}$ & 137.08 & $100.00 \%$ & $91.58 \%$ \\
\cline { 2 - 5 } & $\mathrm{S}_{2}$ & 217.30 & $172.69 \%$ & $158.15 \%$ \\
\cline { 2 - 5 } & $\mathrm{S}_{3}$ & 149.68 & $109.19 \%$ & $100.00 \%$ \\
\cline { 2 - 5 } G1 & $\mathrm{S}_{4}$ & 99.34 & $72.47 \%$ & $66.37 \%$ \\
\cline { 2 - 5 } & $\mathrm{S}_{5}$ & 120.32 & $87.77 \%$ & $80.38 \%$ \\
\cline { 2 - 5 } & $\mathrm{S}_{6}$ & 135.74 & $99.02 \%$ & $90.69 \%$ \\
\cline { 2 - 5 } & $\mathrm{S}_{7}$ & 131.82 & $96.16 \%$ & $88.07 \%$ \\
\cline { 2 - 5 } G2 & $\mathrm{S}_{8}$ & 88.74 & $64.74 \%$ & $59.29 \%$ \\
\cline { 2 - 5 } & $\mathrm{S}_{9}$ & 110.24 & $80.42 \%$ & $73.65 \%$ \\
\cline { 2 - 5 } & $\mathrm{S}_{10}$ & 110.02 & $80.26 \%$ & $83.50 \%$ \\
\cline { 2 - 5 } & $\mathrm{S}_{11}$ & 128.41 & $93.68 \%$ & $65.79 \%$ \\
\hline \multirow{3}{*}{ G3 } & $\mathrm{S}_{12}$ & 97.71 & $71.28 \%$ & $89.51 \%$ \\
\cline { 2 - 5 } & $\mathrm{S}_{13}$ & 117.51 & $85.72 \%$ & $91.44 \%$ \\
\cline { 2 - 5 } & $\mathrm{S}_{14}$ & 133.74 & $97.56 \%$ & \\
\cline { 2 - 5 } & $\mathrm{S}_{15}$ & 136.86 & $99.84 \%$ & \\
\hline
\end{tabular}

Table 4.9 Summary of the deflection at $50 \mathrm{kN}$ for groups G1, G2 and G3 vs slabs $\mathrm{S}_{1}$ and $\mathrm{S}_{3}$

\begin{tabular}{|c|c|c|c|c|}
\hline \multirow[t]{2}{*}{ Group } & \multirow[t]{2}{*}{ Slab } & $\begin{array}{l}\text { Ultimate } \\
\text { deflection }\end{array}$ & \multirow[t]{2}{*}{ Deflection compared to $S_{1}$} & \multirow[t]{2}{*}{ Deflection compared to $S 3$} \\
\hline & & $\mathrm{mm}$ & & \\
\hline \multirow{3}{*}{$\mathrm{CG}$} & $\mathrm{S}_{1}$ & 11.54 & $100 \%$ & $100 \%$ \\
\hline & $\mathrm{S}_{2}$ & 1.070 & $9 \%$ & $9 \%$ \\
\hline & $\mathrm{S}_{3}$ & 11.50 & $100 \%$ & $100 \%$ \\
\hline \multirow{4}{*}{ G1 } & $\mathrm{S}_{4}$ & 9.40 & $81 \%$ & $82 \%$ \\
\hline & $\mathrm{S}_{5}$ & 9.37 & $81 \%$ & $81 \%$ \\
\hline & $\mathrm{S}_{6}$ & 13.25 & $115 \%$ & $115 \%$ \\
\hline & $\mathrm{S}_{7}$ & 9.97 & $86 \%$ & $87 \%$ \\
\hline \multirow{4}{*}{$\mathrm{G} 2$} & $\mathrm{~S}_{8}$ & 13.60 & $118 \%$ & $118 \%$ \\
\hline & $\mathrm{S}_{9}$ & 12.01 & $104 \%$ & $104 \%$ \\
\hline & $\mathrm{S}_{10}$ & 11.37 & $99 \%$ & $99 \%$ \\
\hline & $\mathrm{S}_{11}$ & 12.80 & $111 \%$ & $111 \%$ \\
\hline \multirow{4}{*}{ G3 } & $\mathrm{S}_{12}$ & 10.55 & $91 \%$ & $92 \%$ \\
\hline & $\mathrm{S}_{13}$ & 10.52 & $91 \%$ & $91 \%$ \\
\hline & $\mathrm{S}_{14}$ & 9.69 & $84 \%$ & $84 \%$ \\
\hline & $\mathrm{S}_{15}$ & 10.38 & $90 \%$ & $90 \%$ \\
\hline
\end{tabular}


Table 4.10 Summary of the maximum bottom bar strains for groups G1, G2 and G3 vs slab S3

\begin{tabular}{|c|c|c|c|c|}
\hline \multirow[t]{2}{*}{ Group` } & \multirow[t]{2}{*}{ Slab } & Ultimate load & Max. bar strain & \multirow{2}{*}{$\begin{array}{c}\text { Bar strain compared to } \\
\text { slab } S_{3}\end{array}$} \\
\hline & & $\mathrm{kN}$ & Micro-strain & \\
\hline \multirow{3}{*}{$\mathrm{CG}$} & $\mathrm{S}_{1}$ & 137.08 & - & - \\
\hline & $\mathrm{S}_{2}$ & 217.3 & $10,406.00$ & $66.95 \%$ \\
\hline & $\mathrm{S}_{3}$ & 149.68 & 15543.00 & $100.00 \%$ \\
\hline \multirow{4}{*}{ G1 } & $\mathrm{S}_{4}$ & 99.34 & 16161.00 & $103.98 \%$ \\
\hline & $\mathrm{S}_{5}$ & 120.32 & 17833.00 & $114.73 \%$ \\
\hline & $\mathrm{S}_{6}$ & 135.74 & 23048.00 & $148.29 \%$ \\
\hline & $\mathrm{S}_{7}$ & 131.82 & 21982.00 & $141.43 \%$ \\
\hline \multirow{4}{*}{ G2 } & $\mathrm{S}_{8}$ & 88.74 & 15440.87 & $99.34 \%$ \\
\hline & $\mathrm{S}_{9}$ & 110.24 & 16461.28 & $105.91 \%$ \\
\hline & $\mathrm{S}_{10}$ & 110.02 & 13256.21 & $85.29 \%$ \\
\hline & $\mathrm{S}_{11}$ & 128.41 & 19739.00 & $127.00 \%$ \\
\hline \multirow{4}{*}{ G3 } & $\mathrm{S}_{12}$ & 97.71 & 14241.00 & $91.62 \%$ \\
\hline & $\mathrm{S}_{13}$ & 117.51 & 18920.07 & $121.73 \%$ \\
\hline & $\mathrm{S}_{14}$ & 133.74 & 11787.24 & $75.84 \%$ \\
\hline & $\mathrm{S}_{15}$ & 136.86 & 22278.00 & $143.33 \%$ \\
\hline
\end{tabular}

Table 4.11 Summary of the maximum concrete top strains for group G1, G2 and G3 vs slab $\mathrm{S}_{1}$ and $\mathrm{S}_{3}$

\begin{tabular}{|c|c|c|c|c|c|}
\hline \multirow[t]{2}{*}{ Group } & \multirow[t]{2}{*}{ Slab } & Ultimate load & $\begin{array}{l}\text { Max. concrete } \\
\text { top strain }\end{array}$ & \multirow{2}{*}{$\begin{array}{l}\text { concrete strain } \\
\text { compared to } \\
\text { slab } S_{1}\end{array}$} & \multirow{2}{*}{$\begin{array}{c}\text { concrete strain } \\
\text { compared to } \\
\text { slab } S_{3}\end{array}$} \\
\hline & & $\mathrm{kN}$ & Micro-strain & & \\
\hline \multirow{3}{*}{$\mathrm{CG}$} & $\mathrm{S}_{1}$ & 137.08 & -1668.00 & $100.00 \%$ & $101.15 \%$ \\
\hline & $\mathrm{S}_{2}$ & 217.3 & -1715.50 & $102.85 \%$ & $104.03 \%$ \\
\hline & $\mathrm{S}_{3}$ & 149.68 & -1649.00 & $98.86 \%$ & $100.00 \%$ \\
\hline \multirow{4}{*}{ G1 } & $\mathrm{S}_{4}$ & 99.34 & -864.50 & $51.83 \%$ & $52.43 \%$ \\
\hline & $\mathrm{S}_{5}$ & 120.32 & -628.00 & $37.65 \%$ & $38.08 \%$ \\
\hline & $\mathrm{S}_{6}$ & 135.74 & -624.00 & $37.41 \%$ & $37.84 \%$ \\
\hline & $\mathrm{S}_{7}$ & 131.82 & -443.50 & $26.59 \%$ & $26.90 \%$ \\
\hline \multirow{4}{*}{$\mathrm{G} 2$} & $\mathrm{~S}_{8}$ & 88.74 & -659.04 & $39.51 \%$ & $39.97 \%$ \\
\hline & $\mathrm{S}_{9}$ & 110.24 & -1438.96 & $86.27 \%$ & $87.26 \%$ \\
\hline & $\mathrm{S}_{10}$ & 110.02 & -1075.33 & $64.47 \%$ & $65.21 \%$ \\
\hline & $\mathrm{S}_{11}$ & 128.41 & -446.50 & $26.77 \%$ & $27.08 \%$ \\
\hline \multirow{4}{*}{ G3 } & $\mathrm{S}_{12}$ & 97.71 & -454.00 & $27.22 \%$ & $27.53 \%$ \\
\hline & $\mathrm{S}_{13}$ & 117.51 & -651.43 & $39.05 \%$ & $39.50 \%$ \\
\hline & $\mathrm{S}_{14}$ & 133.74 & -719.90 & $43.16 \%$ & $43.66 \%$ \\
\hline & $\mathrm{S}_{15}$ & 136.86 & -559.50 & $33.54 \%$ & $33.93 \%$ \\
\hline
\end{tabular}


Table 4.12 Summary of experimental moment and shear compared to theoritical values

\begin{tabular}{|c|c|c|c|c|c|c|c|c|c|}
\hline \multirow{3}{*}{ Slab } & \multicolumn{3}{|c|}{ Experimental results/m } & \multicolumn{3}{|c|}{ Theoretical Moment } & \multicolumn{3}{|c|}{ Theoretical Shear } \\
\hline & \multirow[t]{2}{*}{ Failure mode } & $\mathrm{M}_{\mathrm{Exp}} / \mathrm{m}$ & $\mathrm{V}_{\mathrm{Exp}} / m$ & $\mathrm{M}_{r}$ & $\frac{\mathrm{M}_{\text {Exp }}}{\mathrm{M}_{r}}$ & $\frac{0.75 \mathrm{M}_{\mathrm{Exp}}}{\mathrm{M}_{r}}$ & $\mathrm{~V}_{\mathrm{r}}$ & $\frac{V_{\text {Exp }}}{V_{r}}$ & $\frac{0.75 V_{\text {Exp }}}{V_{r}}$ \\
\hline & & kN.m/m & $\mathrm{kN}$ & $\mathrm{kN}$ & & & $\mathrm{kN}$ & & \\
\hline $\mathrm{S}_{1}$ & Flexural-shear & 91.39 & 114.23 & 84.96 & 1.08 & 0.81 & 71.02 & 1.61 & 1.21 \\
\hline $\mathrm{S}_{2}$ & Flexure & - & - & & - & - & - & - & - \\
\hline $\mathrm{S}_{3}$ & Flexural-shear & 98.70 & 123.38 & 83.62 & 1.18 & 0.89 & 69.83 & 1.77 & 1.33 \\
\hline $\mathrm{S}_{4}$ & Flexure & 66.23 & 82.78 & 84.98 & 0.78 & 0.58 & 71.03 & 1.17 & 0.87 \\
\hline $\mathrm{S}_{5}$ & Flexure & 80.21 & 100.27 & 87.41 & 0.92 & 0.69 & 73.23 & 1.37 & 1.03 \\
\hline $\mathrm{S}_{6}$ & Flexural-shear & 90.49 & 113.12 & 85.89 & 1.05 & 0.79 & 71.85 & 1.57 & 1.18 \\
\hline $\mathrm{S}_{7}$ & Flexural-shear & 87.88 & 109.85 & 84.98 & 1.03 & 0.78 & 71.03 & 1.55 & 1.16 \\
\hline $\mathrm{S}_{8}$ & Flexure & 59.16 & 73.95 & 85.23 & 0.69 & 0.52 & 71.26 & 1.04 & 0.78 \\
\hline $\mathrm{S}_{9}$ & Flexure & 73.49 & 91.87 & 81.94 & 0.90 & 0.67 & 68.35 & 1.34 & 1.01 \\
\hline $\mathrm{S}_{10}$ & Flexure & 73.35 & 91.68 & 84.62 & 0.87 & 0.65 & 70.71 & 1.30 & 0.97 \\
\hline $\mathrm{S}_{11}$ & Flexure & 85.61 & 107.01 & 84.49 & 1.01 & 0.76 & 70.59 & 1.52 & 1.14 \\
\hline$\overline{S_{12}}$ & Flexure & 65.14 & 81.43 & 83.62 & 0.78 & 0.58 & 69.83 & 1.17 & 0.87 \\
\hline $\mathrm{S}_{13}$ & Flexure & 78.34 & 97.93 & 83.62 & 0.94 & 0.70 & 69.83 & 1.40 & 1.05 \\
\hline $\mathrm{S}_{14}$ & Flexure & 89.16 & 111.45 & 83.62 & 1.07 & 0.80 & 69.83 & 1.60 & 1.20 \\
\hline $\mathrm{S}_{15}$ & Flexural-shear & 91.24 & 114.05 & 83.62 & 1.09 & 0.82 & 69.83 & 1.63 & 1.22 \\
\hline $\mathrm{S}_{16}$ & Flexure & 89.09 & 111.36 & 95.95 & 0.93 & 0.70 & 69.83 & 1.59 & 1.20 \\
\hline $\mathrm{S}_{17}$ & Flexural-shear & 91.84 & 114.80 & 95.95 & 0.96 & 0.72 & 69.83 & 1.64 & 1.23 \\
\hline $\mathrm{S}_{18}$ & Flexural-shear & 92.65 & 115.81 & 95.95 & 0.97 & 0.72 & 69.83 & 1.66 & 1.24 \\
\hline $\mathrm{S}_{19}$ & Flexural-shear & 101.64 & 127.05 & 95.95 & 1.06 & 0.79 & 69.83 & 1.82 & 1.36 \\
\hline $\mathrm{S}_{20}$ & Flexure & 95.18 & 86.53 & 114.55 & 0.83 & 0.62 & 72.49 & 1.19 & 0.90 \\
\hline $\mathrm{S}_{21}$ & Flexure & 121.63 & 110.57 & 114.55 & 1.06 & 0.80 & 72.49 & 1.53 & 1.14 \\
\hline $\mathrm{S}_{22}$ & Flexural-shear & 124.54 & 113.21 & 115.28 & 1.08 & 0.81 & 72.94 & 1.55 & 1.16 \\
\hline $\mathrm{S}_{23}$ & Flexural-shear & 120.47 & 109.51 & 118.11 & 1.02 & 0.76 & 74.82 & 1.46 & 1.10 \\
\hline $\mathrm{S}_{24}$ & Flexure & 84.82 & 77.11 & 100.53 & 0.84 & 0.63 & 73.23 & 1.05 & 0.79 \\
\hline $\mathrm{S}_{25}$ & Flexure & 103.27 & 93.88 & 100.53 & 1.03 & 0.77 & 73.31 & 1.28 & 0.96 \\
\hline $\mathrm{S}_{26}$ & $\begin{array}{l}\text { Flexural-shear } \\
\text { /Flexure }\end{array}$ & 121.98 & 110.89 & 95.08 & 1.28 & 0.96 & 69.18 & 1.60 & 1.20 \\
\hline $\mathrm{S}_{27}$ & Flexure & 116.15 & 105.59 & 99.11 & 1.17 & 0.88 & 72.22 & 1.46 & 1.10 \\
\hline
\end{tabular}


Table 4.13 Specified maximum spacing between girders for jointed slabs

\begin{tabular}{|c|c|c|c|c|c|c|c|}
\hline \multirow{3}{*}{ Group } & \multirow{3}{*}{ Slab } & \multirow{2}{*}{$\begin{array}{l}\text { Splice } \\
\text { spacing }\end{array}$} & \multirow{2}{*}{$\begin{array}{c}\text { Main bar } \\
\text { spacing }\end{array}$} & \multirow{2}{*}{$\begin{array}{l}\text { Splice } \\
\text { length }\end{array}$} & \multirow{2}{*}{$\begin{array}{l}\text { Joint } \\
\text { width }\end{array}$} & \multicolumn{2}{|c|}{ Girder spacing limit } \\
\hline & & & & & & $\begin{array}{c}\text { Inner portion of } \\
\text { simple span }\end{array}$ & $\begin{array}{l}\text { Inner portion of } \\
\text { continuous span }\end{array}$ \\
\hline & & $\mathrm{mm}$ & $\mathrm{mm}$ & & $\mathrm{mm}$ & $\mathrm{m}$ & $\mathrm{m}$ \\
\hline \multirow{4}{*}{ G1 } & $\mathrm{S}_{4}$ & \multirow{4}{*}{0} & \multirow{4}{*}{200} & 105 & 125 & 1.65 & 2.10 \\
\hline & $\mathrm{S}_{5}$ & & & 135 & 155 & 2.09 & 2.58 \\
\hline & $\mathrm{S}_{6}$ & & & 165 & 185 & 2.35 & 2.91 \\
\hline & $\mathrm{S}_{7}$ & & & 75 & 215 & 2.30 & 2.85 \\
\hline \multirow{4}{*}{$\mathrm{G} 2$} & $\mathrm{~S}_{8}$ & \multirow{4}{*}{50} & \multirow{4}{*}{200} & 105 & 125 & 1.45 & 1.87 \\
\hline & $\mathrm{S}_{9}$ & & & 135 & 155 & 1.87 & 2.35 \\
\hline & $\mathrm{S}_{10}$ & & & 165 & 185 & 1.87 & 2.35 \\
\hline & $\mathrm{S}_{11}$ & & & 75 & 215 & 2.25 & 2.76 \\
\hline \multirow{4}{*}{ G3 } & $\mathrm{S}_{12}$ & \multirow{4}{*}{100} & \multirow{4}{*}{200} & 105 & 125 & 1.62 & 2.05 \\
\hline & $\mathrm{S}_{13}$ & & & 135 & 155 & 2.00 & 2.52 \\
\hline & $\mathrm{S}_{14}$ & & & 165 & 185 & 2.35 & 2.80 \\
\hline & $\mathrm{S}_{15}$ & & & 75 & 215 & 2.40 & 2.98 \\
\hline \multirow{4}{*}{ G4 } & $\mathrm{S}_{16}$ & \multirow{4}{*}{75} & \multirow{4}{*}{150} & 105 & 125 & 2.35 & 2.85 \\
\hline & $\mathrm{S}_{17}$ & & & 135 & 155 & 2.41 & 2.90 \\
\hline & $\mathrm{S}_{18}$ & & & 165 & 185 & 2.41 & 2.90 \\
\hline & $\mathrm{S}_{19}$ & & & 75 & 215 & 2.68 & 3.30 \\
\hline \multirow{4}{*}{ G5 } & $\mathrm{S}_{20}$ & \multirow{4}{*}{50} & \multirow{4}{*}{100} & 105 & 125 & 2.50 & 3.05 \\
\hline & $\mathrm{S}_{21}$ & & & 135 & 155 & 3.21 & 3.88 \\
\hline & $\mathrm{S}_{22}$ & & & 165 & 185 & 3.30 & 3.99 \\
\hline & $\mathrm{S}_{23}$ & & & 75 & 215 & 3.22 & 3.89 \\
\hline \multirow{4}{*}{ G6 } & $\mathrm{S}_{24}$ & \multirow{4}{*}{75} & \multirow{4}{*}{150} & 105 & 125 & 2.20 & 2.75 \\
\hline & $\mathrm{S}_{25}$ & & & 135 & 155 & 2.75 & 3.37 \\
\hline & $\mathrm{S}_{26}$ & & & 165 & 185 & 3.25 & 3.9 \\
\hline & $\mathrm{S}_{27}$ & & & 75 & 215 & 3.05 & 3.7 \\
\hline
\end{tabular}




\section{Figures}

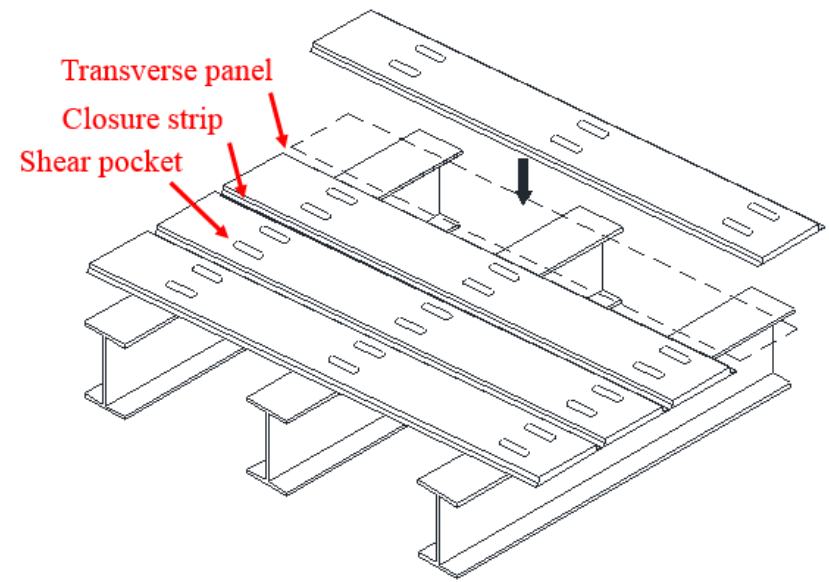

a) Transverse panels placed over girders

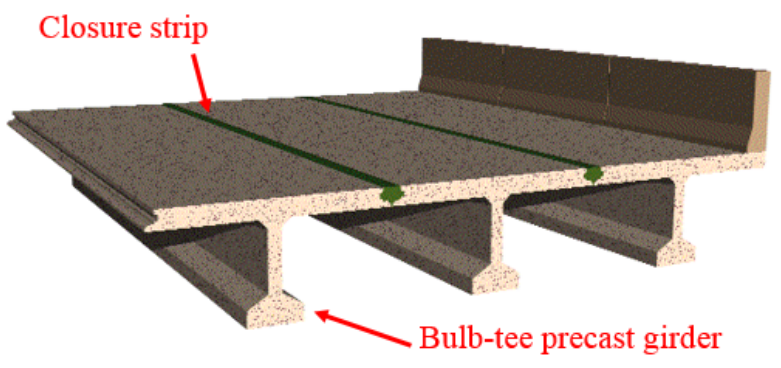

b) Bulb-tee precast girders with closure strips

Figure. 1.1 Views of two types of prefabricated bridge systems to accelerate bridge construction
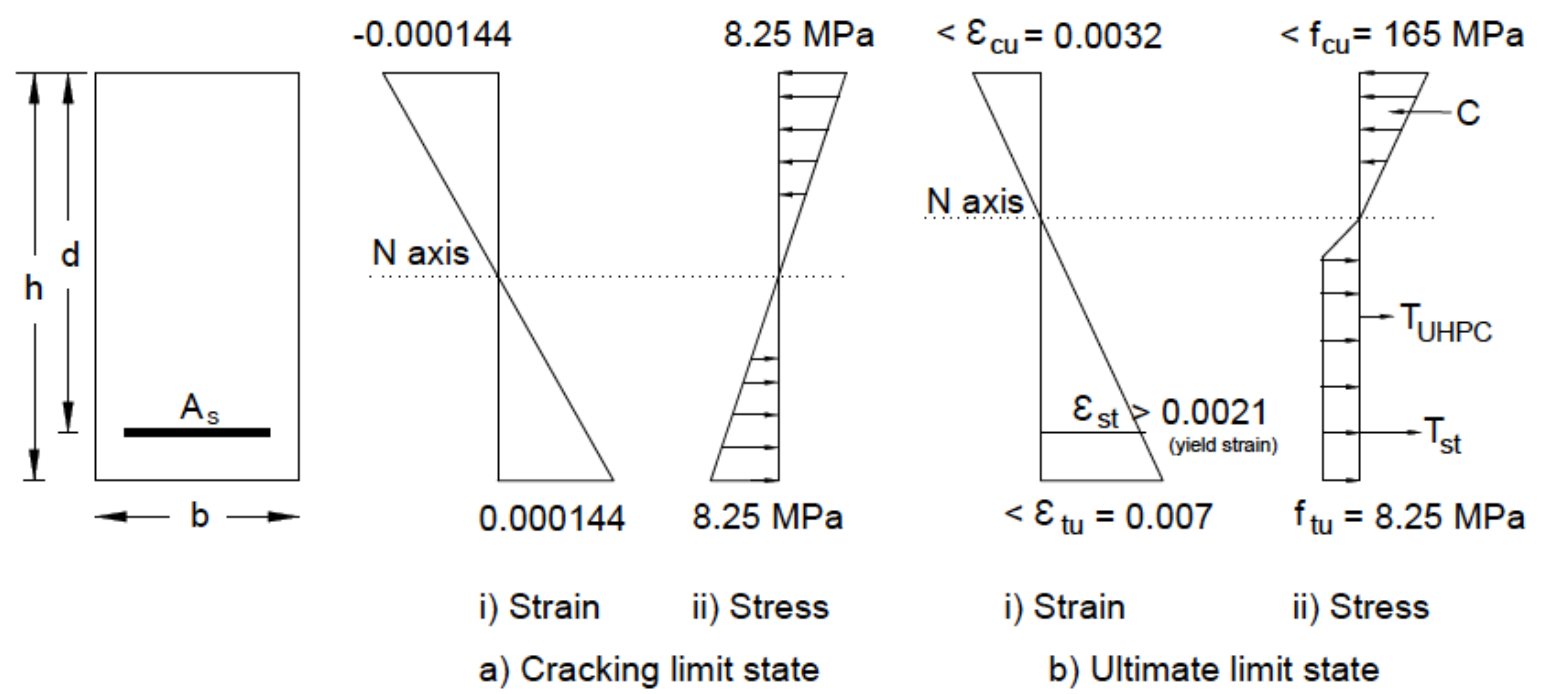
a) Cracking limit state

i) Strain

ii) Stress

b) Ultimate limit state

Figure 2.1 Stress-strain behavior and internal forces of UHPC Section (Aalet et al., 2013) 


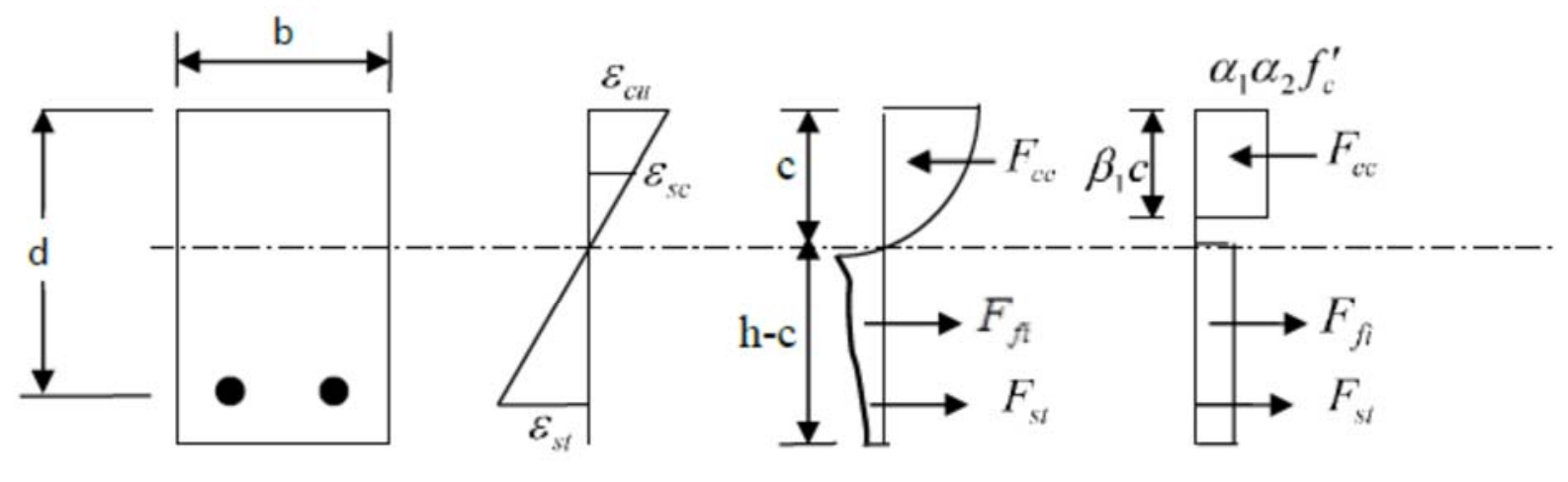

(a)

(b)

(c)

(d)

Figure 2.2 Stress strain behavior and internal forces of UHPC section: (a) beam section, (b) strain distribution, (c) concrete stress, (d) equivalent stress blocks (Hussein, 2015) 


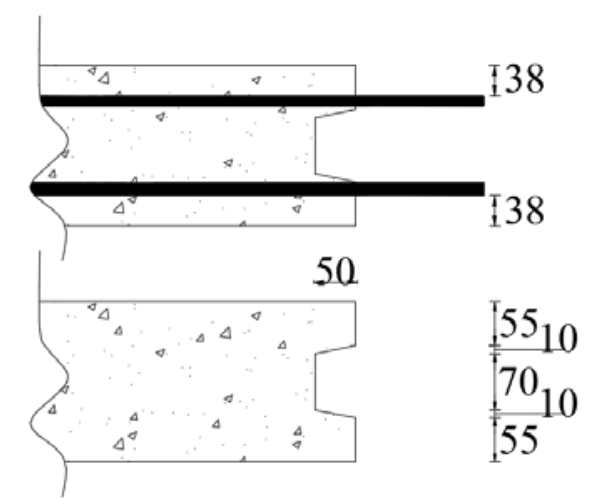

Figure 3.1 Geometry and dimensions of the shear key

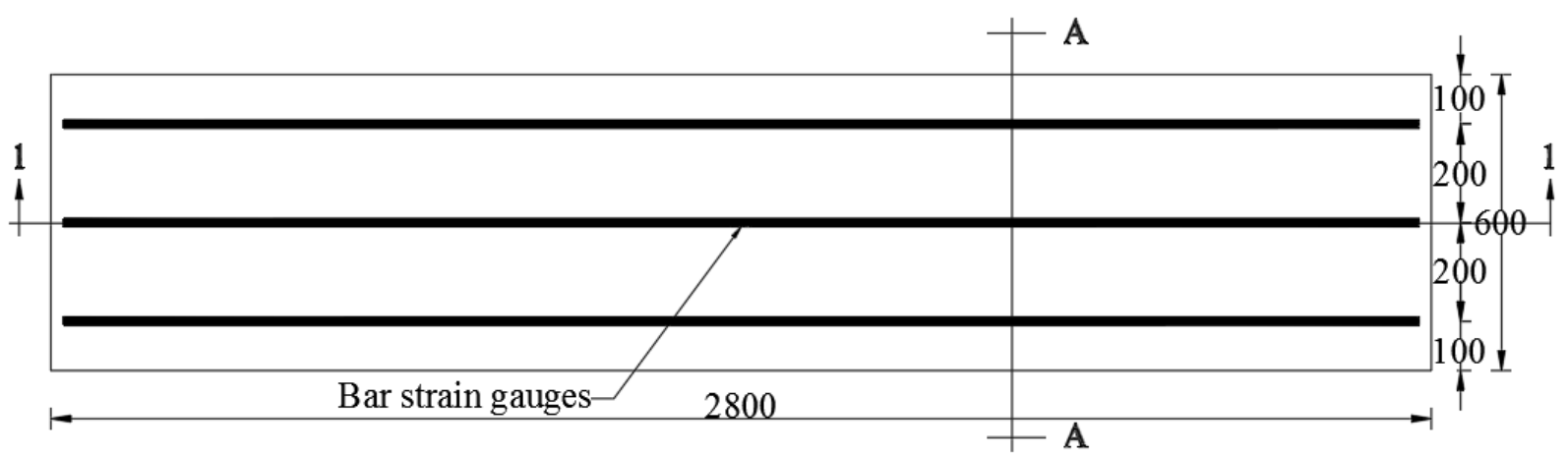

(a) Top view

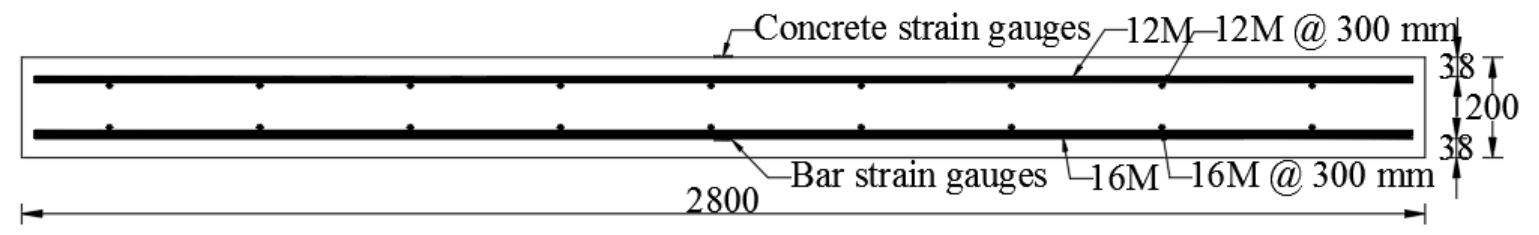

(b) Section $1-1$

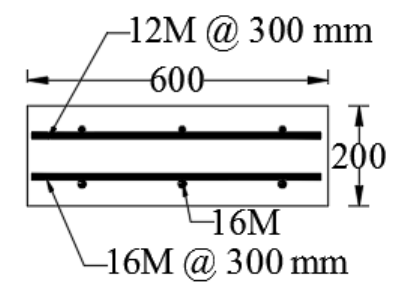

(c) Section A-A

Figure 3.2 Dimensions, joint configuration and GFRP bar arrangement for $\mathrm{Slab}_{1} \mathrm{~S}_{1}$ and $\mathrm{S}_{2}$ in

group CG 


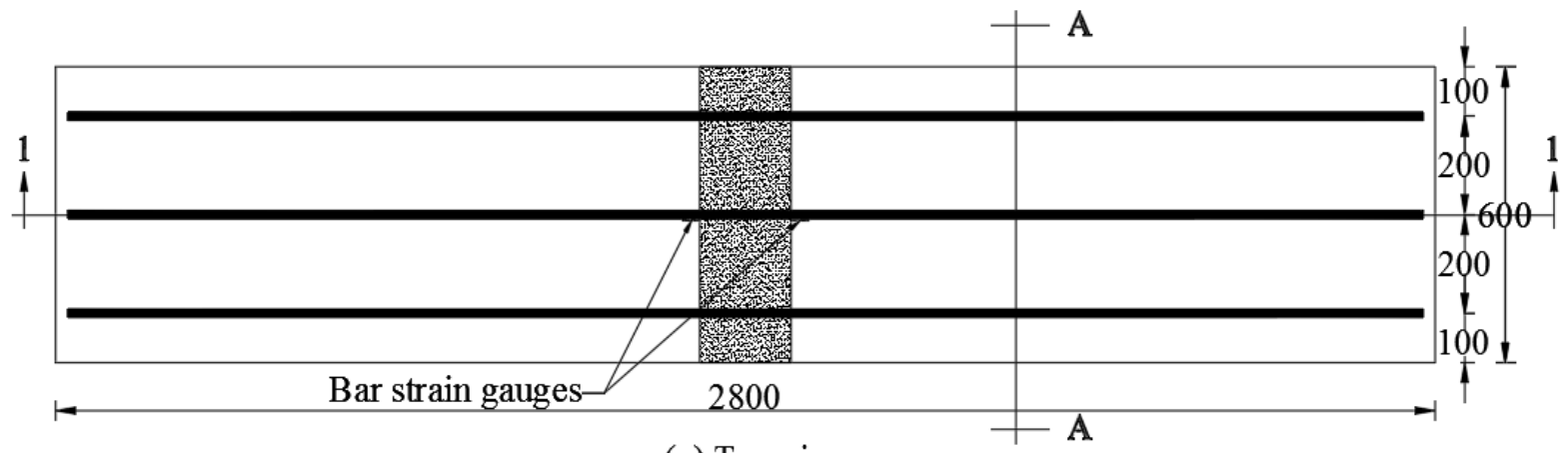

(a) Top view

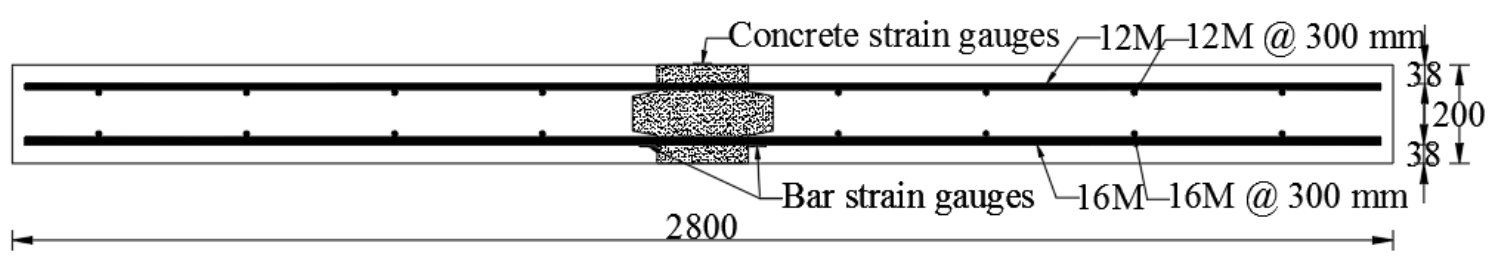

(b) Section 1 - 1

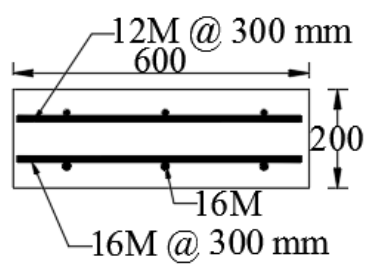

(c) Section A-A

Figure 3.3 Dimensions, joint configuration and GFRP bar arrangement for $\mathrm{Slab}_{3} \mathrm{~S}_{3}$ in group CG 


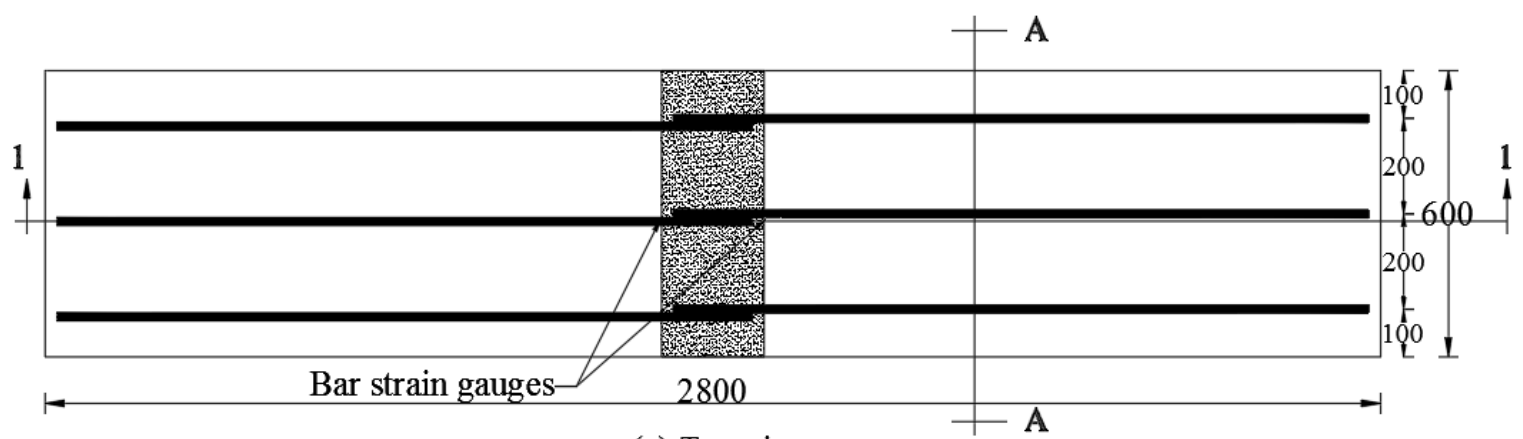

(a) Top view

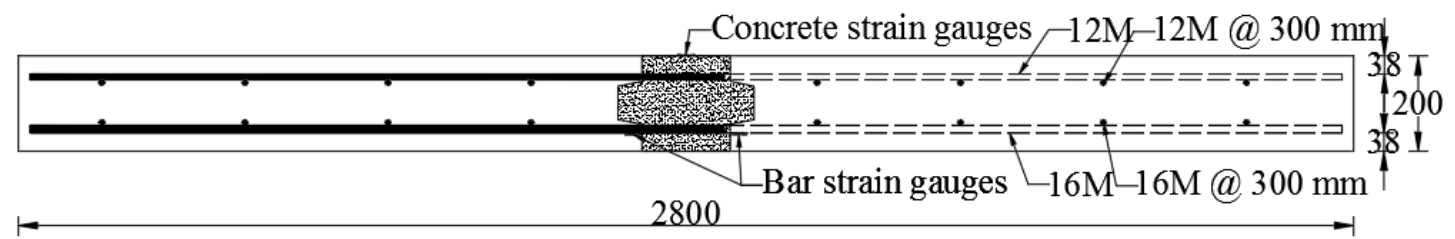

(b) Section 1 - 1

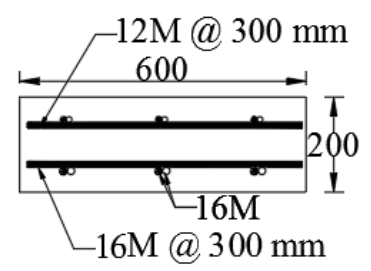

(c) Section A-A

Figure 3.4 Dimensions, joint configuration and GFRP bar arrangement for slab in group G1 


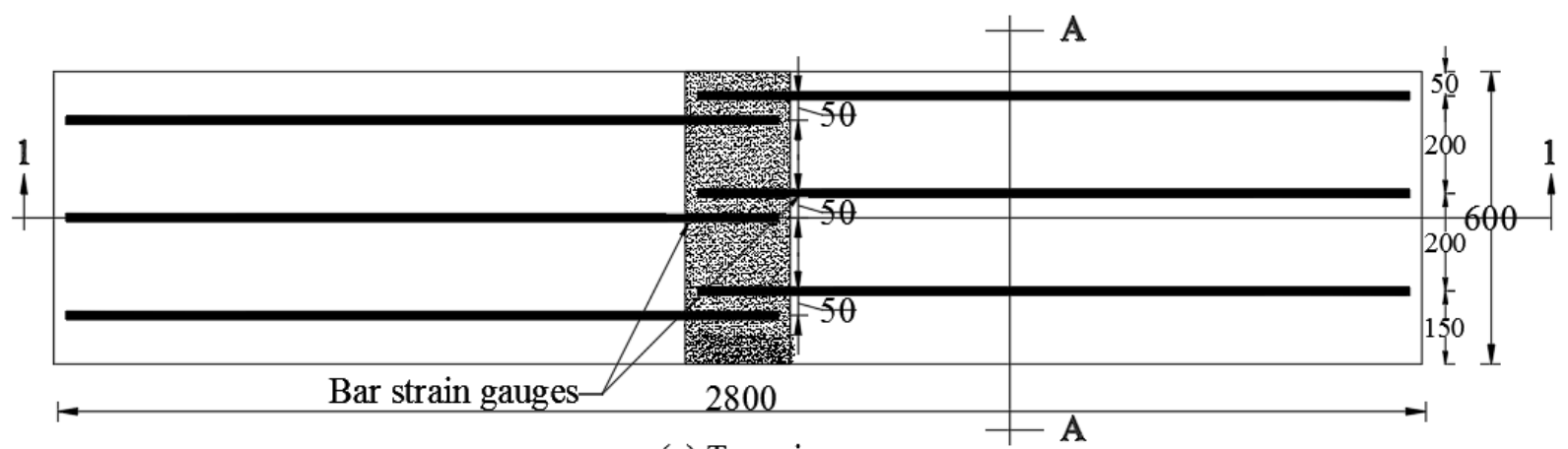

(a) Top view

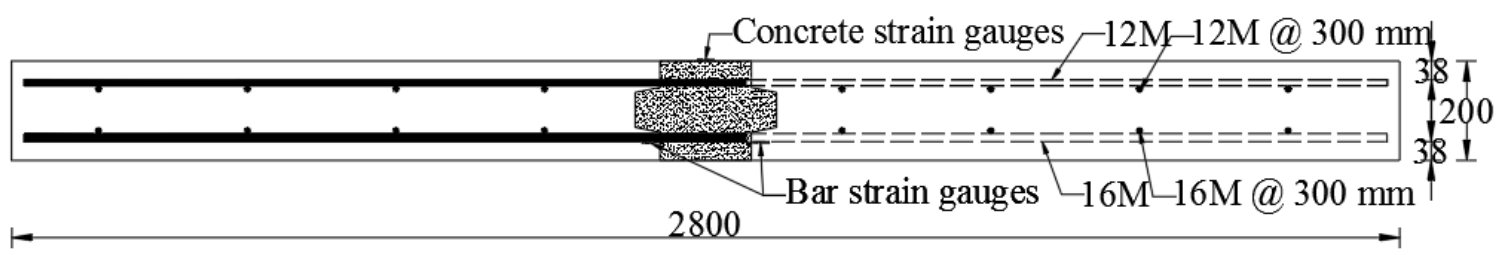

(b) Section 1 - 1

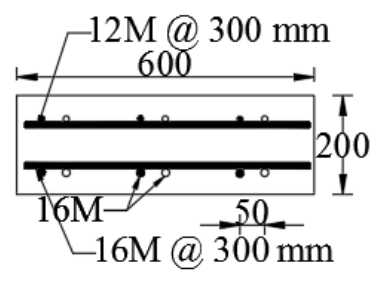

(c) Section A-A

Figure 3.5 Dimensions, joint configuration and GFRP bar arrangement for slabs in group G2 


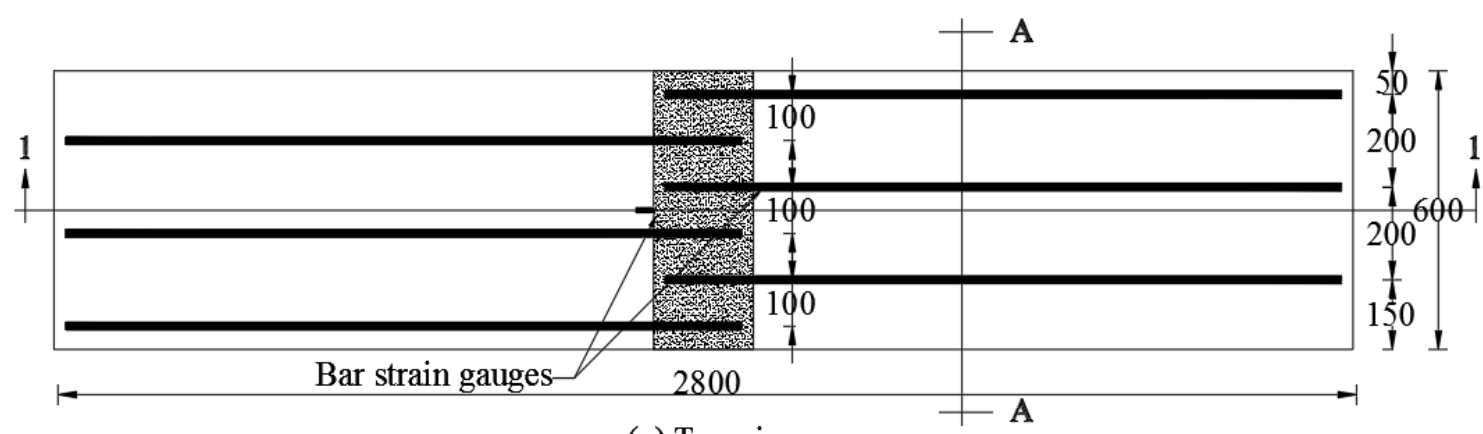

(a) Top view

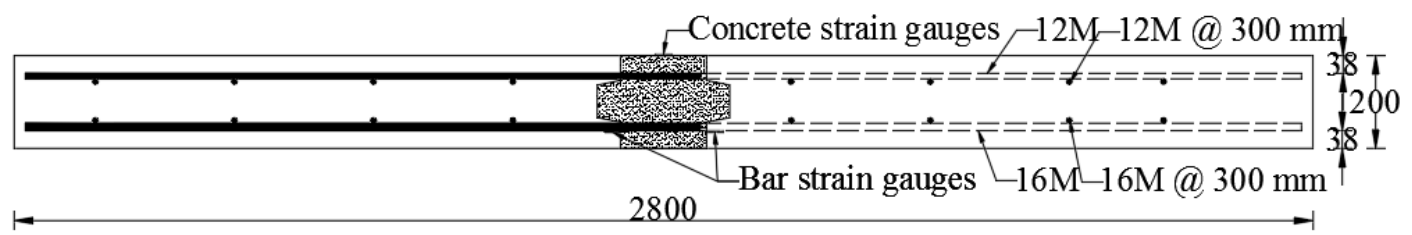

(b) Section 1 - 1

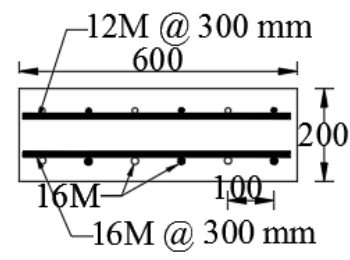

(c) Section A-A

Figure 3.6 Dimensions, joint configuration and GFRP bar arrangement for slabs in group G3 


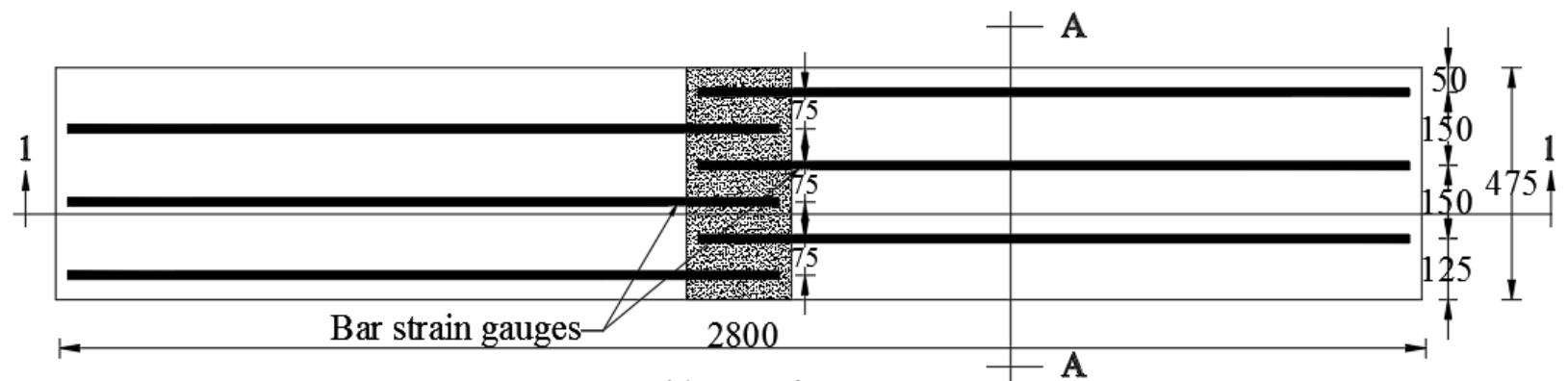

(a) Top view

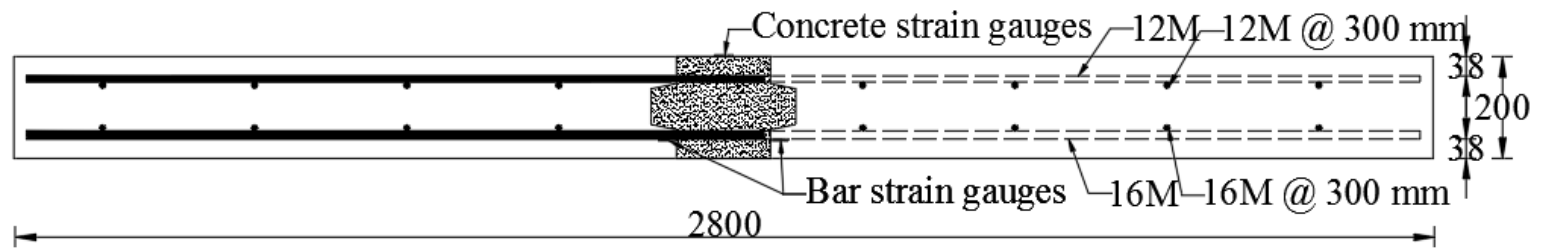

(b) Section $1-1$

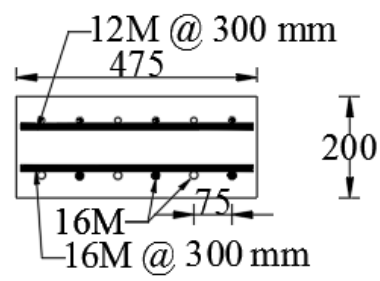

(c) Section A-A

Figure 3.7 Dimensions, joint configuration and bar arrangement for slabs in groups G4 and G6 

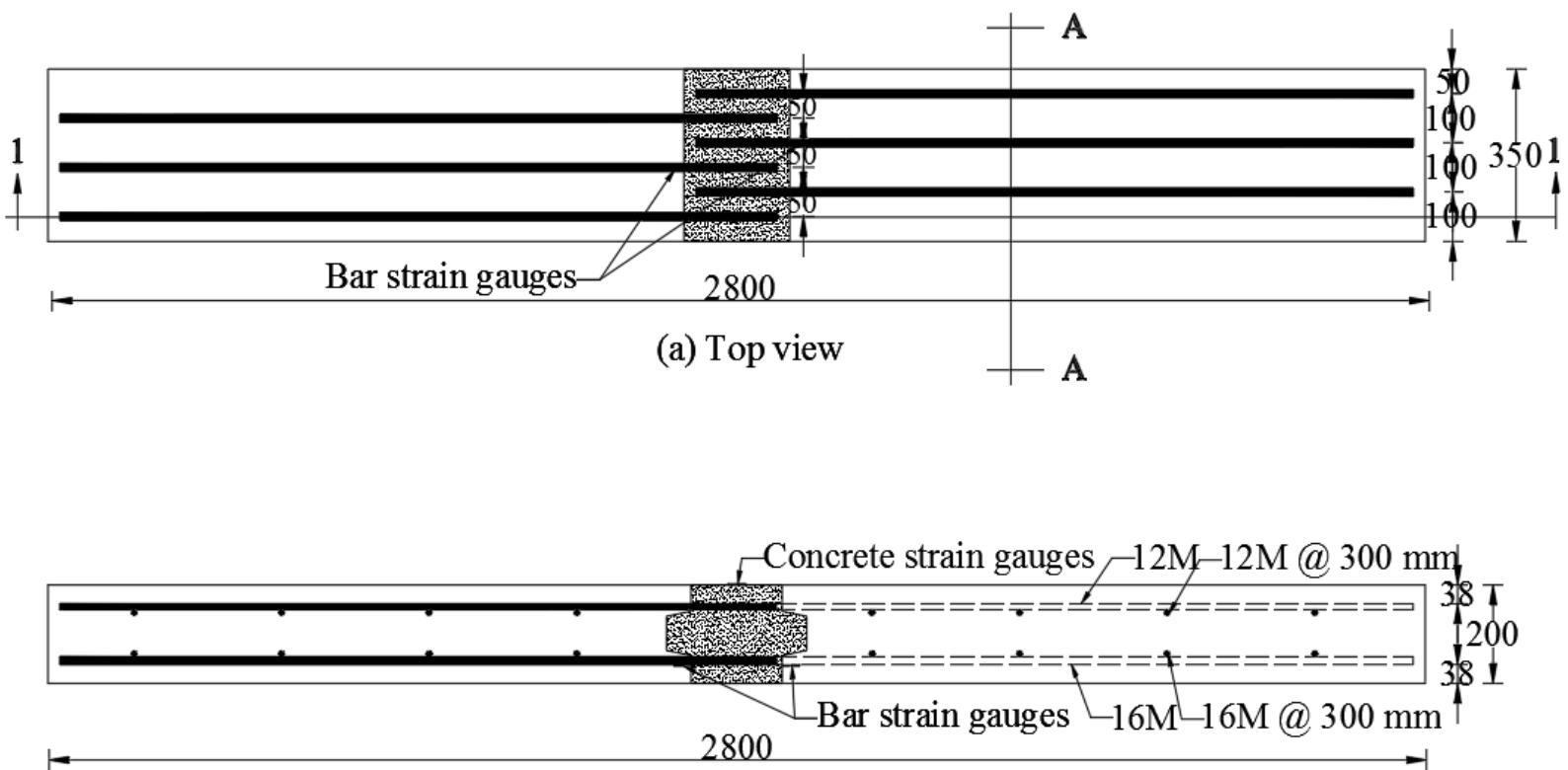

(b) Section 1 - 1

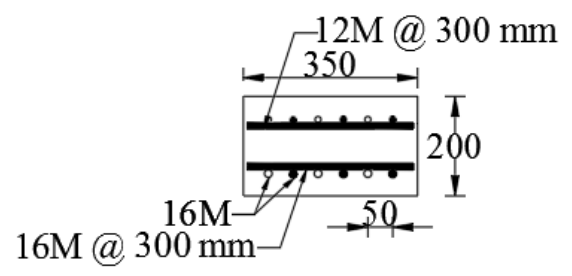

(c) Section A-A

Figure 3.8 Dimensions, joint configuration and GFRP bar arrangement for slabs in groups G5

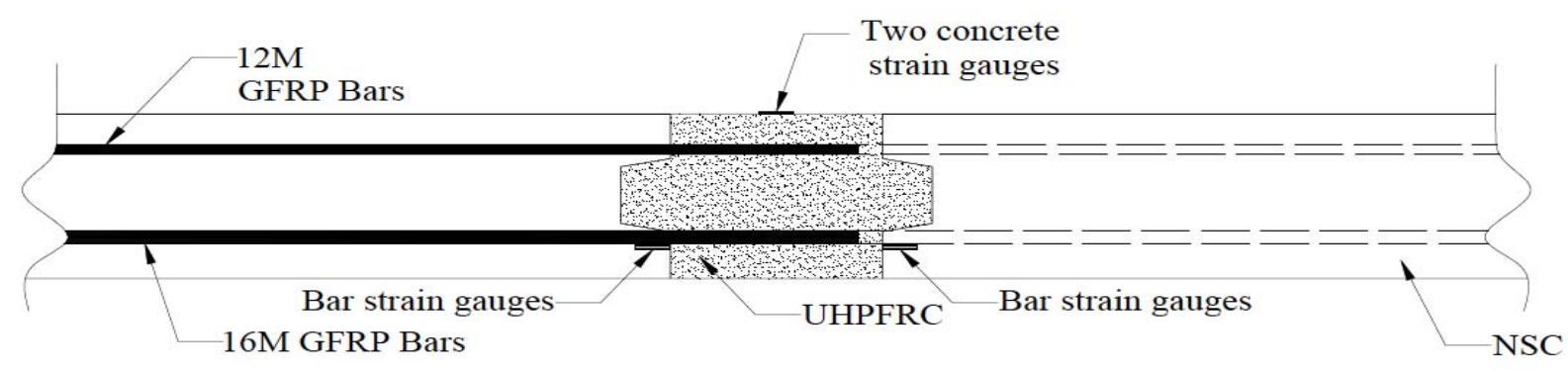

Figure 3.9 Location of strain gauges on bottom GFRP bars 


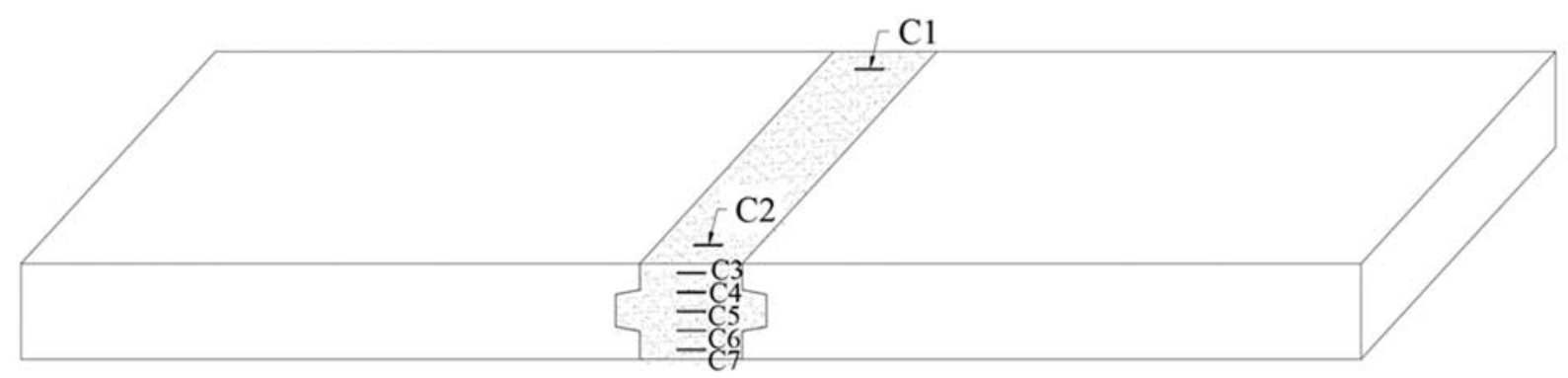

Figure 3.10 3D view of a typical jointed slab showing the locations of Concrete strain gauges
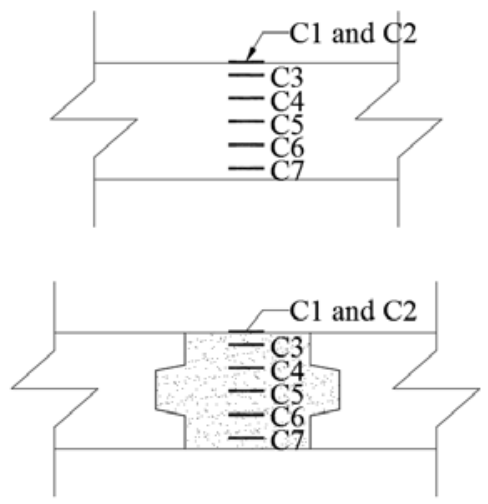

Figure 3.11 locations of Concrete strain gauges across the slab thickness

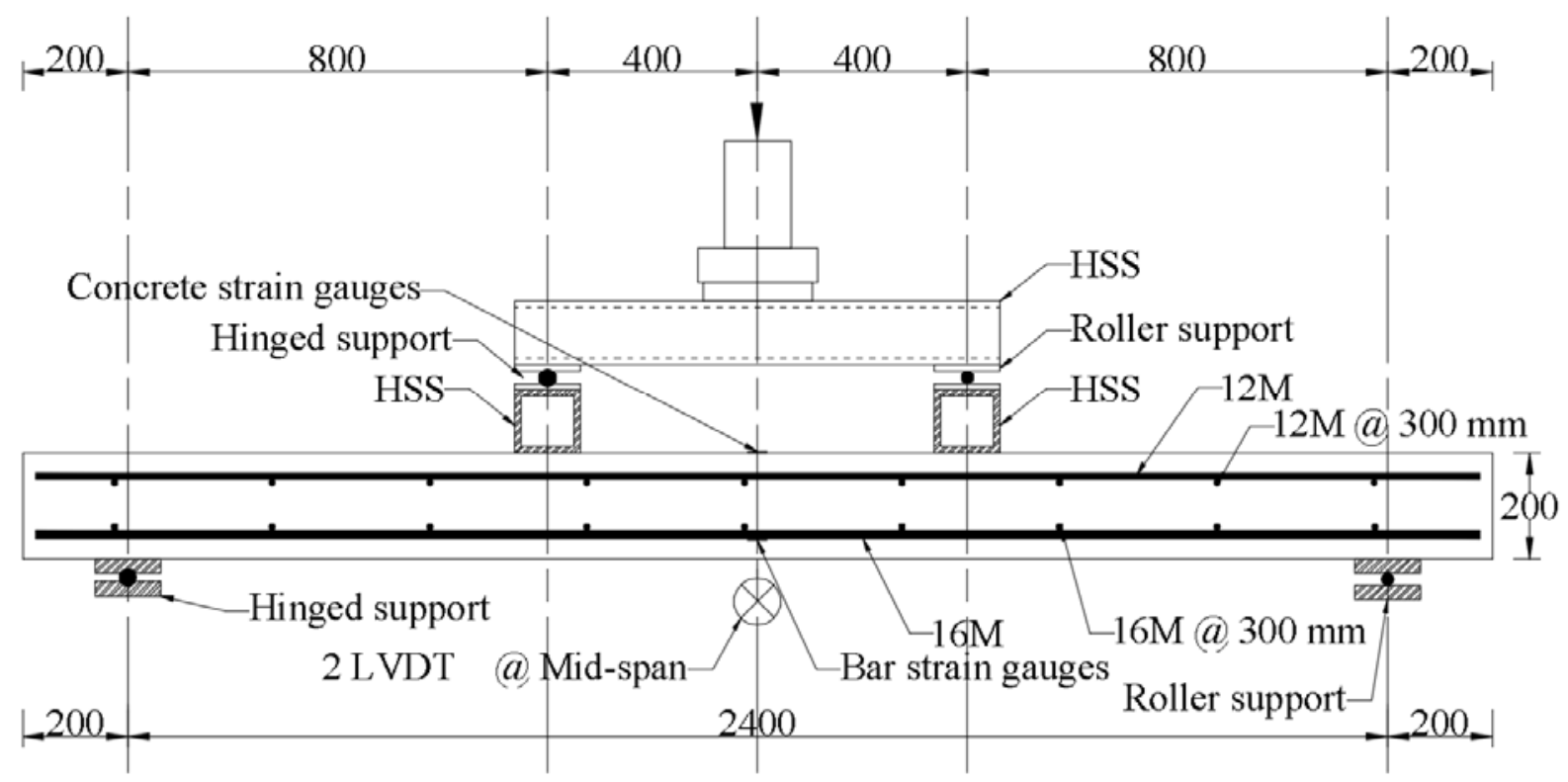

Figure 3.12 Test setup for slabs $\mathrm{S}_{1}$ through $\mathrm{S}_{2}$ 


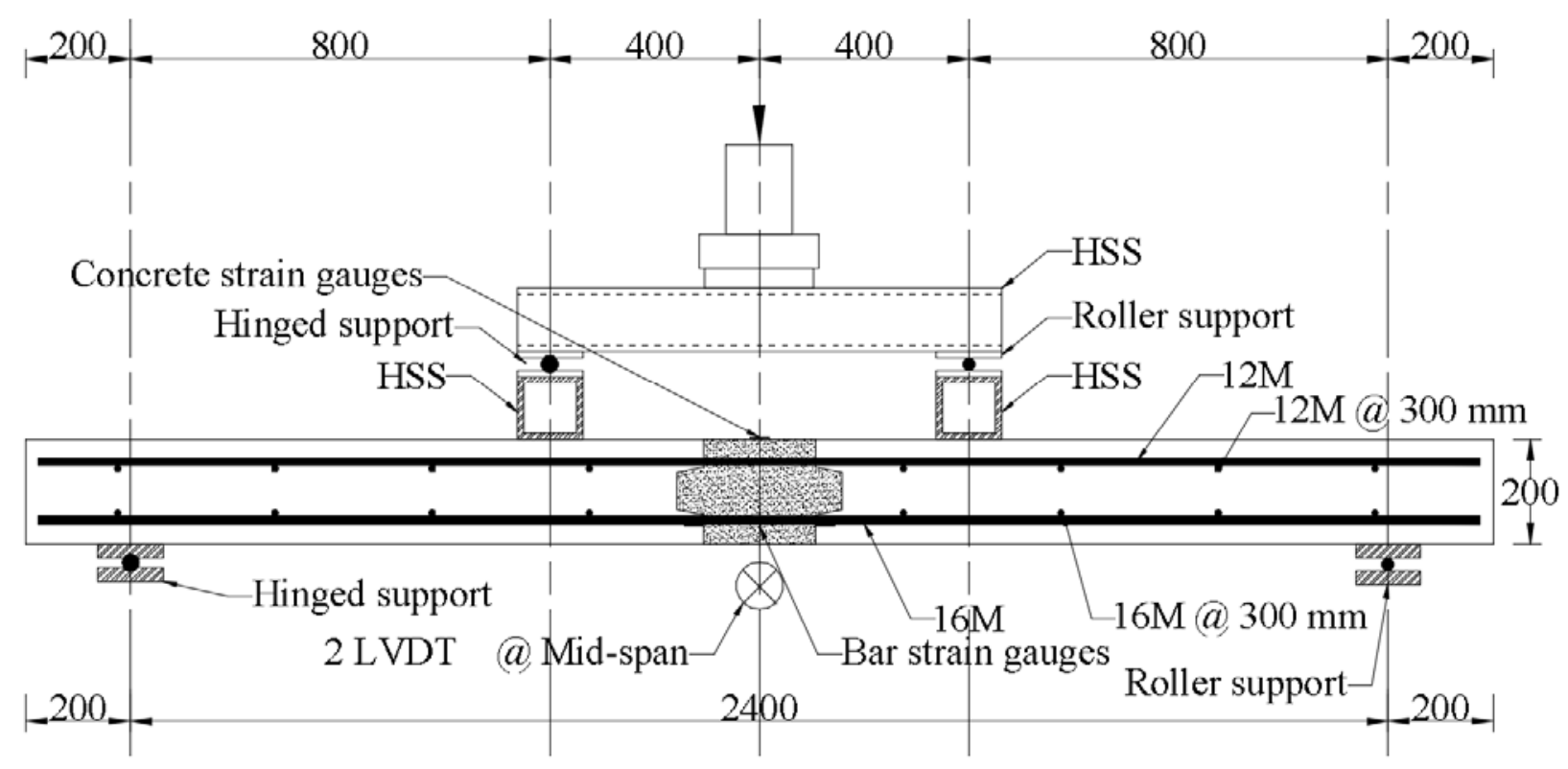

Figure 3.13 Test setup for slabs $\mathrm{S}_{3}$ through $\mathrm{S}_{19}$

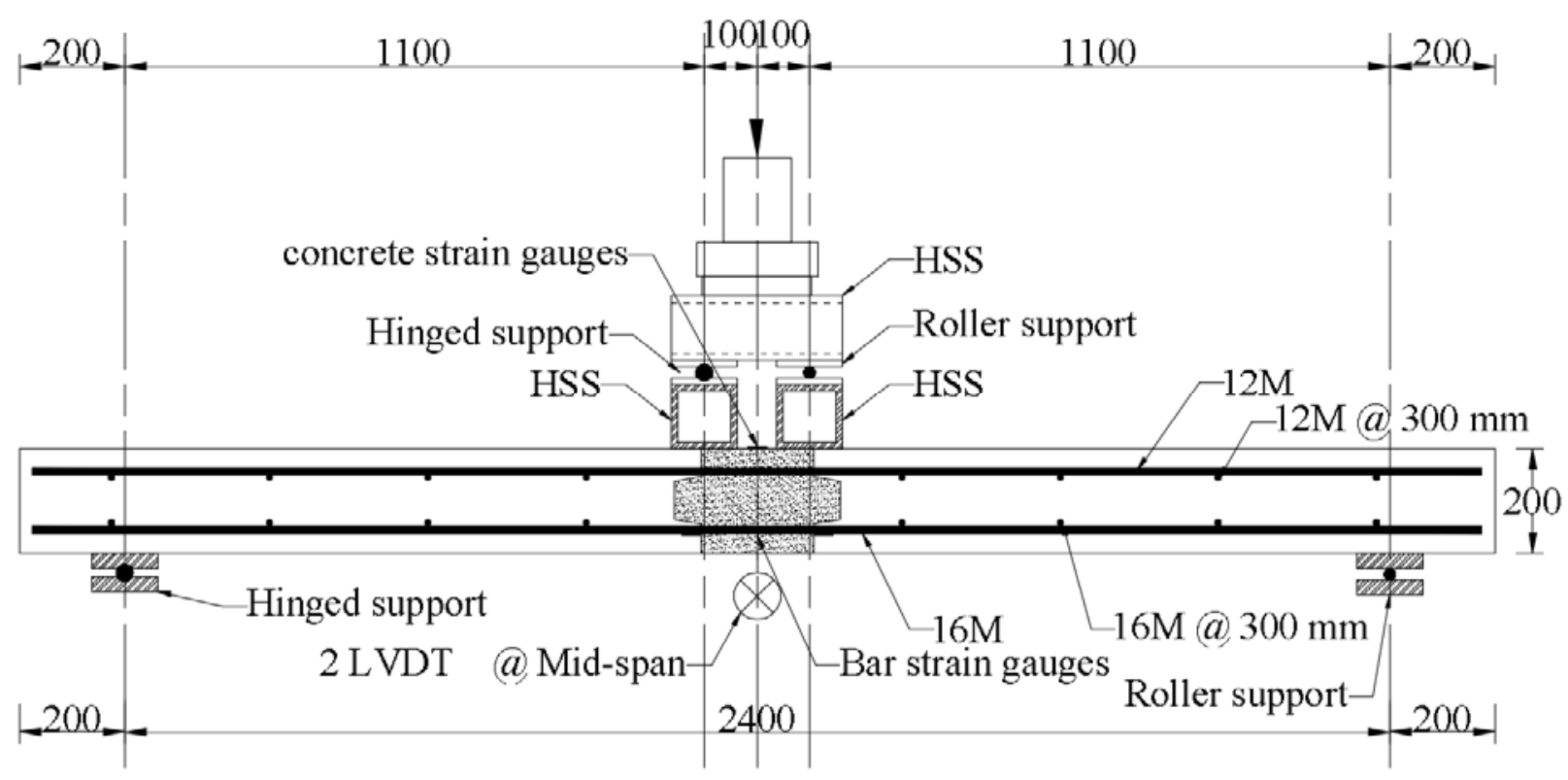

Figure 3.14 test setup for slabs for $\mathrm{S}_{20}$ and $\mathrm{S}_{27}$ 


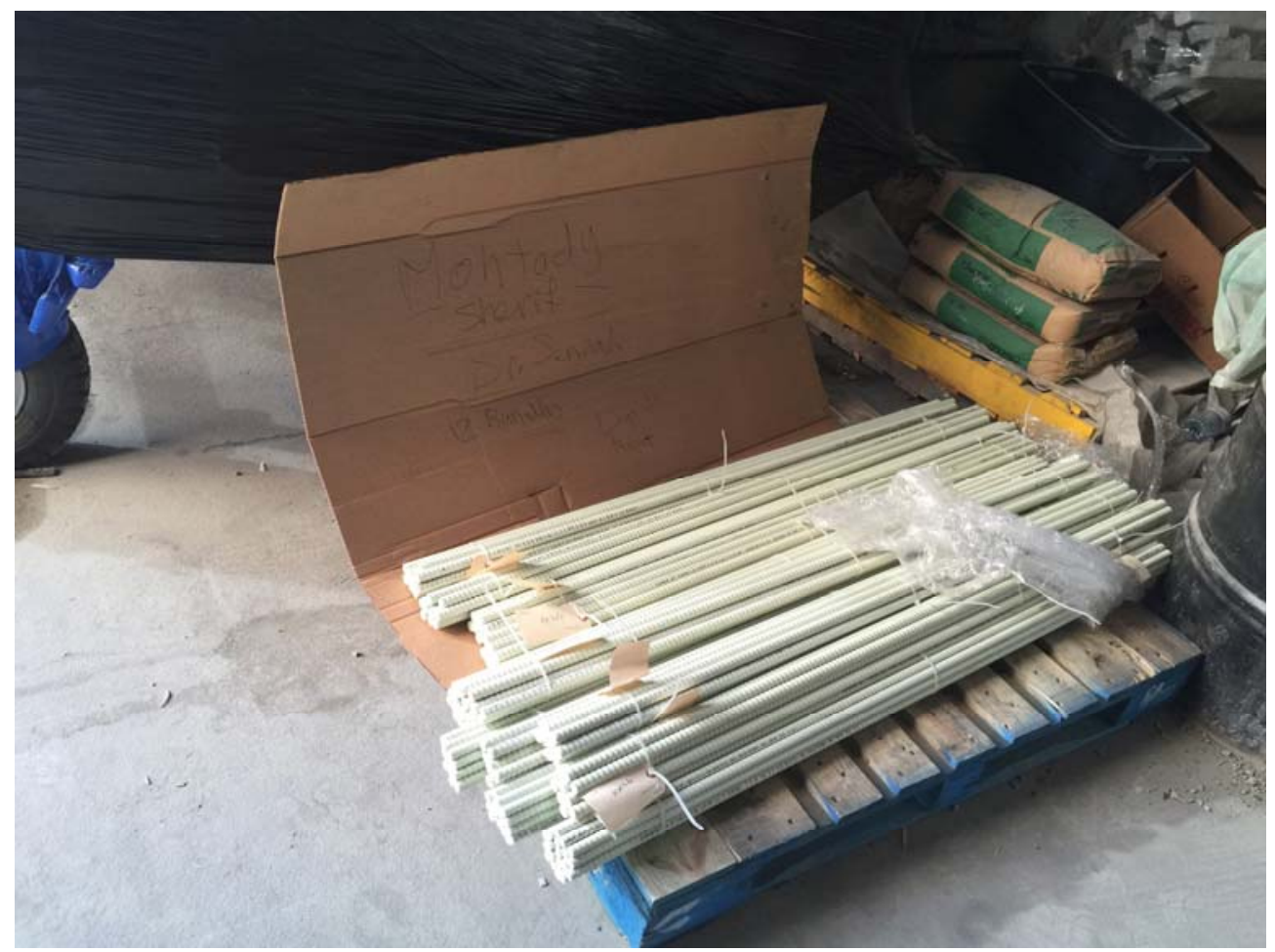

Figure 3.15 GFRP view of bars delivered by the manufacturer cut to size and tagged

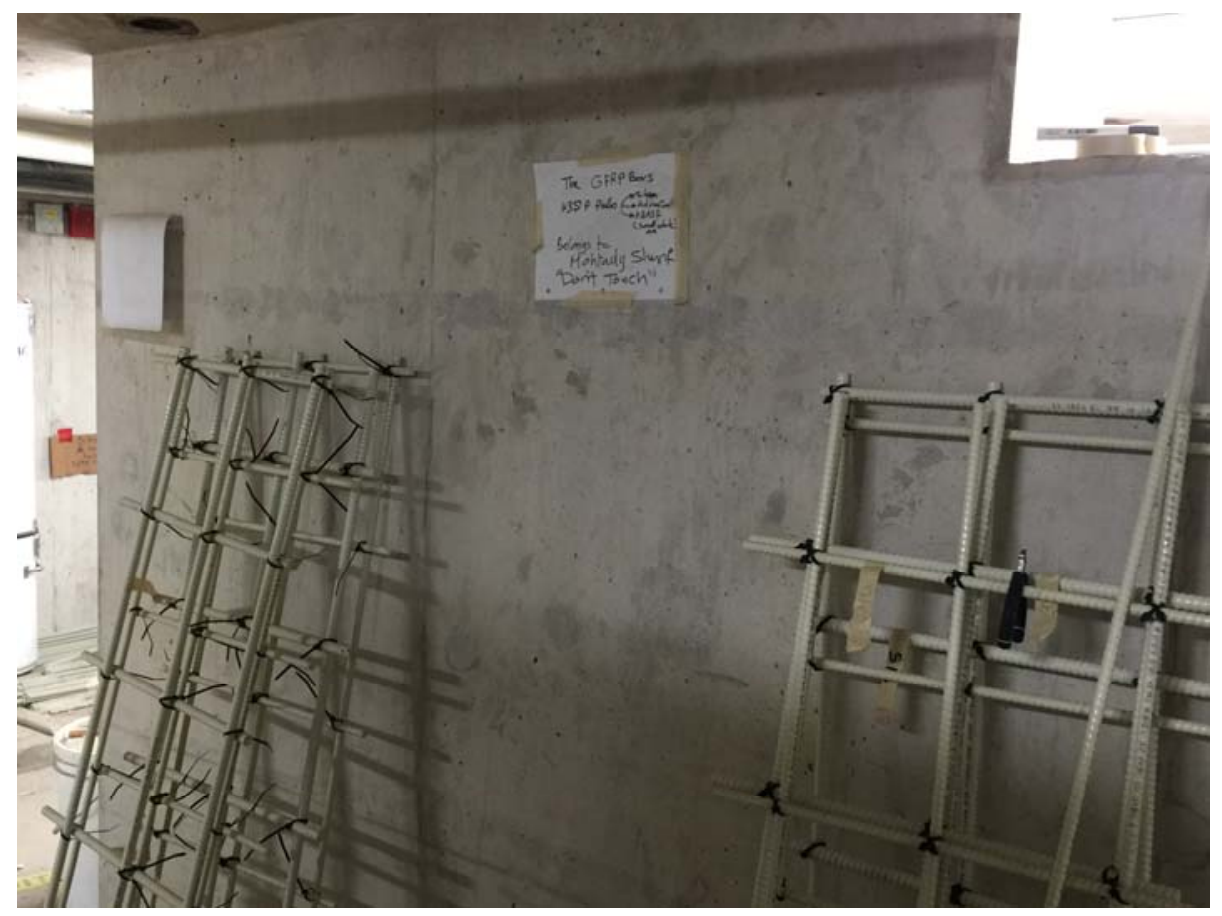

Figure 3.16 View of the GFRP bars tied with zip ties, tagged and ready to be placed in the forms 


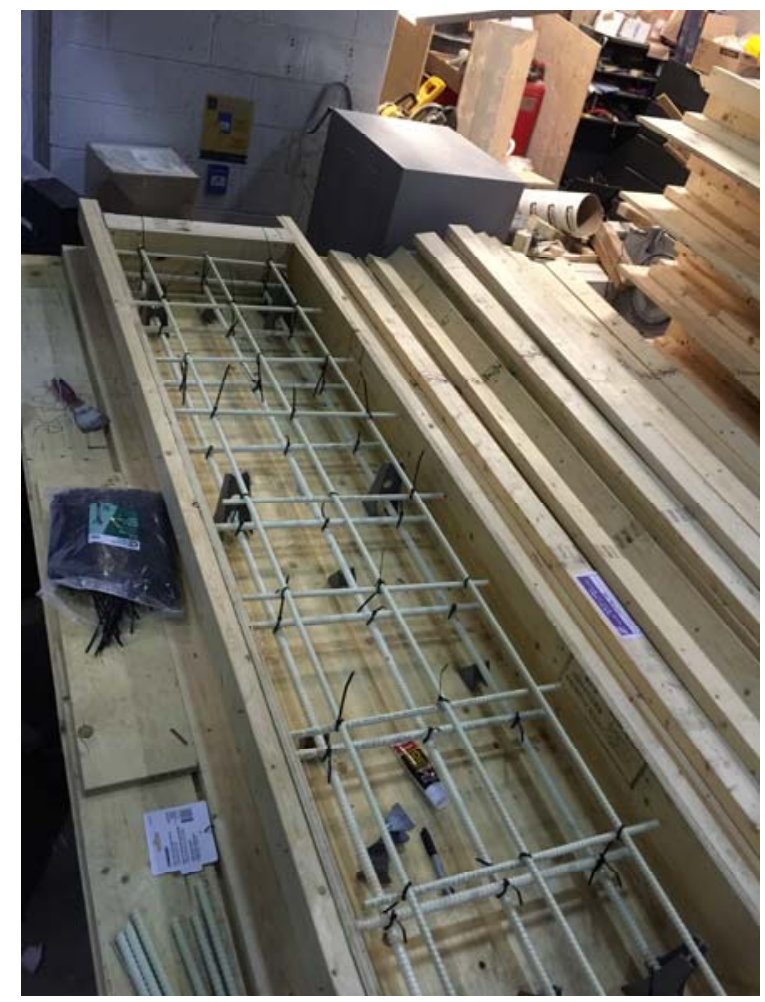

Figure 3.17 View of the inner form for slab $\mathrm{S}_{1}$ during the assembly of GFRP bars over the seats

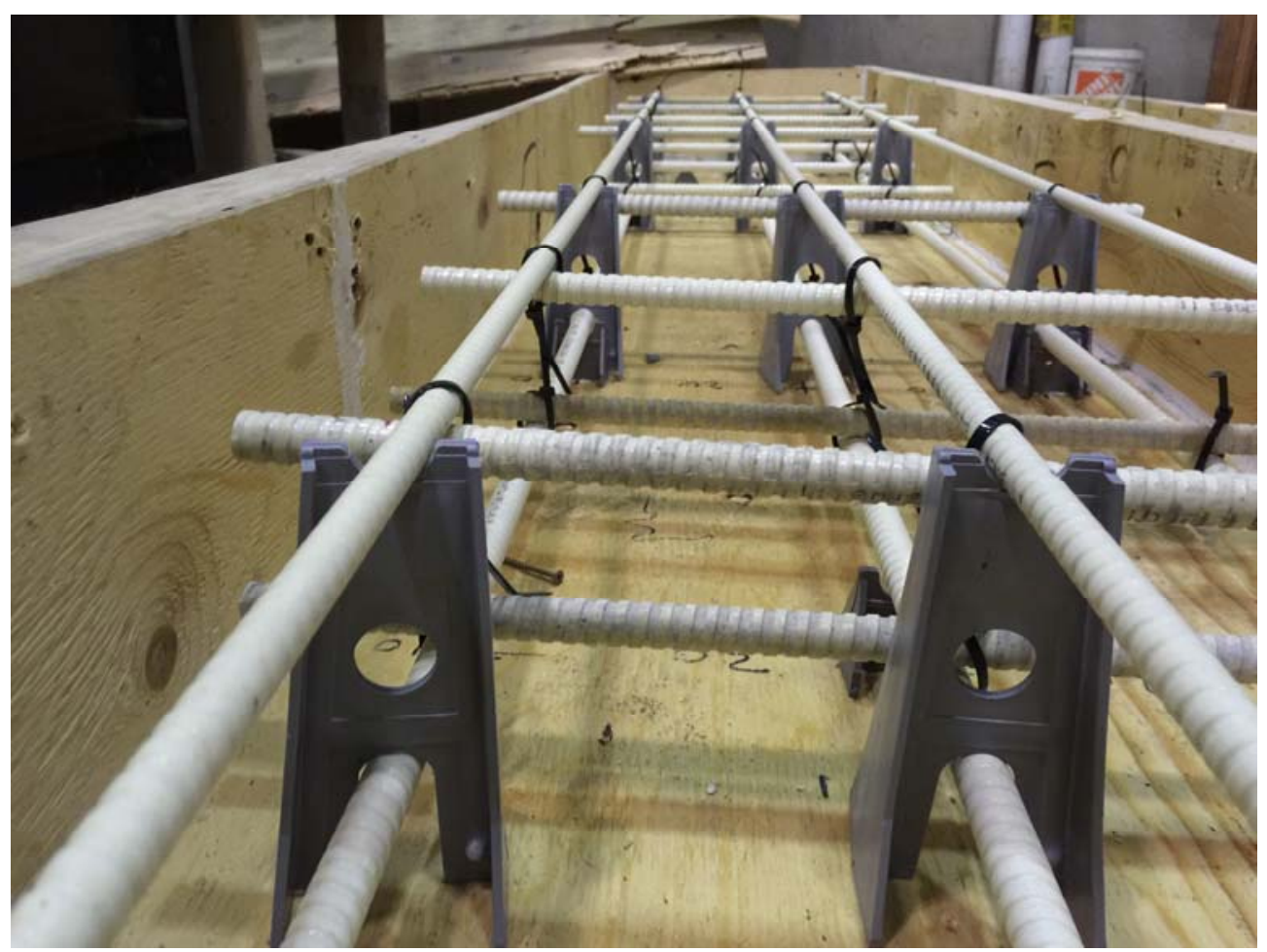

Figure 3.18 View of the inner form for slab $\mathrm{S}_{3}$ showing GFRP bars assembled and placed over the seats 


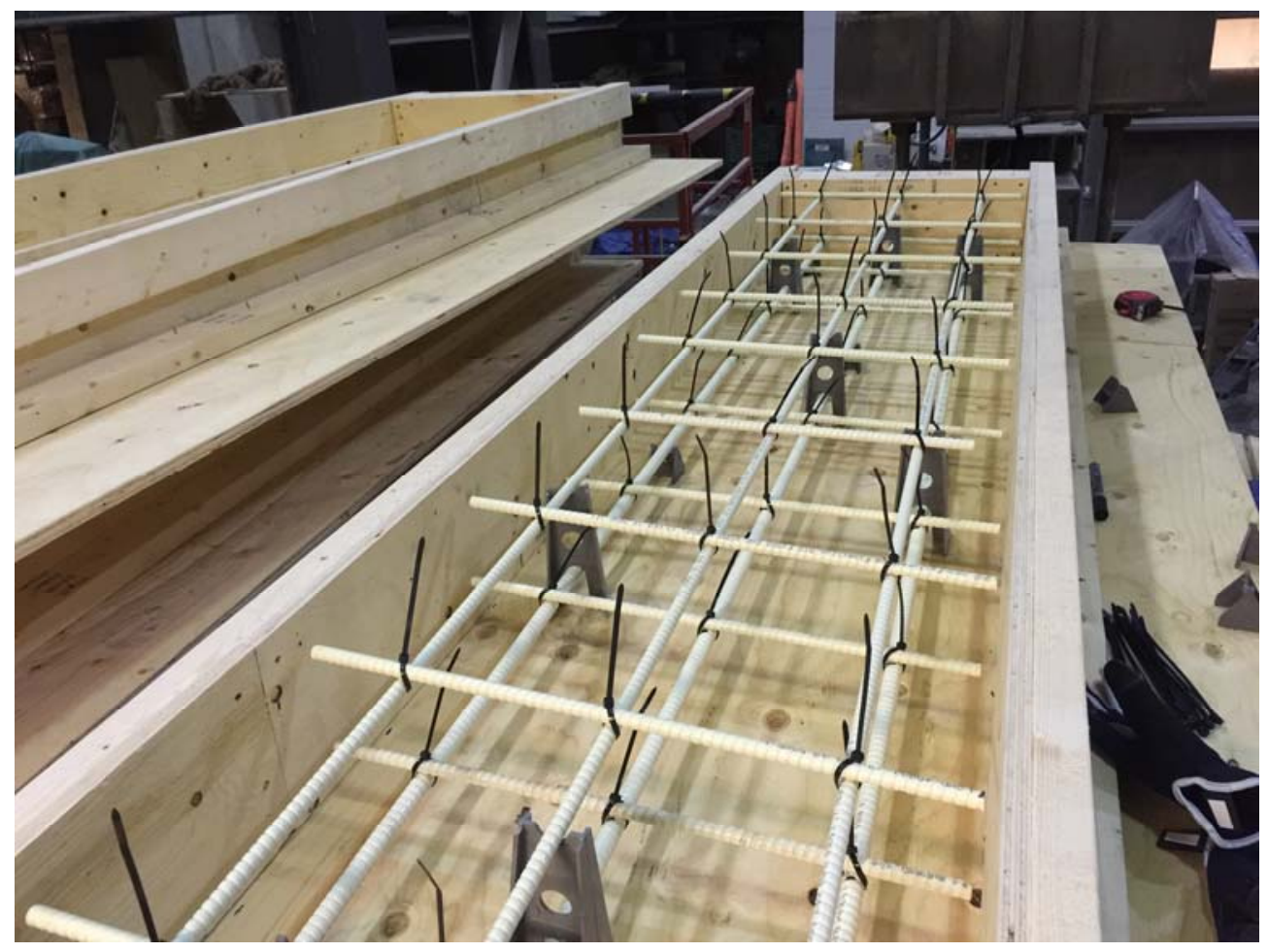

Figure 3.19 View of the inner form for slab S1 showing GFRP bars assembled and placed over the seats

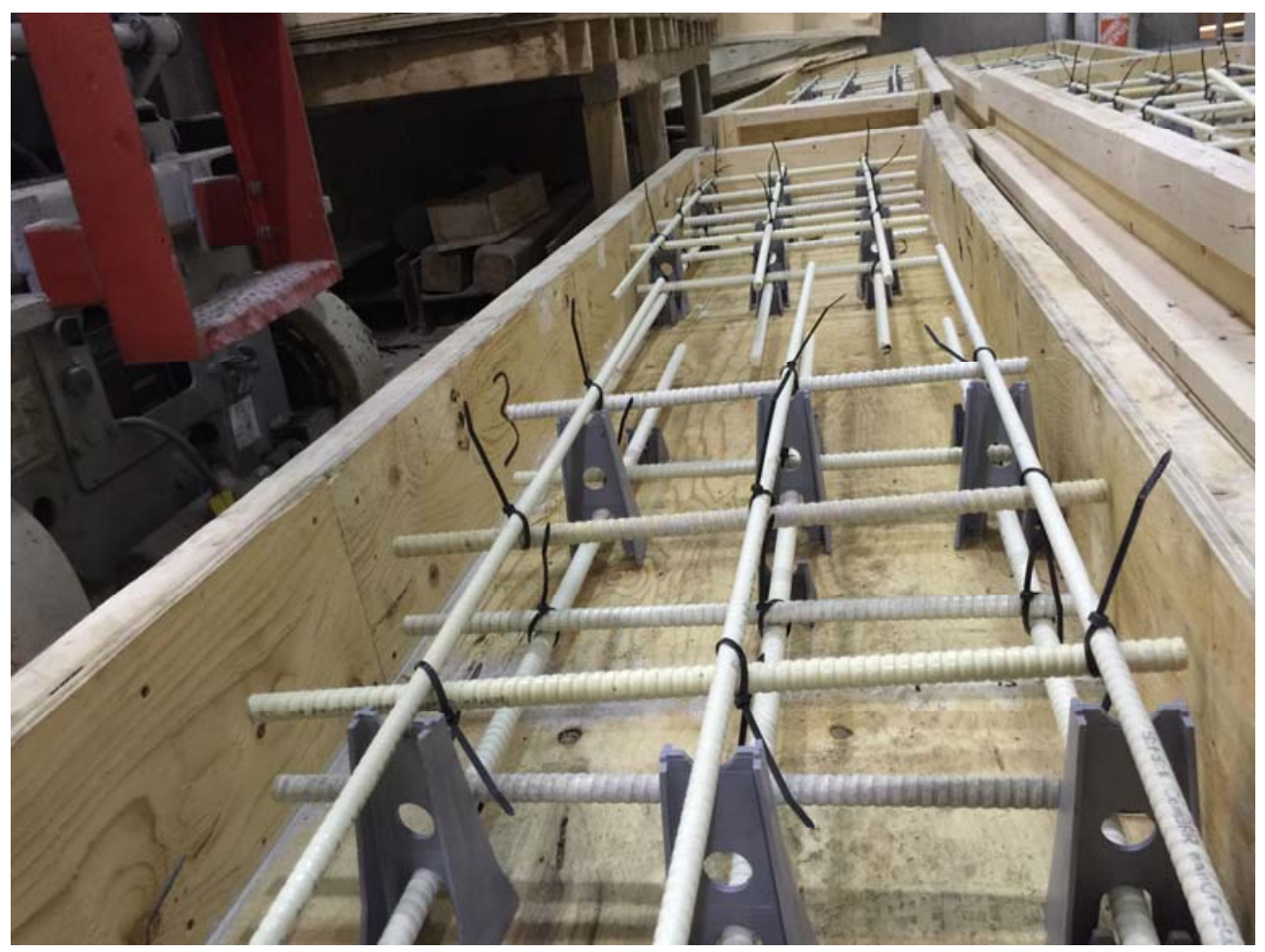

Figure 3.20 View of the inner form for the slab with $50 \mathrm{~mm}$ spliced bar offset at the joint 


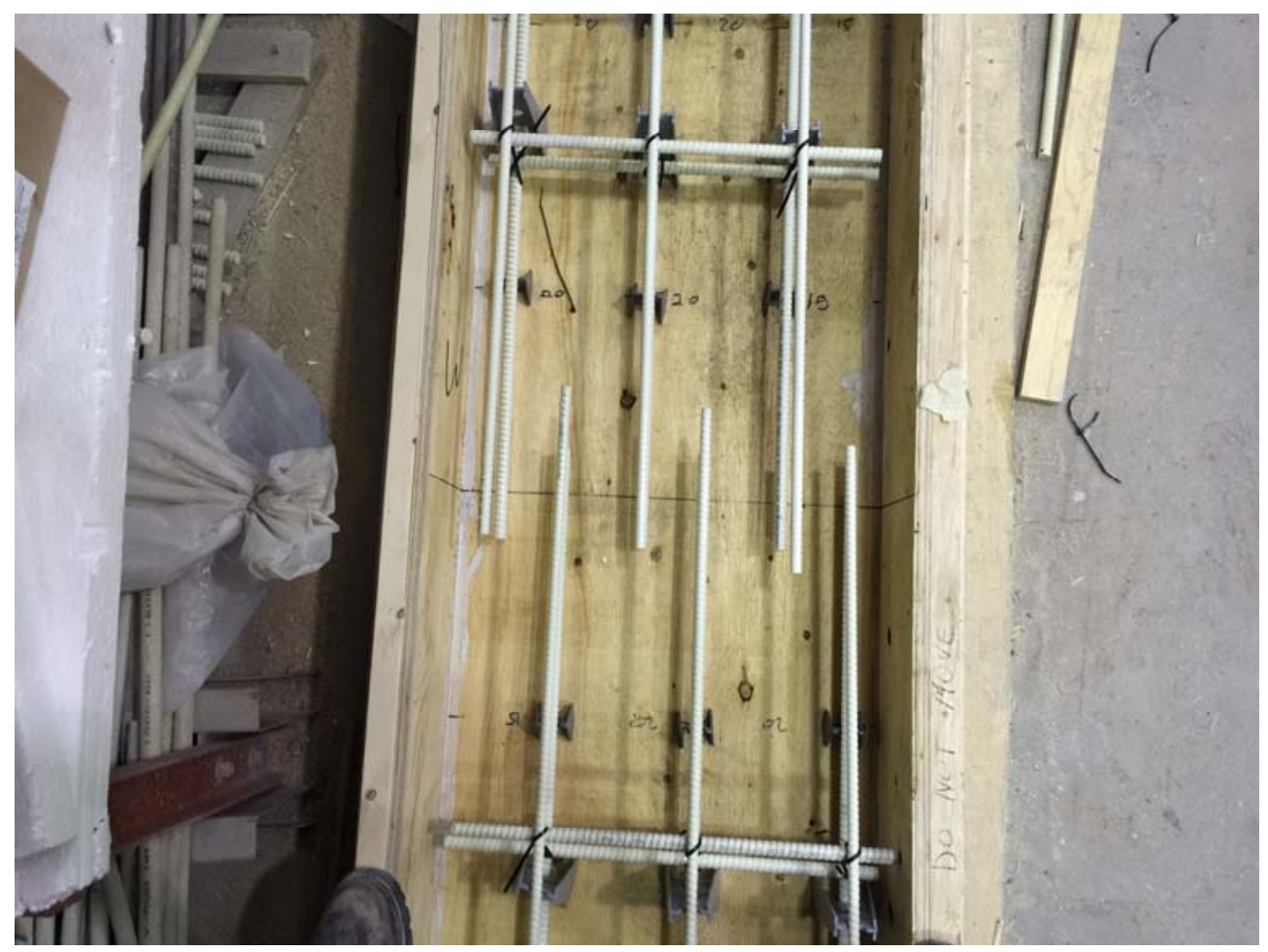

Figure 3.21 View of the inner form for the slab with equally spaced spliced bars

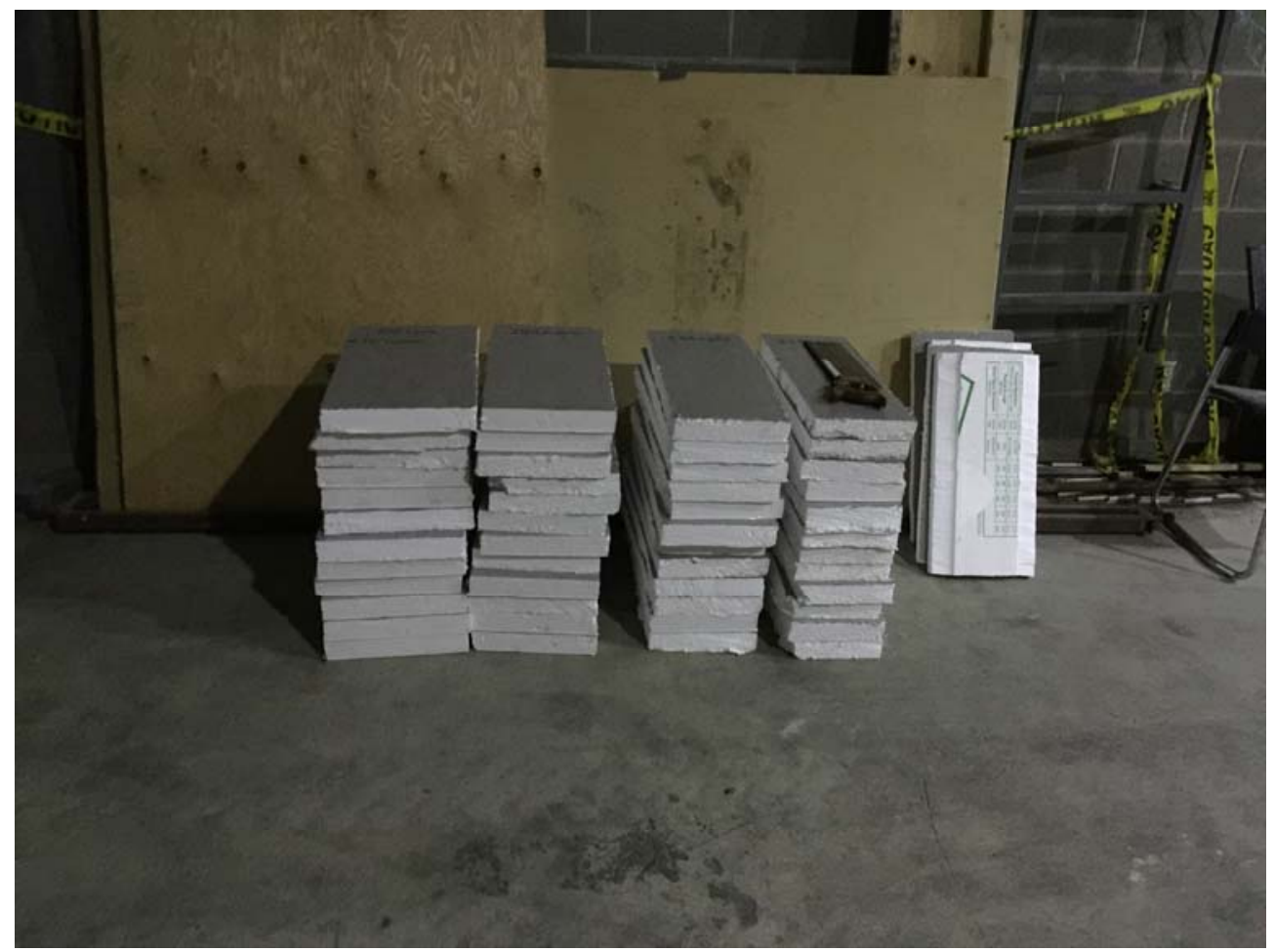

Figure 3.22 View of styrofoam boards cut to the dimensions of the joint and ready to be shaped with the hot wire 


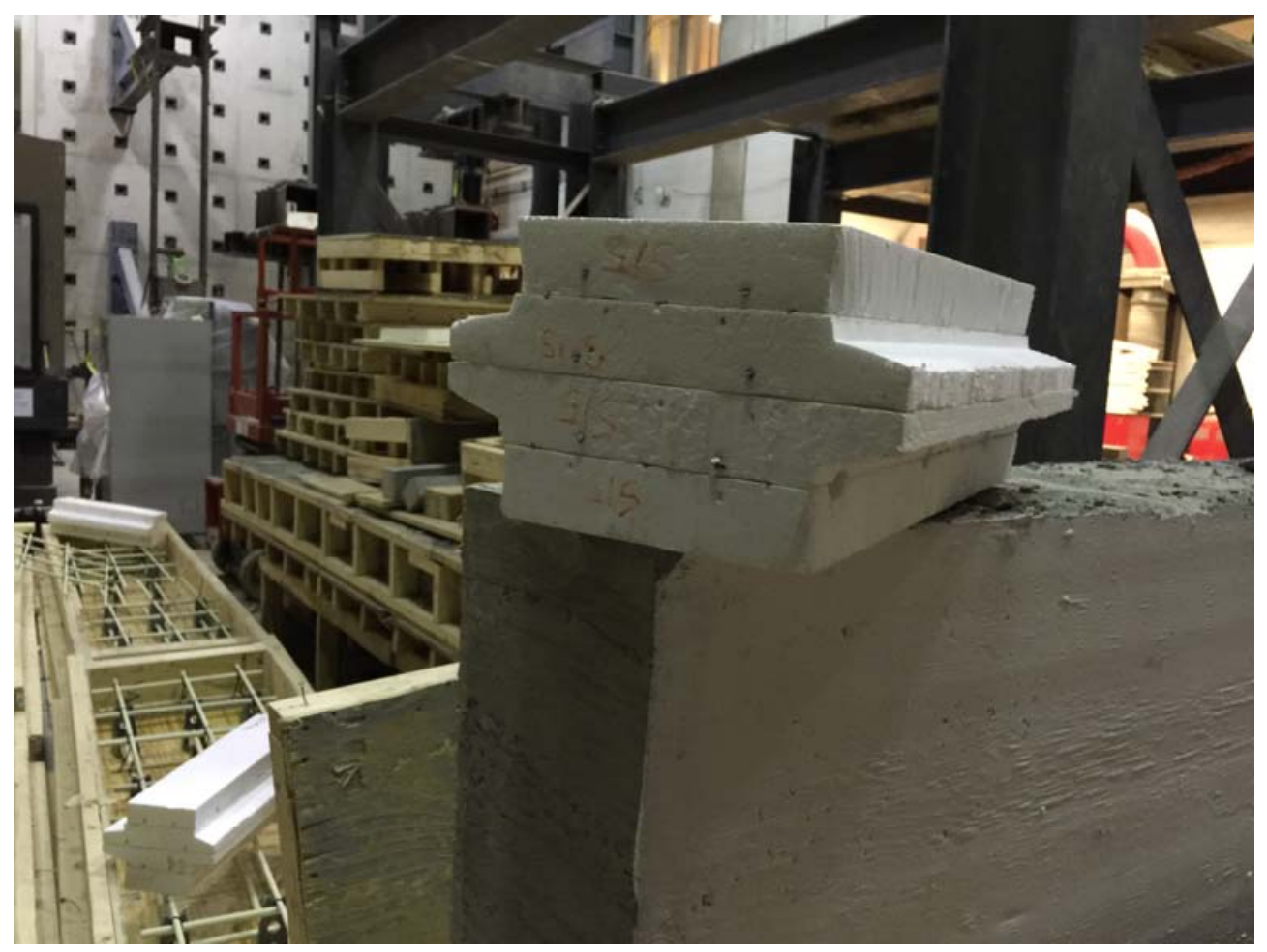

Figure 3.23 3D view of the joint foam cut to size and grooved for the GFRP bars locations

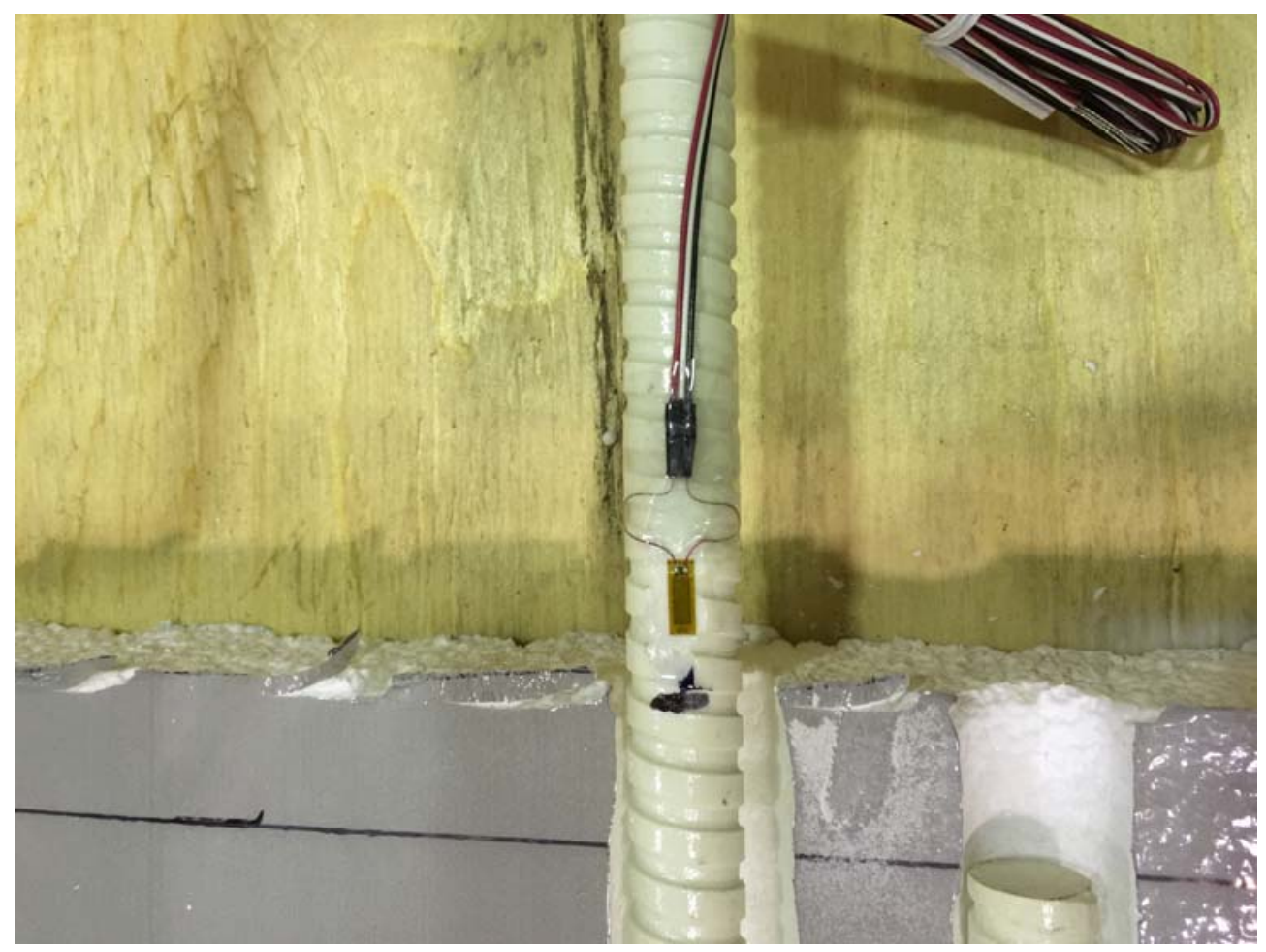

Figure 3.24 Close-up view of a strain gauge attached to the bar 


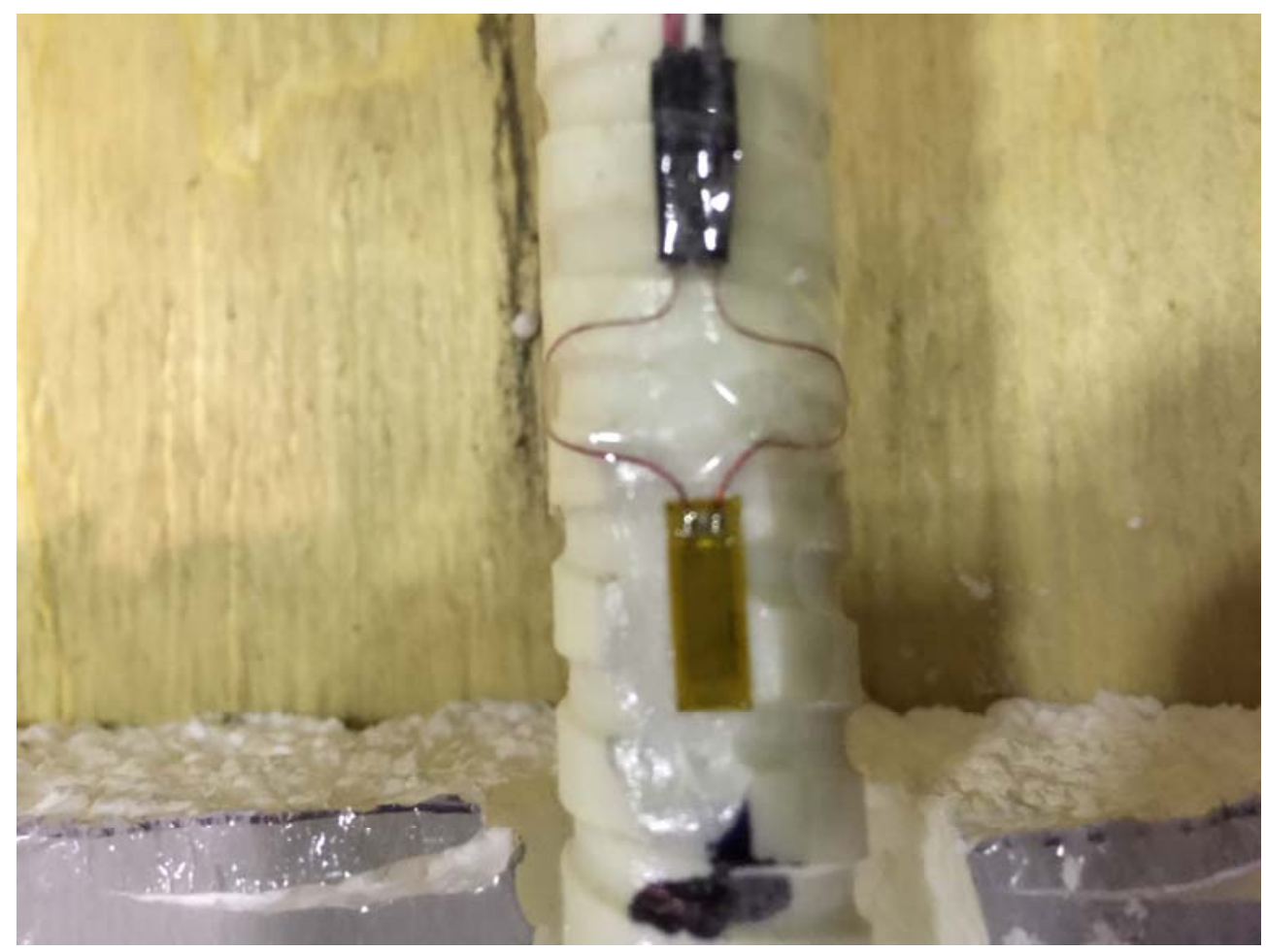

Figure 3.25 View of a strain gauge attached to the bar

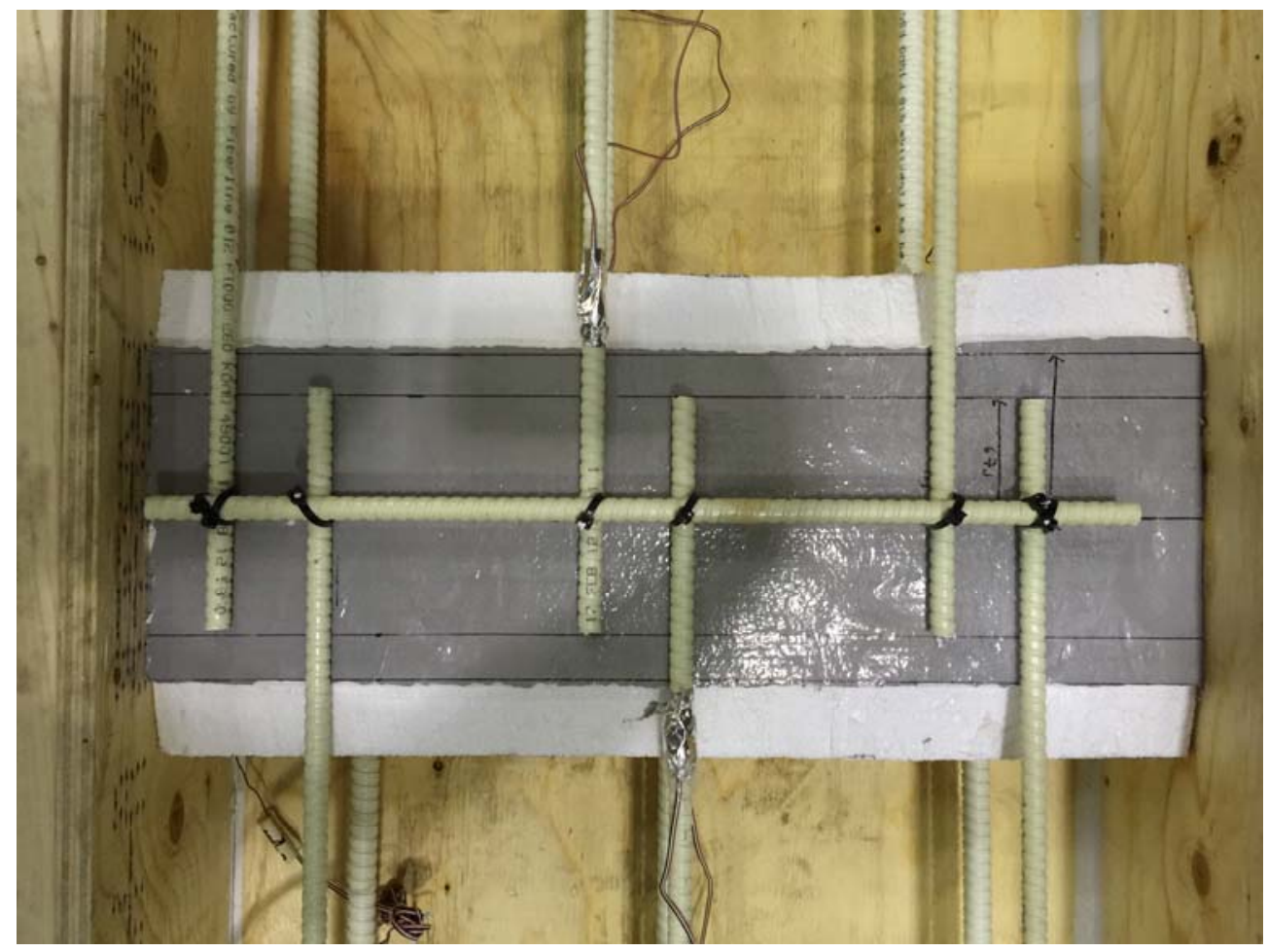

Figure 3.26 View of the joint foam and bars for the slab with $50 \mathrm{~mm}$ spliced bar offset 


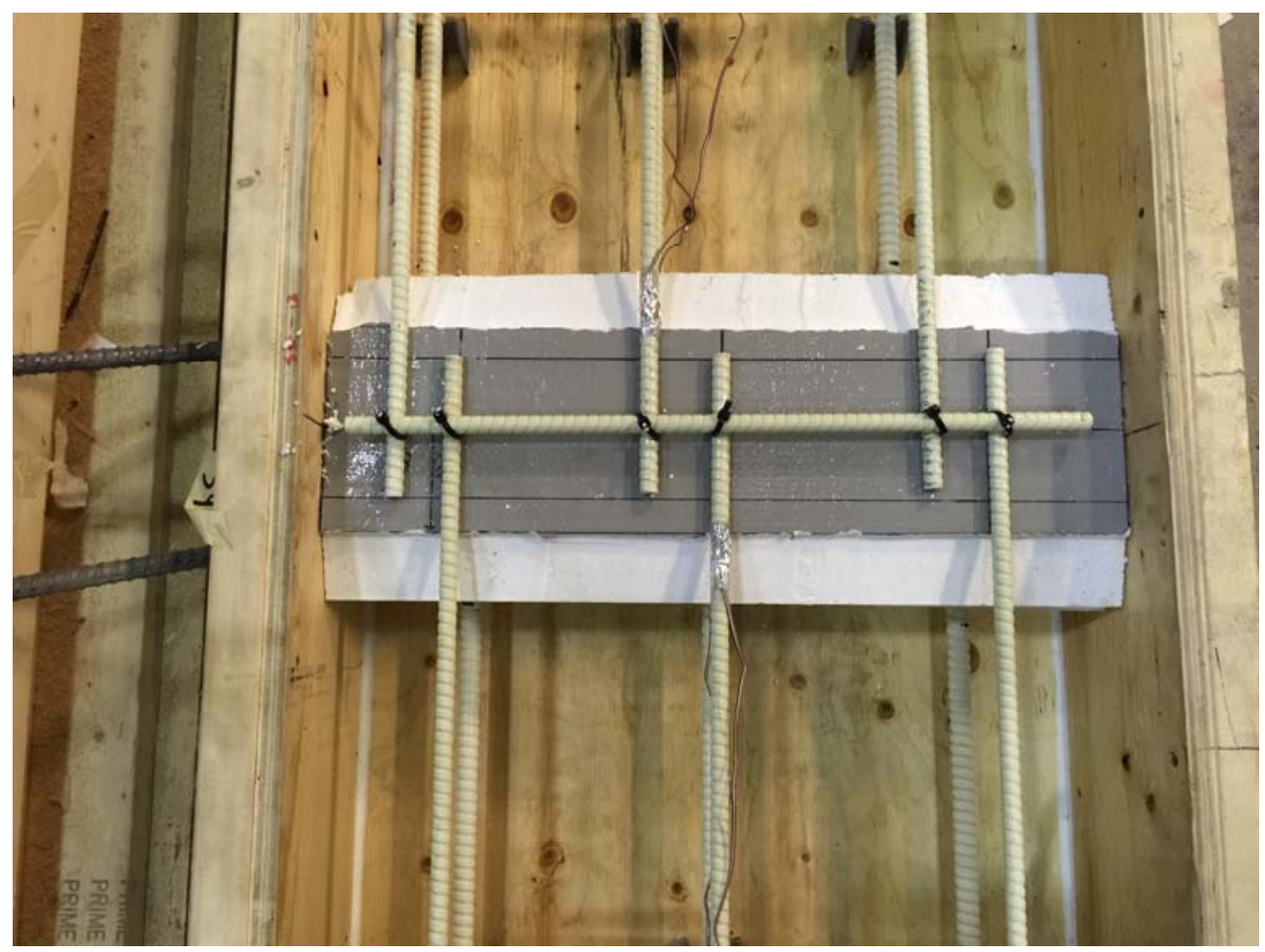

Figure 3.27 View of the joint foam and bars for the slab with $50 \mathrm{~mm}$ spliced bar offset

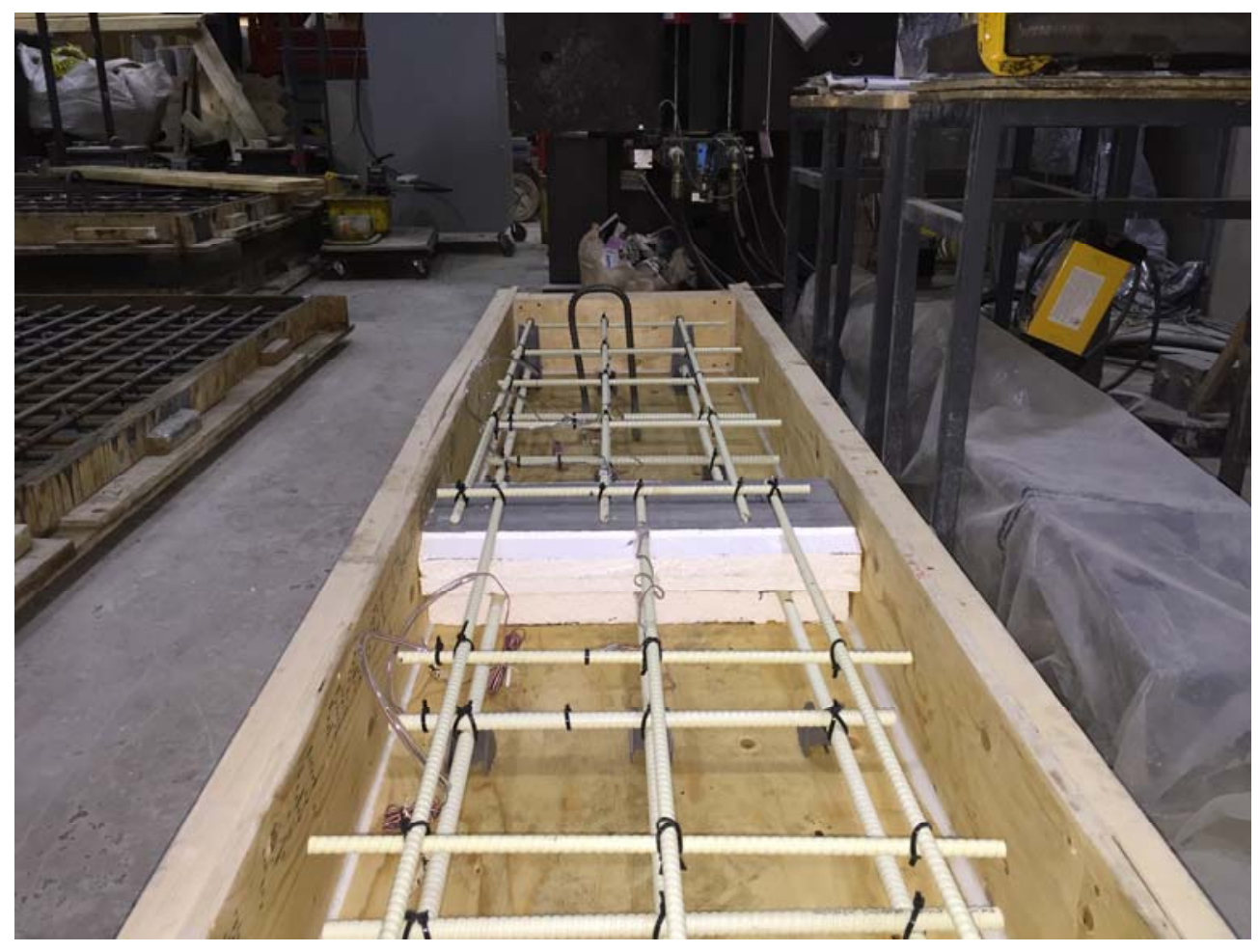

Figure 3.28 View of the joint foam and bars for the slab with $50 \mathrm{~mm}$ spliced bar offset 


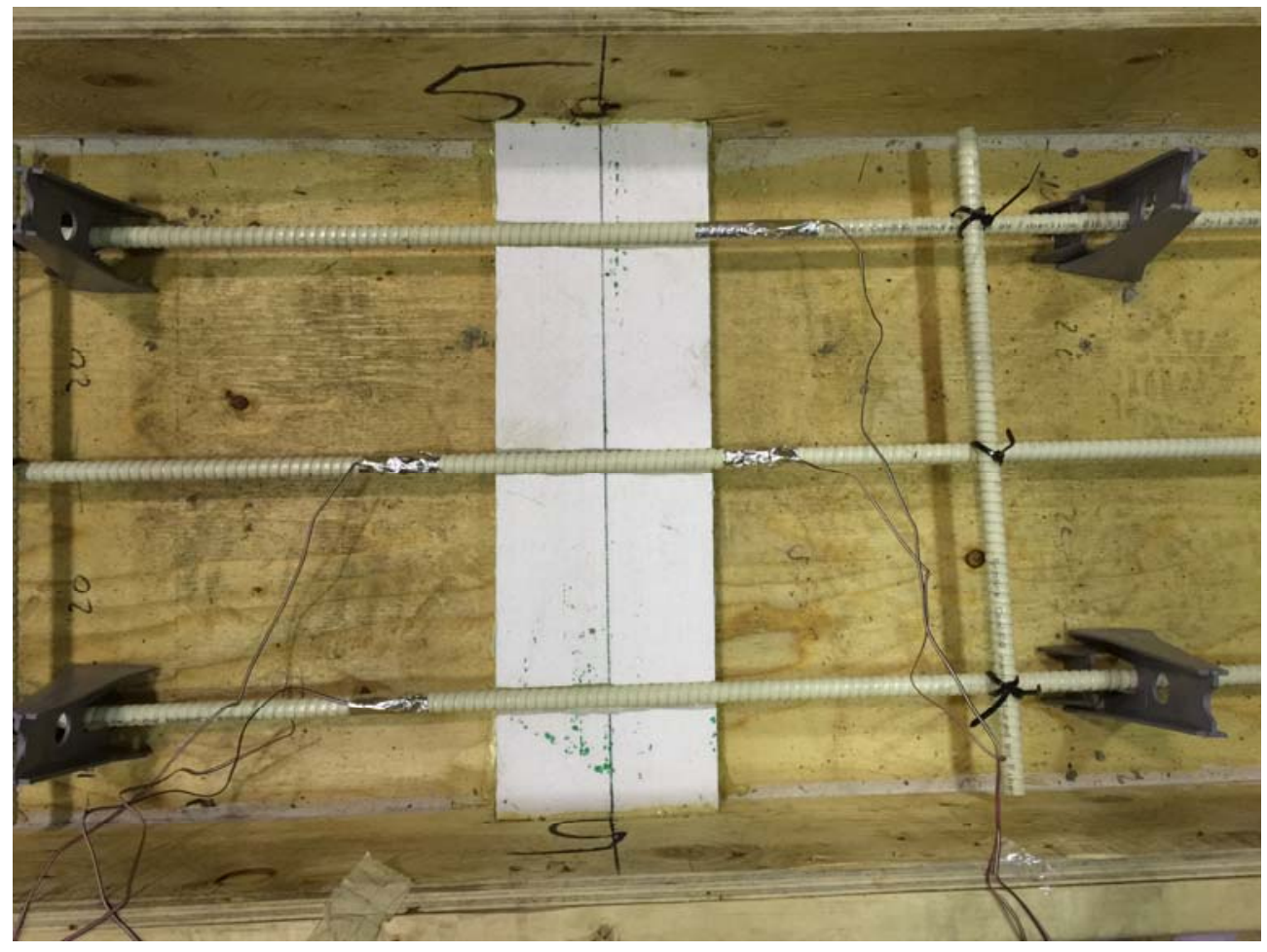

Figure 3.29 View of the bottom layer of the joint foam for slab $\mathrm{S}_{3}$ with GFRP bars

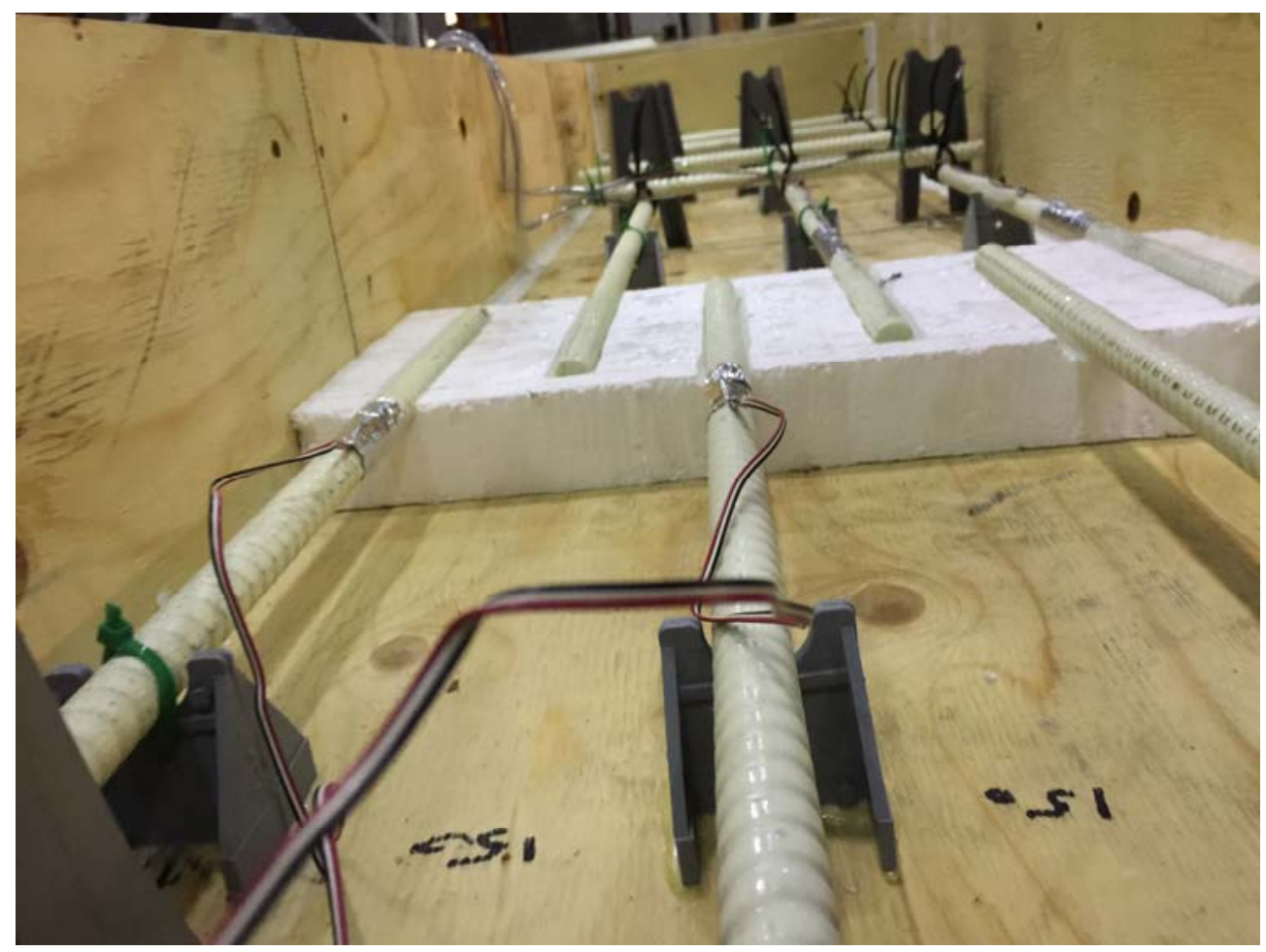

Figure 3.30 View of the bottom layer of the joint foam for slab with equal spliced bars 


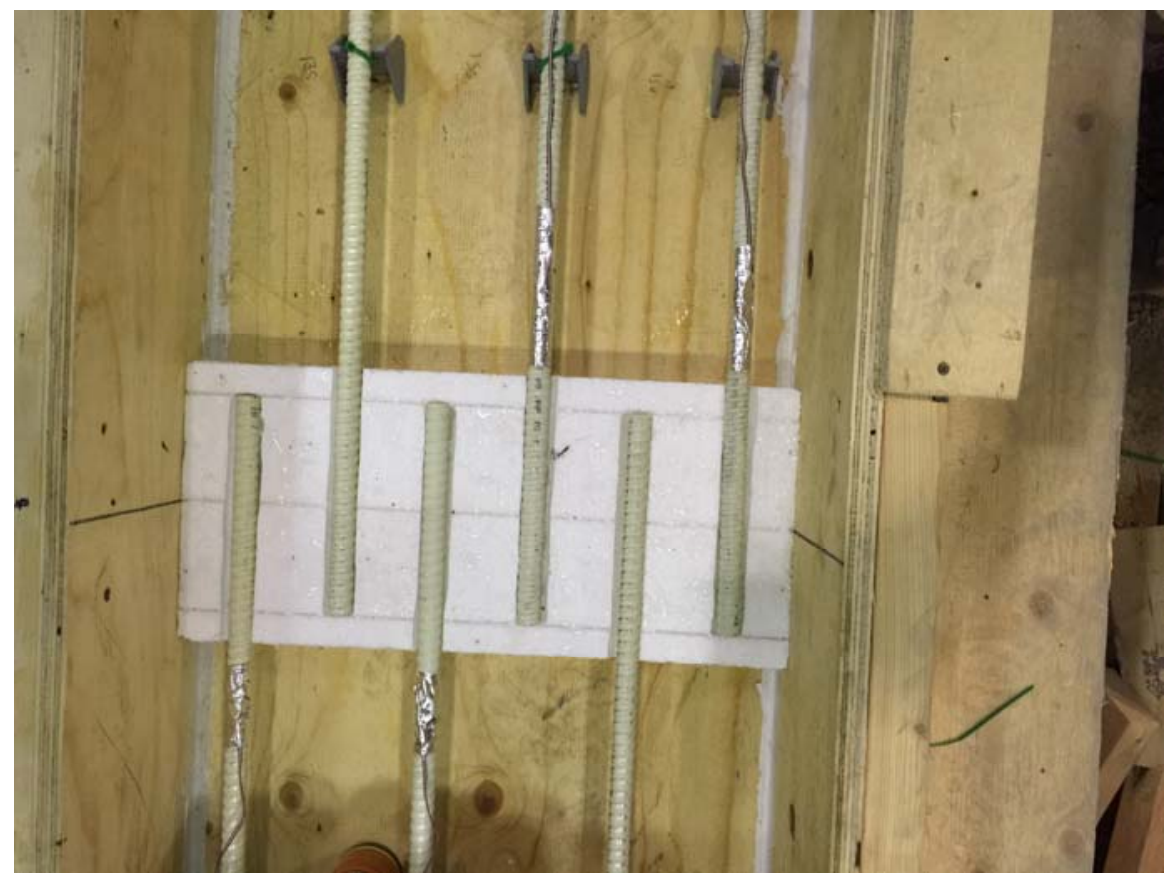

Figure 3.31 View of the bottom layer of the joint foam with the slab equally spliced

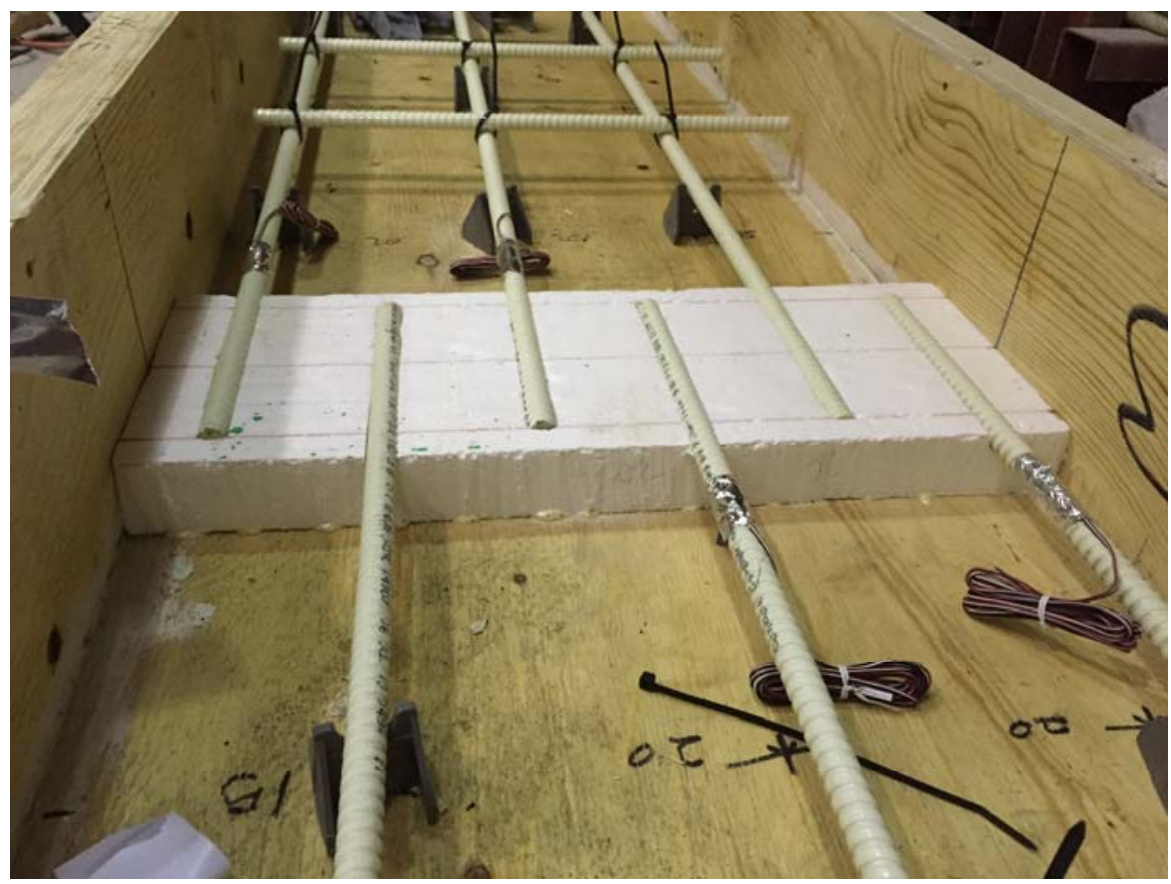

Figure 3.32 View of the bottom layer of the joint foam for slab with equally spliced bar 


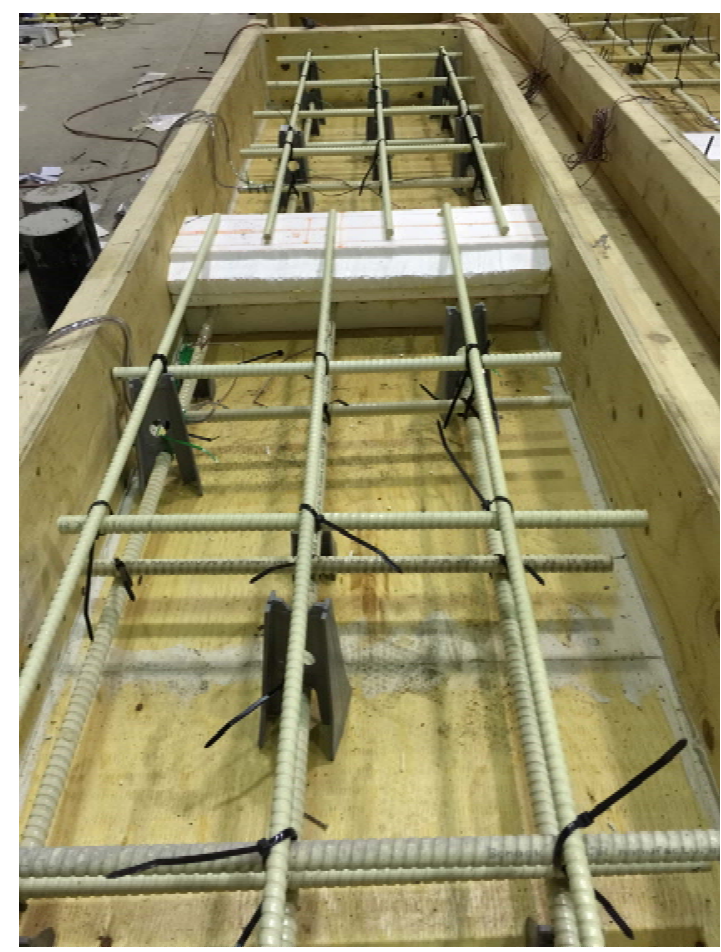

Figure 3.33 View of the joint foam for the slab with equally spliced bars

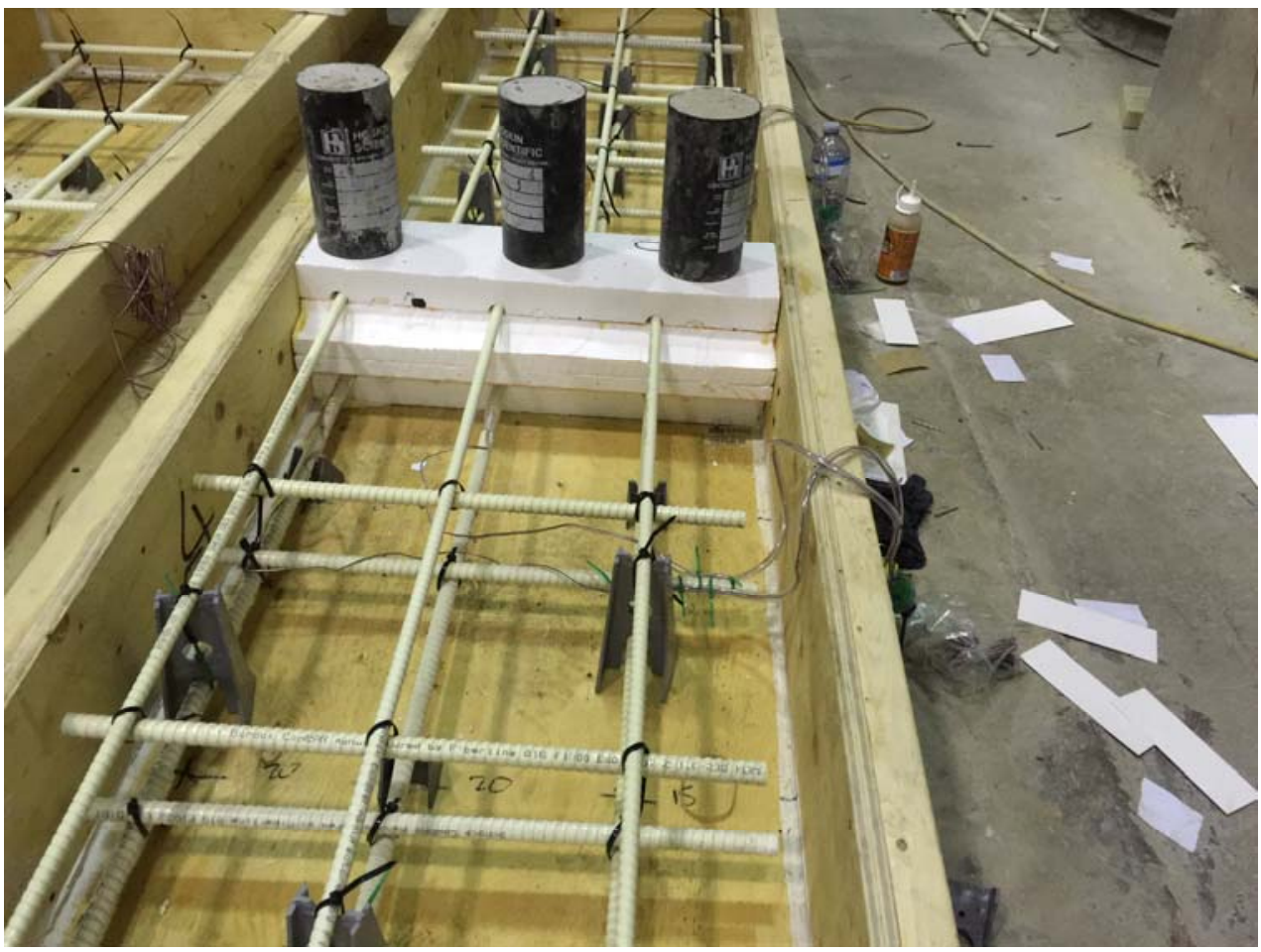

Figure 3.34 View of the joint foam where all layers of foam were placed and weight placed on top of the joint to fix it in position till the glue hardened 


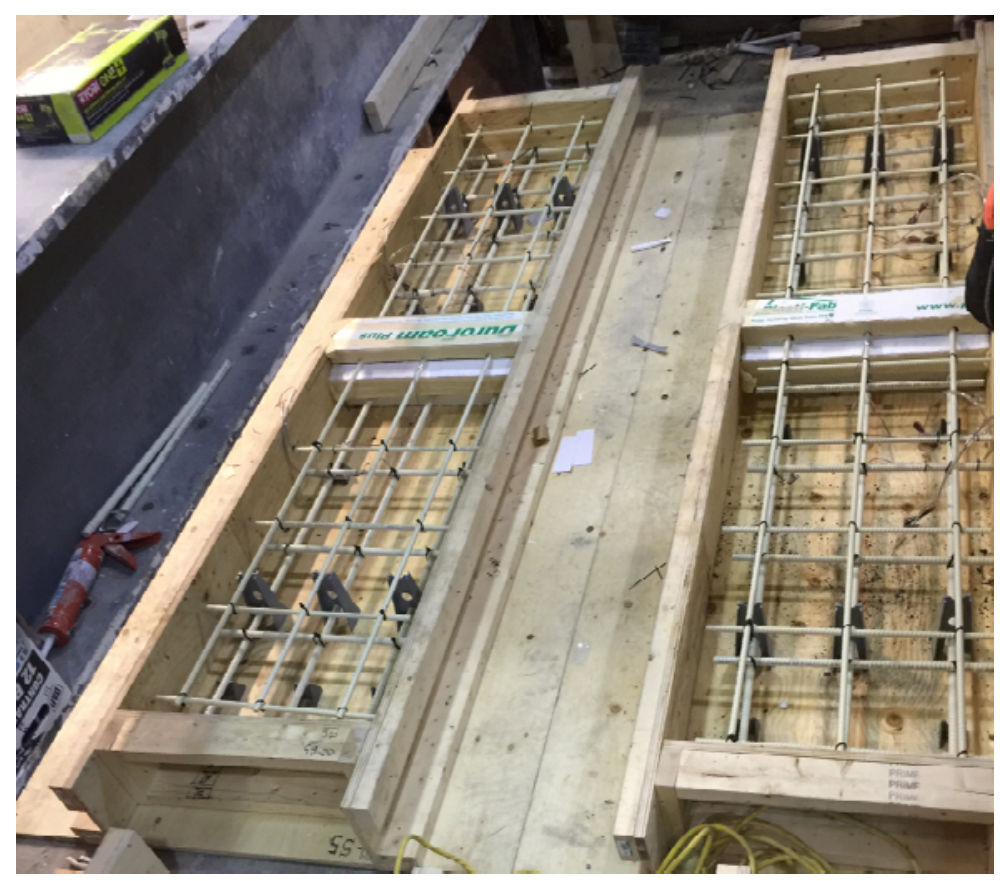

Figure 3.35 View of slabs $\mathrm{S}_{4}$ and $\mathrm{S}_{5}$ with bar-contacted splice connection before casting

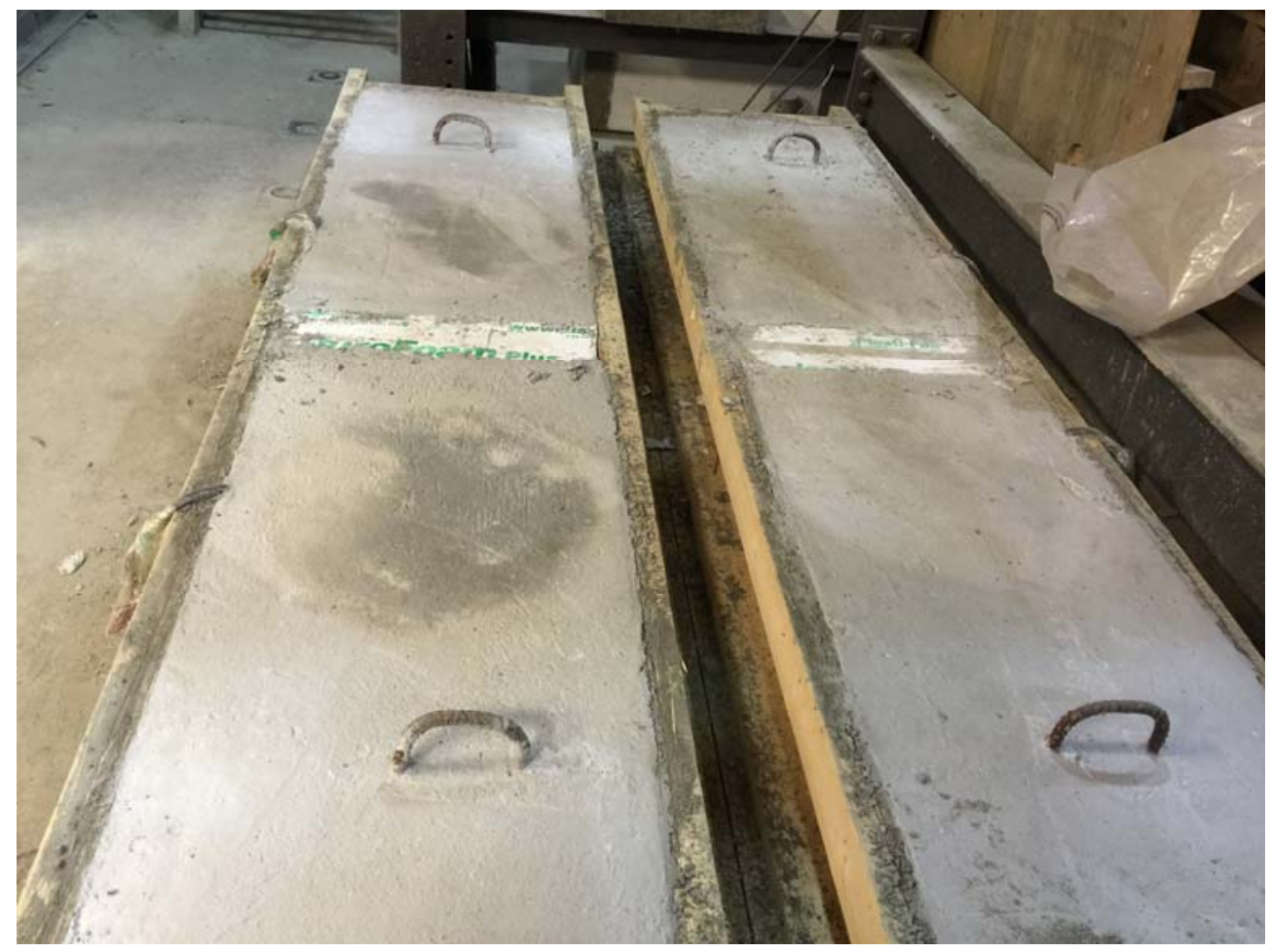

Figure 3.36 View of slabs after concrete casting 


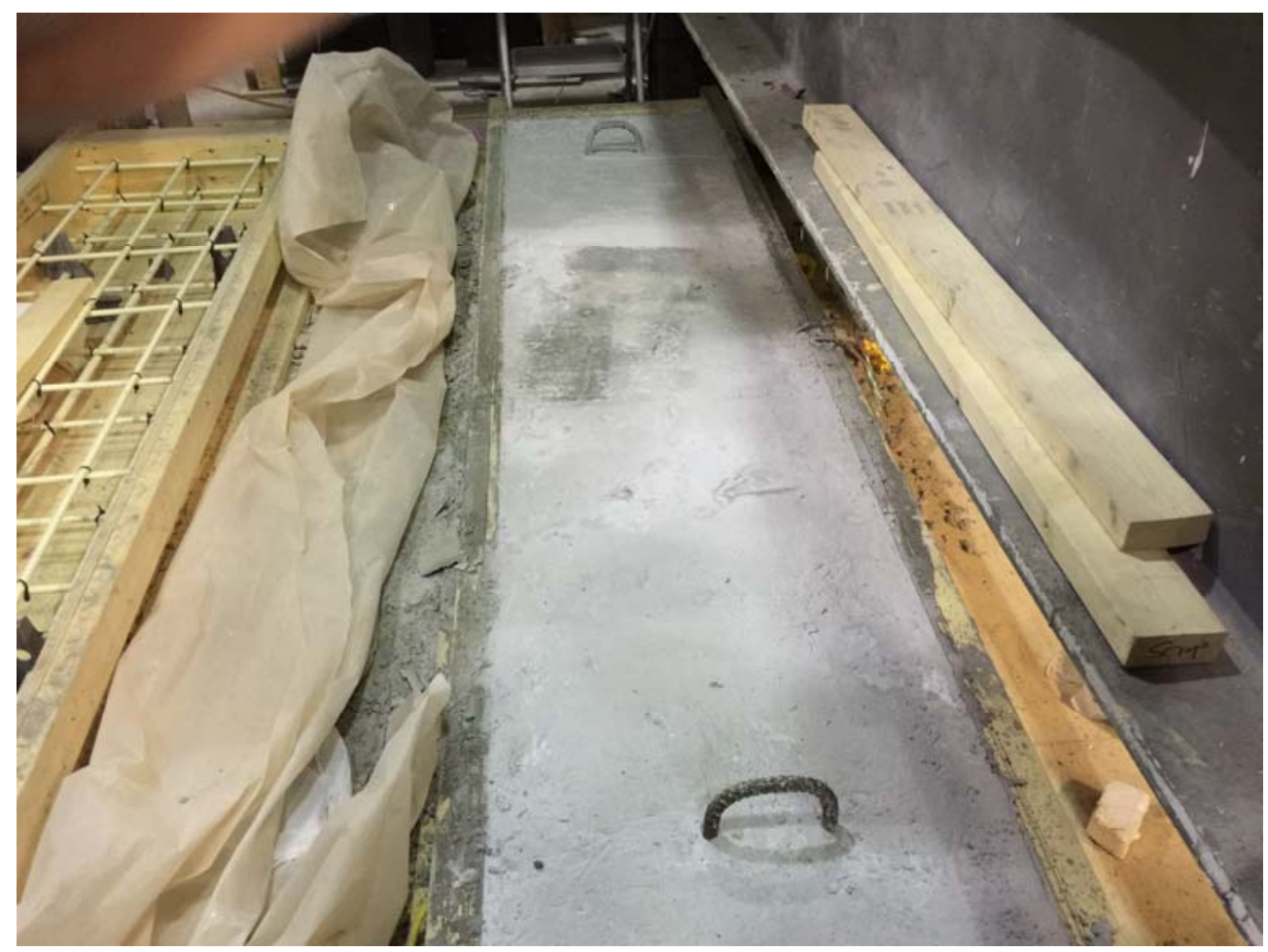

Figure 3.37 View of slab $\mathrm{S}_{1}$ after concrete casting

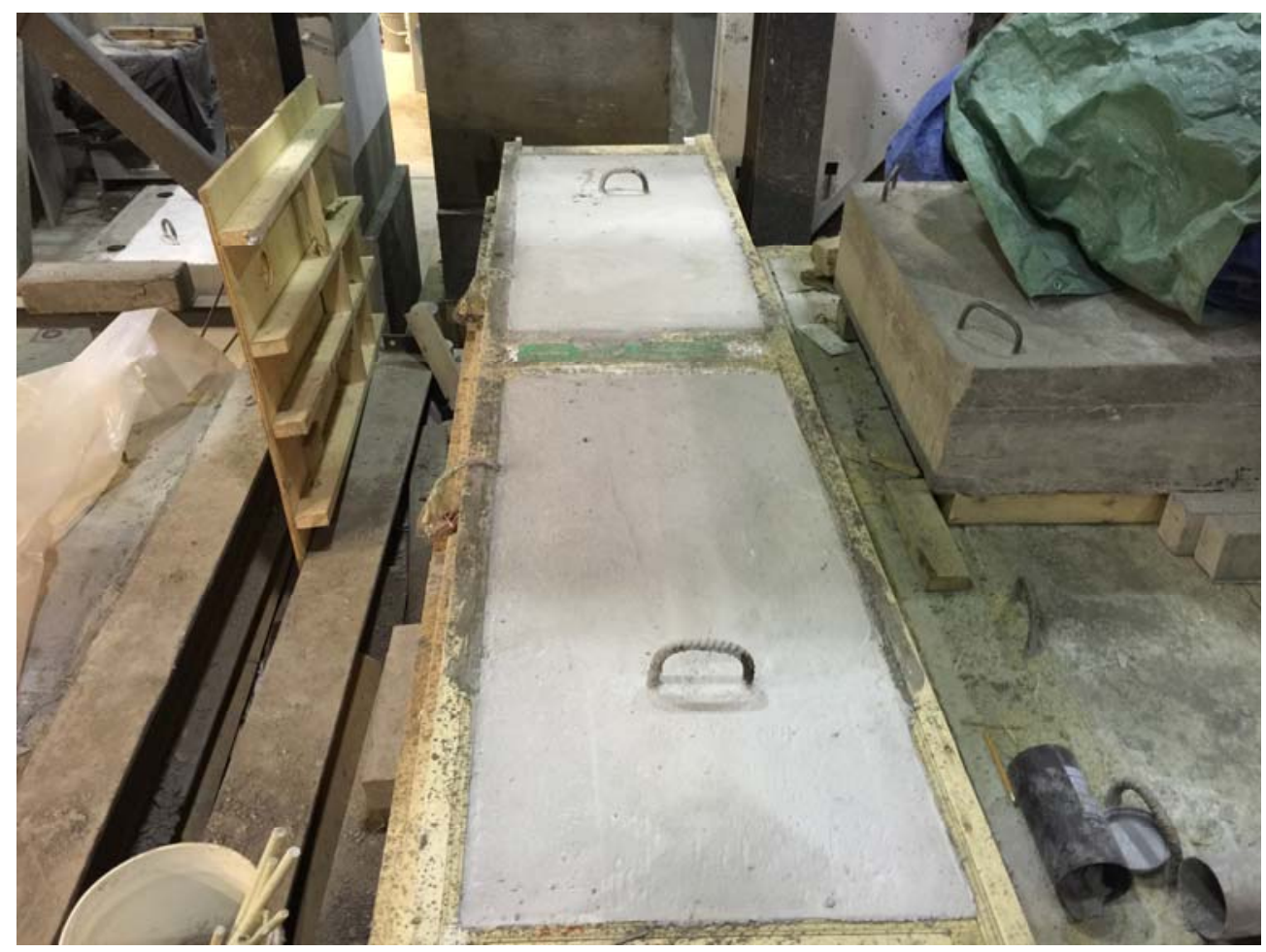

Figure 3.38 View of slab after concrete casting showing the foam for the joint at the mid-span 


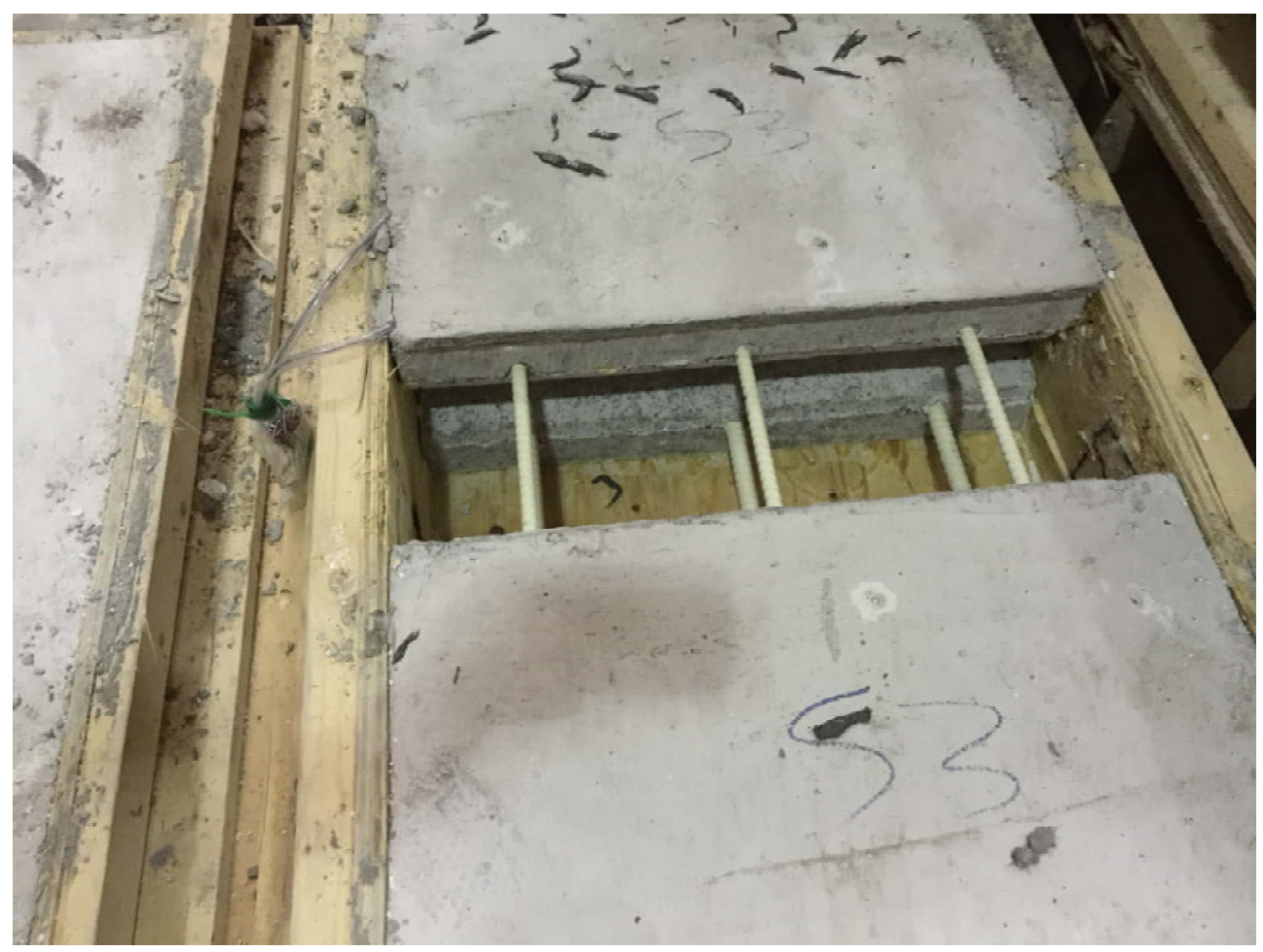

Figure 3.39 View of slab $\mathrm{S}_{3}$ after removing the Styrofoam from the joint

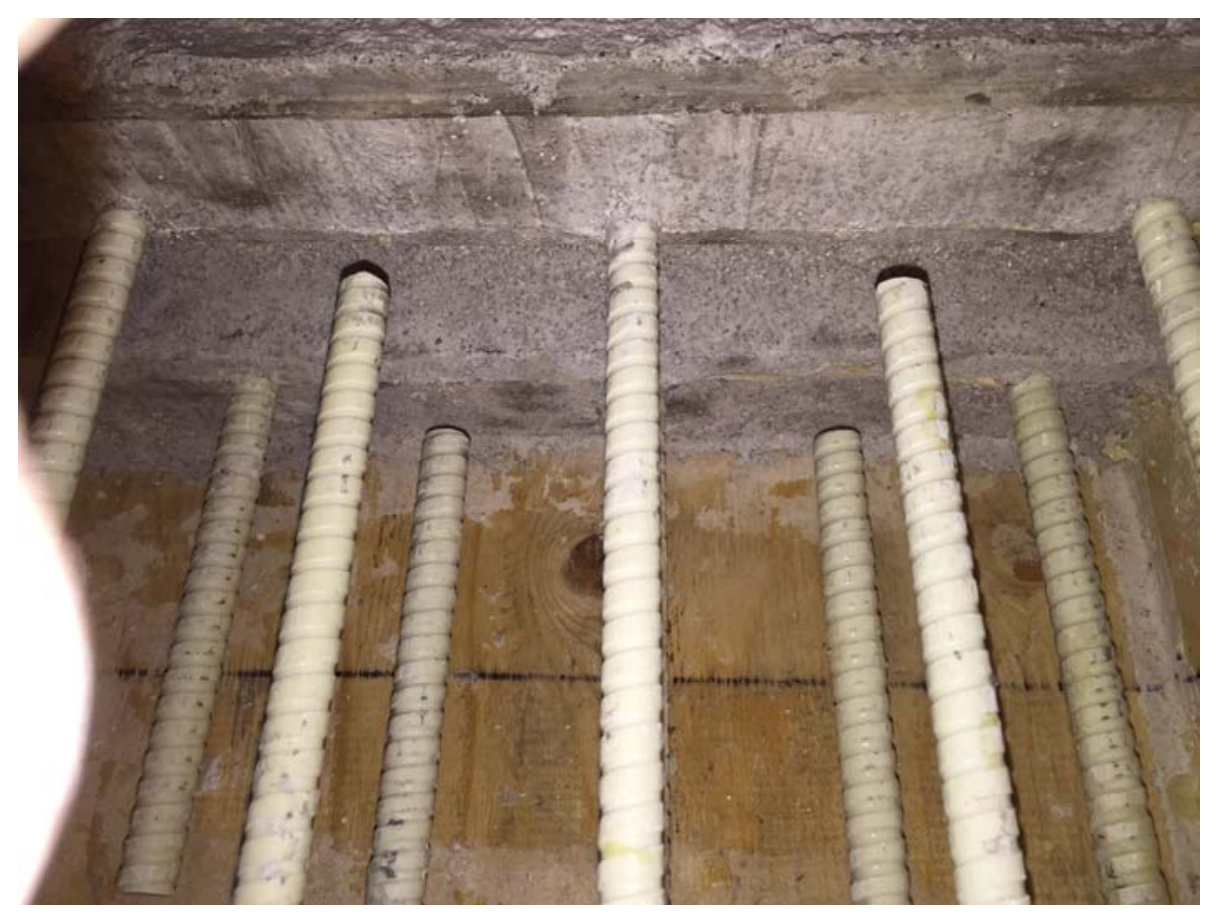

Figure 3.40 View of a cleaned joint after removing the Styrofoam in the joint 


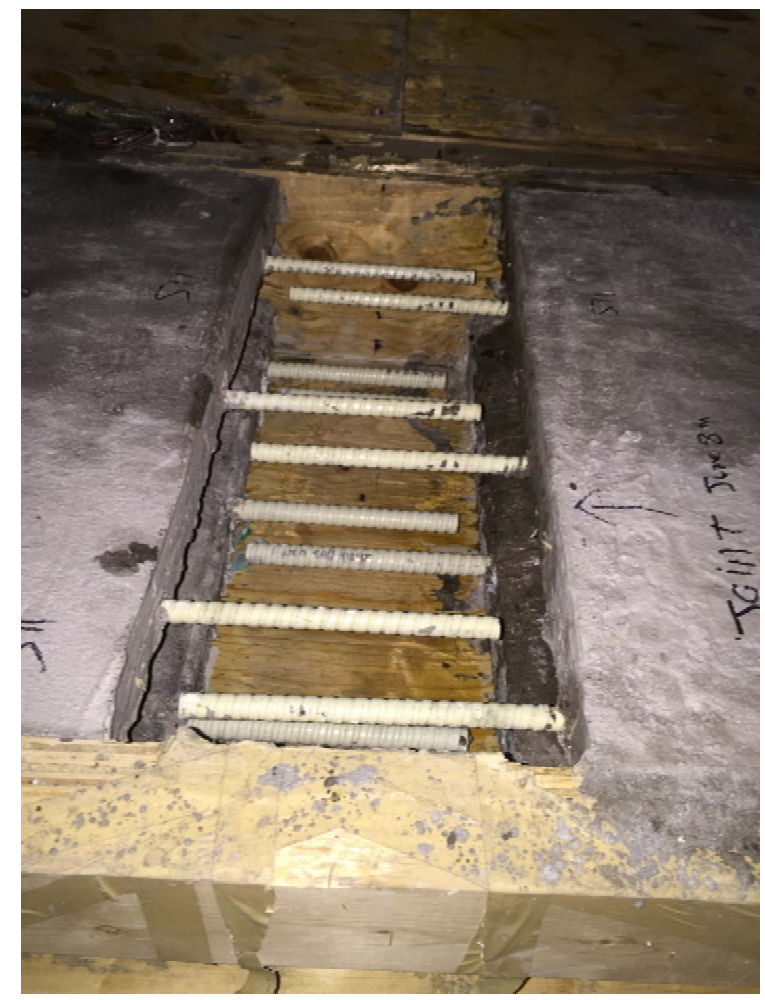

Figure 3.41 view of slab $\mathrm{S}_{11}$ with $50 \mathrm{~mm}$ bar offset after removing the Styrofoam in the joint

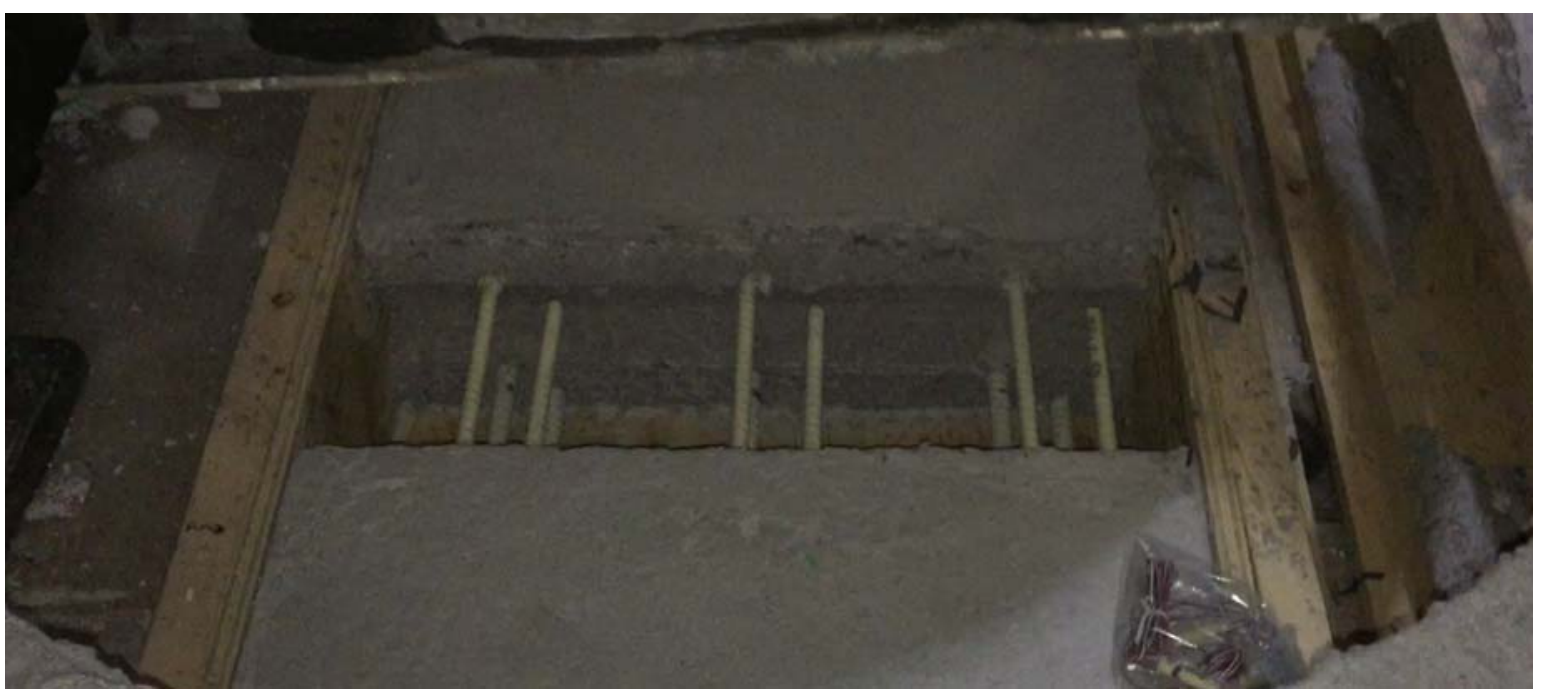

Figure 3.42 View of the joint with $50 \mathrm{~mm}$ bar offset after removing the Styrofoam 


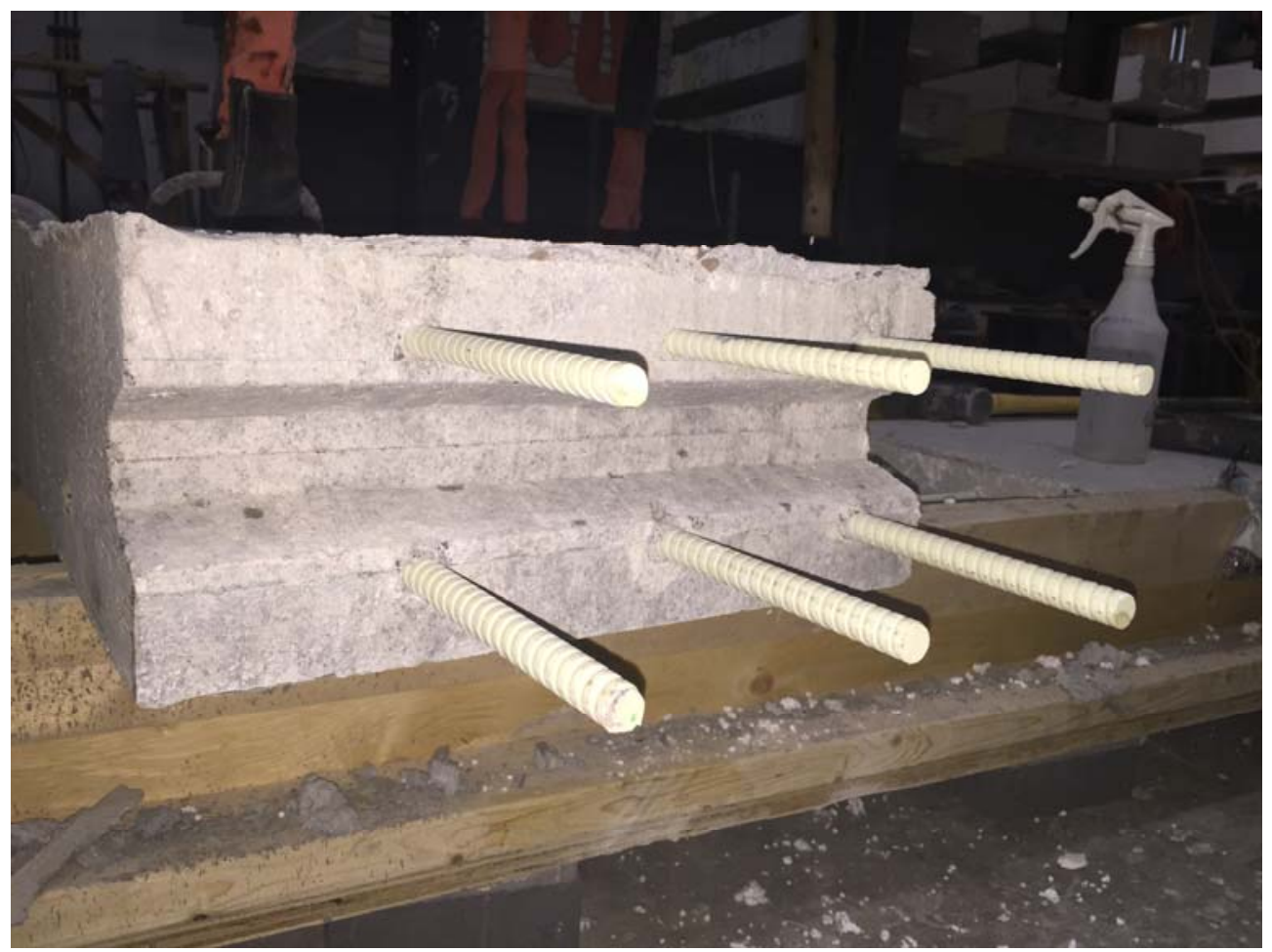

Figure 3.43 View of the shear key with projecting bars

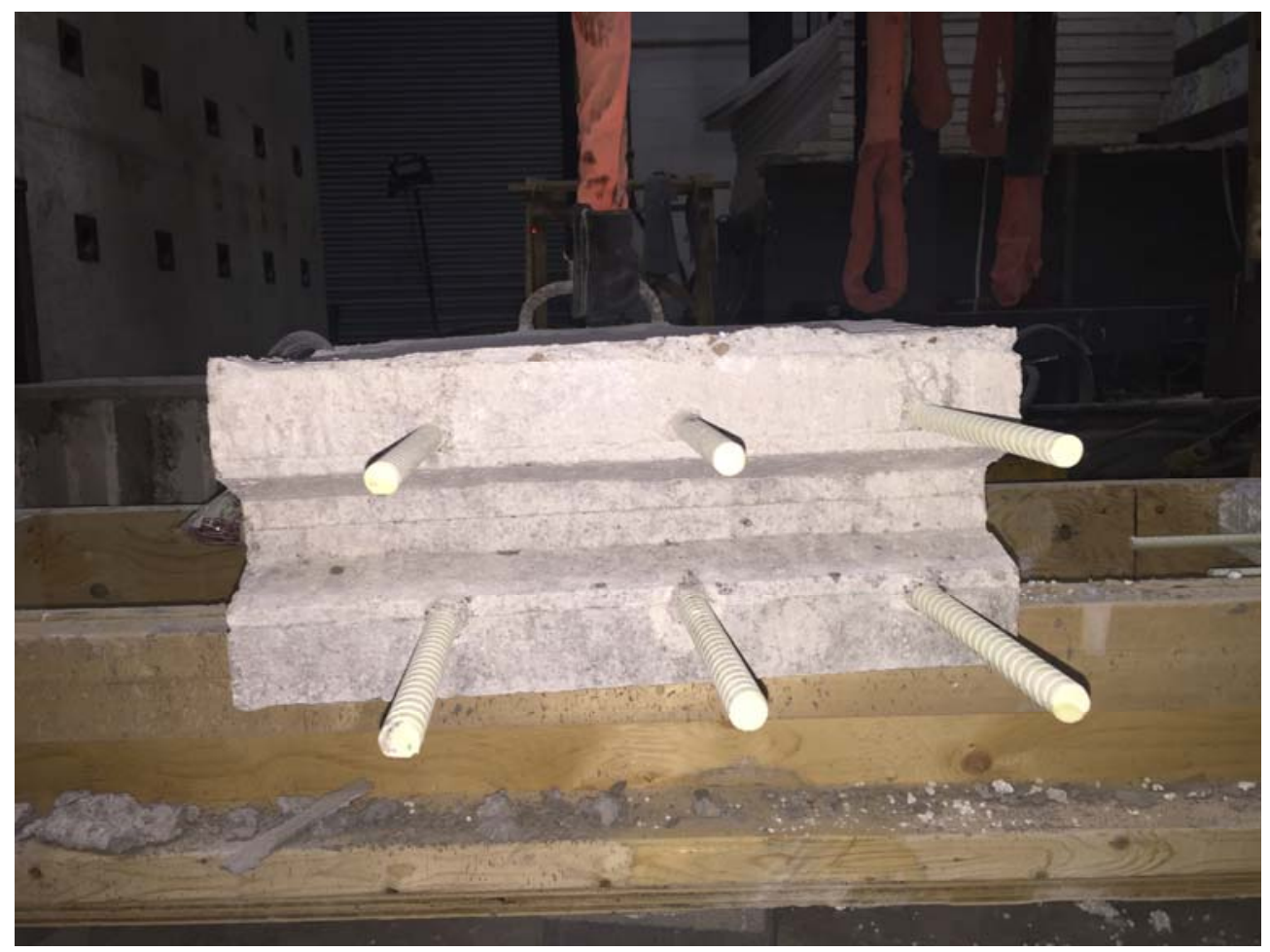

Figure 3.44 Front view of the shear key with projected GFRP bars 


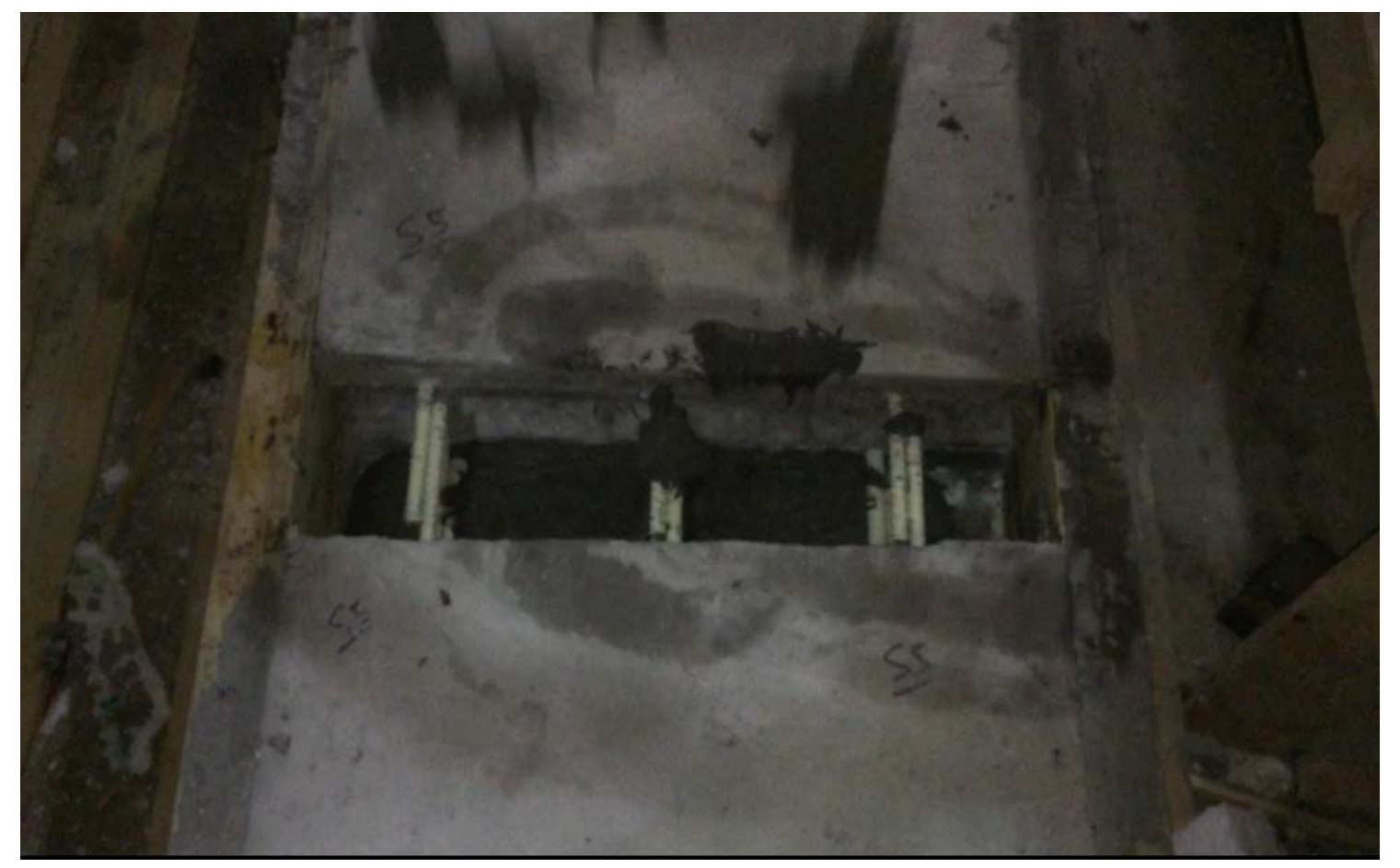

Figure 3.45 View of the joint in slab $\mathrm{S}_{5}$ with contact lap splice during casting the UHPFRC

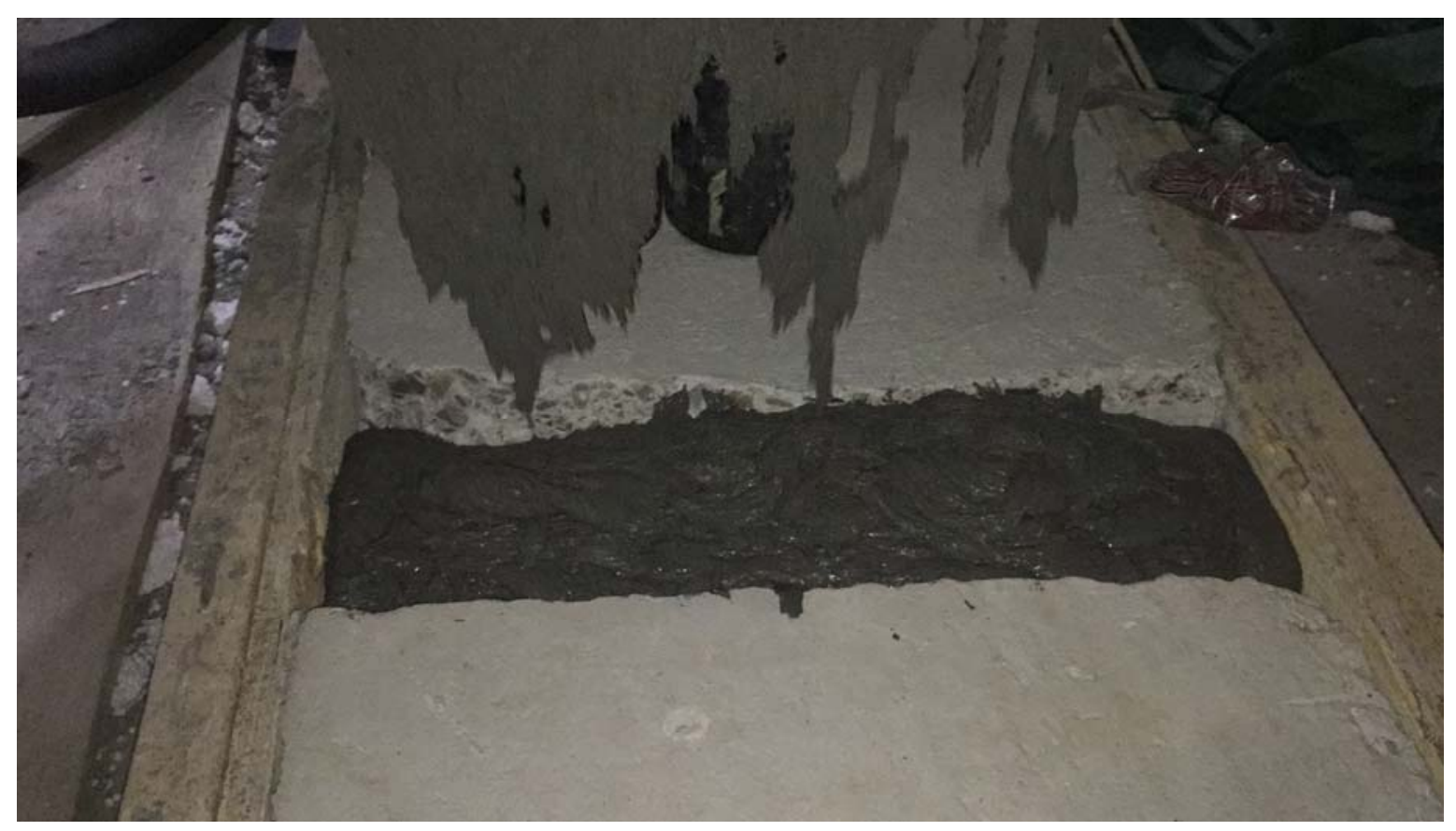

Figure 3.46 View of a joint during casting the UHPFRC 


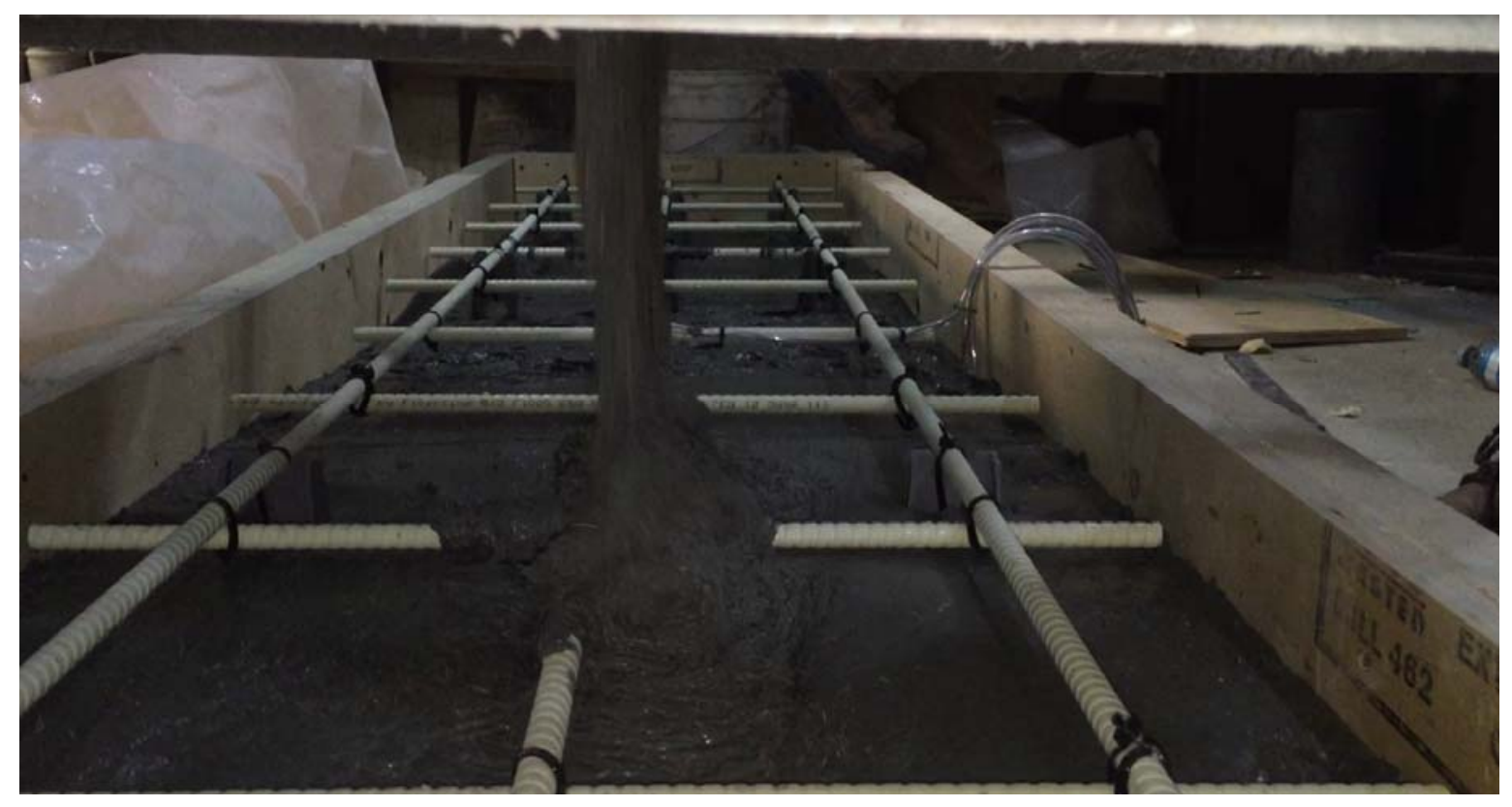

Figure 3.47 View of slab $\mathrm{S}_{2}$ during casting the UHPFRC

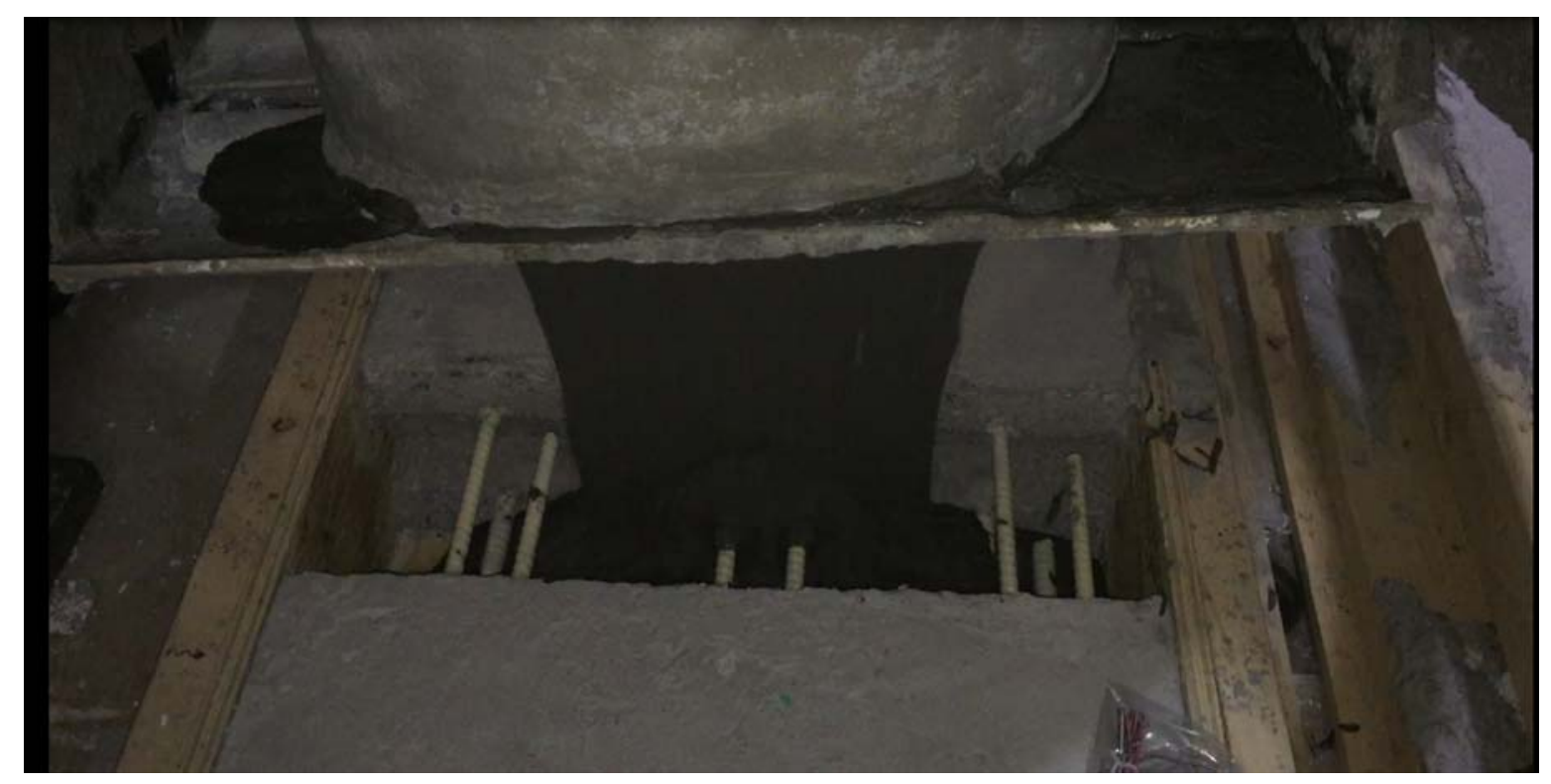

Figure 3.48 View of a $50 \mathrm{~mm}$ offset spliced joint during casting the UHPFRC 


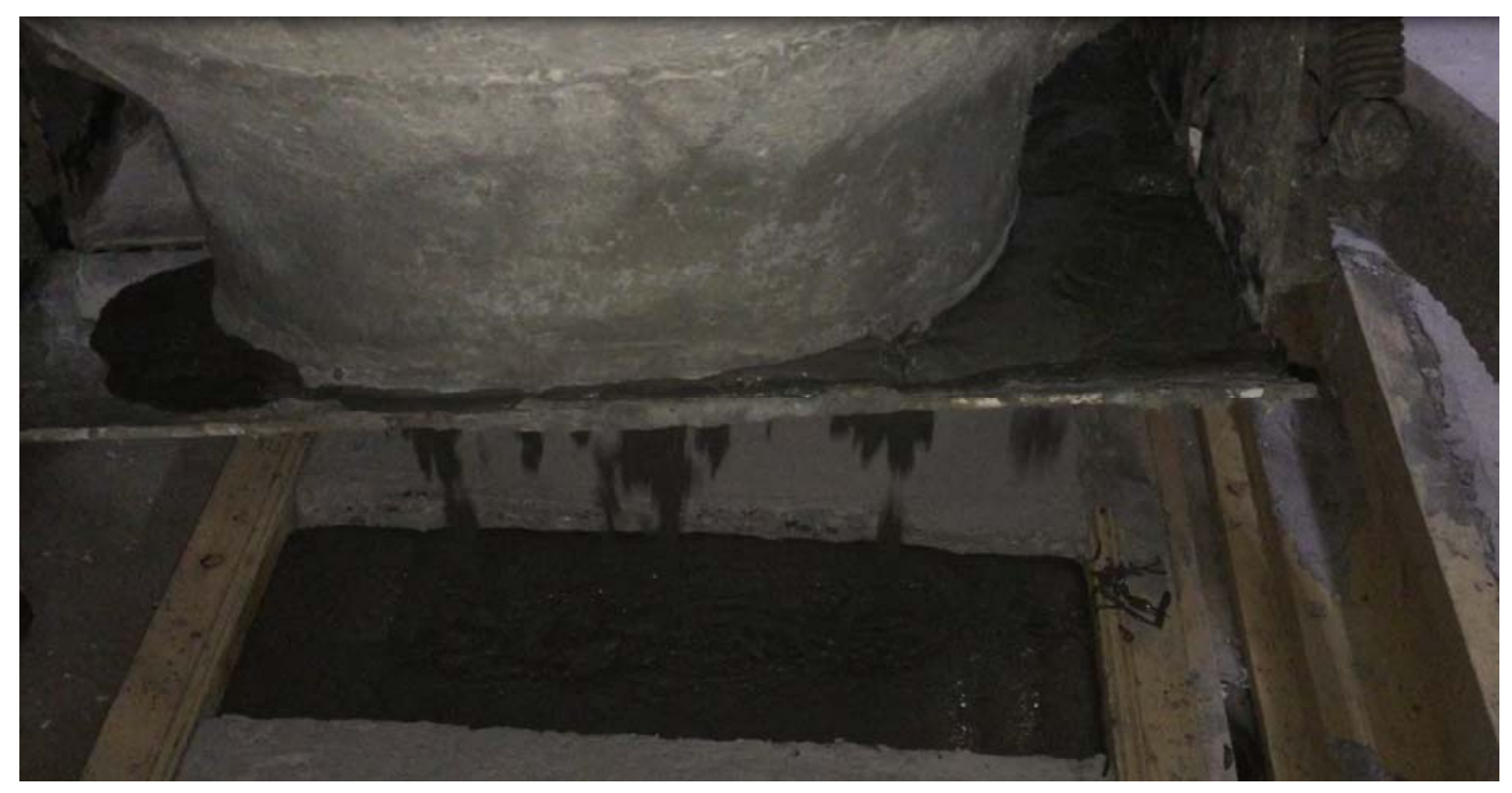

Figure 3.49 View of a $50 \mathrm{~mm}$ offset spliced joint during casting the UHPFRC

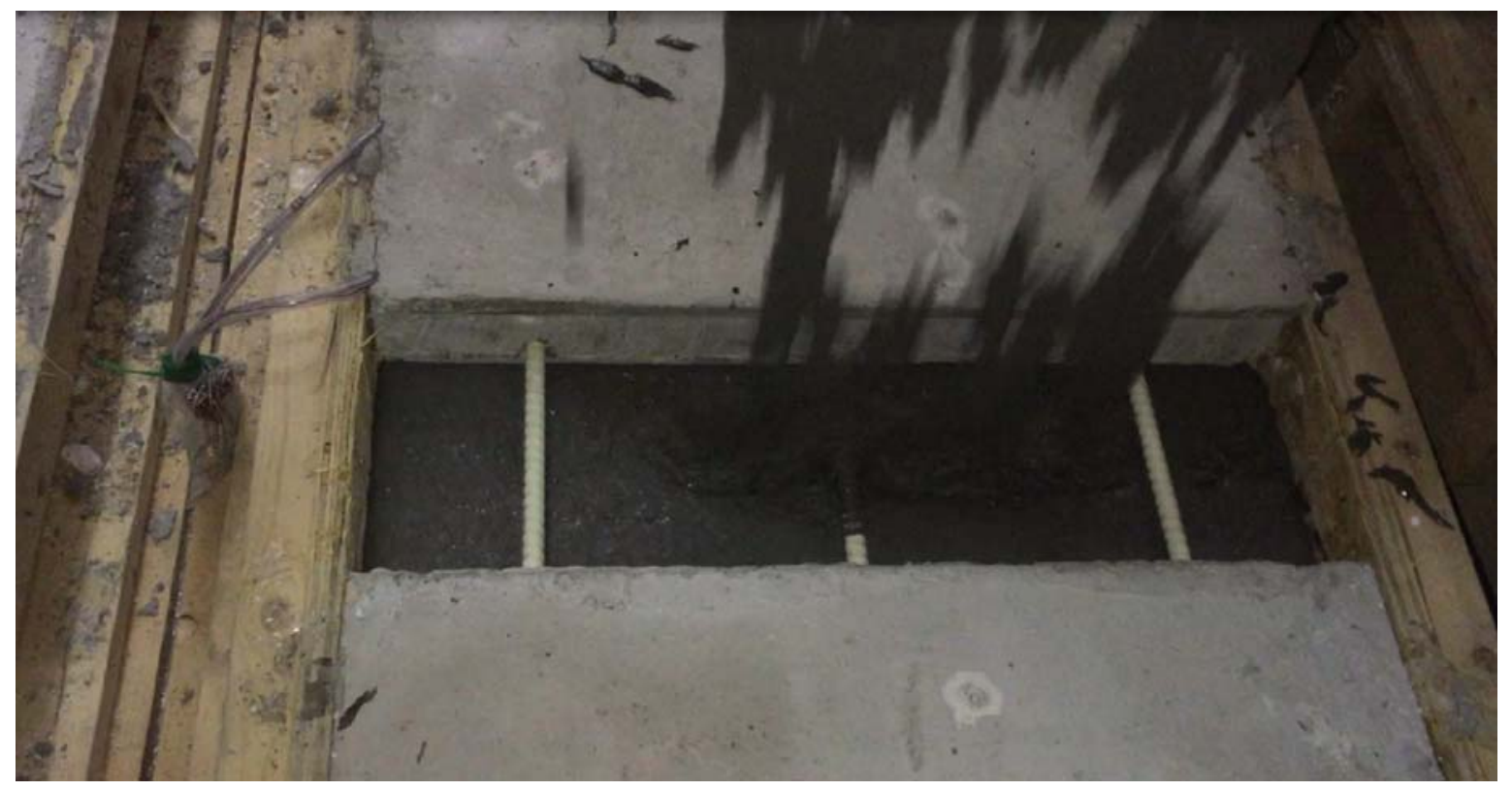

Figure $3.50 \mathrm{View}$ of the joint of slab $\mathrm{S}_{3}$ during casting the UHPFRC 


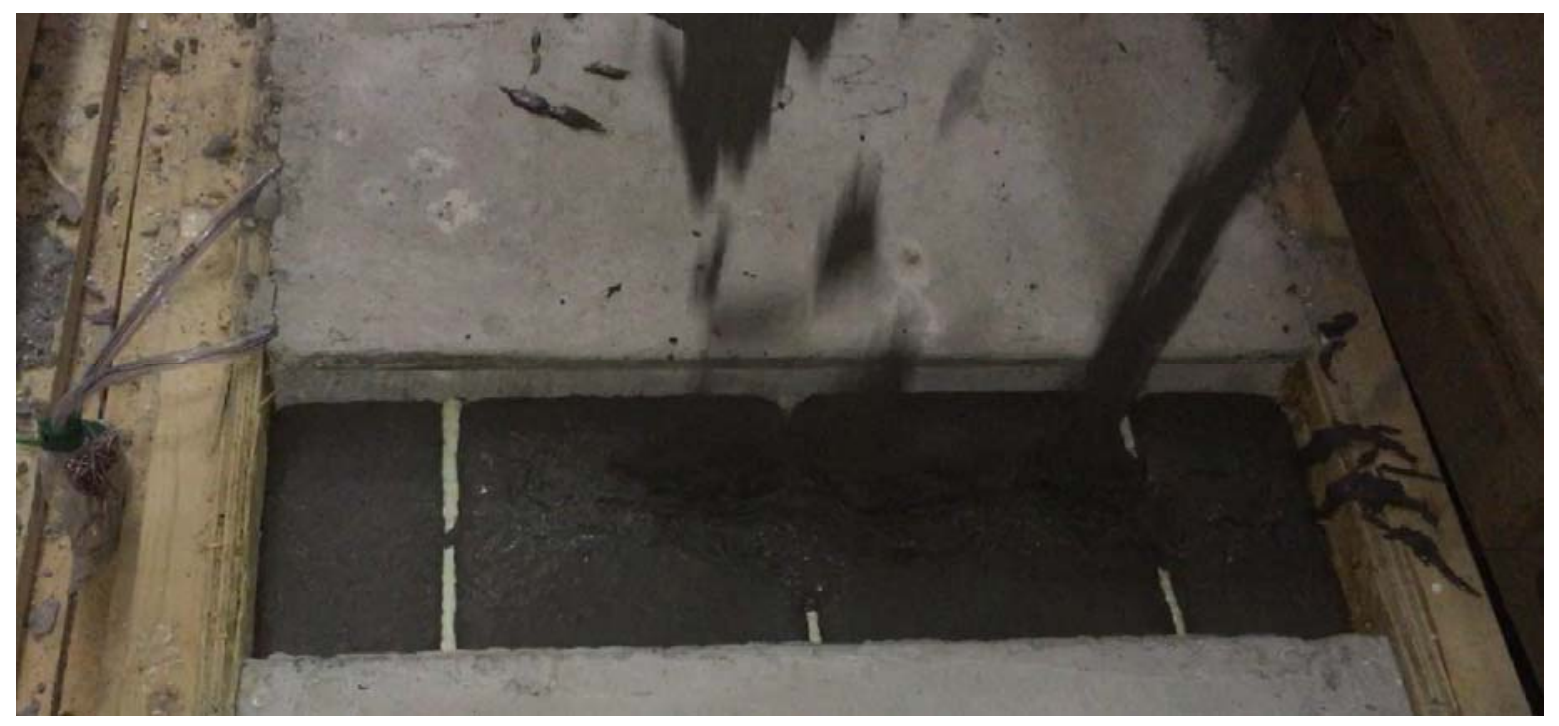

Figure 3.51 View of the joint of slab $\mathrm{S}_{3}$ during casting the UHPFRC

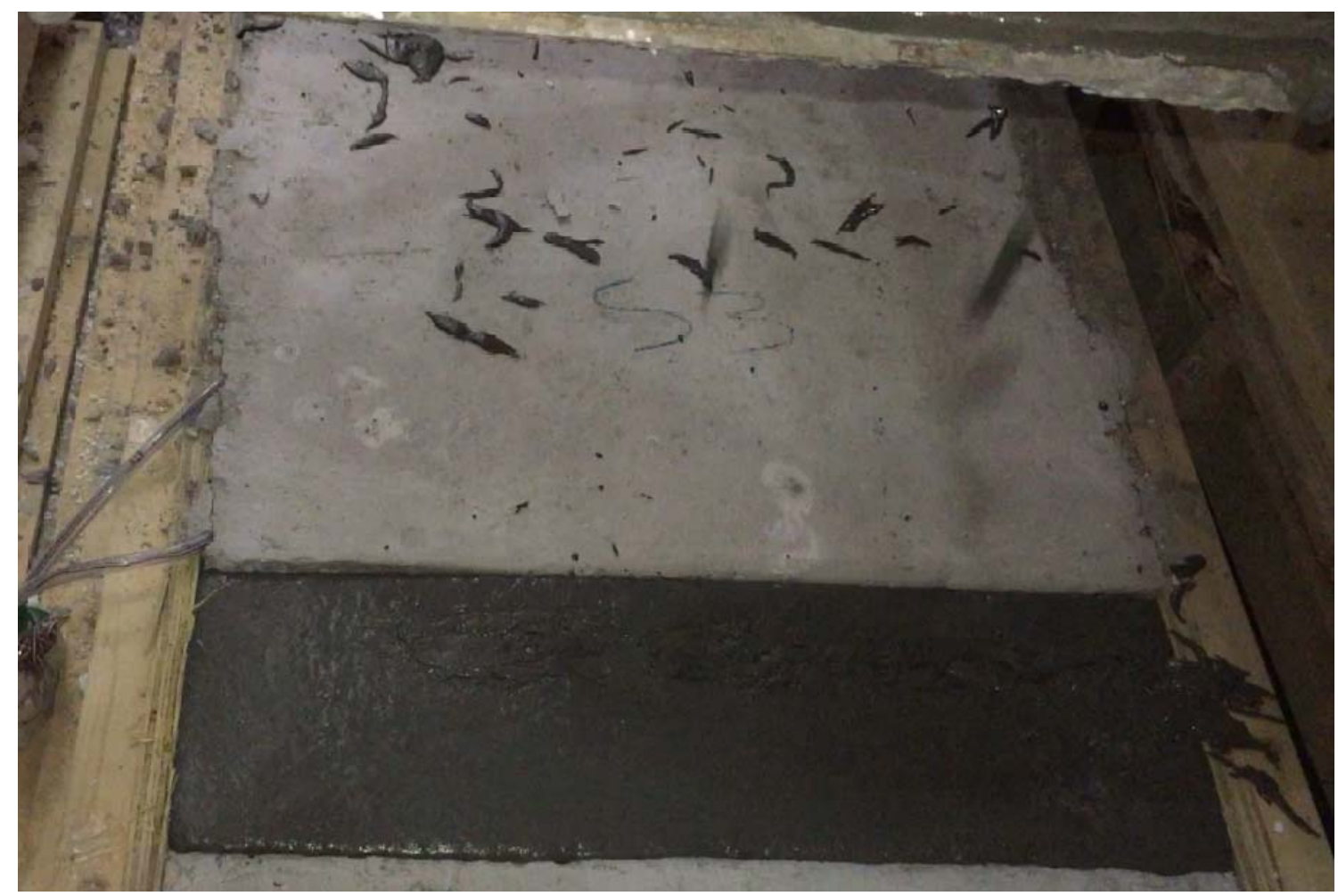

Figure 3.52 View of the joint of slab $\mathrm{S}_{3}$ during casting the UHPFRC 


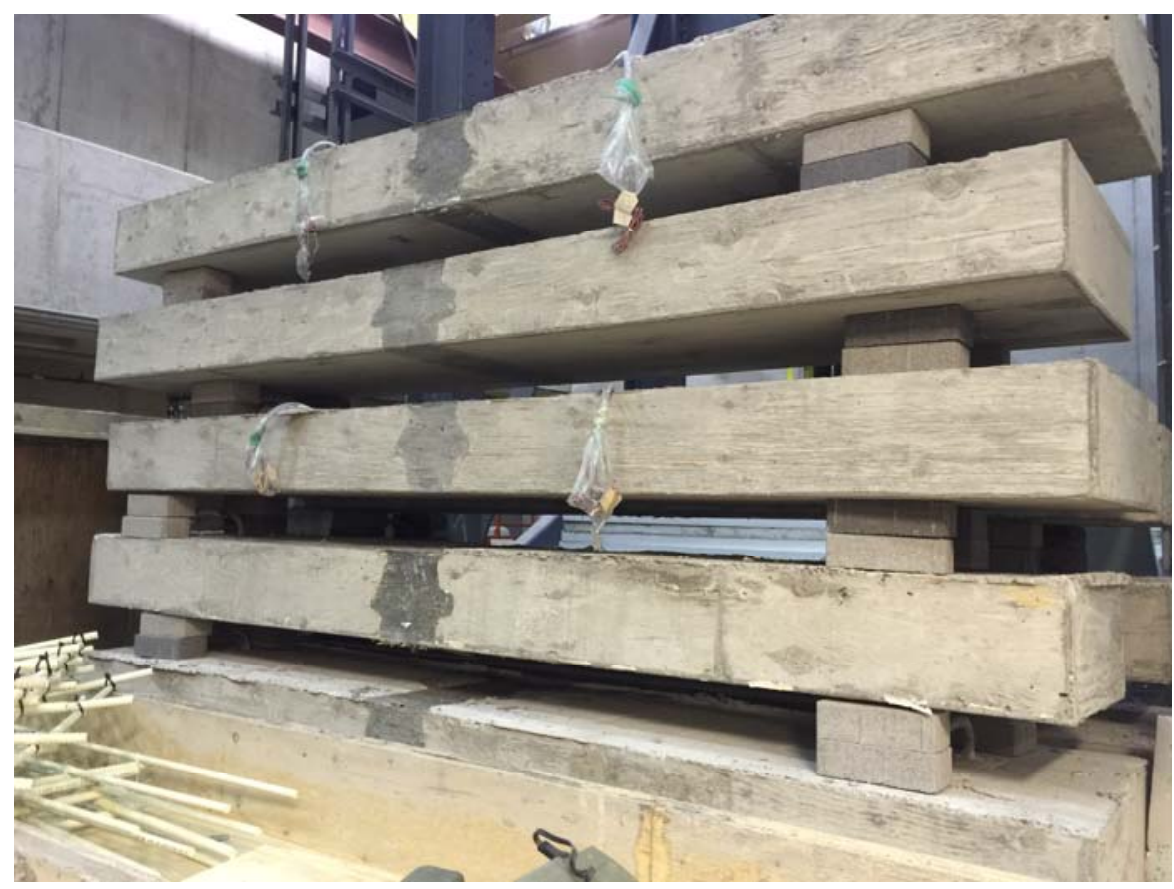

Figure 3.53 View of demolded slabs ready to be painted and for the application of concrete strain gauges 


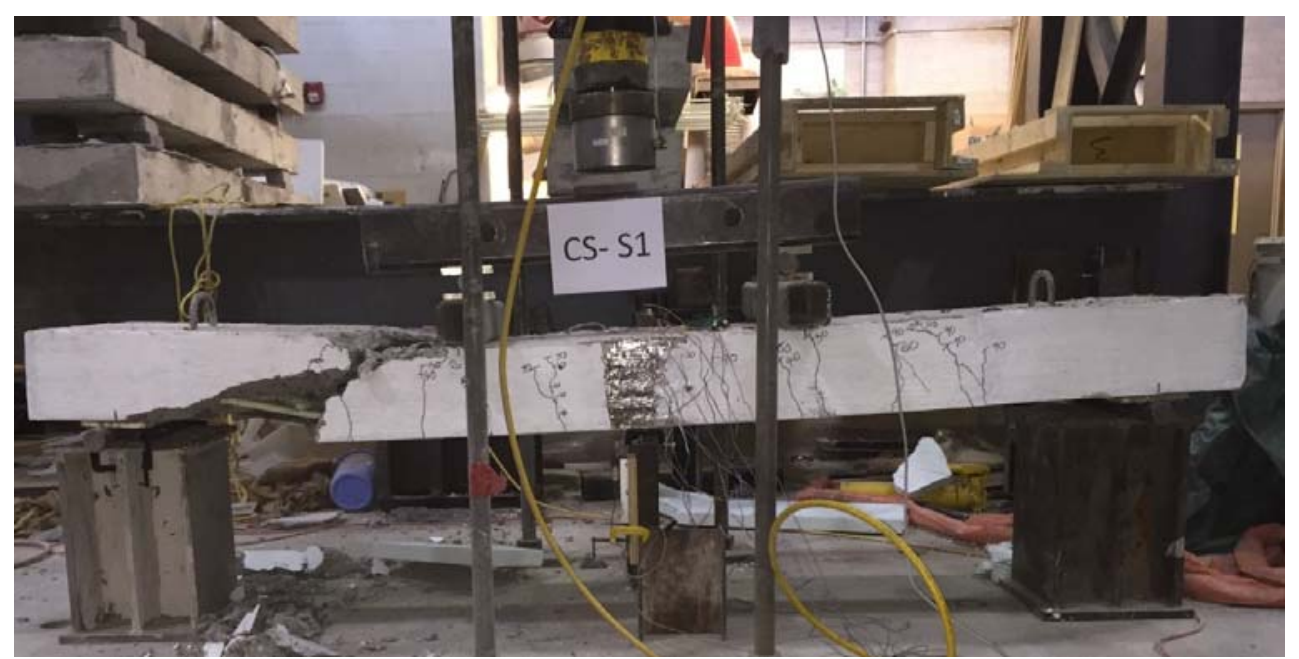

Figure 4.1 View of crack pattern of slab $\mathrm{S}_{1}$ after failure

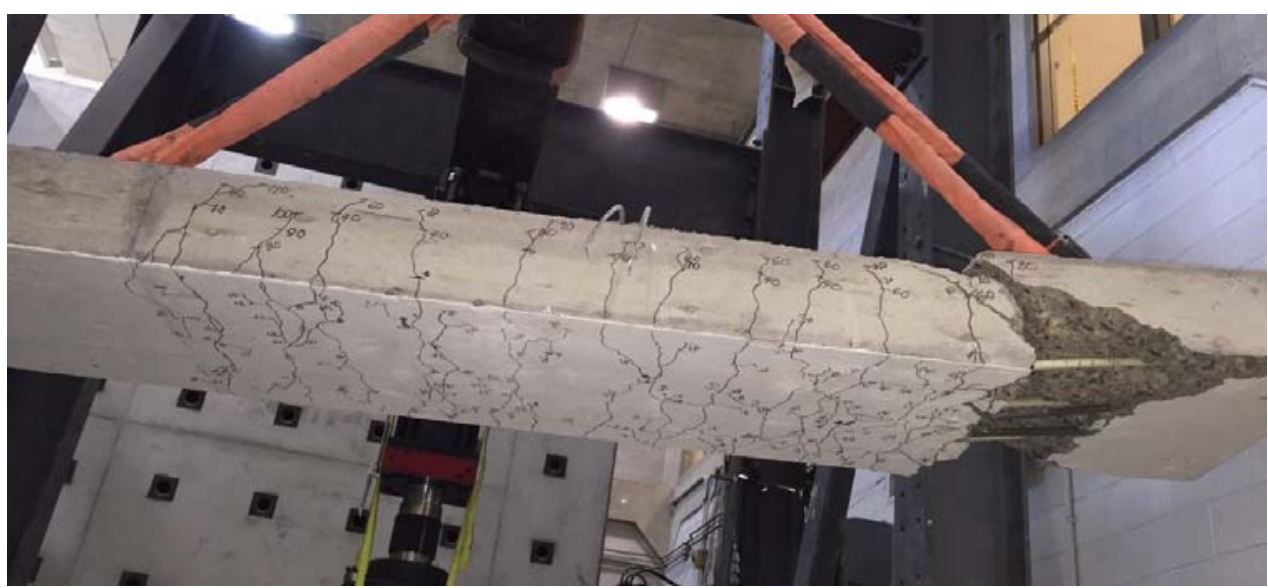

(a) View of the crack pattern at the bottom of slab $S_{1}$ after failure

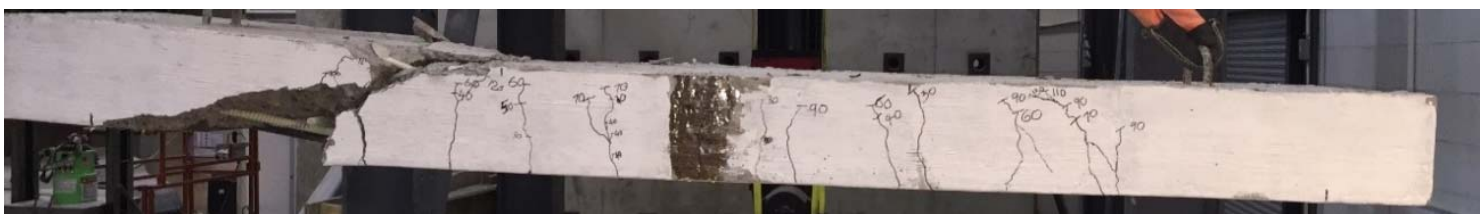

(a) Side 1

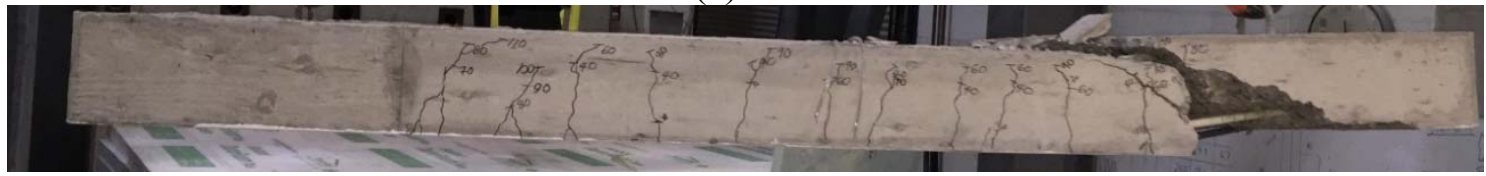

(b) Side 2

Figure 4.2 View of the crack pattern at the bottom and two sides of slab $\mathrm{S}_{1}$ 


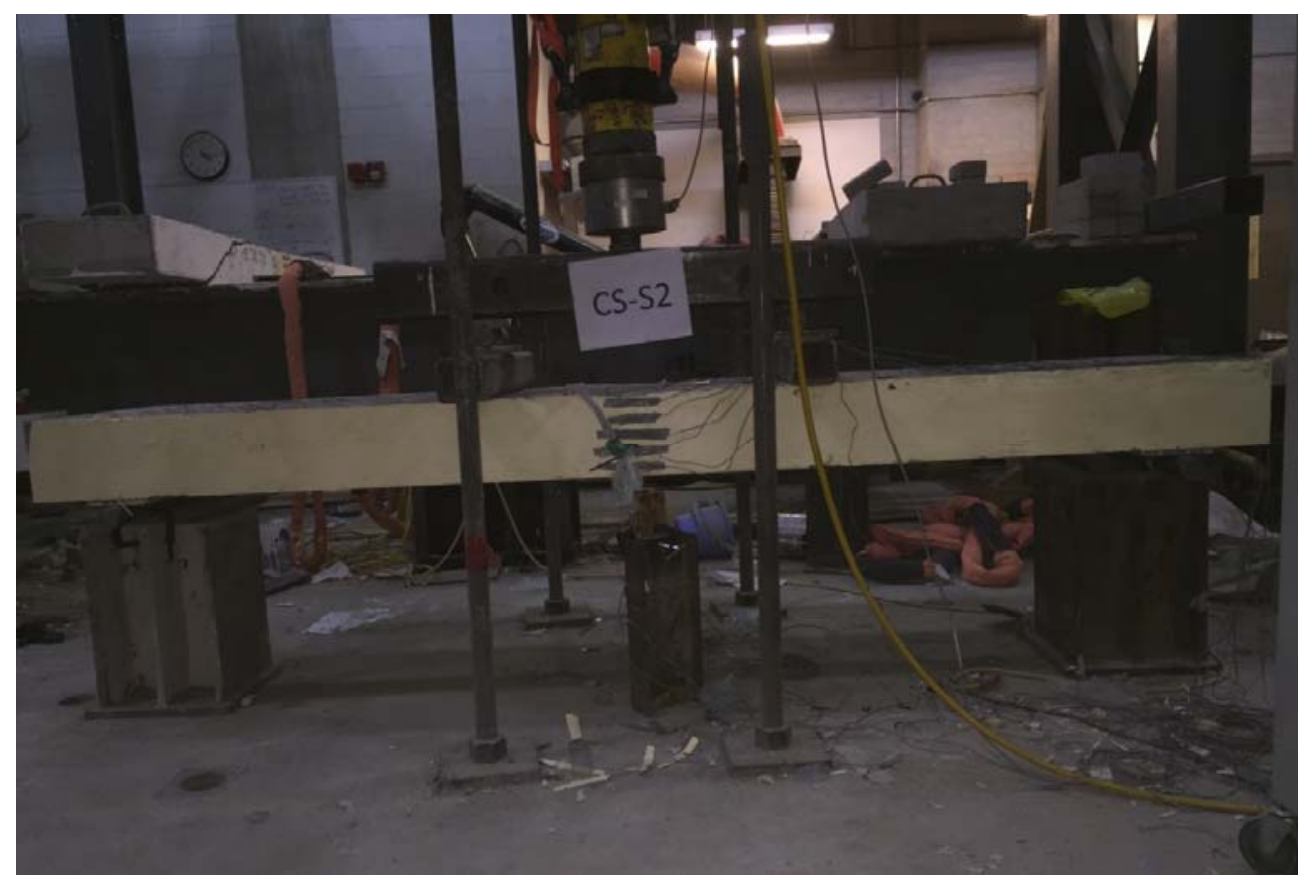

Figure 4.3 Test setup of slab S2 before testing

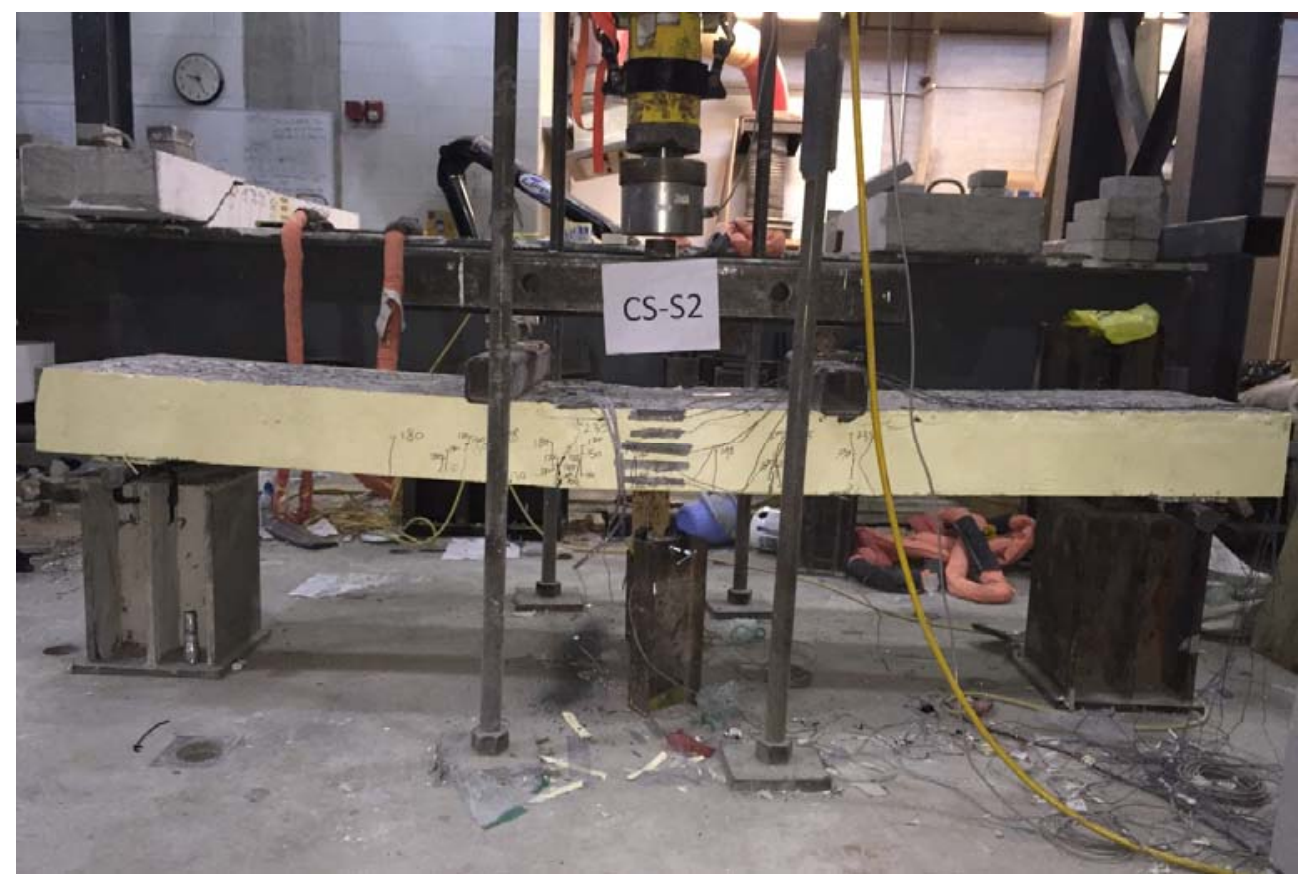

Figure 4.4 View of crack pattern of slab $\mathrm{S}_{2}$ after failure 




(a) View of the crack pattern at the bottom of slab $\mathrm{S}_{2}$

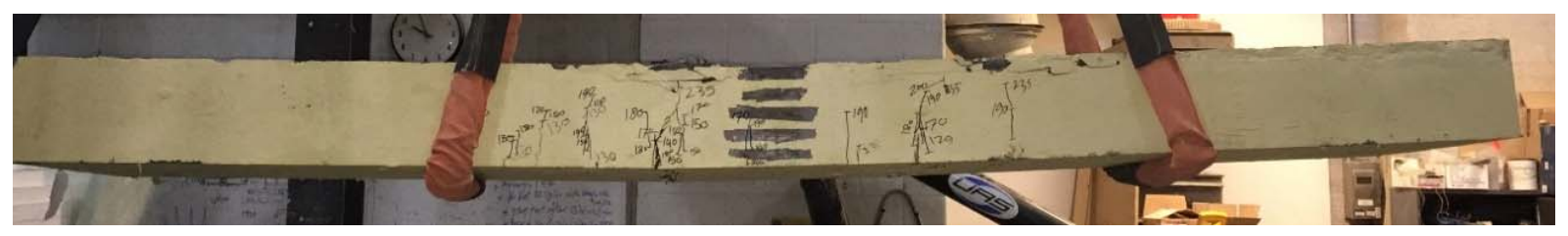

(b) Side 1

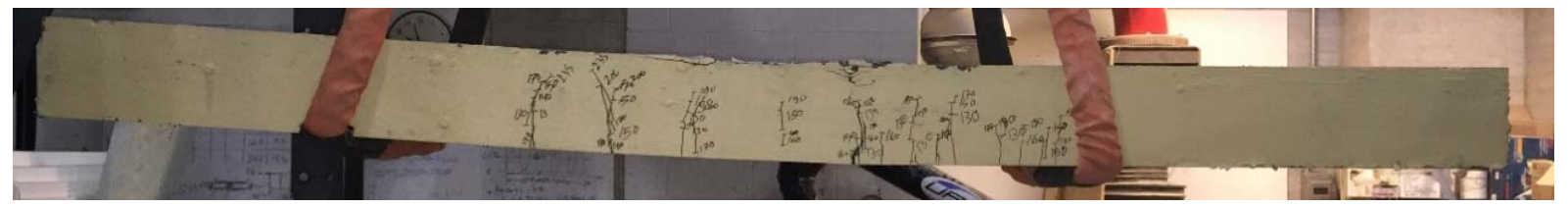

(c) Side 2

Figure 4.5 View of the crack pattern at the bottom and two sides of slab $\mathrm{S}_{2}$ 


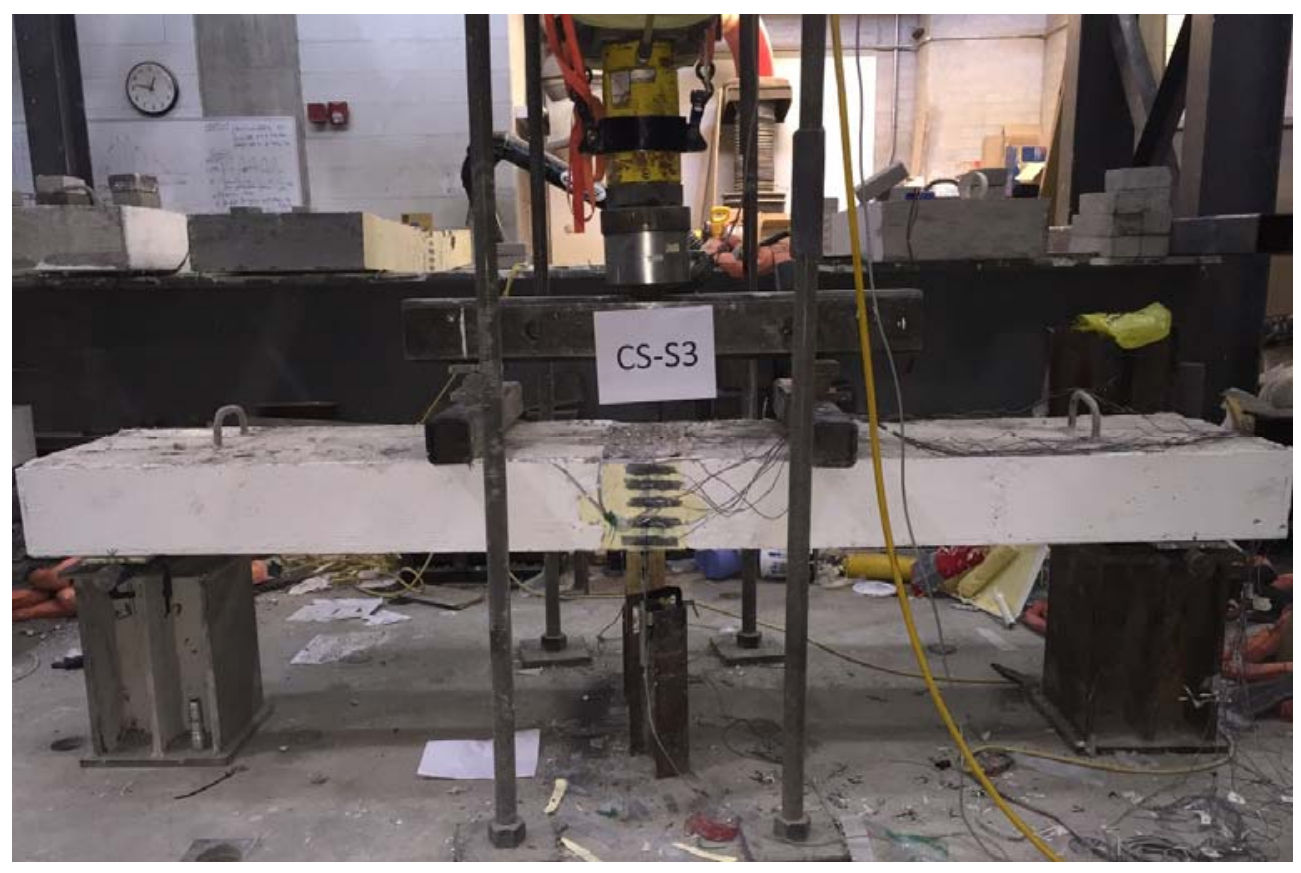

Figure 4.6 Test setup of slab $\mathrm{S}_{3}$ before testing

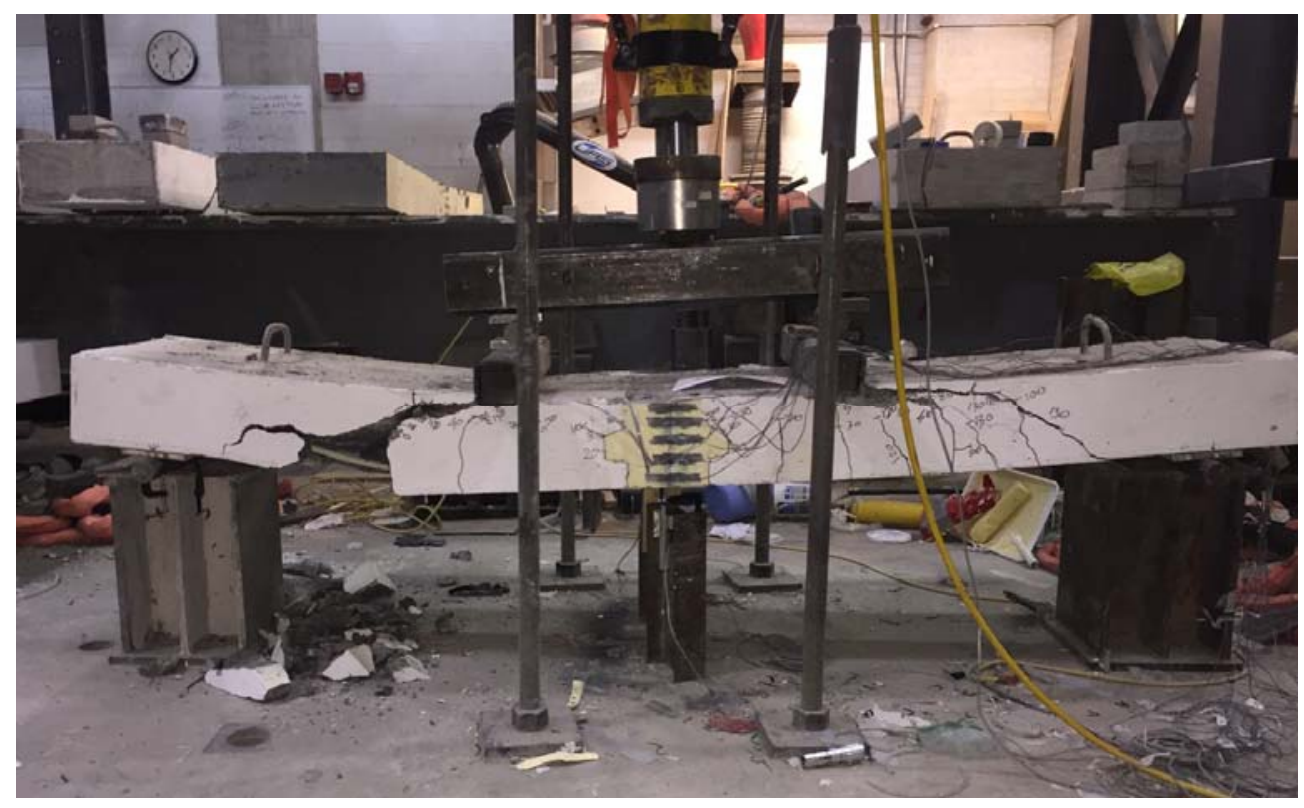

Figure 4.7 View of crack pattern of slab $\mathrm{S}_{3}$ after failure 


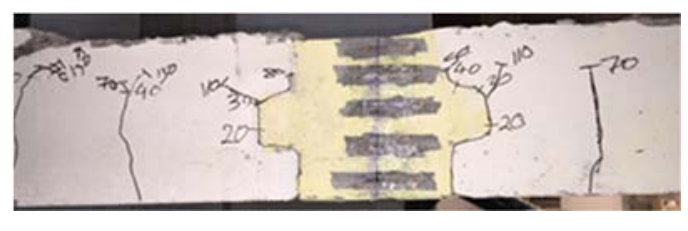

(a) Side 1

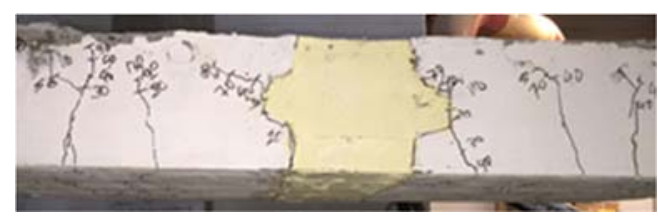

(b) Side 2

Figure 4.8 Close-up view of the flexural cracks at the joint of slab S3

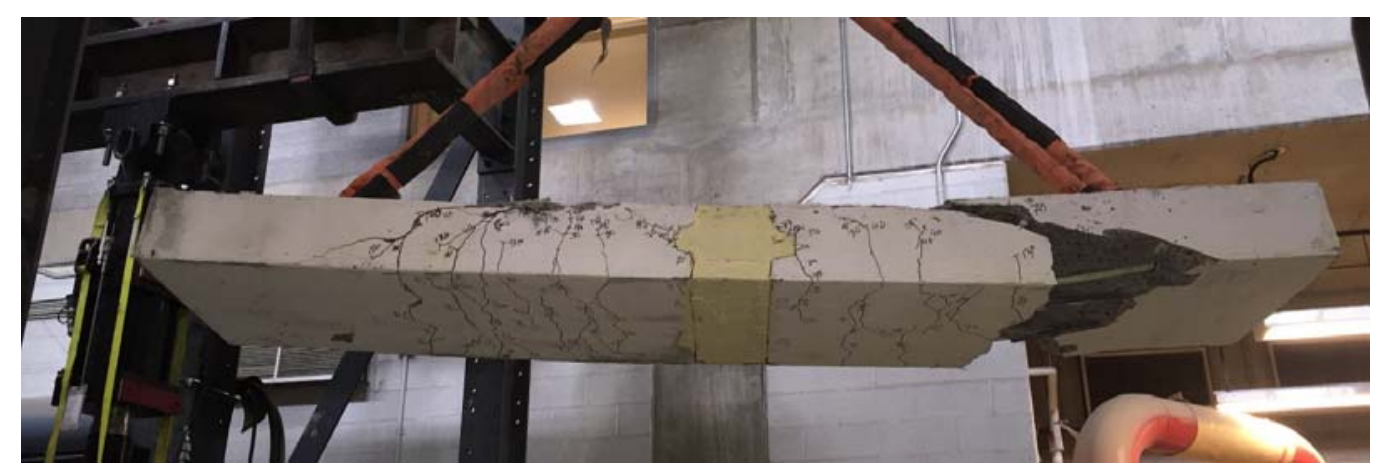

(a) View of the crack pattern at the bottom of slab $\mathrm{S}_{3}$

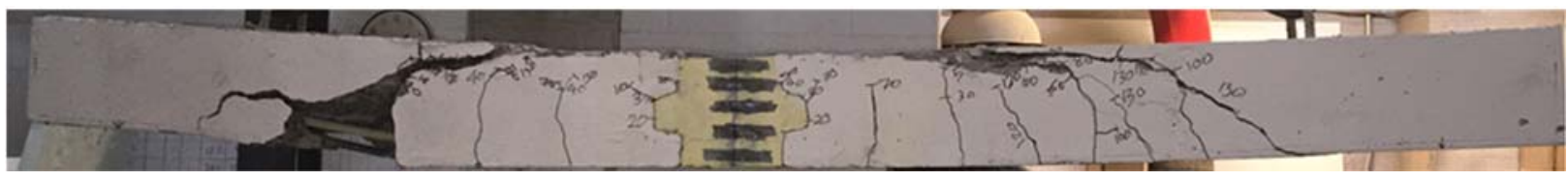

(b) Side 1

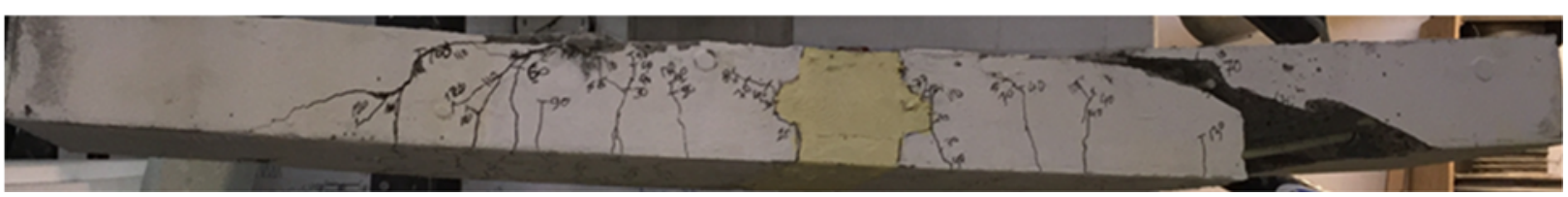

(c) Side 2

Figure 4.9 View of the crack pattern at the bottom and two sides of slab $\mathrm{S}_{3}$ 


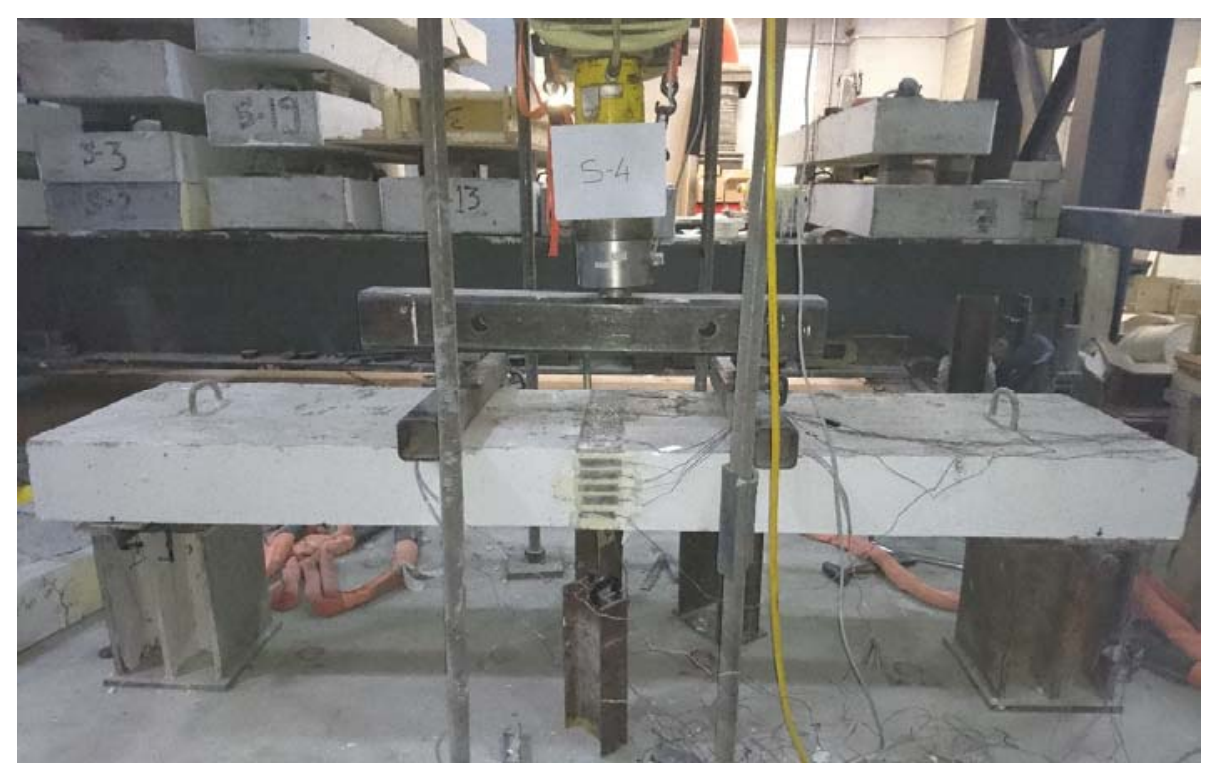

Figure 4.10 Test setup of slab $\mathrm{S}_{4}$ before testing

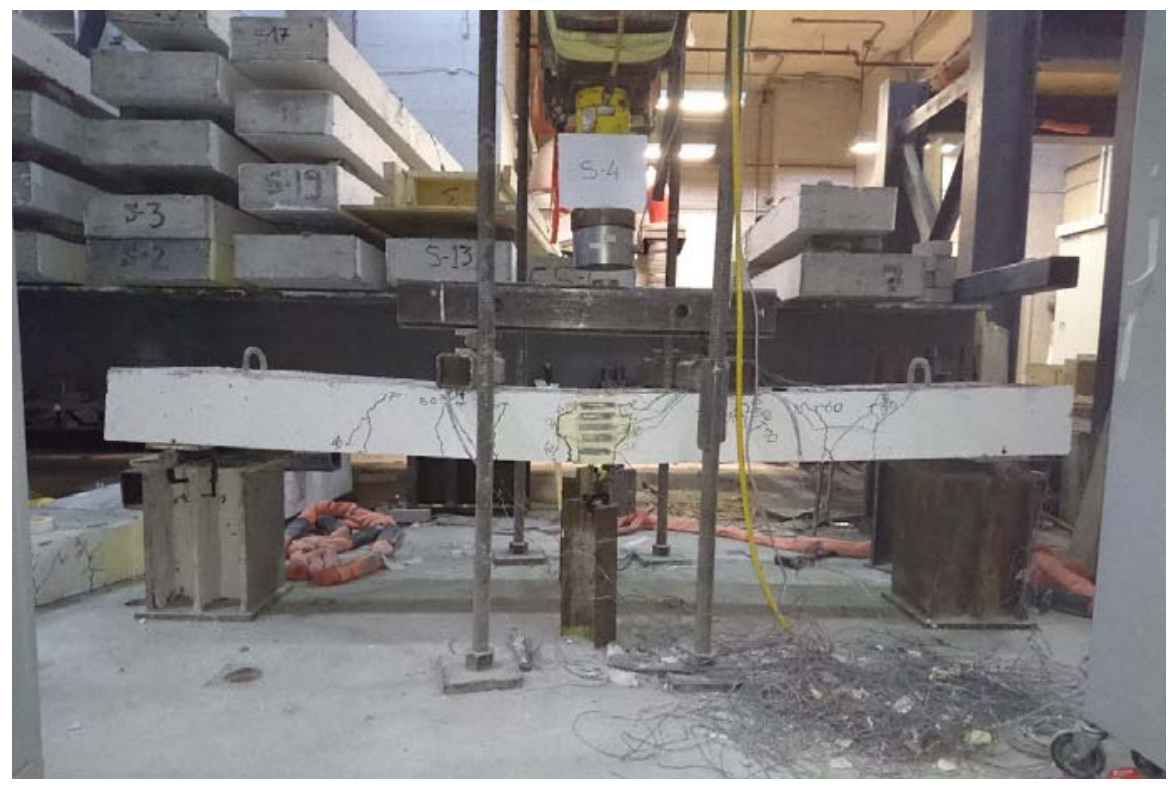

Figure 4.11 View of crack pattern of slab $\mathrm{S}_{4}$ after failure 


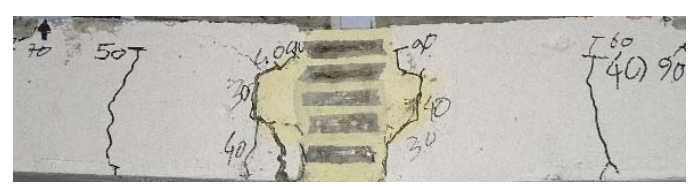

(a) Side 1

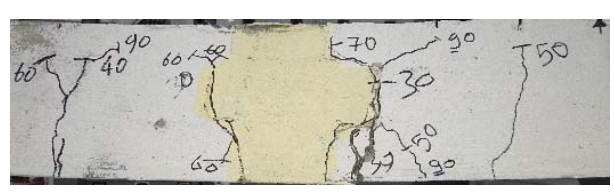

(b) Side 2

Figure 4.12 Close-up view of the flexural cracks at the joint of slab $\mathrm{S}_{4}$

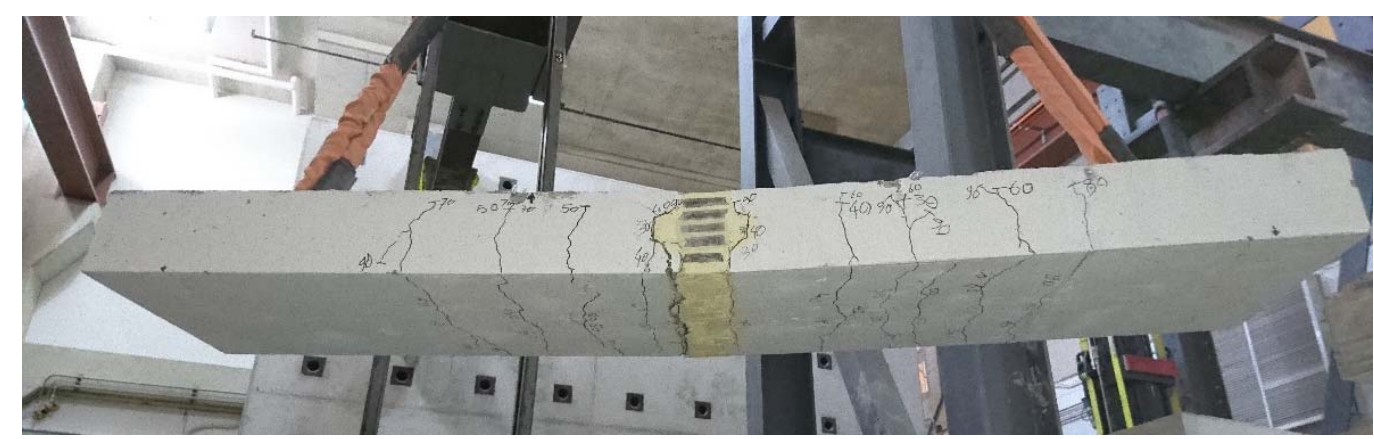

(a) View of crack pattern at the bottom of slab $\mathrm{S}_{4}$

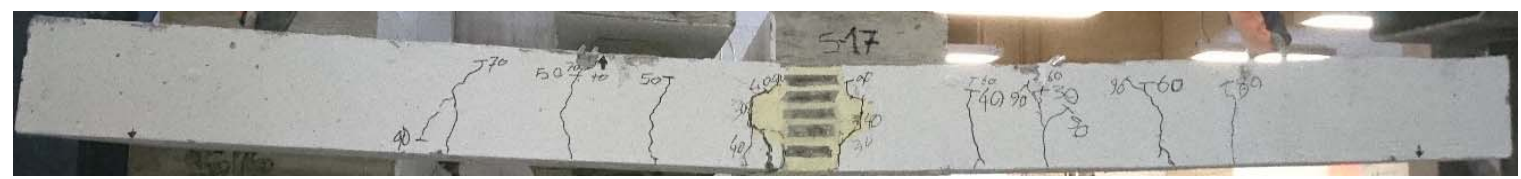

(b) Side 1

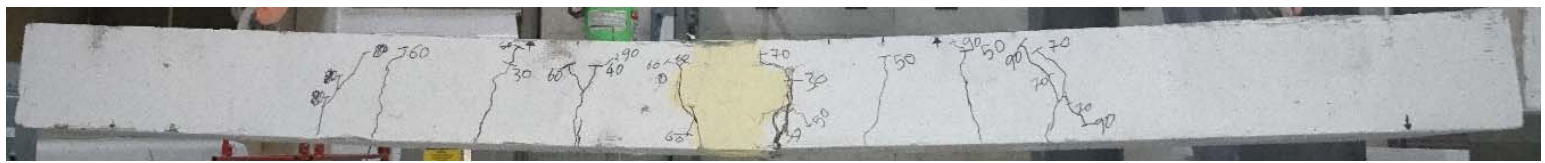

(c) Side 2

Figure 4.13 View of the crack pattern at the bottom and two sides of slab $\mathrm{S}_{4}$ 


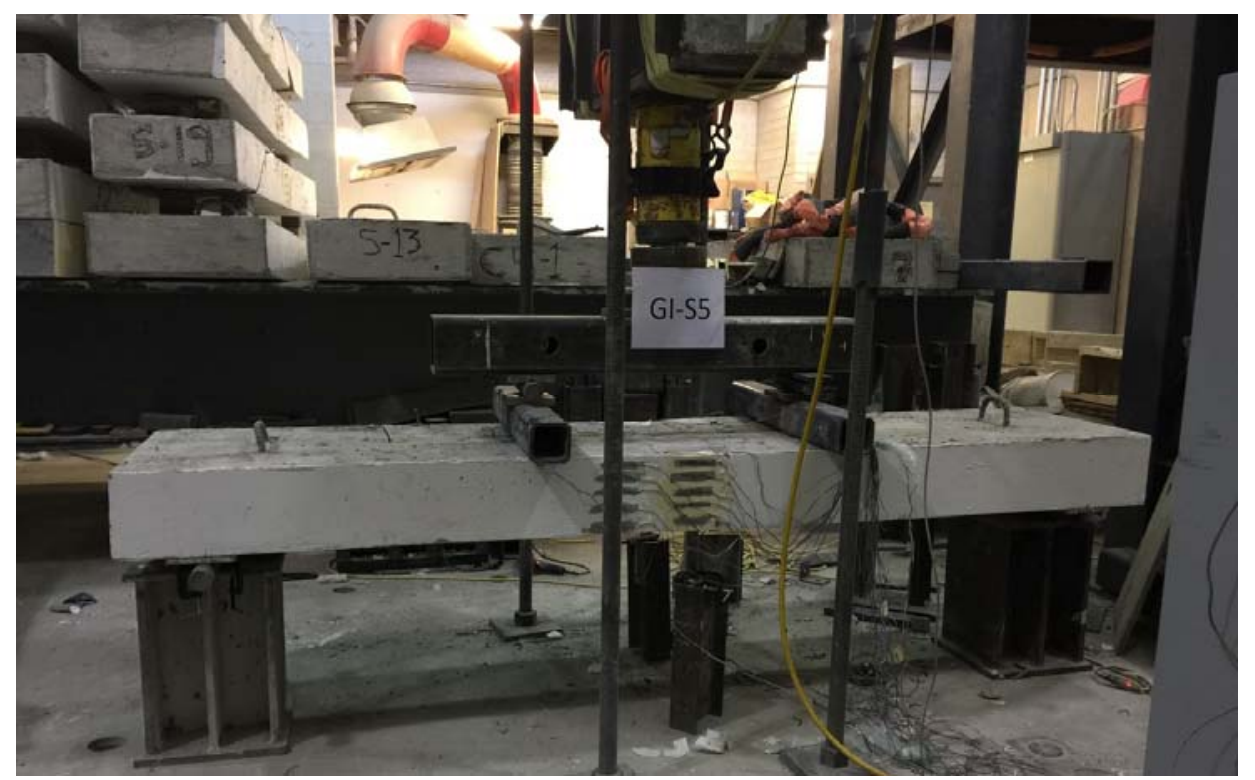

Figure 4.14 test setup of slab $\mathrm{S}_{5}$ before testing

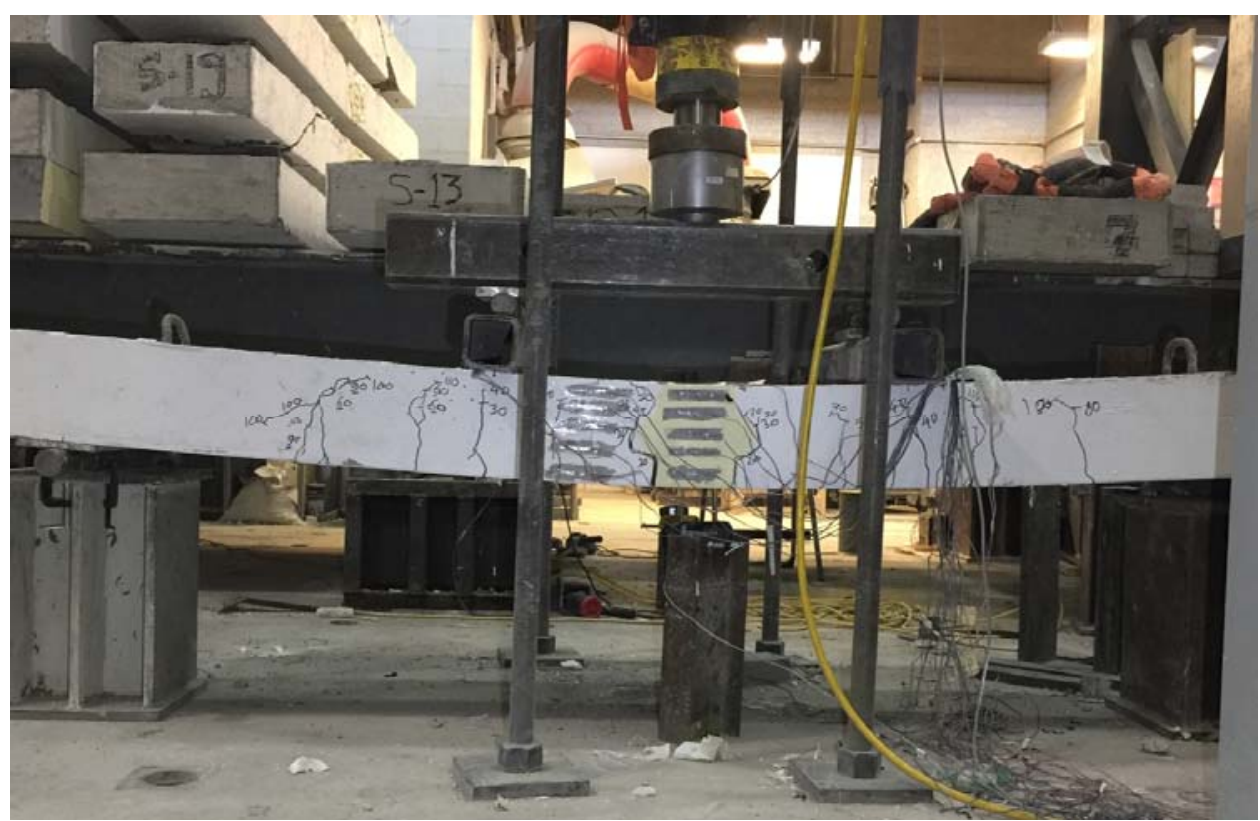

Figure 4.15 View of crack pattern of slab $\mathrm{S}_{5}$ after failure 


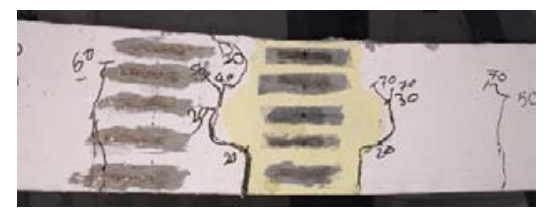

(a) Side 1

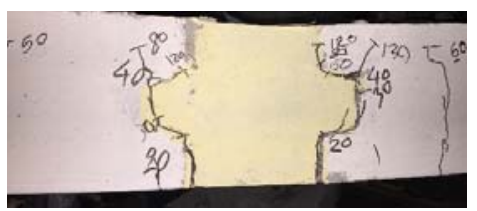

(b) Side 2

Figure 4.16 Close-up view of flexural cracks at the joint of slab $\mathrm{S}_{5}$

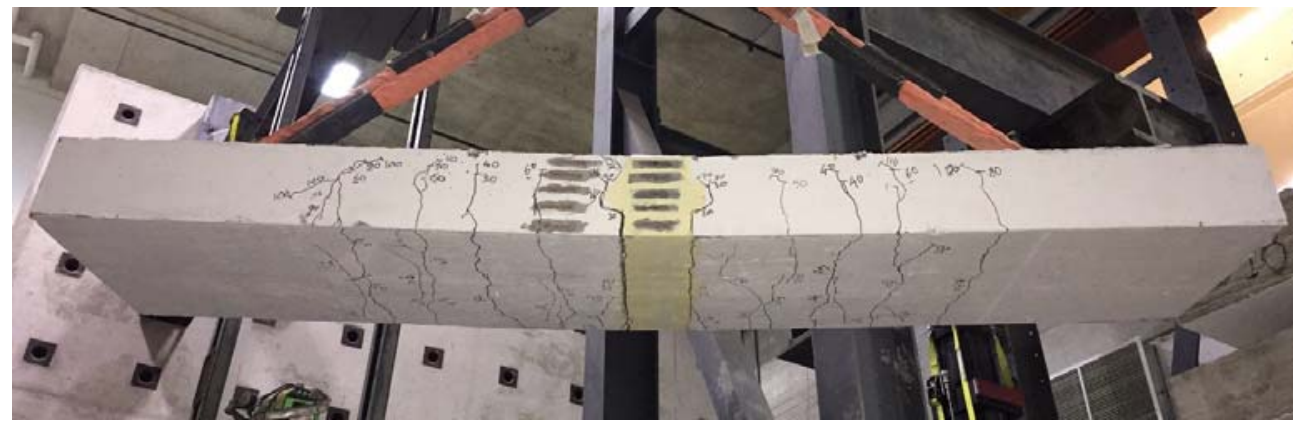

(a) View of crack pattern at the bottom of slab $\mathrm{S}_{5}$

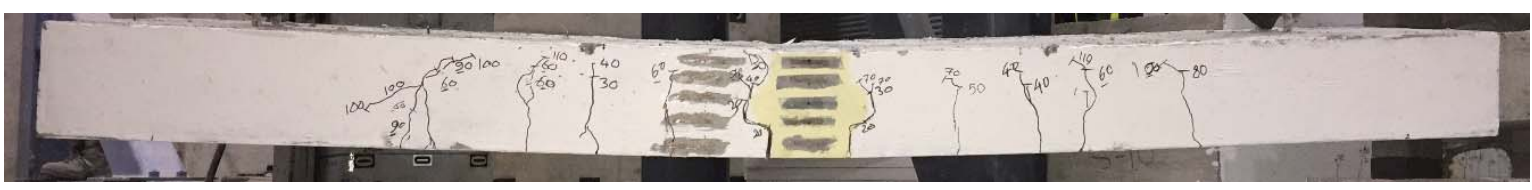

(b) Side 1

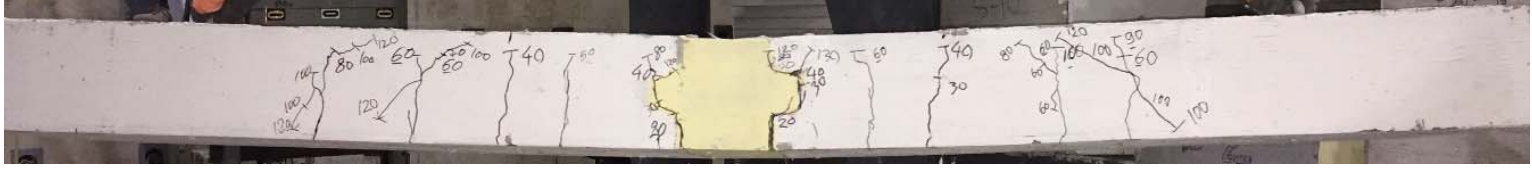

(c) Side 2

Figure 4.17 View of the crack pattern at the bottom and two sides of slab $\mathrm{S}_{5}$ 


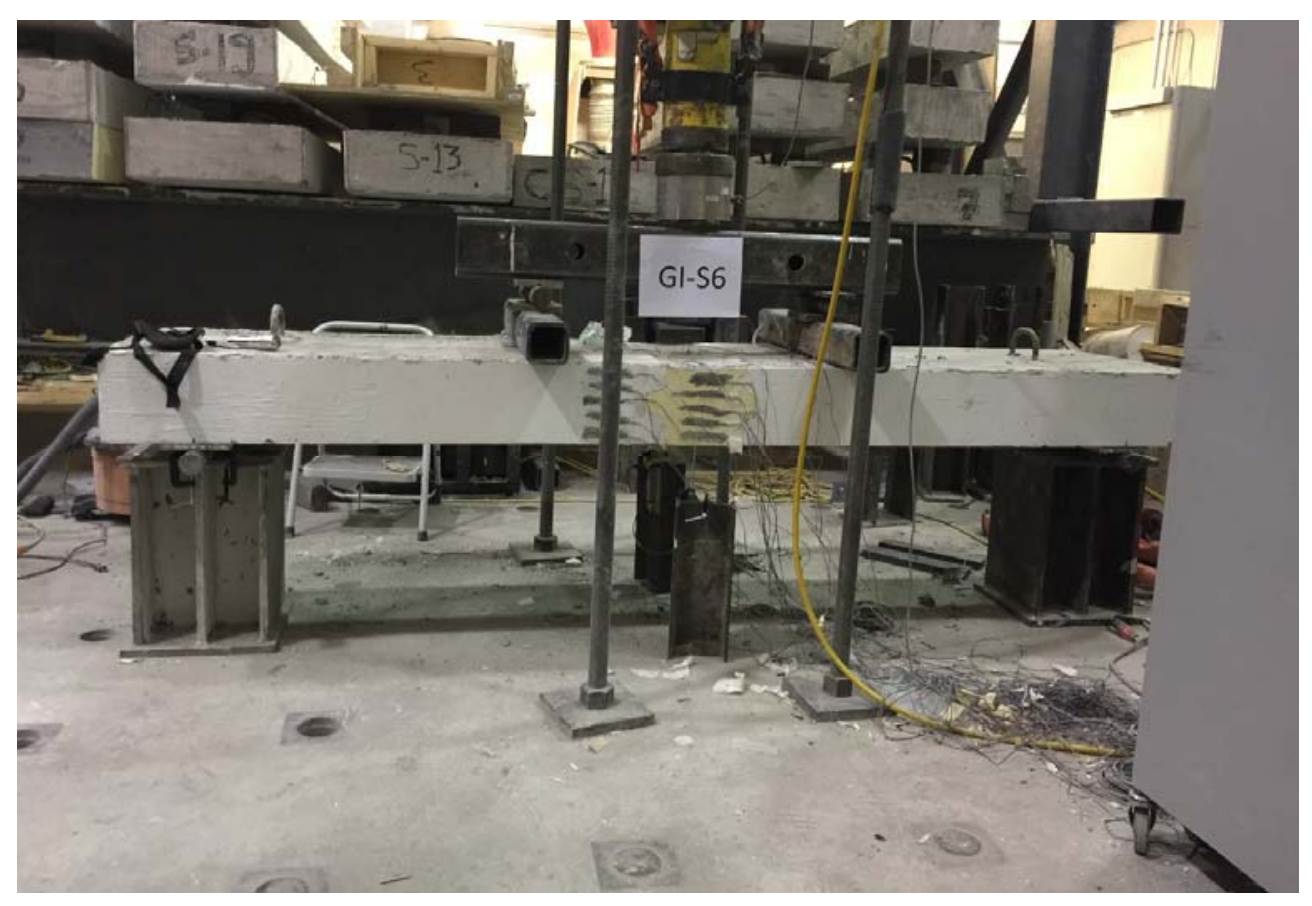

Figure 4.18 Test setup of slab $\mathrm{S}_{6}$ before testing

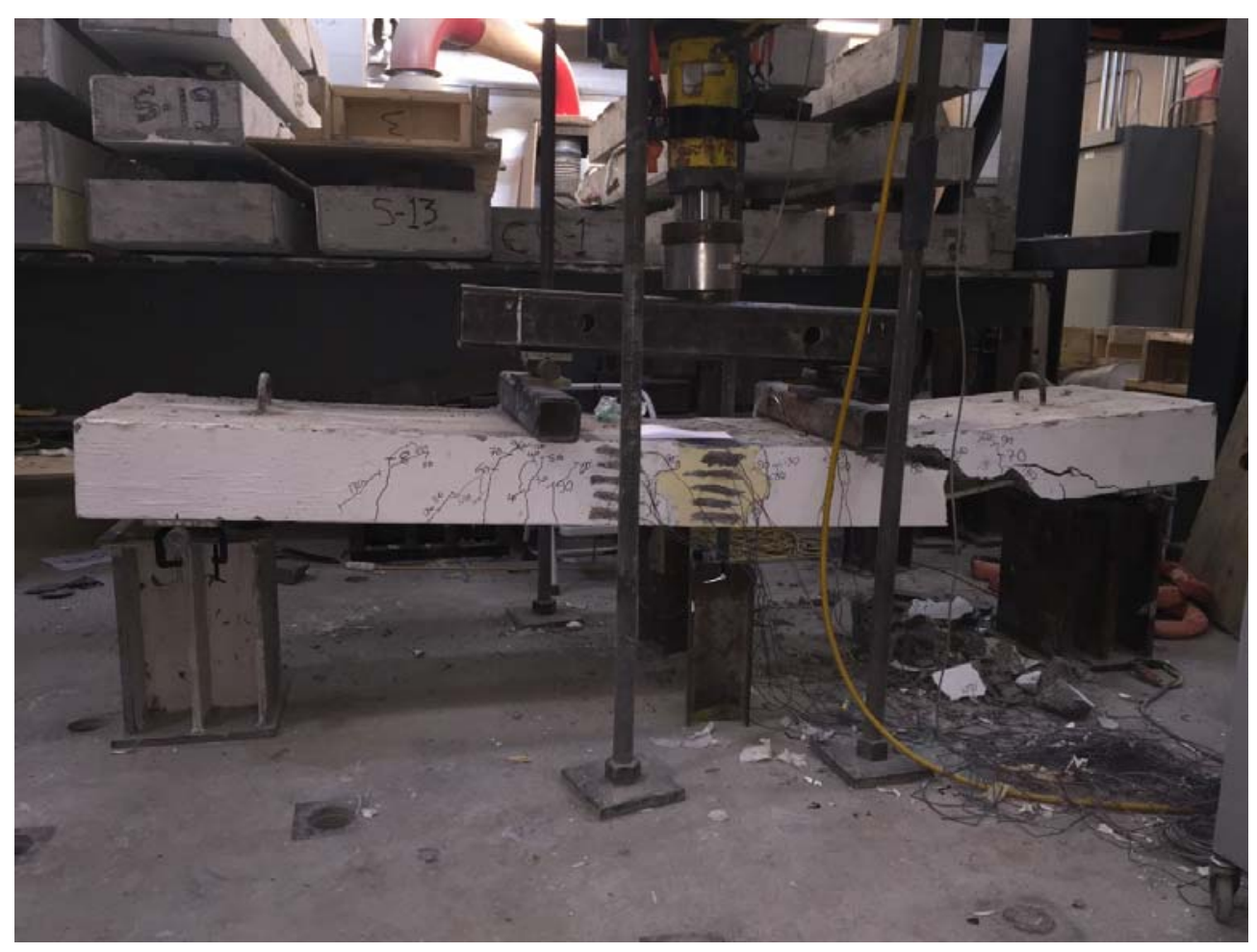

Figure 4.19 View of crack pattern of slab $\mathrm{S}_{6}$ after failure 


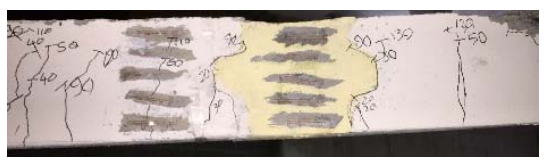

(a) Side 1



(b) Side 2

Figure 4.20 Close-up view of flexural cracks at the joint of slab $\mathrm{S}_{6}$

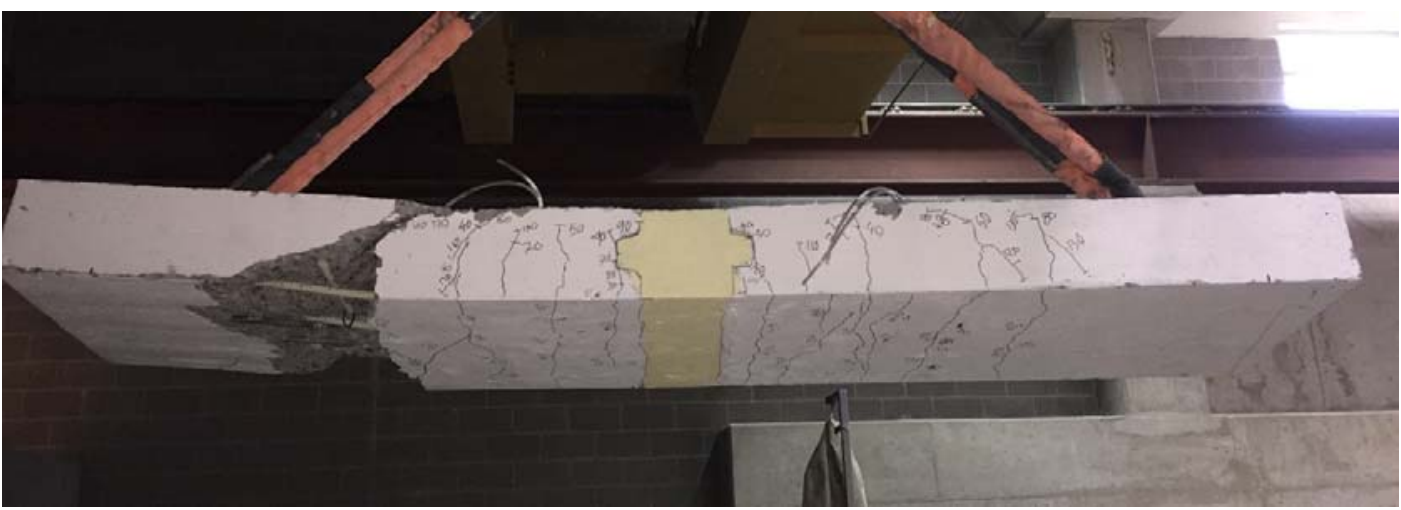

(a) View of crack pattern at the bottom of slab $\mathrm{S}_{6}$

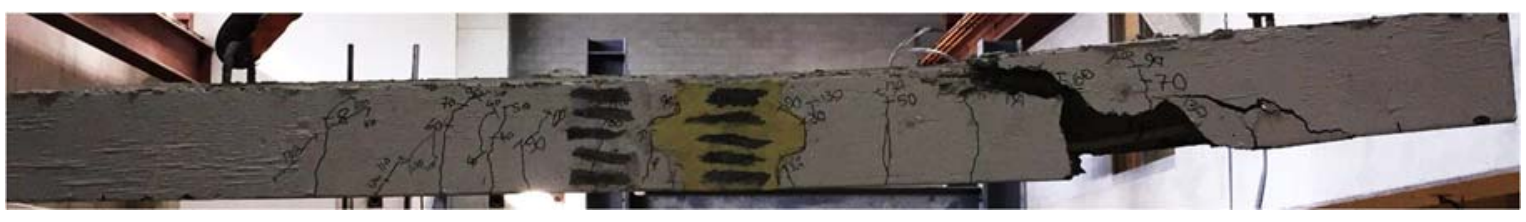

(b) Side 1

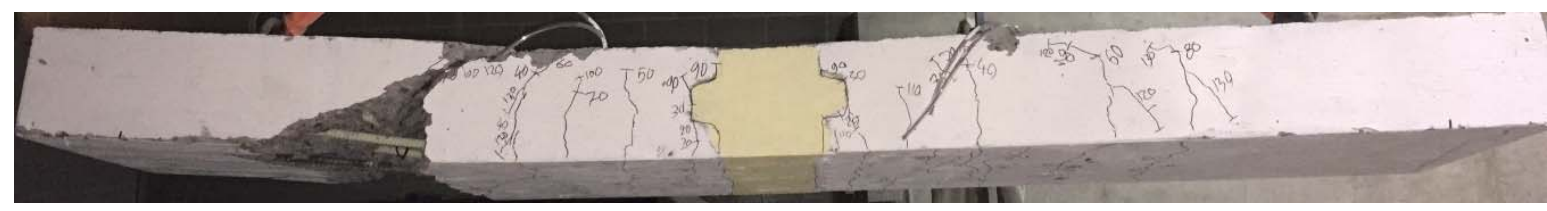

(c) Side 2

Figure 4.21 View of the crack pattern at the bottom and two sides of slab $\mathrm{S}_{6}$ 


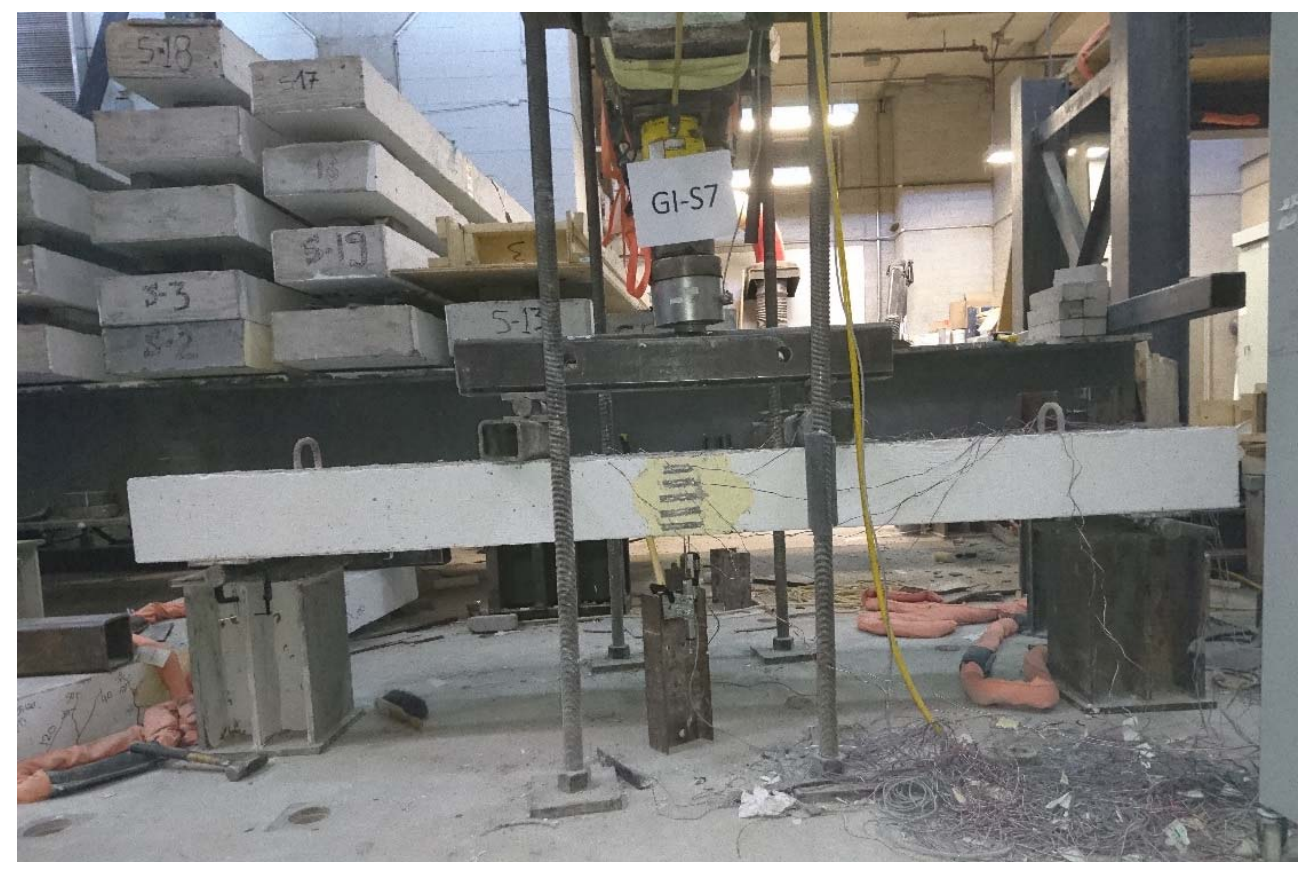

Figure 4.22 Test setup of slab $\mathrm{S}_{7}$ before testing

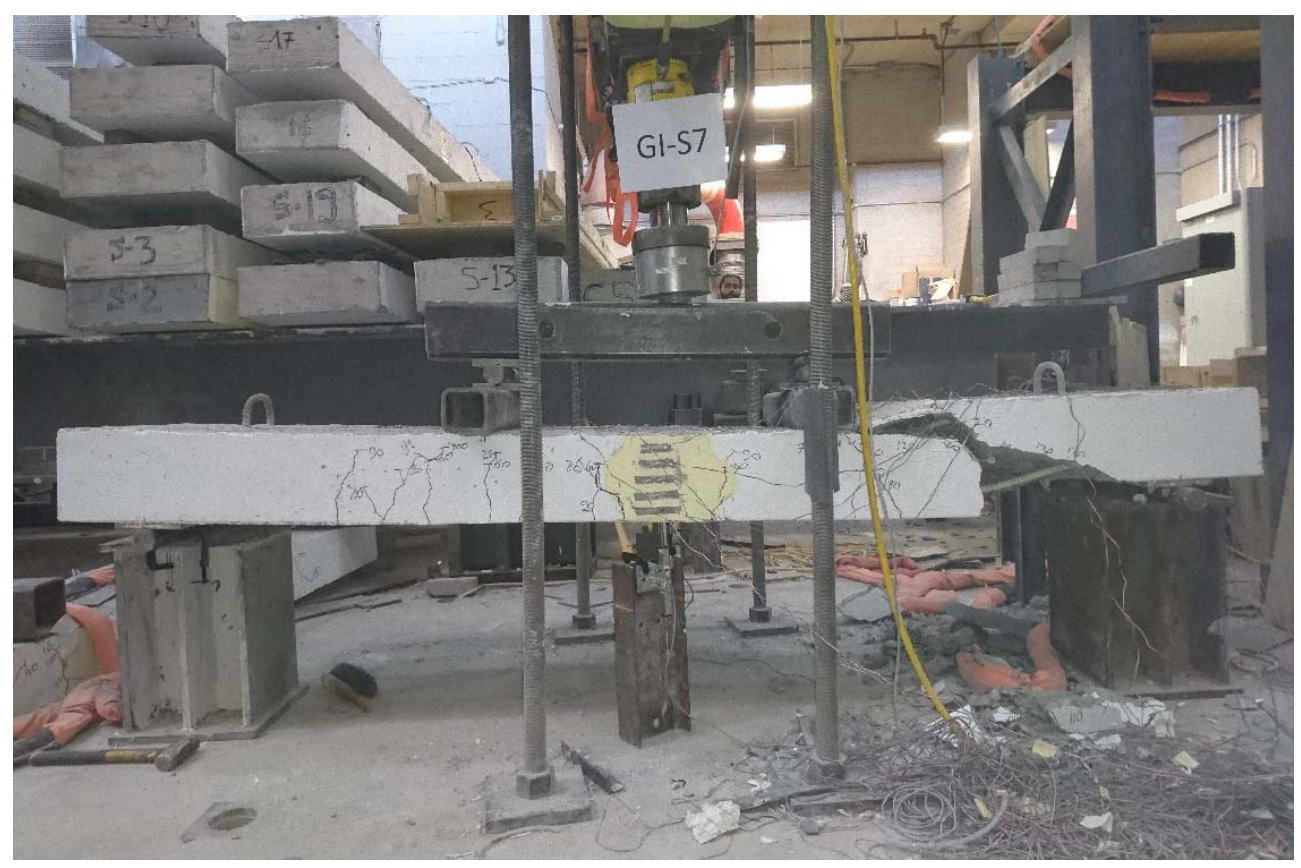

Figure 4.23 View of crack pattern of slab $\mathrm{S}_{7}$ after failure 


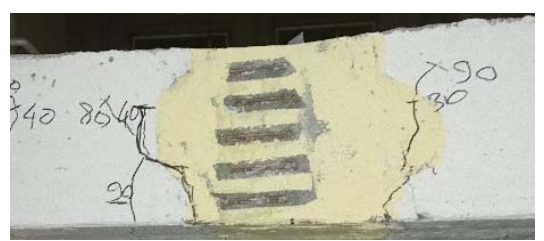

(a) Side 1

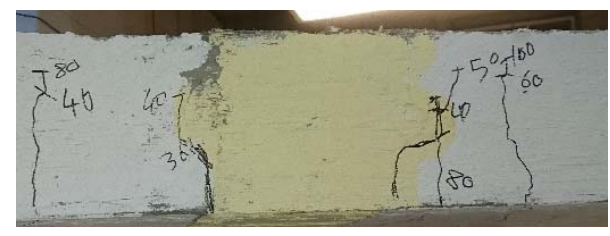

(b) Side 2

Figure 4.24 Close-up view of flexural cracks at the joint of slab $\mathrm{S}_{7}$

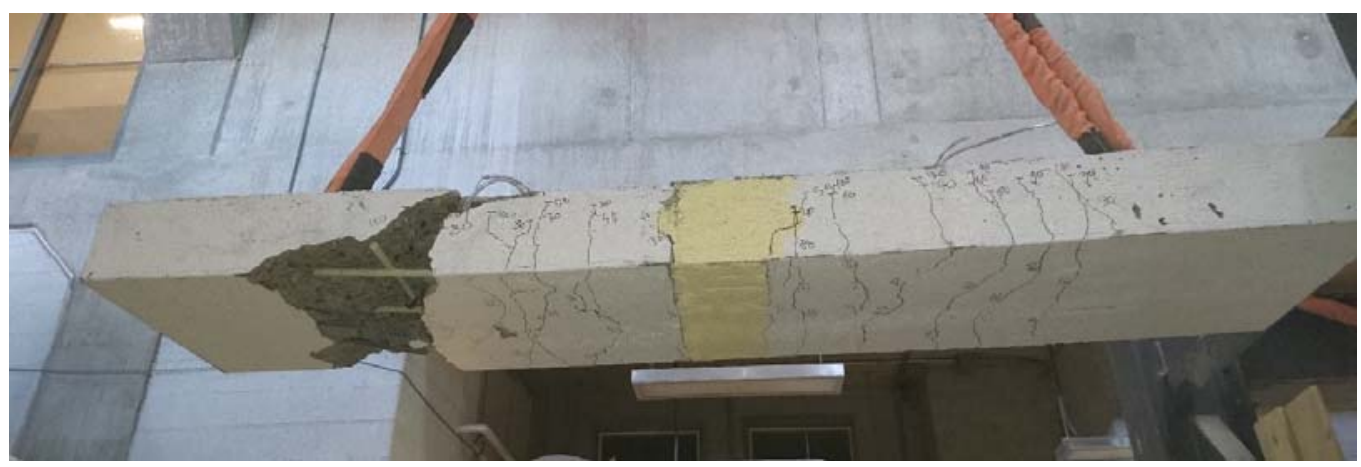

(a) View of crack pattern at the bottom of slab $\mathrm{S}_{7}$

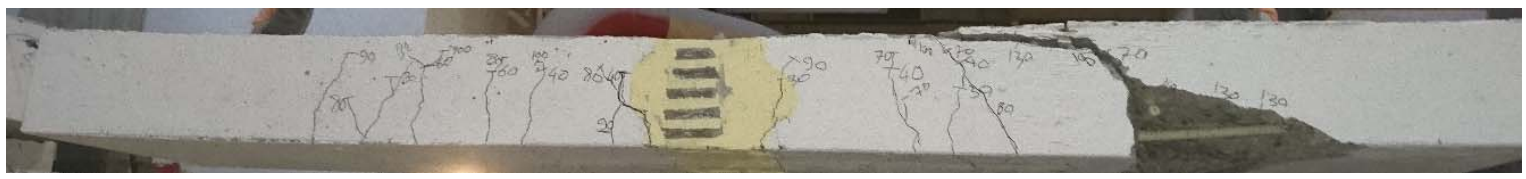

(b) Side 1

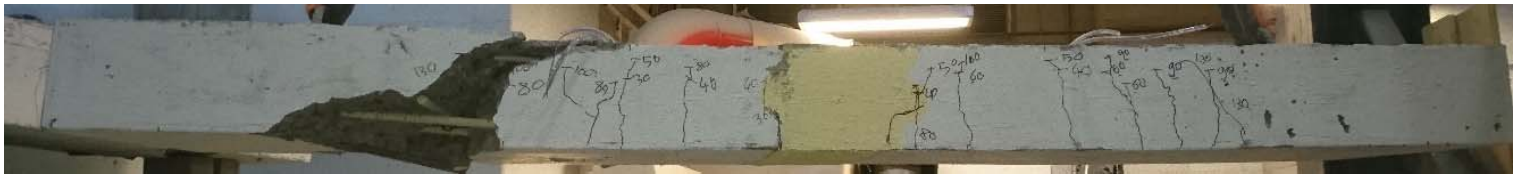

(c) Side 2

Figure 4.25 View of the crack pattern at the bottom and two sides of slab $S_{7}$ 


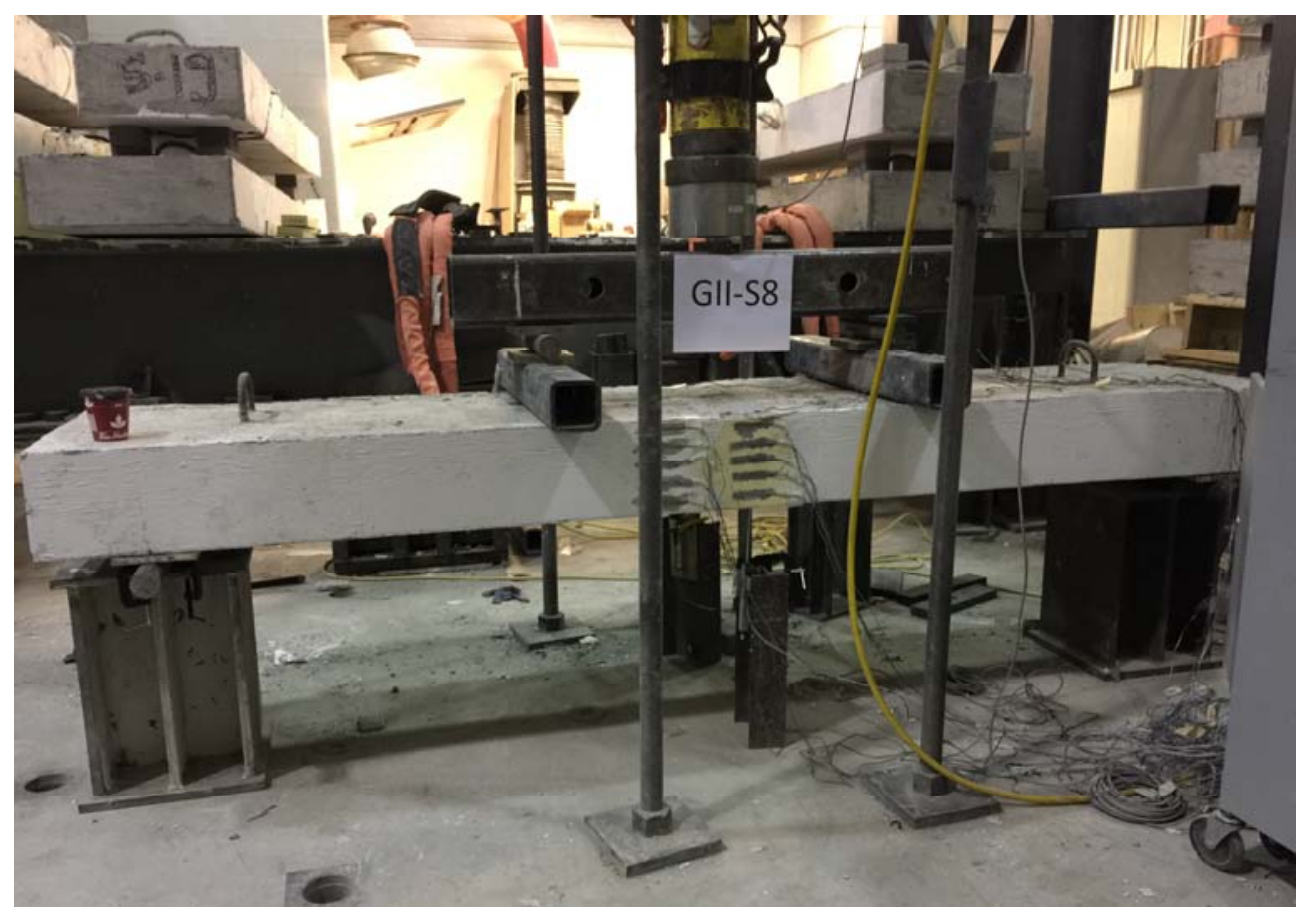

Figure 4.26 Test setup of slab $\mathrm{S}_{8}$ before testing

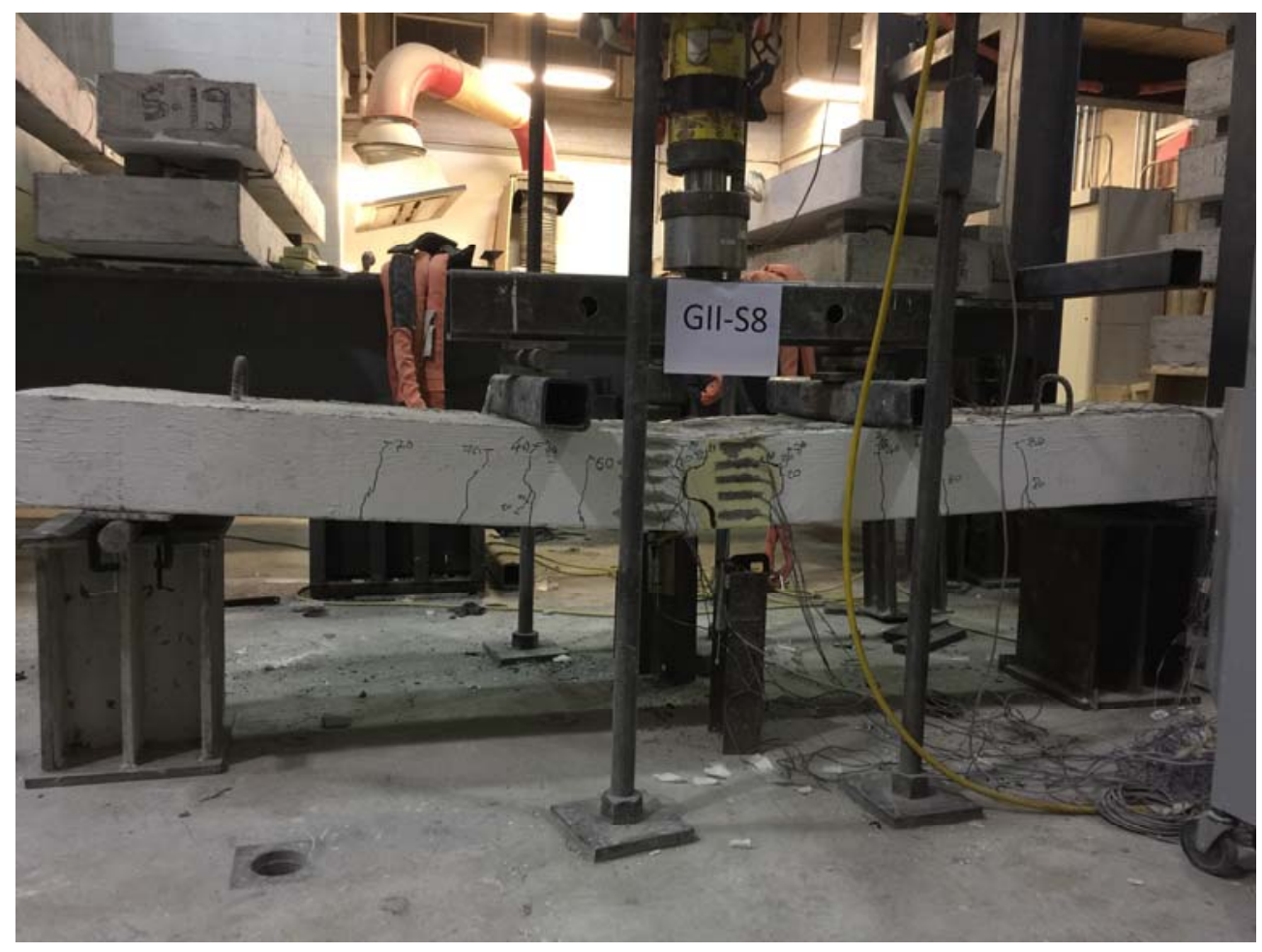

Figure 4.27 View of crack pattern of slab $\mathrm{S}_{8}$ after failure 


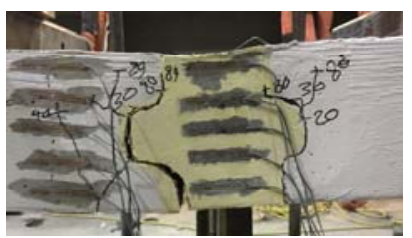

(a) Side 1

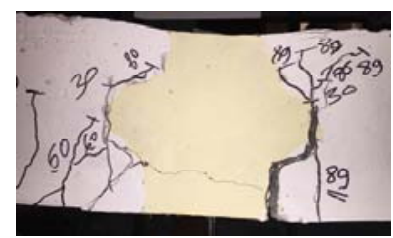

(b) Side 2

Figure 4.28 Close-up view of flexural cracks at the joint of slab $\mathrm{S}_{8}$

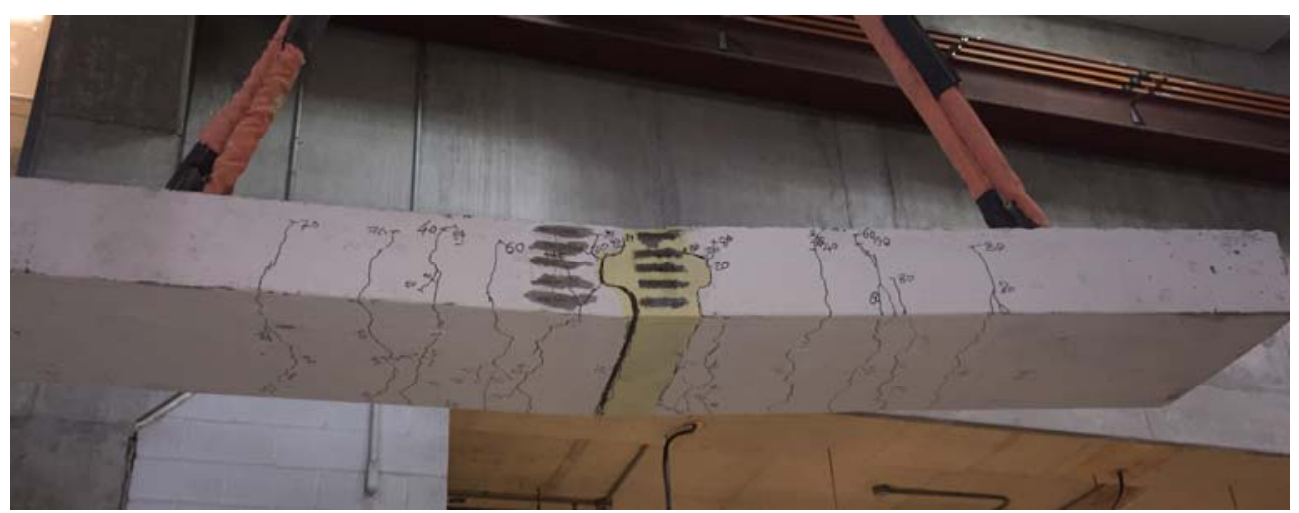

(a) View of the crack pattern at the bottom of slab $\mathrm{S}_{8}$

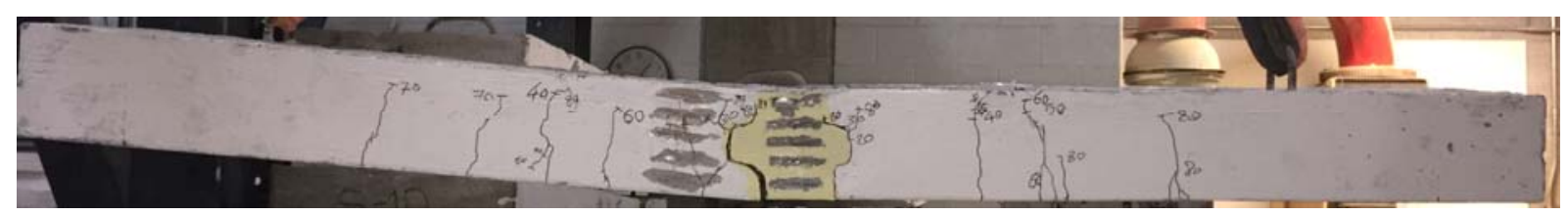

(b) Side 1

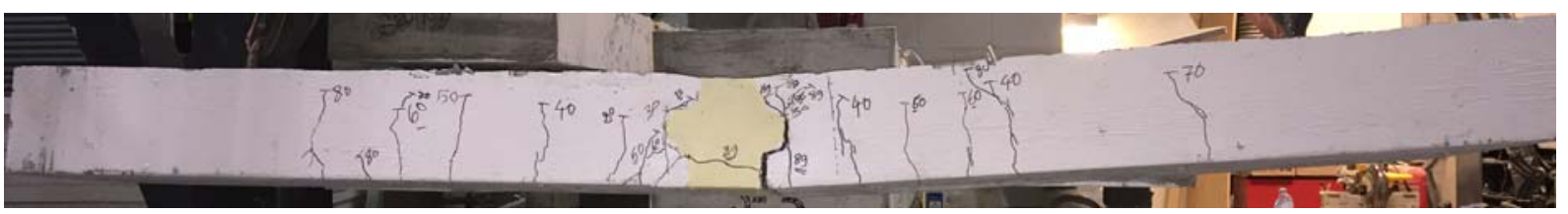

(c) Side 2

Figure 4.29 View of the crack pattern at the bottom and two sides of slab $\mathrm{S}_{8}$ 


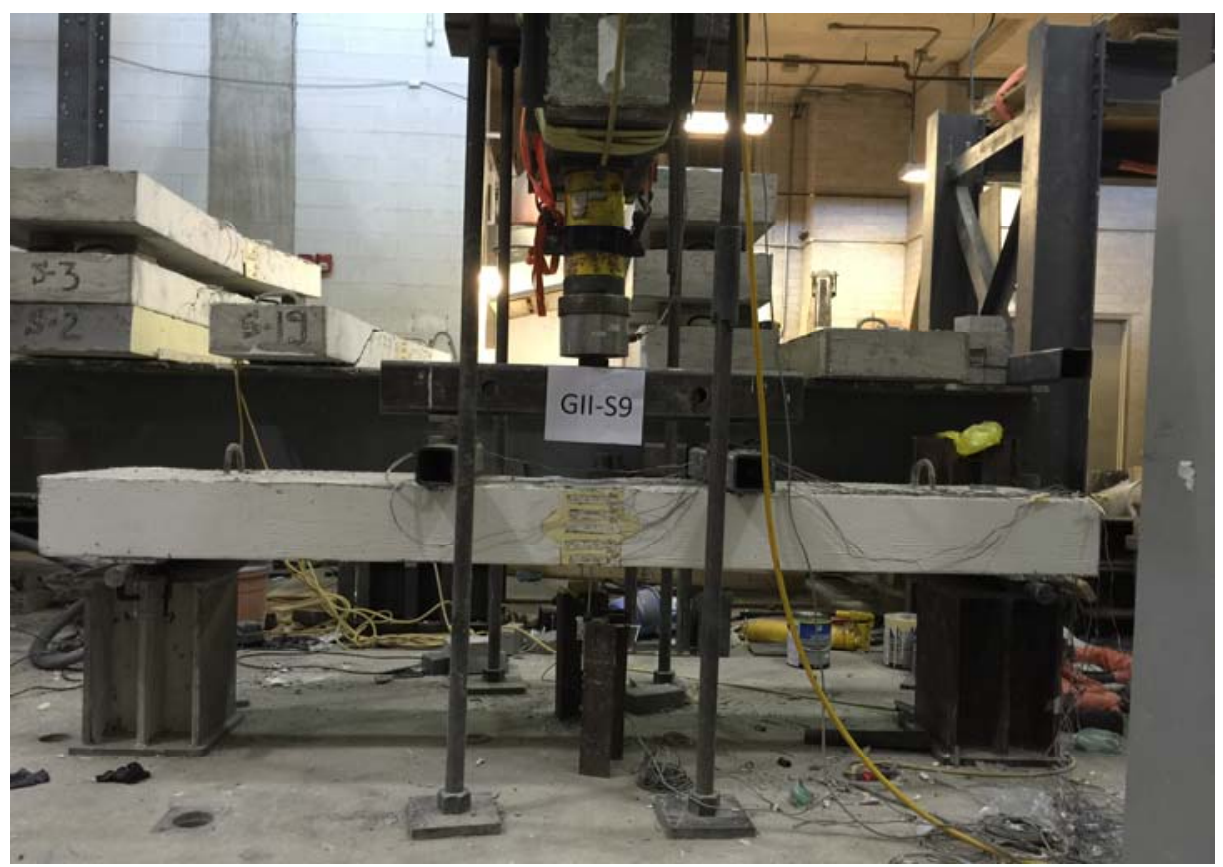

Figure 4.30 Test setup of slab $\mathrm{S}_{9}$ before testing

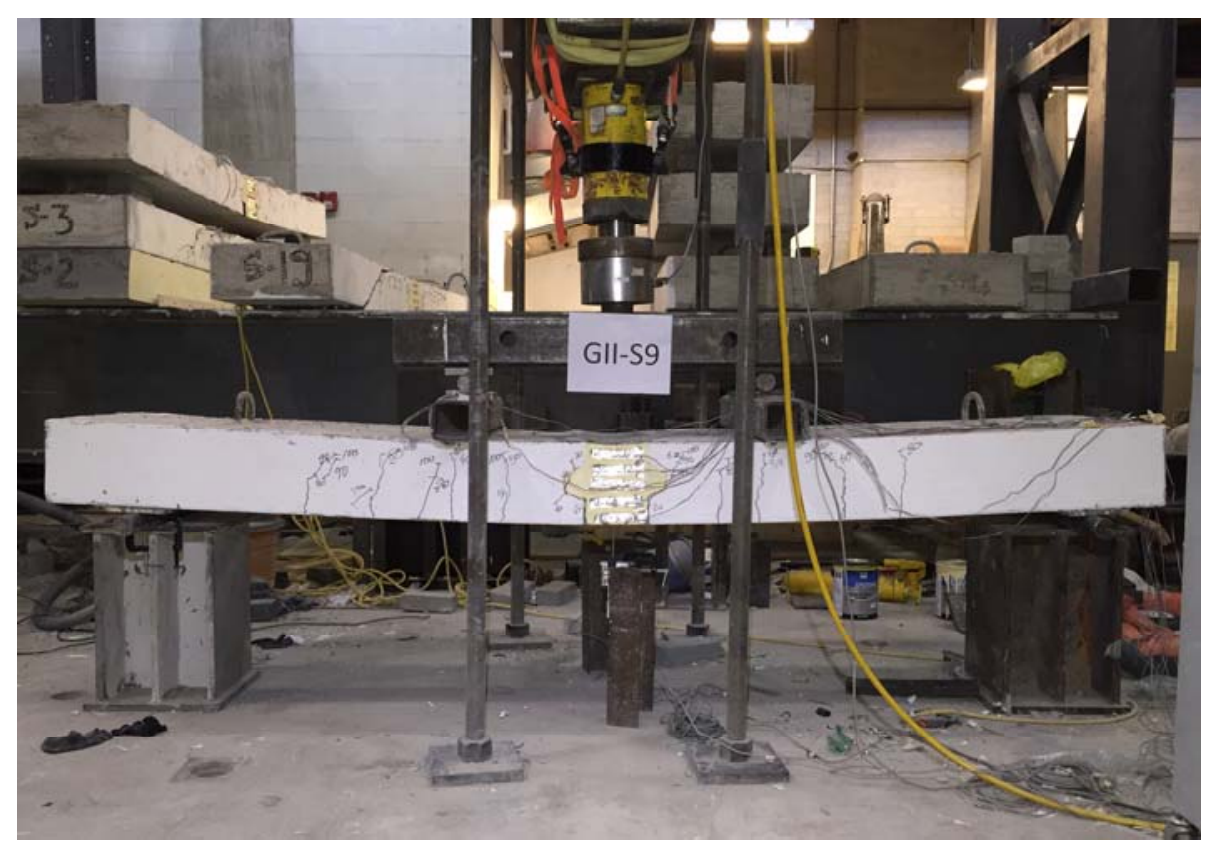

Figure 4.31 View of crack pattern of slab $\mathrm{S}_{9}$ after failure 


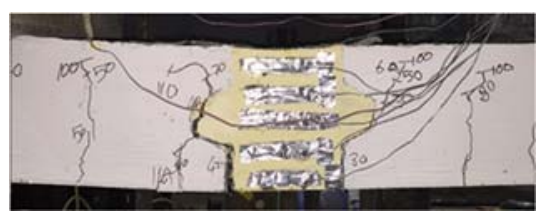

(a) Side 1

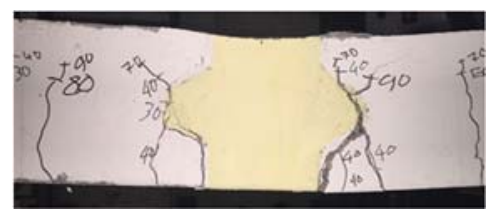

(b) Side 2

Figure 4.32 Close-up view of flexural cracks at the joint of slab $\mathrm{S}_{9}$

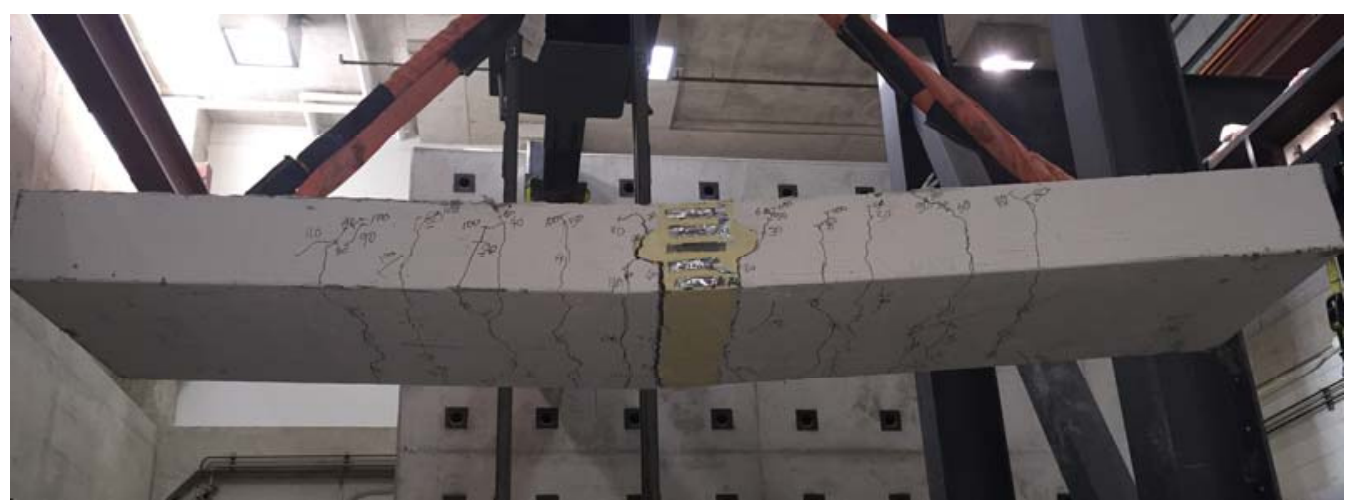

(a) View of crack pattern at the bottom of slab $\mathrm{S}_{9}$

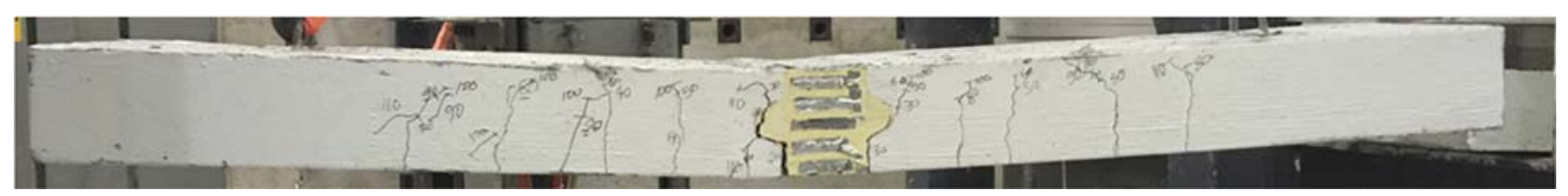

(b) Side 1

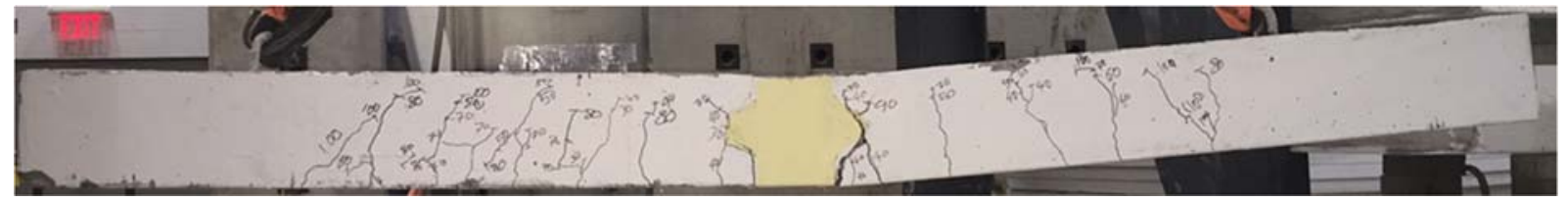

(c) Side 2

Figure 4.33 View of the crack pattern at the bottom and two sides of slab $\mathrm{S}_{9}$ 


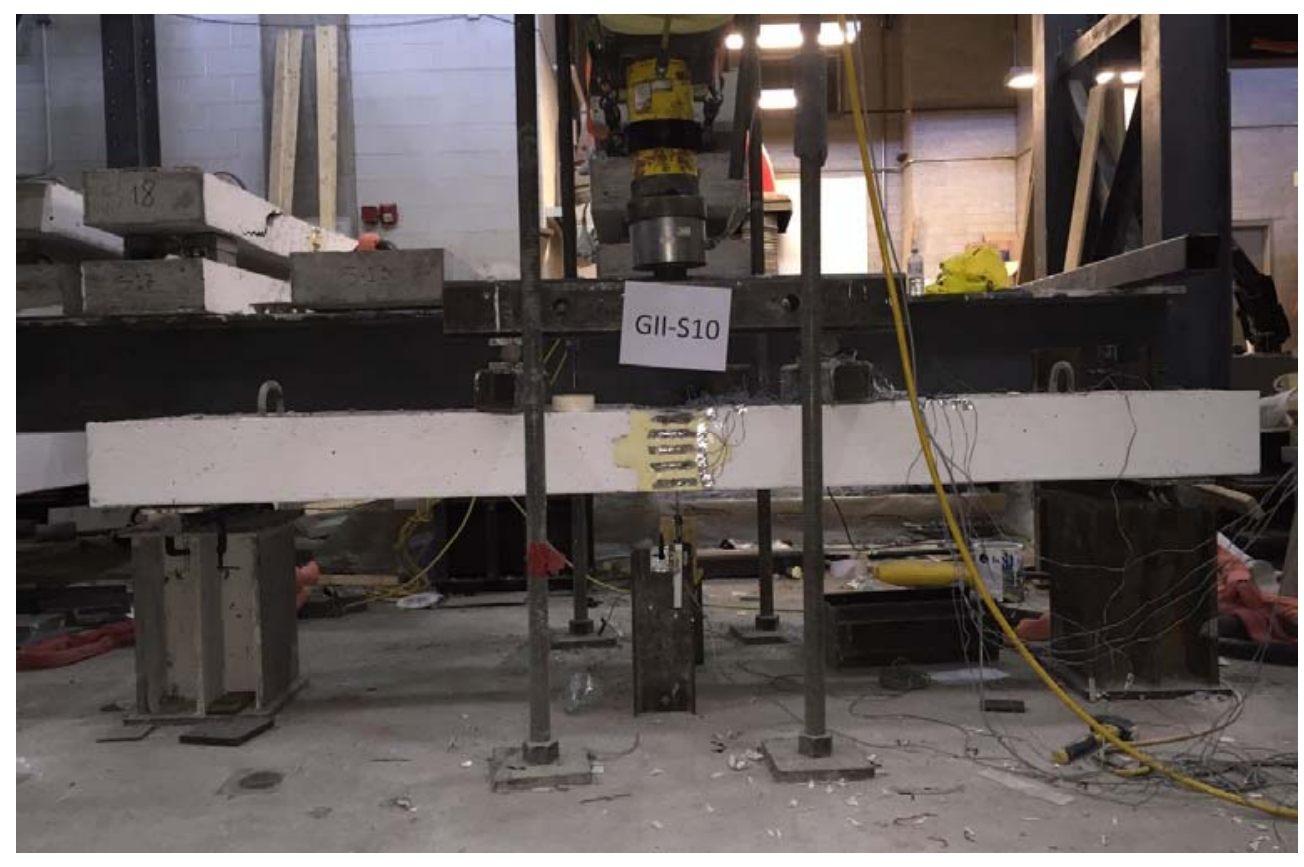

Figure 4.34 Test setup of slab $\mathrm{S}_{10}$ before testing

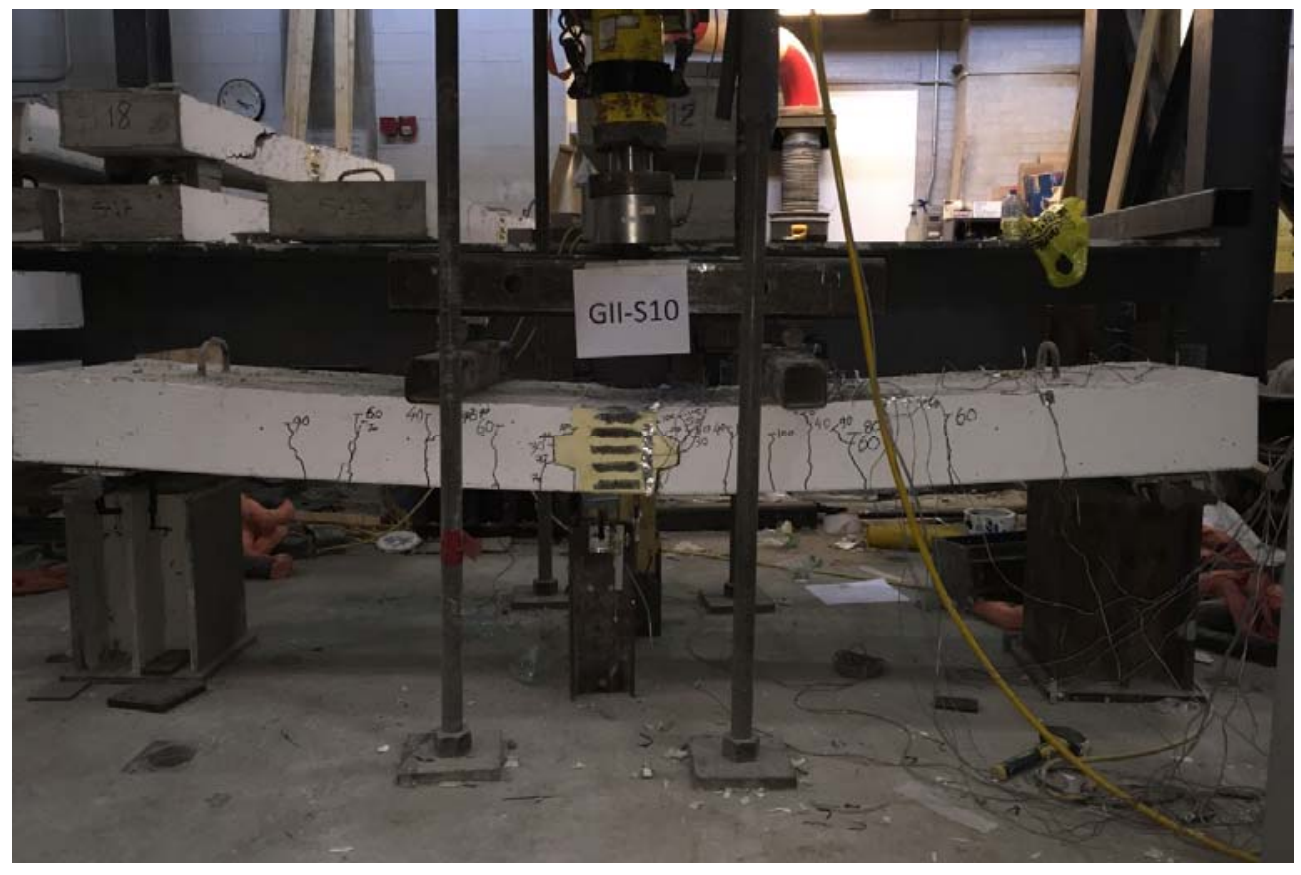

Figure 4.35 View of crack pattern of slab $\mathrm{S}_{10}$ after failure 


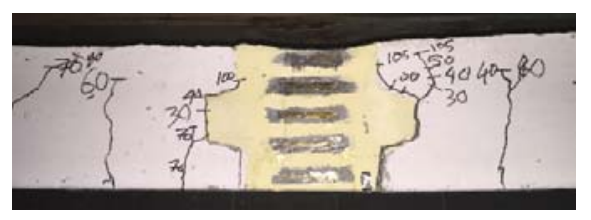

(a) Side 1

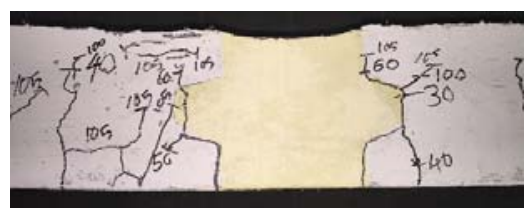

(b) Side 2

Figure 4.36 Close-up view of flexural cracks at the joint of slab $\mathrm{S}_{10}$

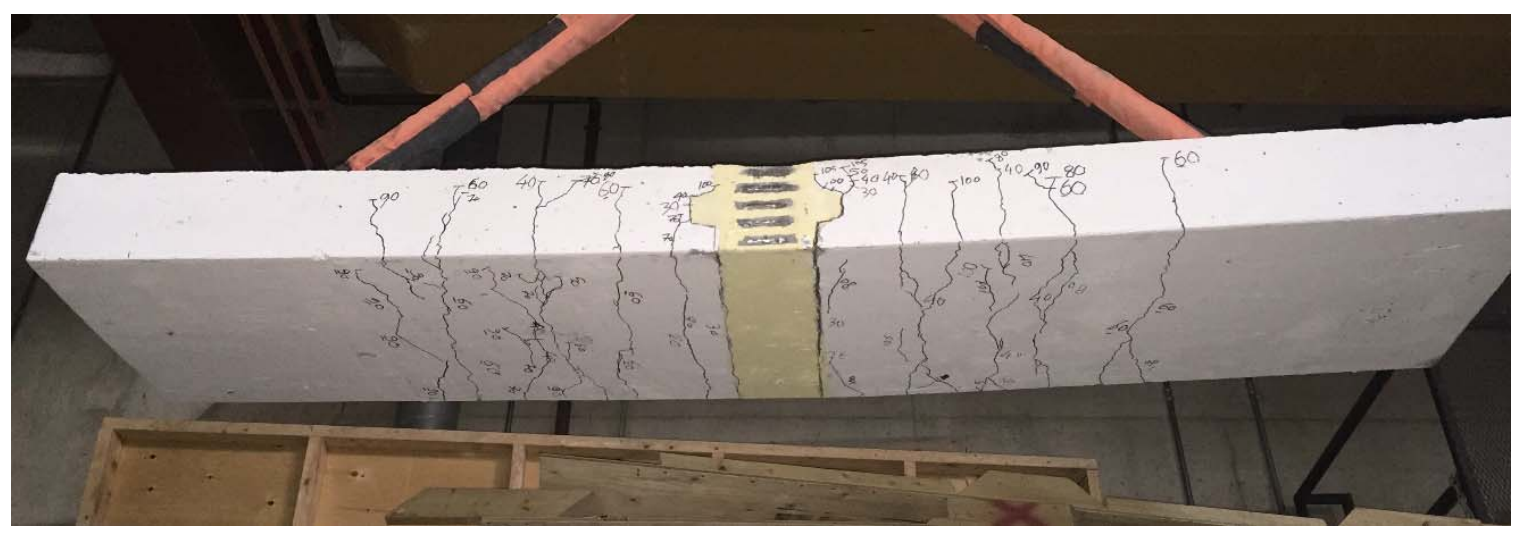

(a) View of the crack pattern at the bottom Slab $\mathrm{S}_{10}$

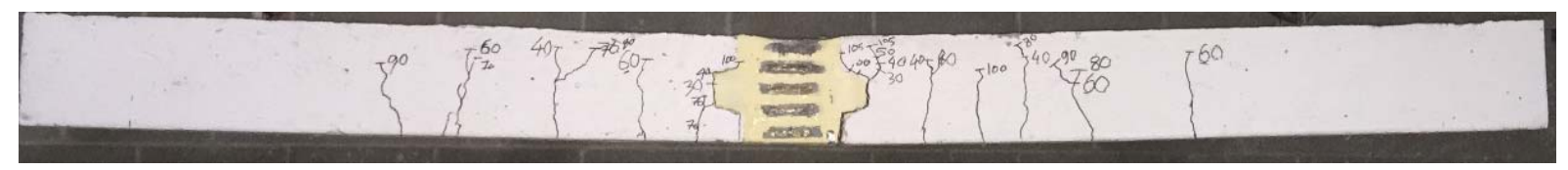

(b) Side 1

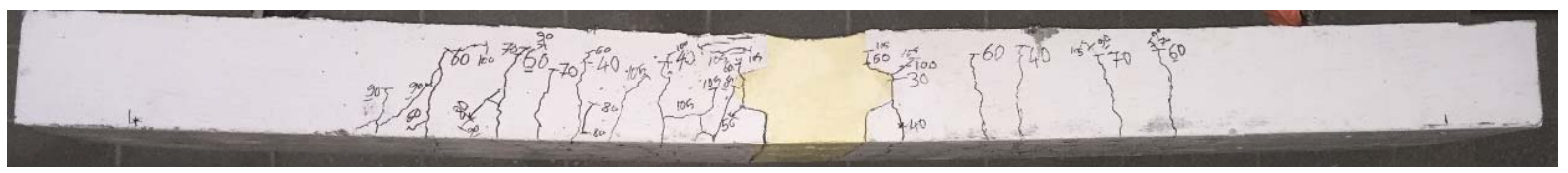

(c) Side 2

Figure 4.37 View of crack pattern at the two sides of slab $\mathrm{S}_{10}$ 


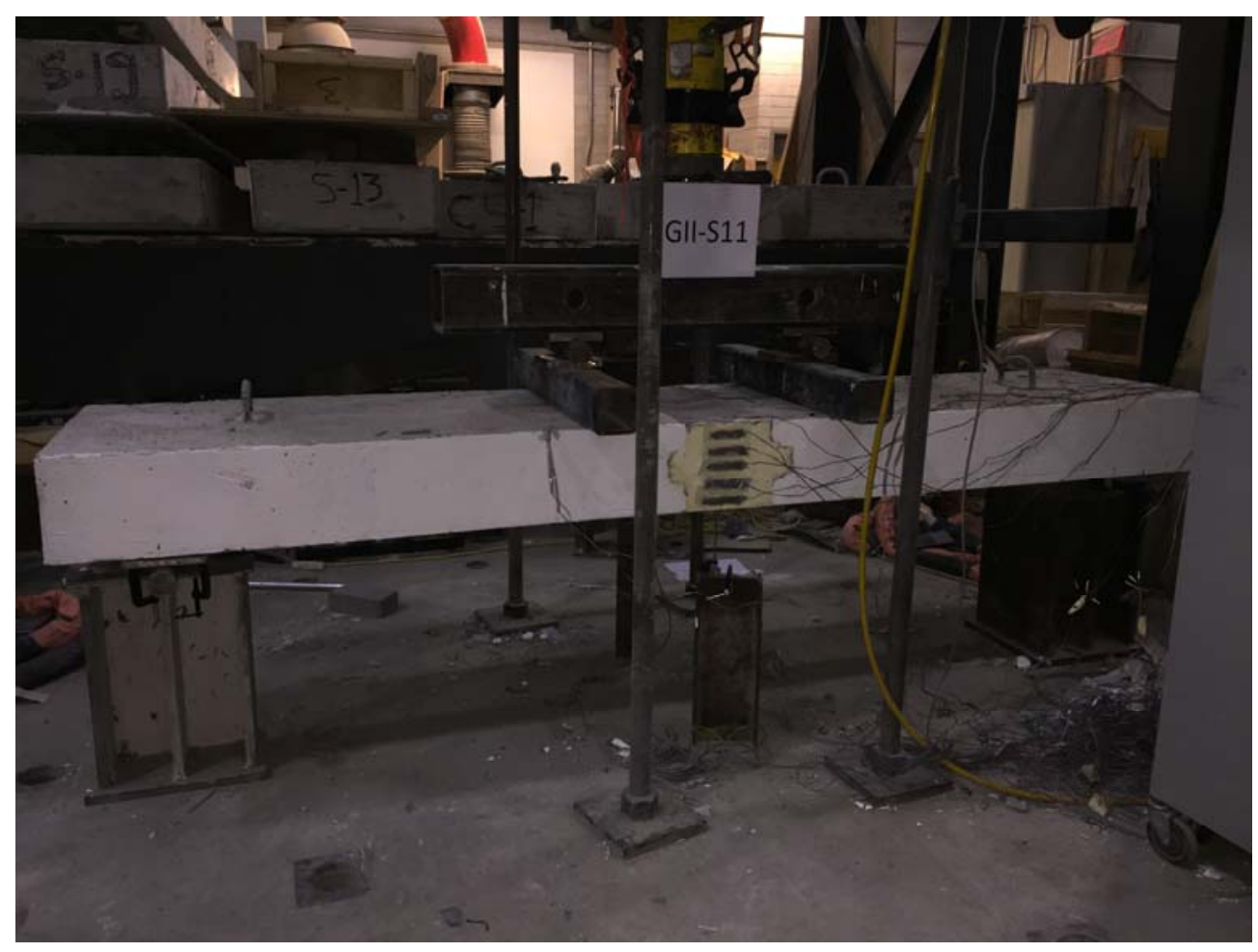

Figure 4.38 Test setup of slab $\mathrm{S}_{11}$ before testing.

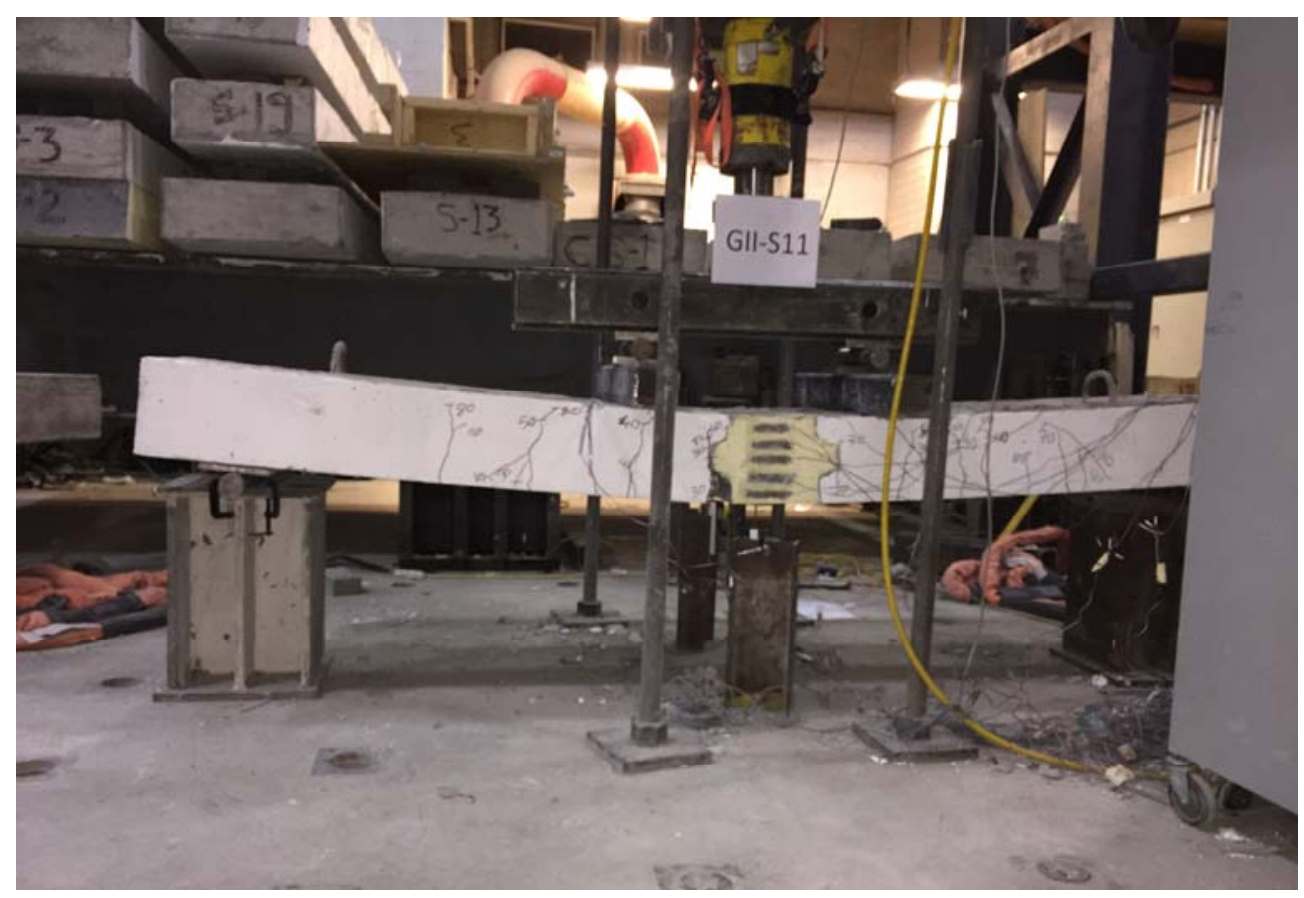

Figure 4.39 View of crack pattern of slab $\mathrm{S}_{11}$ after failure 


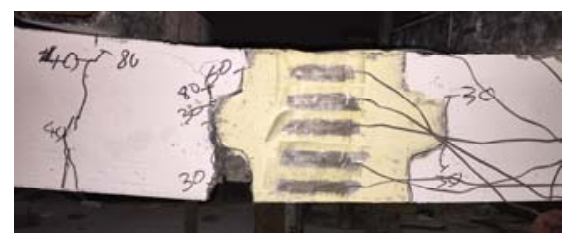

(a) Side 1

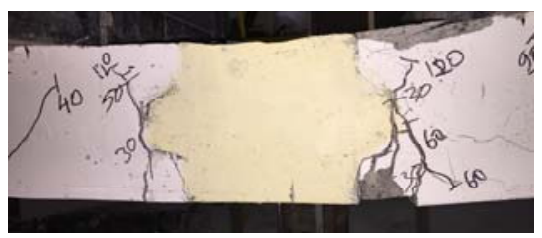

(b) Side 2

Figure 4.40 Close-up view of flexural cracks at the joint of slab $\mathrm{S}_{11}$

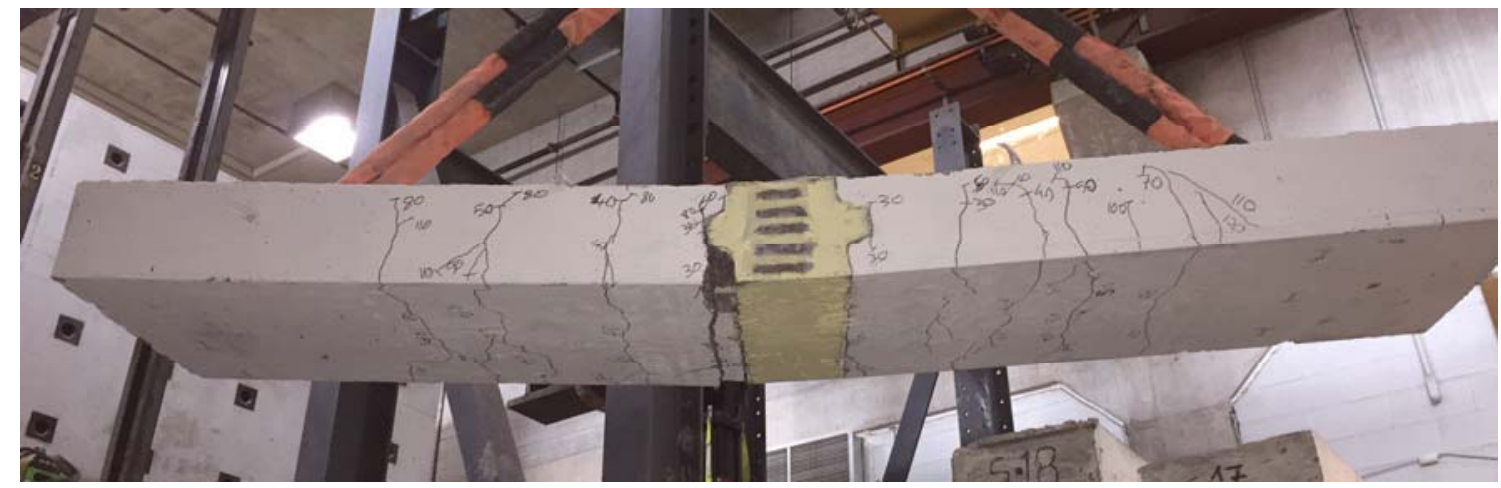

(a) View of crack pattern at the bottom of slab $S_{11}$

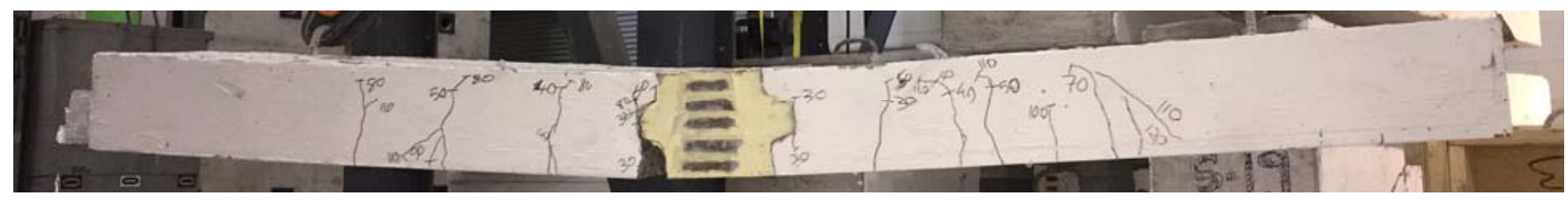

(b) Side 1

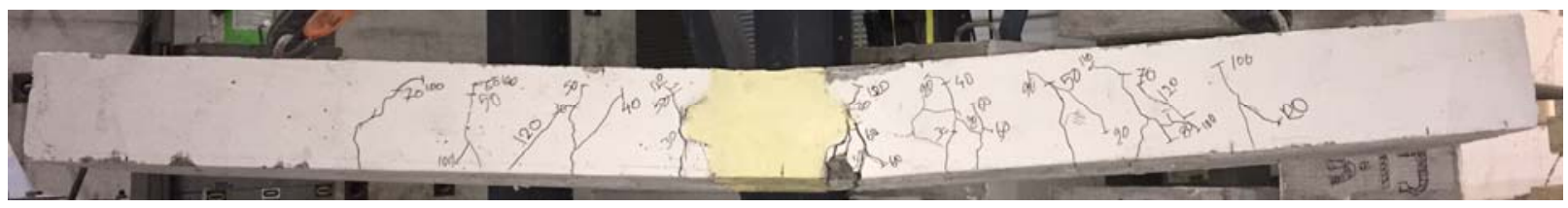

(c) Side 2

Figure 4.41 View of the crack pattern at the bottom and two sides of slab $\mathrm{S}_{11}$ 


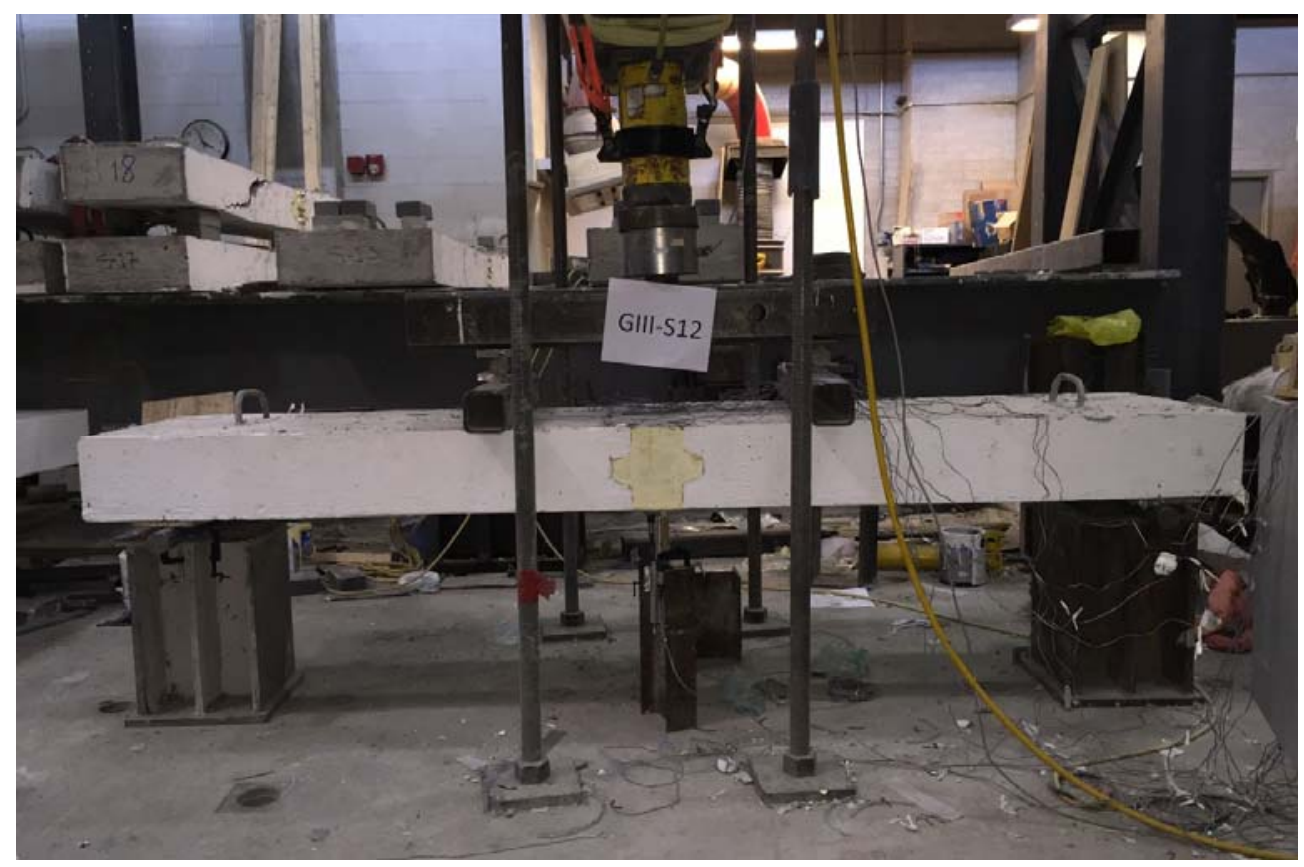

Figure 4.42 Test setup of slab $\mathrm{S}_{12}$ before testing

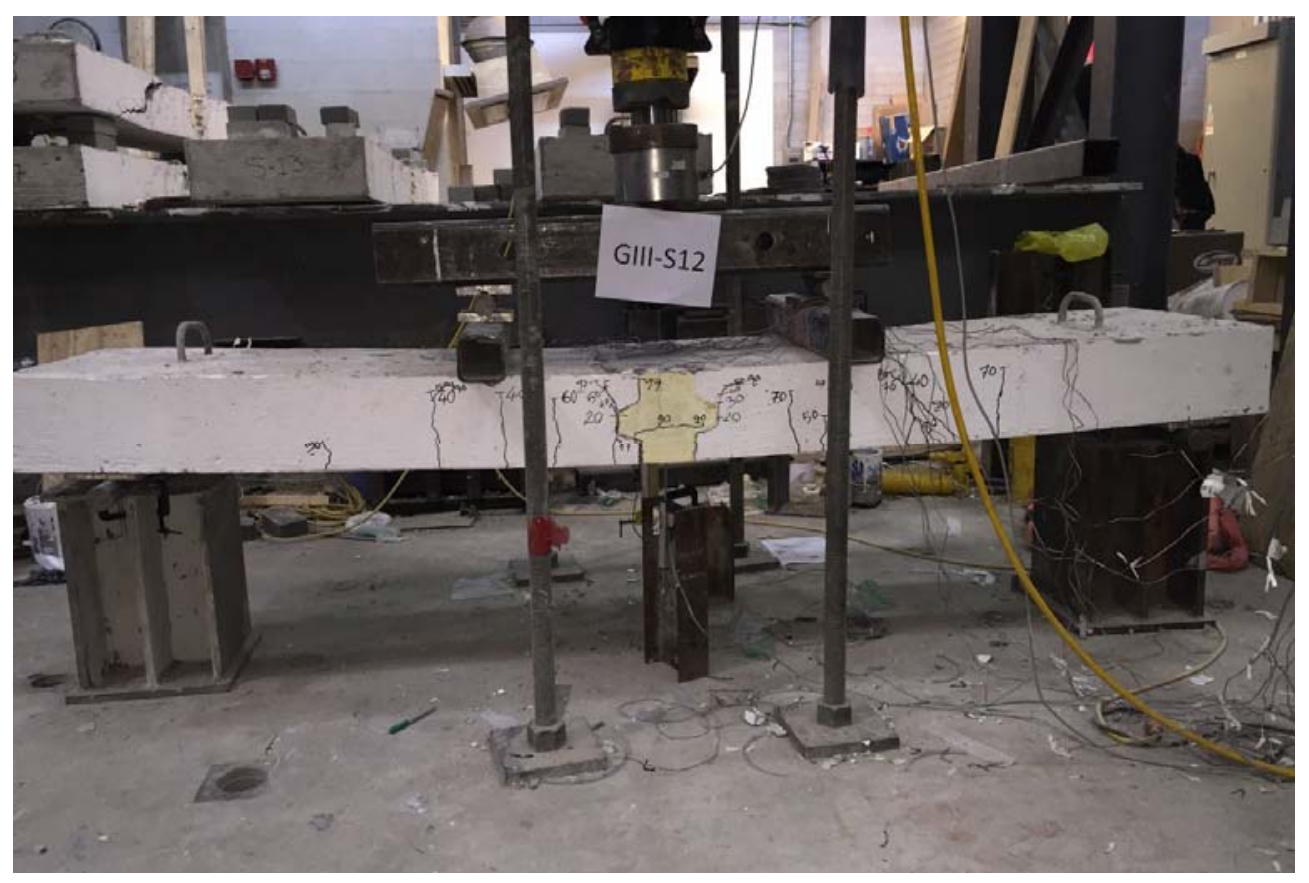

Figure 4.43 View of crack pattern of slab $\mathrm{S}_{12}$ after failure 


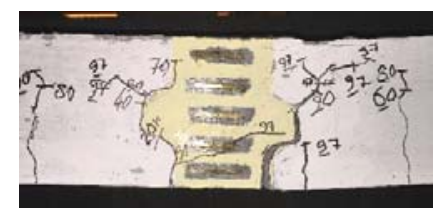

(a) Side 1

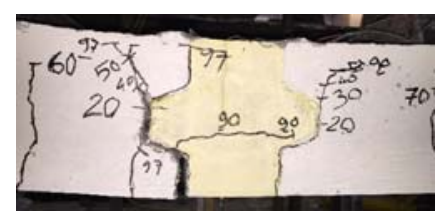

(b) Side 2

Figure 4.44 Close-up view of flexural cracks at the joint of slab $\mathrm{S}_{12}$

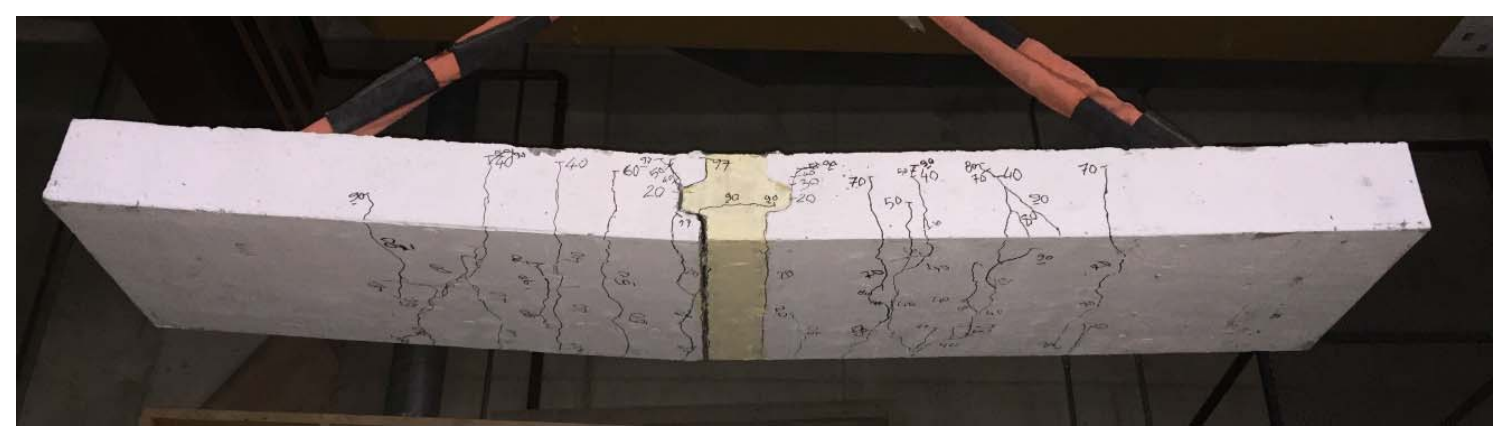

(a) View of crack pattern at the bottom slab $\mathrm{S}_{12}$

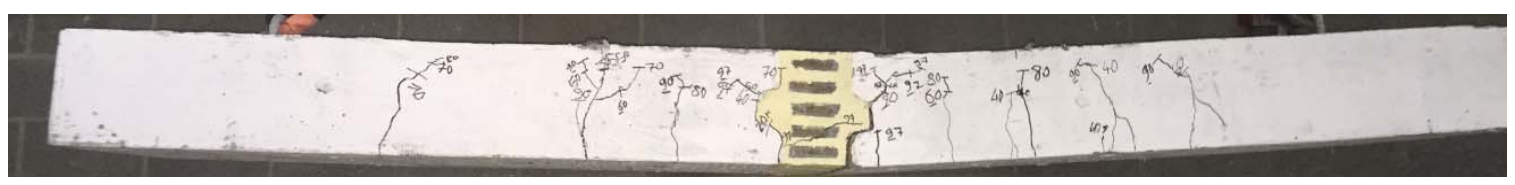

(b) Side 1

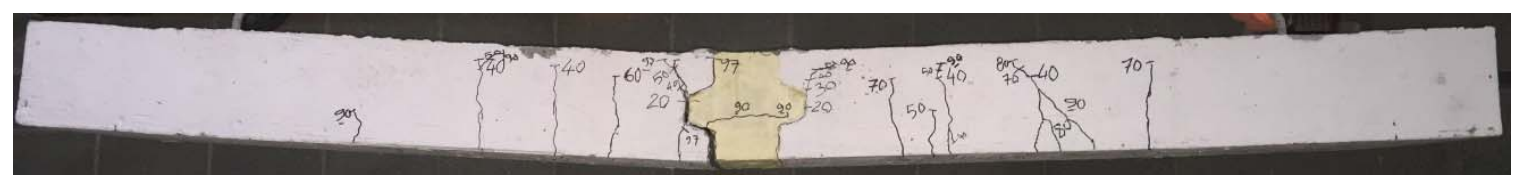

(c) Side 2

Figure 4.45 View of the crack pattern at the bottom and two sides of slab $\mathrm{S}_{12}$ 


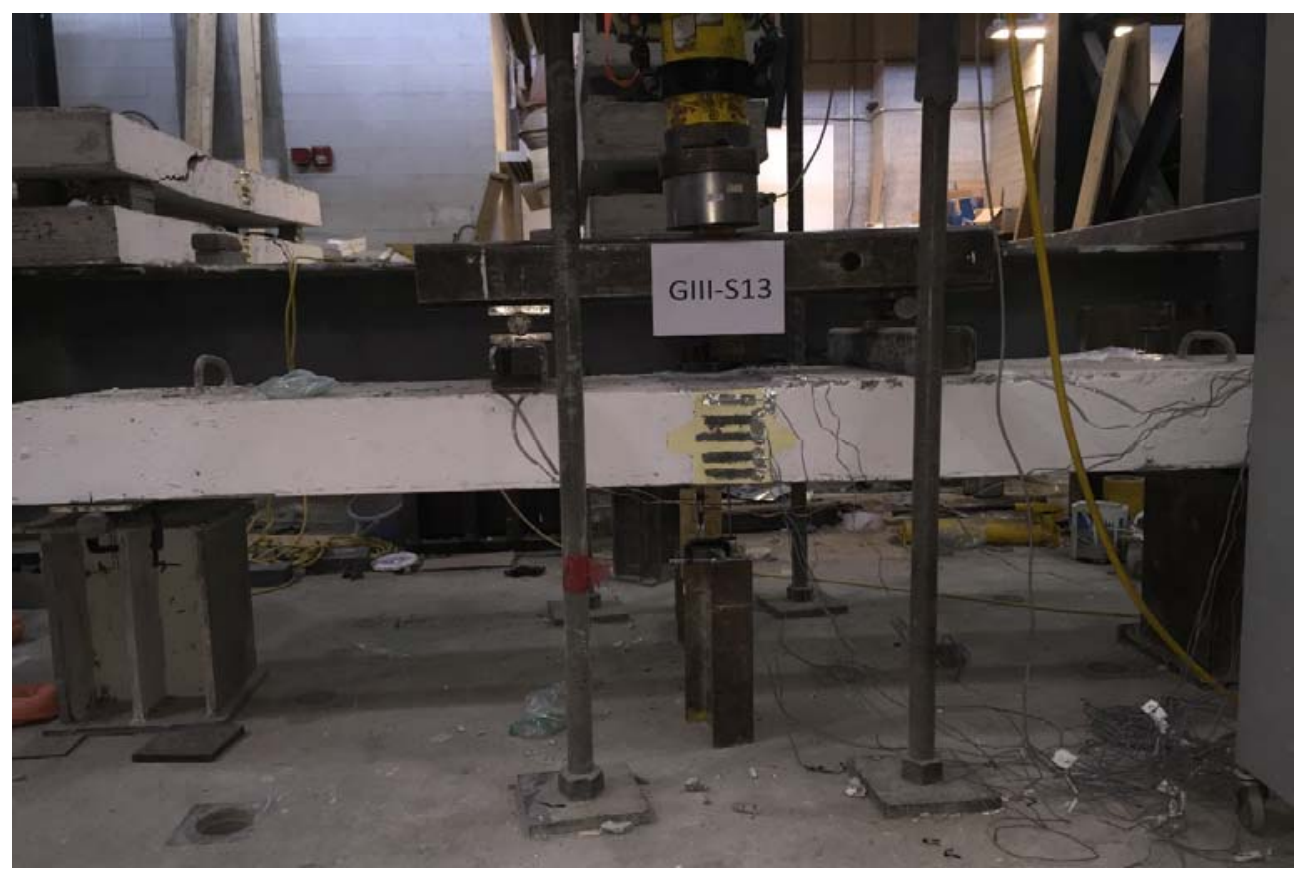

Figure 4.46 Test setup of slab $\mathrm{S}_{13}$ before testing

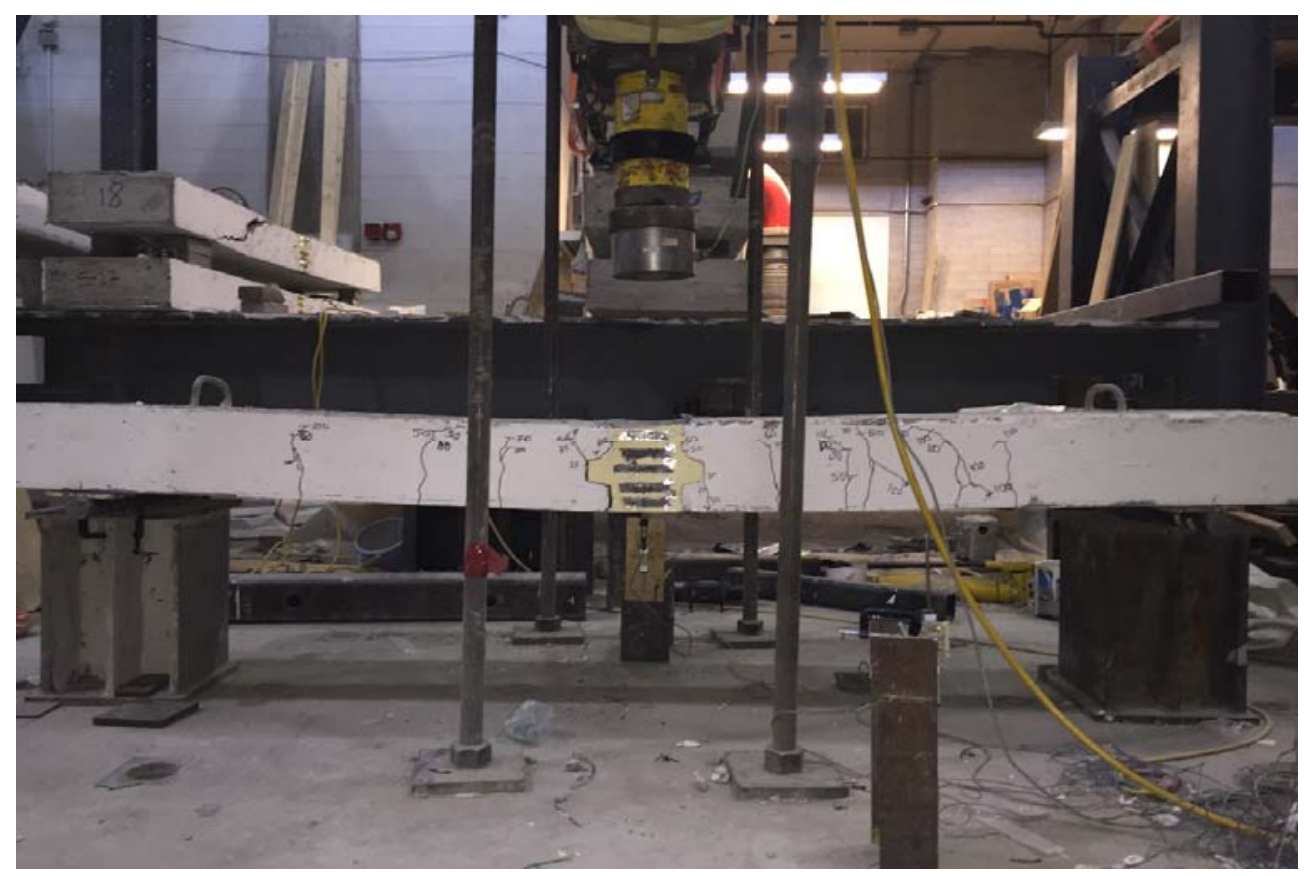

Figure 4.47 View of crack pattern of slab $\mathrm{S}_{13}$ after failure 


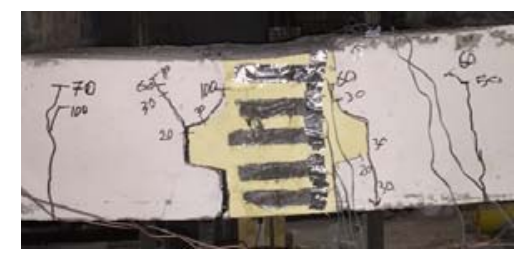

(a) Side 1

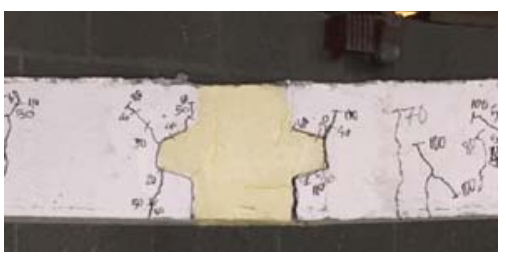

(b) Side 2

Figure 4.48 Close-up view of flexural cracks at the joint of slab $\mathrm{S}_{13}$

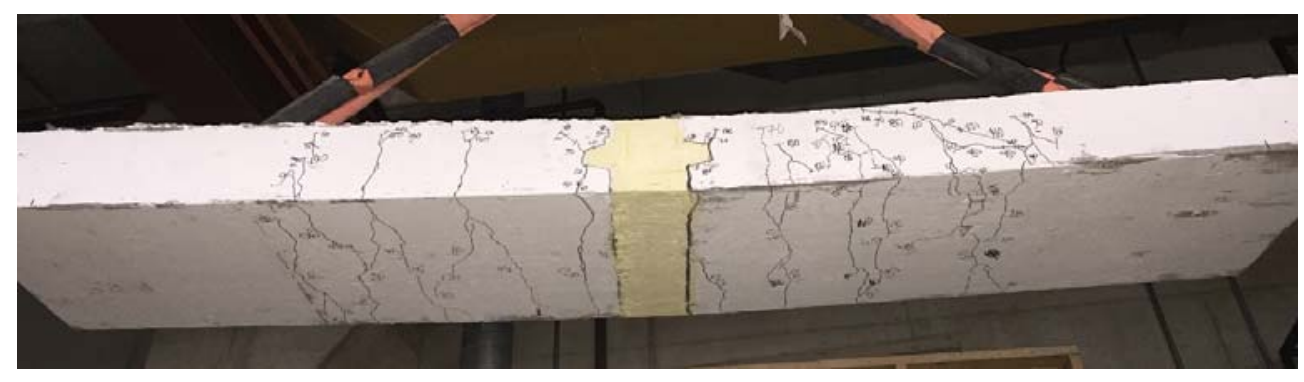

(a) View of crack pattern at the bottom slab $\mathrm{S}_{13}$

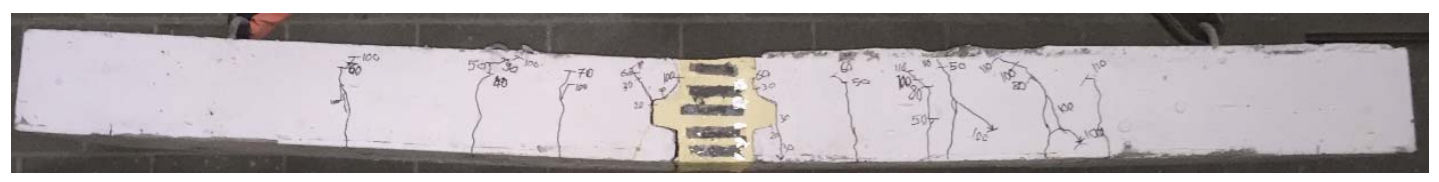

(b) Side 1

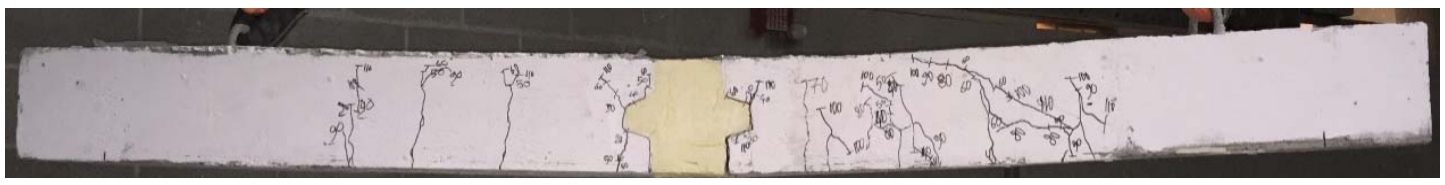

(c) Side 2

Figure 4.49 View of the crack pattern at the bottom and two sides of slab $\mathrm{S}_{13}$ 


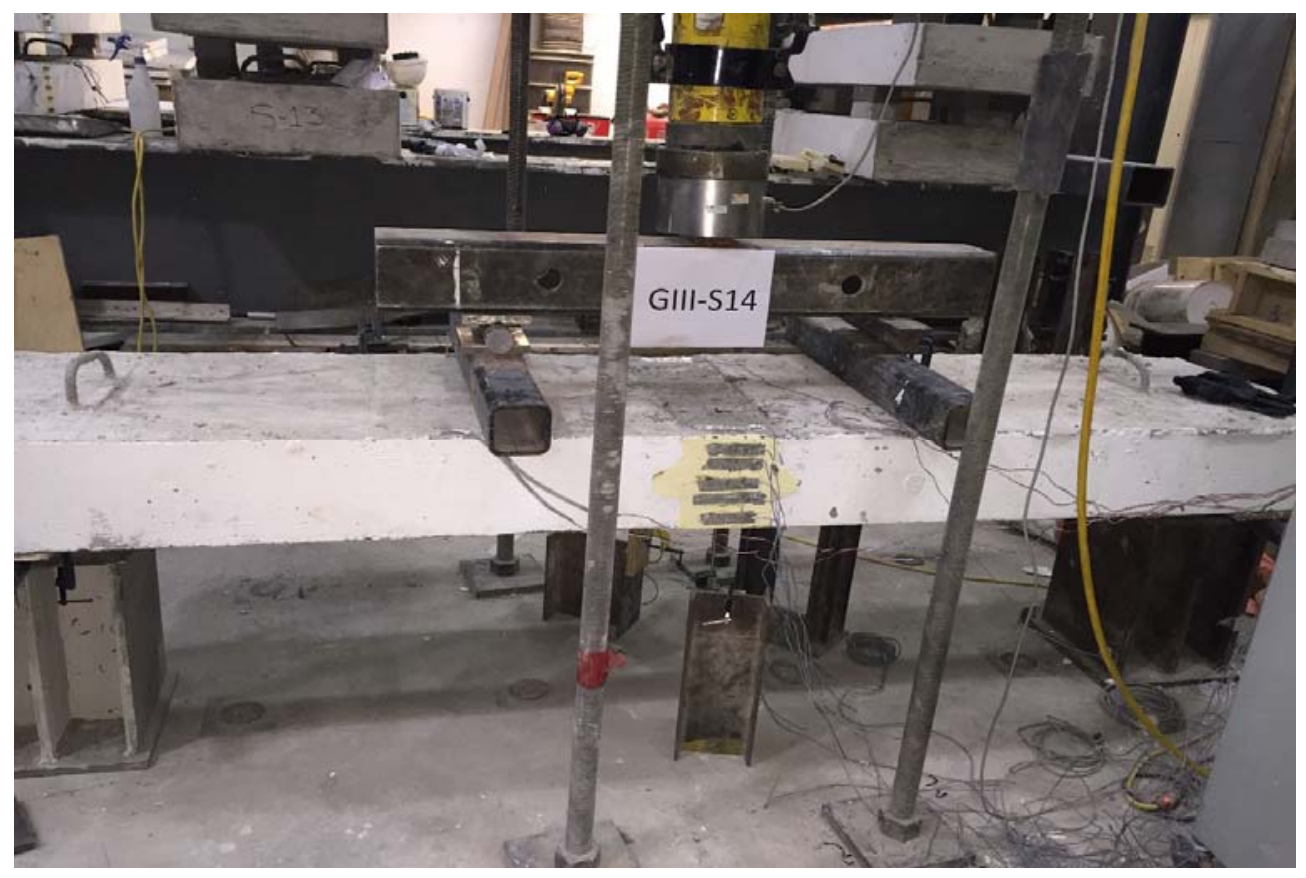

Figure 4.50 Test setup of slab $\mathrm{S}_{14}$ before testing

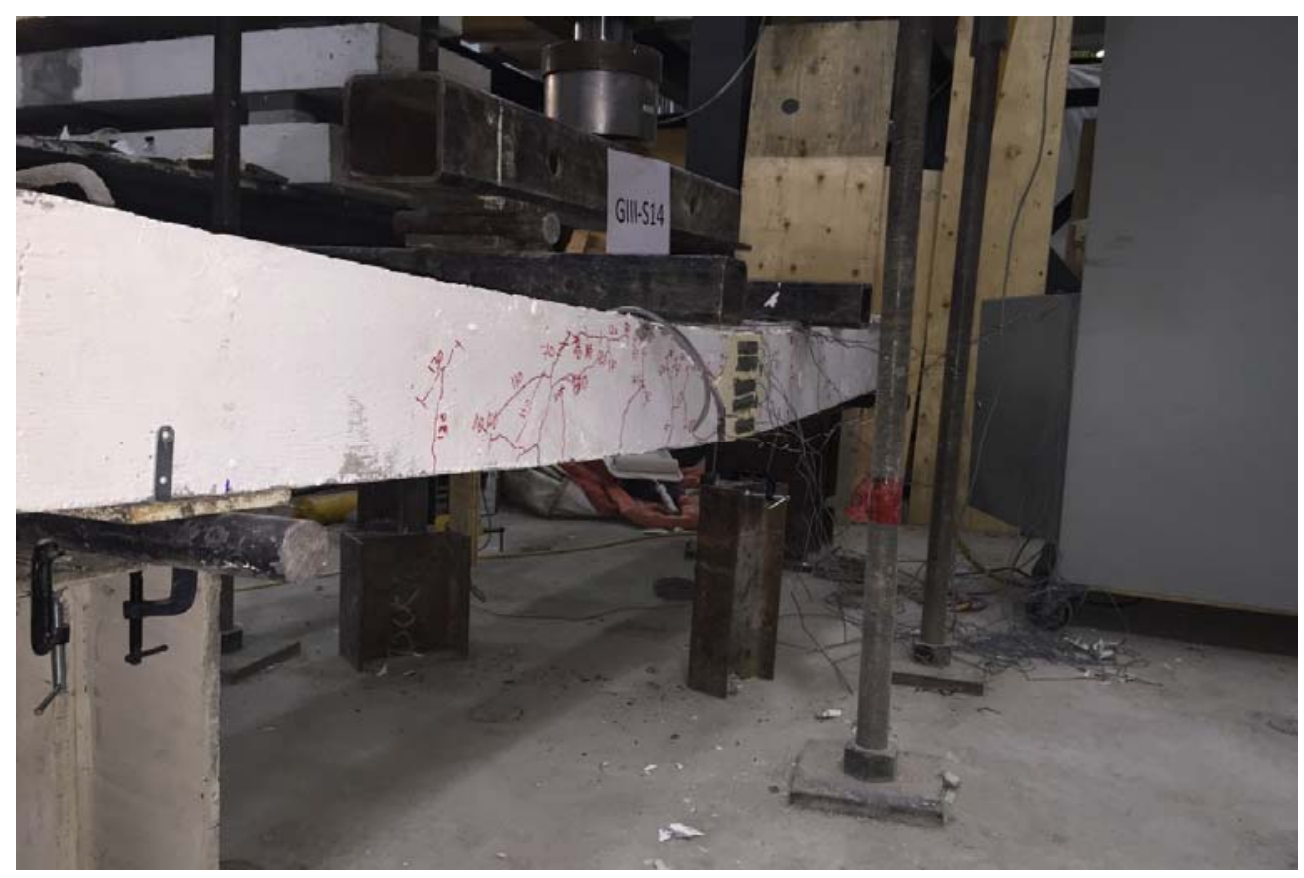

Figure 4.51 View of crack pattern of slab $\mathrm{S}_{14}$ after failure 


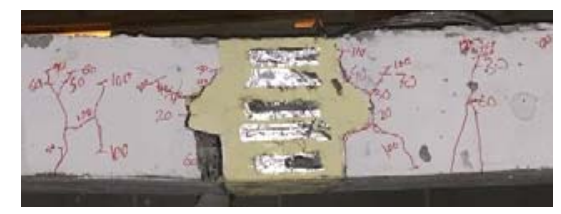

(a) Side 1

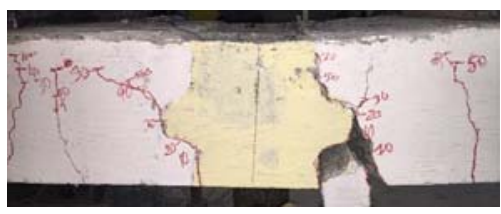

(b) Side 2

Figure 4.52 Close-up view of flexural cracks at the joint of slab $\mathrm{S}_{14}$

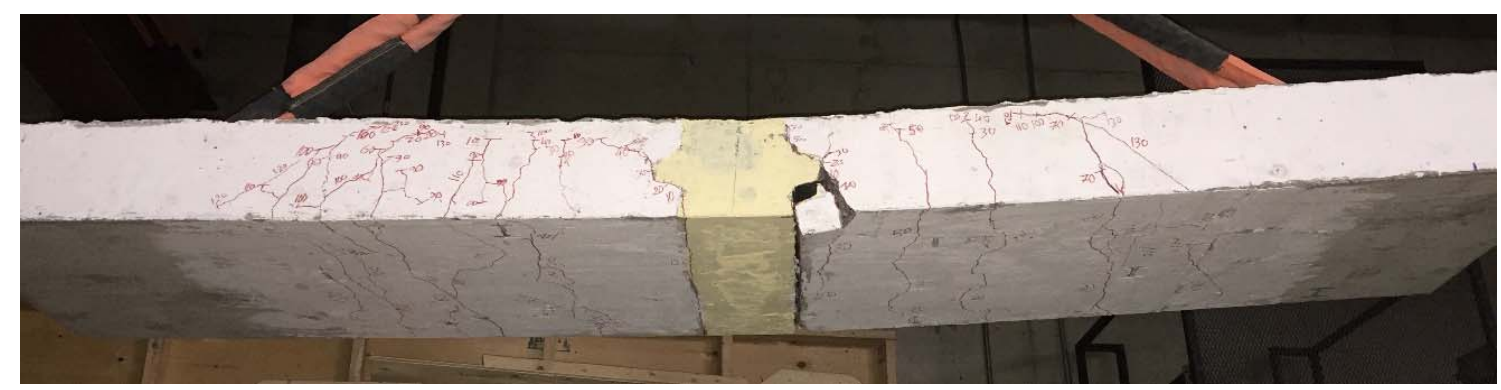

(a) View of crack pattern at the bottom of slab $\mathrm{S}_{14}$

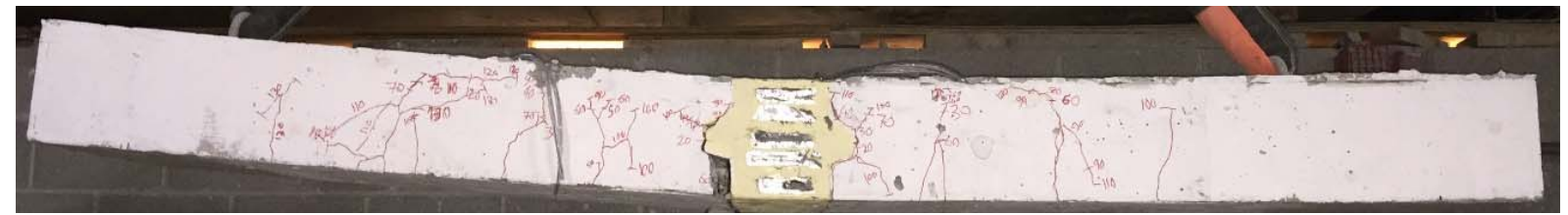

(b) Side 1

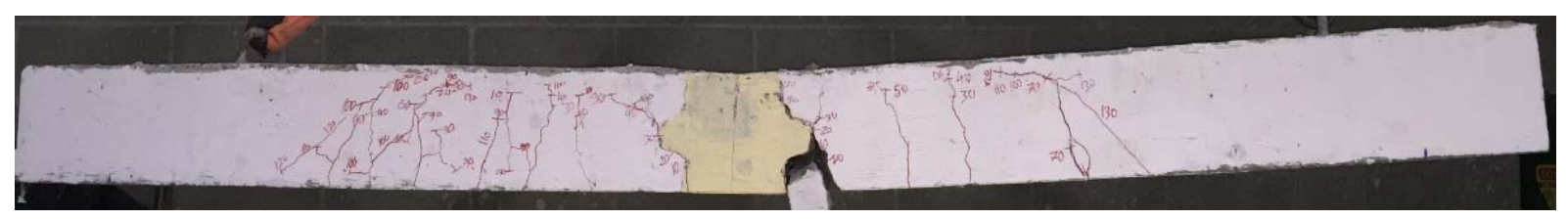

(c) Side 2

Figure 4.53 View of the crack pattern at the bottom and two sides of slab $\mathrm{S}_{14}$ 


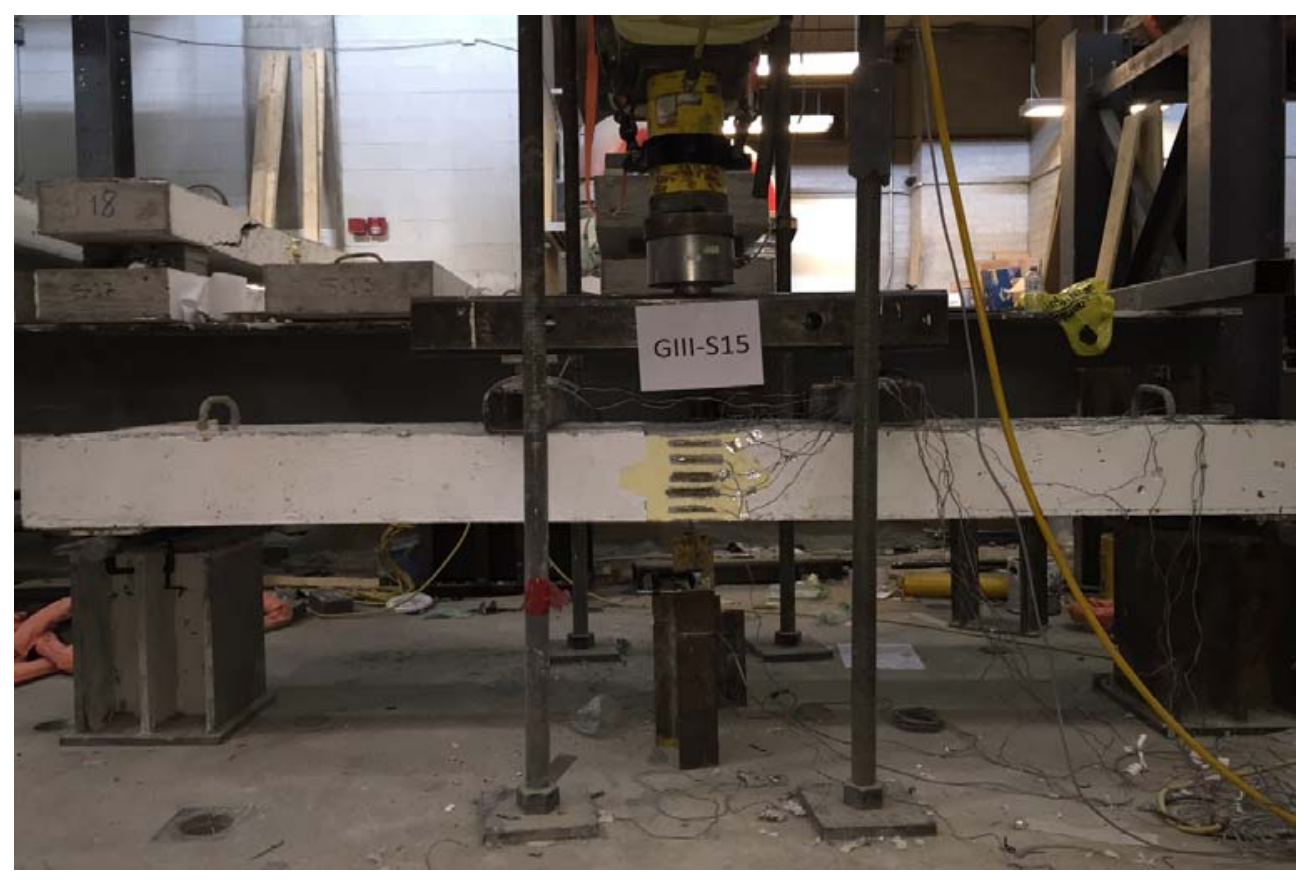

Figure 4.54 Test setup of slab $\mathrm{S}_{15}$ before testing

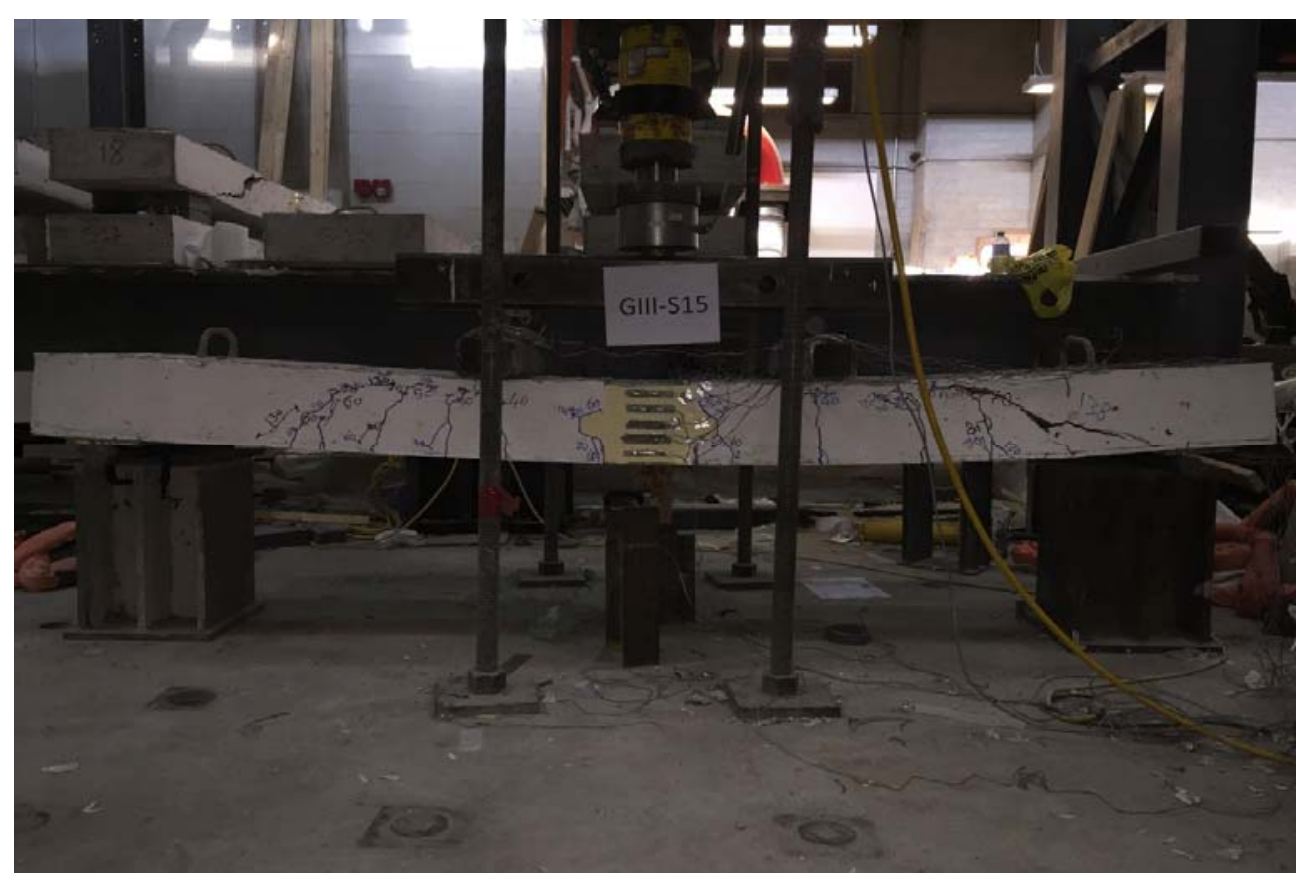

Figure 4.55 View of crack pattern of slab $\mathrm{S}_{15}$ after failure 


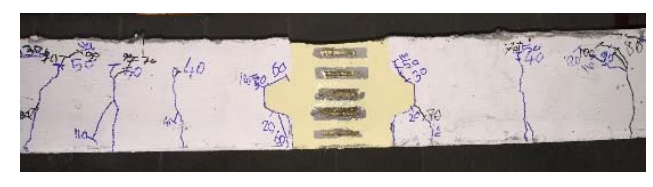

(a) Side 1

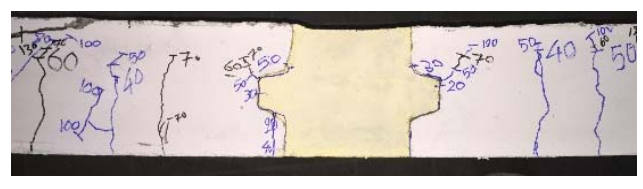

(b) Side 2

Figure 4.56 Close-up view of flexural cracks at the joint of slab $\mathrm{S}_{15}$

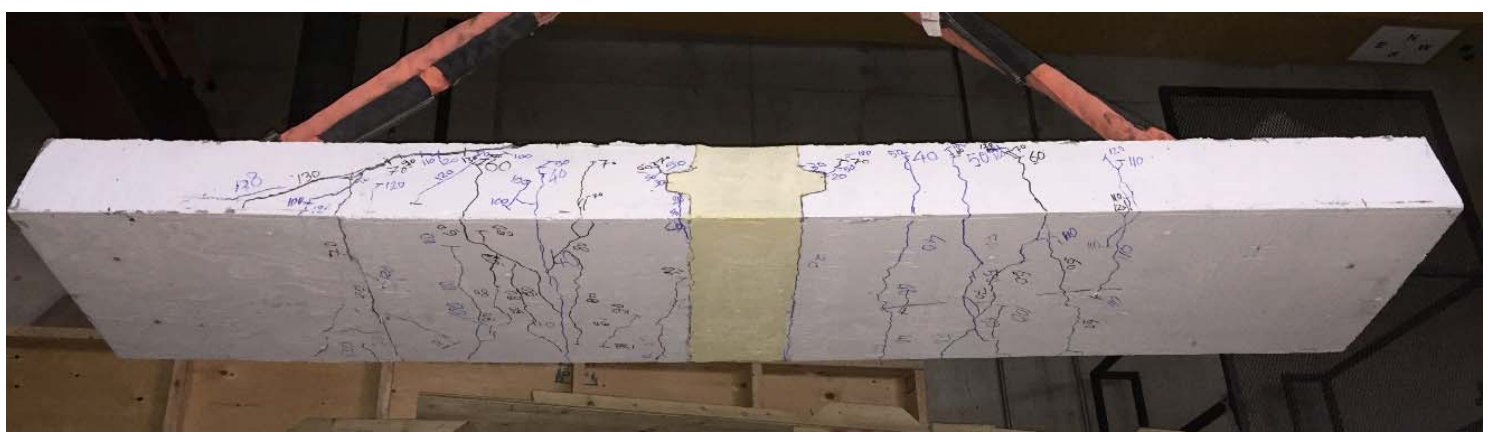

(a) View of crack pattern at the bottom of slab $\mathrm{S}_{15}$

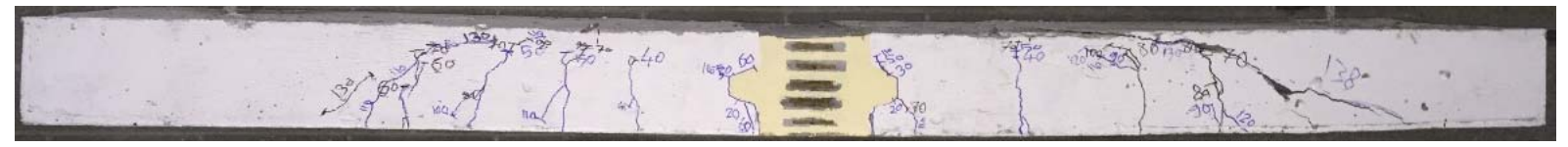

(b) Side 1

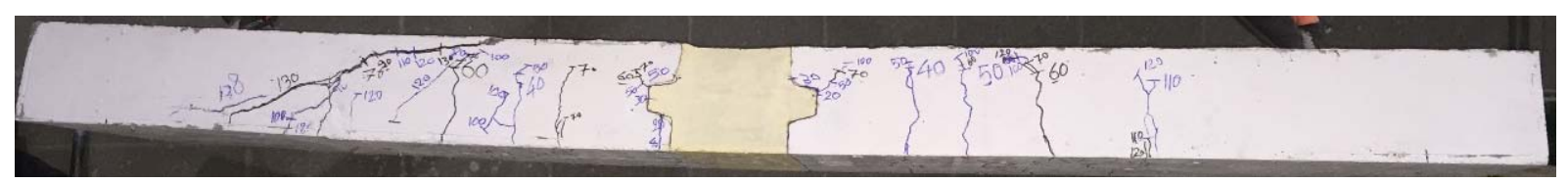

(c) Side 2

Figure 4.57 View of crack pattern at the two sides of slab $\mathrm{S}_{15}$ 


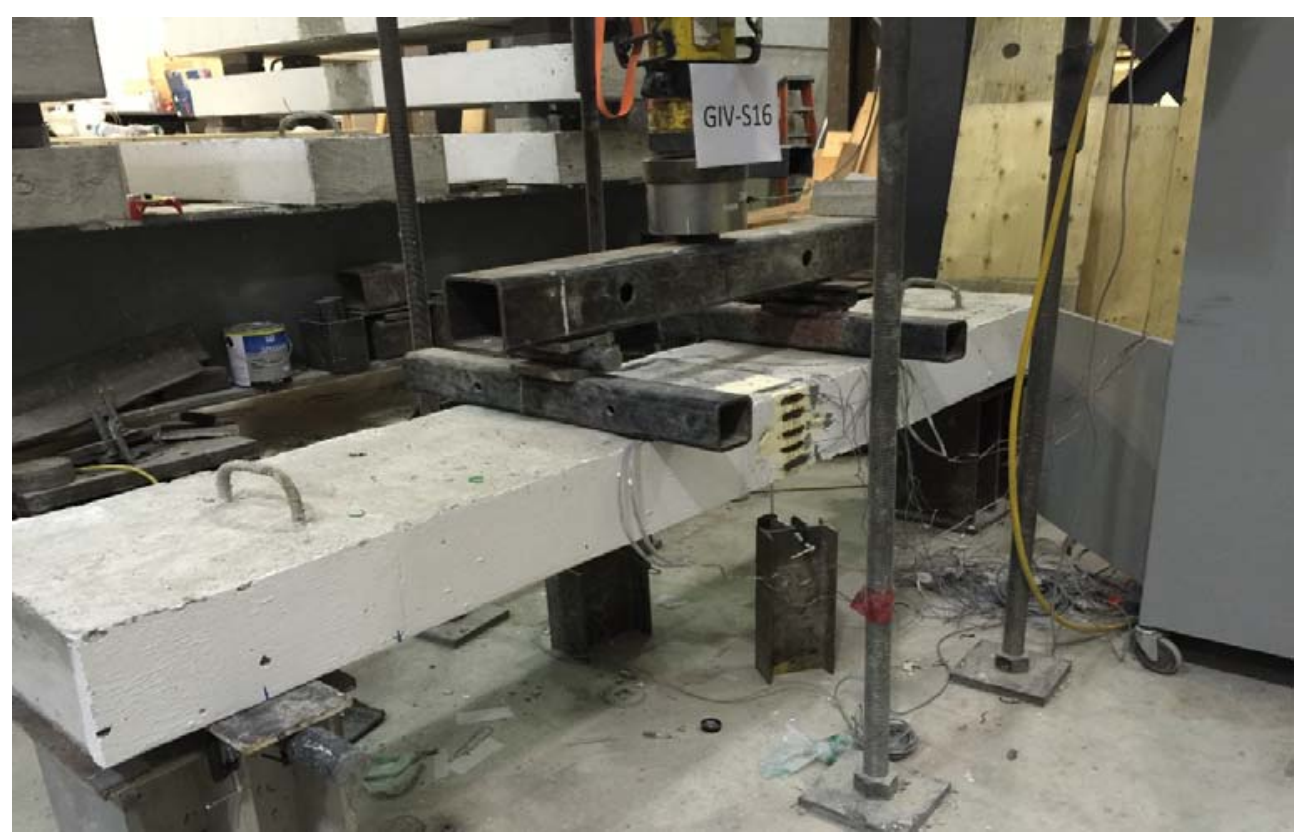

Figure 4.58 Test setup of slab $\mathrm{S}_{16}$ before testing

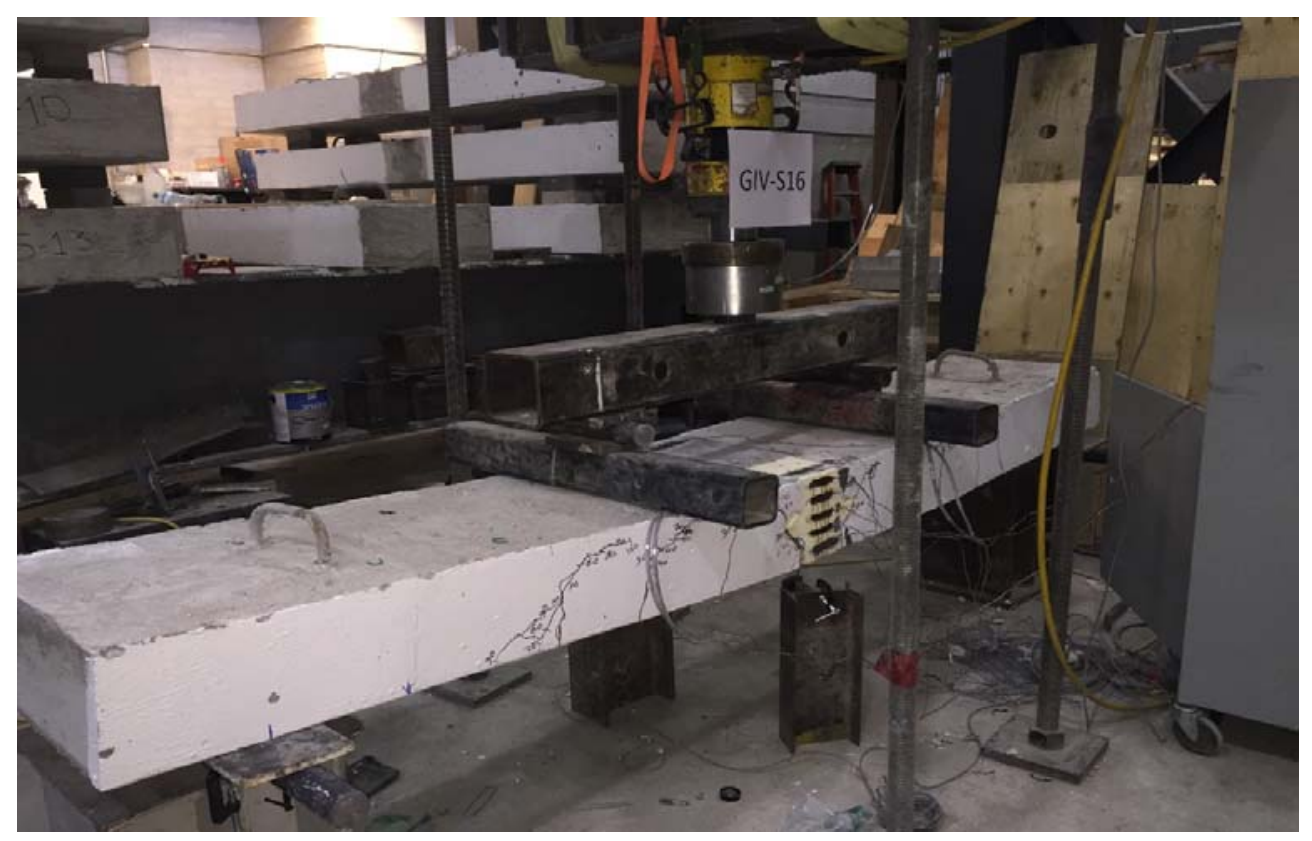

Figure 4.59 View of crack pattern of slab $\mathrm{S}_{16}$ after failure 


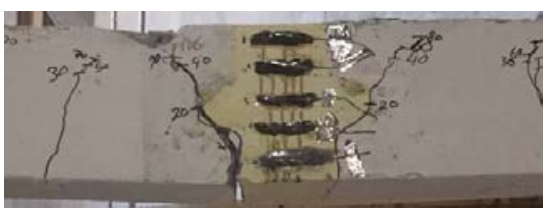

(a) Side 1

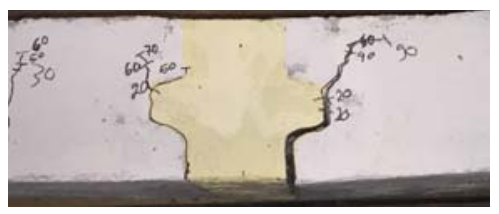

(b) Side 2

Figure 4.60 Close-up view of flexural cracks at the joint of slab $\mathrm{S}_{16}$

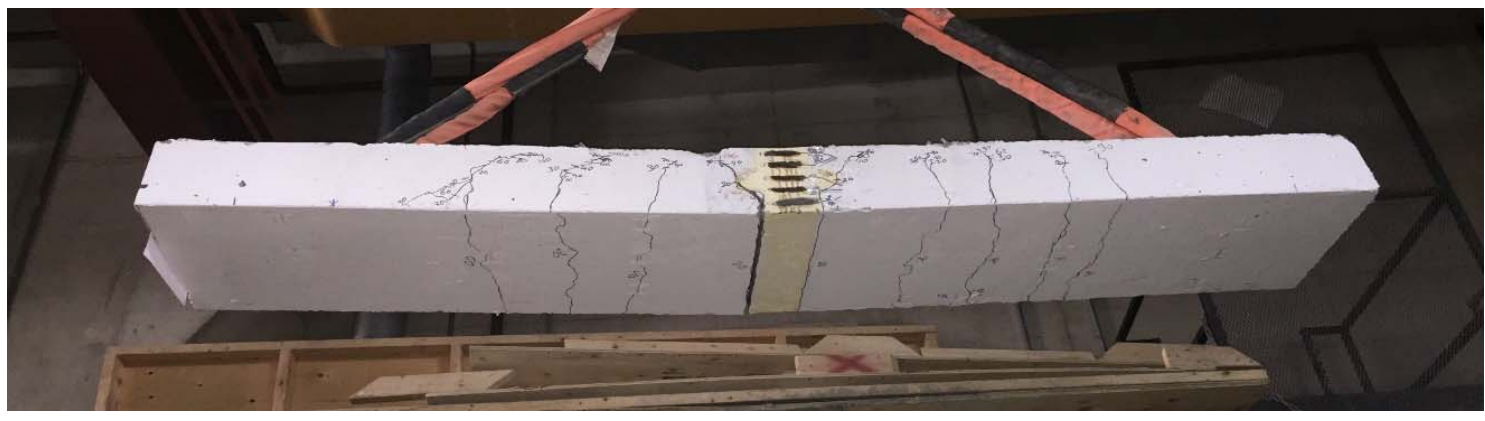

(a) View of crack pattern at the bottom of the Slab $\mathrm{S}_{16}$

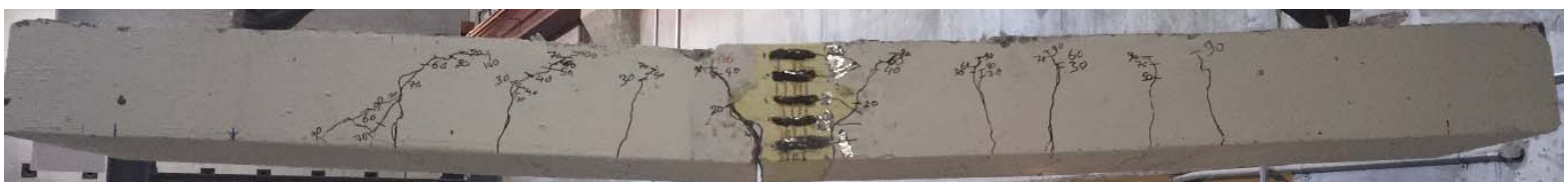

(b) Side 1

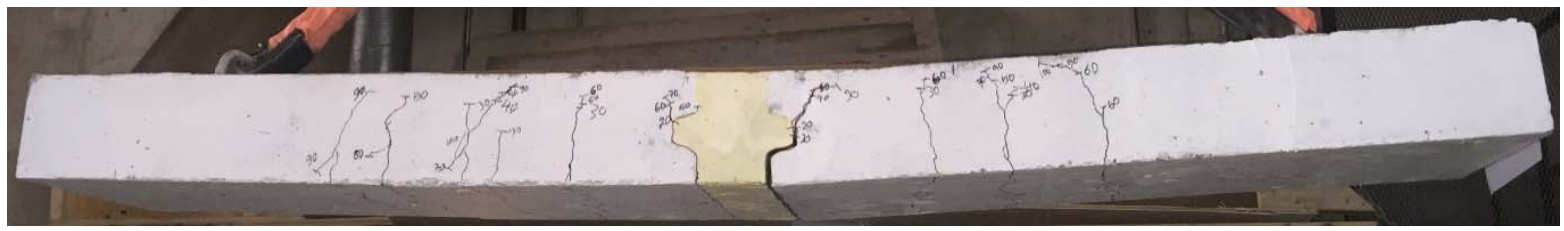

(c) Side 2

Figure 4.61 View of the crack pattern at the bottom and two sides of slab $\mathrm{S}_{16}$ 


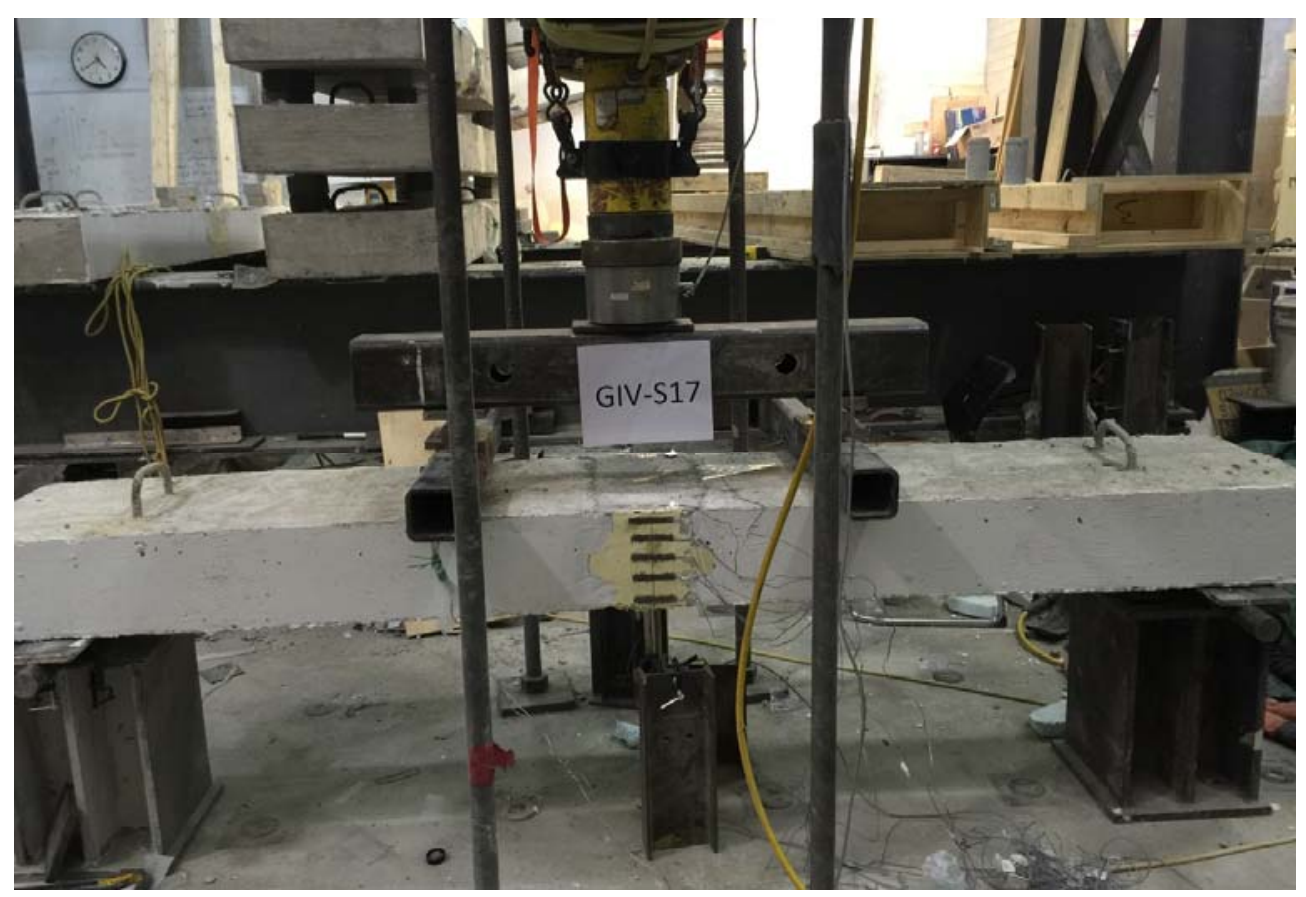

Figure 4.62 Test setup of slab $\mathrm{S}_{17}$ before testing

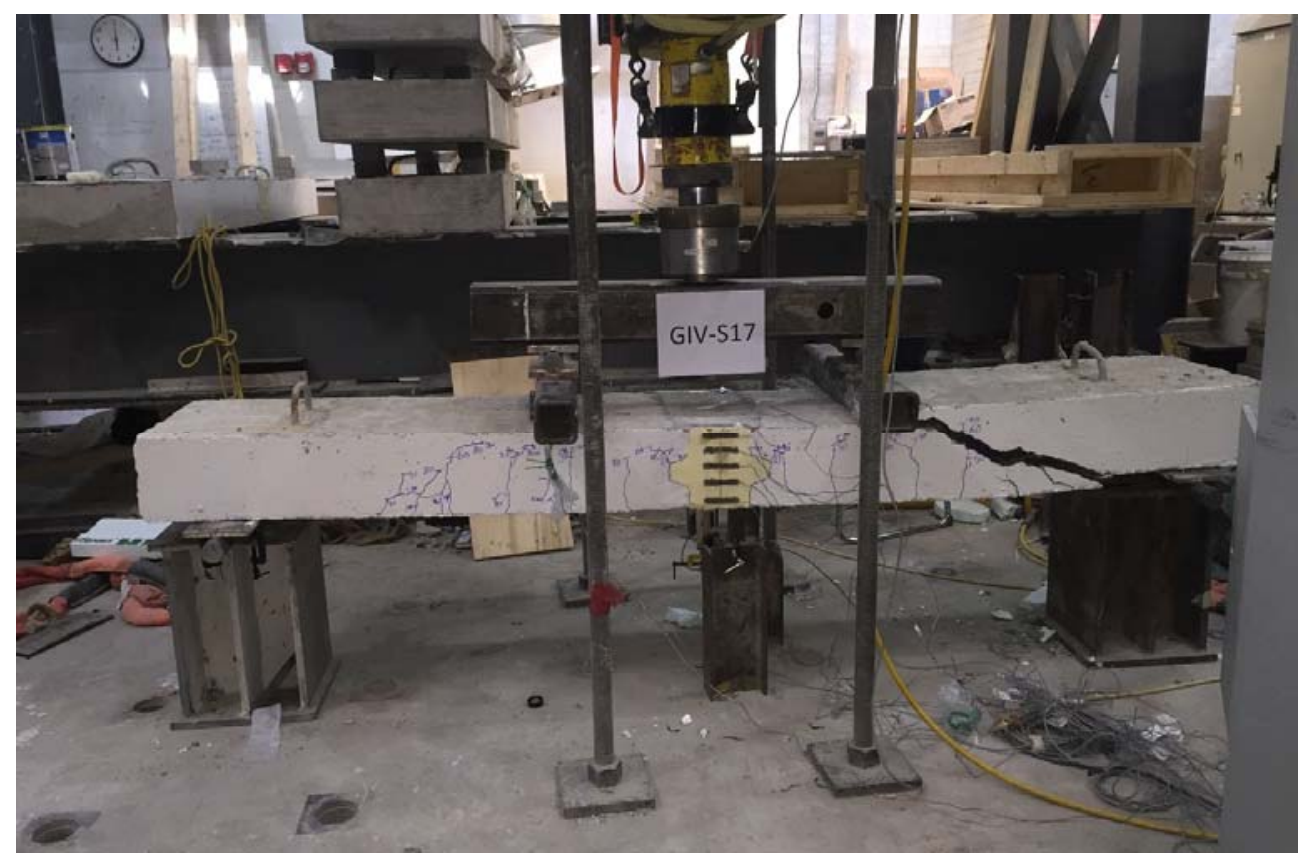

Figure 4.63 View of crack pattern of slab $\mathrm{S}_{17}$ after failure 


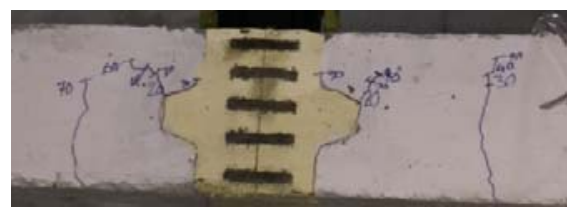

(a) Side 1

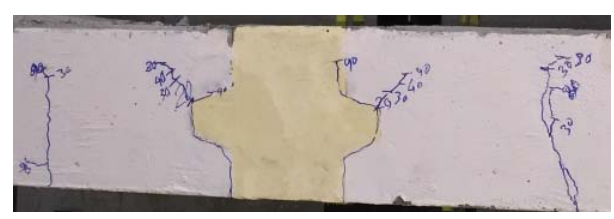

(b) Side 2

Figure 4.64 Close-up view of flexural cracks at the joint of slab $\mathrm{S}_{17}$

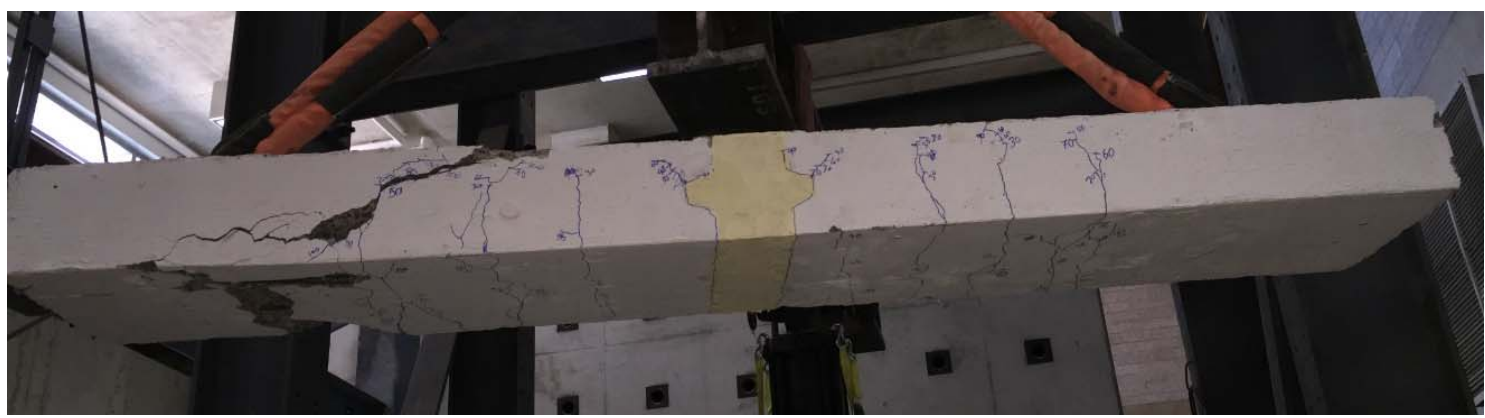

(a) View of crack pattern at the bottom of slab $\mathrm{S}_{17}$

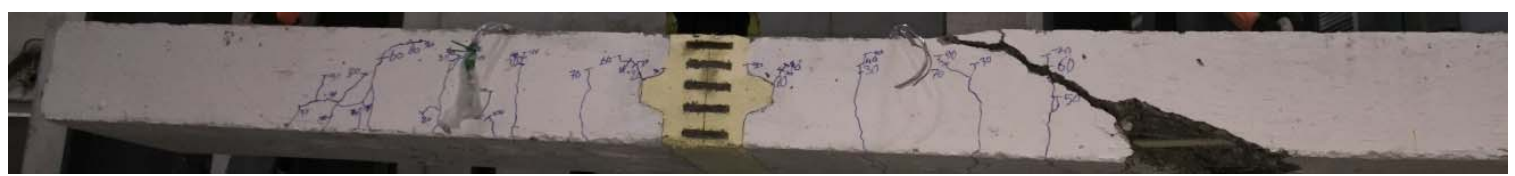

(b) Side 1

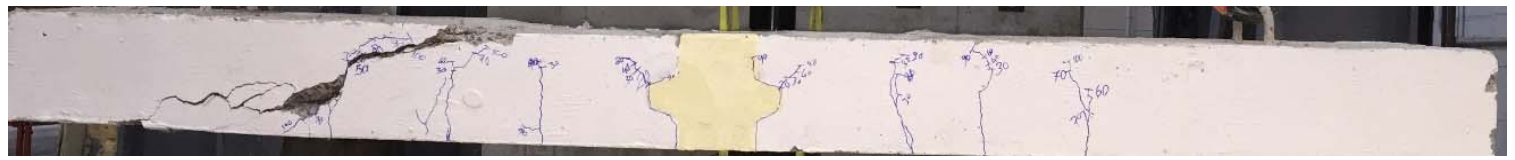

(c) Side 2

Figure 4.65 View of the crack pattern at the bottom and two sides of slab $\mathrm{S}_{17}$ 


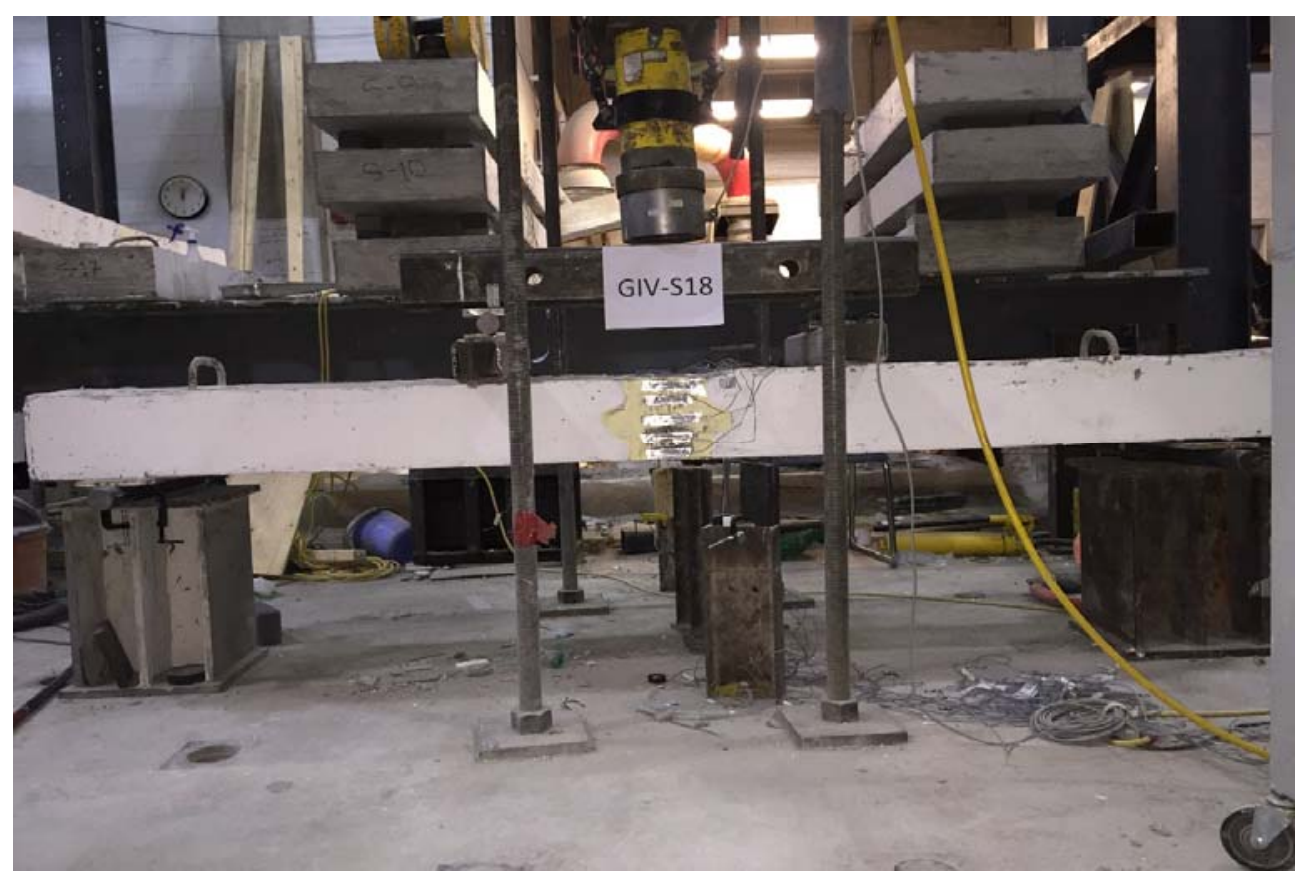

Figure 4.66 Test setup of slab $\mathrm{S}_{18}$ before testing.

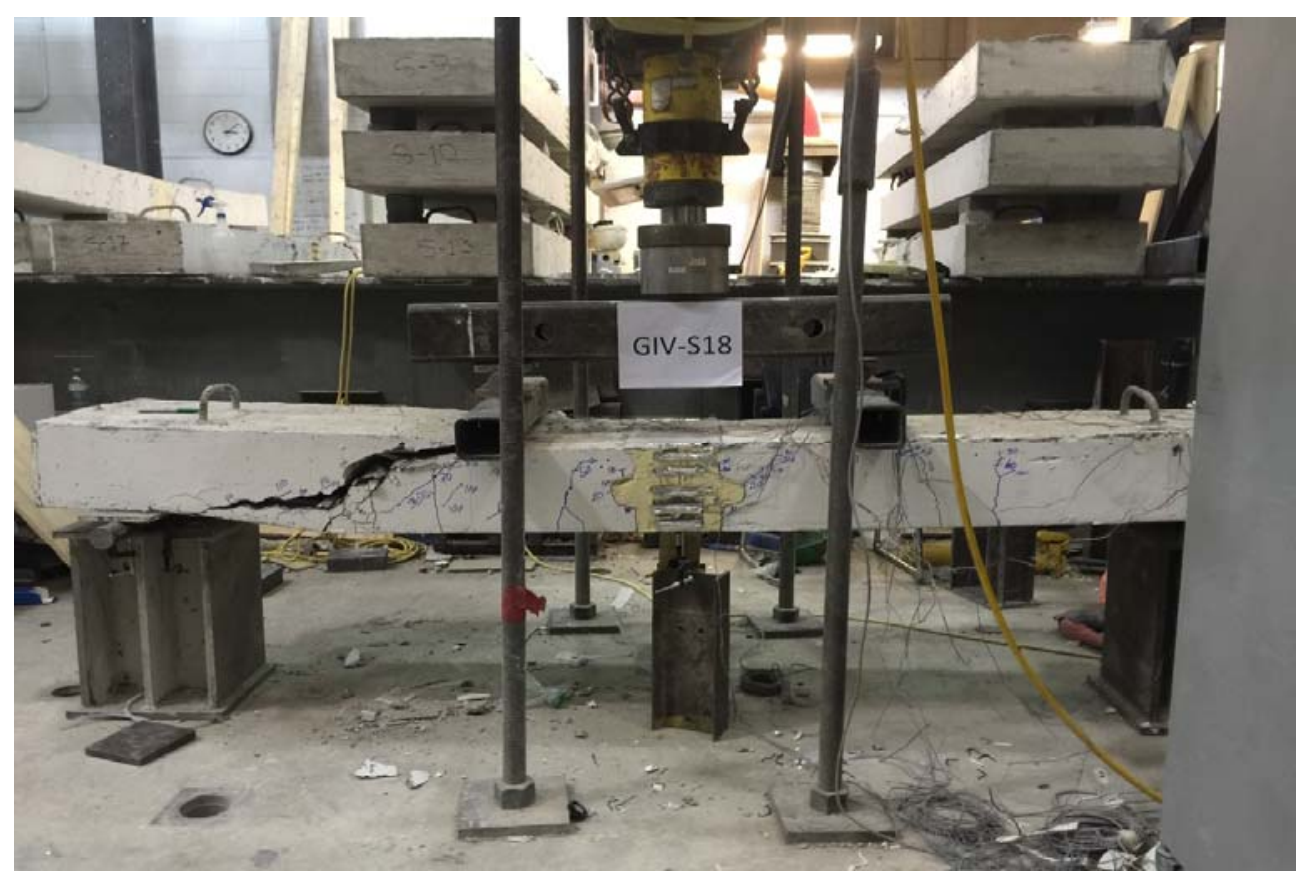

Figure 4.67 View of crack pattern of slab $\mathrm{S}_{18}$ after failure 


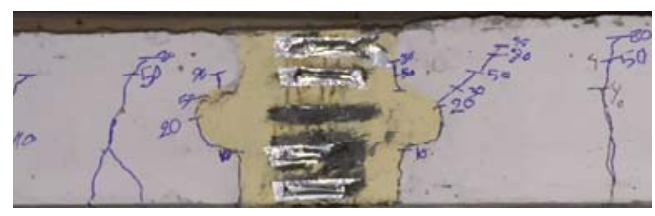

(a) Side 1

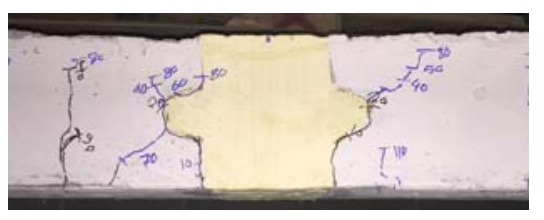

(b) Side 2

Figure 4.68 Close-up view of the flexure cracks at the joint of slab $\mathrm{S}_{18}$

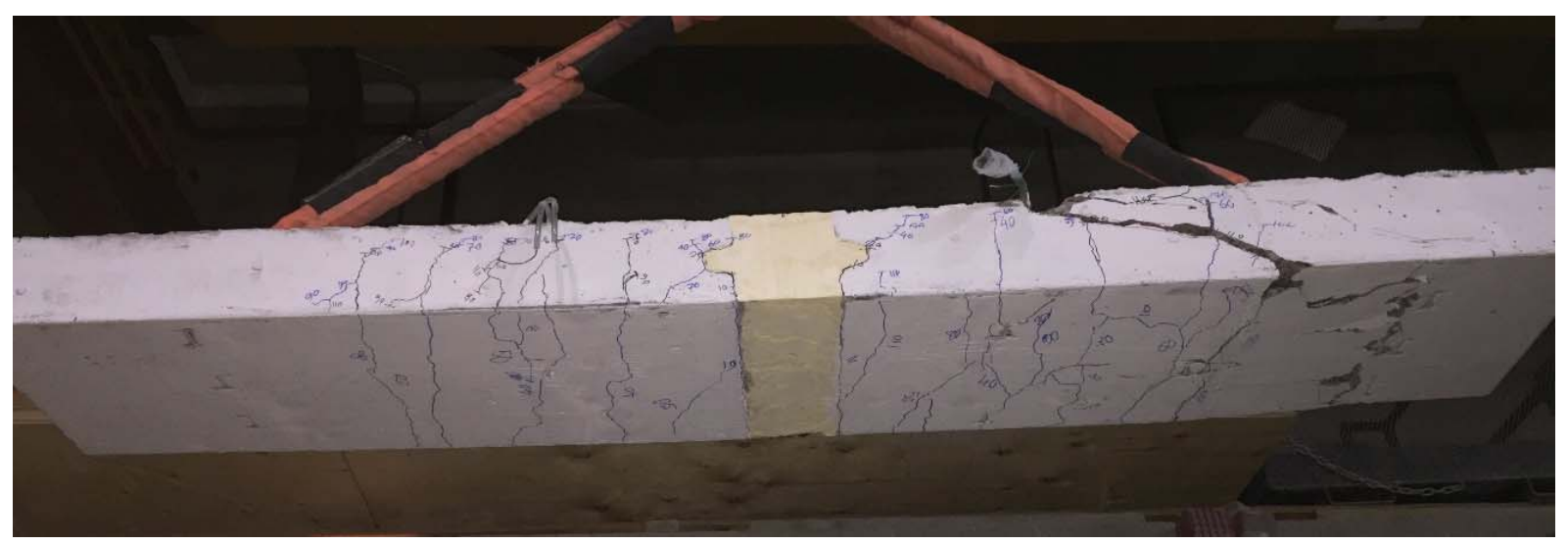

(a) View of crack pattern at the bottom of Slab $\mathrm{S}_{18}$

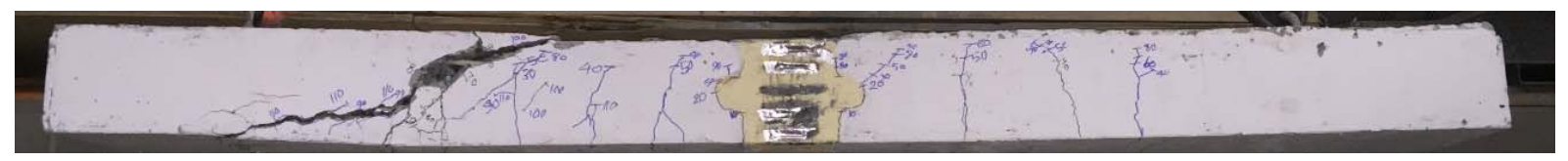

(b) Side 1

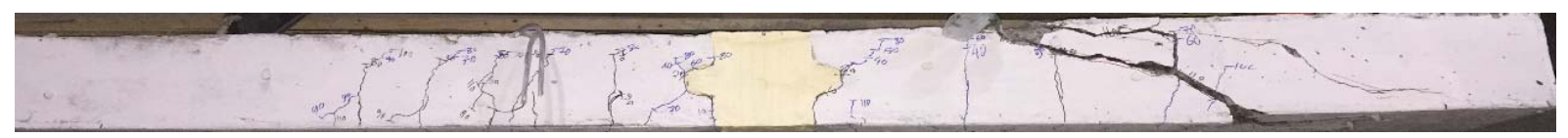

(c) Side 2

Figure 4.69 View of the crack pattern at the bottom and two sides of slab $\mathrm{S}_{18}$ 


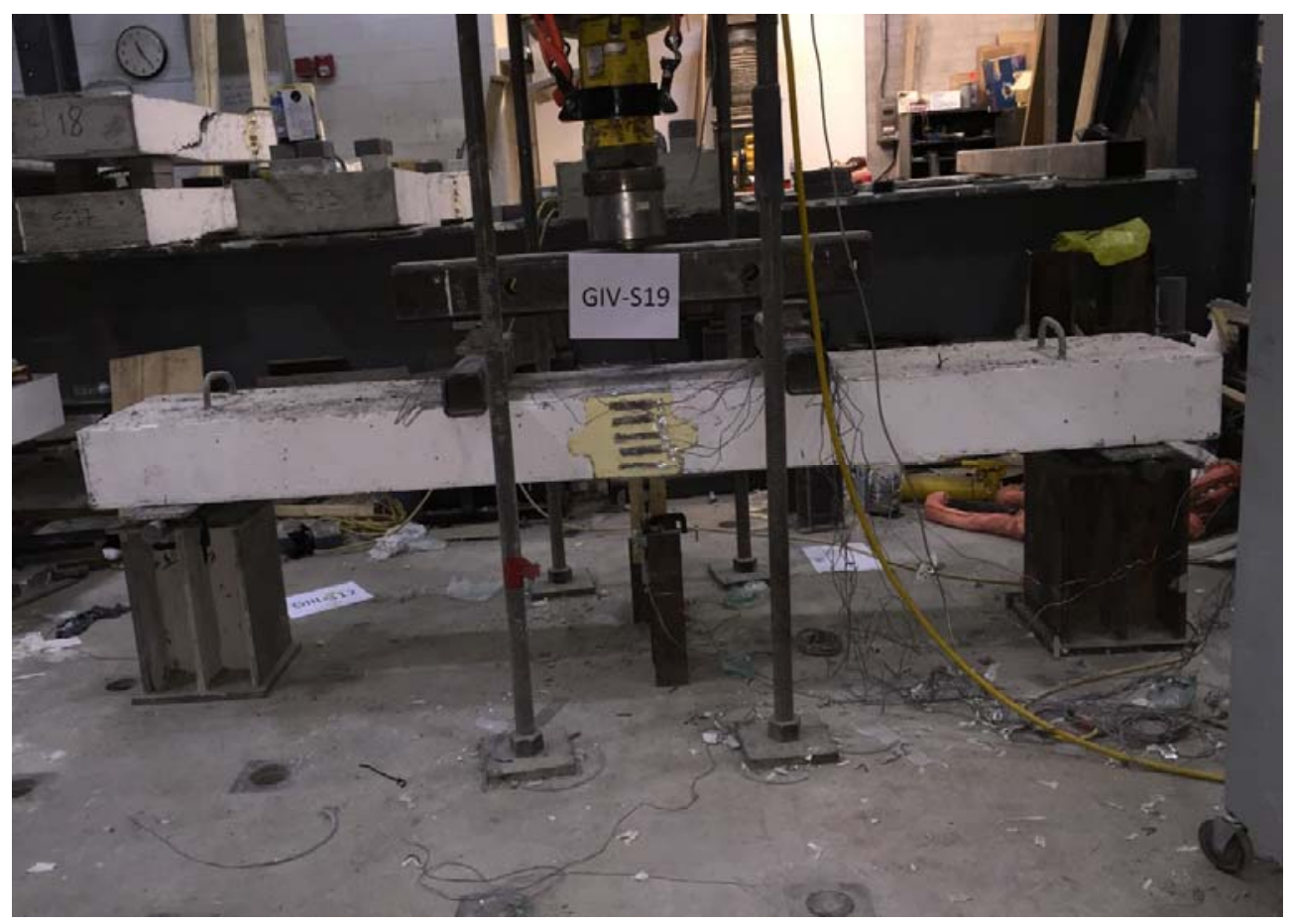

Figure 4.70 Test setup of slab $\mathrm{S}_{19}$ before testing

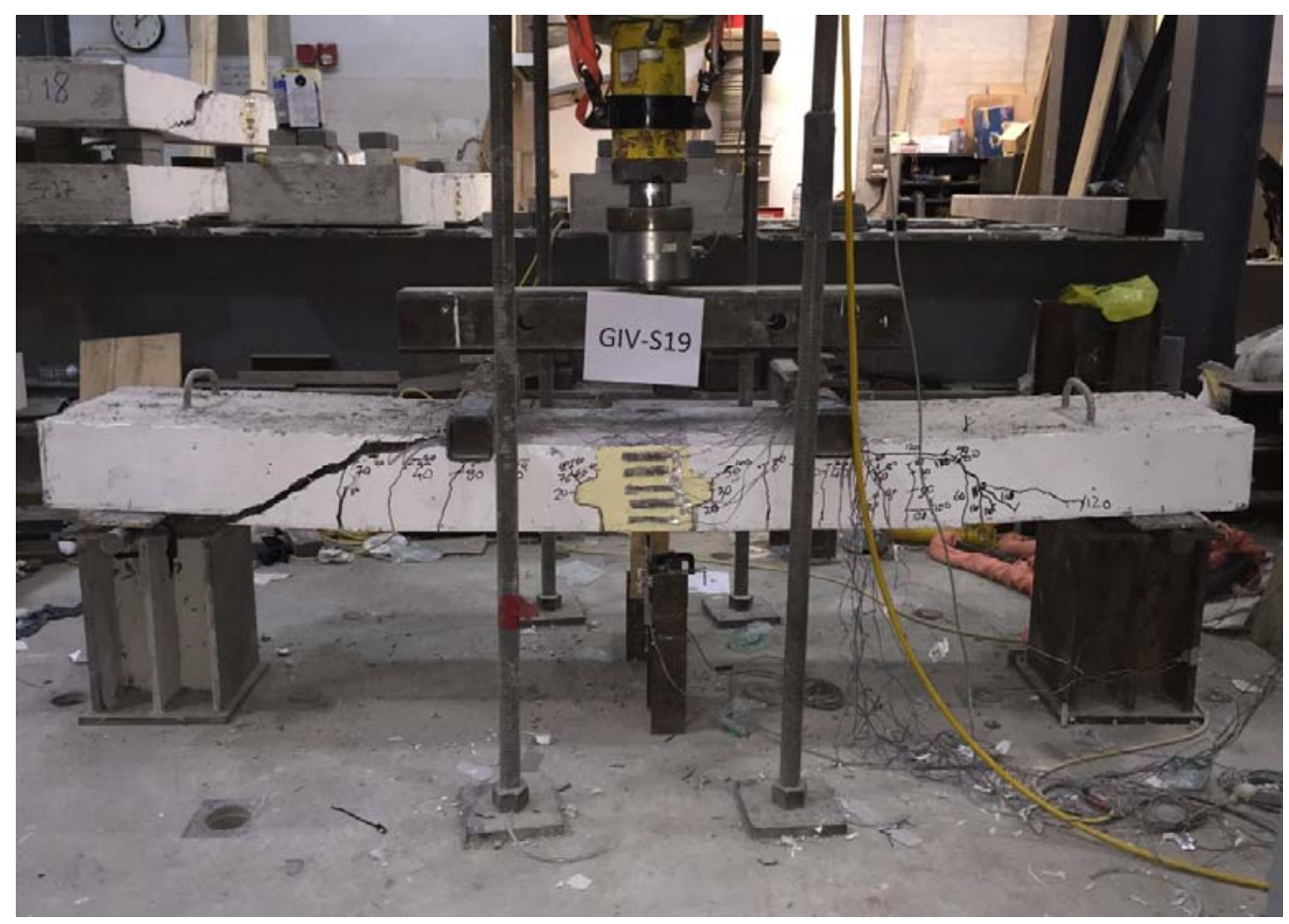

Figure 4.71 View of crack pattern of slab $\mathrm{S}_{19}$ after failure 


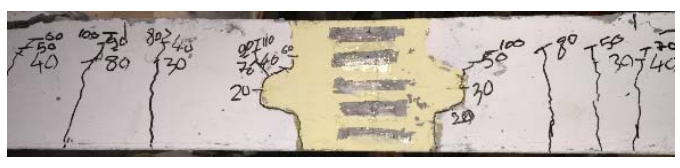

(a) Side 1

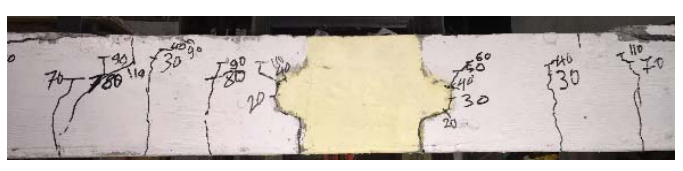

(b) Side 2

Figure 4.72 Close-up view of flexural cracks at the joint of slab $S_{19}$

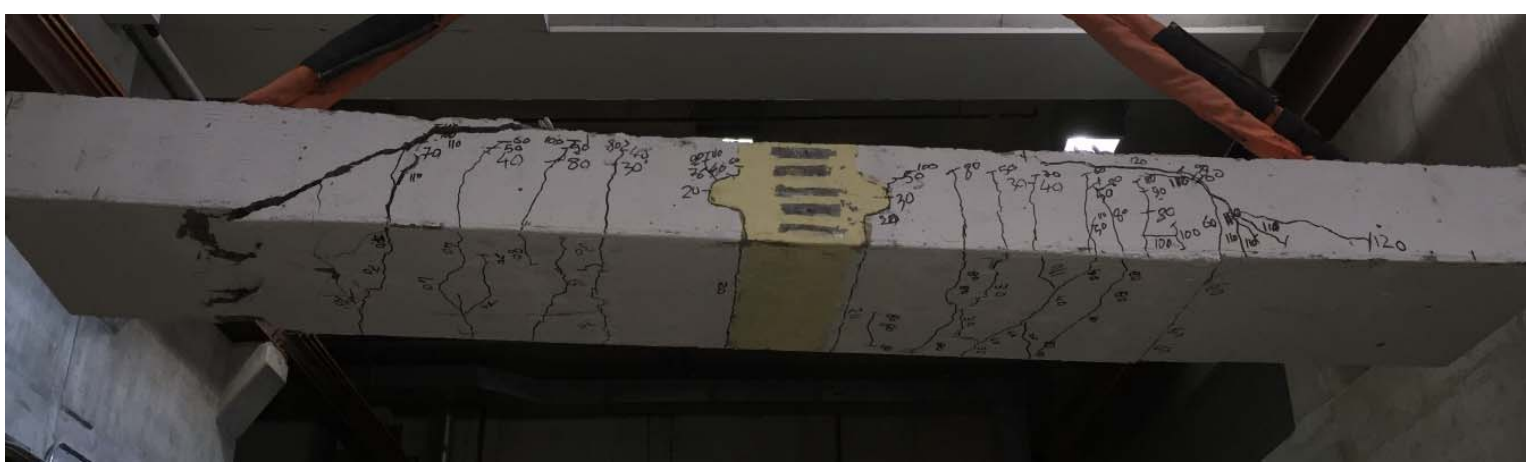

(a) View of crack pattern at the bottom of slab $\mathrm{S}_{19}$

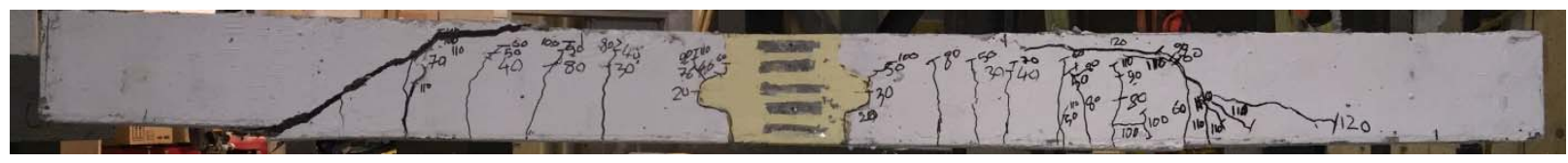

(b) Side 1

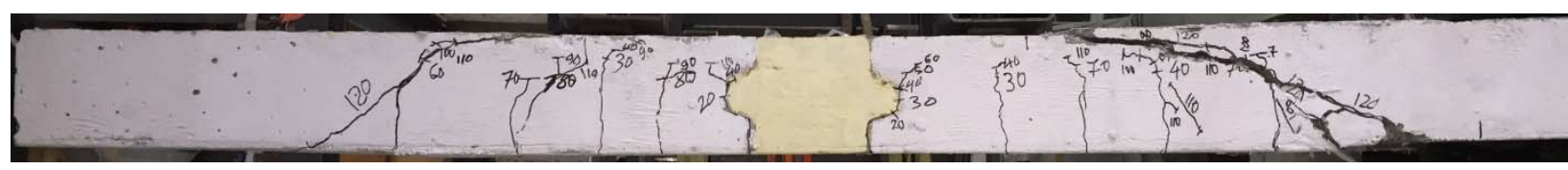

(c) Side 2

Figure 4.73 View of the crack pattern at the bottom and two sides of slab $\mathrm{S}_{19}$ 


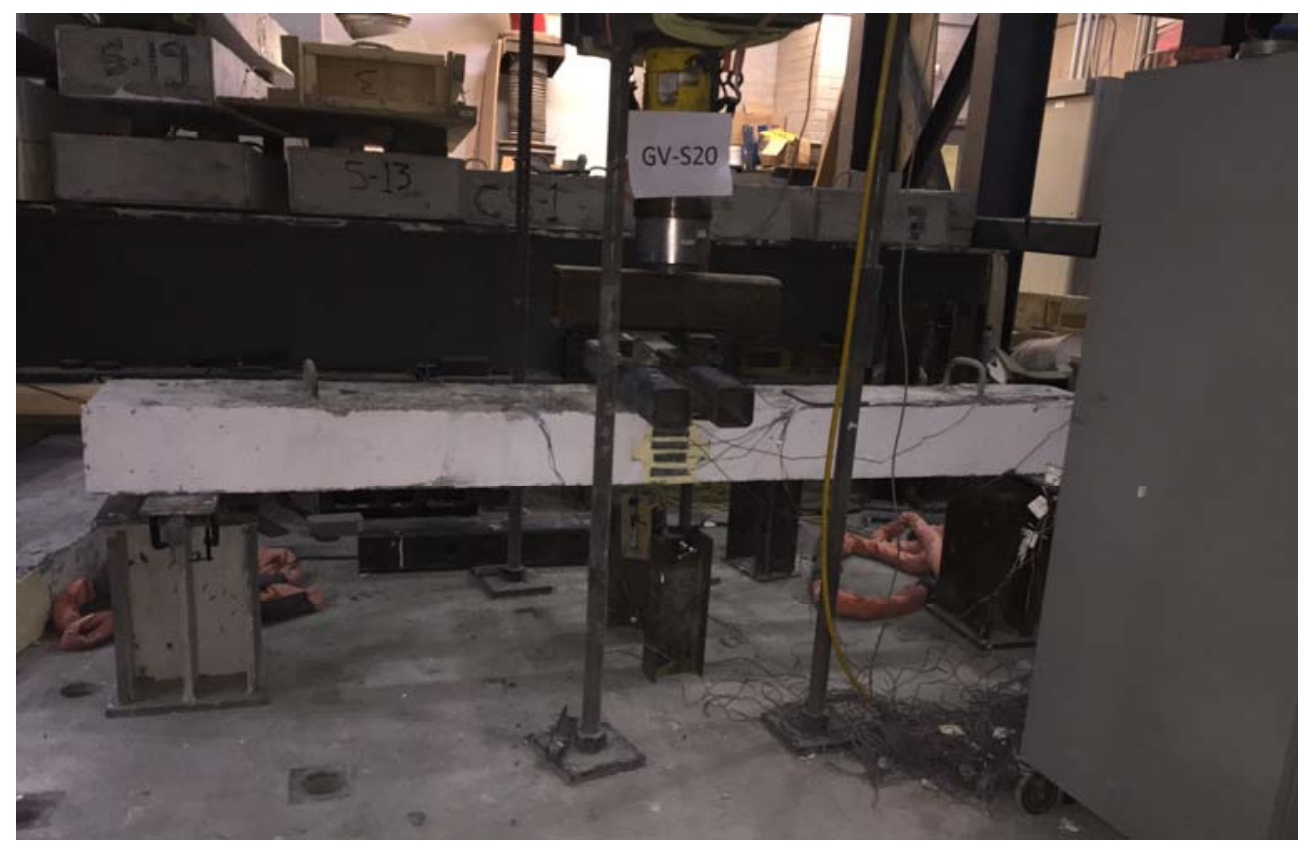

Figure 4.74 Test setup of slab $\mathrm{S}_{20}$ before testing

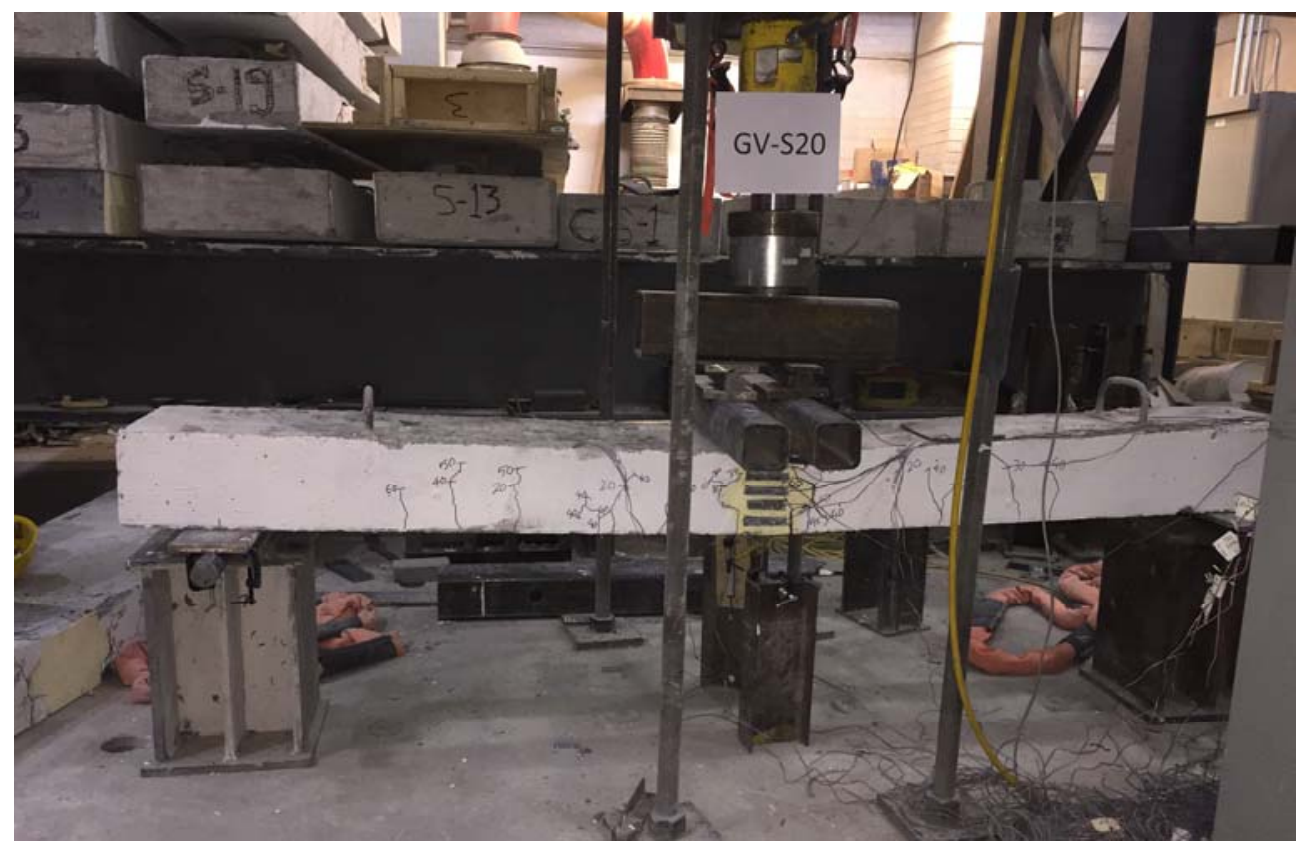

Figure 4.75 View of crack pattern of slab $\mathrm{S}_{20}$ after failure 


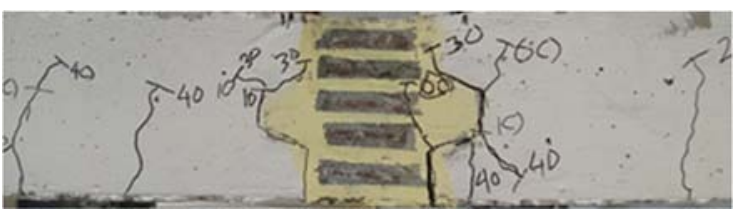

(a) Side 1

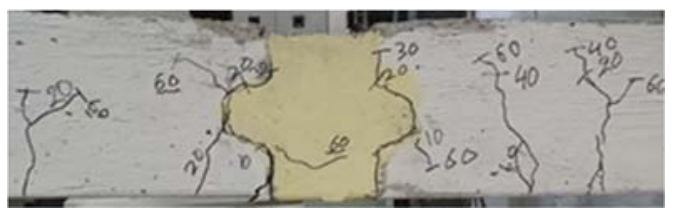

(b) Side 2

Figure 4.76 Close-up view of flexural cracks at the joint of slab $\mathrm{S}_{20}$

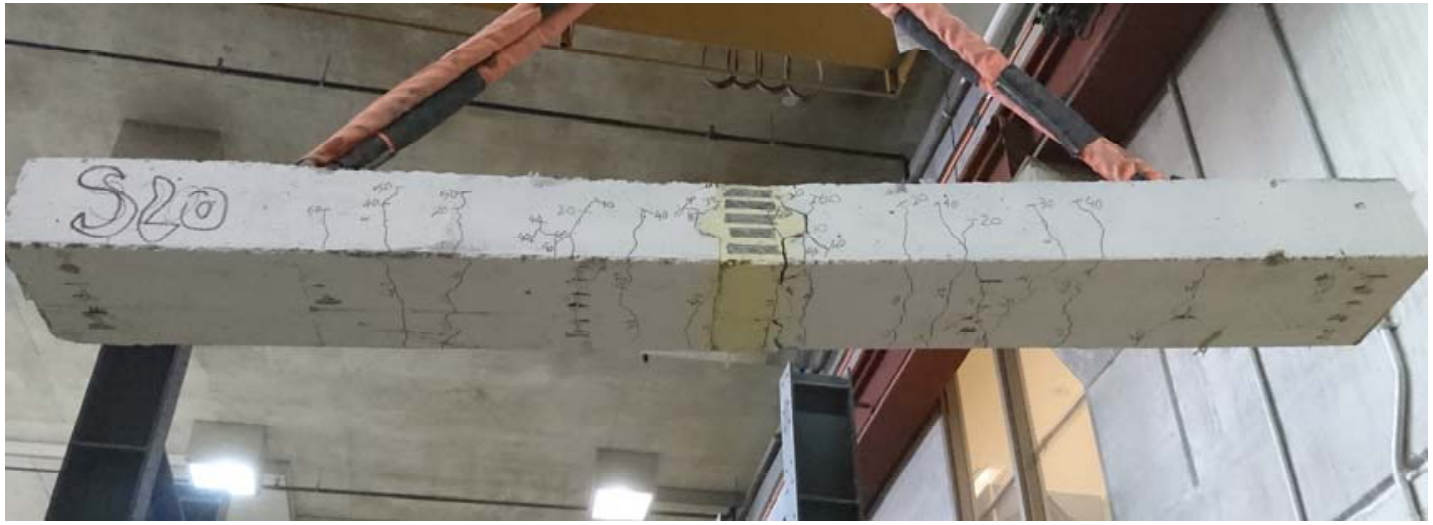

(a) View of the crack pattern at the bottom of the Slab $\mathrm{S}_{20}$

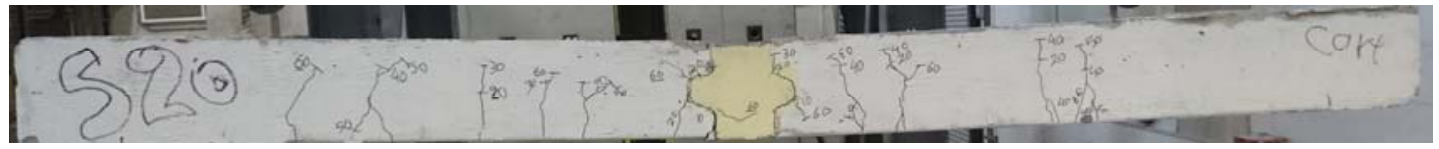

(b) Side 1

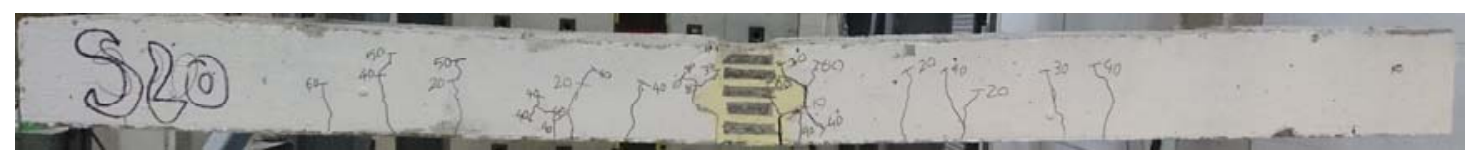

(c) Side 2

Figure 4.77 View of crack pattern at the bottom of slab $\mathrm{S}_{20}$ 


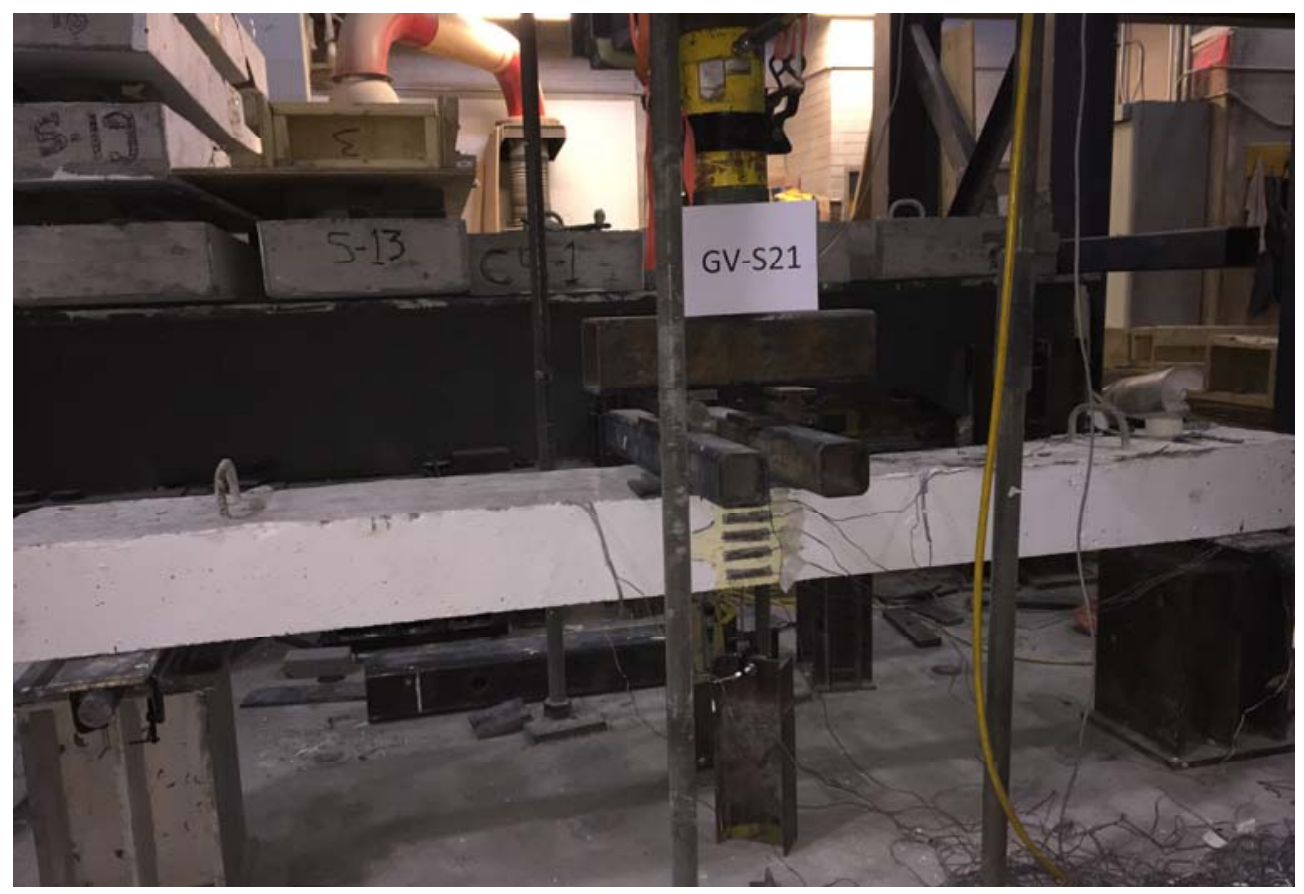

Figure 4.78 Test setup of slab $\mathrm{S}_{21}$ before testing

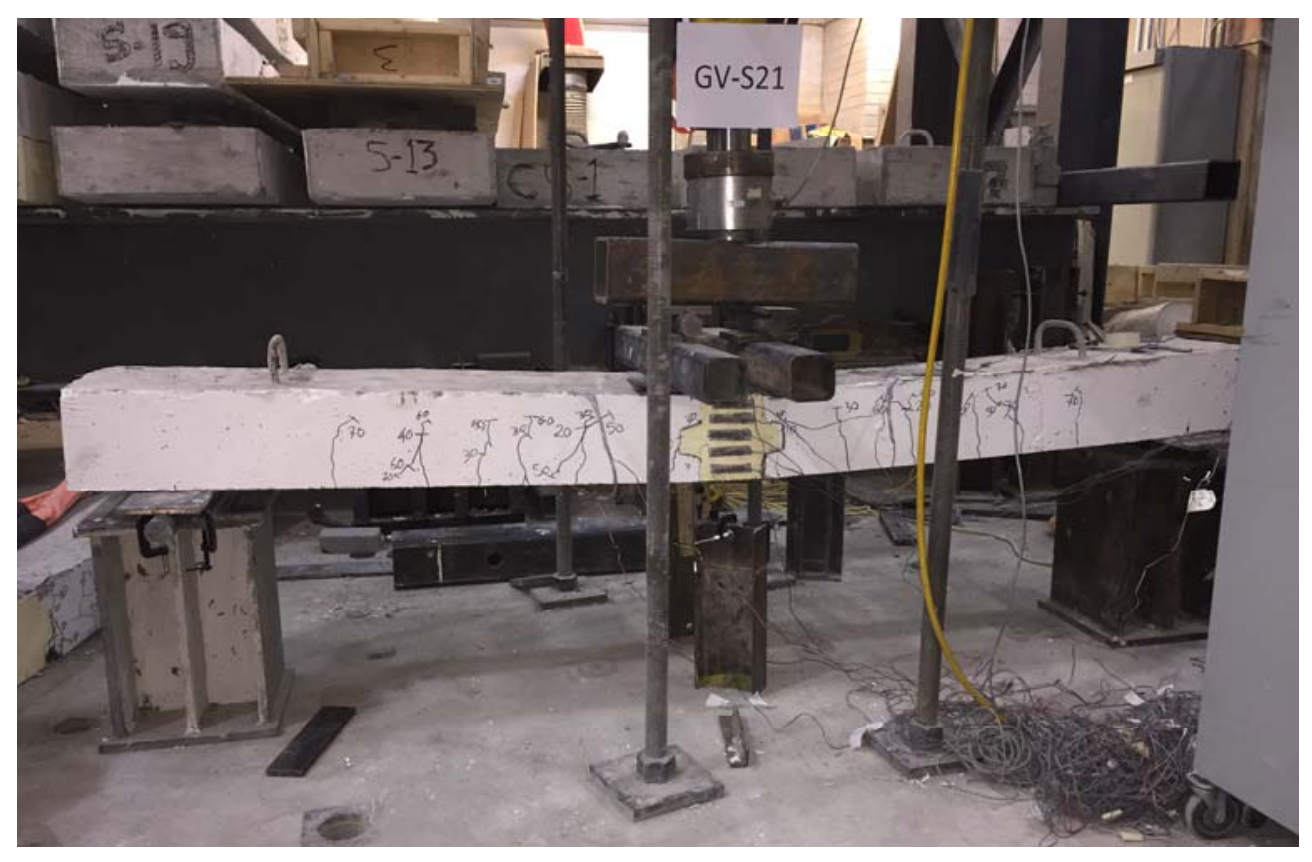

Figure 4.79 View of crack pattern of slab $\mathrm{S}_{21}$ after failure 


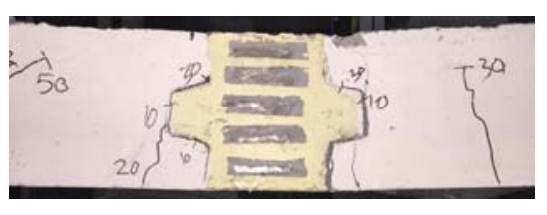

(a) Side 1

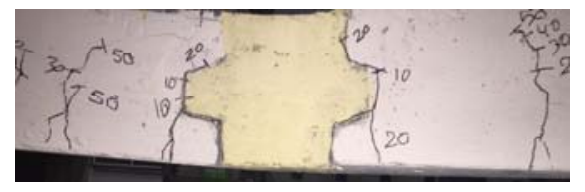

(b) Side 2

Figure 4.80 Close-up view of flexural cracks at the joint of slab $\mathrm{S}_{21}$

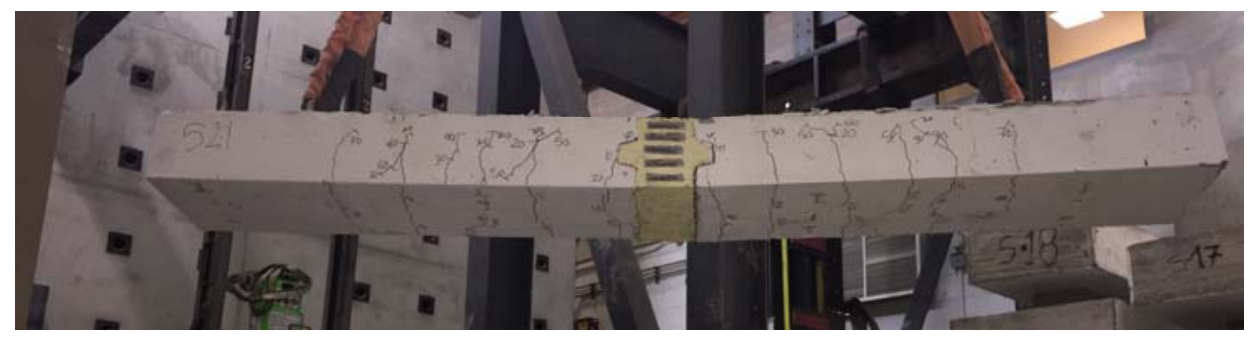

(a) View of crack pattern at the bottom of slab $S_{21}$

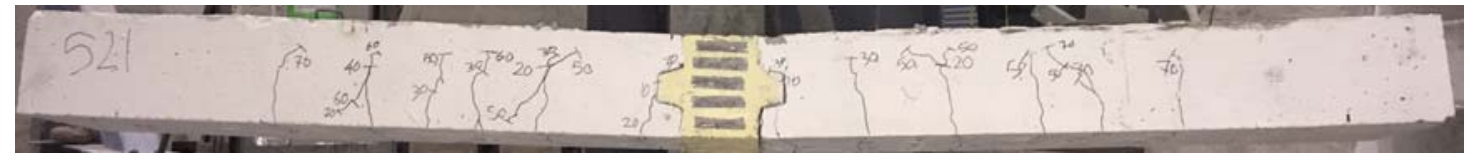

(b) Side 1

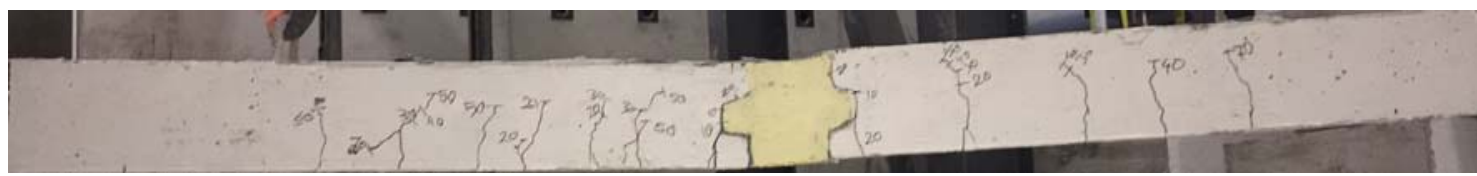

(c) Side 2

Figure 4.81 View of the crack pattern at the bottom and two sides of slab $\mathrm{S}_{21}$ 


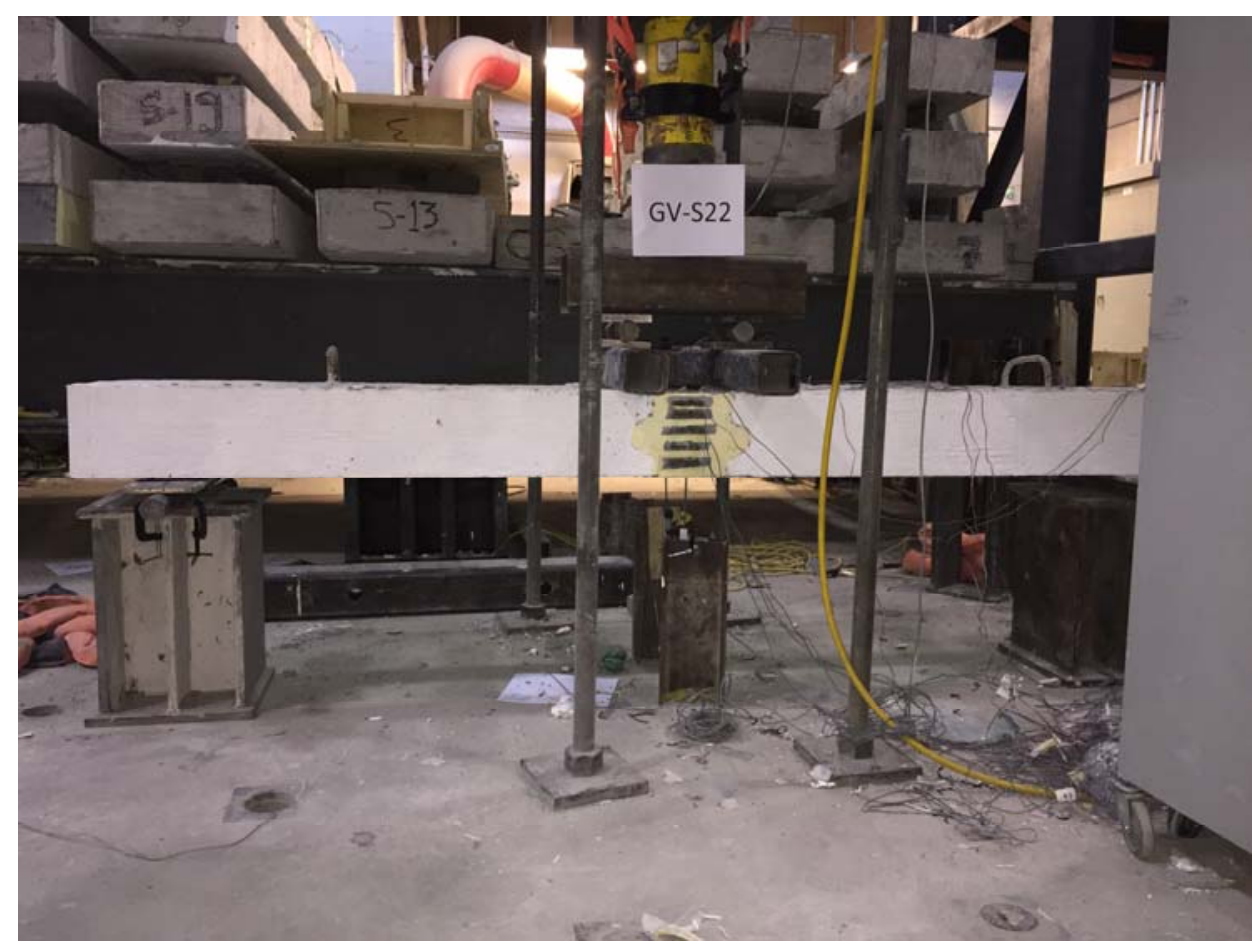

Figure 4.82 Test setup of slab $\mathrm{S}_{22}$ before testing

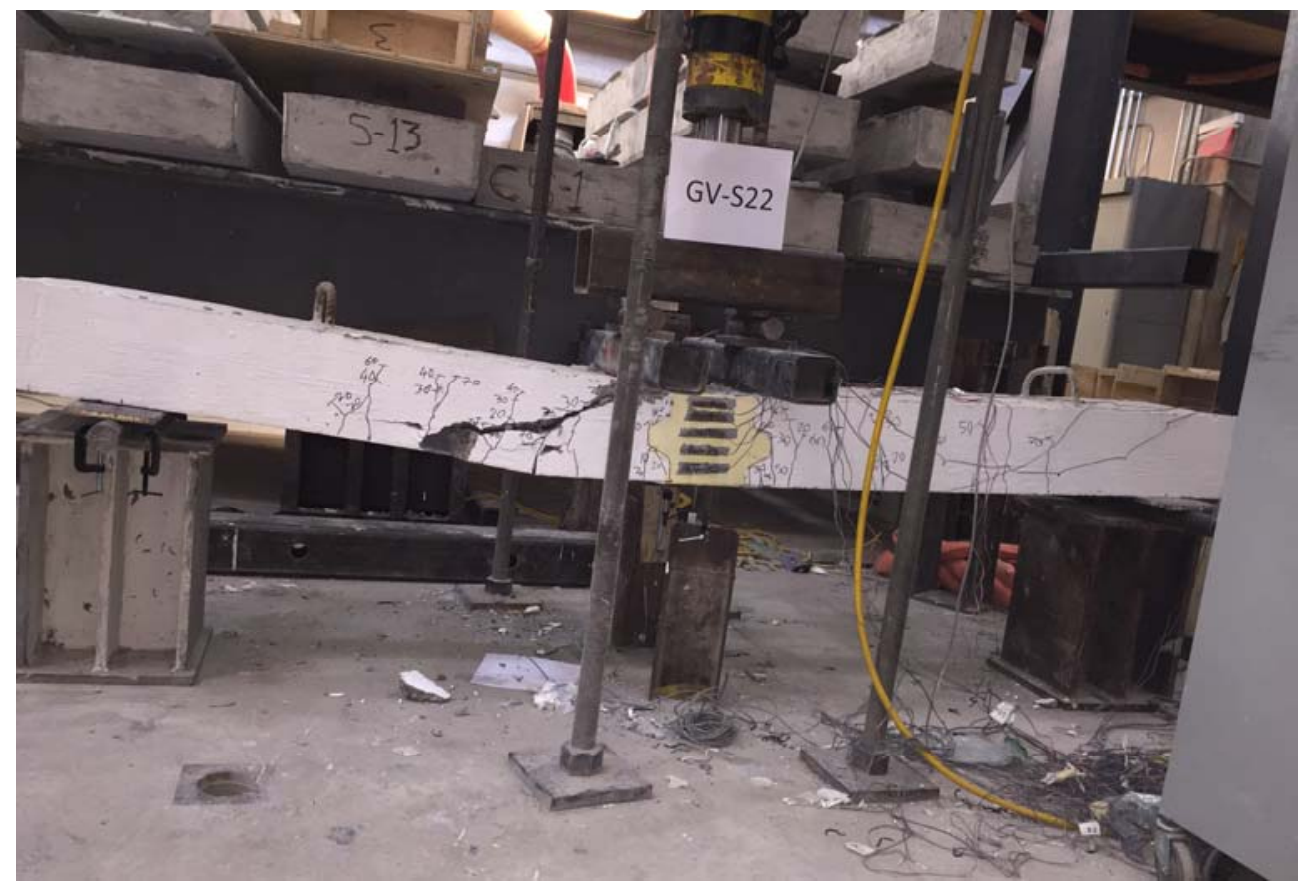

Figure 4.83 View of crack pattern of slab $\mathrm{S}_{22}$ after failure 


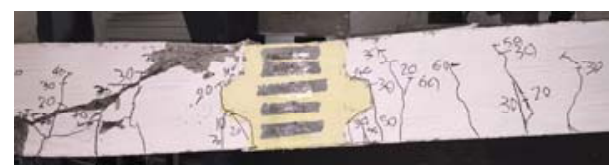

(a) Side 1

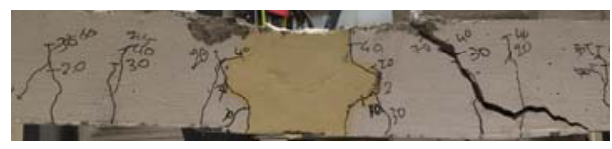

(b) Side 2

Figure 4.84 Close-up view of the flexure cracks at the joint of slab $\mathrm{S}_{22}$

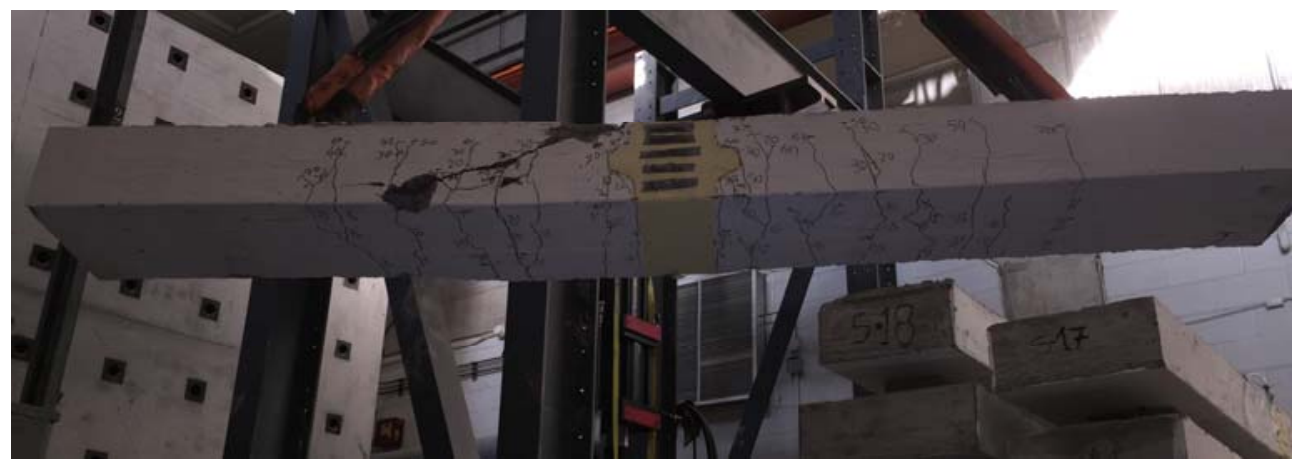

(a) View of crack pattern at the bottom of slab $\mathrm{S}_{22}$

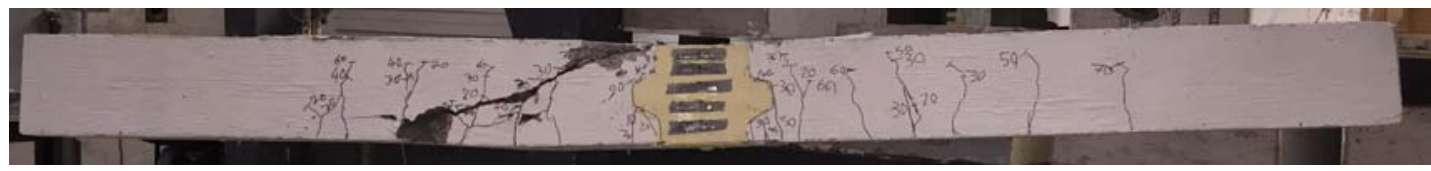

(b) Side 1

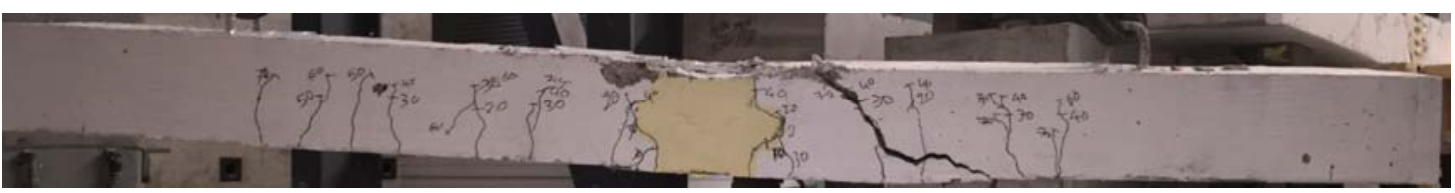

(c) Side 2

Figure 4.85 View of the crack pattern at the bottom and two sides of slab $\mathrm{S}_{22}$ 


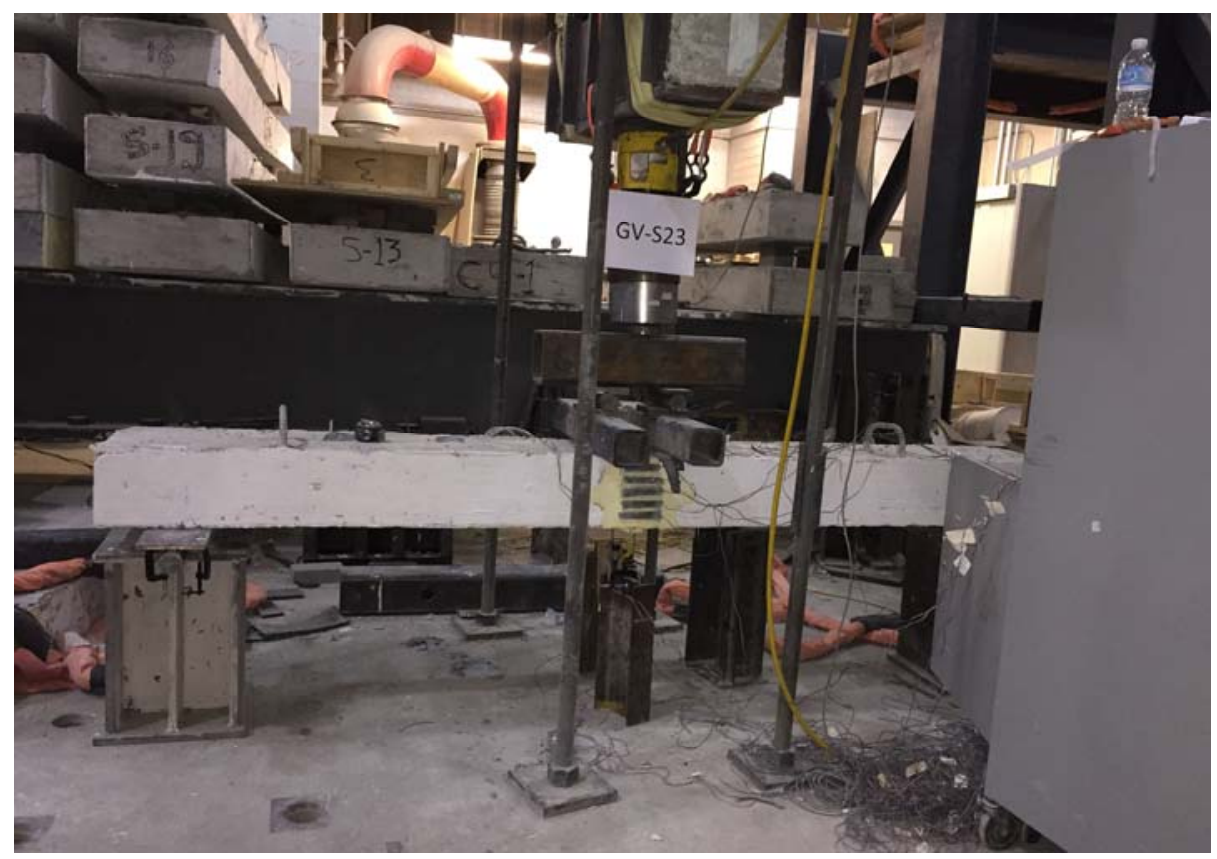

Figure 4.86 Test setup of slab $\mathrm{S}_{23}$ before testing

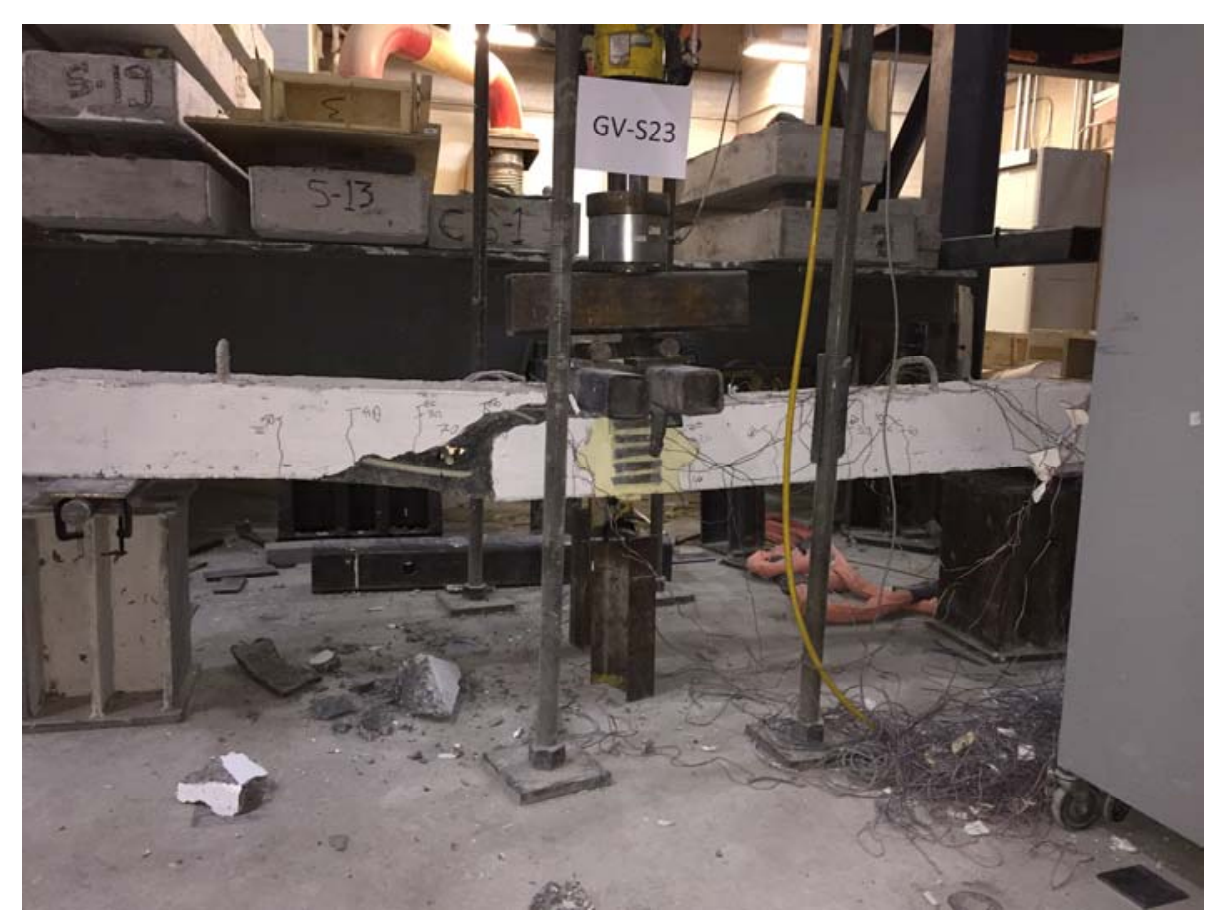

Figure 4.87 View of crack pattern of slab $\mathrm{S}_{23}$ after failure 


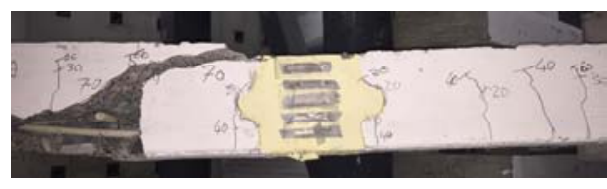

(a) Side 1

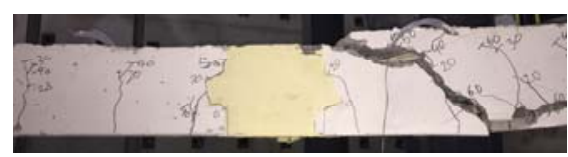

(b) Side 2

Figure 4.88 Close-up view of cracks at the joint of slab $\mathrm{S}_{23}$

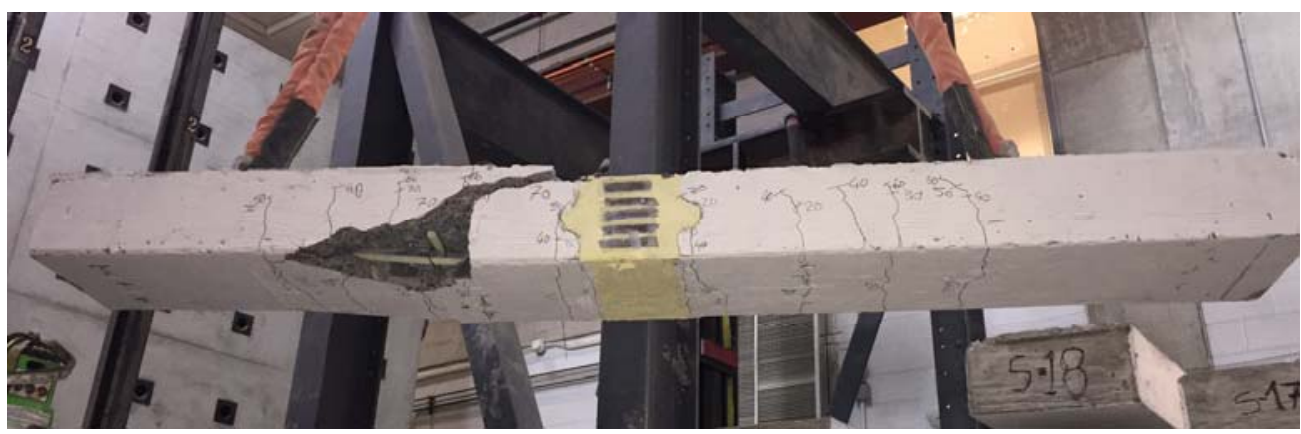

(a) View of crack pattern at the bottom of slab $\mathrm{S}_{23}$

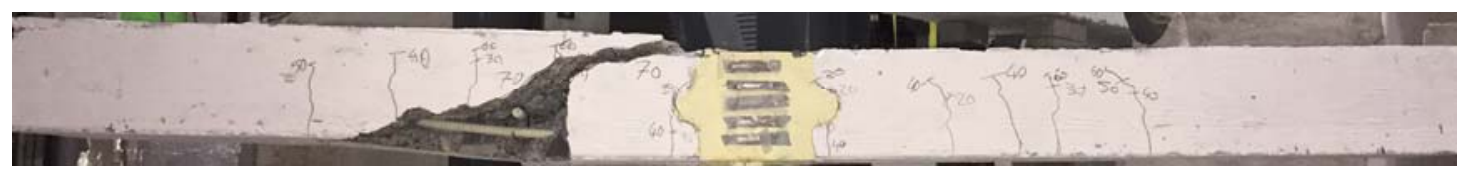

(b) Side 1

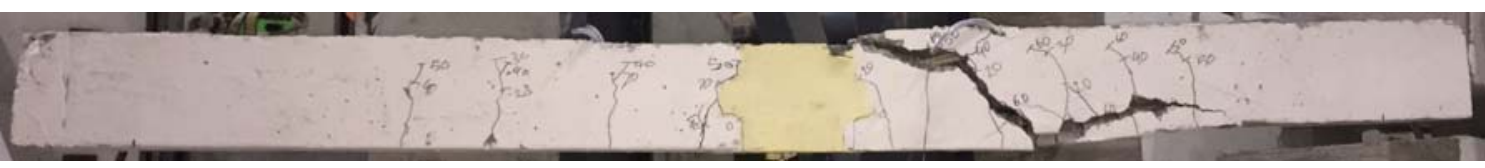

(c) Side 2

Figure 4.89 View of the crack pattern at the bottom and two sides of slab $\mathrm{S}_{23}$ 


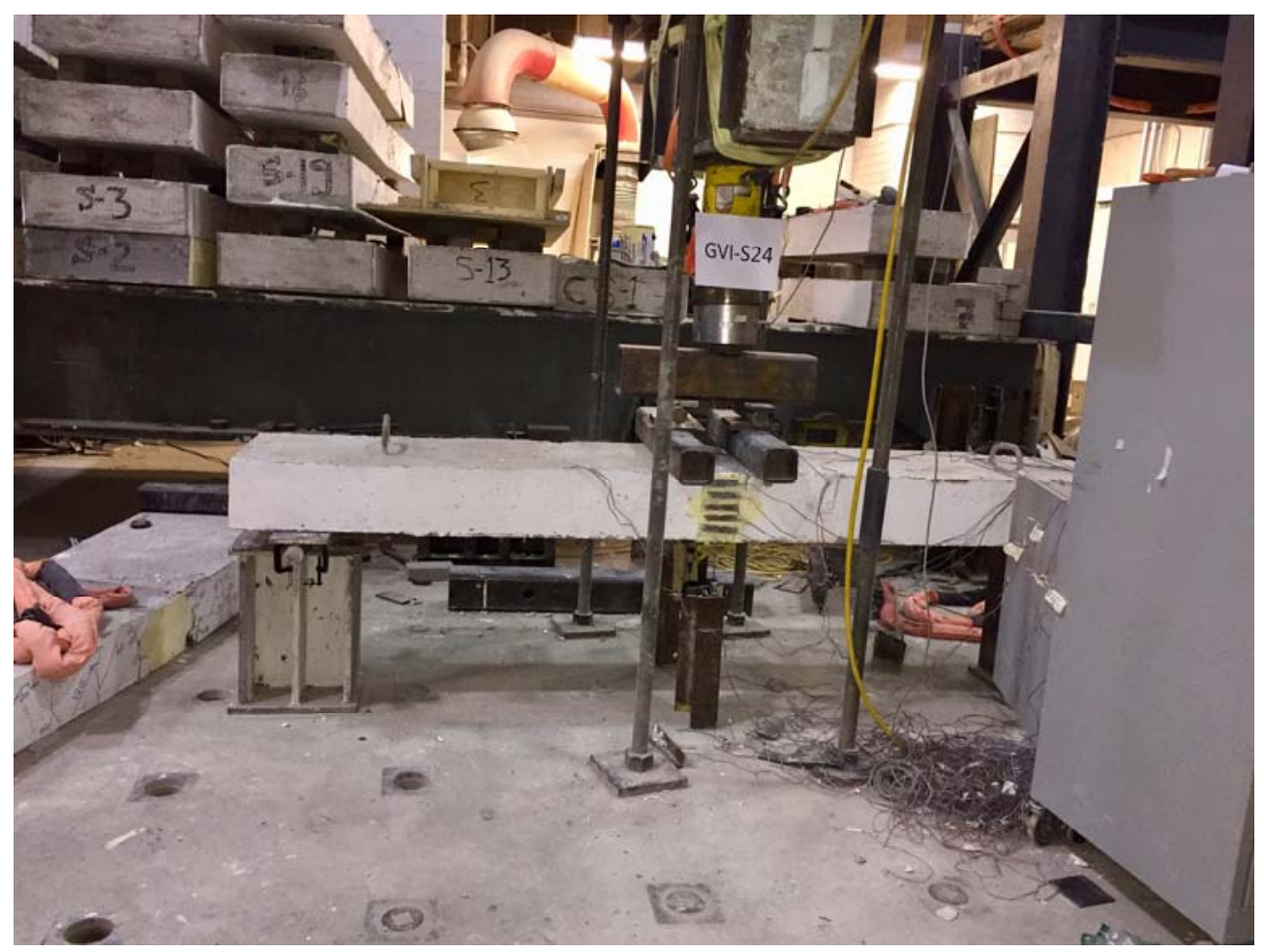

Figure 4.90 Test setup of slab $\mathrm{S}_{24}$ before testing



Figure 4.91 View of crack pattern of slab $\mathrm{S}_{24}$ after failure 


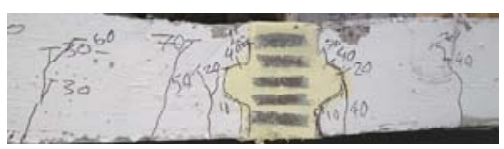

(a) Side 1

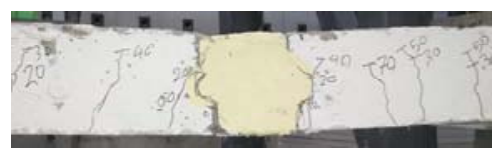

(b) Side 2

Figure 4.92 Close up view of cracks at the joint of slab $\mathrm{S}_{24}$

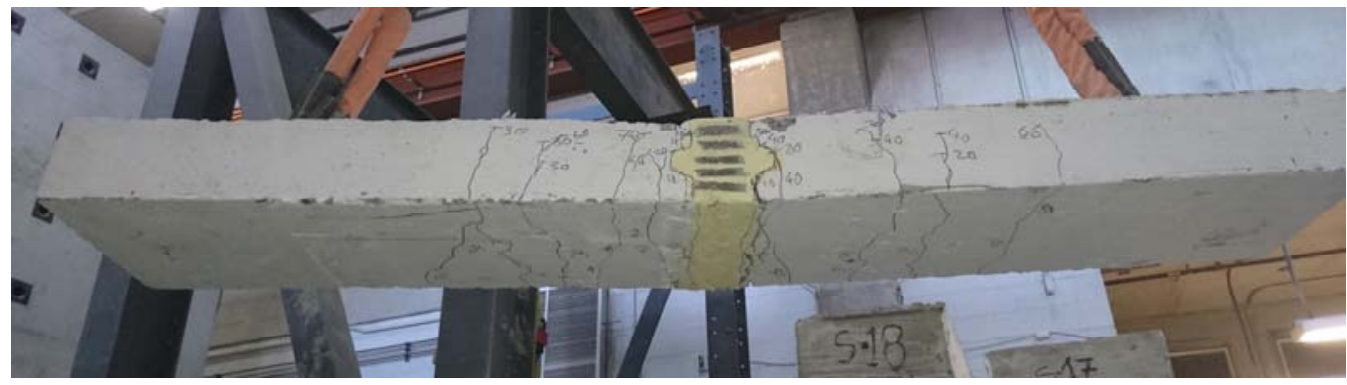

(a) View of crack pattern at the bottom Slab $\mathrm{S}_{24}$

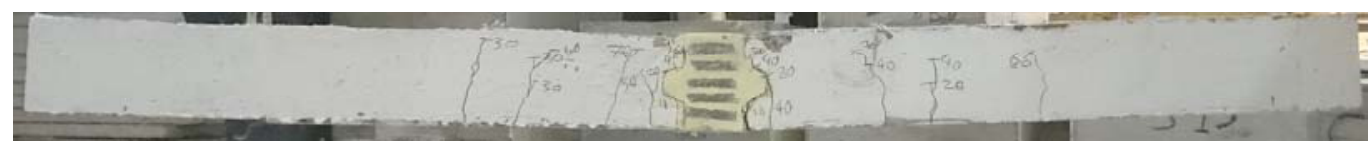

(b) Side 1

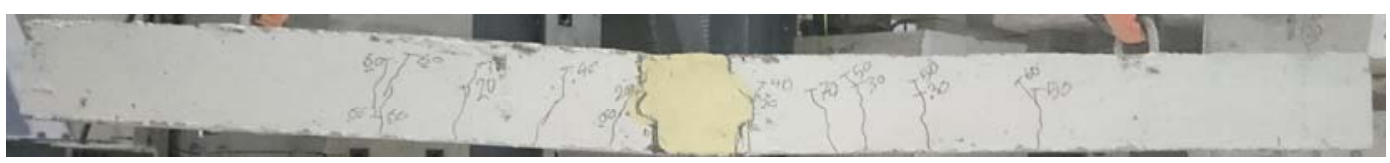

(c) Side 2

Figure 4.93 View of the crack pattern at the bottom and two sides of slab $\mathrm{S}_{24}$ 


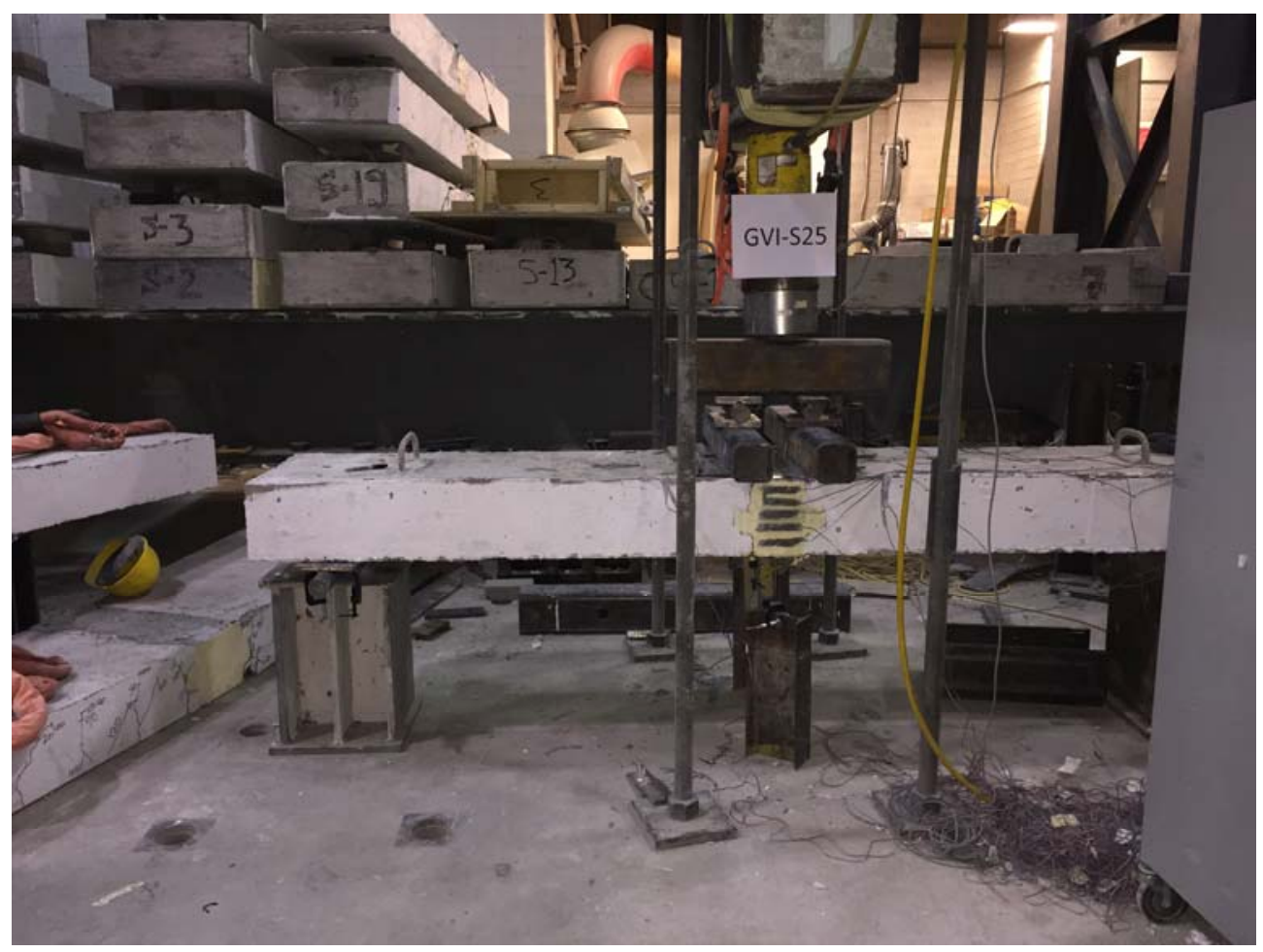

Figure 4.94 Test setup of slab $\mathrm{S}_{25}$ before testing

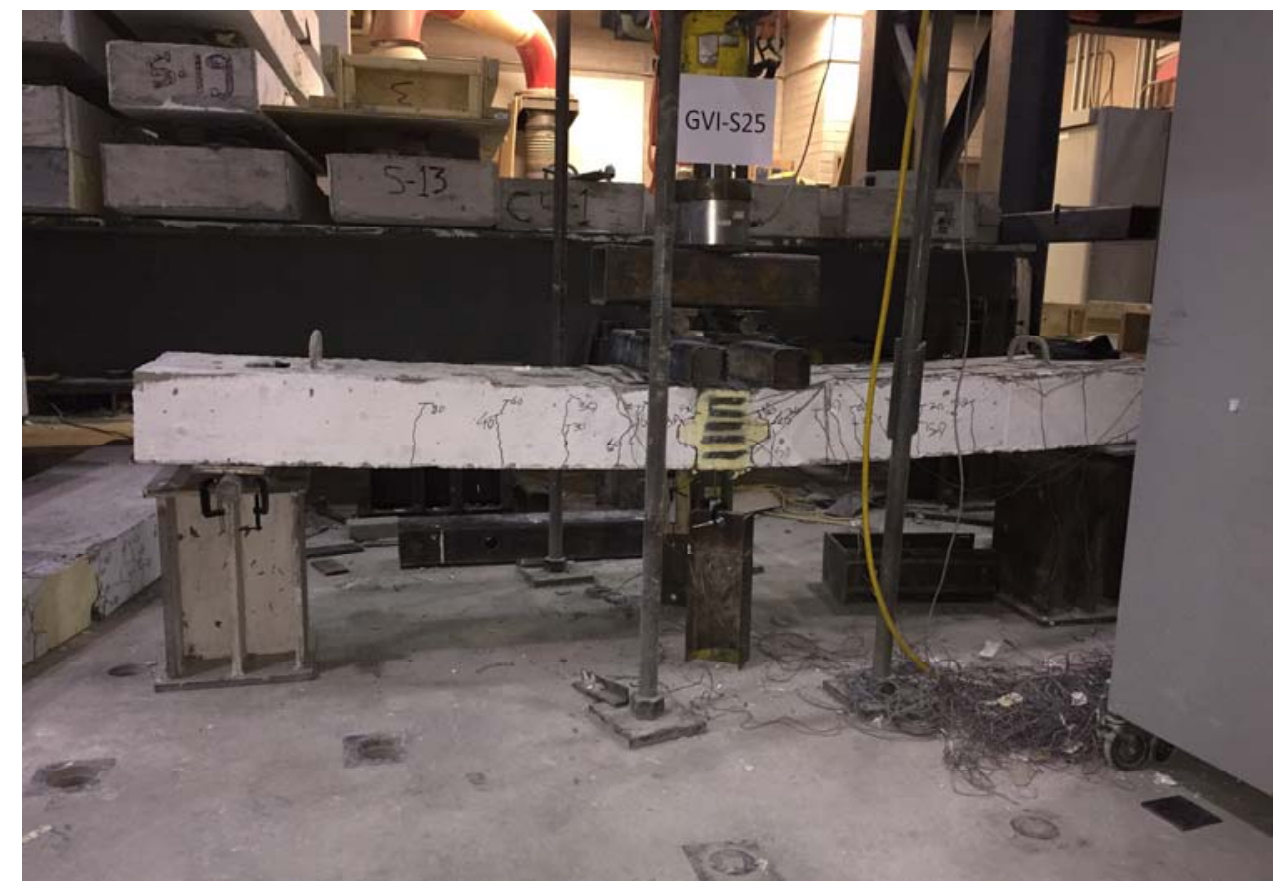

Figure 4.95 View of crack pattern of slab $\mathrm{S}_{25}$ after failure 


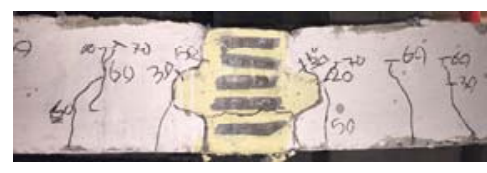

Side 1

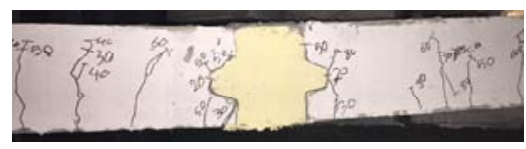

Side 2

(a) Close-up view of flexural cracks at the joint of the slab

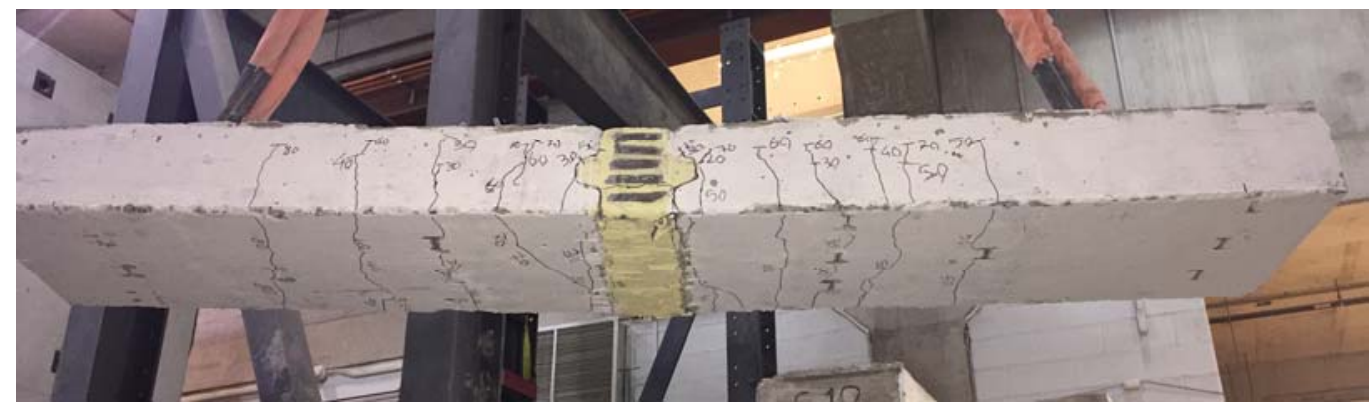

(b) View of crack pattern at the bottom of the slab

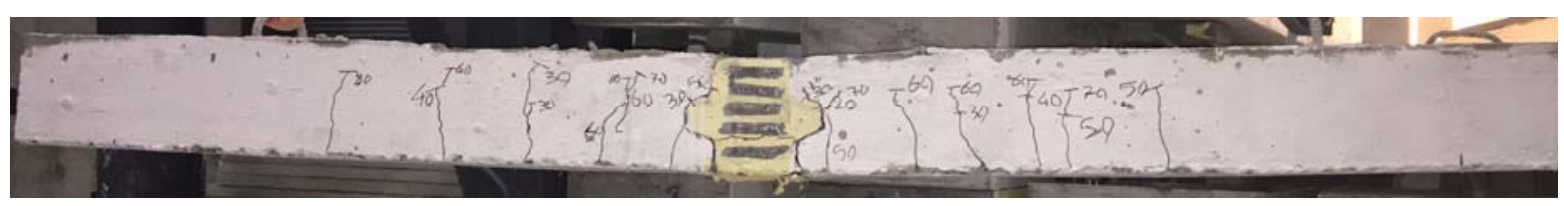

Side 1

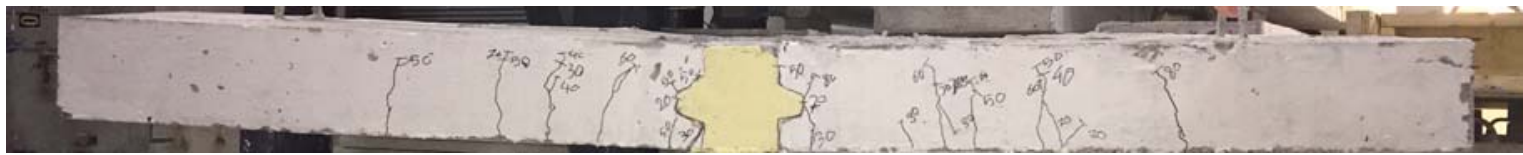

Side 2

(c) View of the crack pattern at the bottom and two sides of the slab

Figure 4.96 Different views of crack pattern in slab $\mathrm{S}_{25}$ 


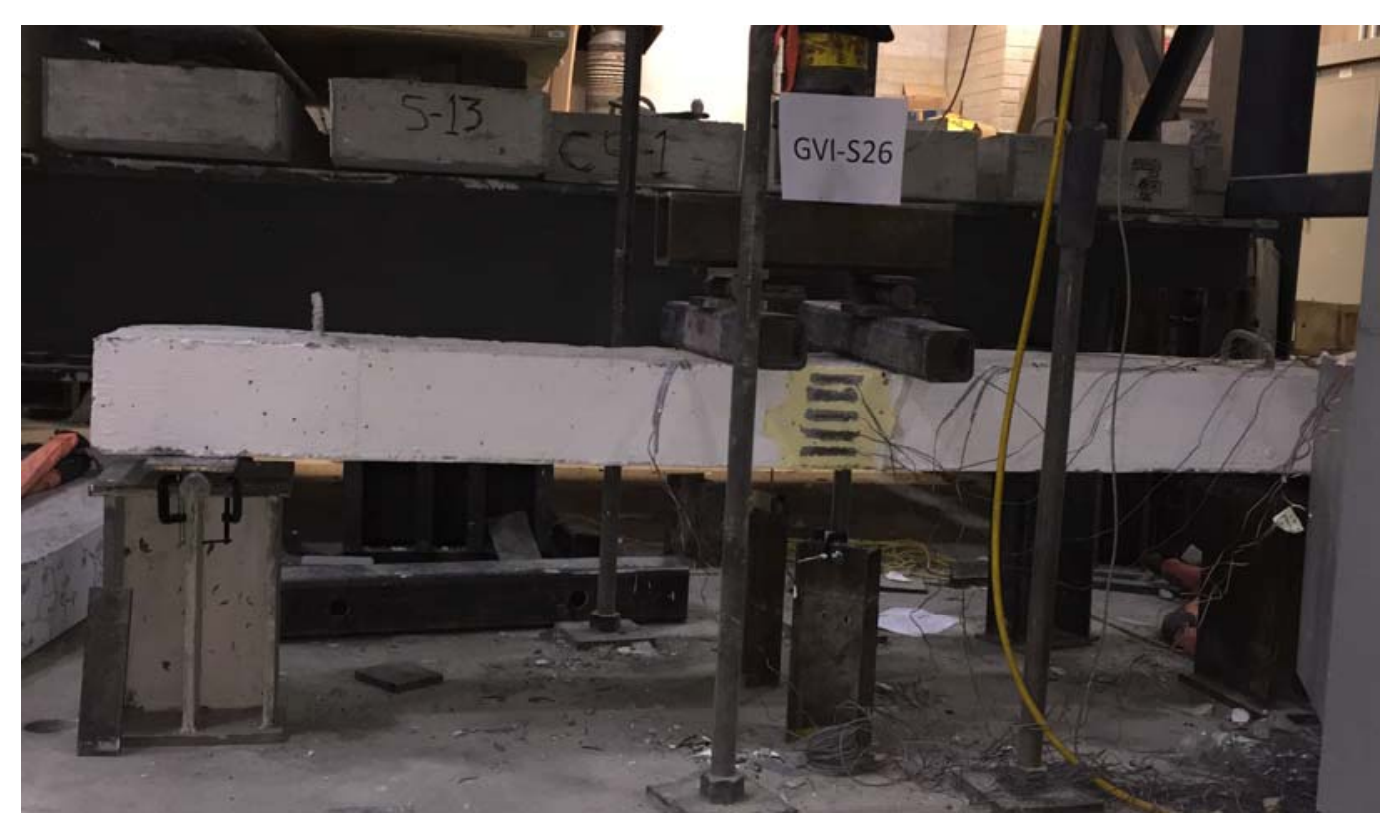

Figure 4.97 Test setup of slab $\mathrm{S}_{26}$ before testing

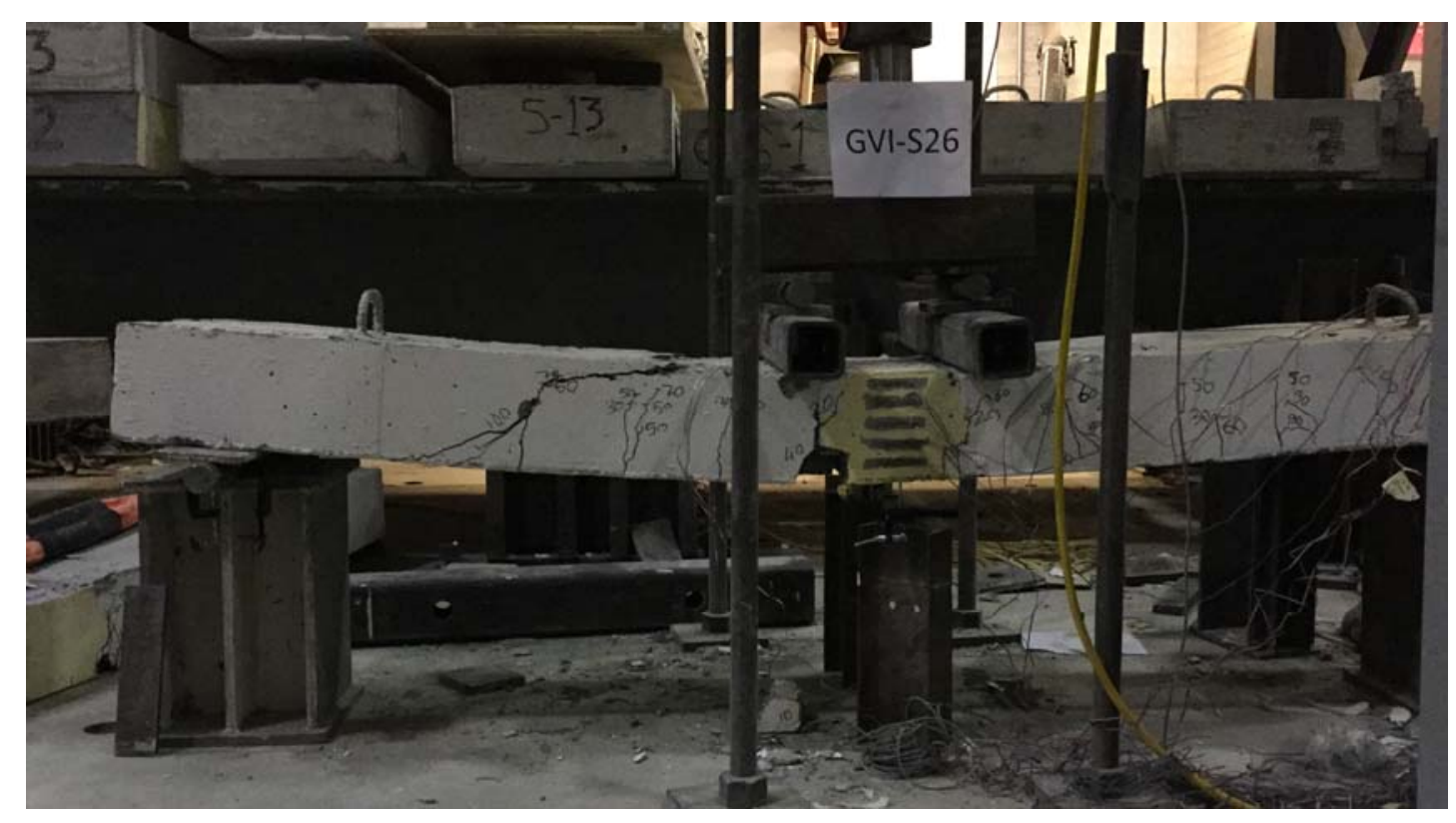

Figure 4.98 View of crack pattern of slab $\mathrm{S}_{26}$ after failure 


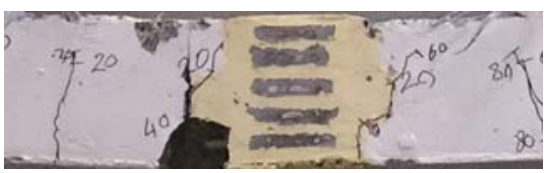

(a) Side 1

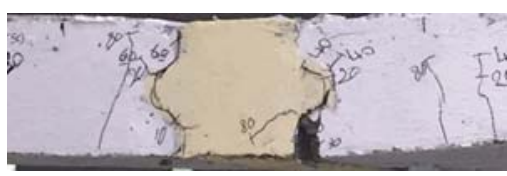

(b) Side 2

Figure 4.99 Close-up view of the flexure cracks at the joint of $\mathrm{S}_{26}$

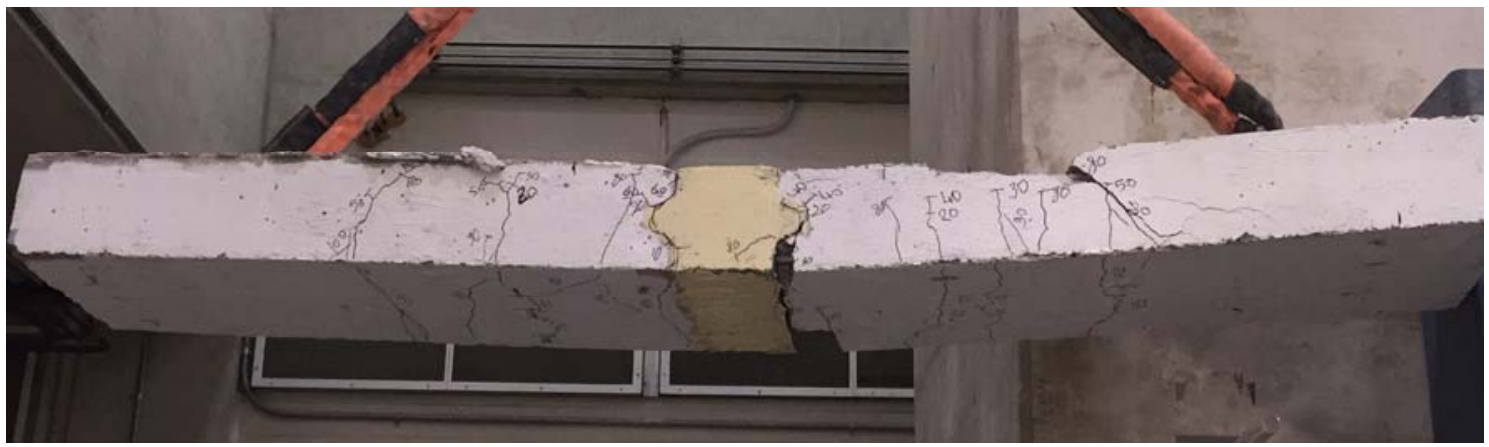

(a) View of crack pattern at the bottom of slab S26

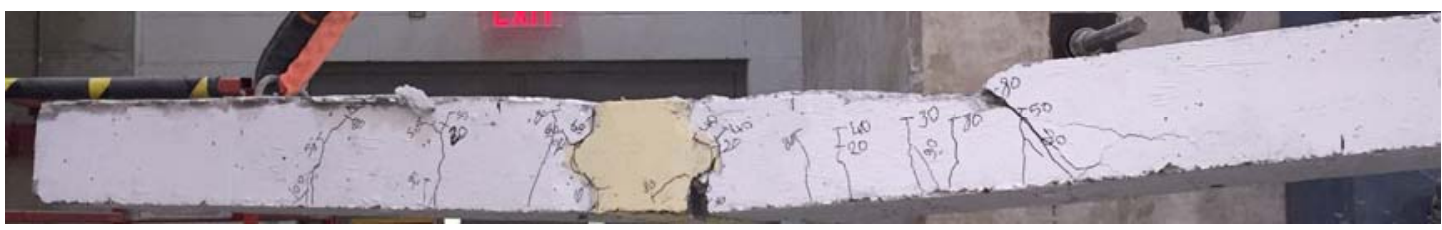

(b) Side 1

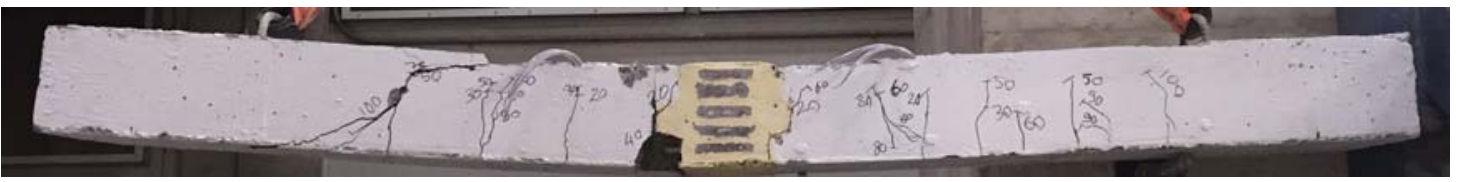

(c) Side 2

Figure 4.100 View of the crack pattern at the bottom and two sides of slab $\mathrm{S}_{26}$ 


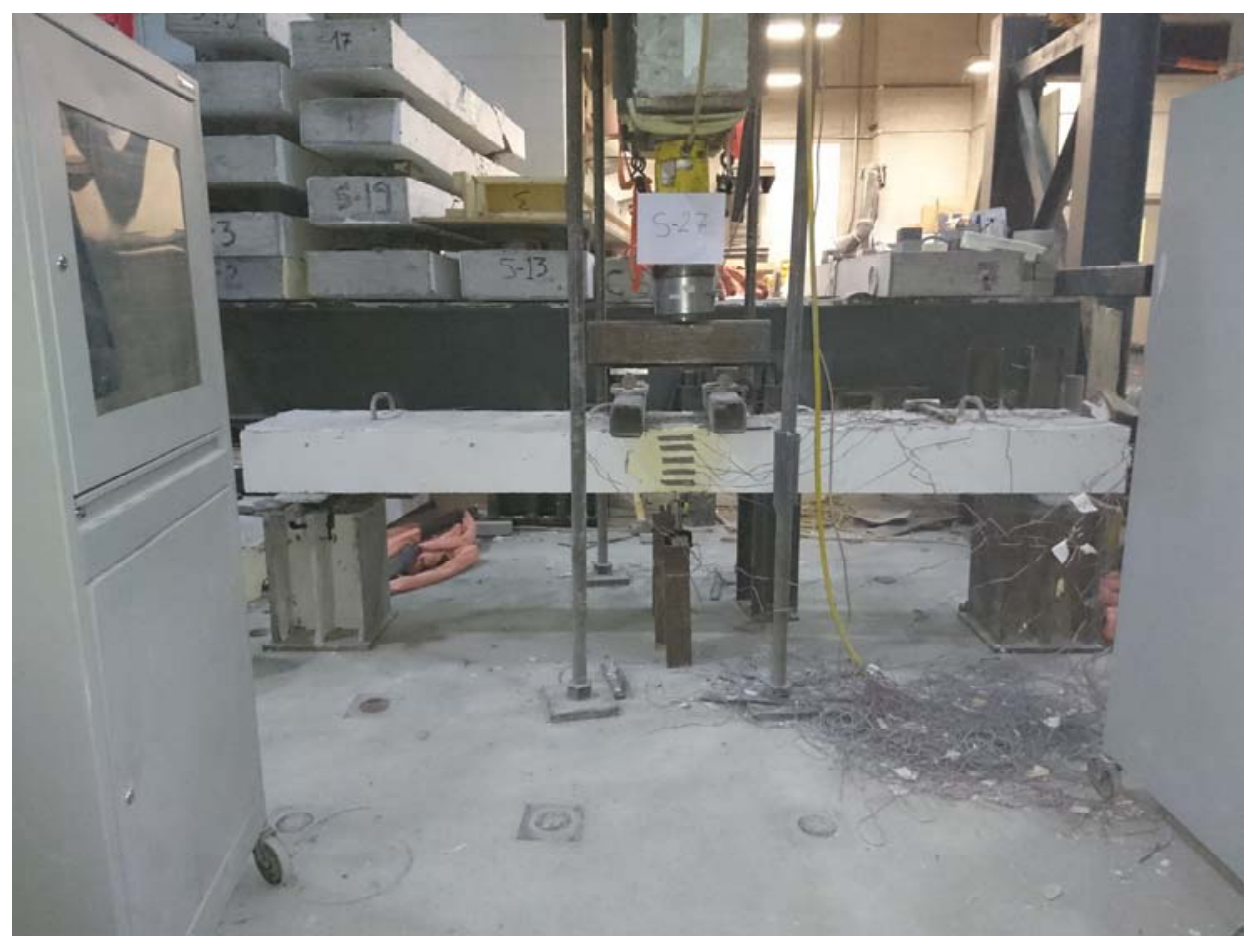

Figure 4.101 Test setup of slab $\mathrm{S}_{27}$ before testing

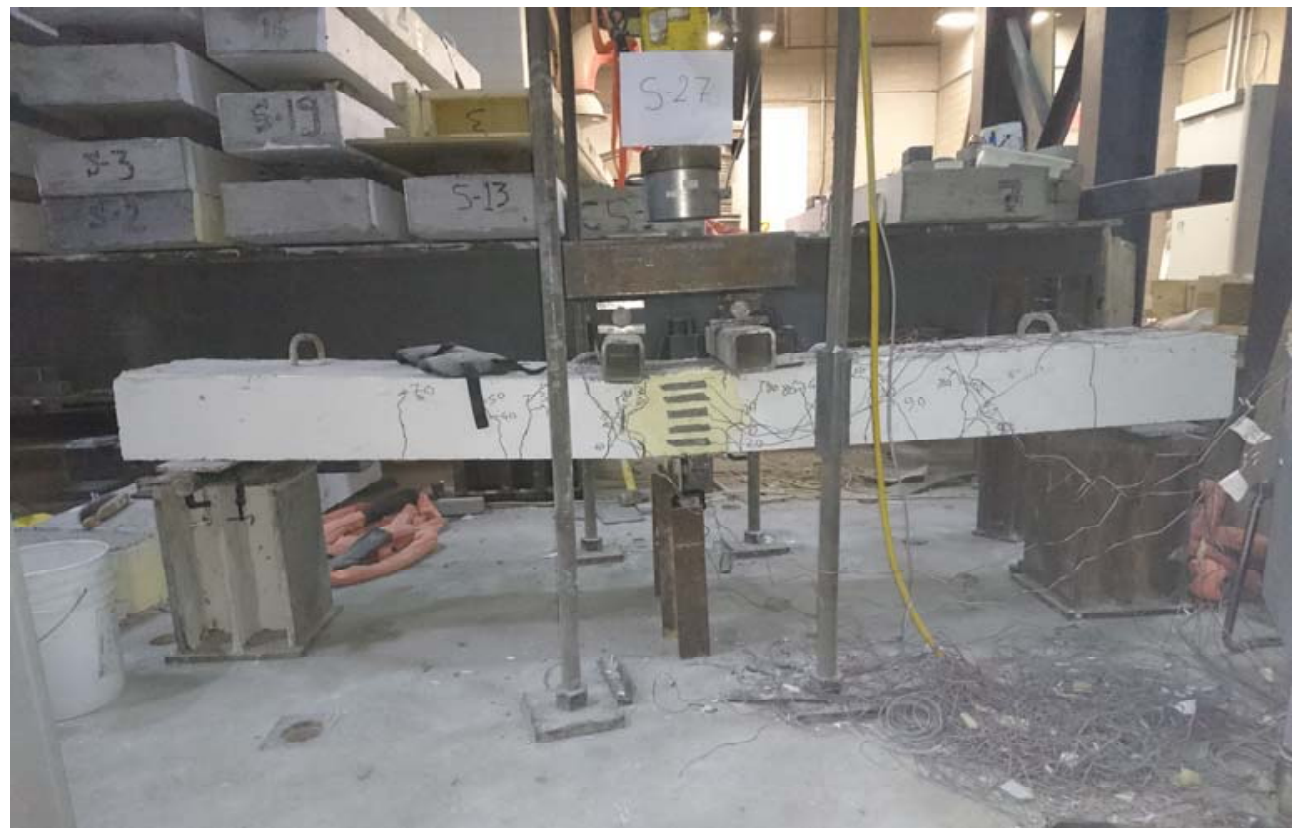

Figure 4.102 View of crack pattern of slab $\mathrm{S}_{27}$ after failure 


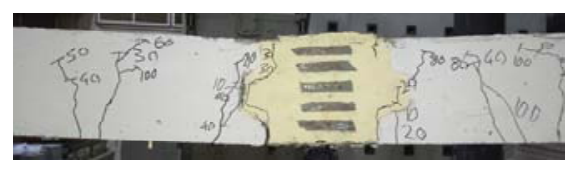

(a) Side 1

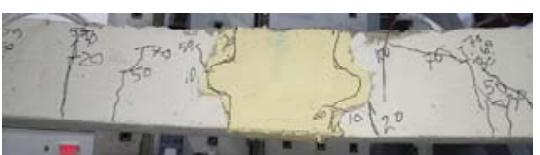

(b) Side 2

Figure 4.103 Close-up view of the flexure cracks at the joint of $\mathrm{S}_{27}$

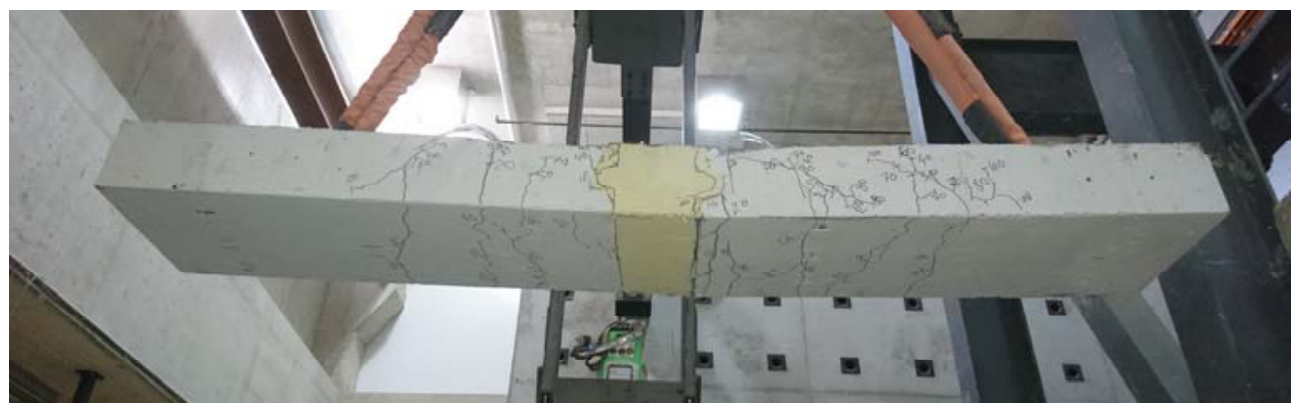

(a) View of crack pattern at the bottom of slab $\mathrm{S}_{27}$

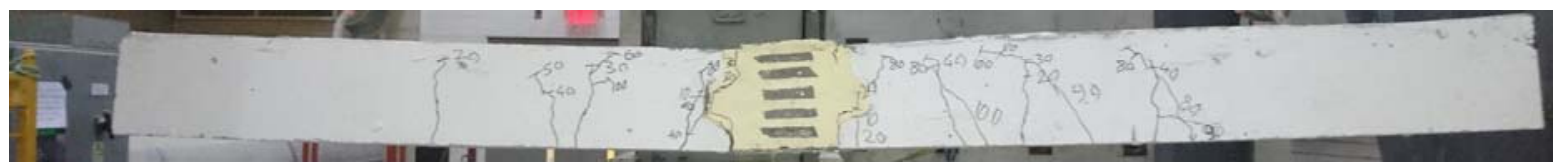

(b) Side 1

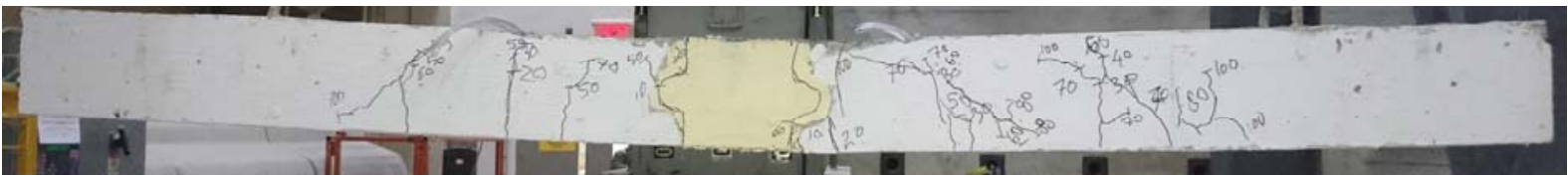

(c) Side 2

Figure 4.104 View of the crack pattern at the bottom and two sides of slab $\mathrm{S}_{27}$ 


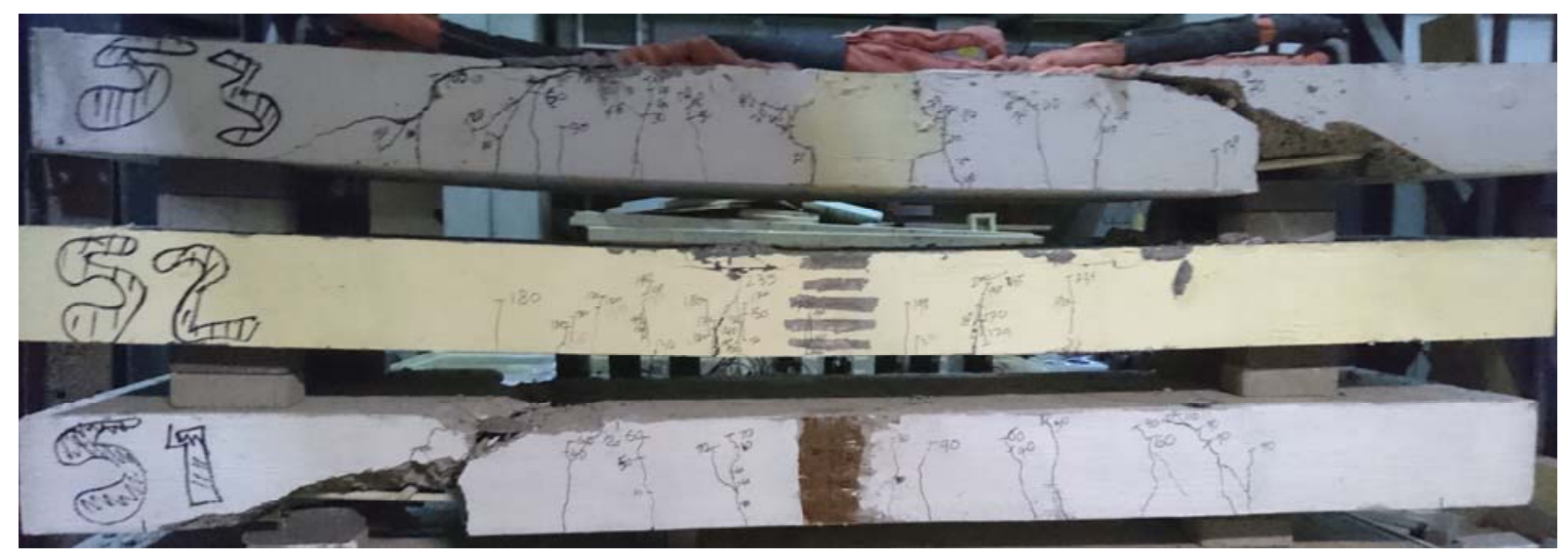

Figure 4.105 View of failure modes of slabs from side 1 in group G

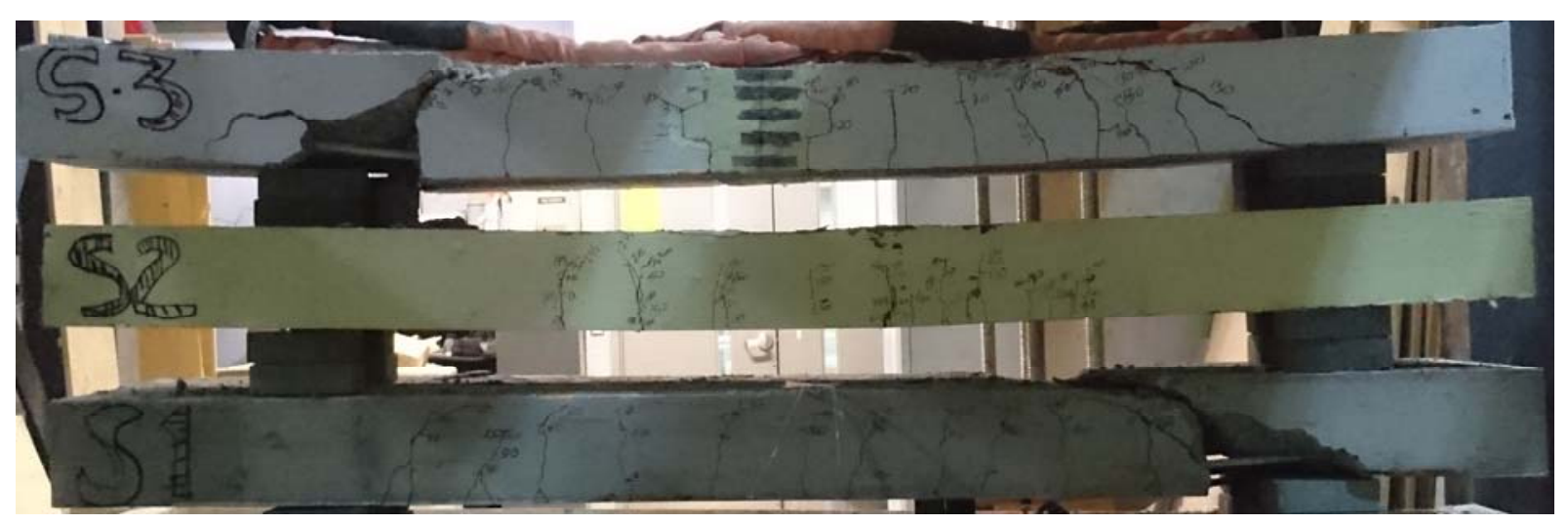

Figure 4.106 View of failure modes of slabs from side 2 in group G 


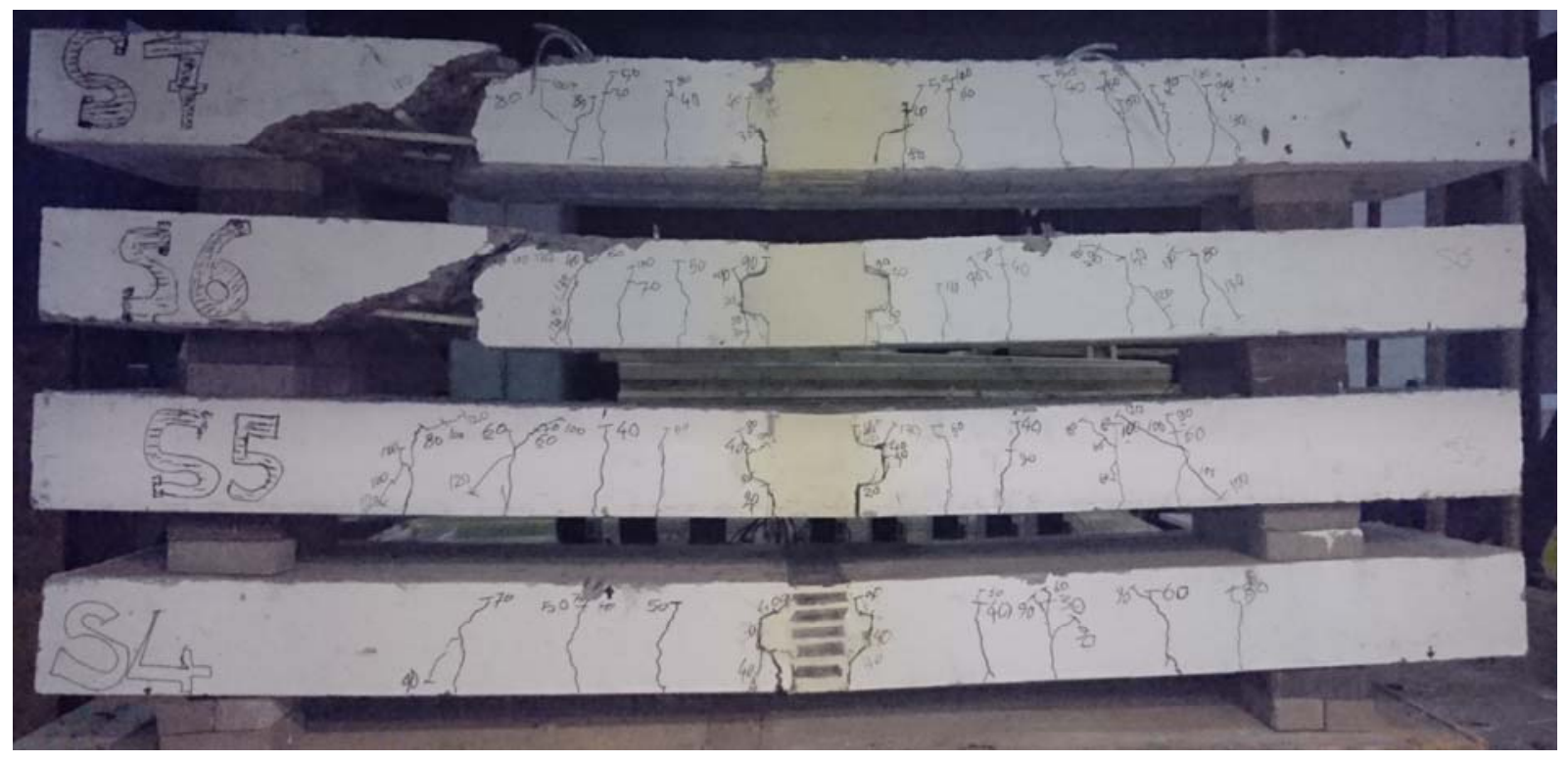

Figure 4.107 View of failure modes of slabs from side 1 in group G1

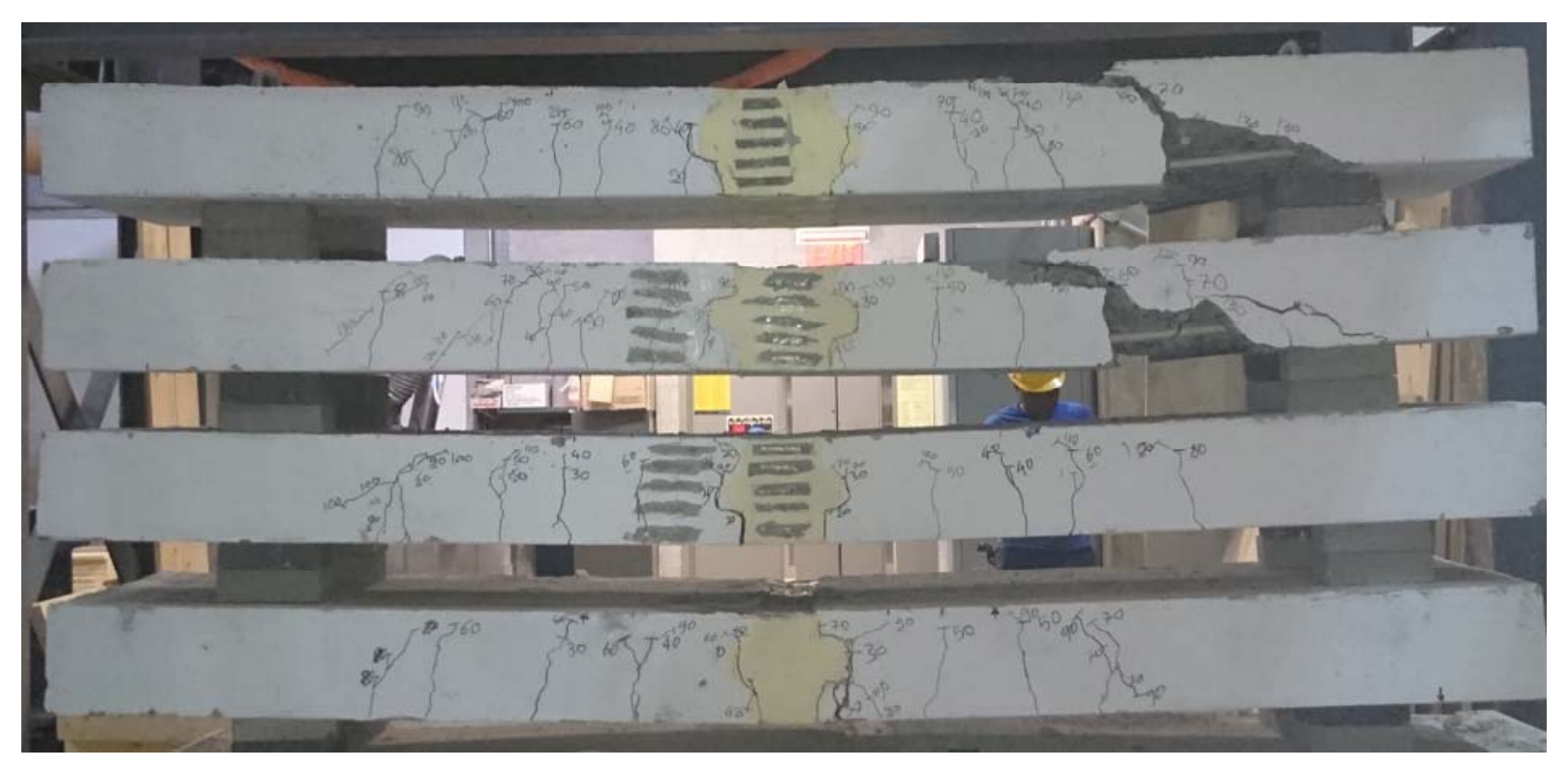

Figure 4.108 View of failure modes of slabs from side 2 in group G1 


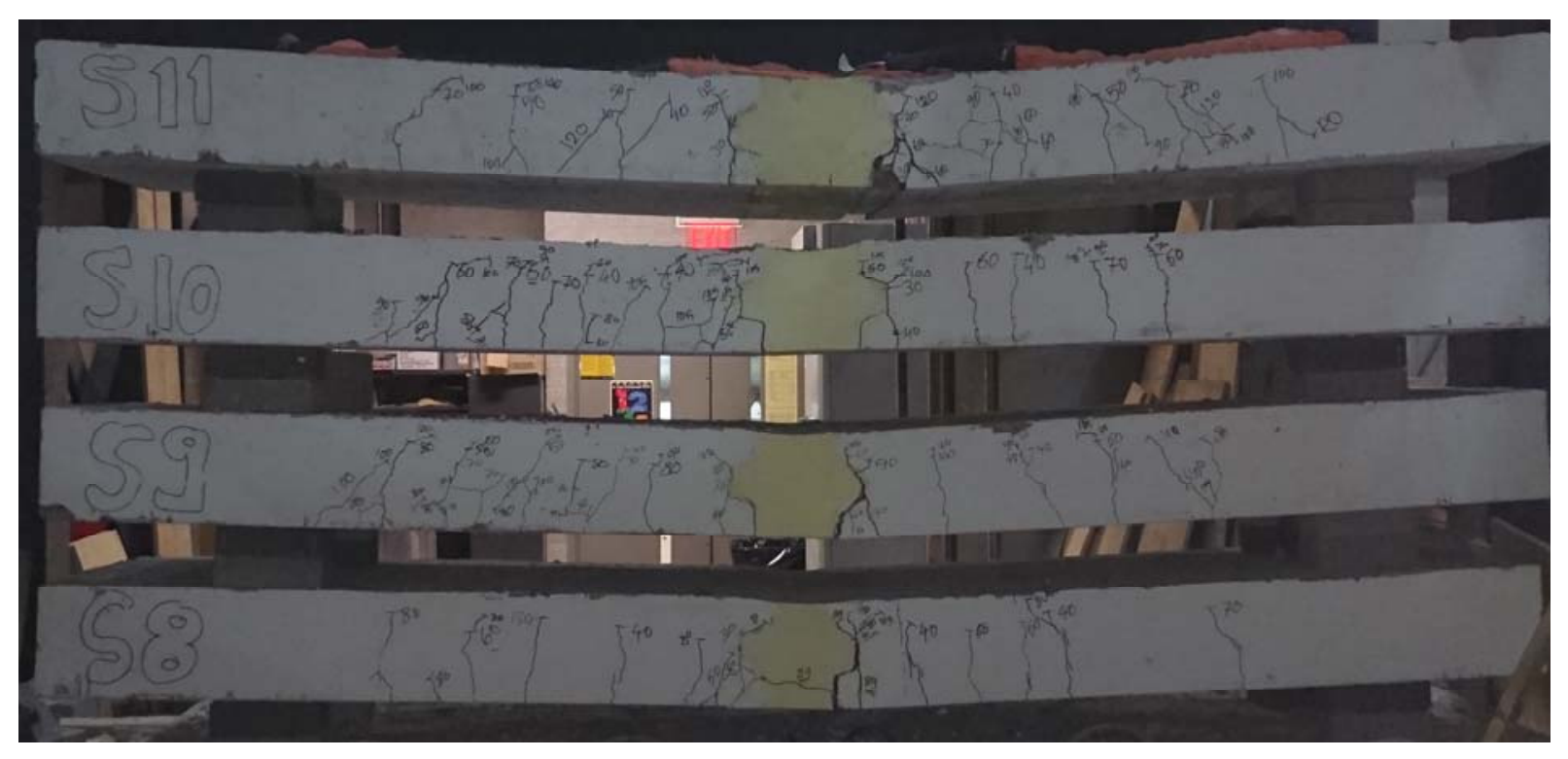

Figure 4.109 View of failure modes of slabs from side 1 in group G2

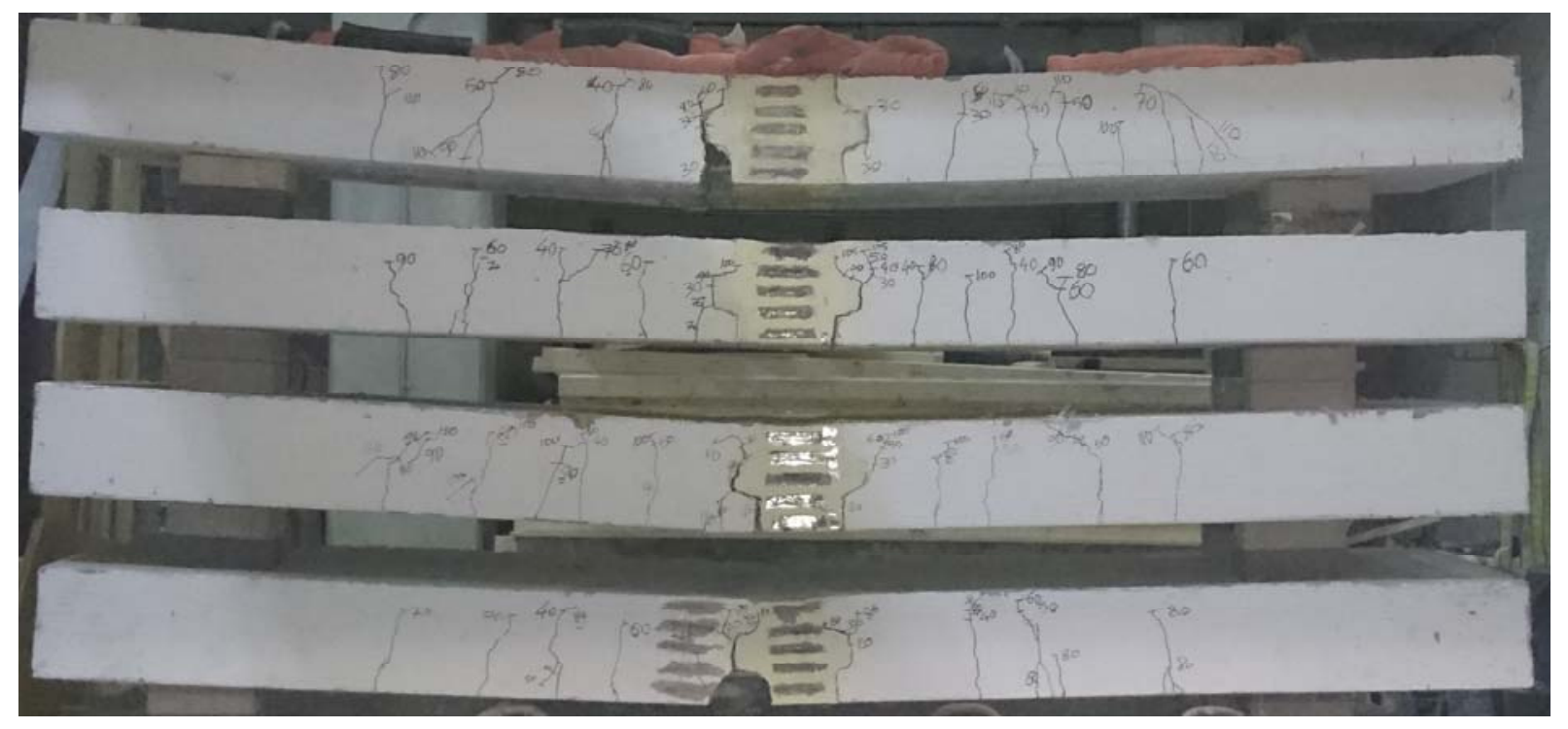

Figure 4.110 View of failure modes of slabs from side 2 in group G2 


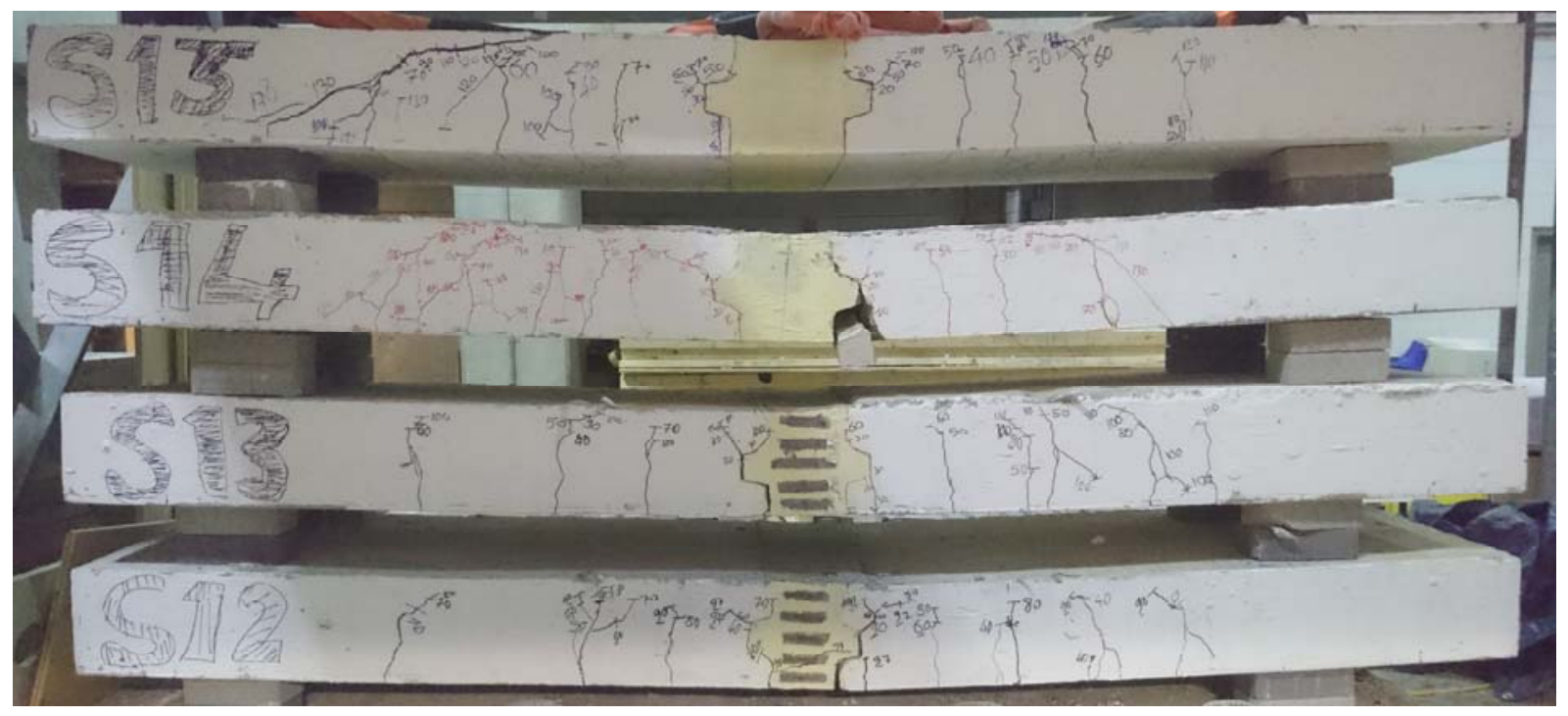

Figure 4.111 View of failure modes of slabs from side 1 in group G3

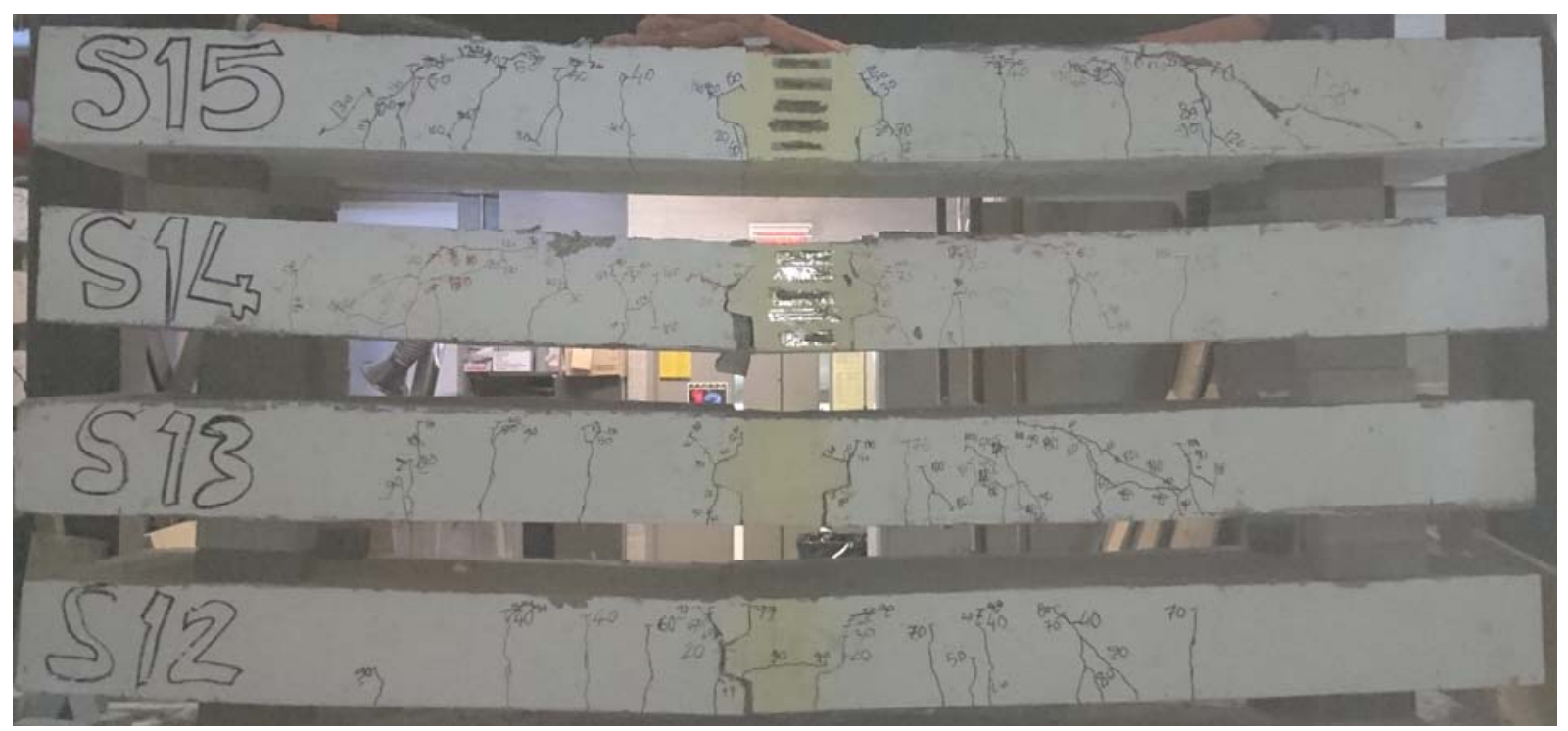

Figure 4.112 View of failure modes of slabs from side 2 in group G3 


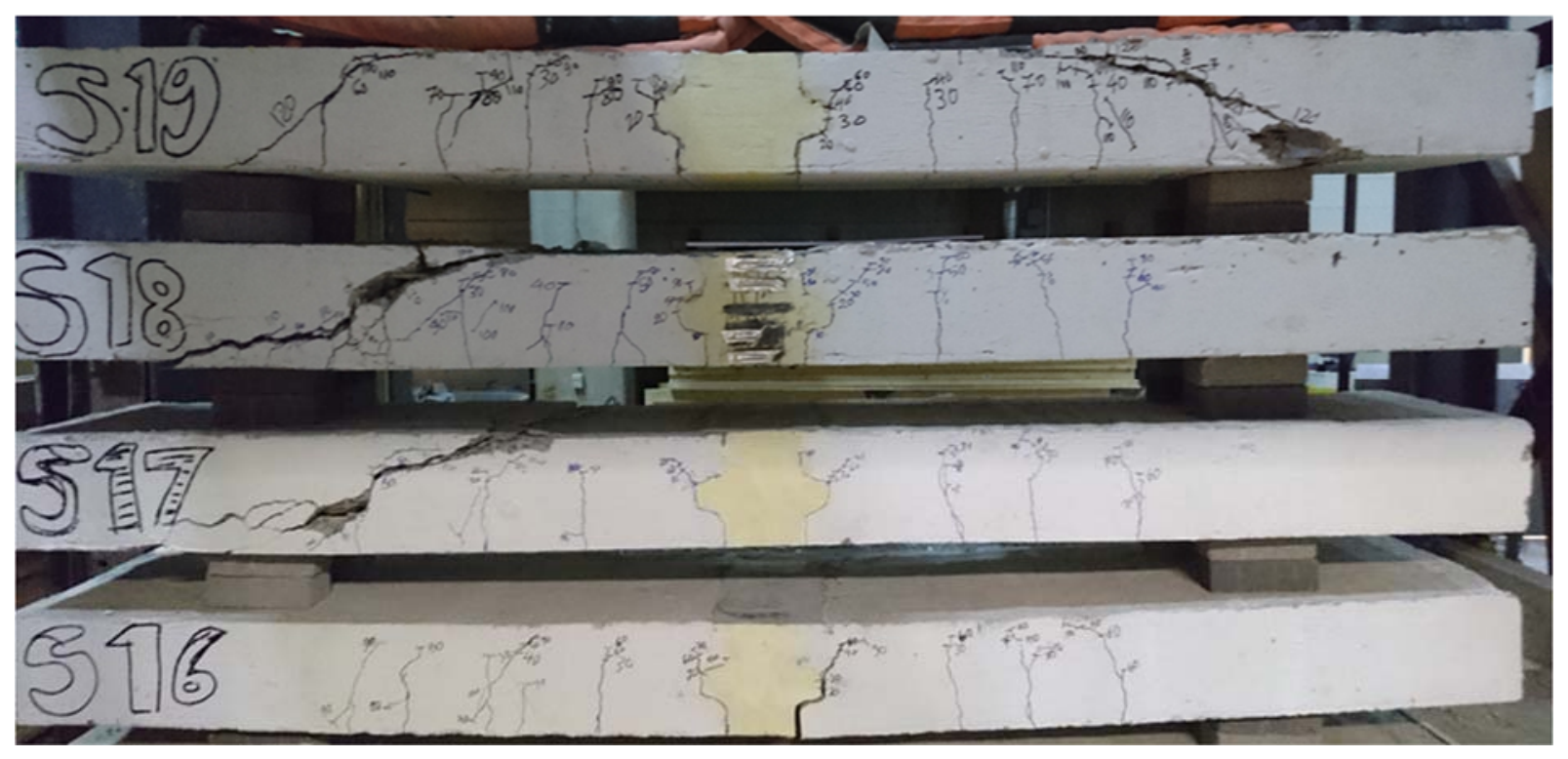

Figure 4.113 View of failure modes of slabs from side 1 in group G4

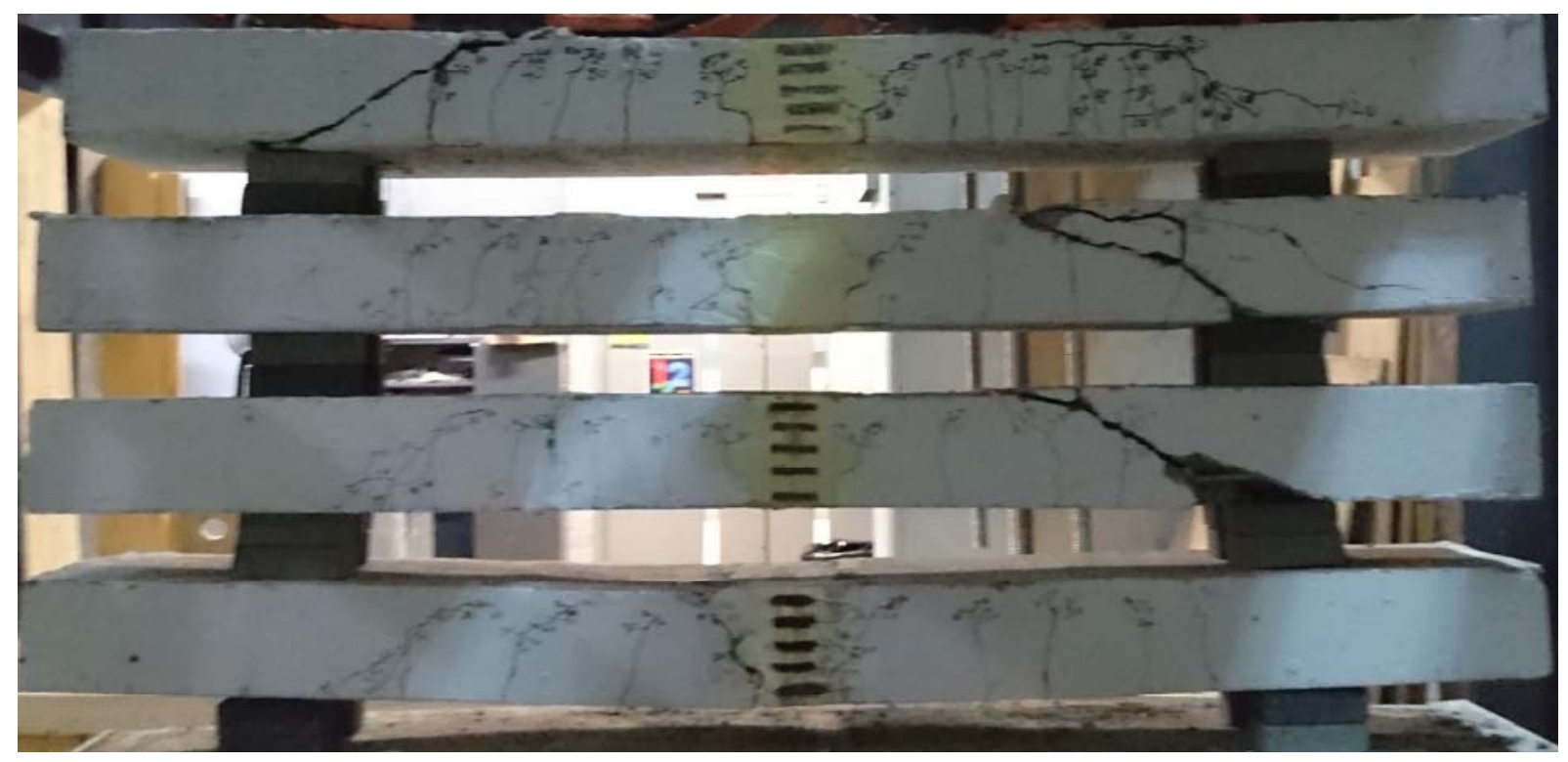

Figure 4.114 View of failure modes of slabs from side 2 in group G4 


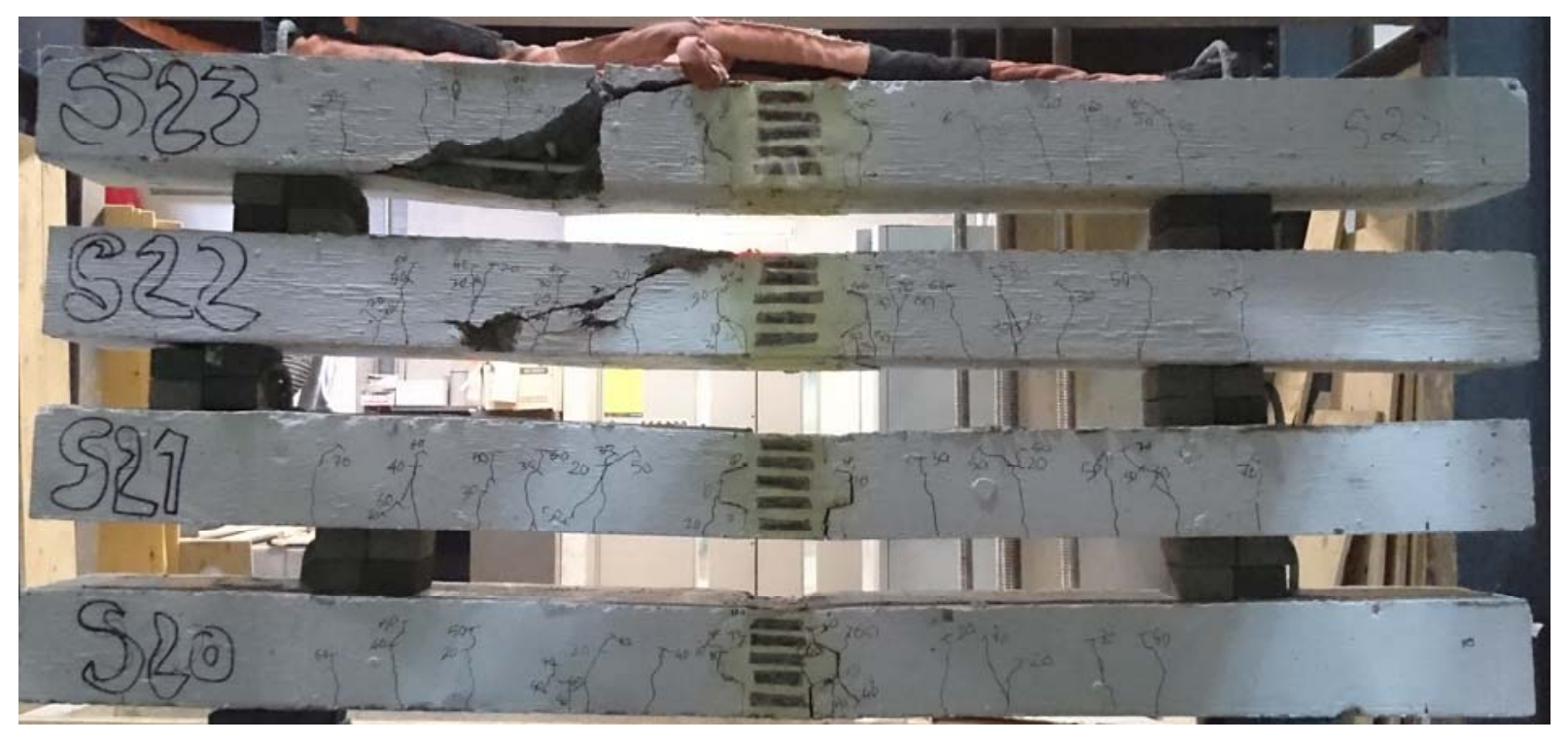

Figure 4.115 View of failure modes of slabs from side 1 in group G5

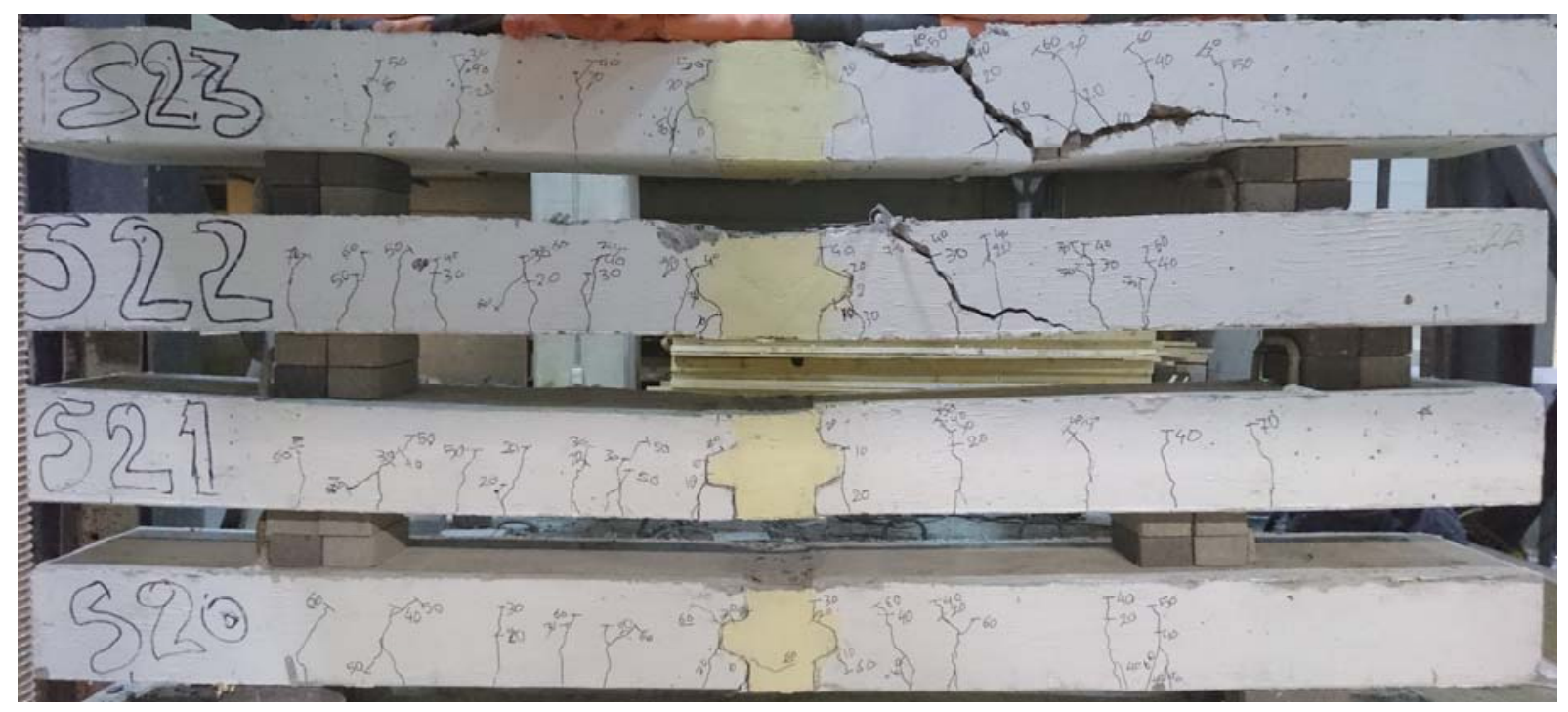

Figure 4.116 View of failure modes of slabs from side 2 in group G5 


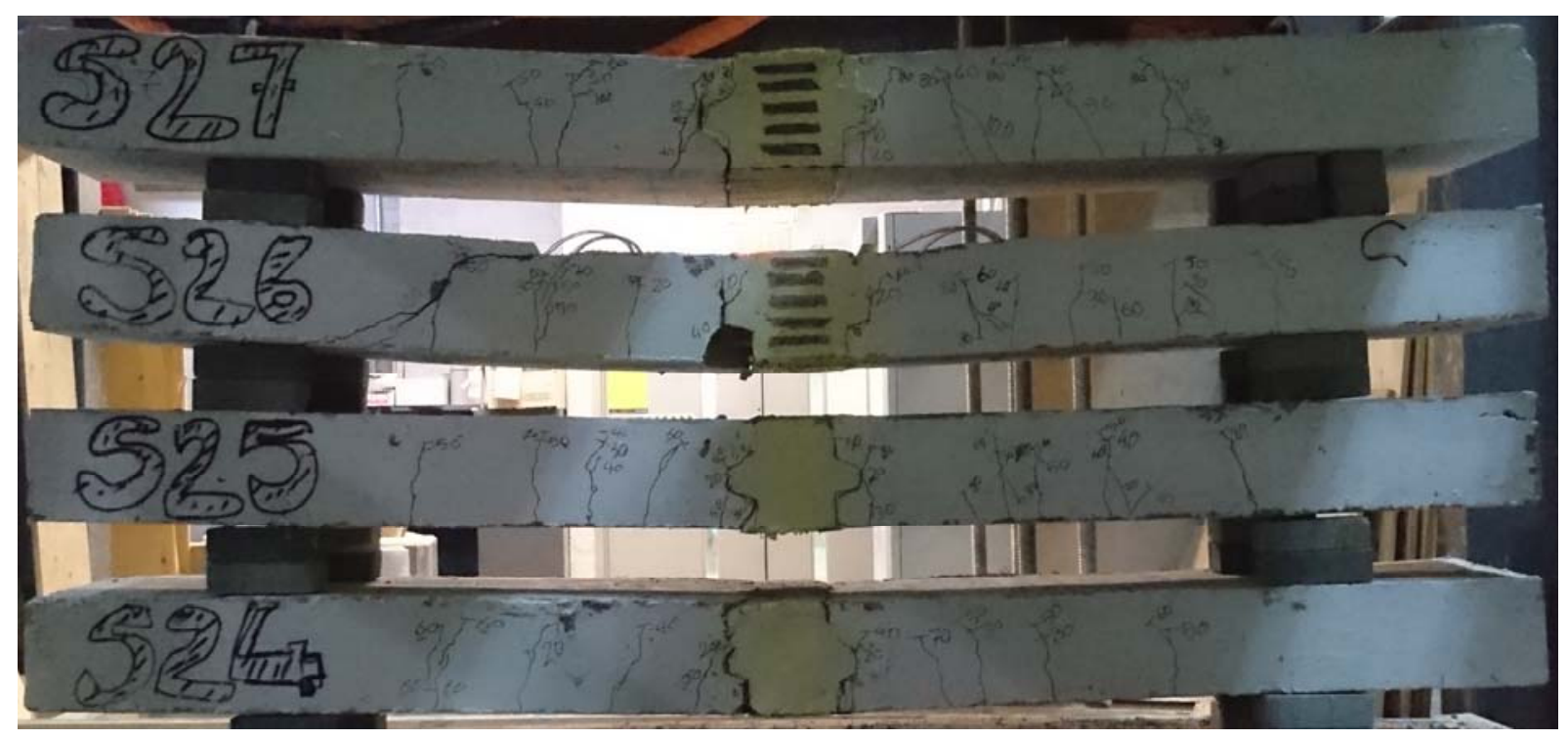

Figure 4.117 View of failure modes of slabs from side 1 in group G6

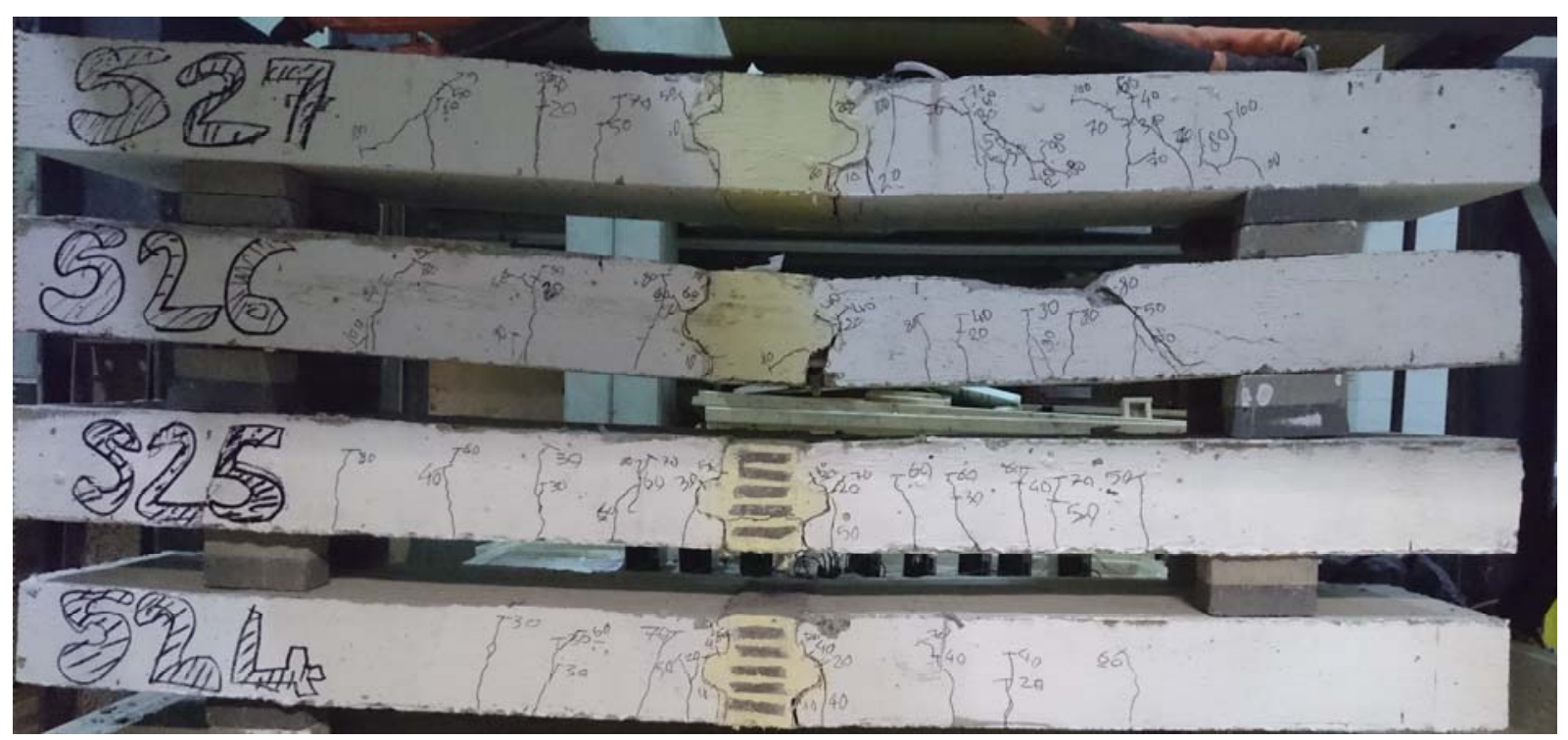

Figure 4.118 View of failure modes of slabs from side 2 in group G6 

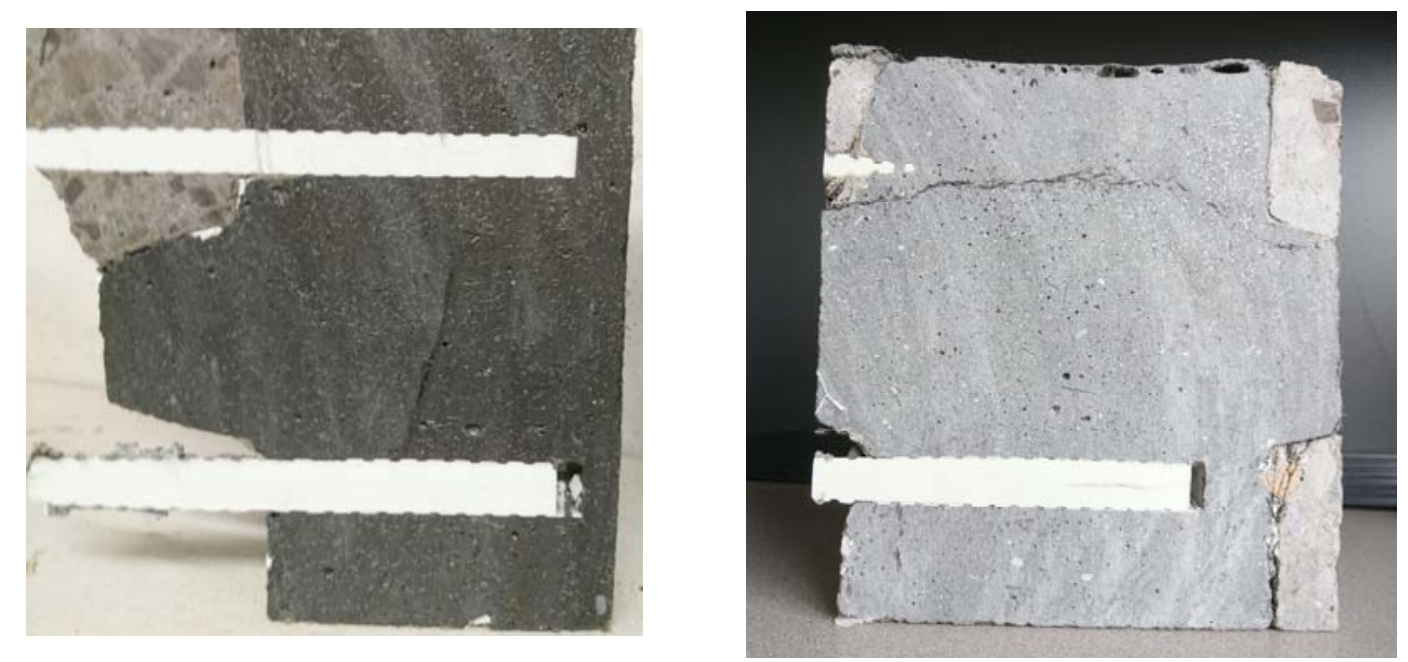

Figure 4.119 View of bar slippage in the UHPFRC joint after taking a core sample and slicing it at the bar location

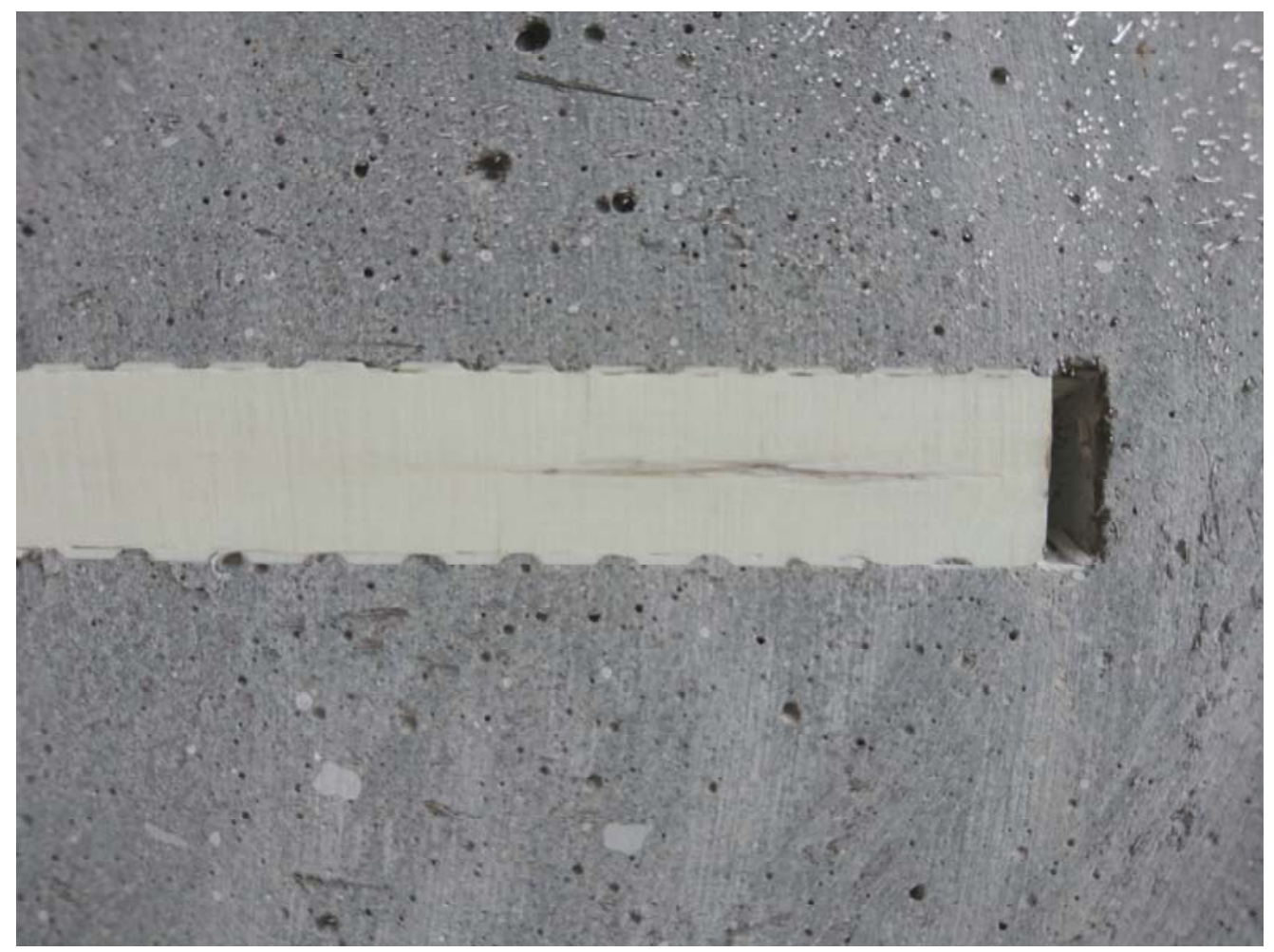

Figure 4.120 View of bar slippage failure due to shearing of the bar ribs 


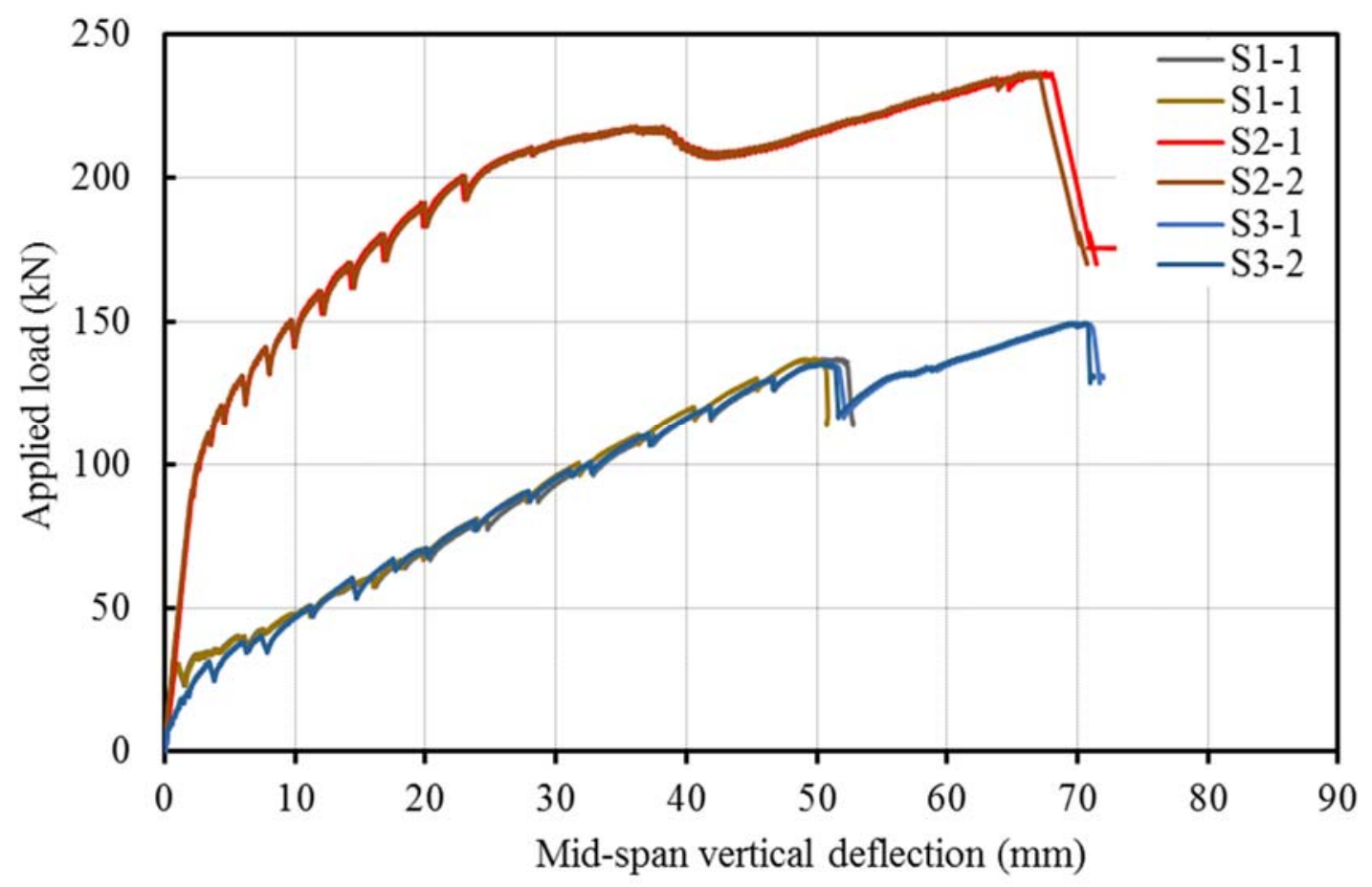

Figure 4.121 Moment vs deflection relationship for slabs in group CG

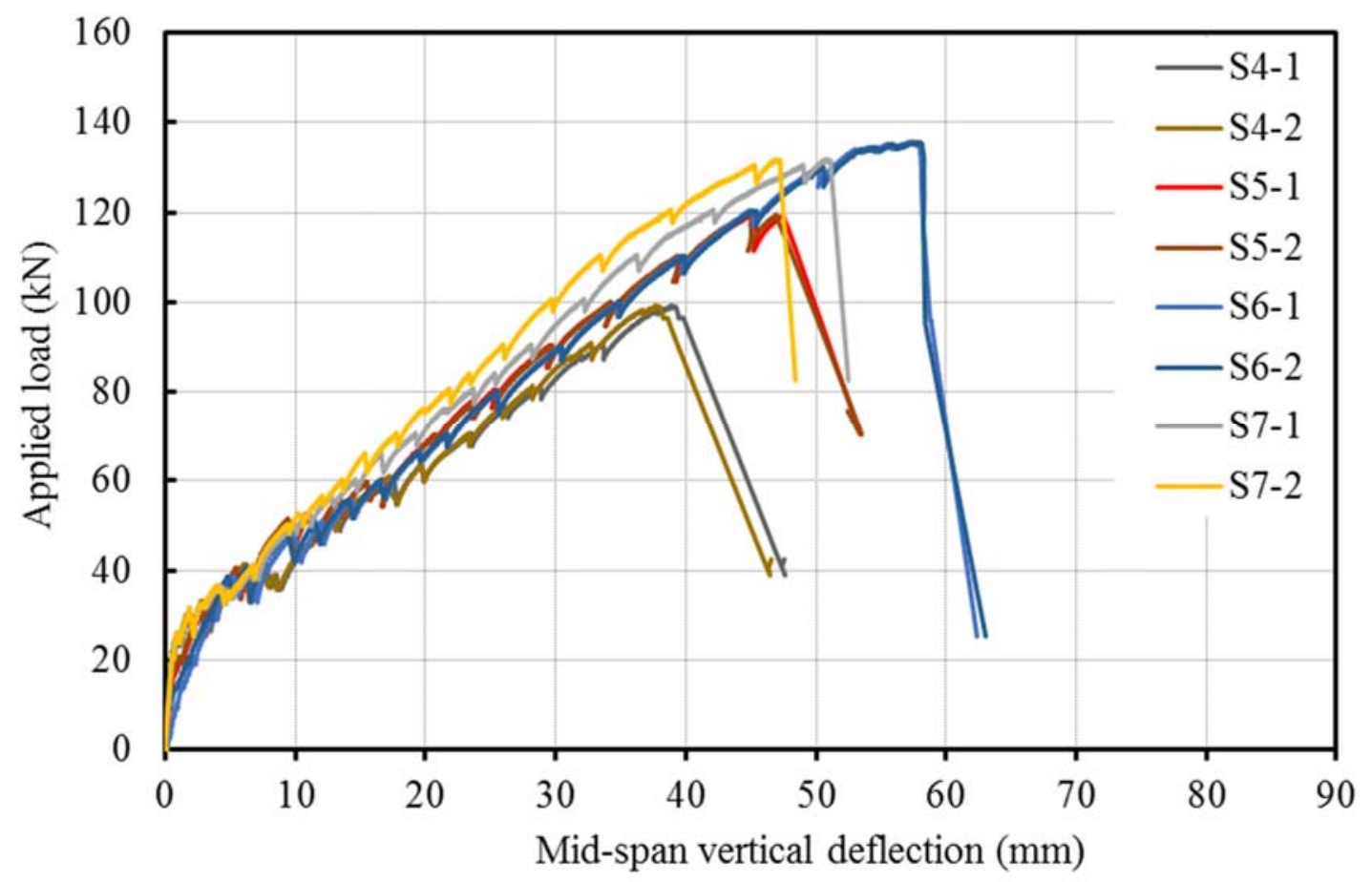

Figure 4.122 Moment vs deflection relationship for slabs in group G1 


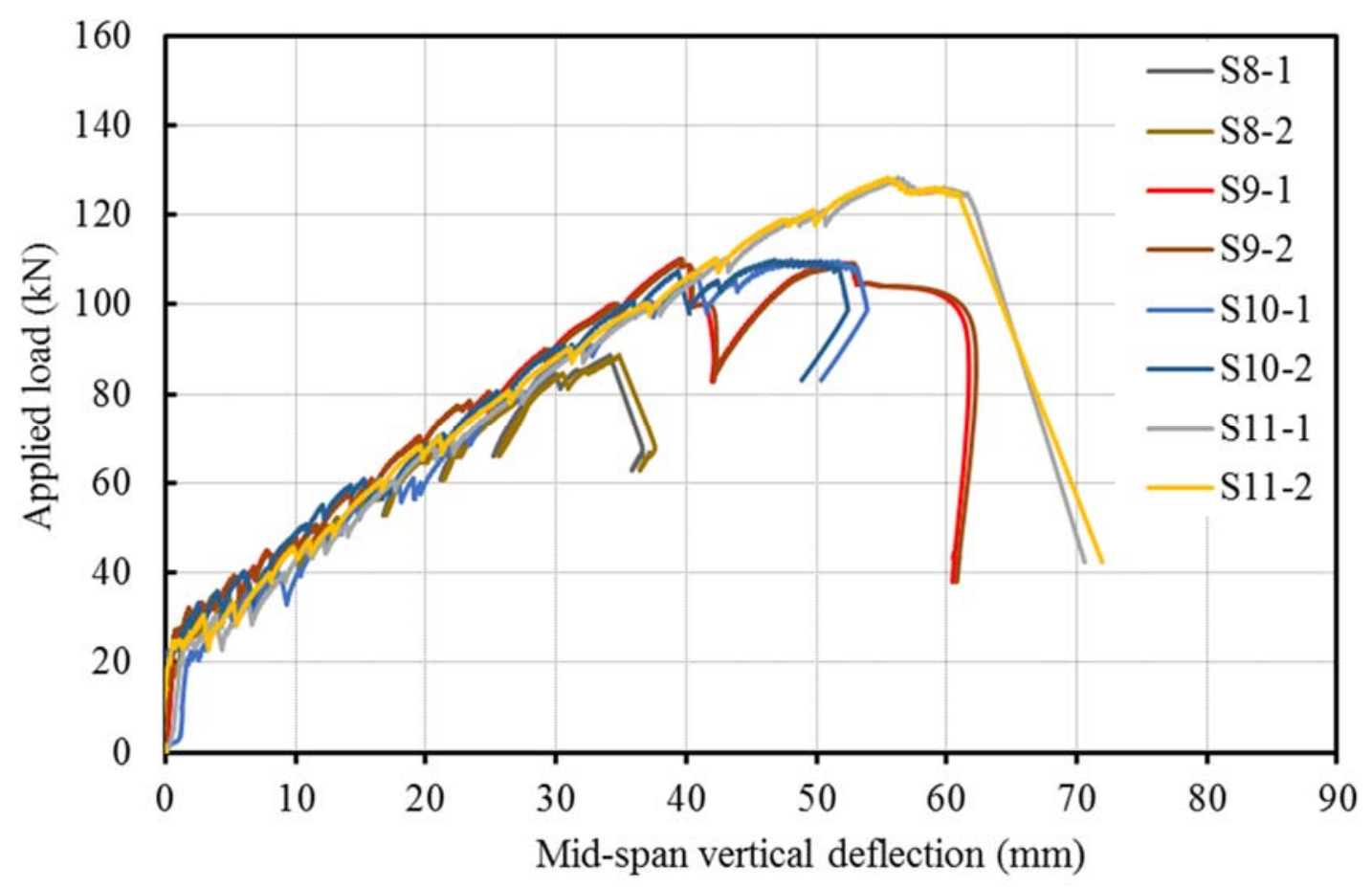

Figure 4.123 Moment vs deflection relationship for slabs in group G2

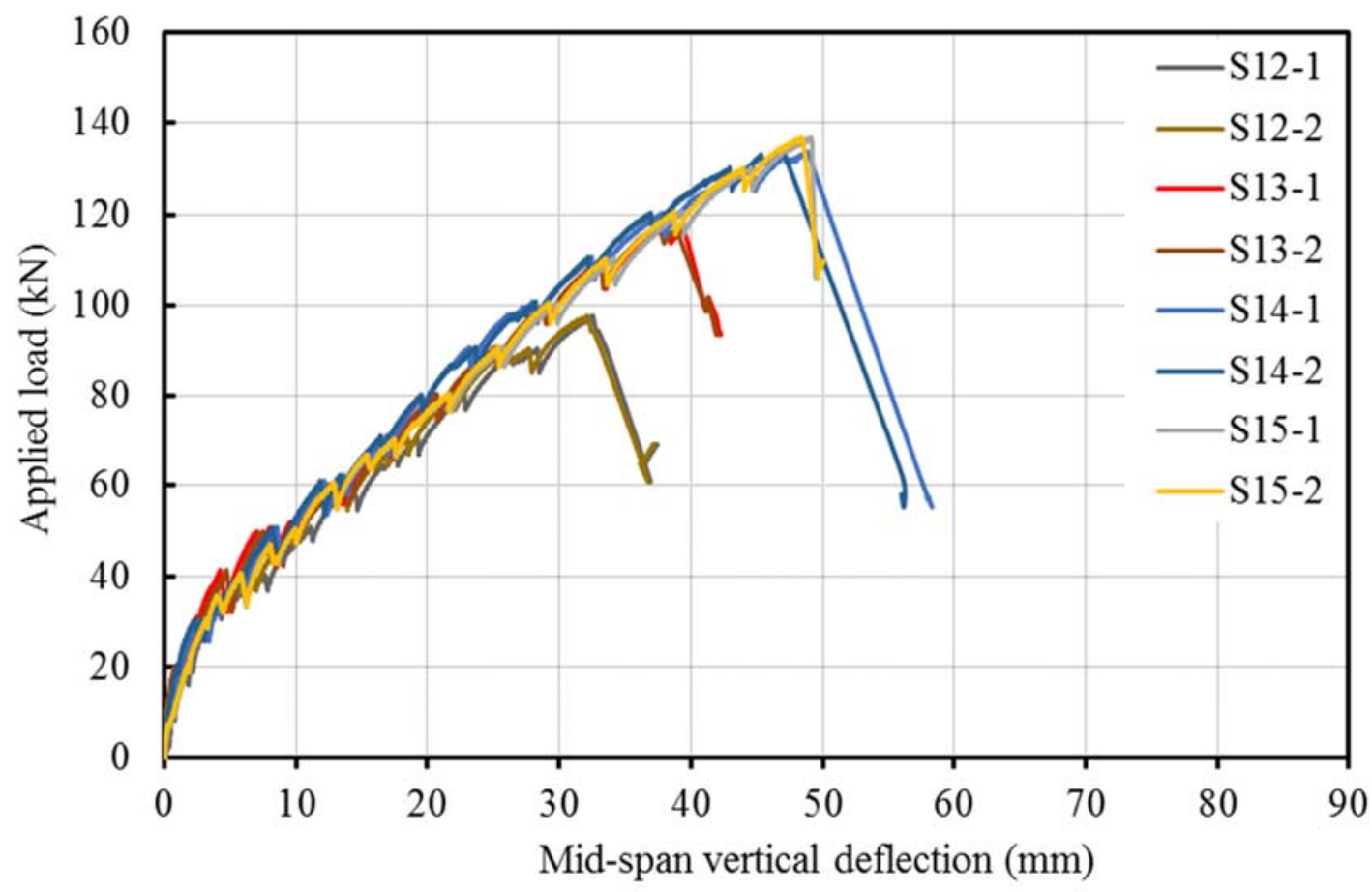

Figure 4.124 Moment vs deflection relationship for slabs in group G3 


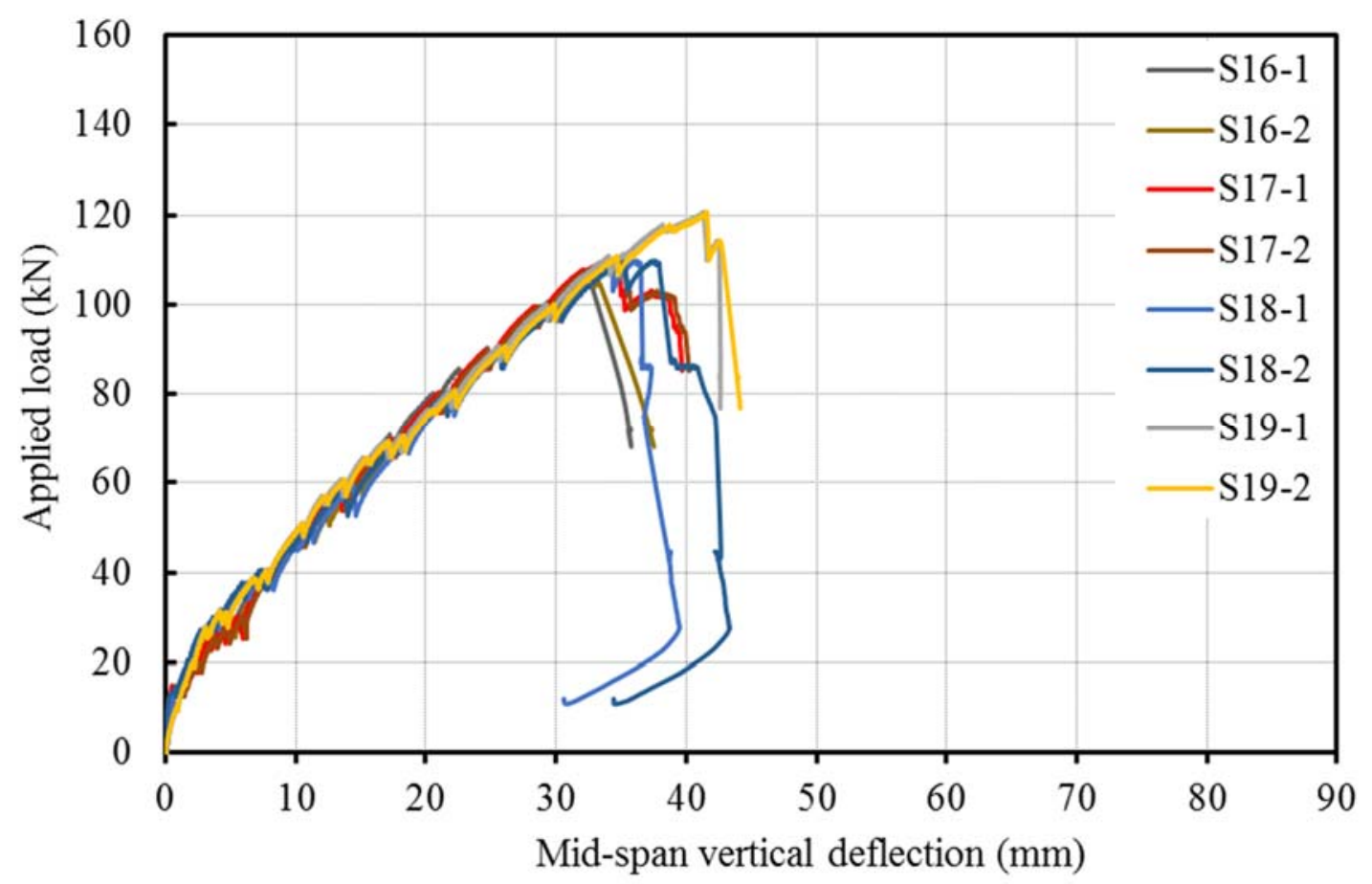

Figure 4.125 Moment vs deflection relationship for slabs in group G4

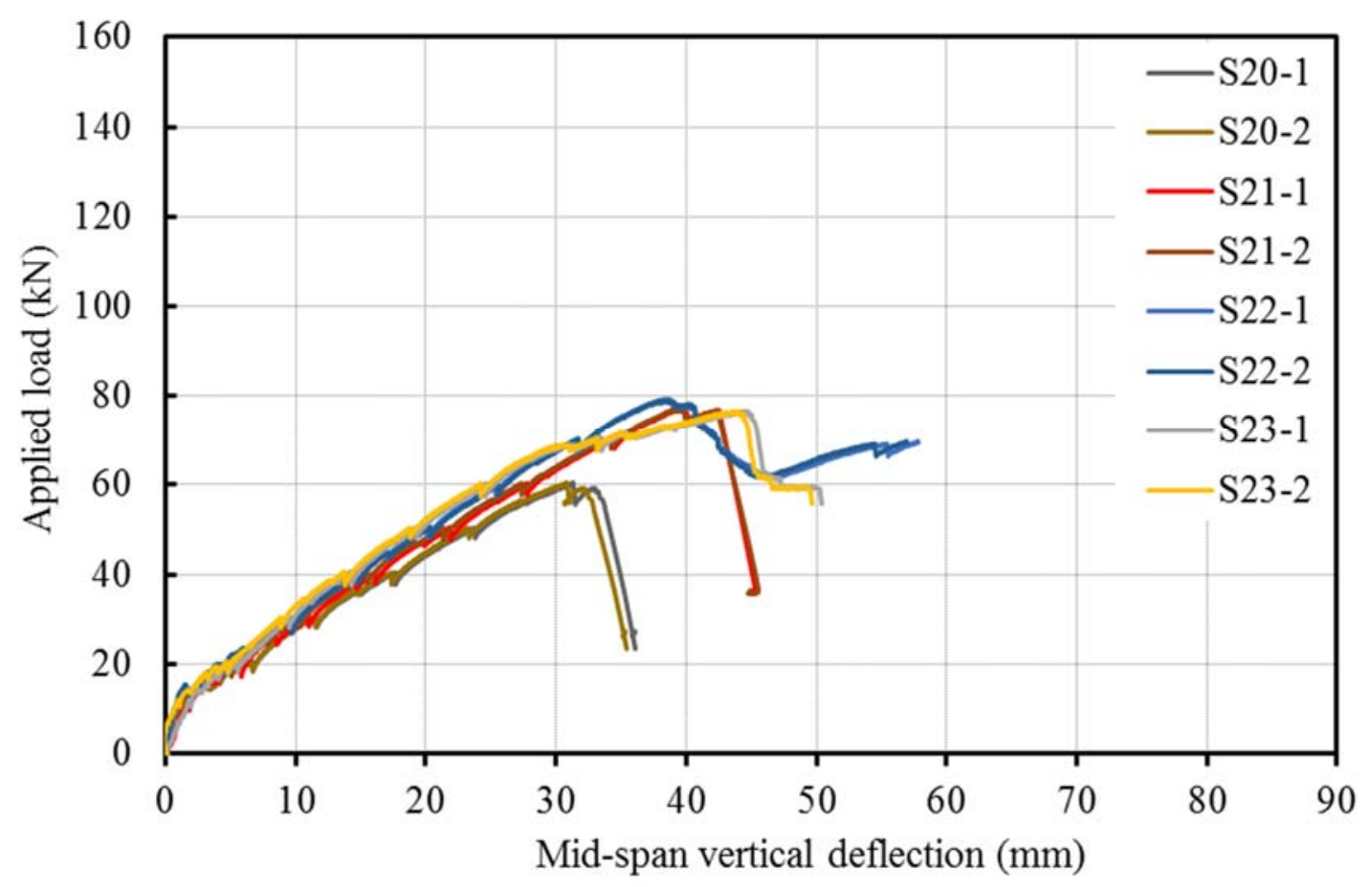

Figure 4.126 Moment vs deflection relationship for slabs in group G5 


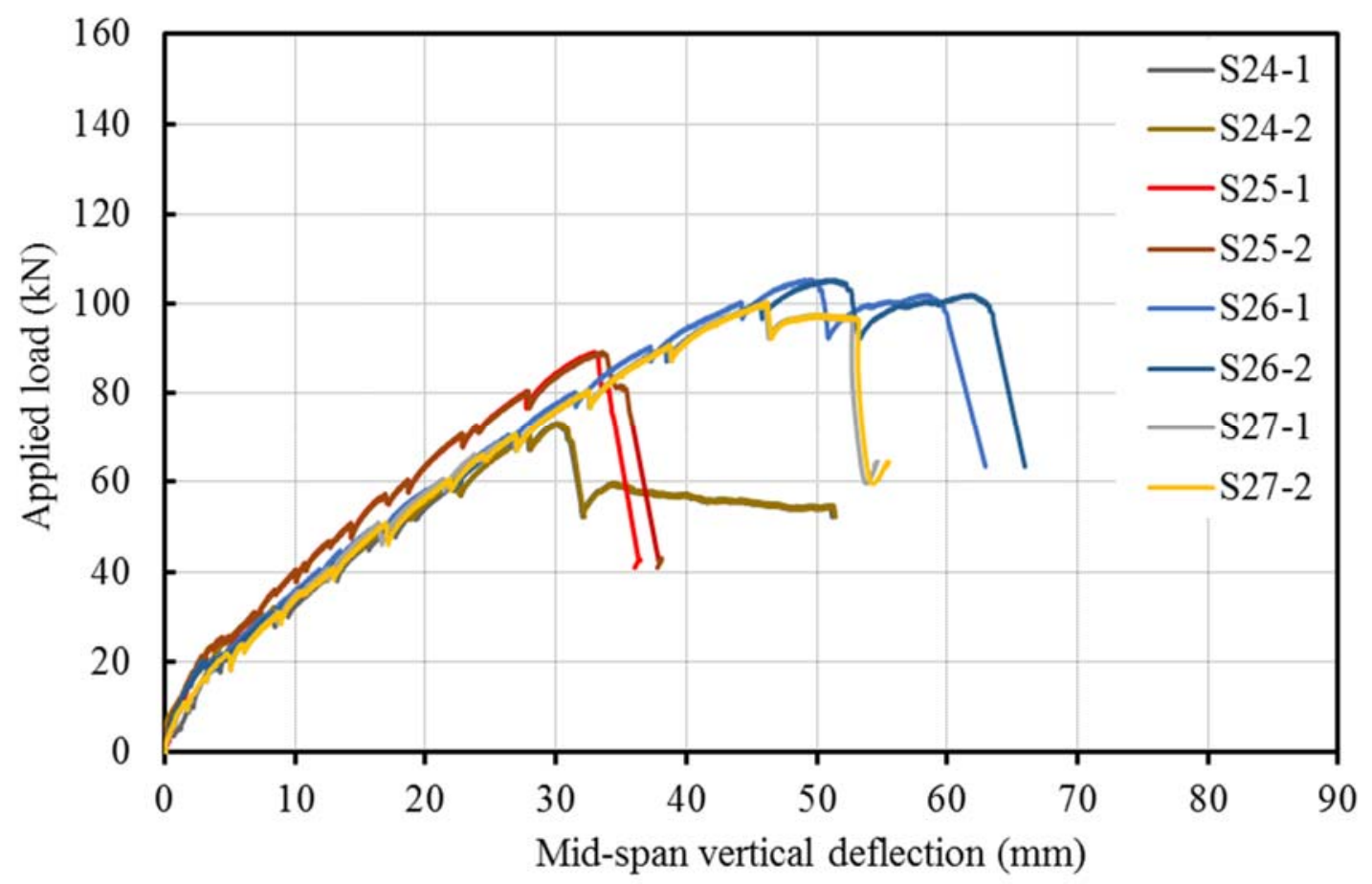

Figure 4.127 Moment vs deflection relationship for slabs in group G6 


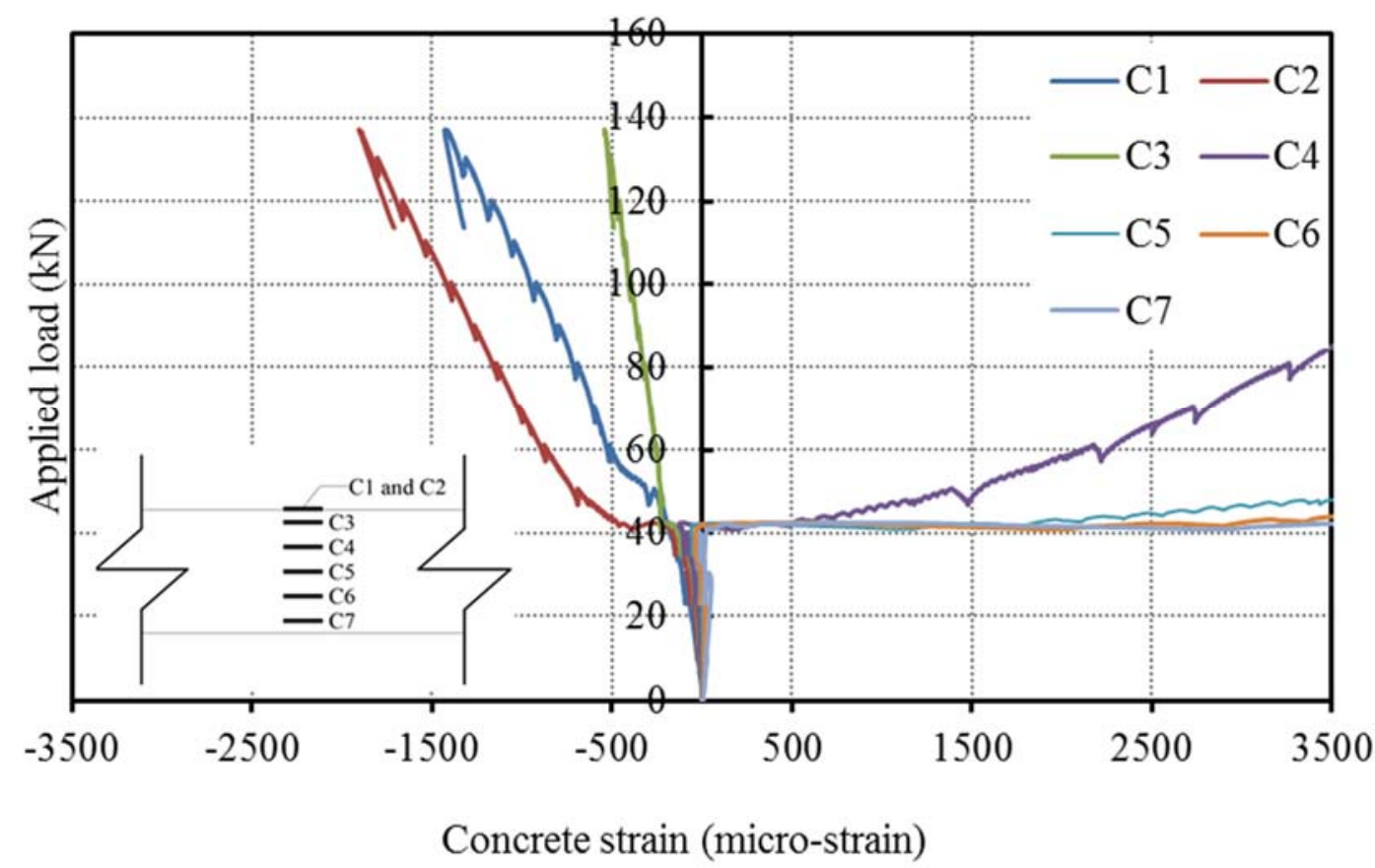

Figure 4.128 Load-concrete strain relationship for slab $\mathrm{S}_{1}$

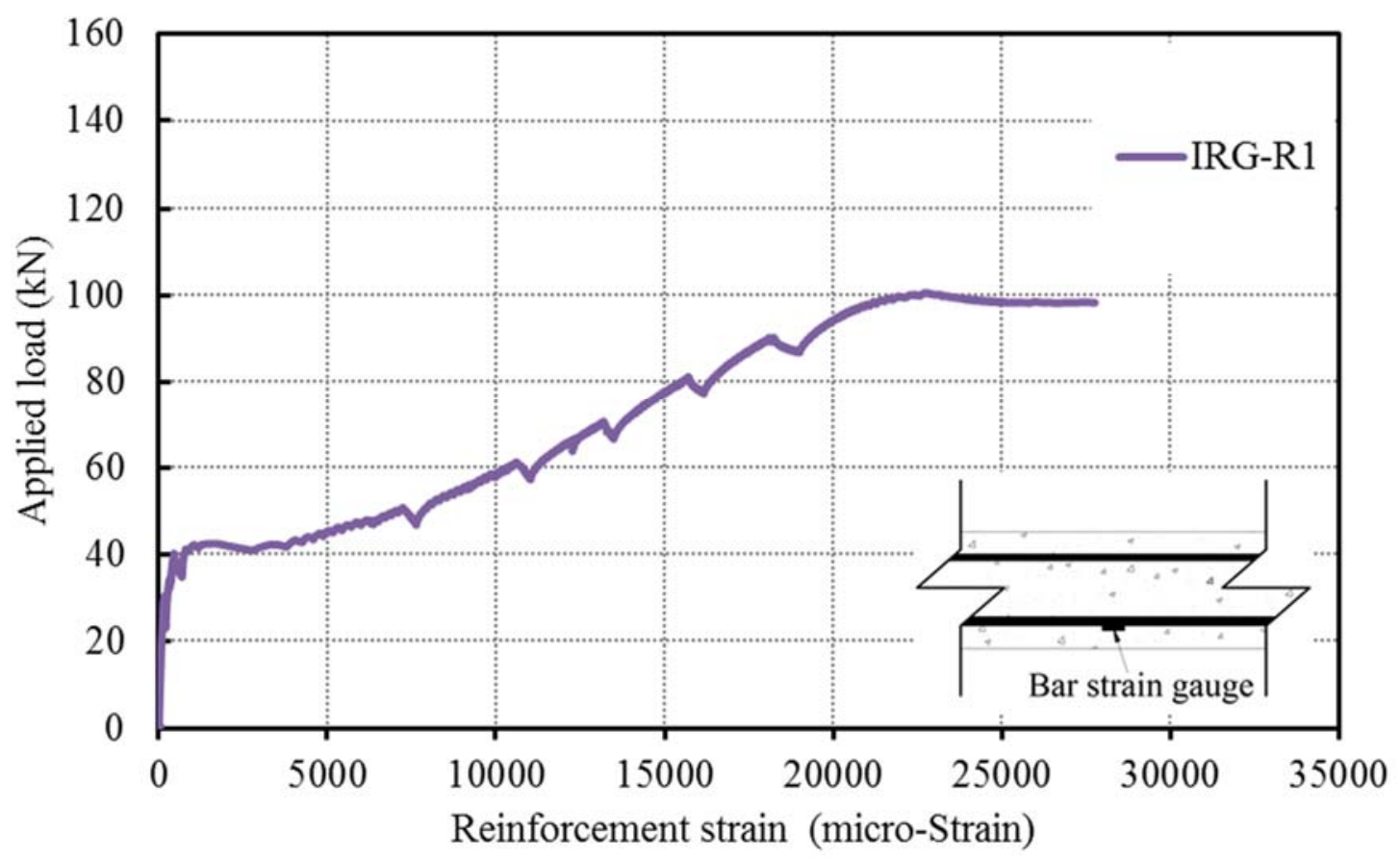

Figure 4.129 Load-bar strain relationship for slab $\mathrm{S}_{1}$ (Note: the strain gauge did not work to the ultimate load) 


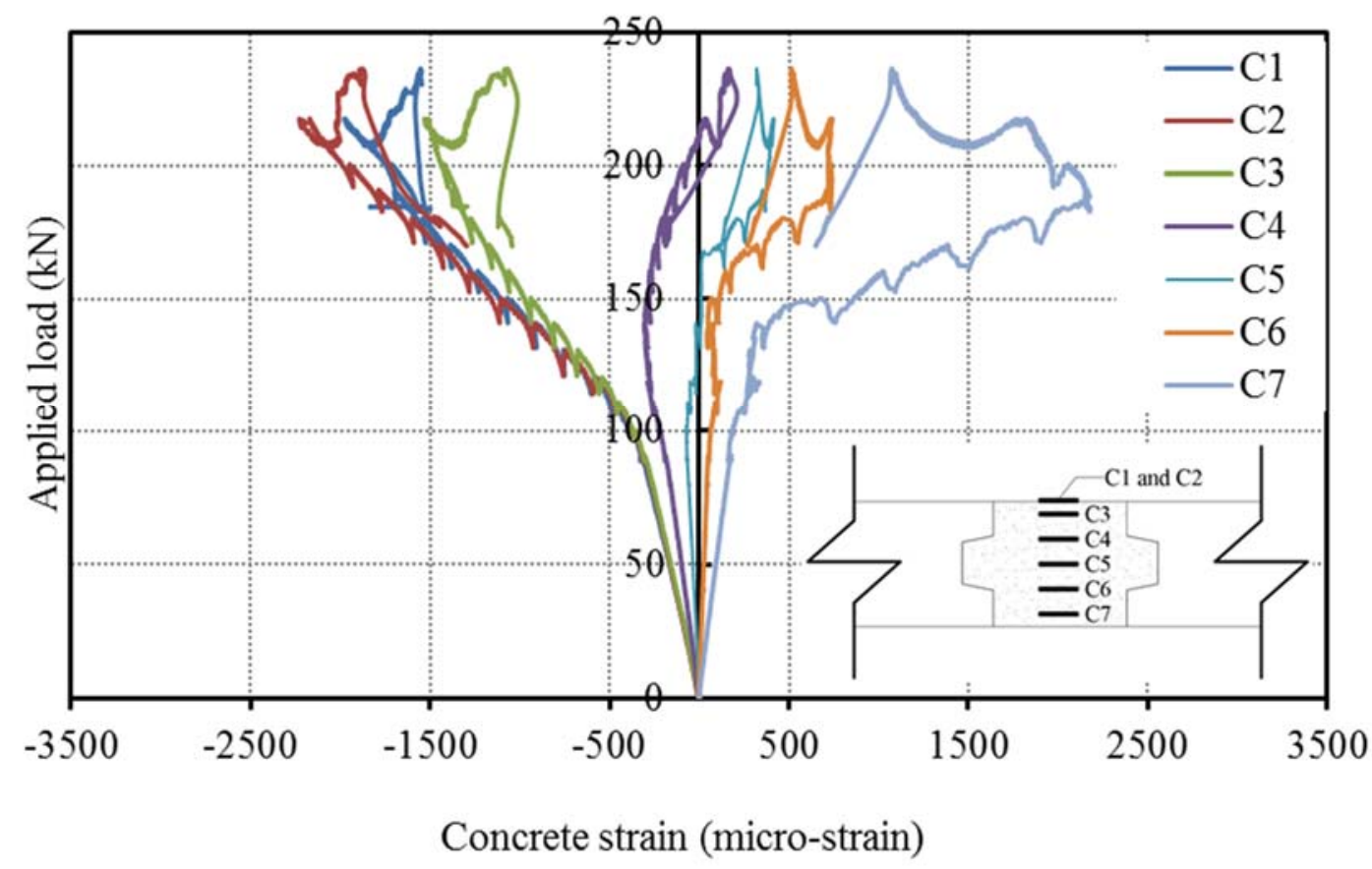

Figure 4.130 Load-concrete strain relationship for slab $\mathrm{S}_{2}$

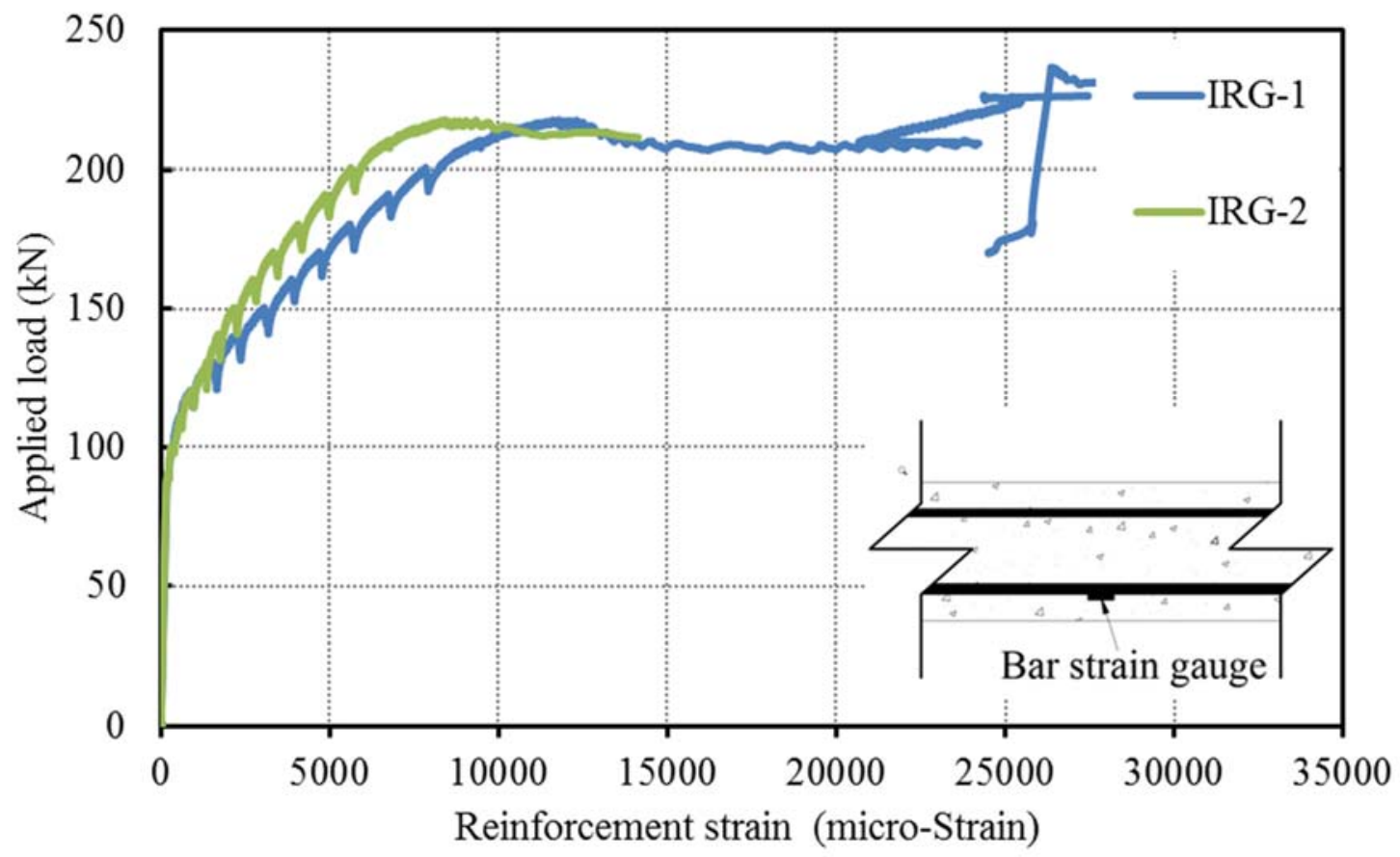

Figure 4.131 Load-bar strain relationship for slab $\mathrm{S}_{2}$ 


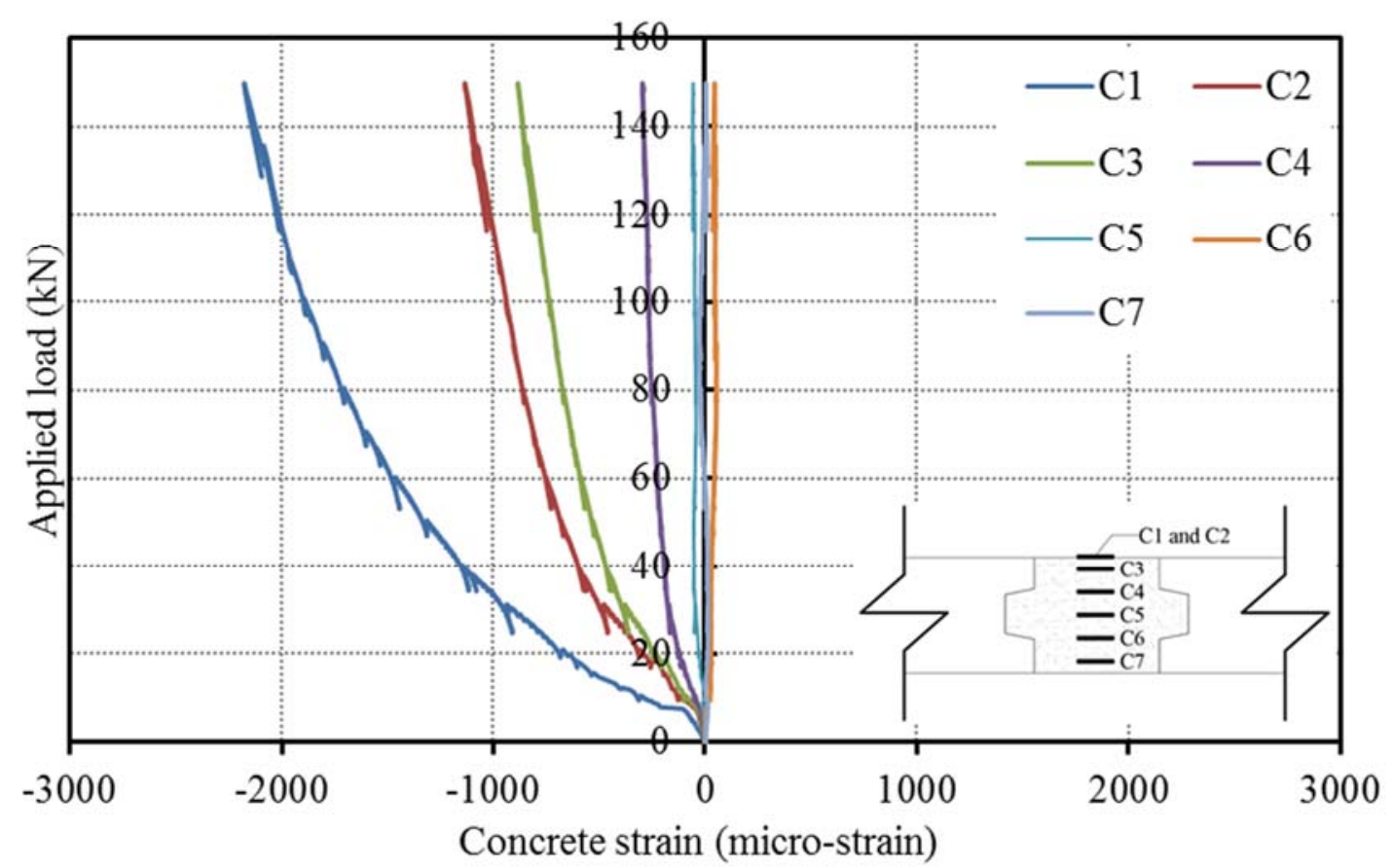

Figure 4.132 Load-concrete strain relationship for slab $\mathrm{S}_{3}$

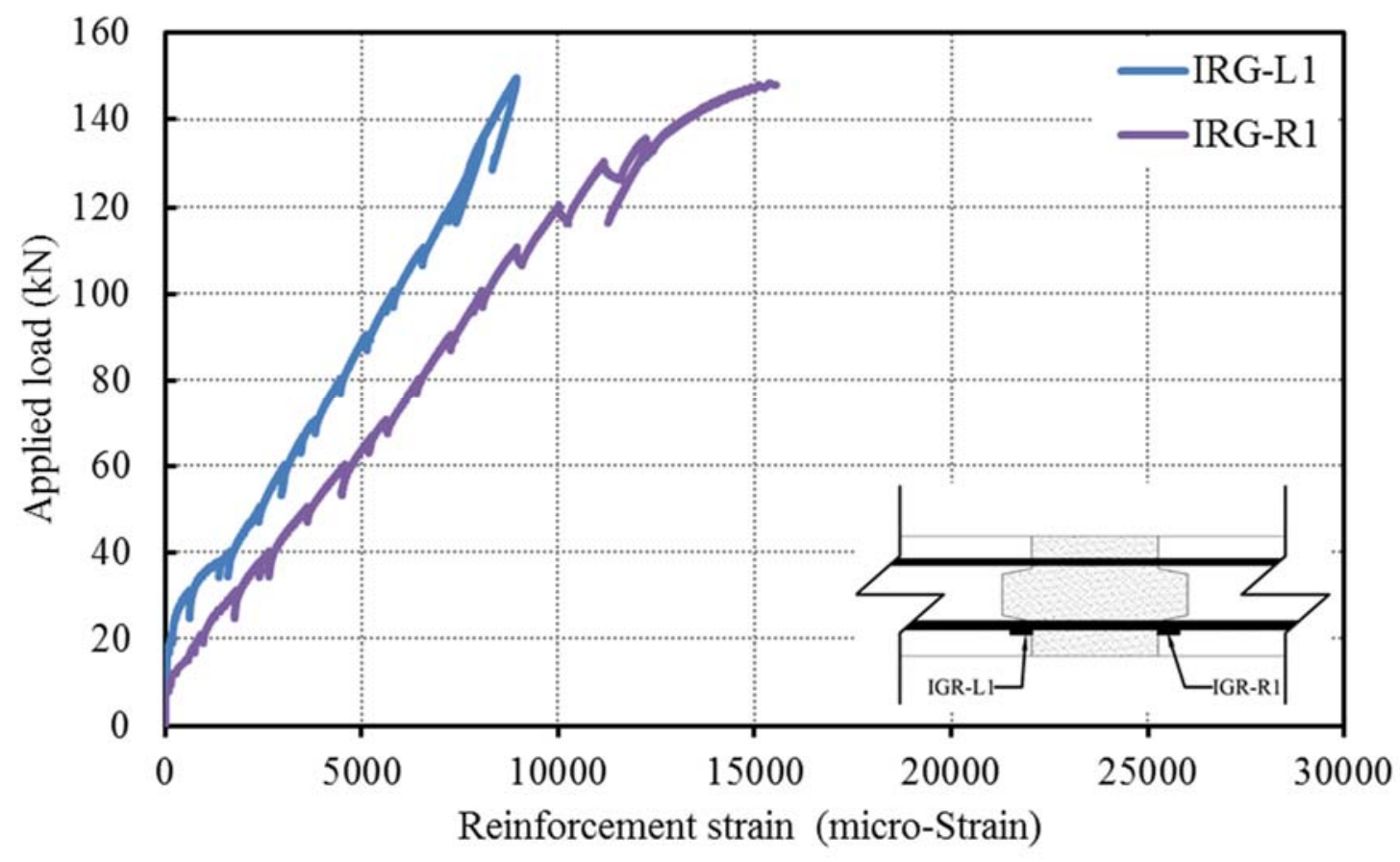

Figure 4.133 Load-bar strain relationship for slab $\mathrm{S}_{3}$ 


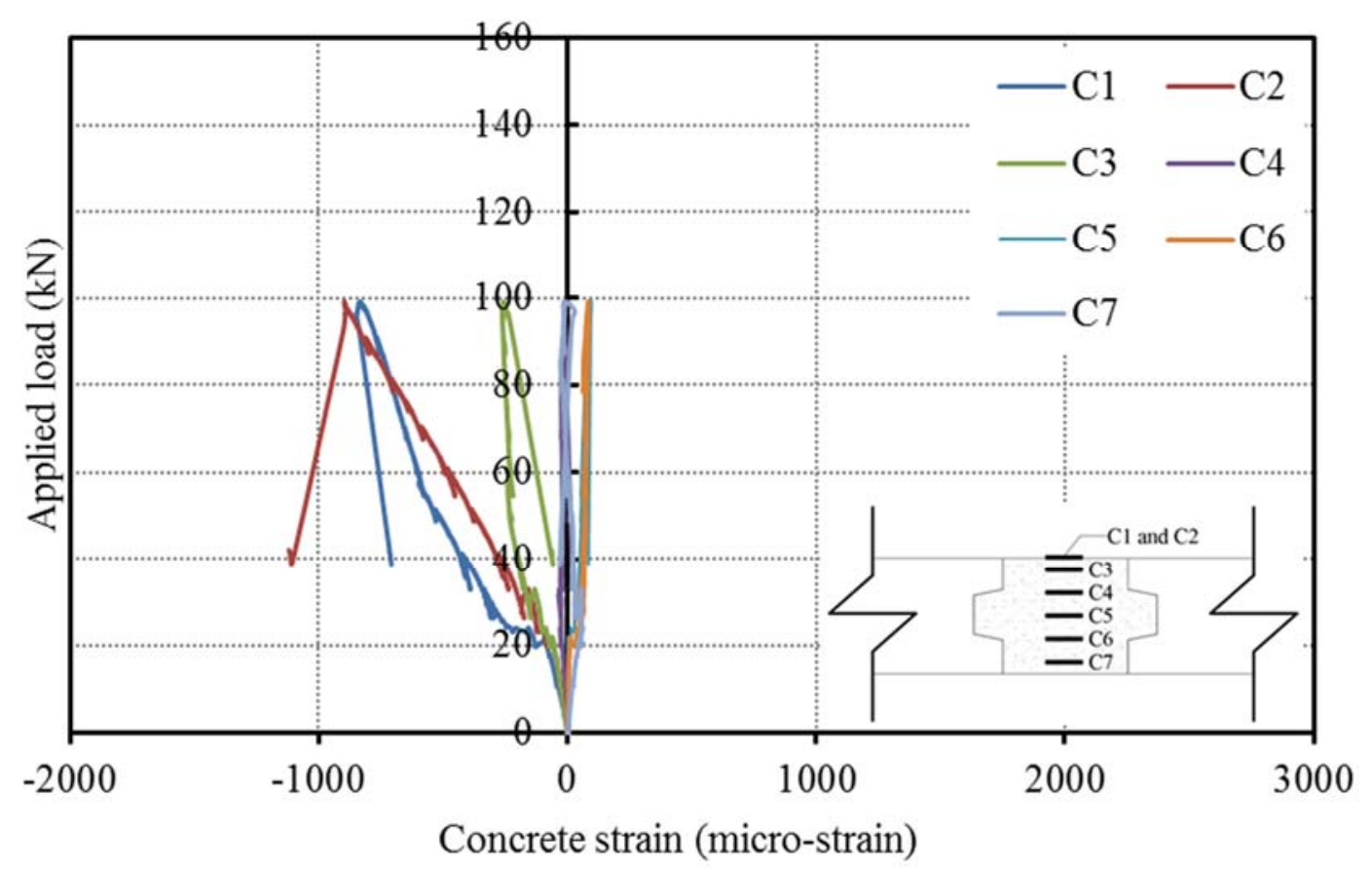

Figure 4.134 Load-concrete strain relationship for slab $\mathrm{S}_{4}$

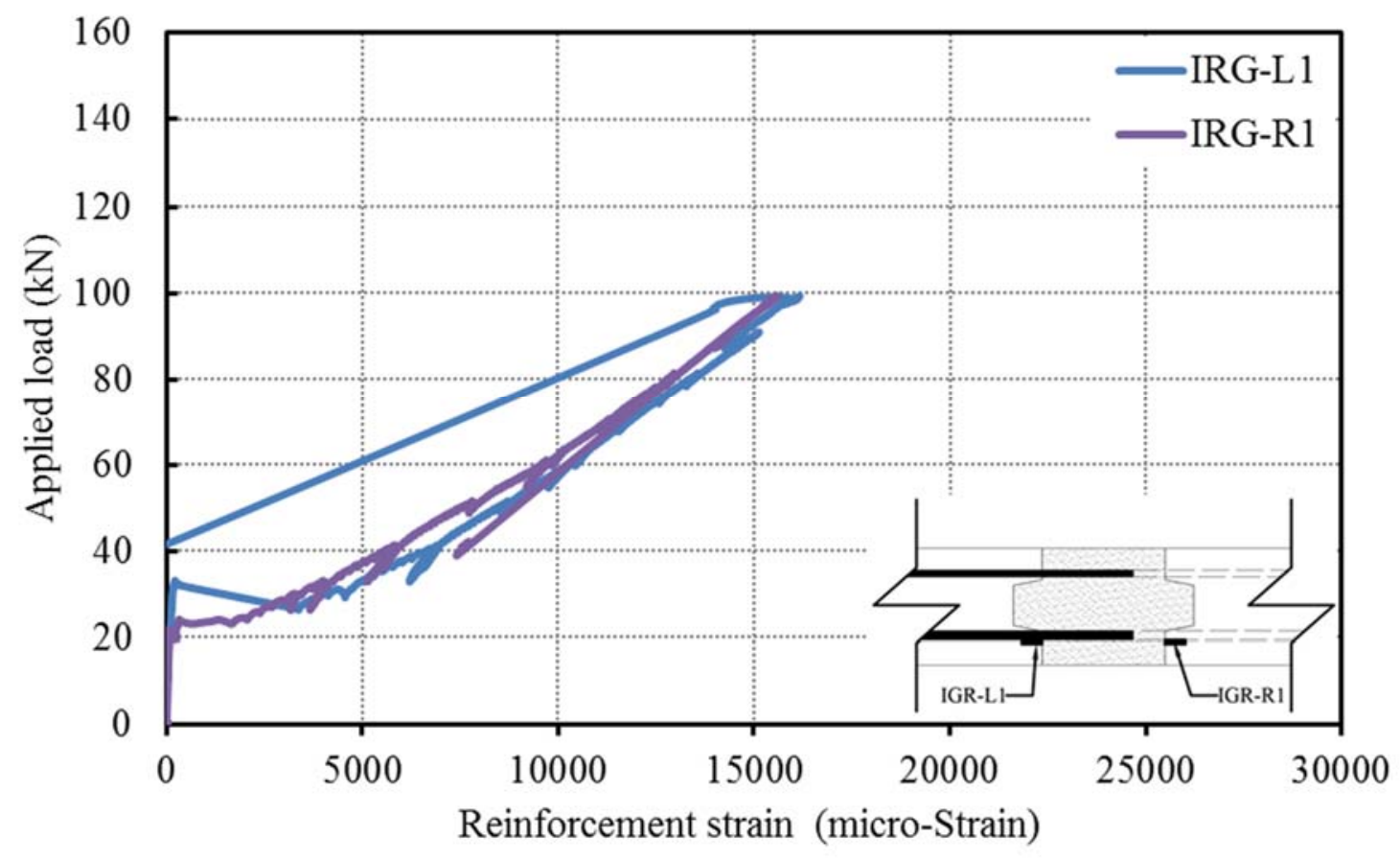

Figure 4.135 Load-bar strain relationship for slab $\mathrm{S}_{4}$ 


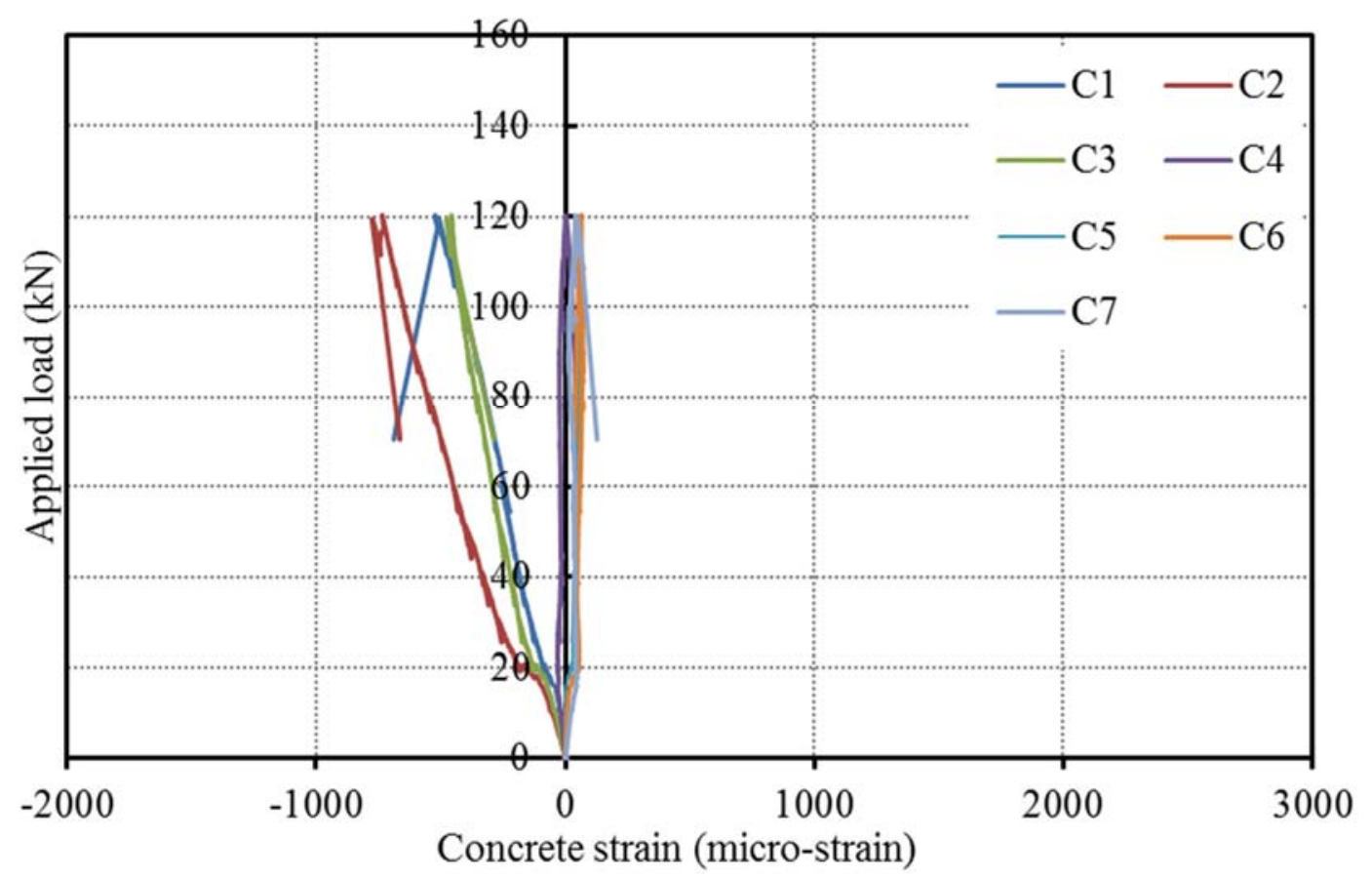

Figure 4.136 Load-concrete strain relationship for slab $\mathrm{S}_{5}$

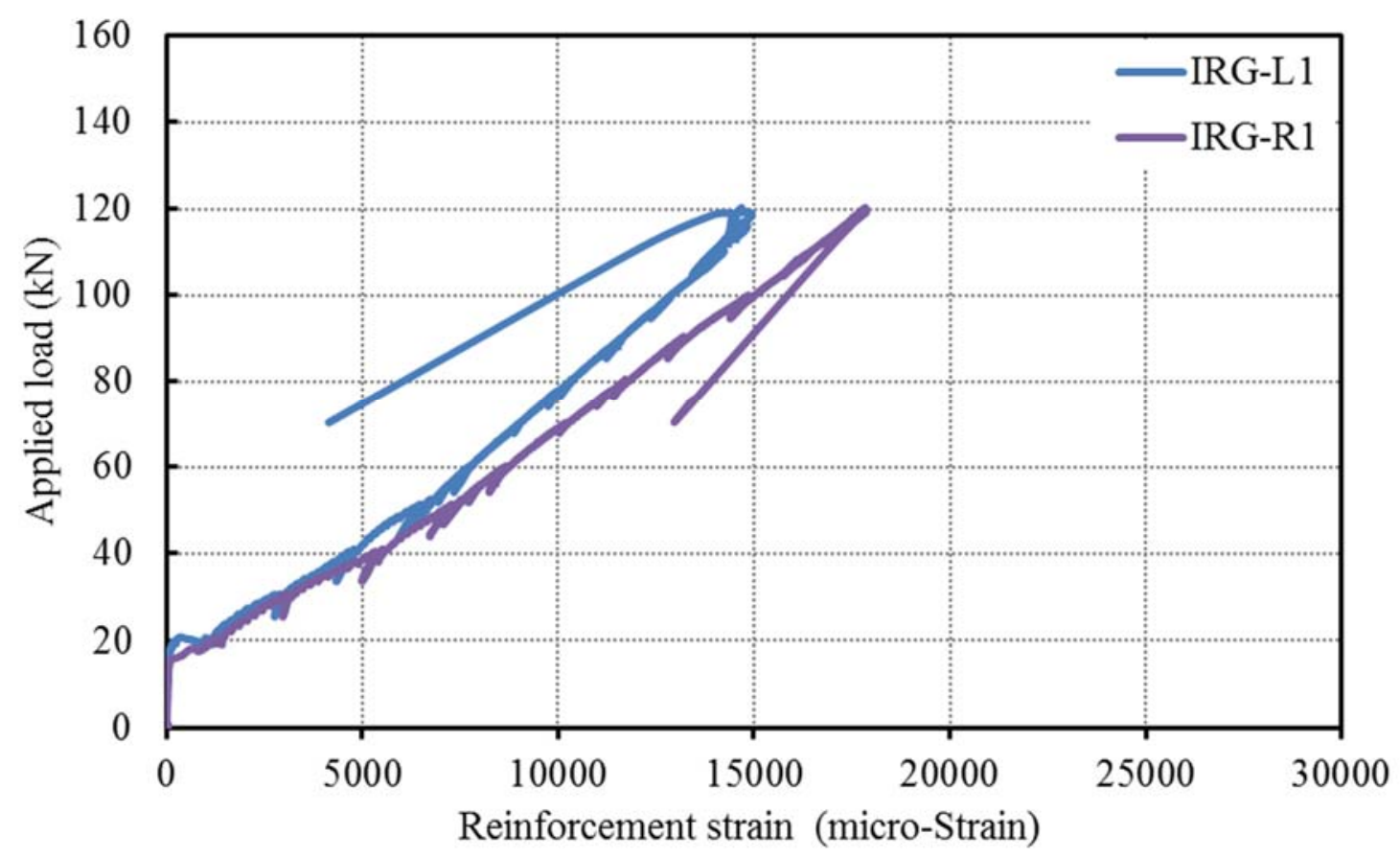

Figure 4.137 Load-bar strain relationship for slab $\mathrm{S}_{5}$ 


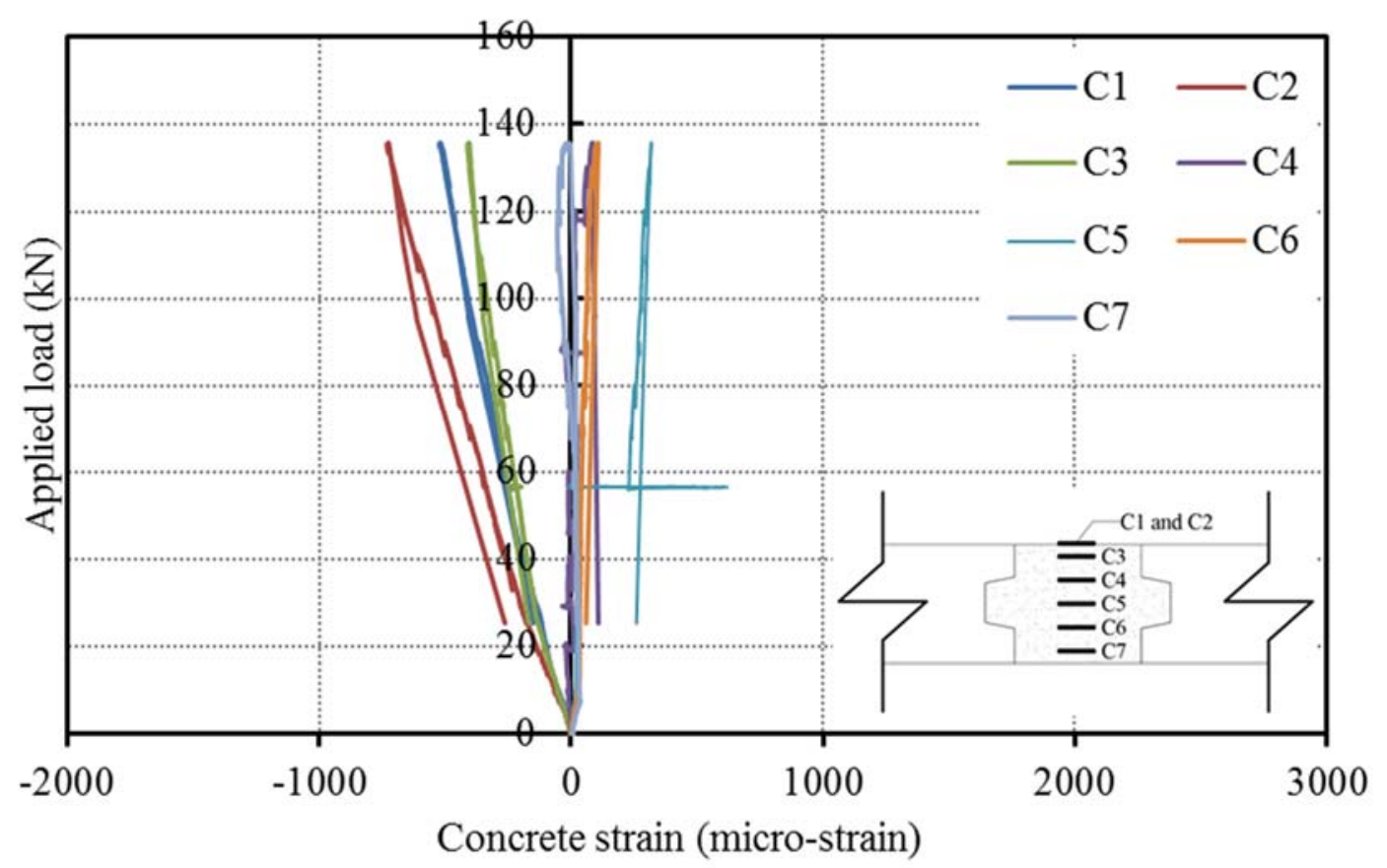

Figure 4.138 Load-concrete strain relationship for slab $\mathrm{S}_{6}$

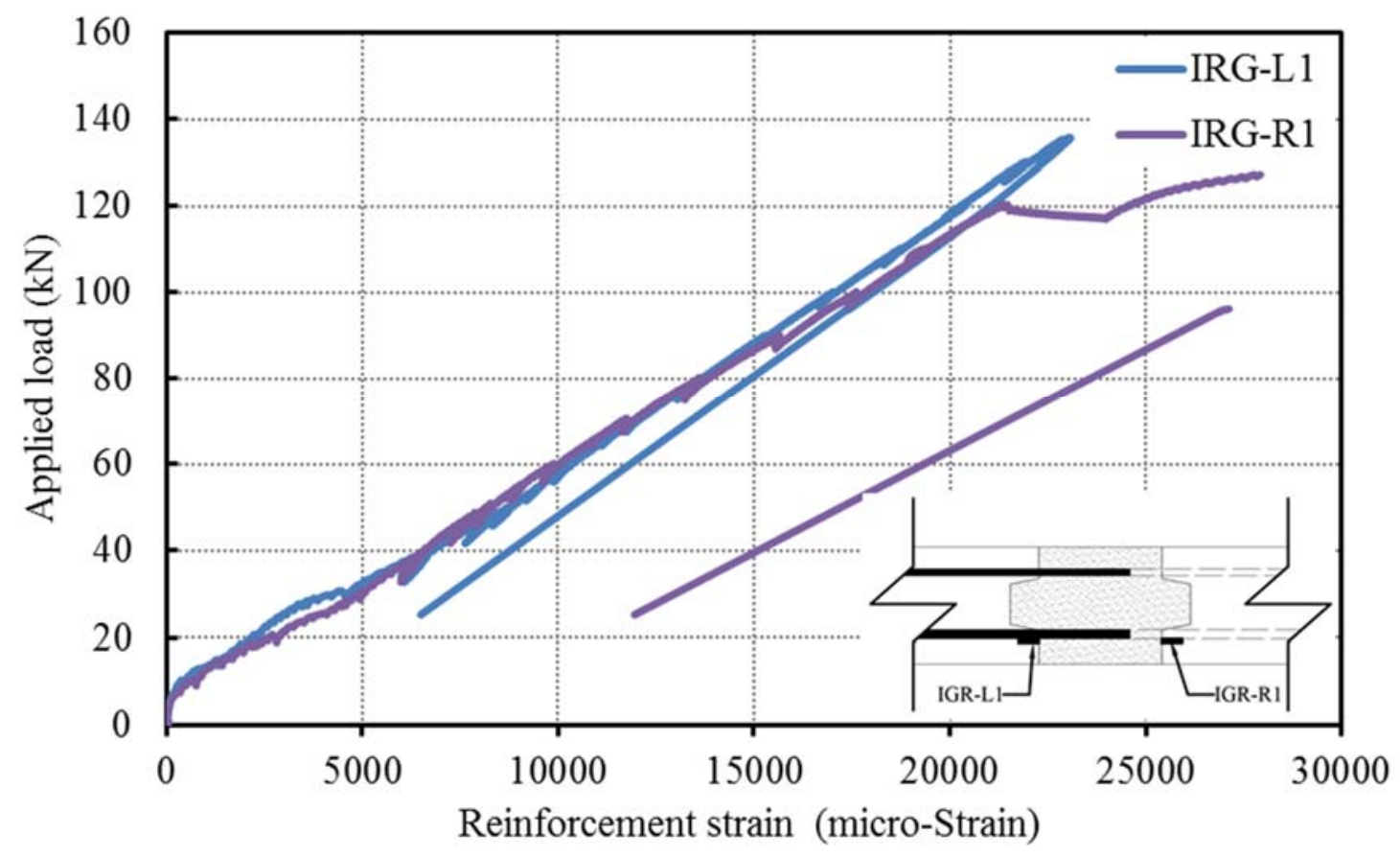

Figure 4.139 Load-bar strain relationship for slab $\mathrm{S}_{6}$ 


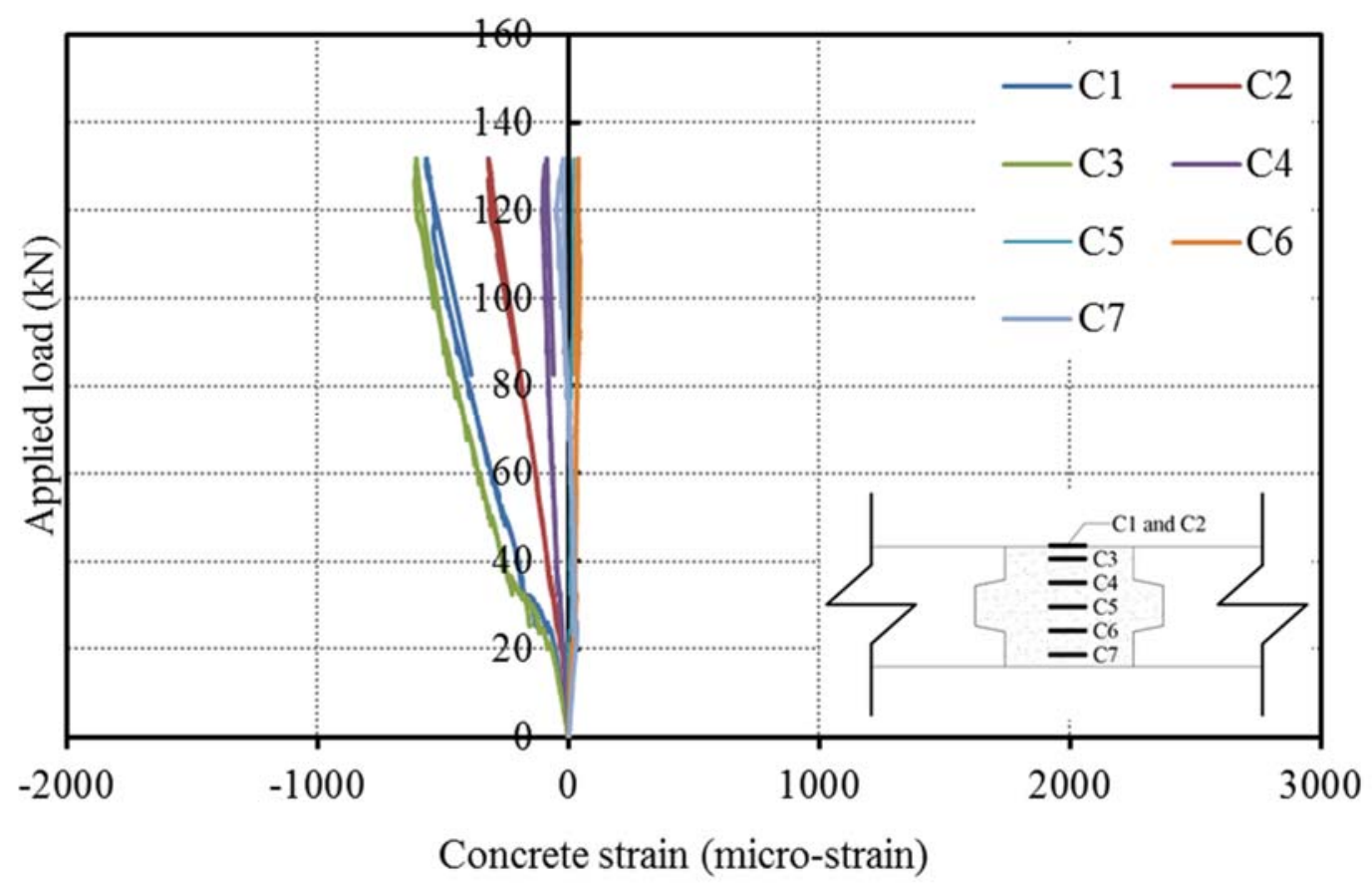

Figure 4.140 Load-concrete strain relationship for slab $\mathrm{S}_{7}$

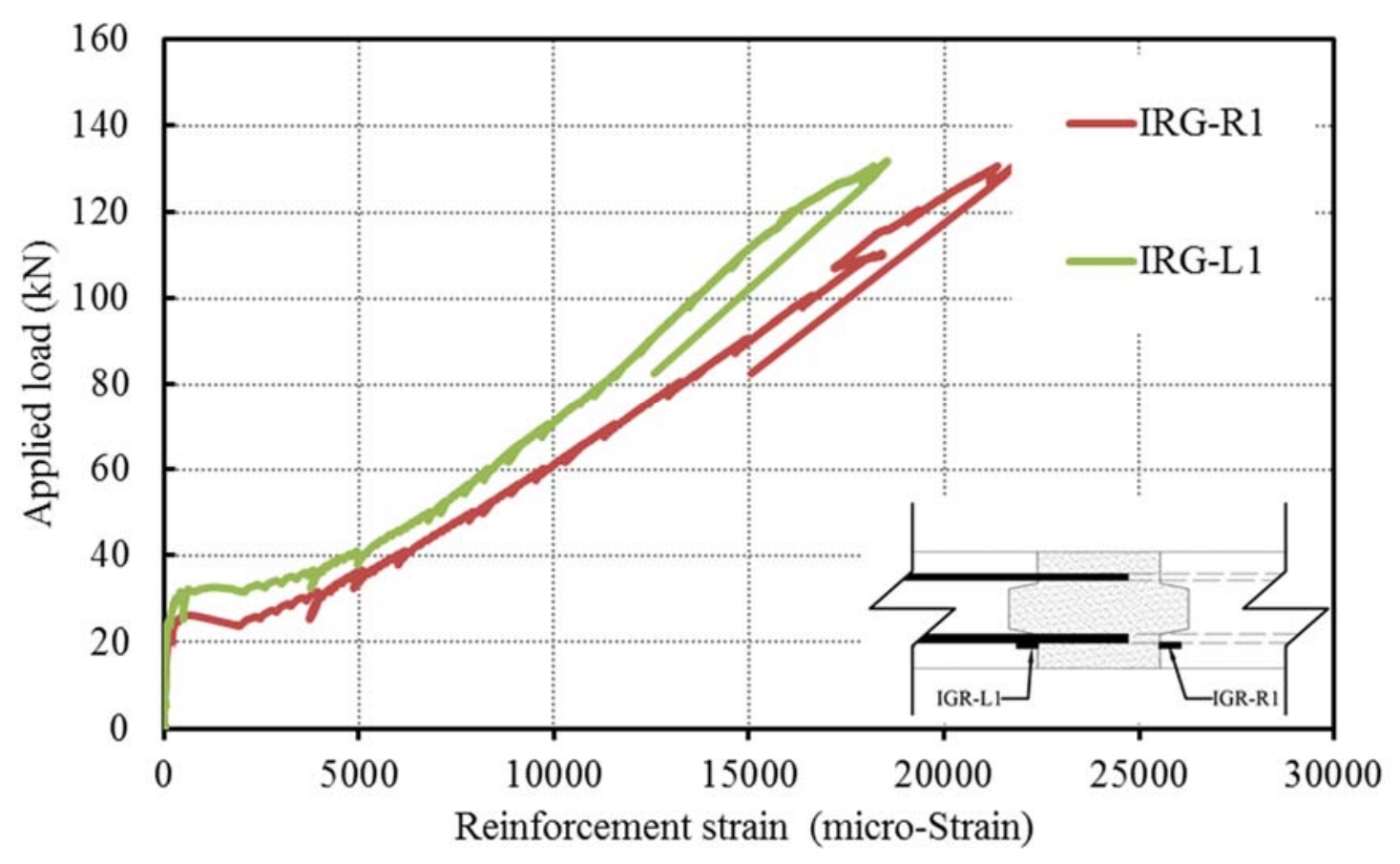

Figure 4.141 Load-bar strain relationship for slab $\mathrm{S}_{7}$ 


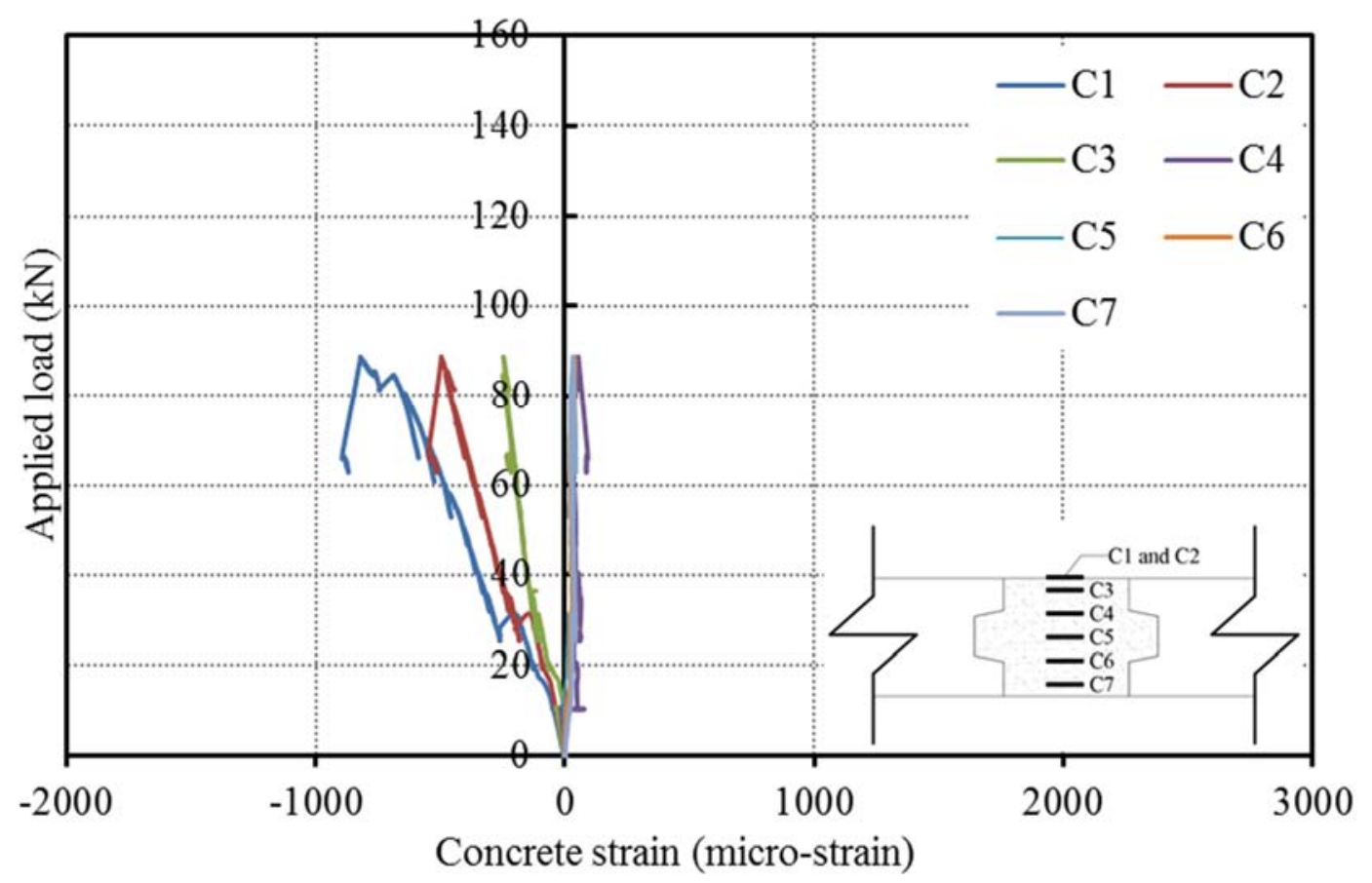

Figure 4.142 Load-concrete strain relationship for slab $\mathrm{S}_{8}$

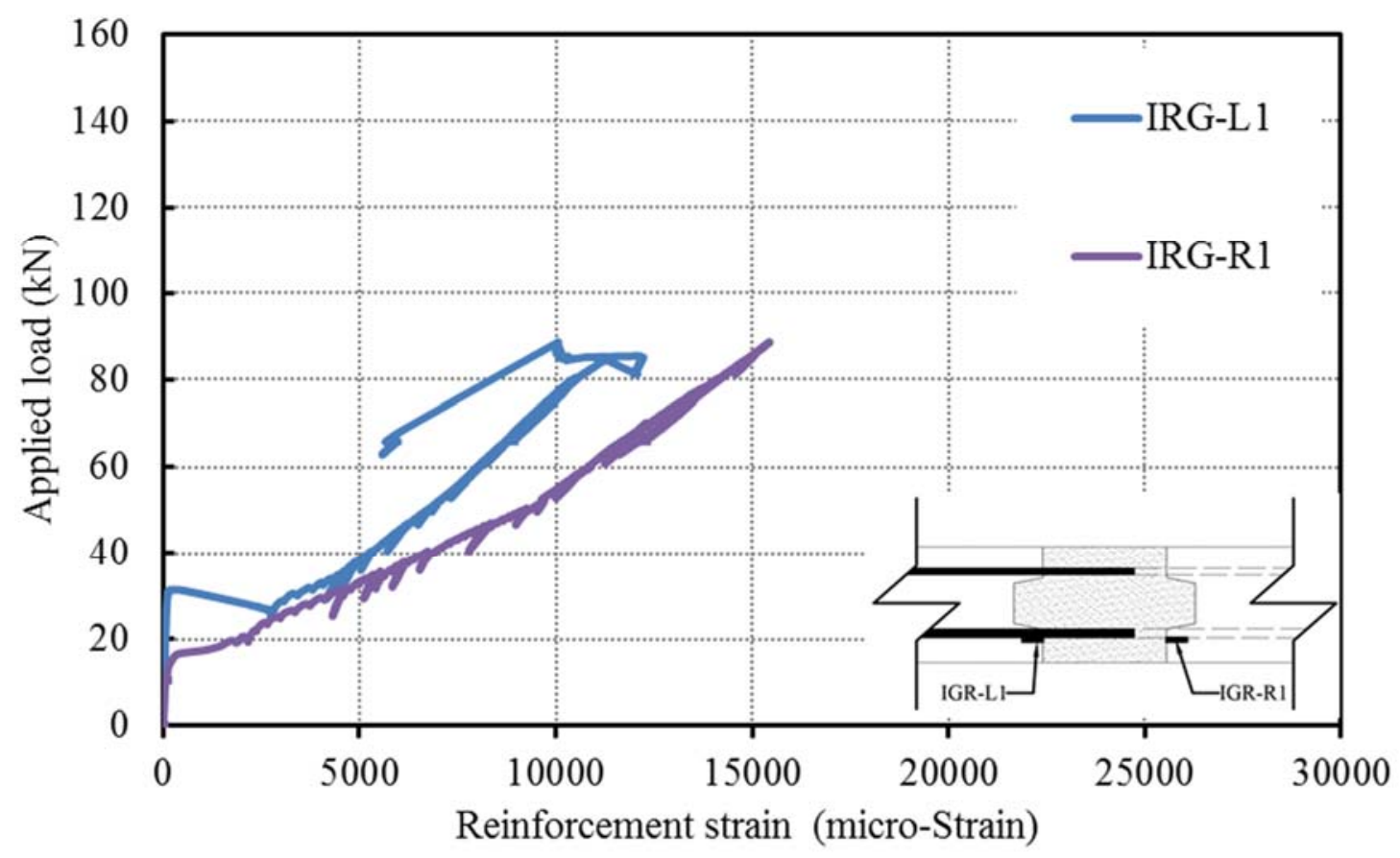

Figure 4.143 Load-bar strain relationship for slab $\mathrm{S}_{8}$ 


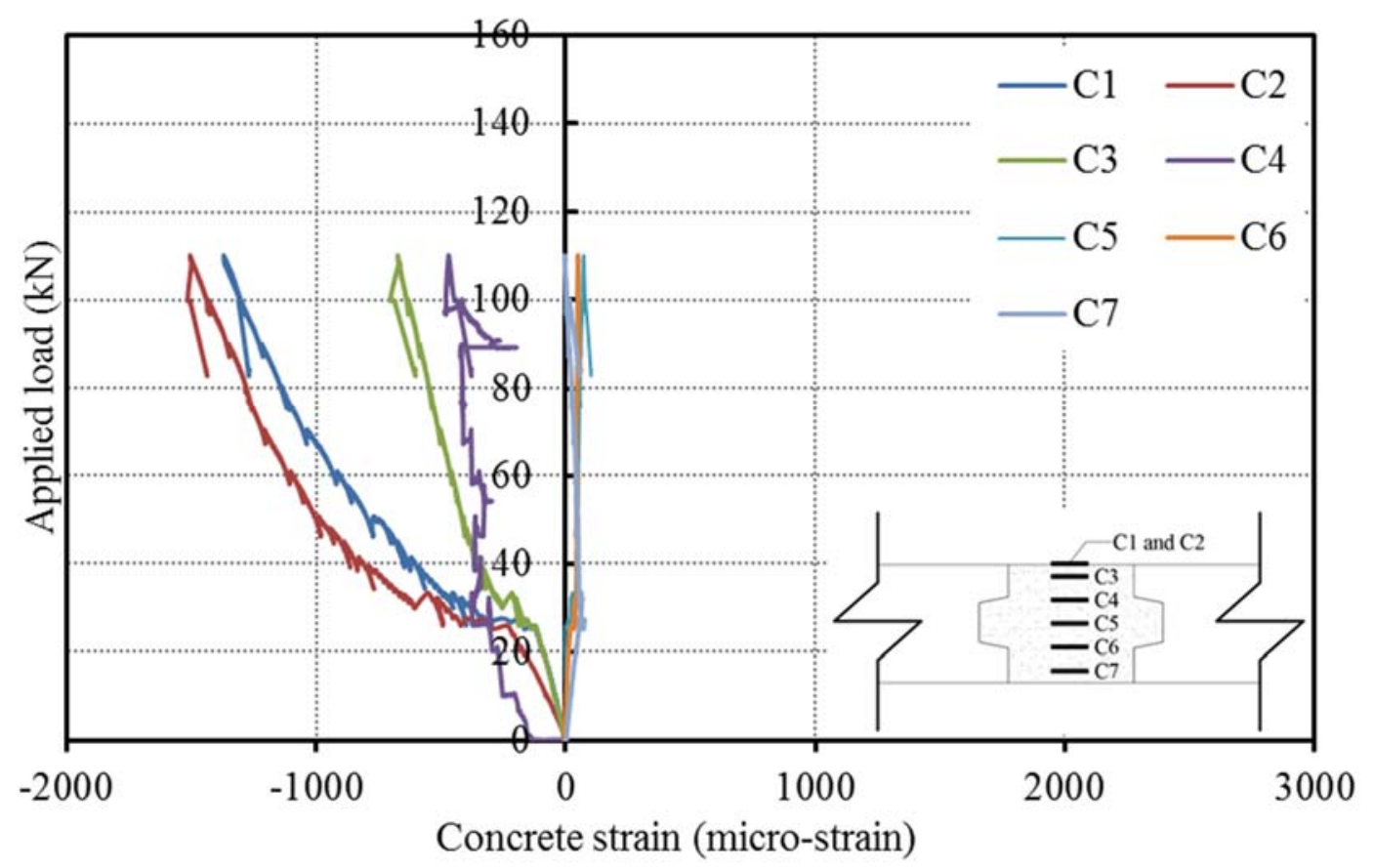

Figure 4.144 Load-concrete strain relationship for slab S9

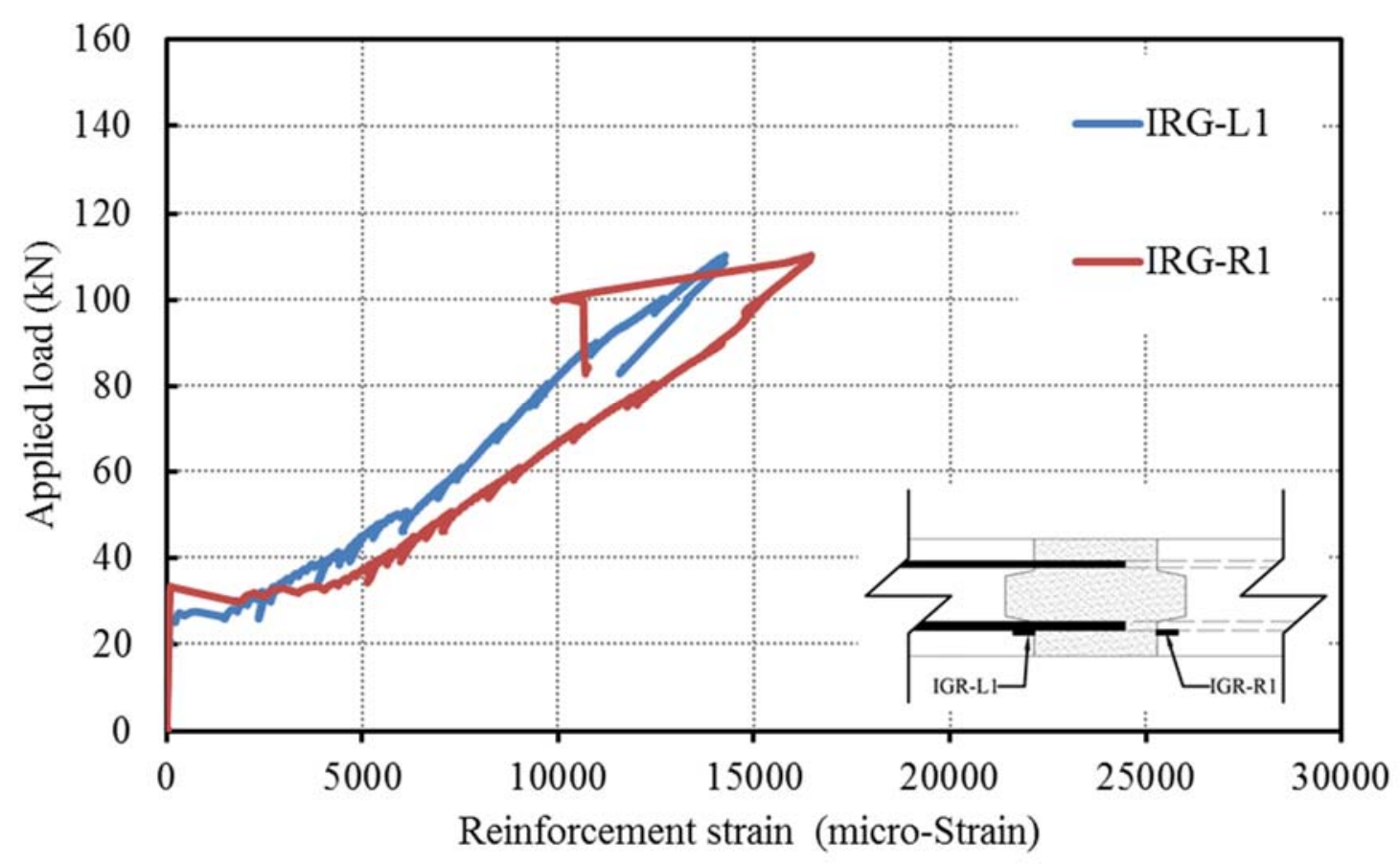

Figure 4.145 Load-bar strain relationship for slab S9 


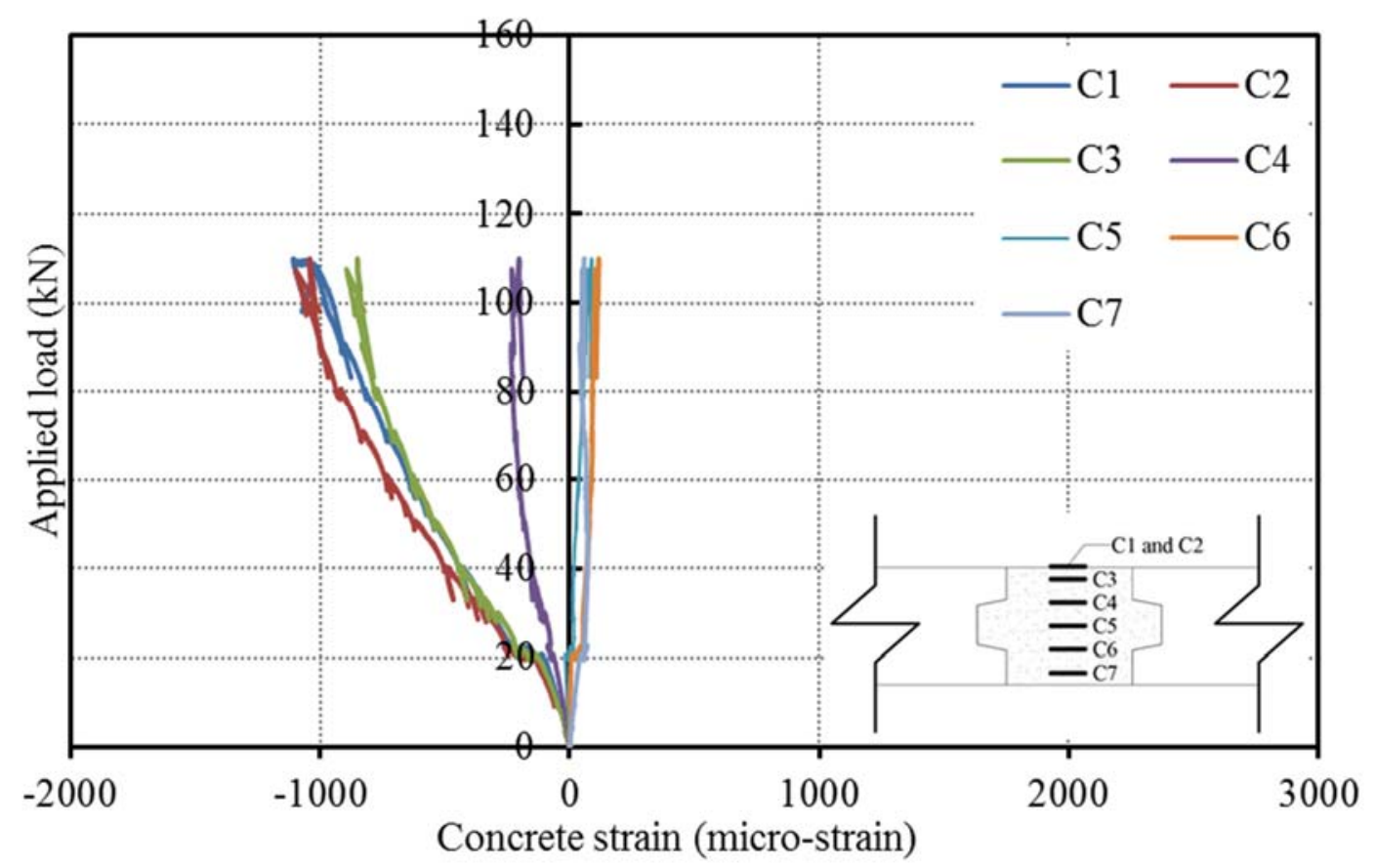

Figure 4.146 Load-concrete strain relationship for slab $\mathrm{S}_{10}$

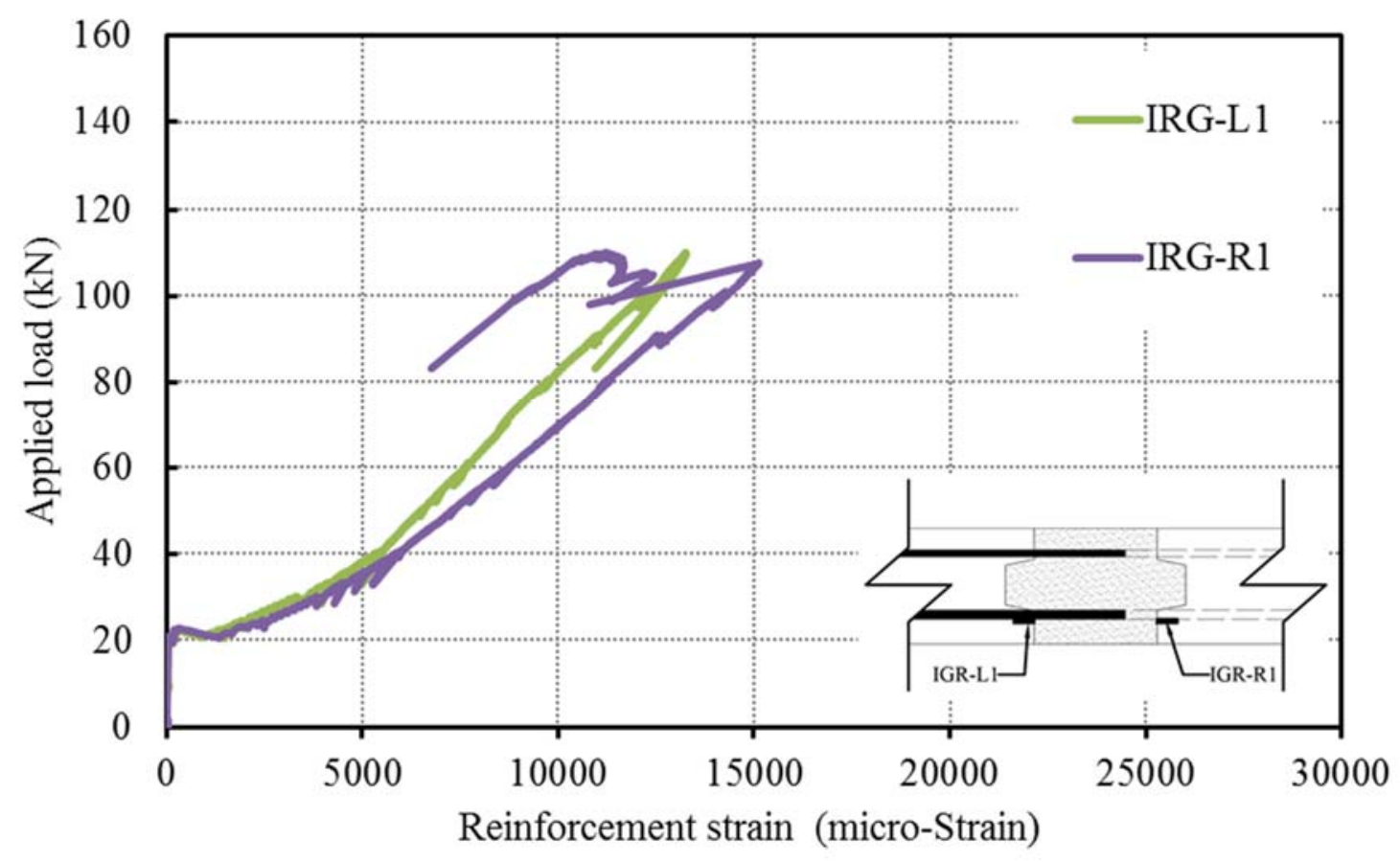

Figure 4.147 Load-bar strain relationship for slab $\mathrm{S}_{10}$ 


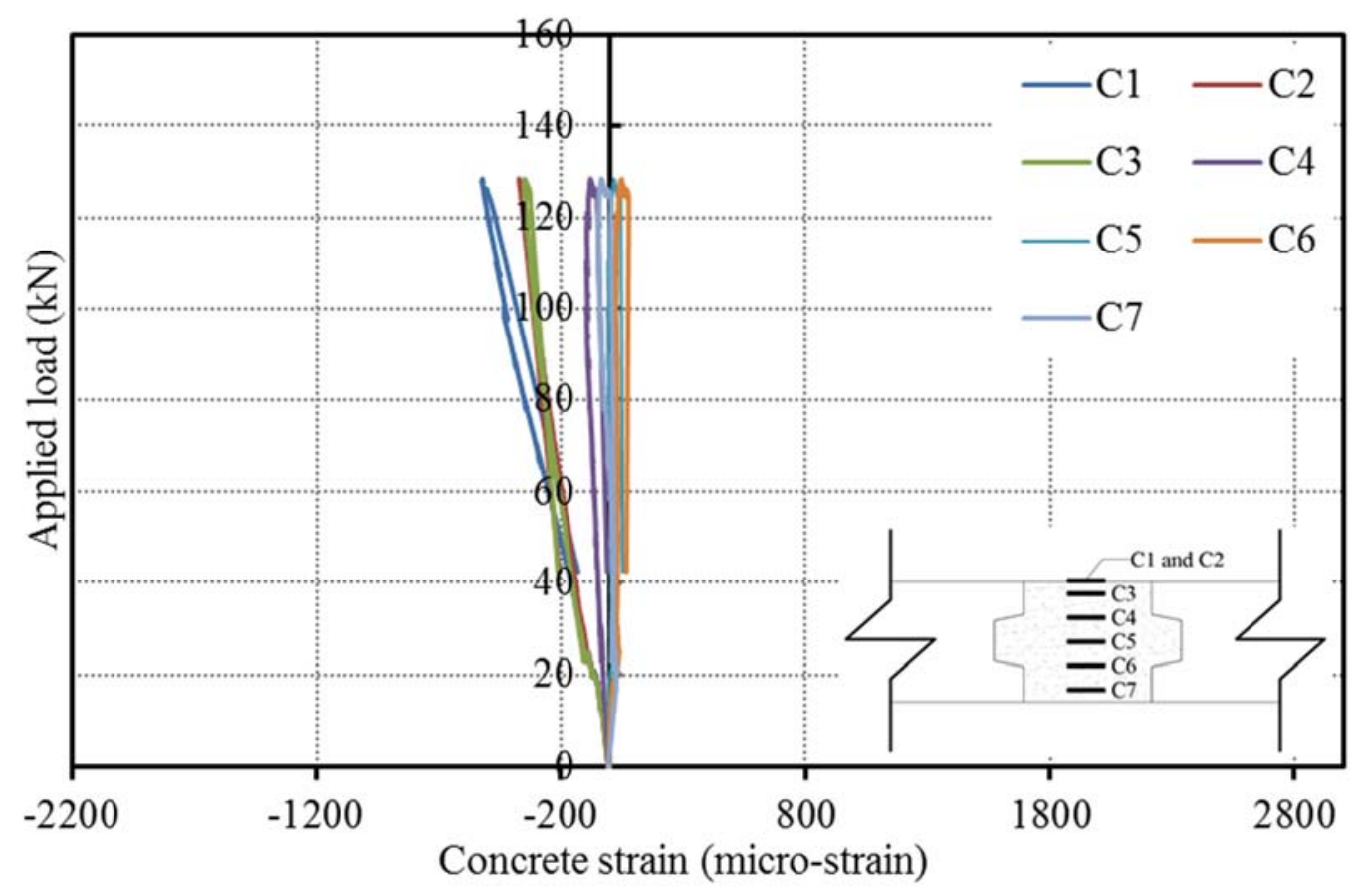

Figure 4.148 Load-concrete strain relationship for slab $\mathrm{S}_{11}$

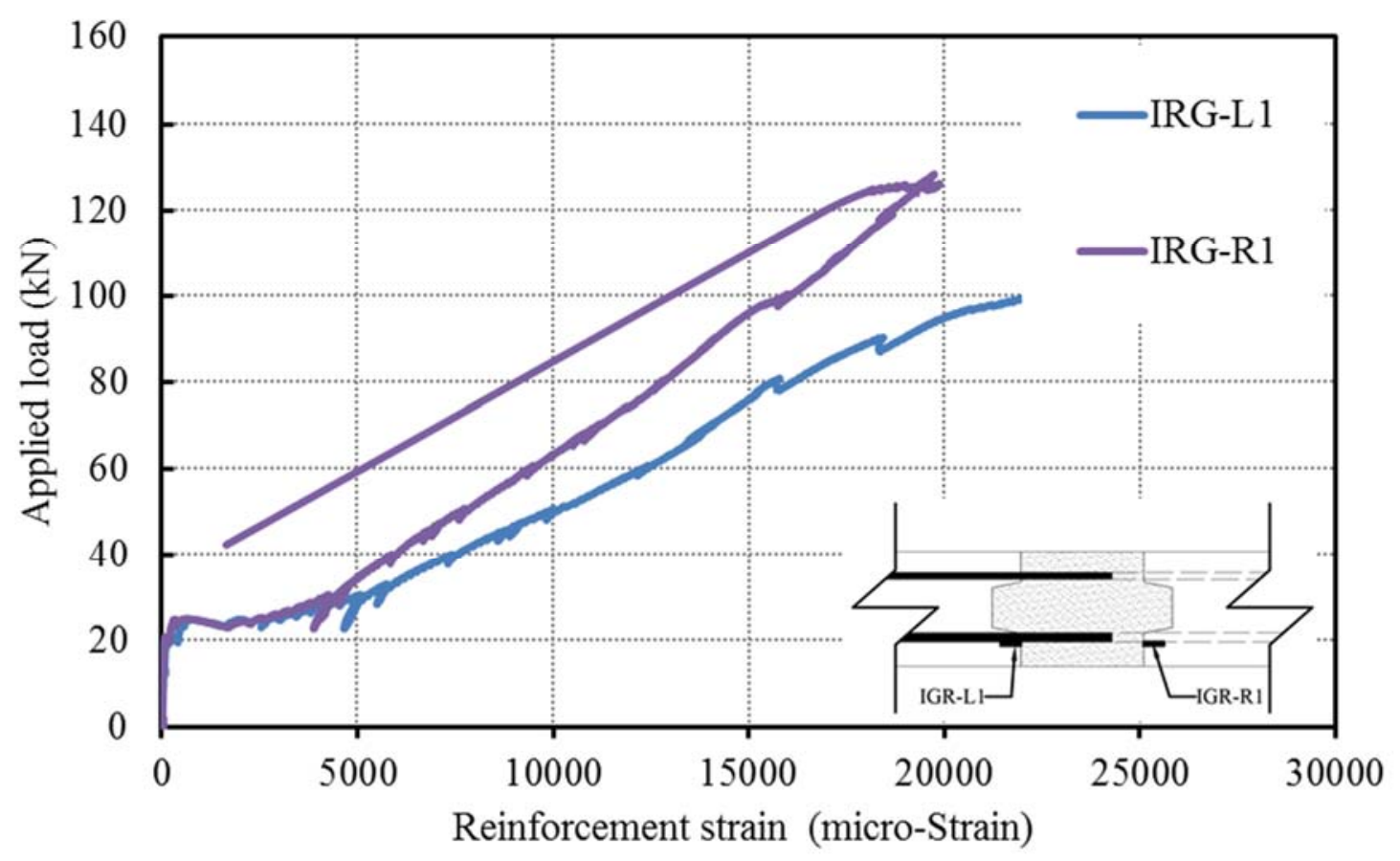

Figure 4.149 Load-bar strain relationship for slab $\mathrm{S}_{11}$ 


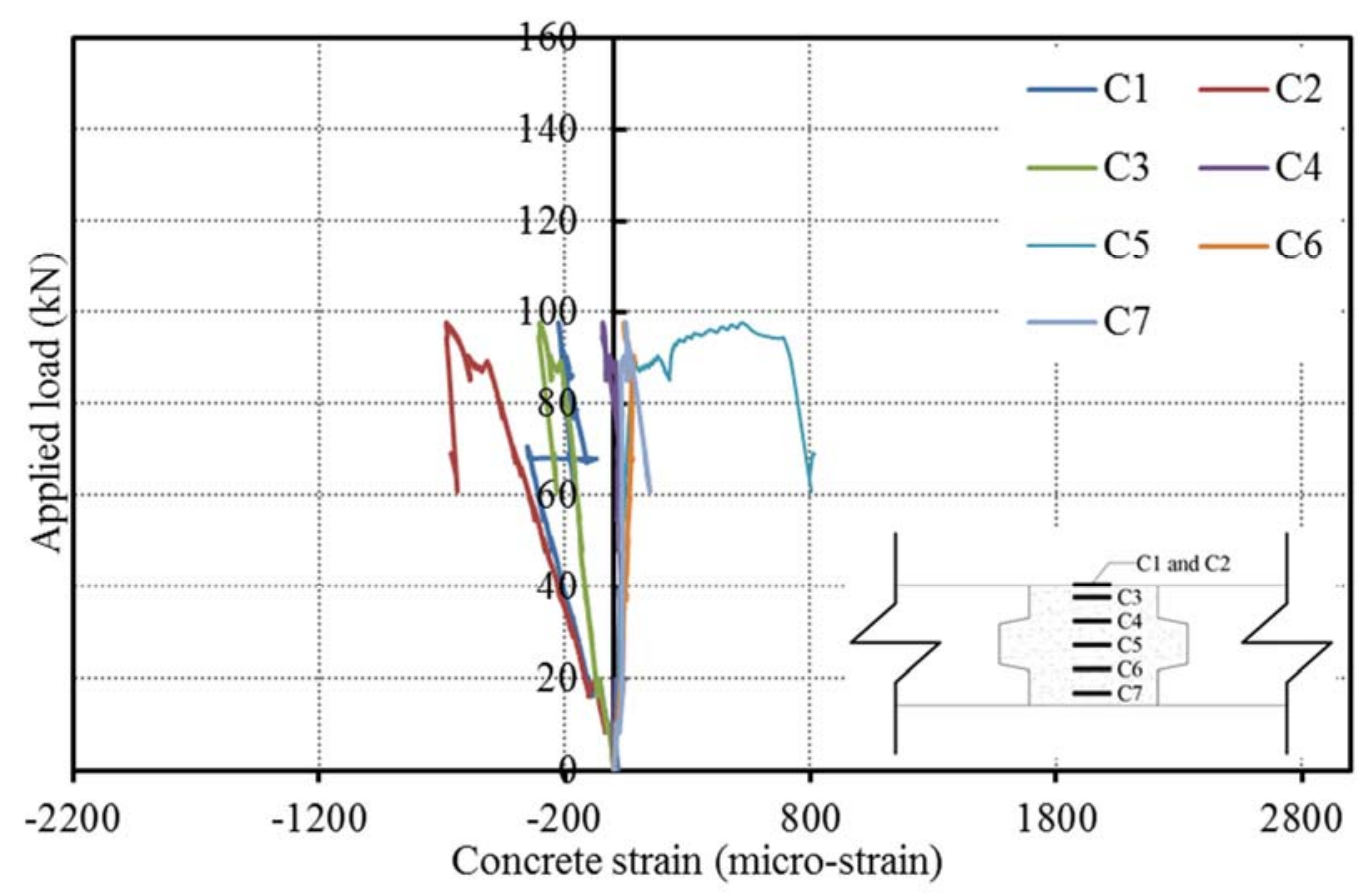

Figure 4.150 Load-concrete strain relationship for slab $\mathrm{S}_{12}$

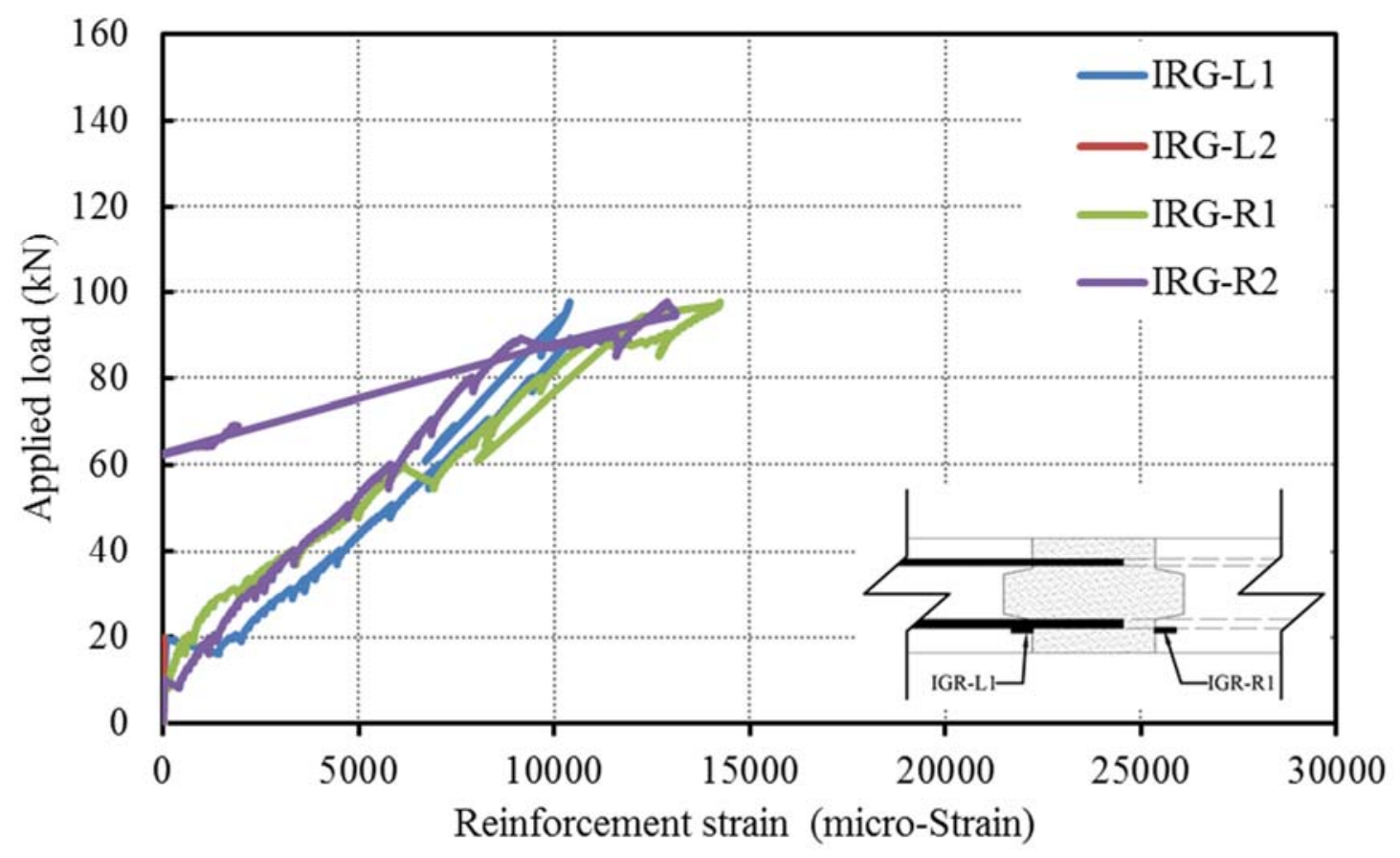

Figure 4.151 Load-bar strain relationship for slab $\mathrm{S}_{12}$ 


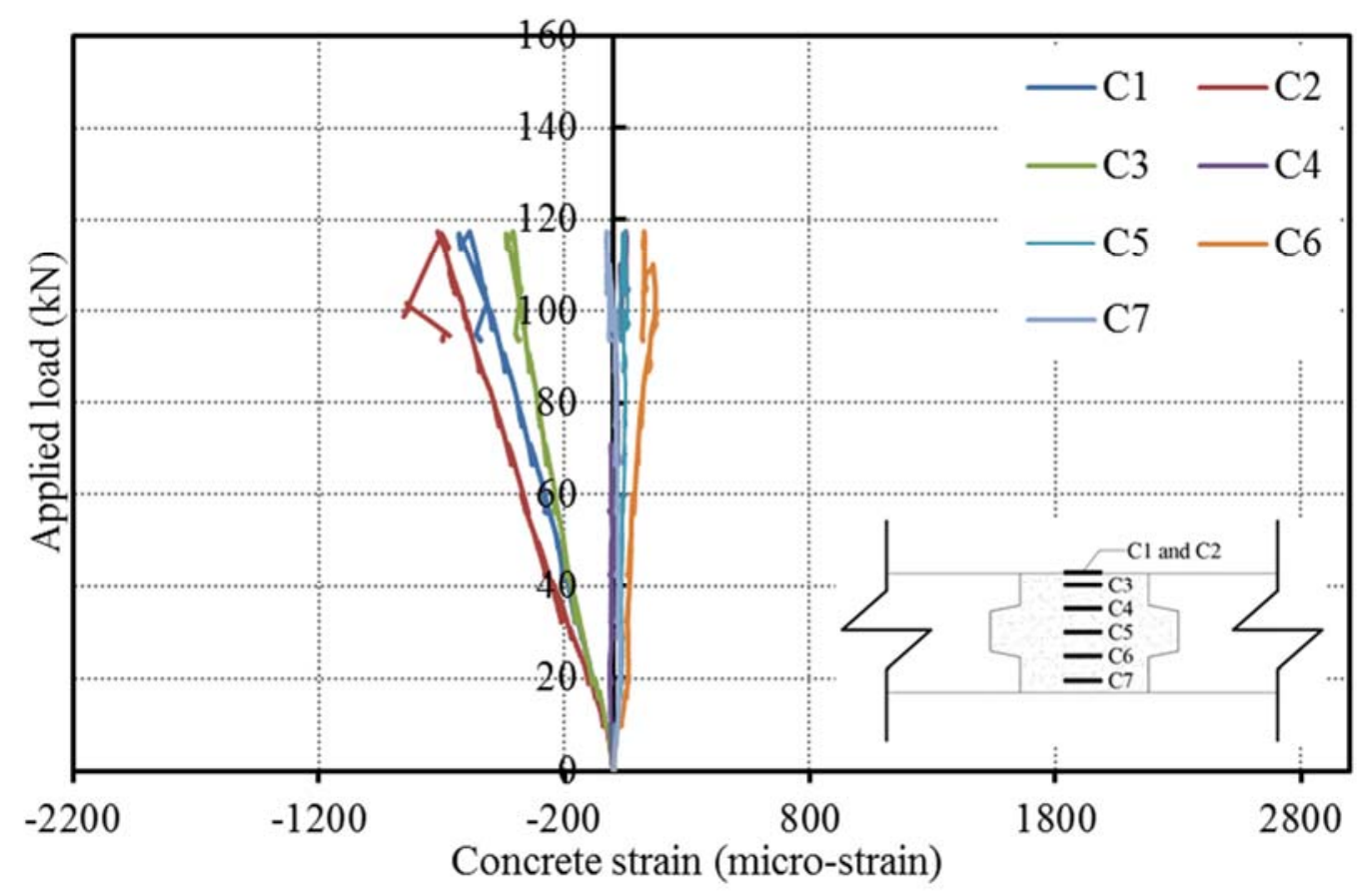

Figure 4.152 Load-concrete strain relationship for slab $S_{13}$

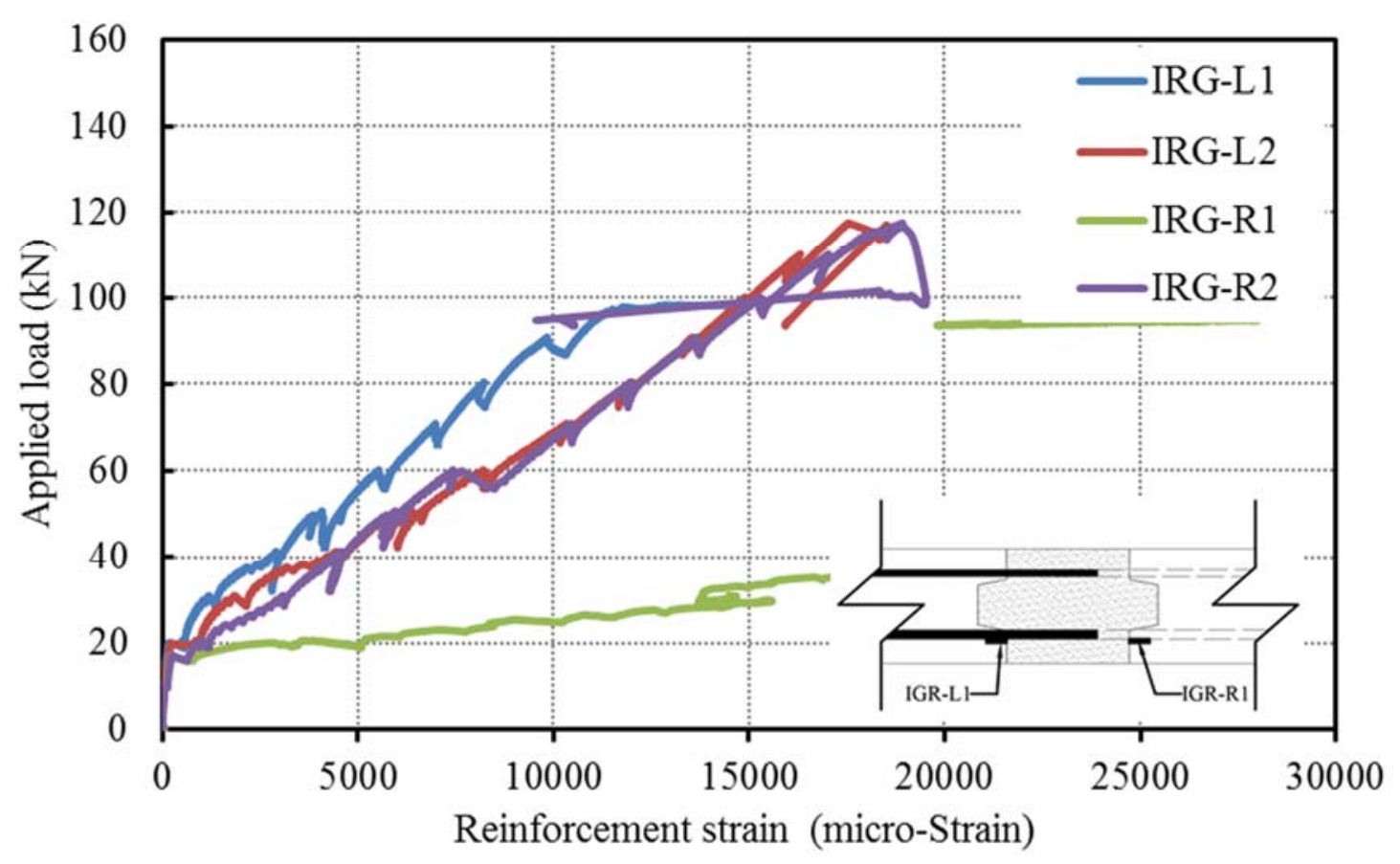

Figure 4.153 Load-bar strain relationship for slab $\mathrm{S}_{13}$ 


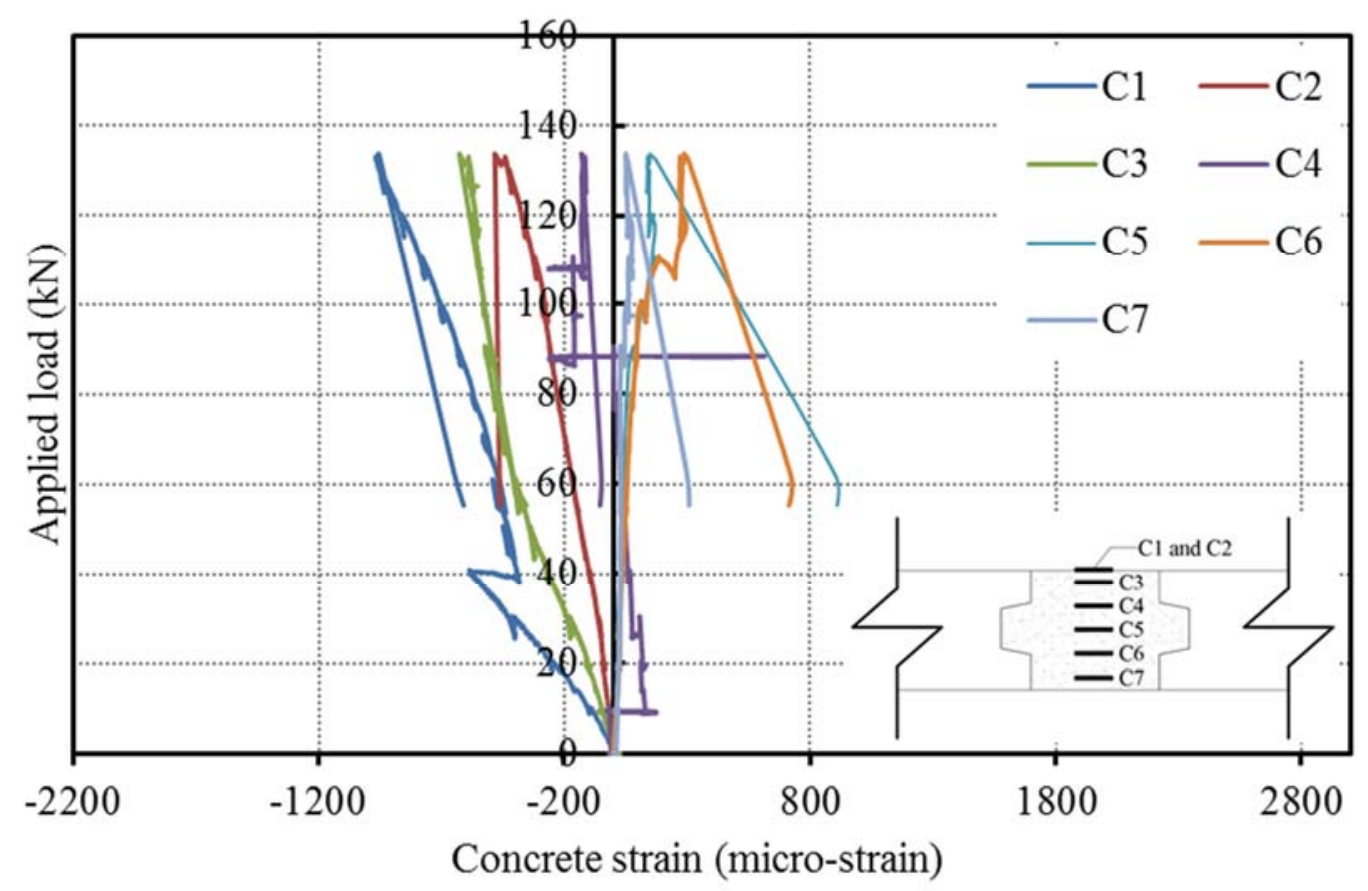

Figure 4.154 Load-concrete strain relationship for slab $\mathrm{S}_{14}$

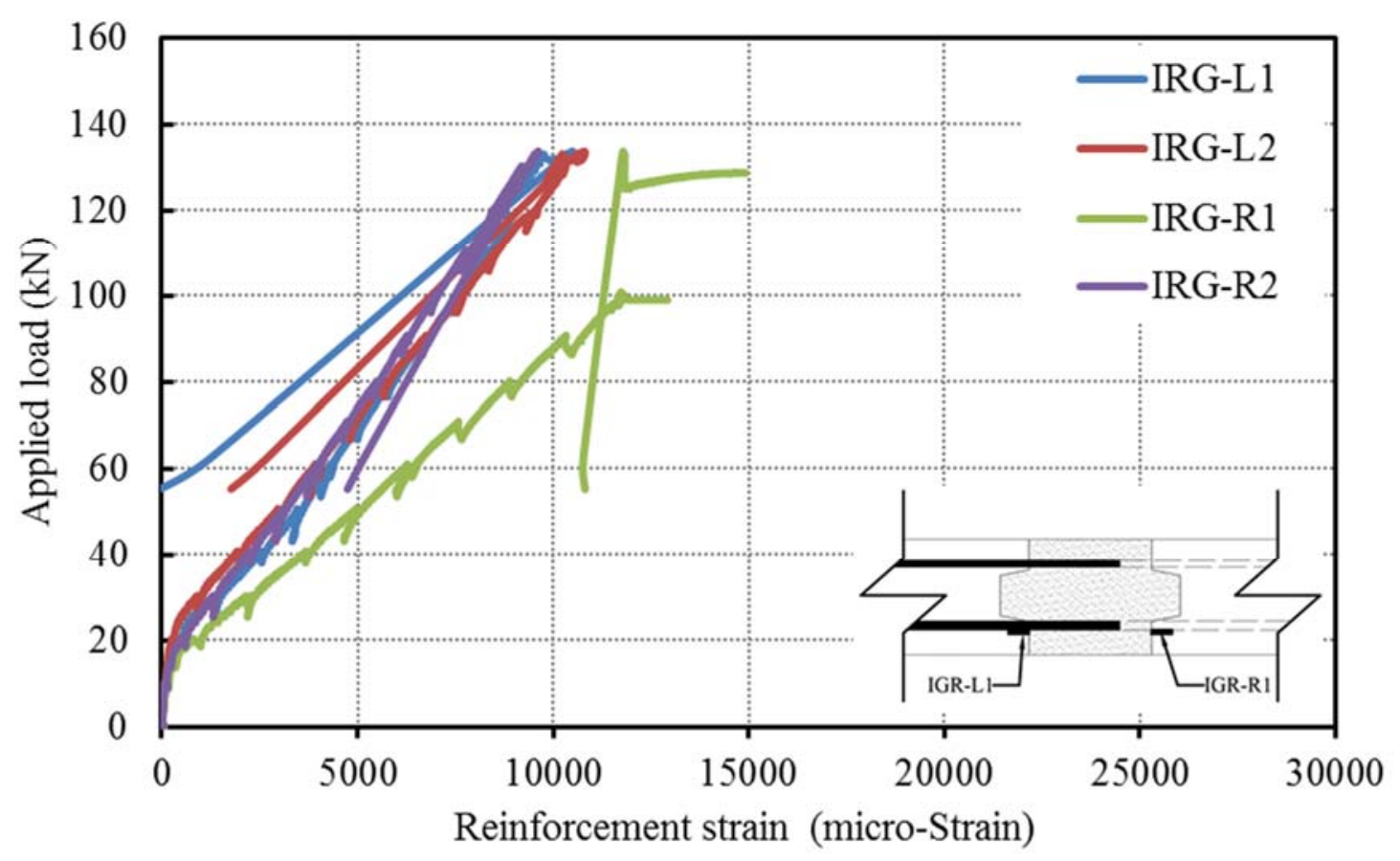

Figure 4.155 Load-bar strain relationship for slab $\mathrm{S}_{14}$ 


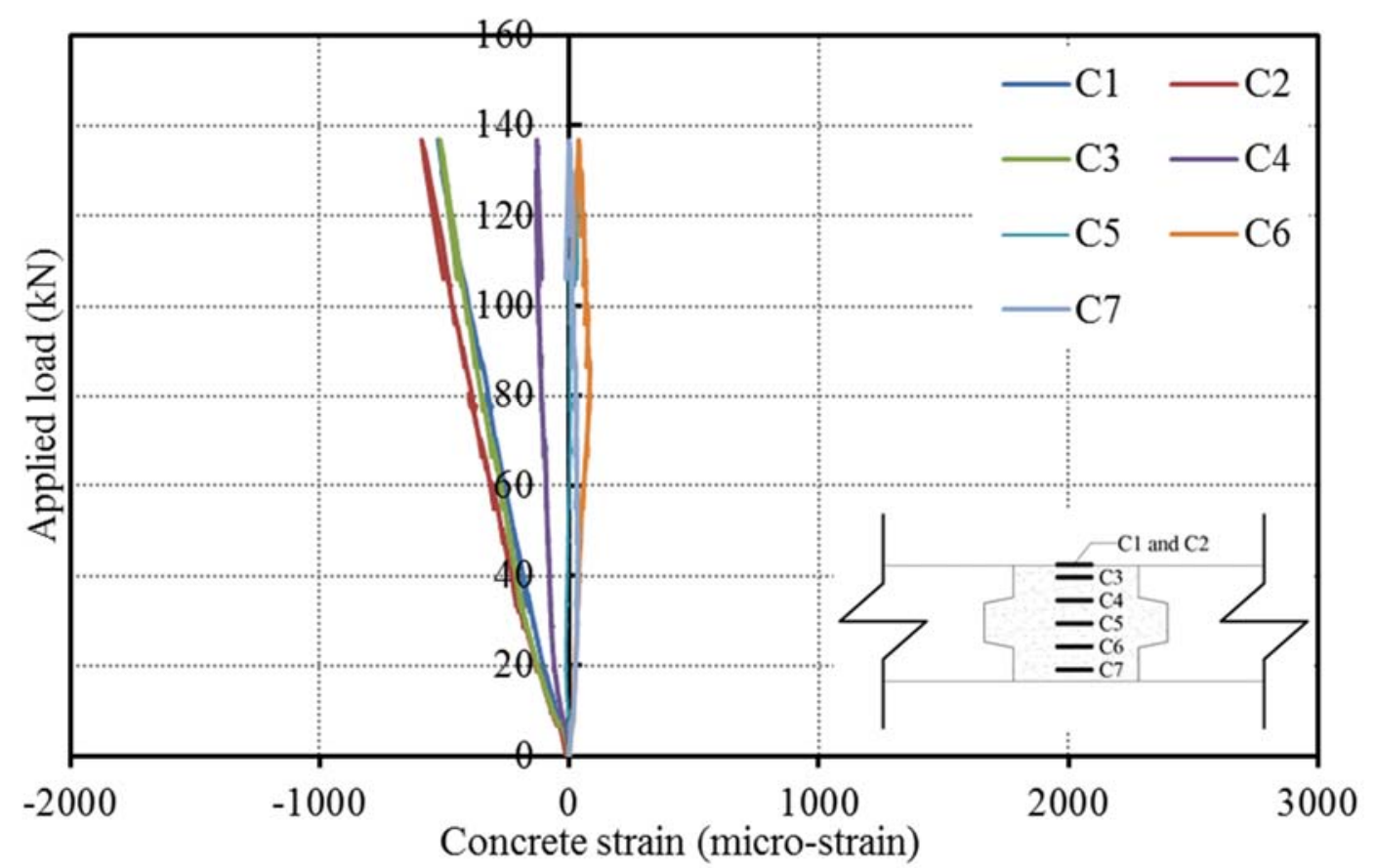

Figure 4.156 Load-concrete strain relationship for slab $\mathrm{S}_{15}$

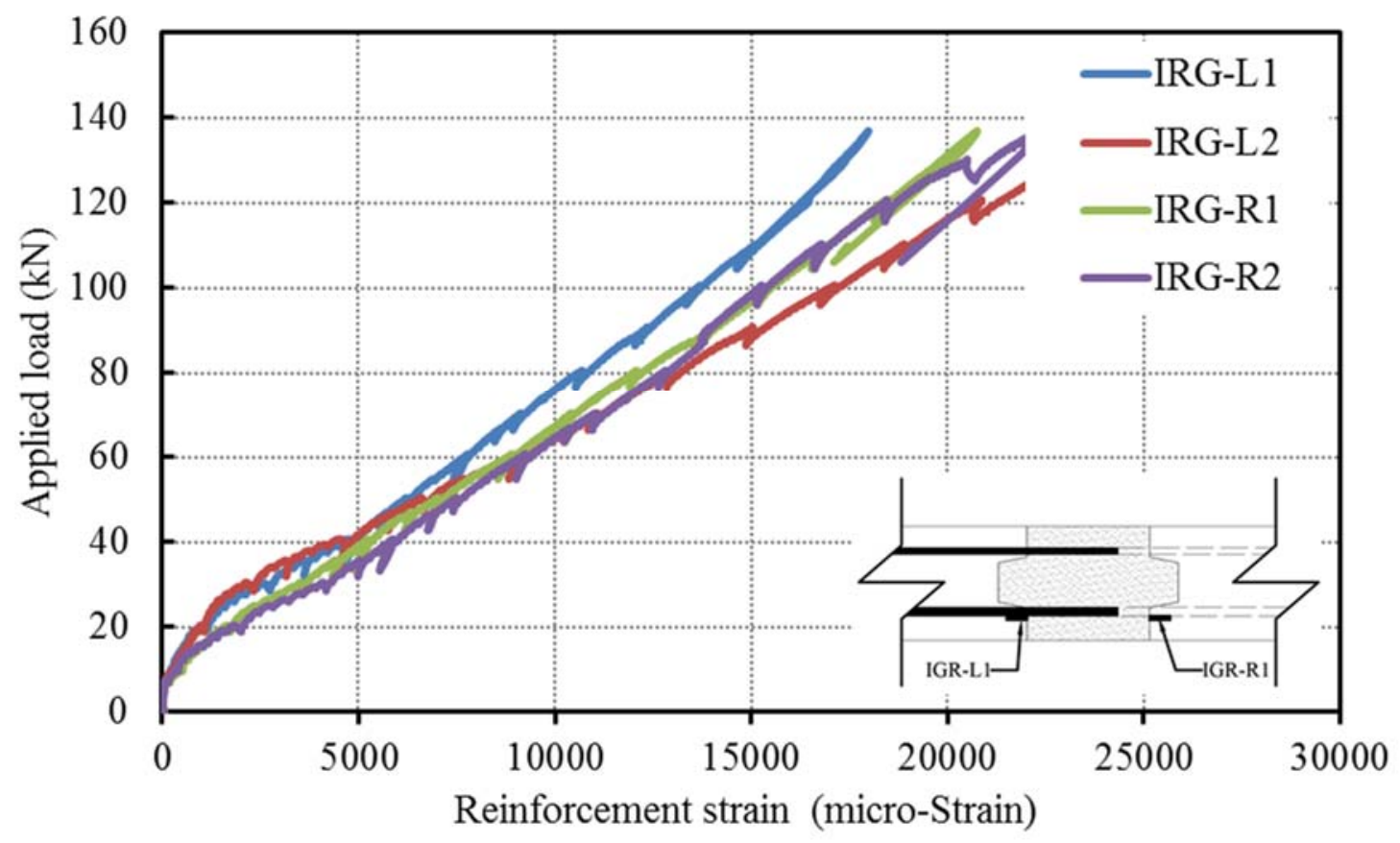

Figure 4.157 Load-bar strain relationship for slab $\mathrm{S}_{15}$ 


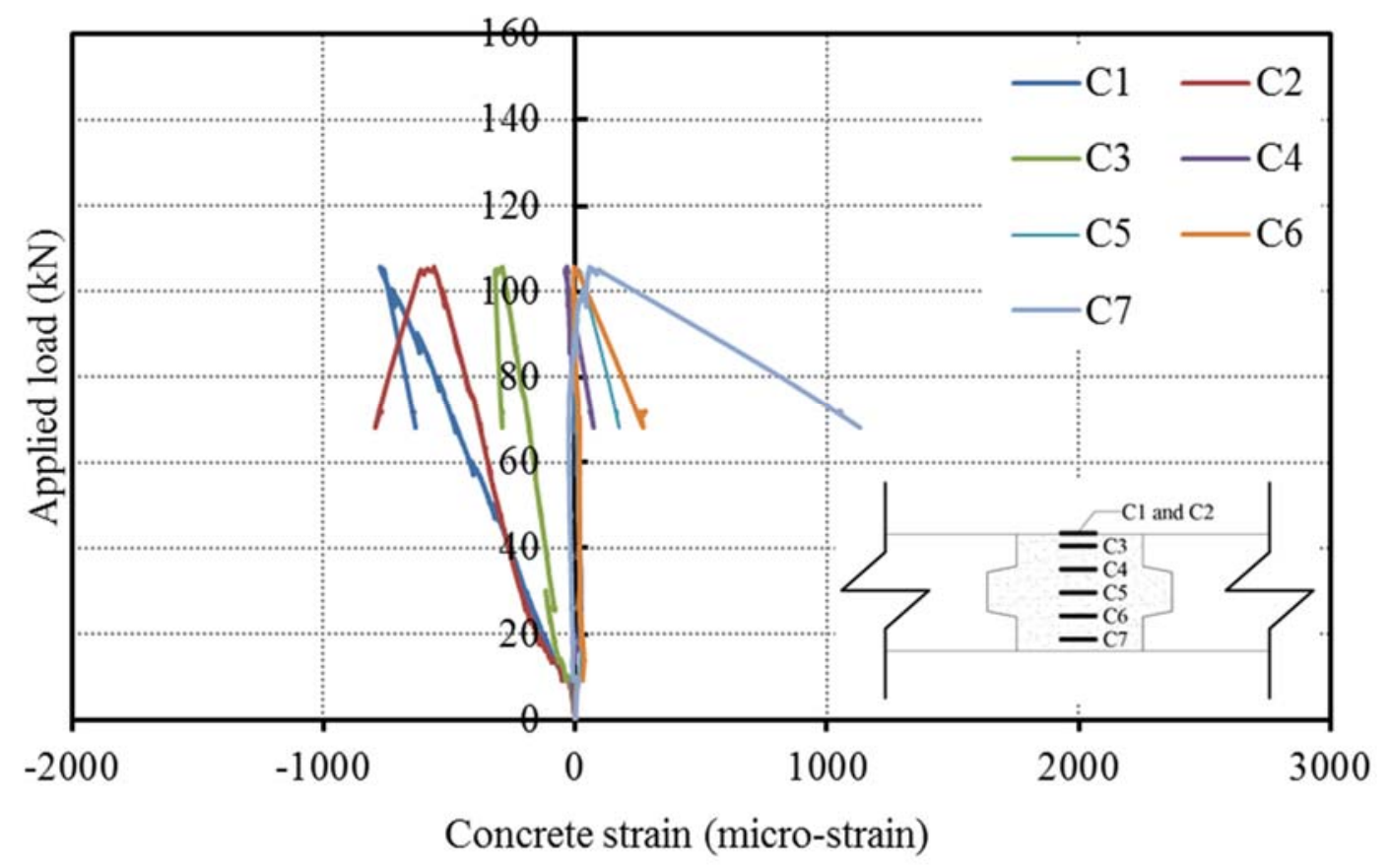

Figure 4.158 Load-concrete strain relationship for slab $\mathrm{S}_{16}$

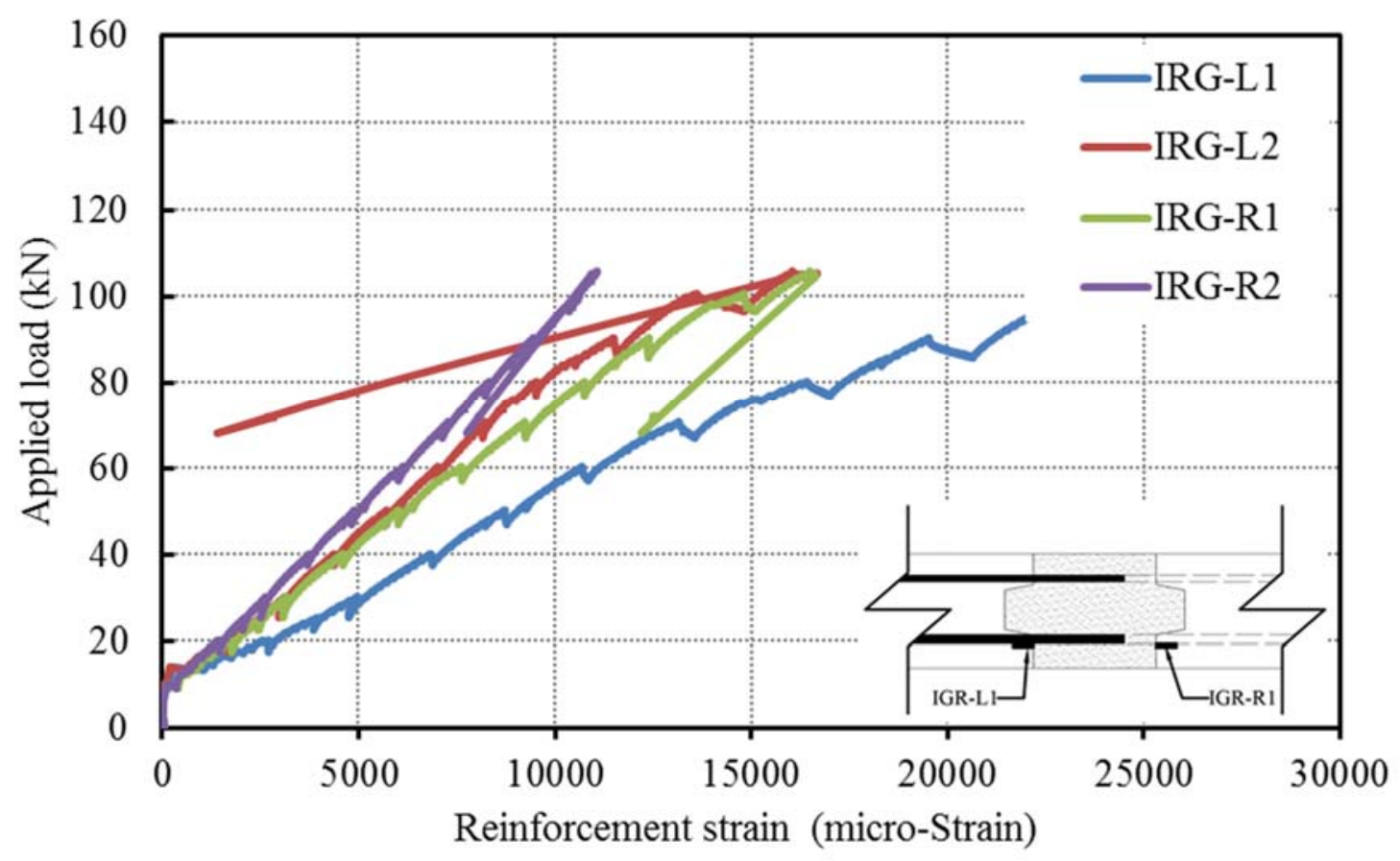

Figure 4.159 Load-bar strain relationship for slab $\mathrm{S}_{16}$ 


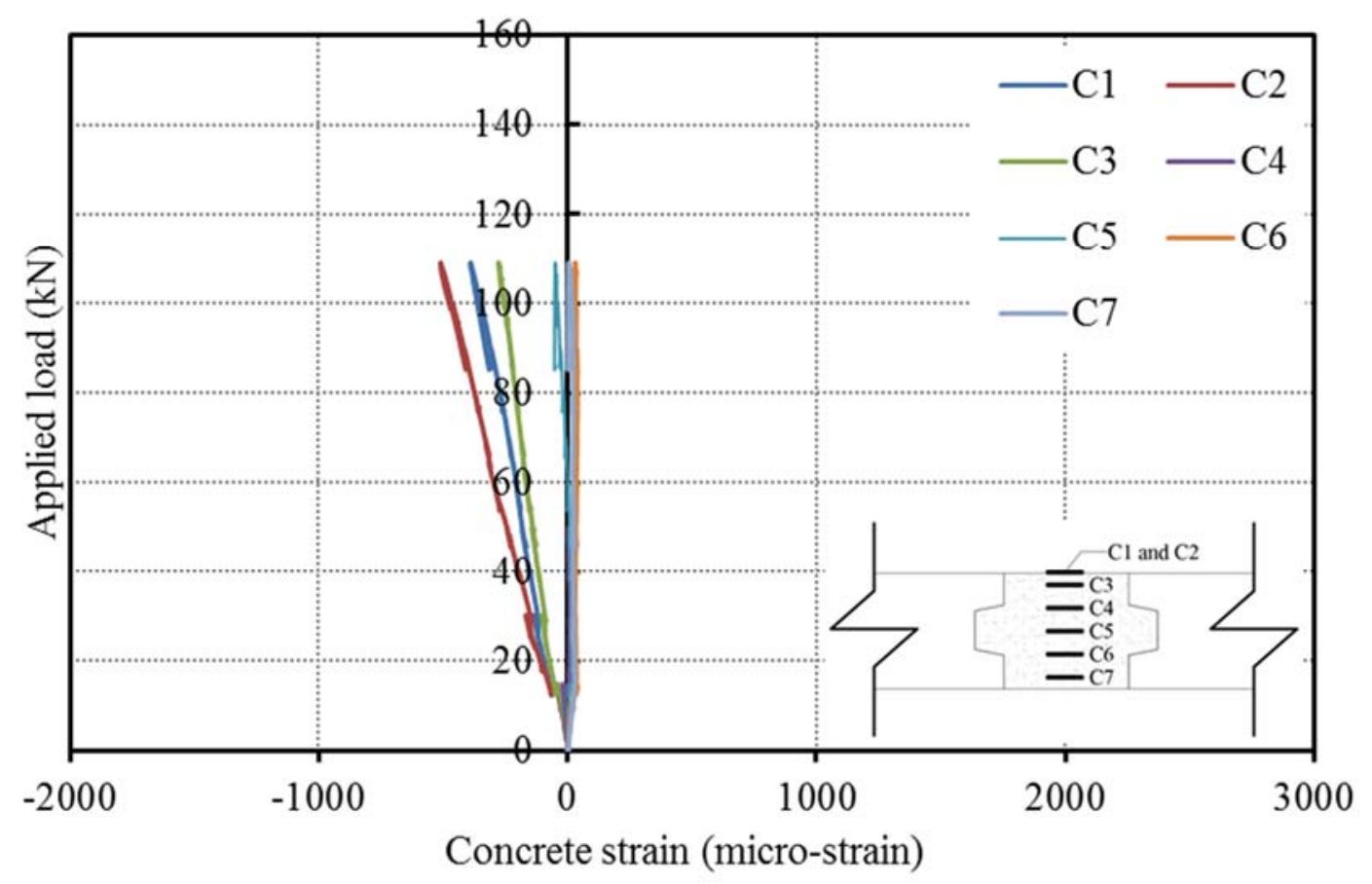

Figure 4.160 Load-concrete strain relationship for slab $\mathrm{S}_{17}$

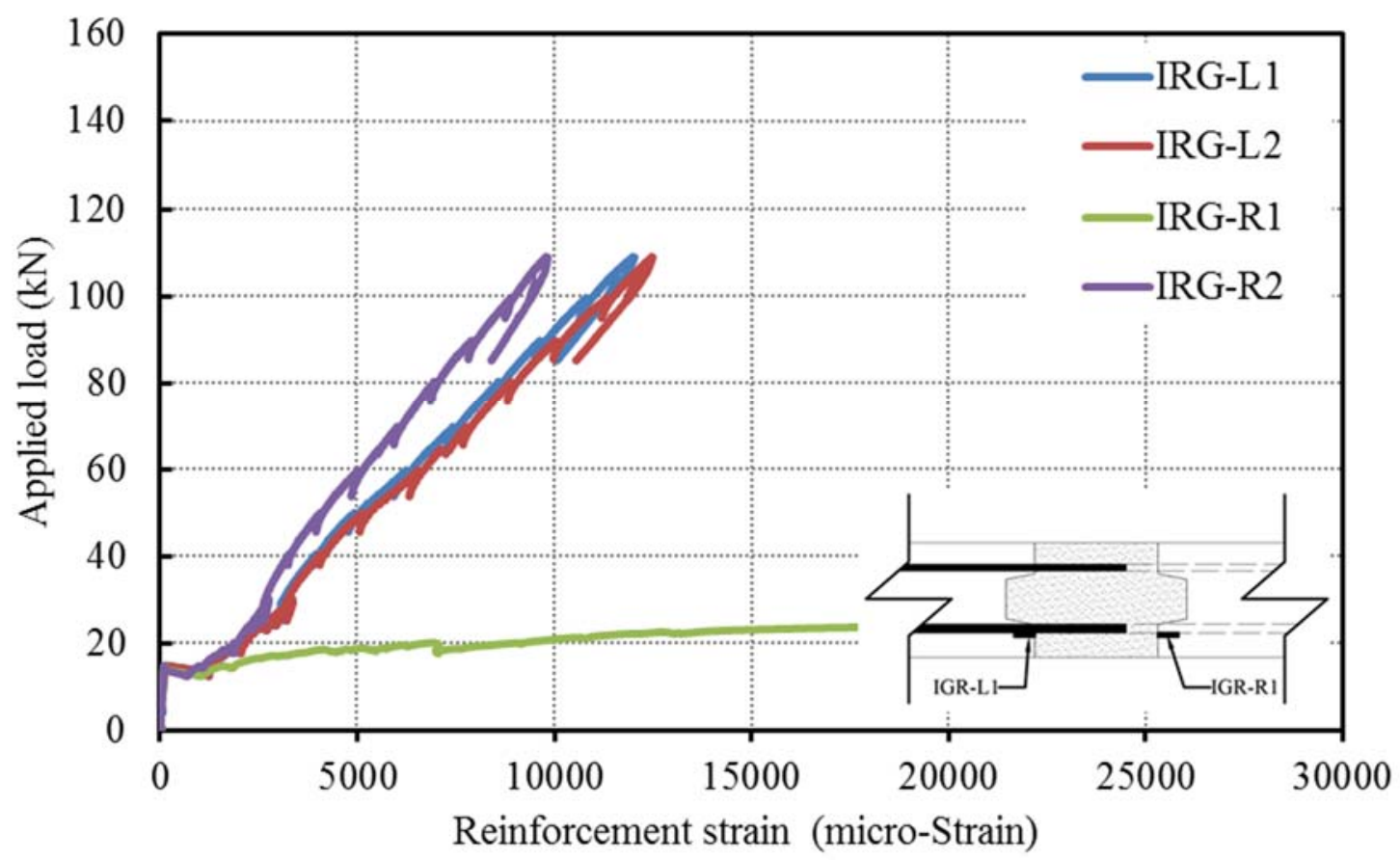

Figure 4.161 Load-bar strain relationship for slab $\mathrm{S}_{17}$ 


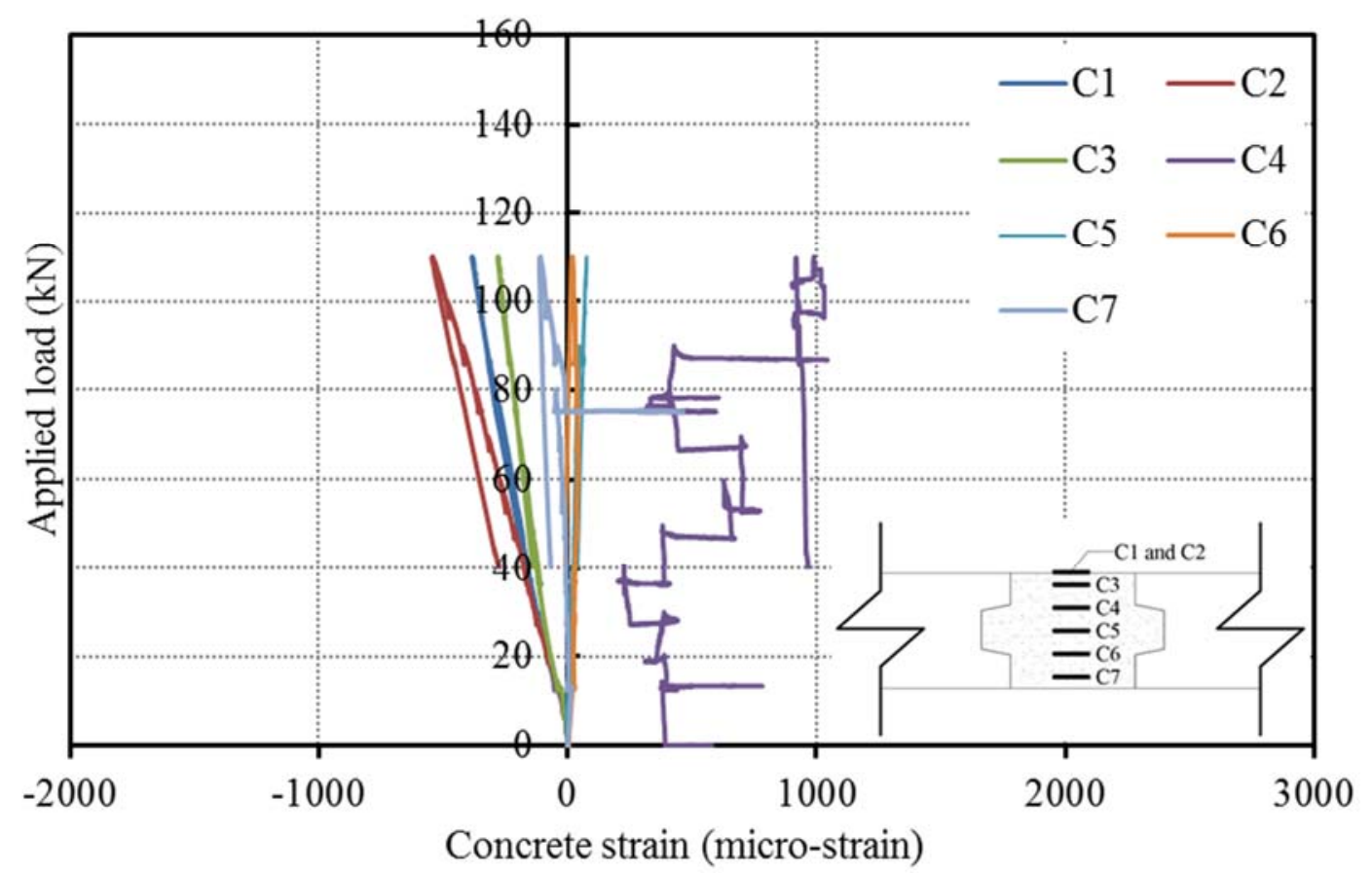

Figure 4.162 Load-concrete strain relationship for slab $\mathrm{S}_{18}$

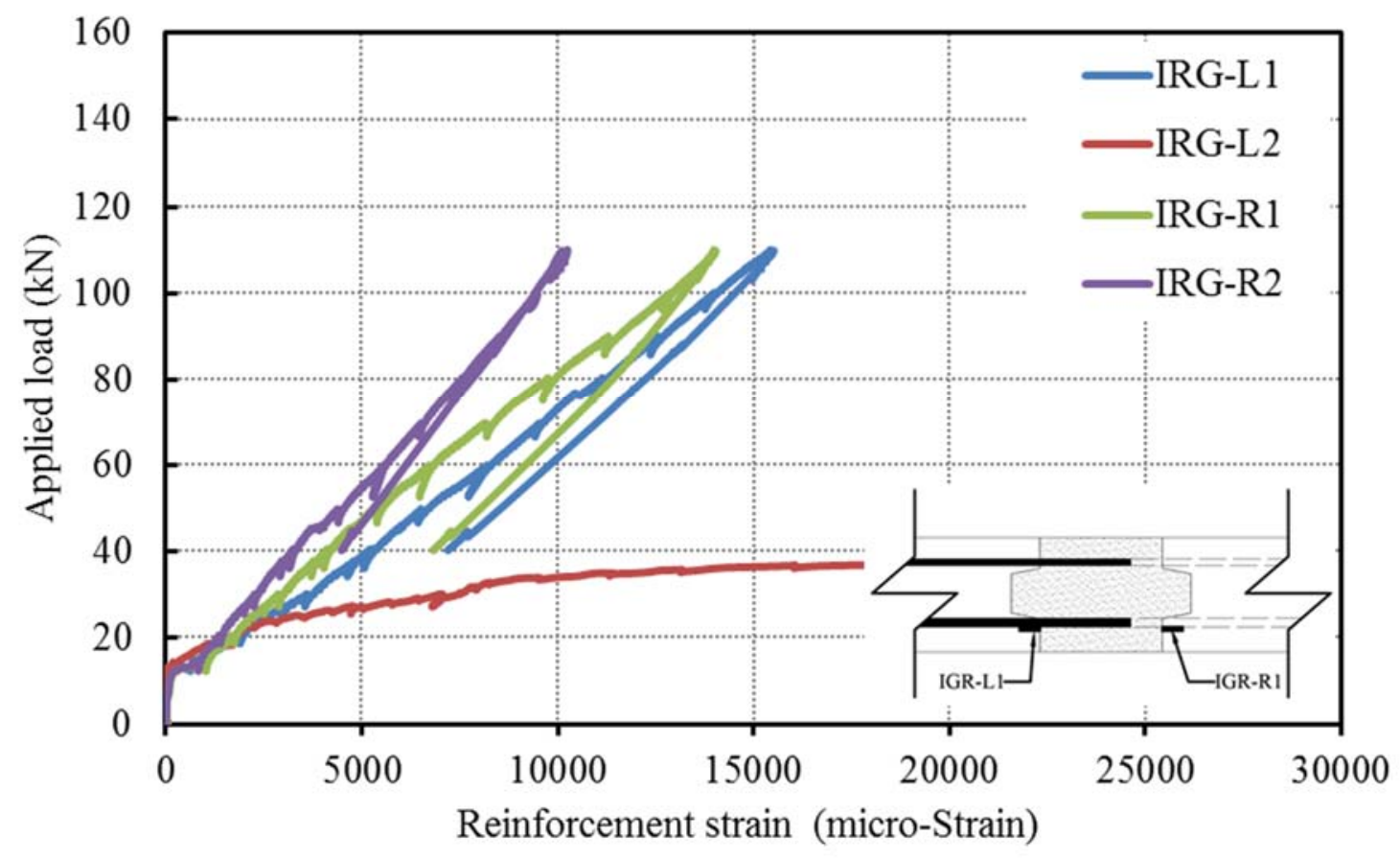

Figure 4.163 Load-bar strain relationship for slab $\mathrm{S}_{18}$ 


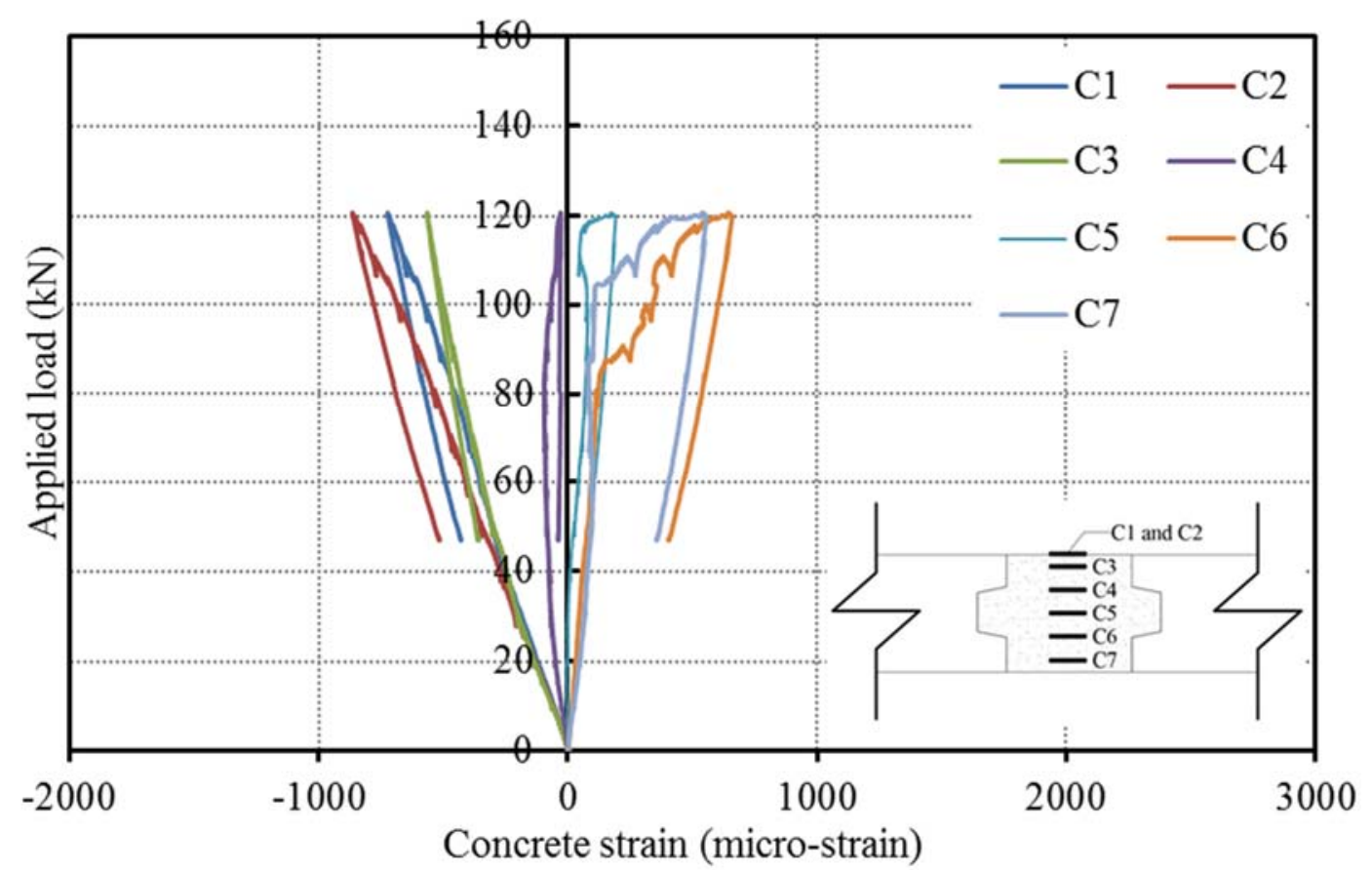

Figure 4.164 Load-concrete strain relationship for slab $\mathrm{S}_{19}$

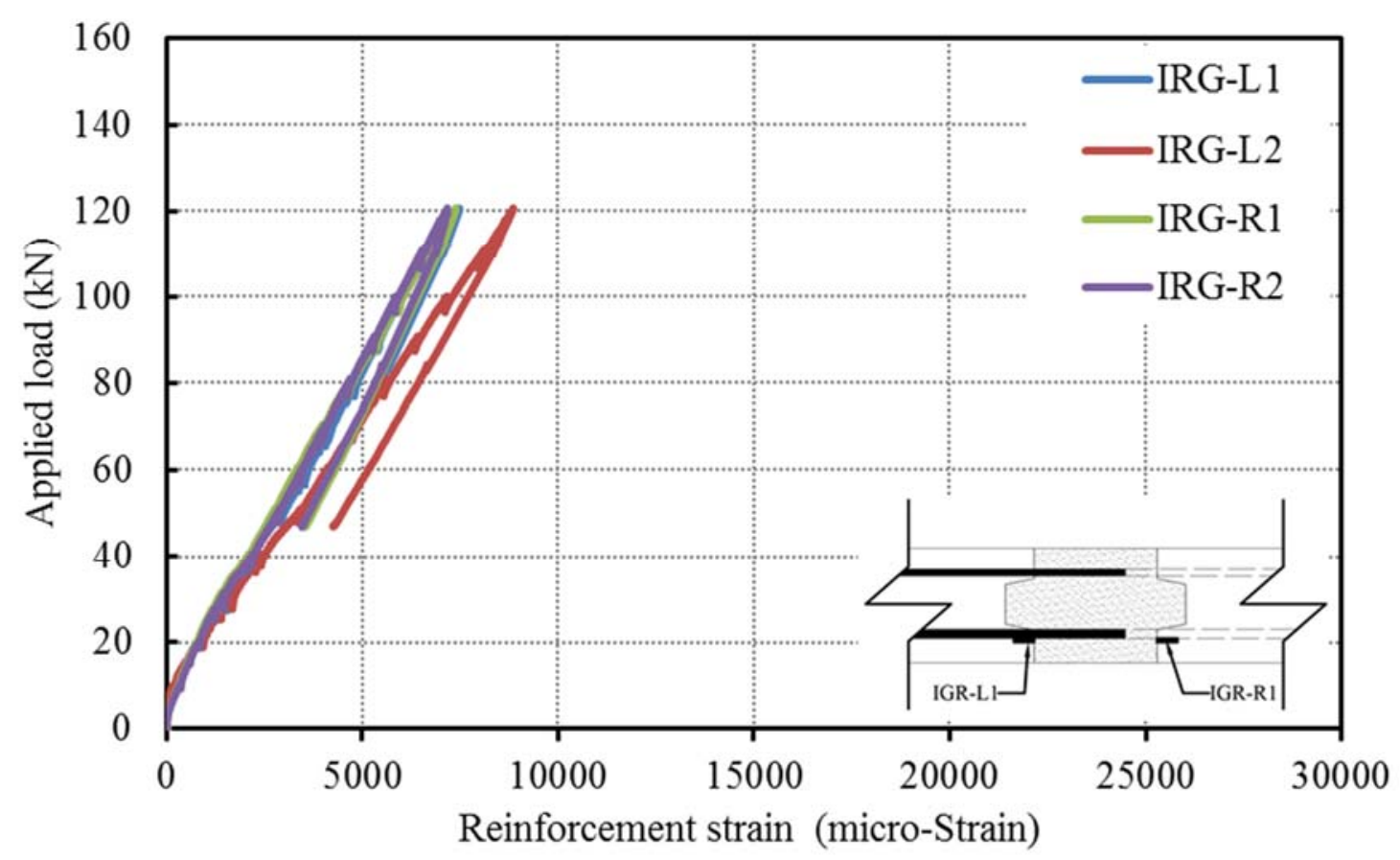

Figure 4.165 Load-bar strain relationship for slab $\mathrm{S}_{19}$ 


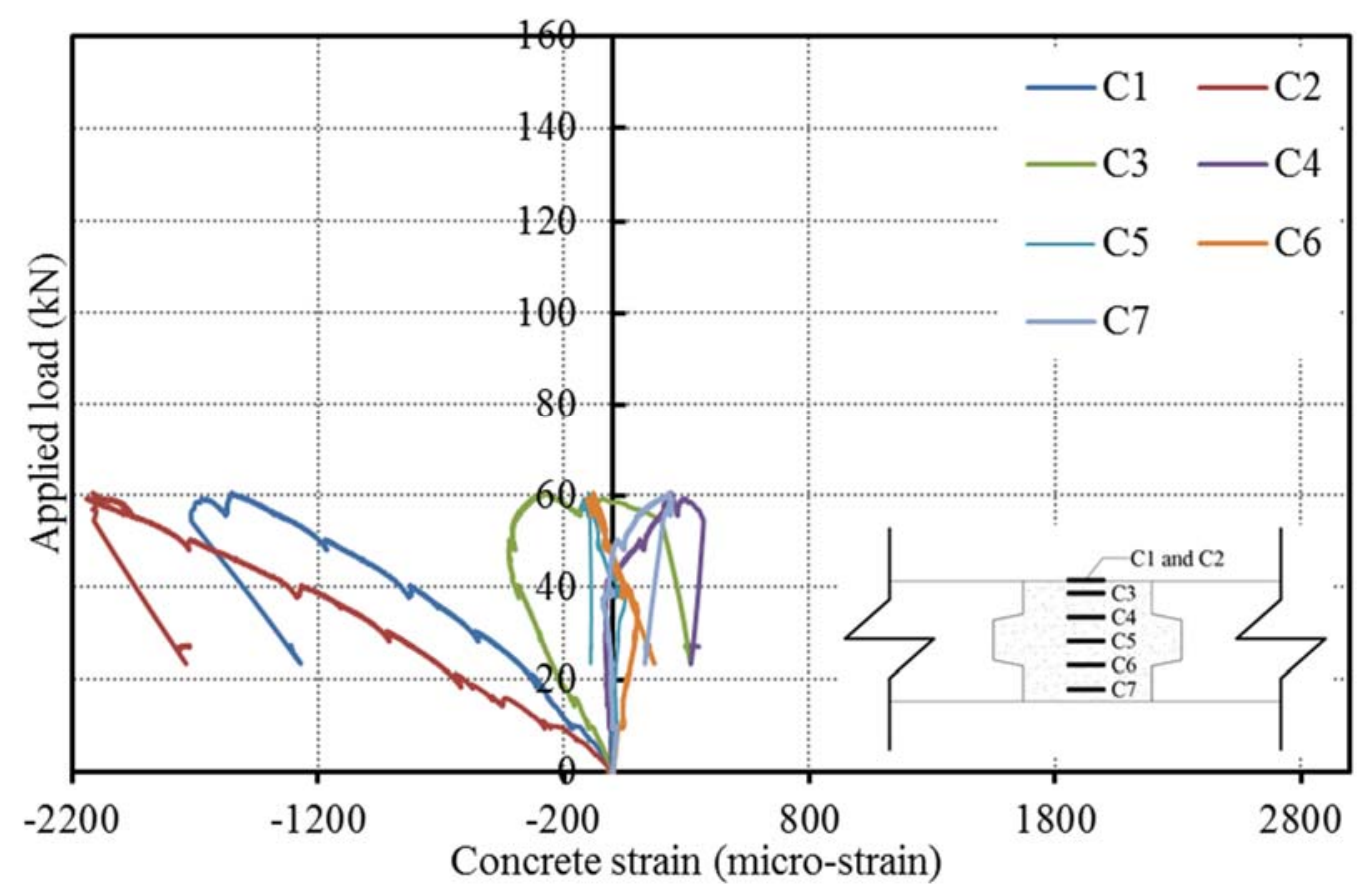

Figure 4.166 Load-concrete strain relationship for slab $\mathrm{S}_{20}$

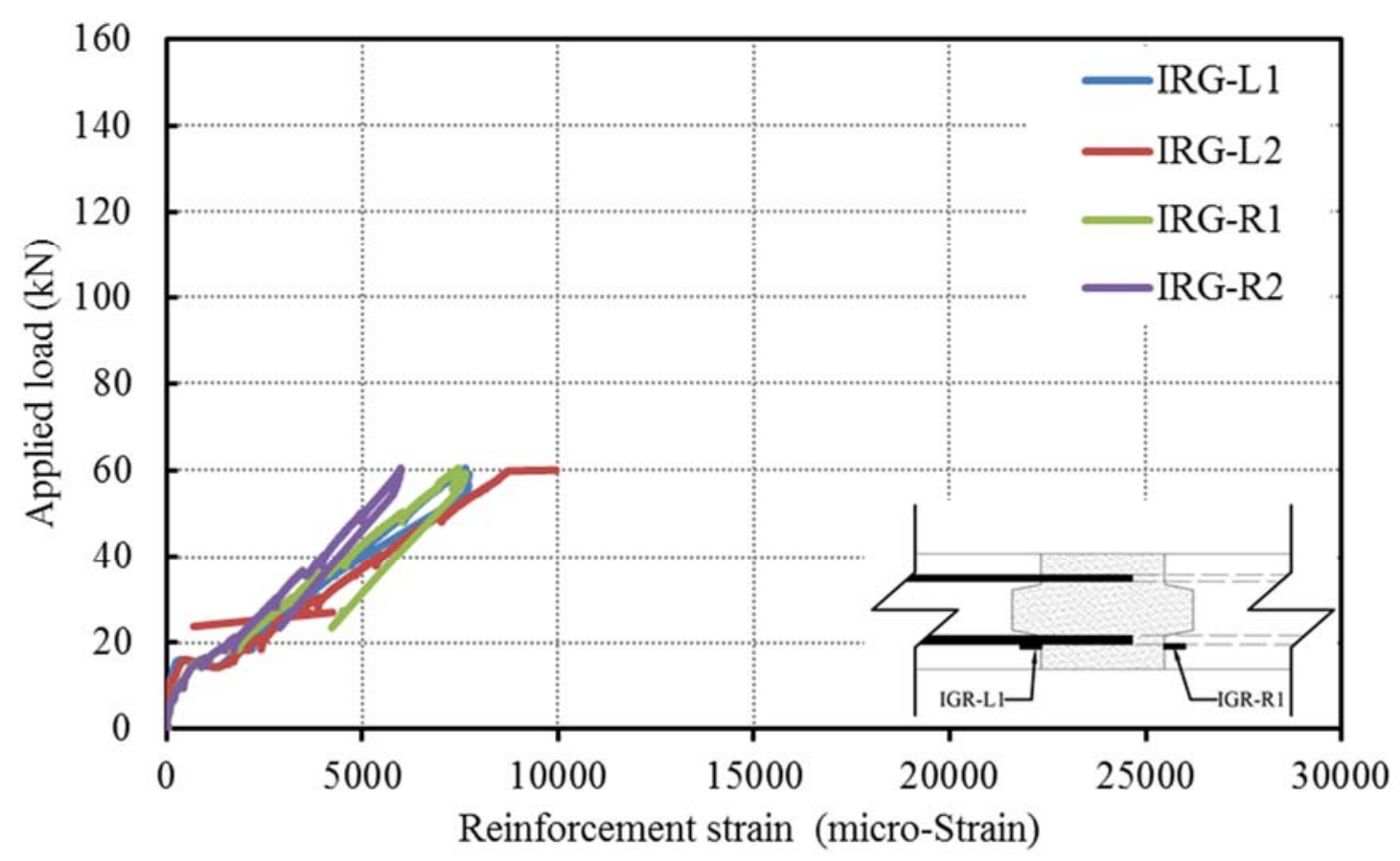

Figure 4.167 Load-bar strain relationship for slab $\mathrm{S}_{20}$ 


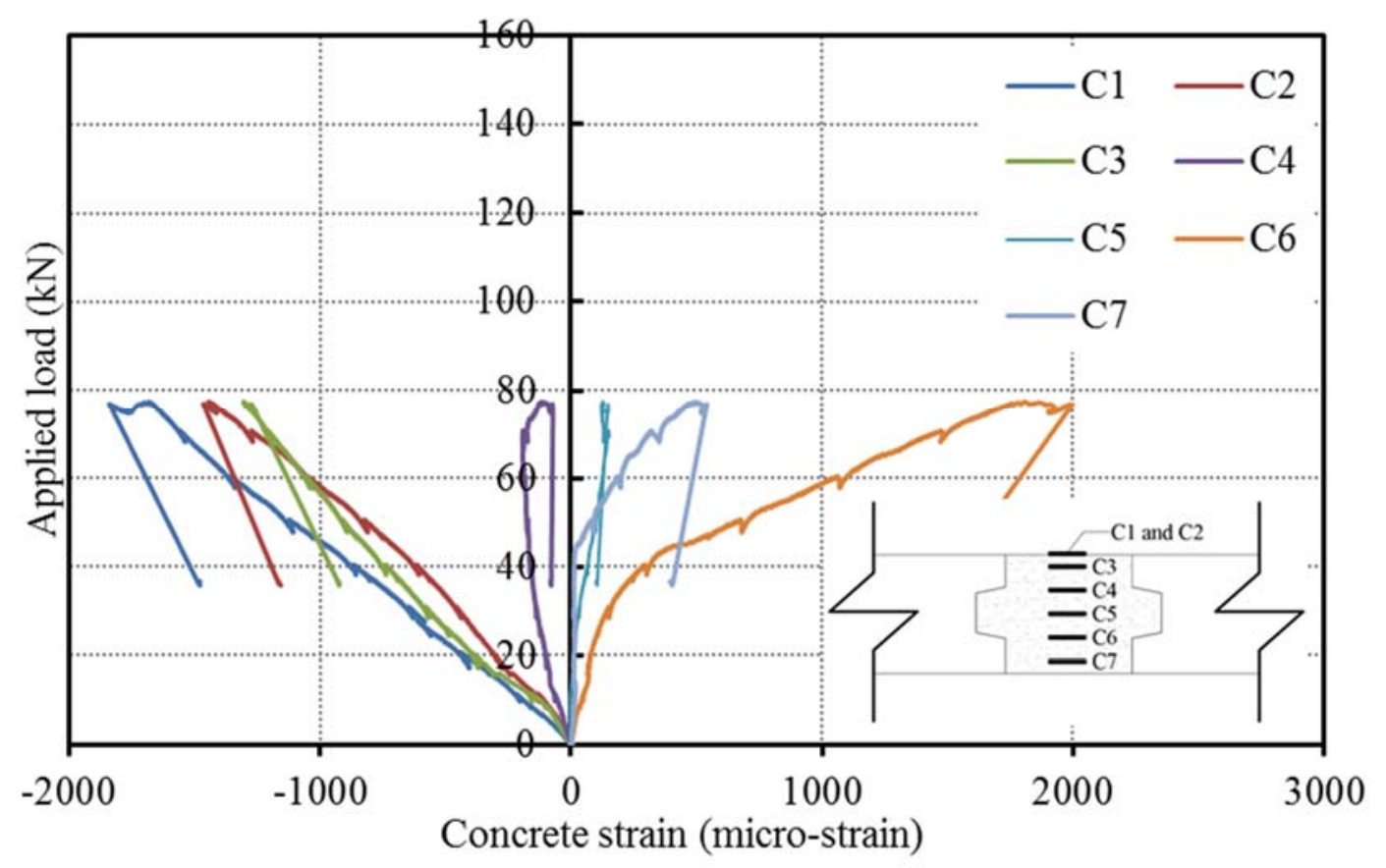

Figure 4.168 Load-concrete strain relationship for slab $\mathrm{S}_{21}$

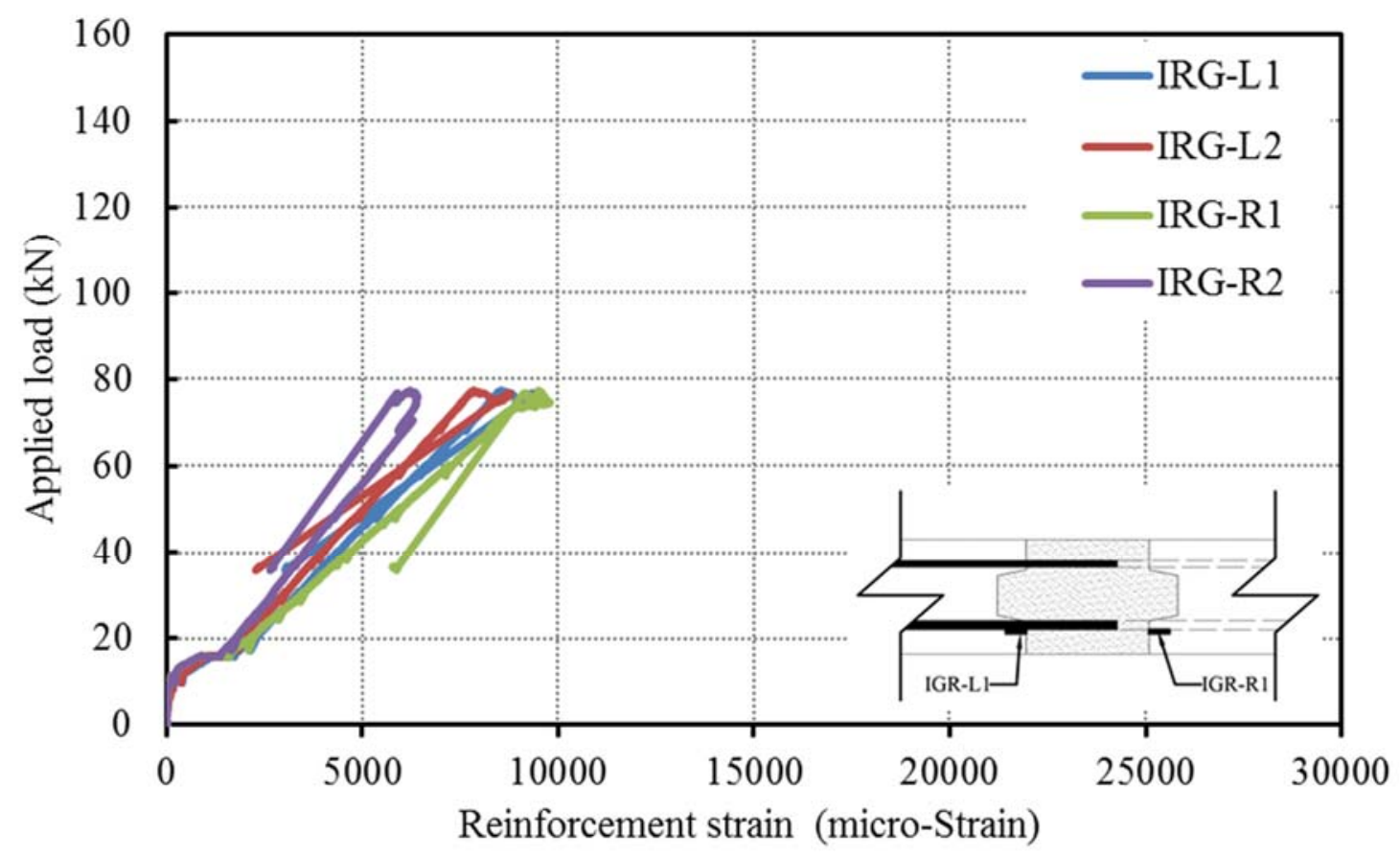

Figure 4.169 Load-bar strain relationship for slab $\mathrm{S}_{21}$ 


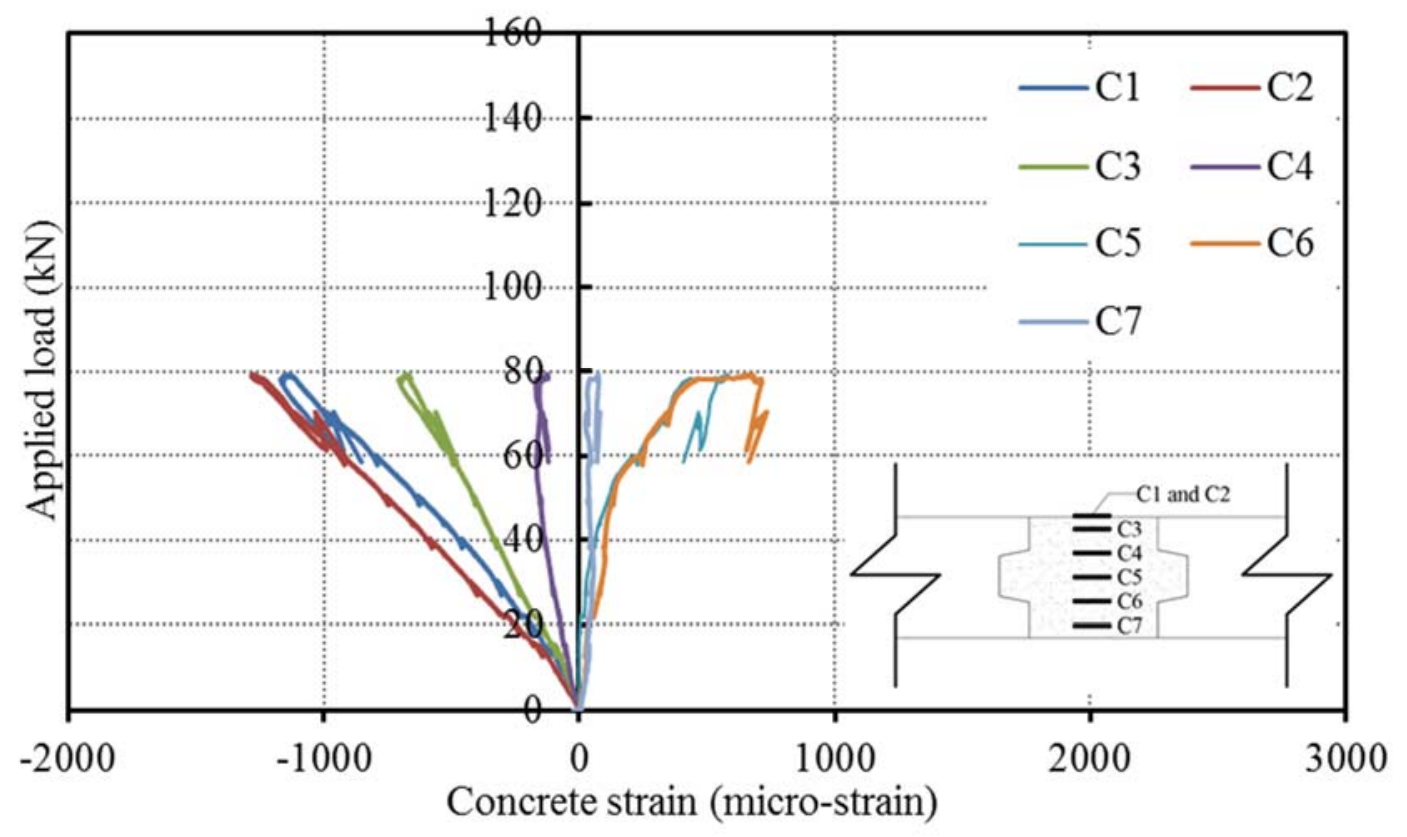

Figure 4.170 Load-concrete strain relationship for slab $\mathrm{S}_{22}$

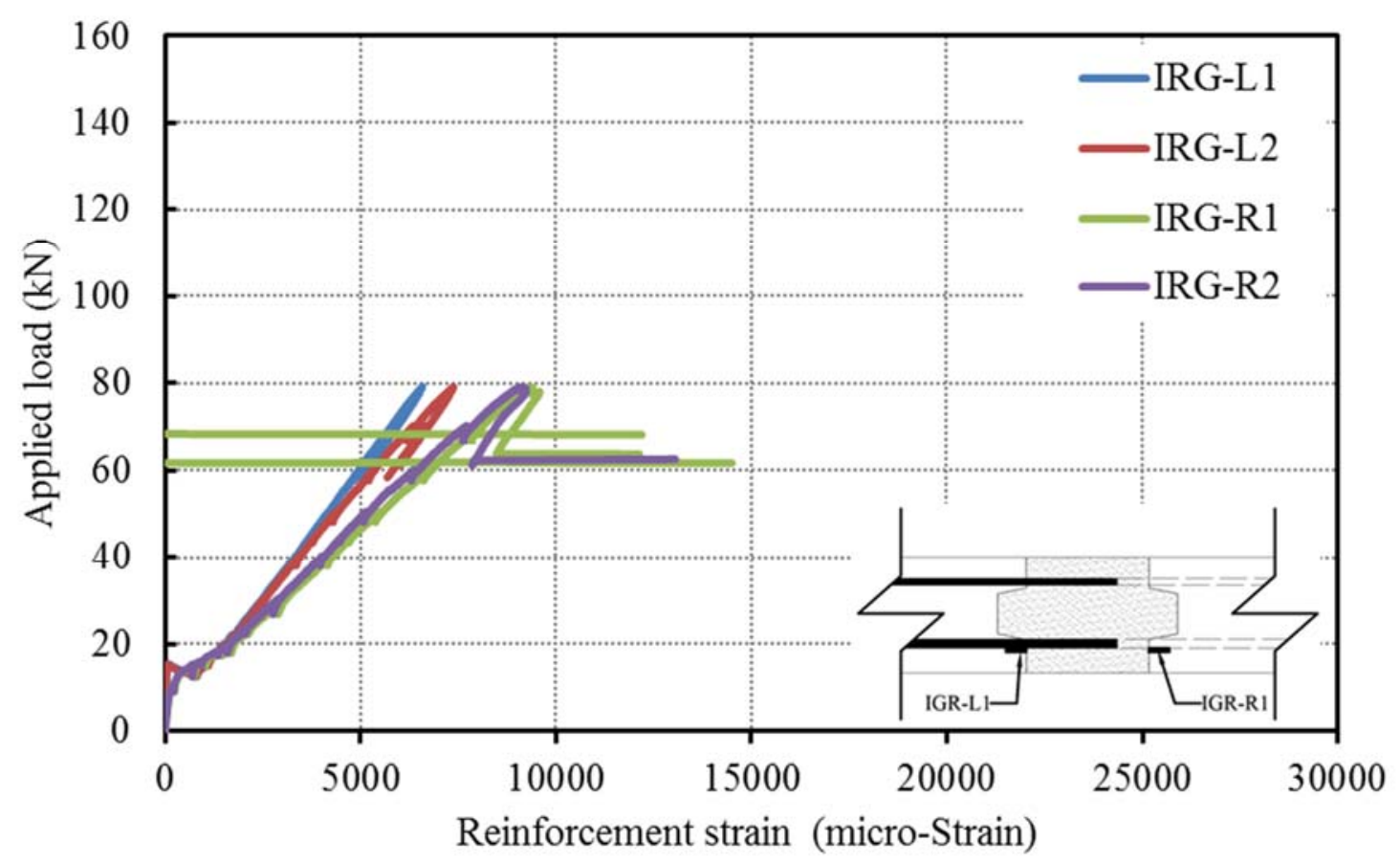

Figure 4.171 Load-bar strain relationship for slab $\mathrm{S}_{22}$ 


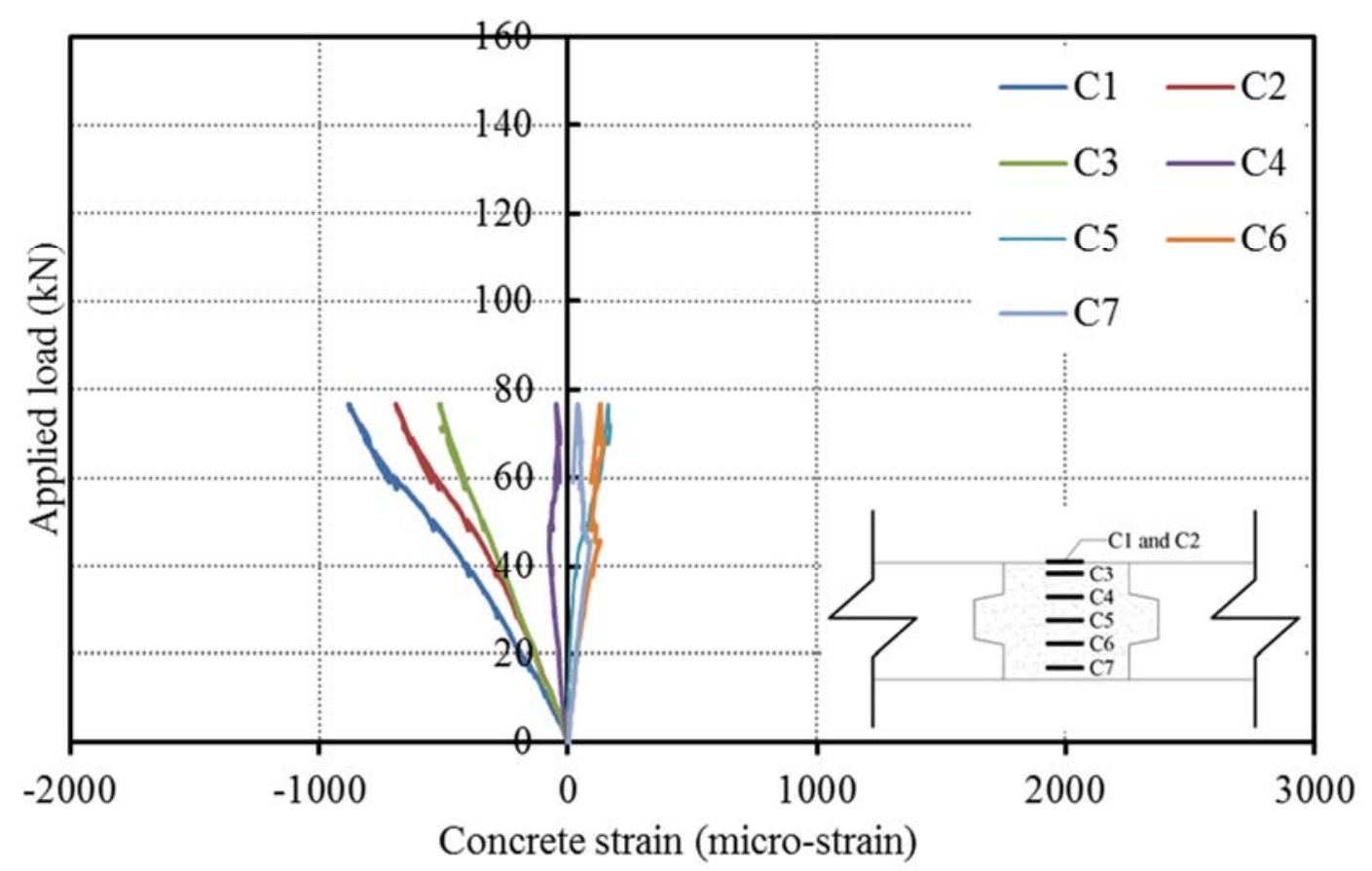

Figure 4.172 Load-concrete strain relationship for slab $\mathrm{S}_{23}$

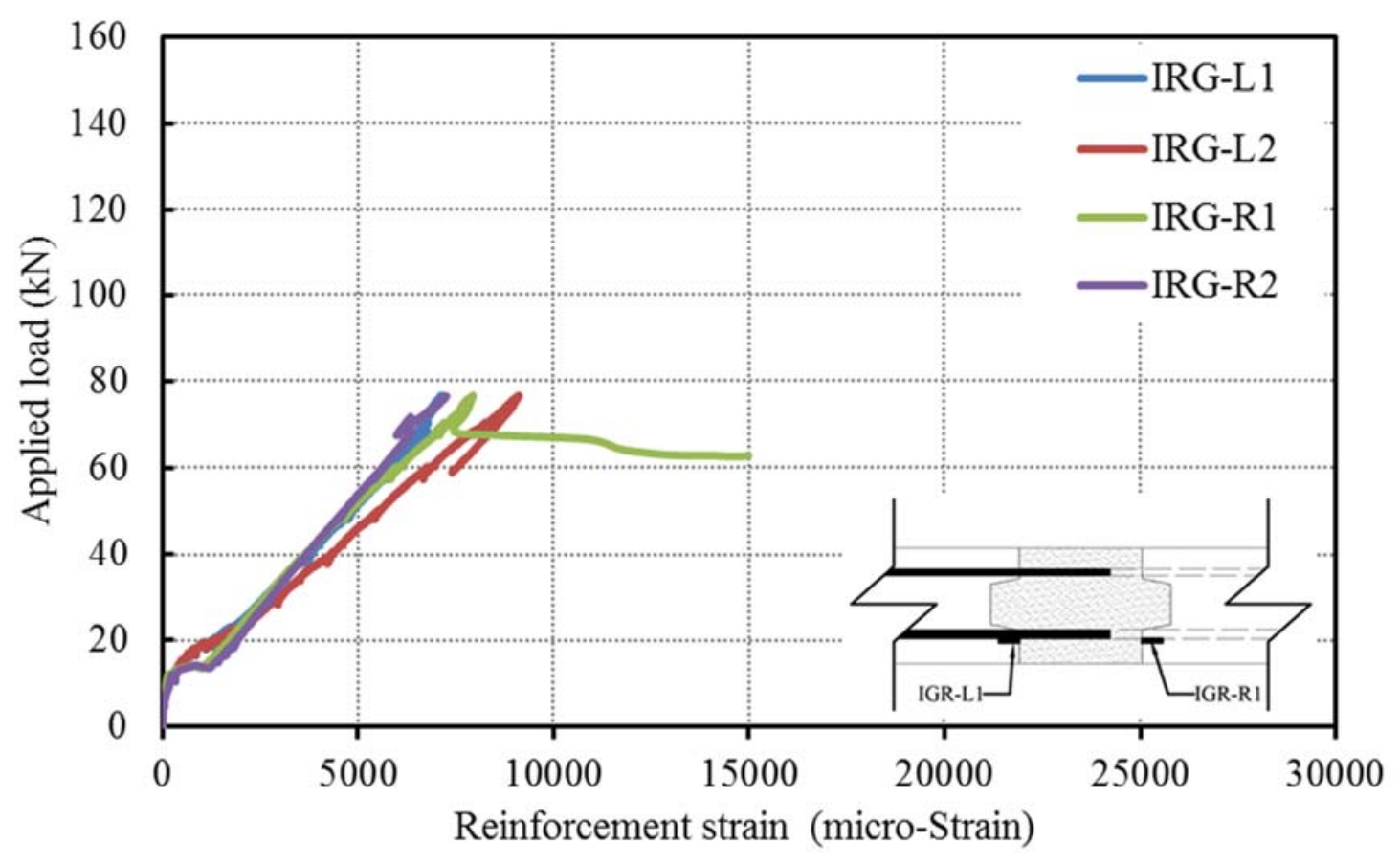

Figure 4.173 Load-bar strain relationship for slab $\mathrm{S}_{23}$ 


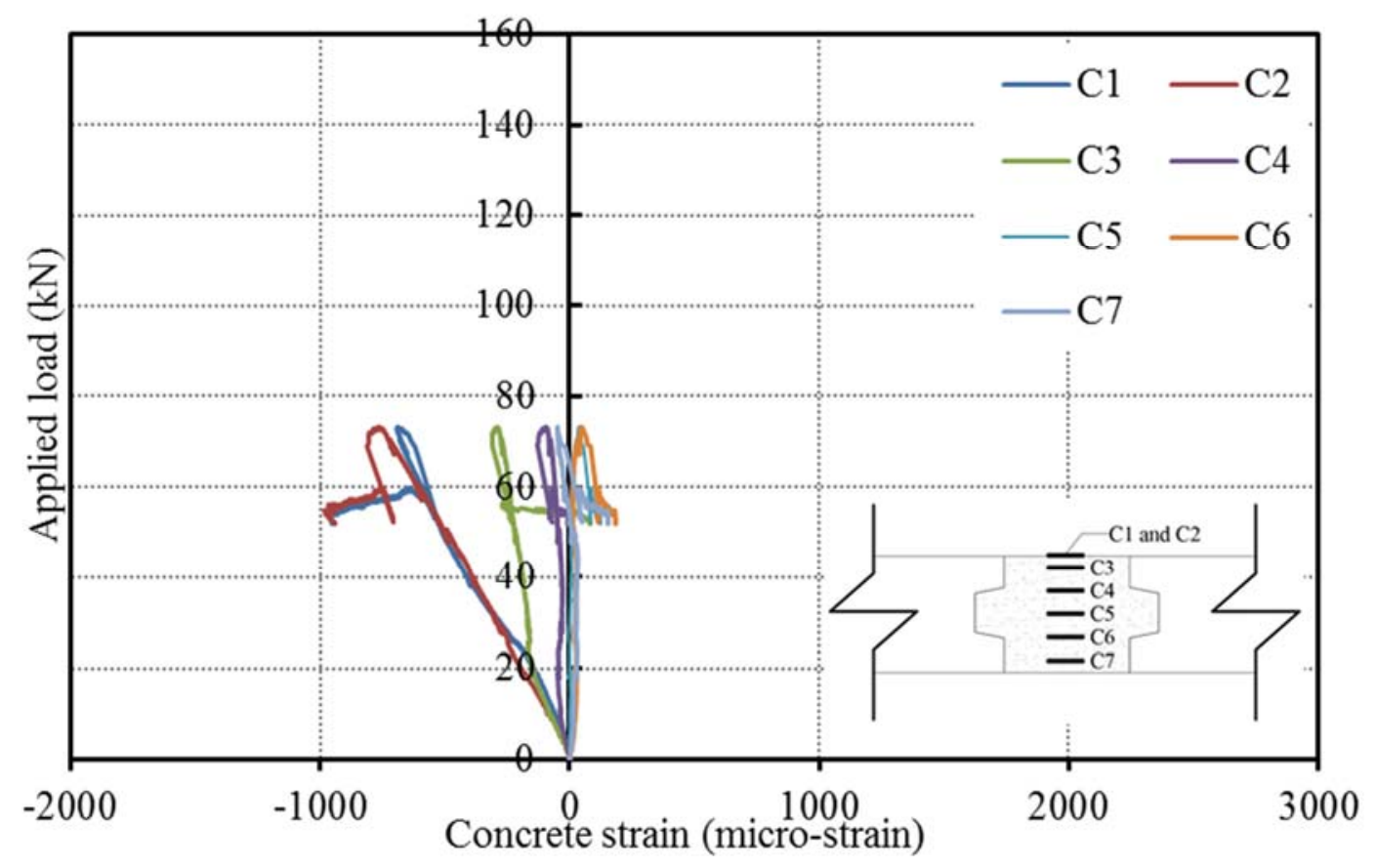

Figure 4.174 Load-concrete strain relationship for slab $\mathrm{S}_{24}$

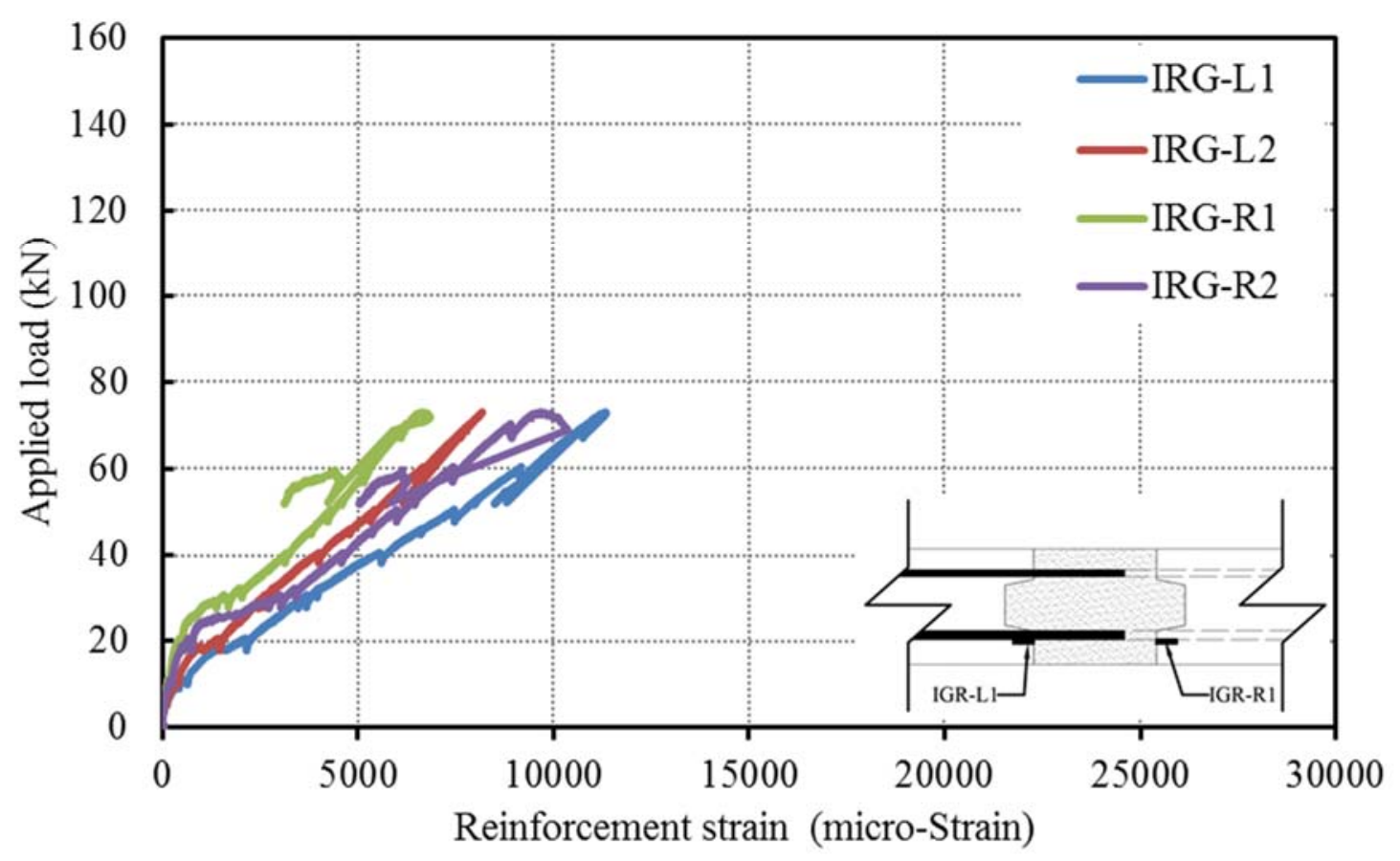

Figure 4.175 Load-bar strain relationship for slab $\mathrm{S}_{24}$ 


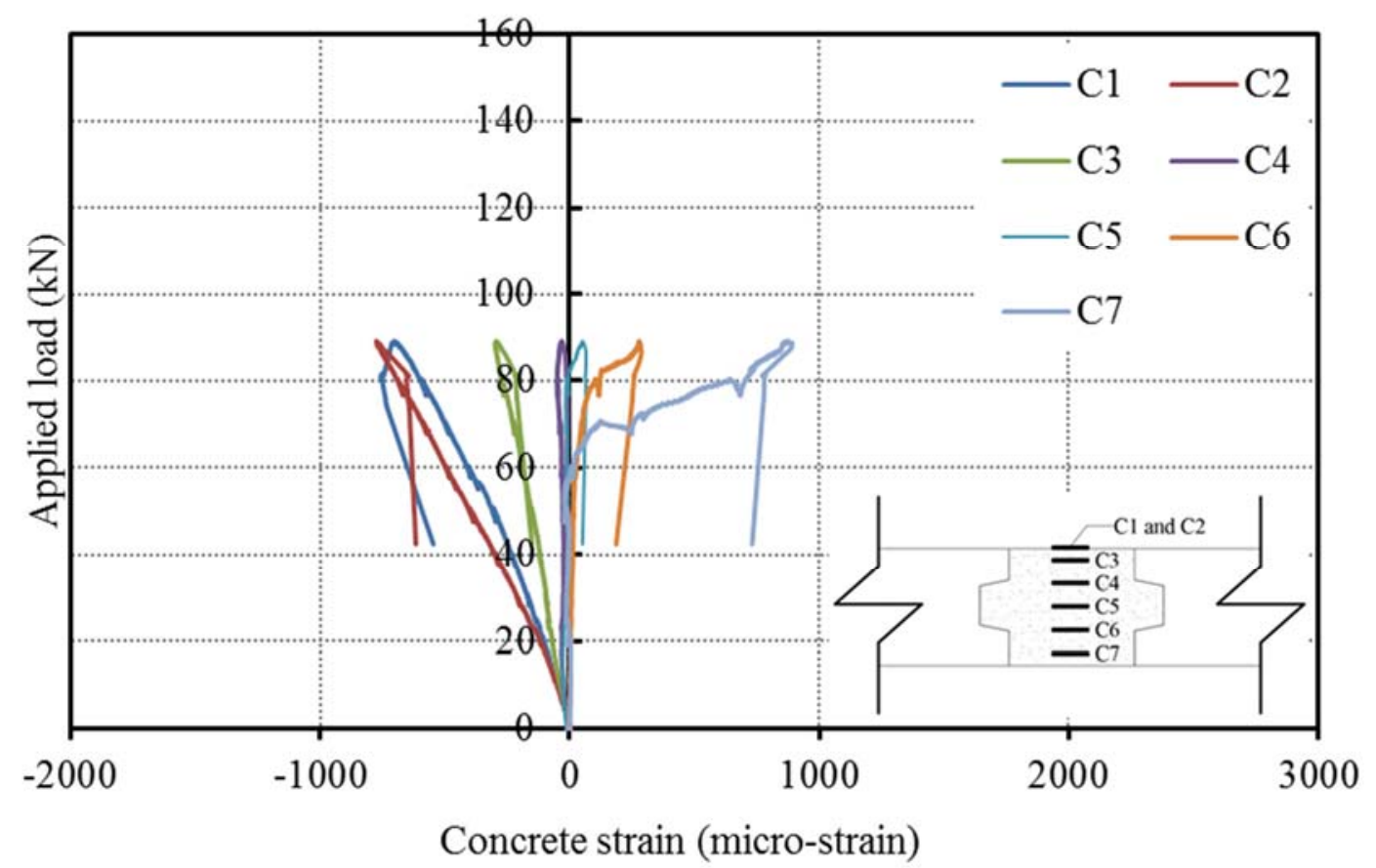

Figure 4.176 Load-concrete strain relationship for slab $\mathrm{S}_{25}$

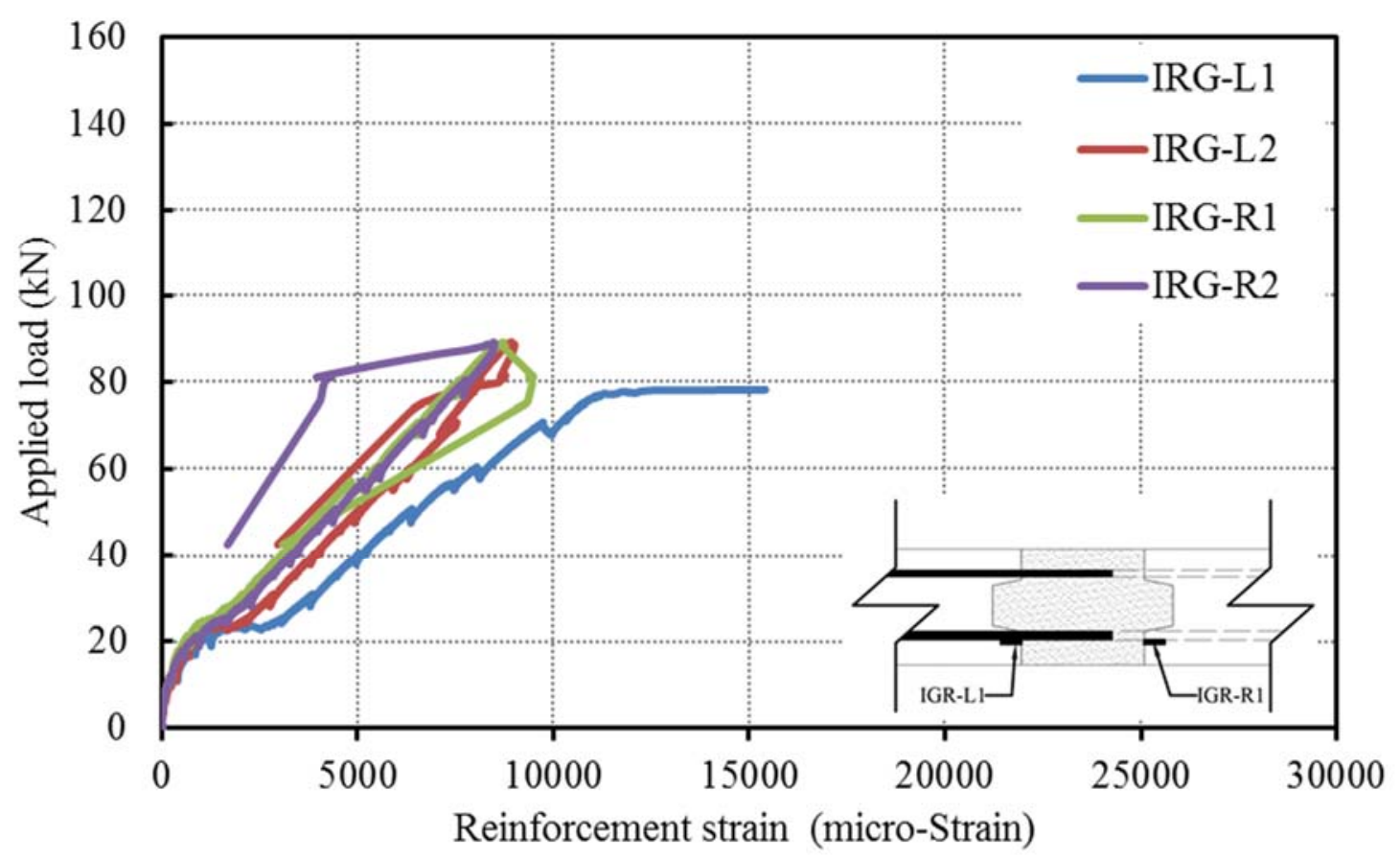

Figure 4.177 Load-bar strain relationship for slab $\mathrm{S}_{25}$ 


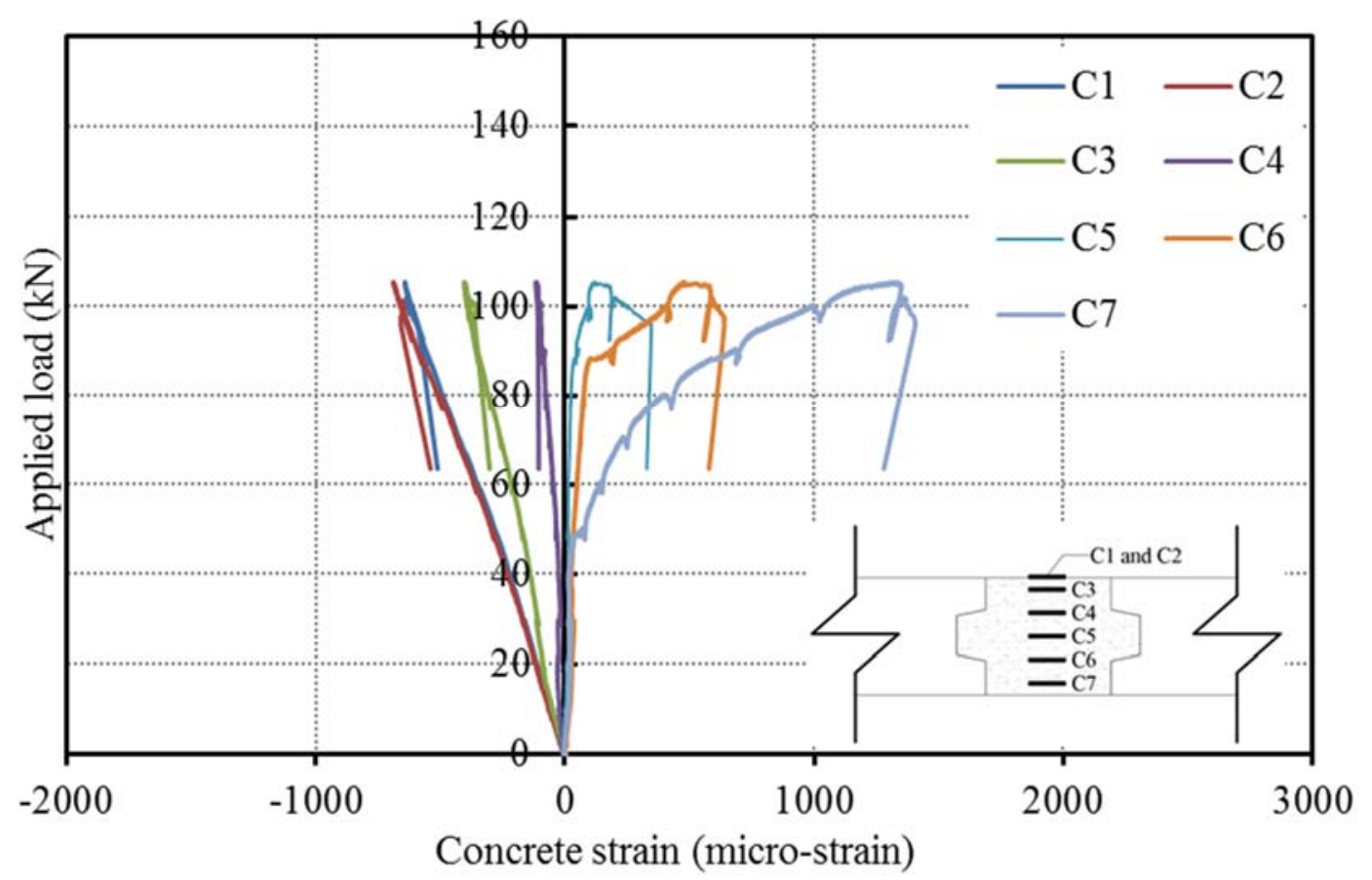

Figure 4.178 Load-concrete strain relationship for slab $\mathrm{S}_{26}$

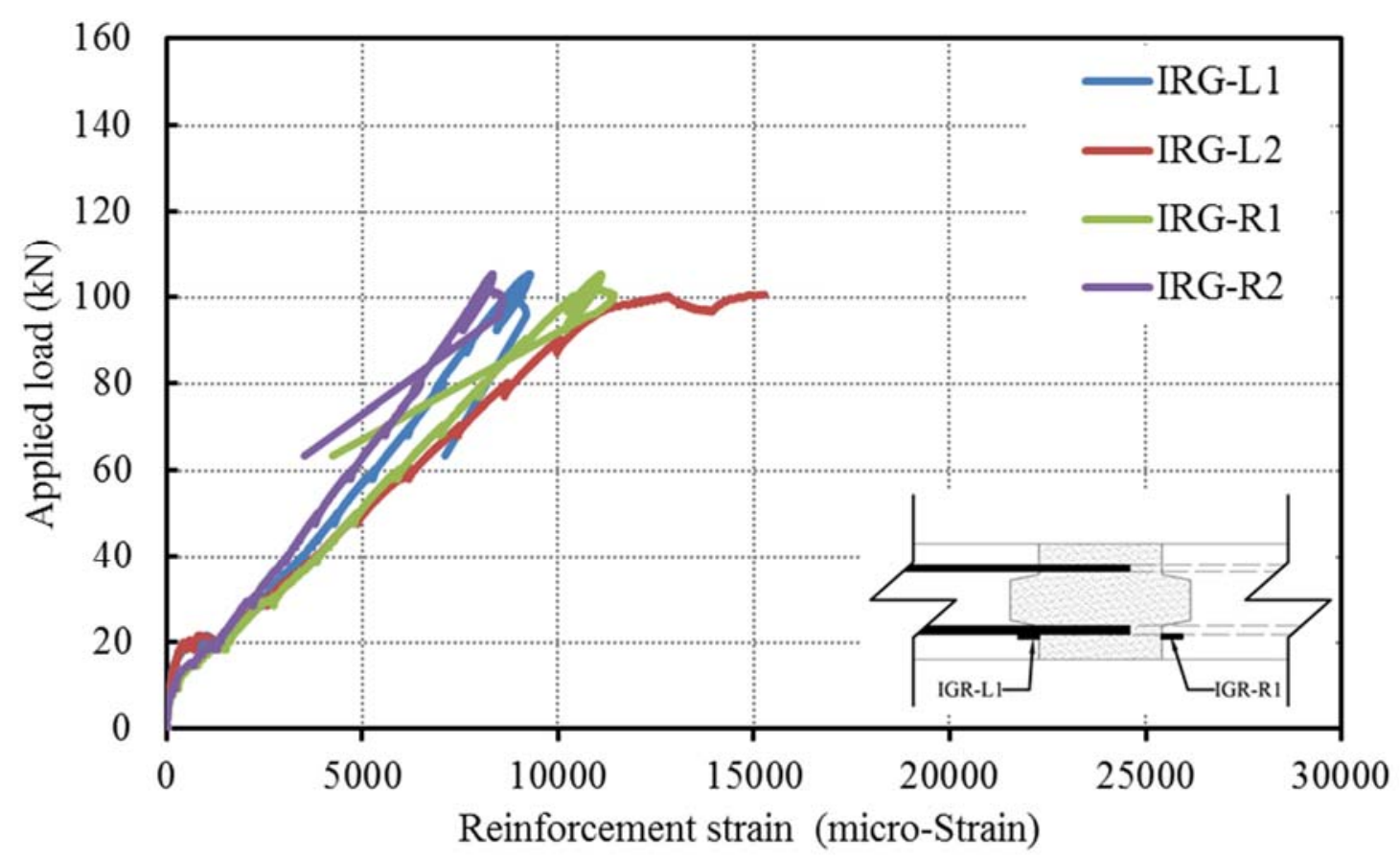

Figure 4.179 Load-bar strain relationship for slab $\mathrm{S}_{26}$ 


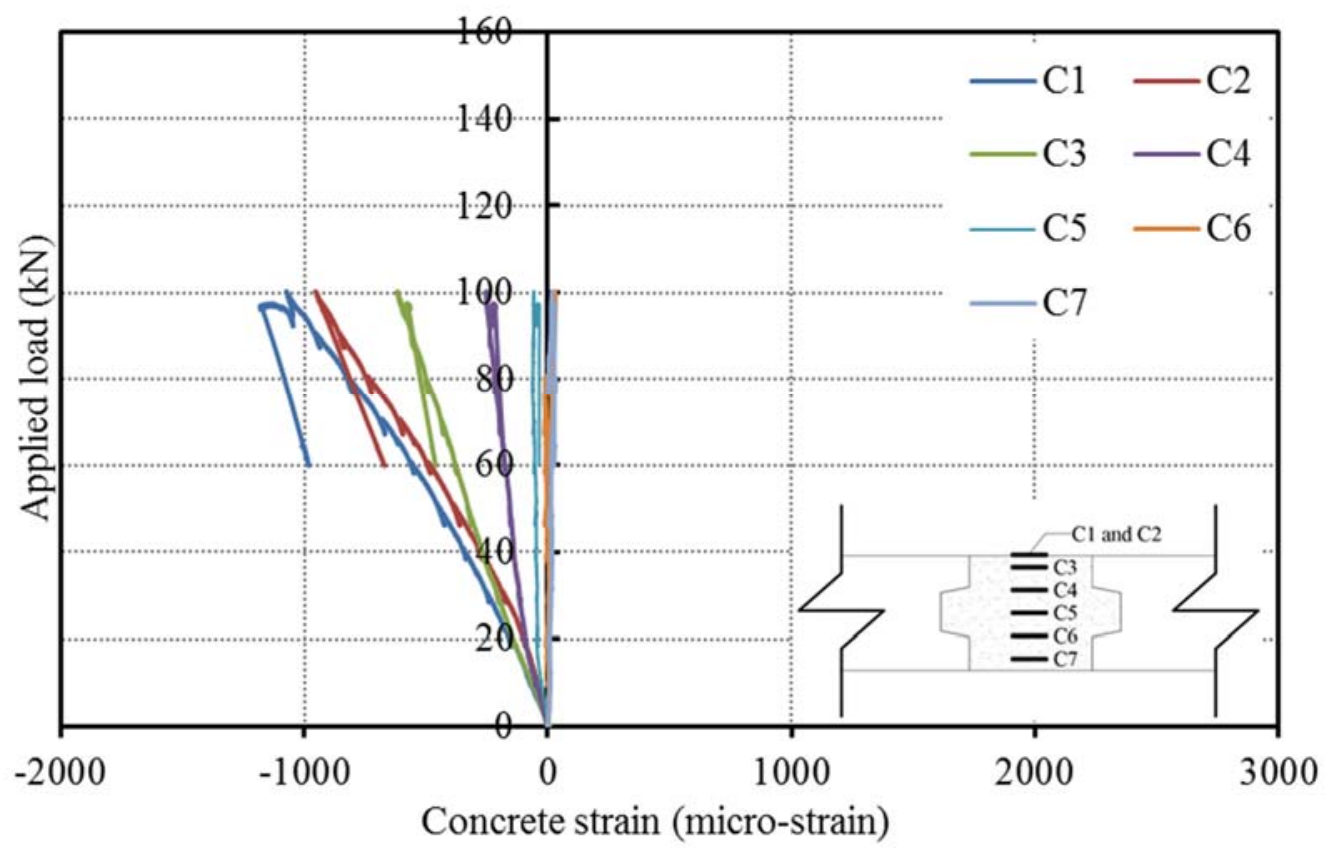

Figure 4.180 Load-concrete strain relationship for slab $\mathrm{S}_{27}$

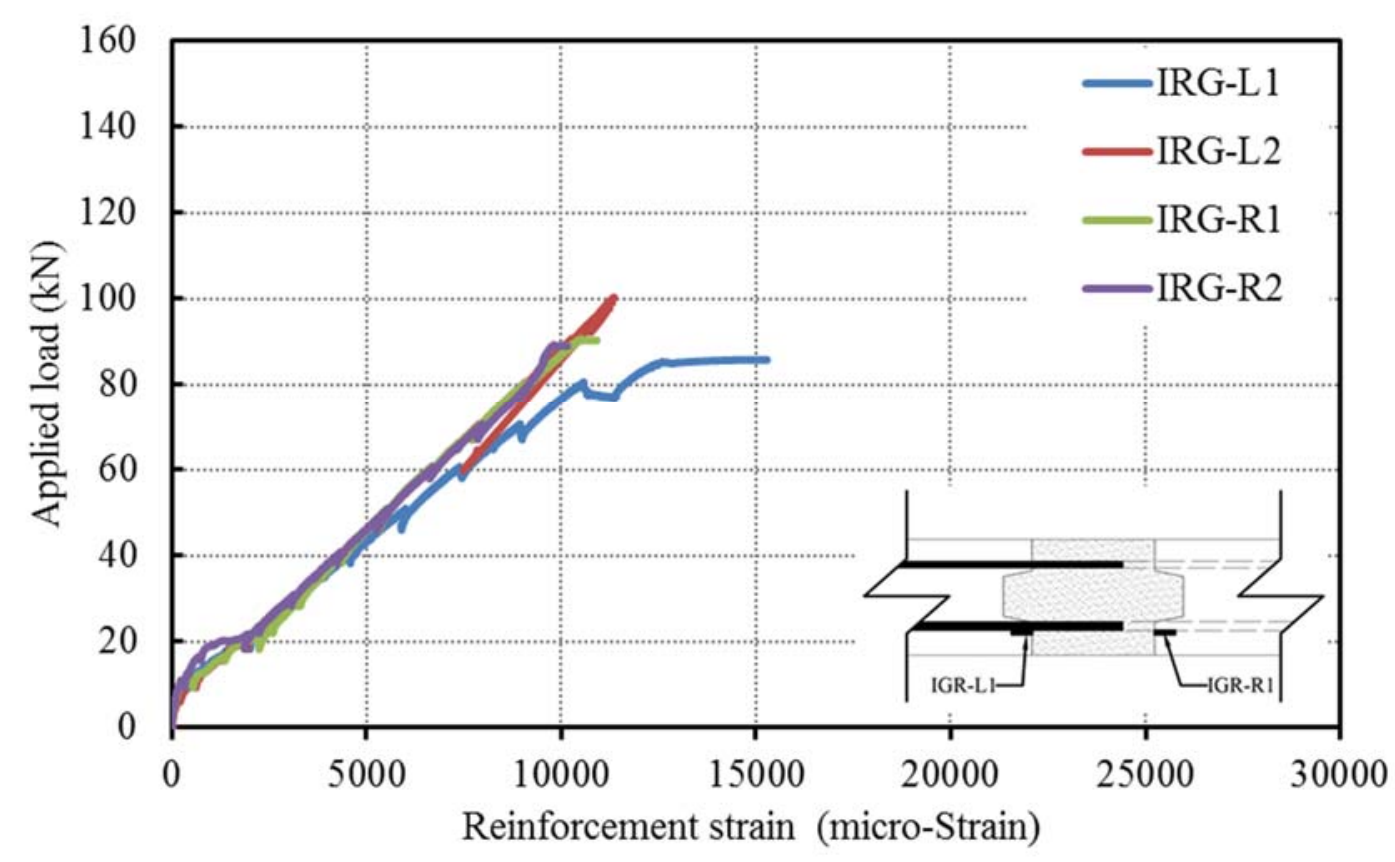

Figure 4.181 Load-bar strain relationship for slab $\mathrm{S}_{27}$ 


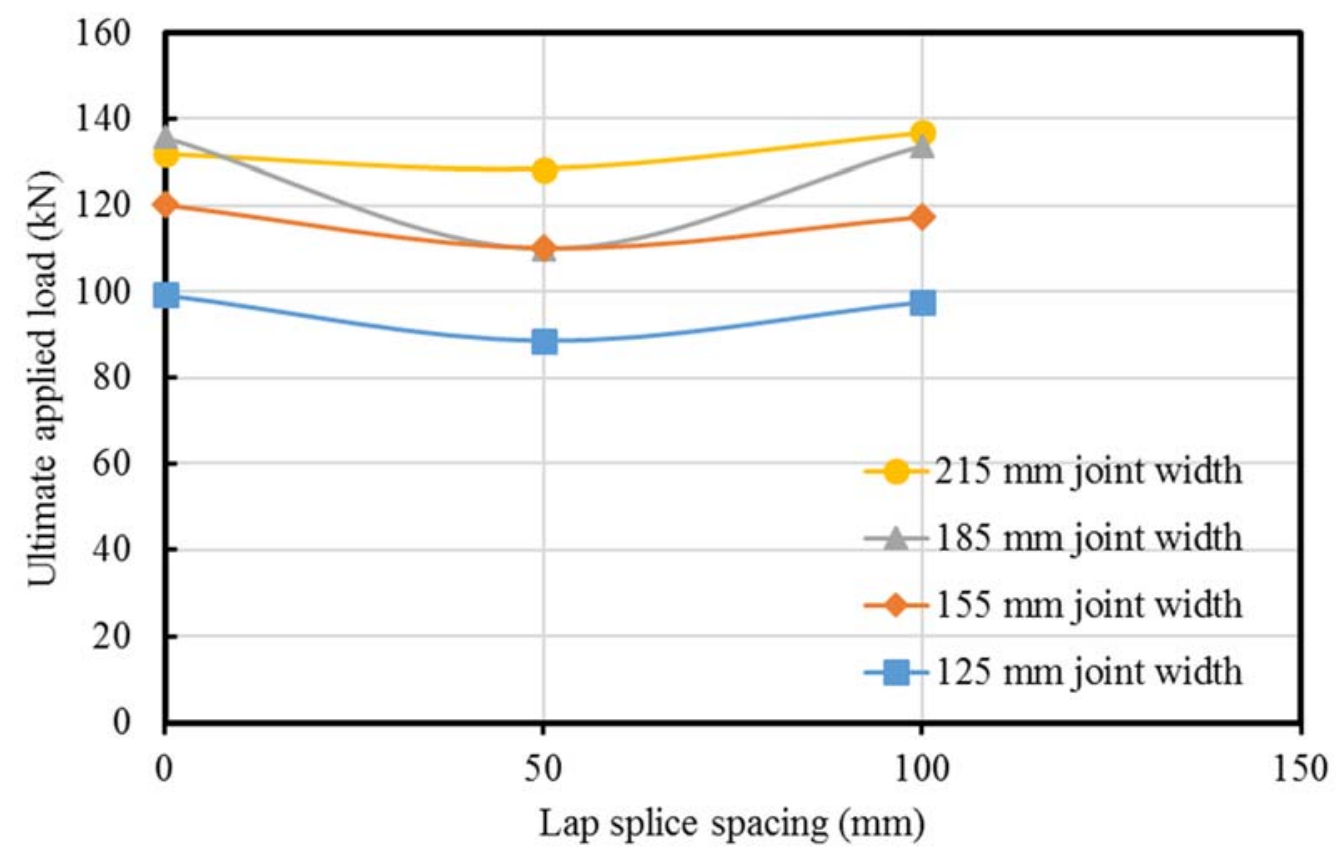

Figure 4.182 Effect of lap splice spacing and joint width on the capacity

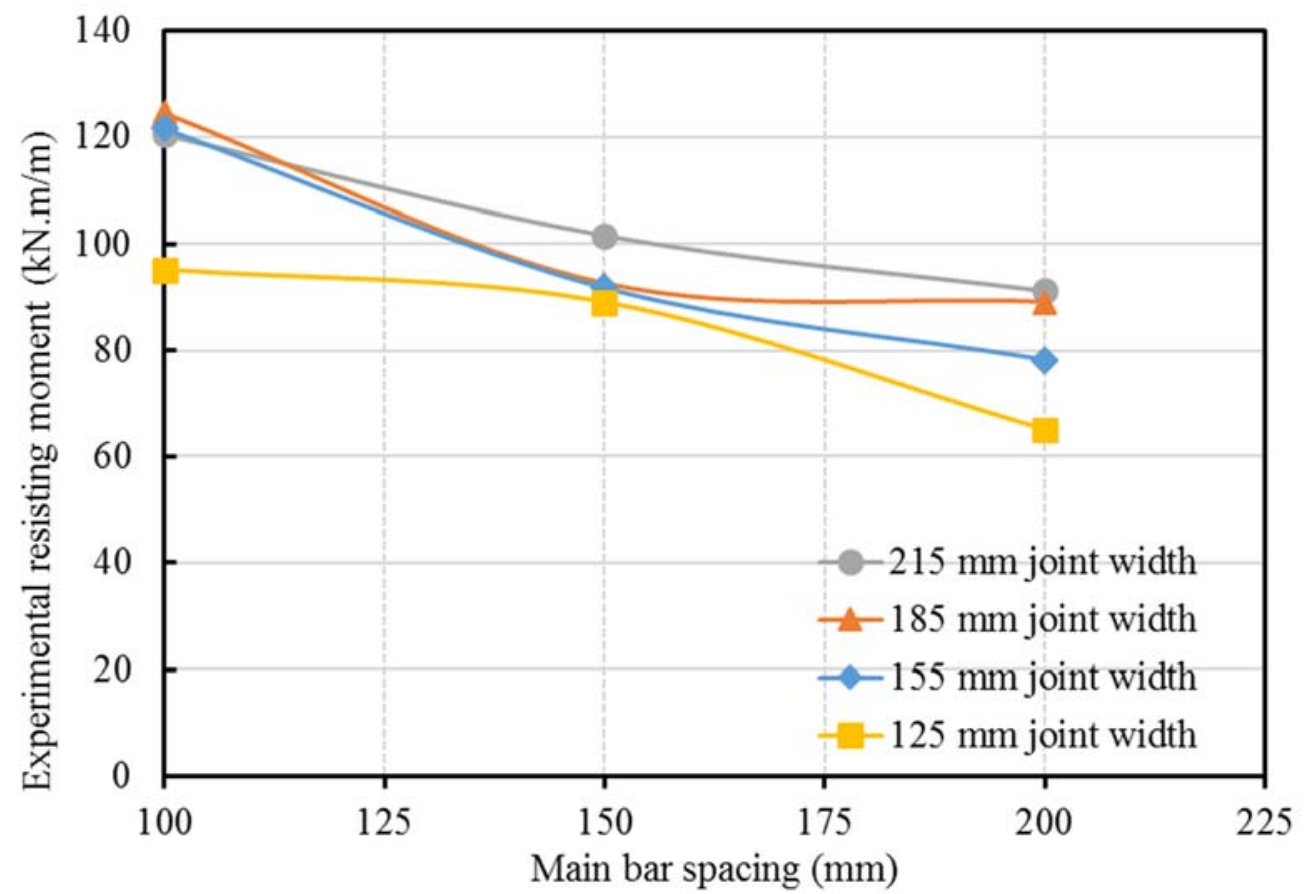

Figure 4.183 Effect of main bar spacing and joint width on the capacity 


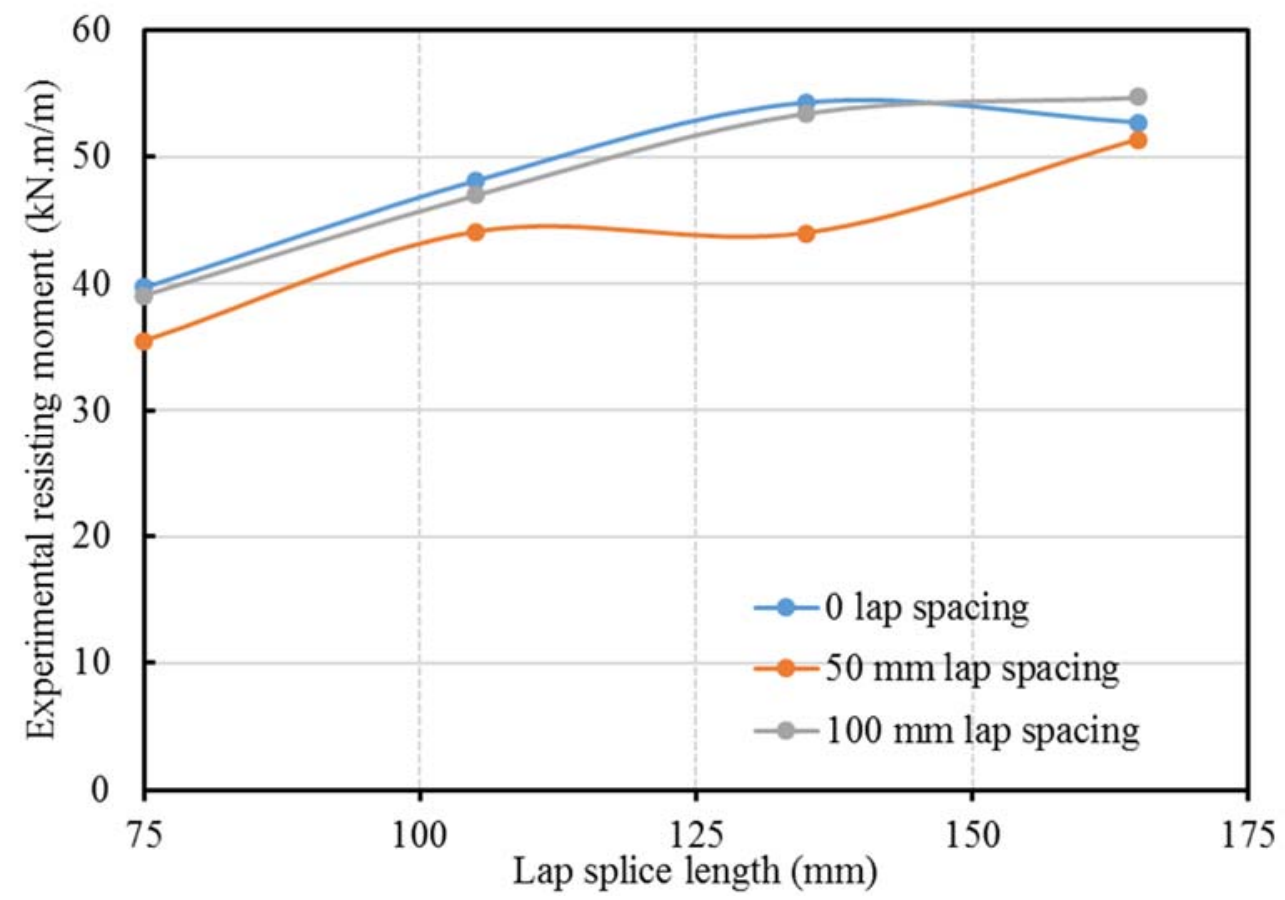

Figure 4.184 Effect of lap splice length on the capacity

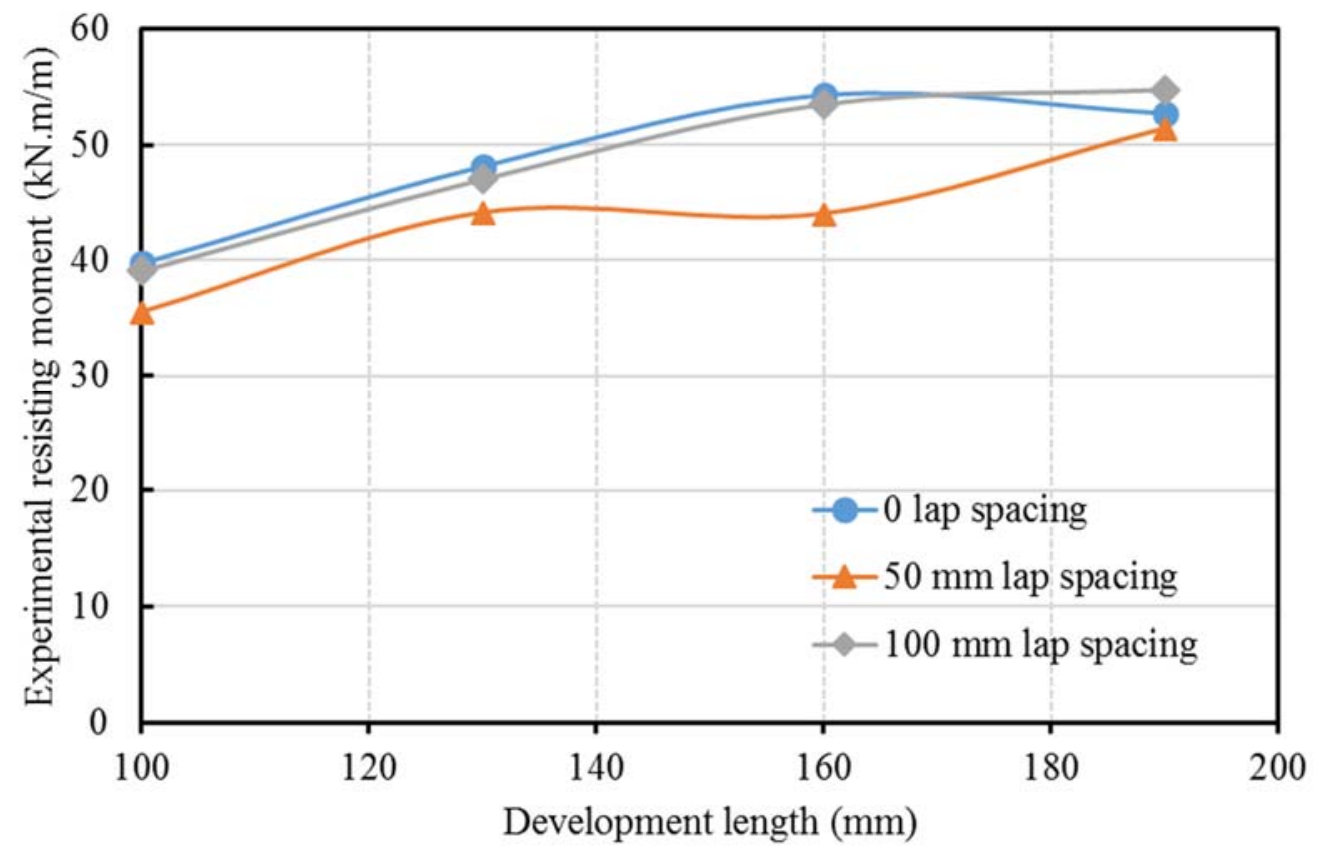

Figure 4.185 Effect of the development length on the capacity 


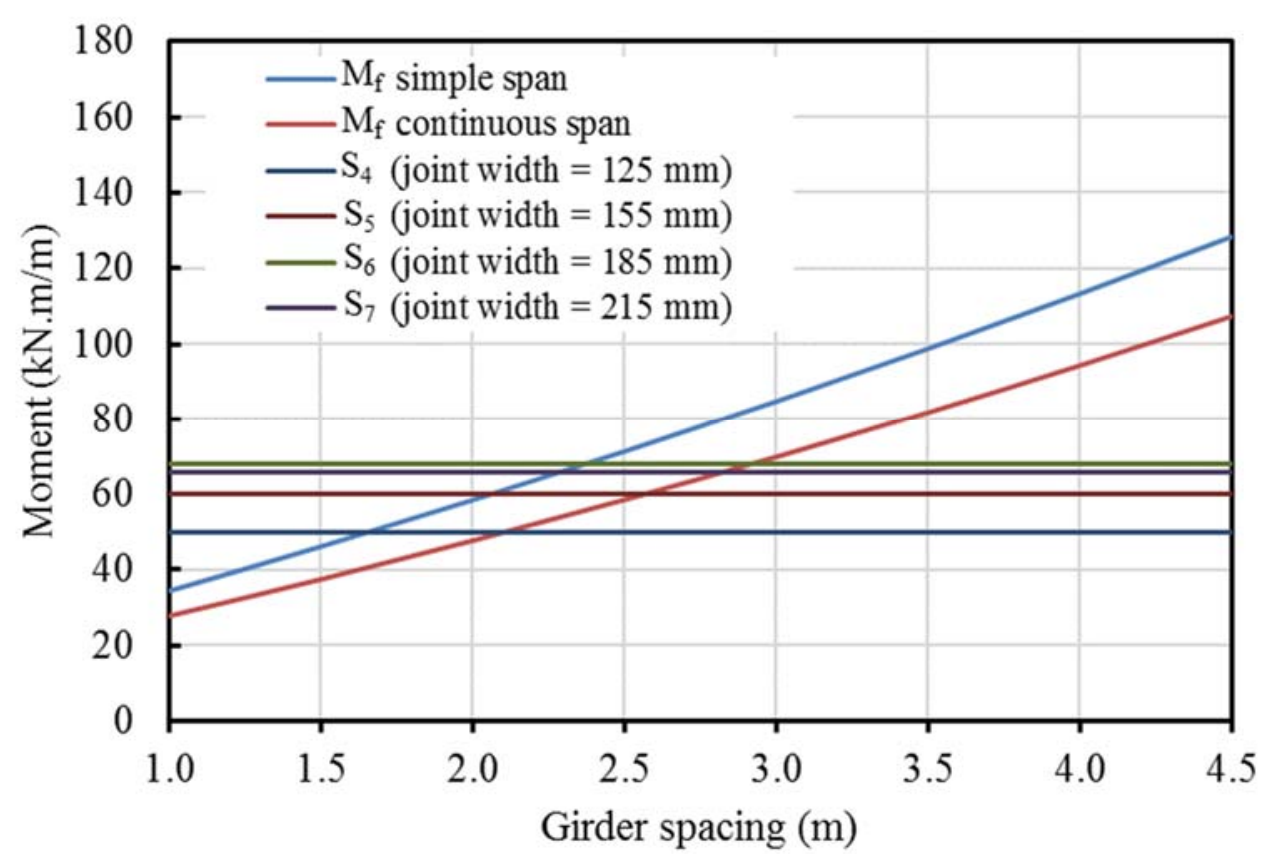

Figure 4.186 Specified maximum spacing between girders for jointed slabs in group G1 with full contact splice bars

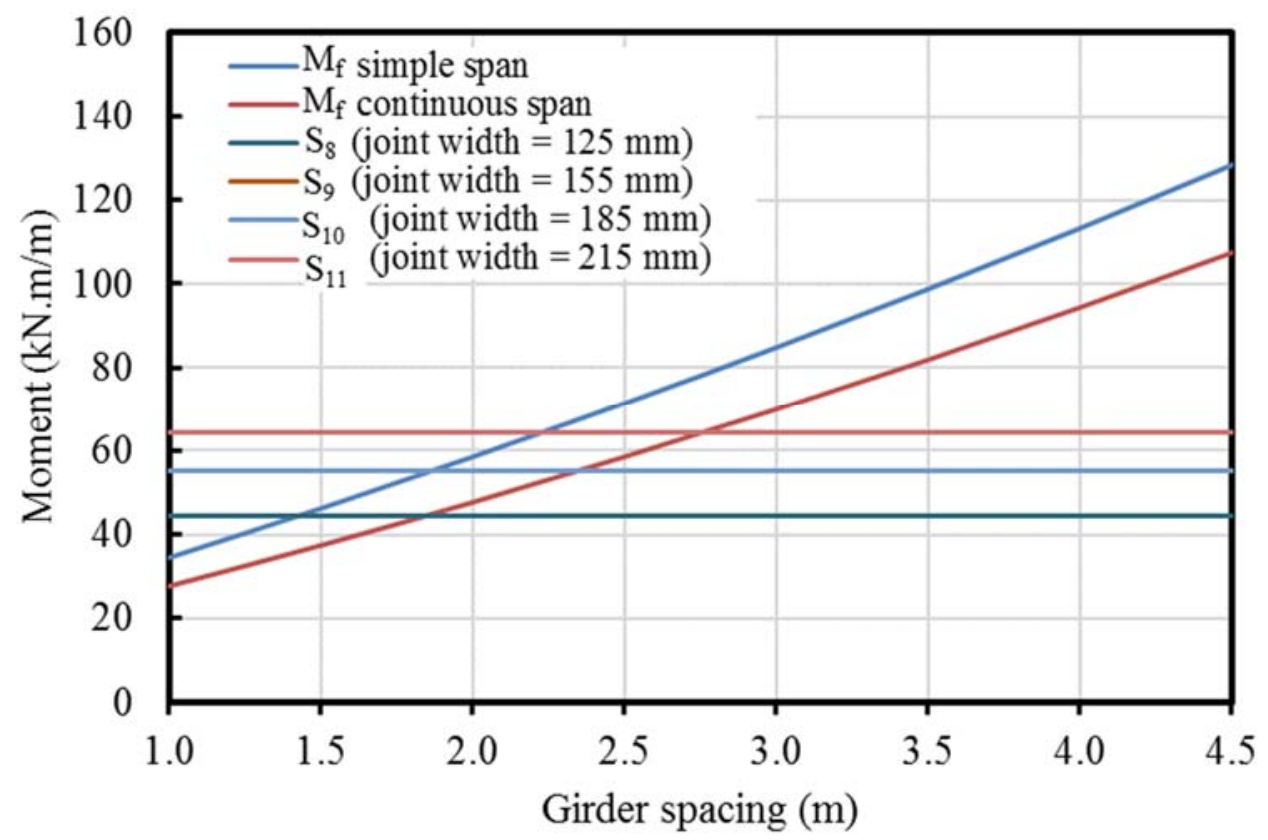

Figure 4.187 Specified maximum spacing between girders for jointed slabs in group G2 with 50 $\mathrm{mm}$ spacing between spliced bars 


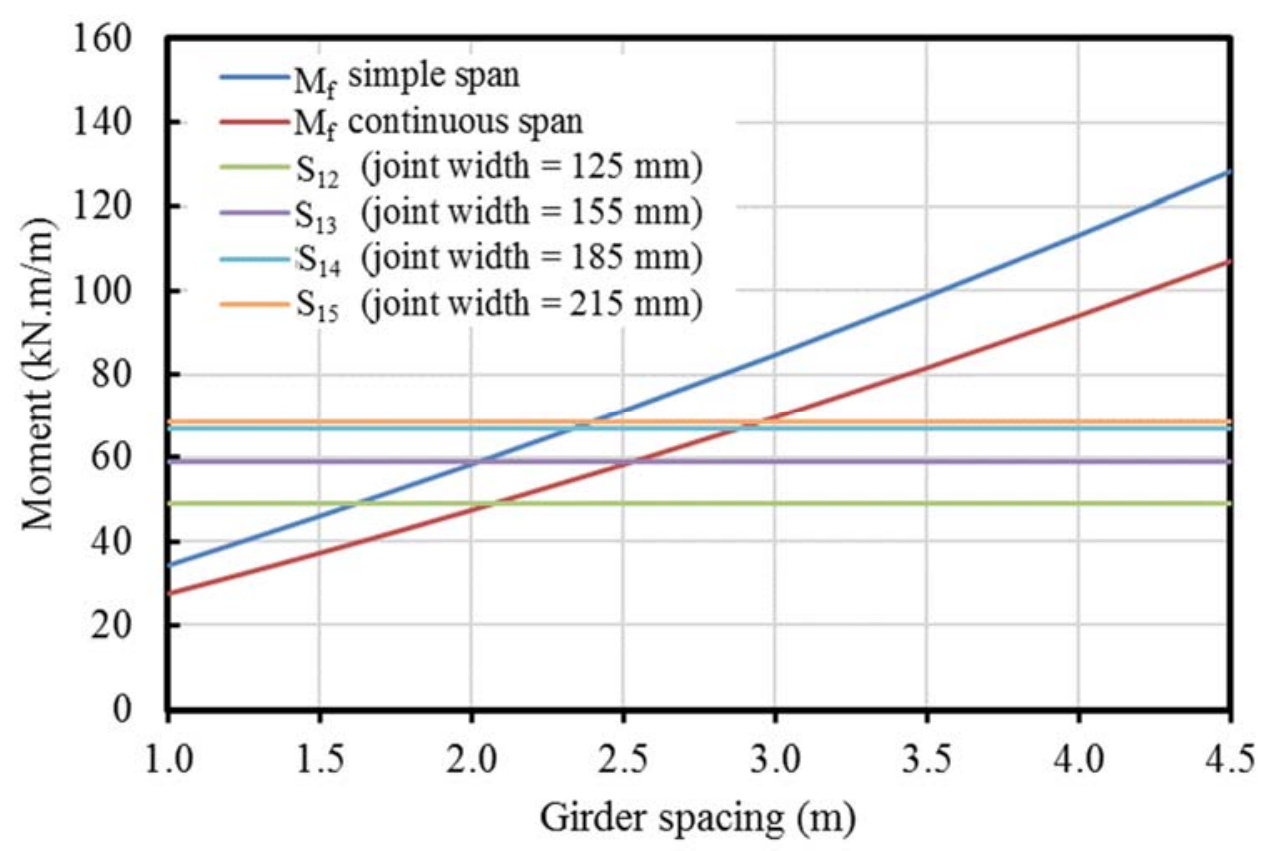

Figure 4.188 Specified maximum spacing between girders for jointed slabs in group G3 with 100 $\mathrm{mm}$ spacing between spliced bar

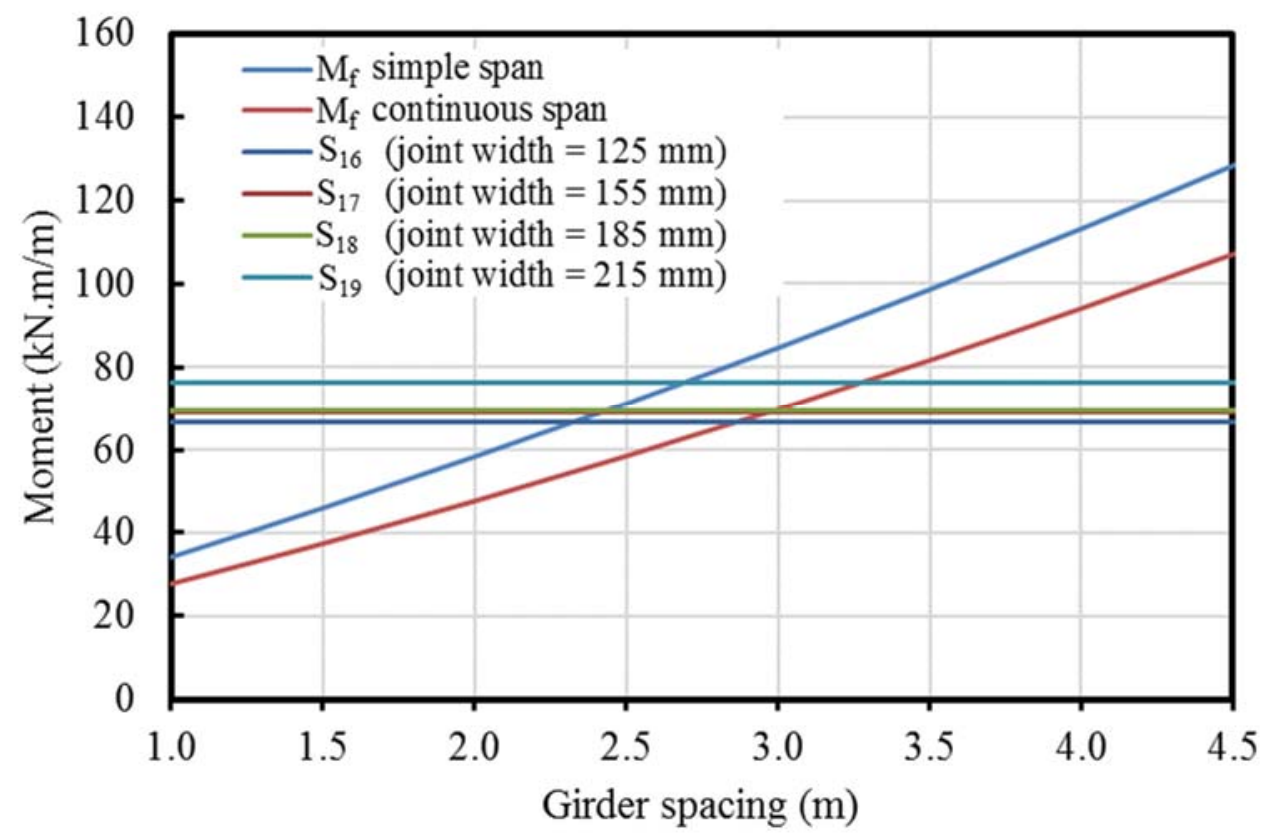

Figure 4.189 Specified maximum spacing between girders for jointed slabs in group G4 with 75 $\mathrm{mm}$ spacing between spliced bars 


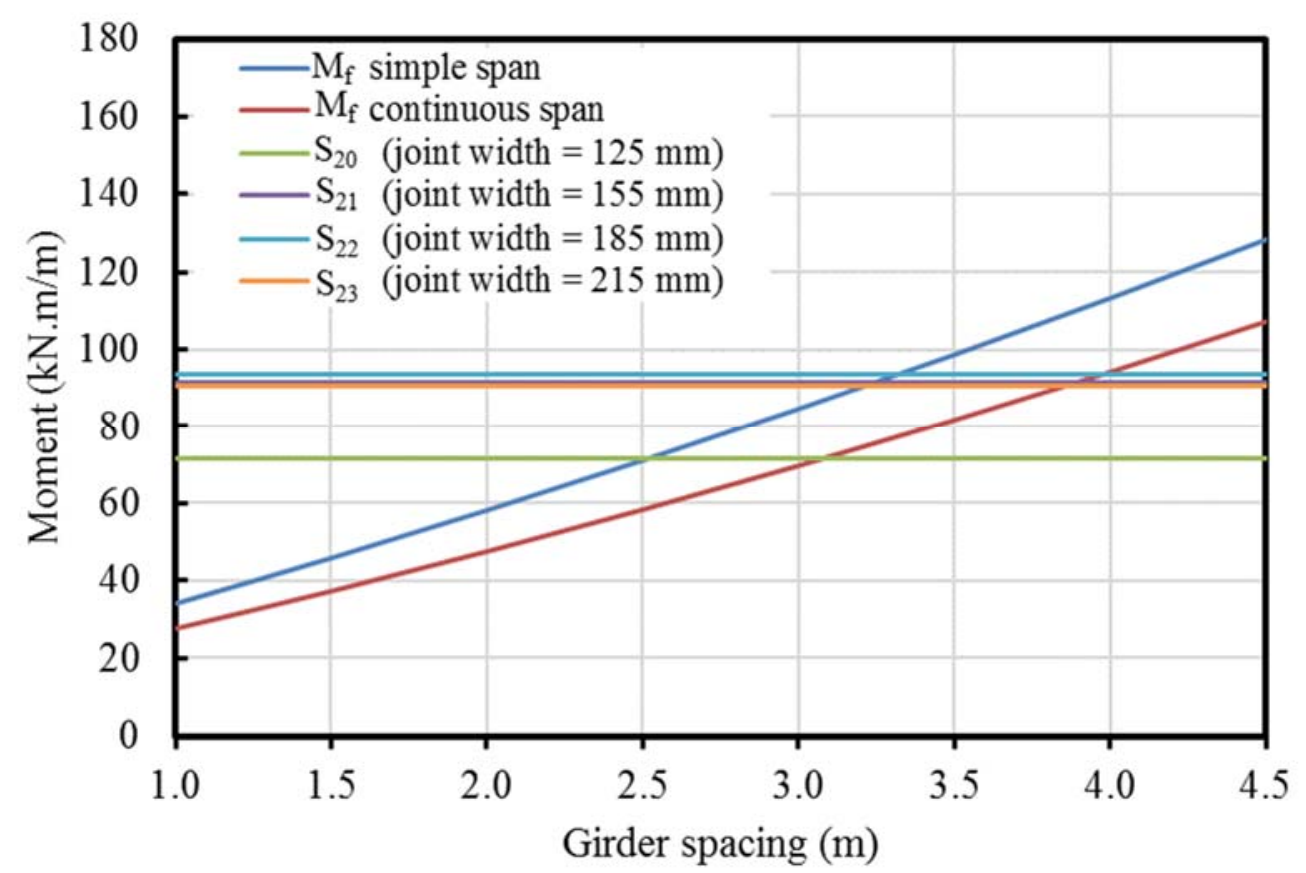

Figure 4.190 Specified maximum spacing between girders for jointed slabs in group G5 with 50 $\mathrm{mm}$ spacing between spliced bars

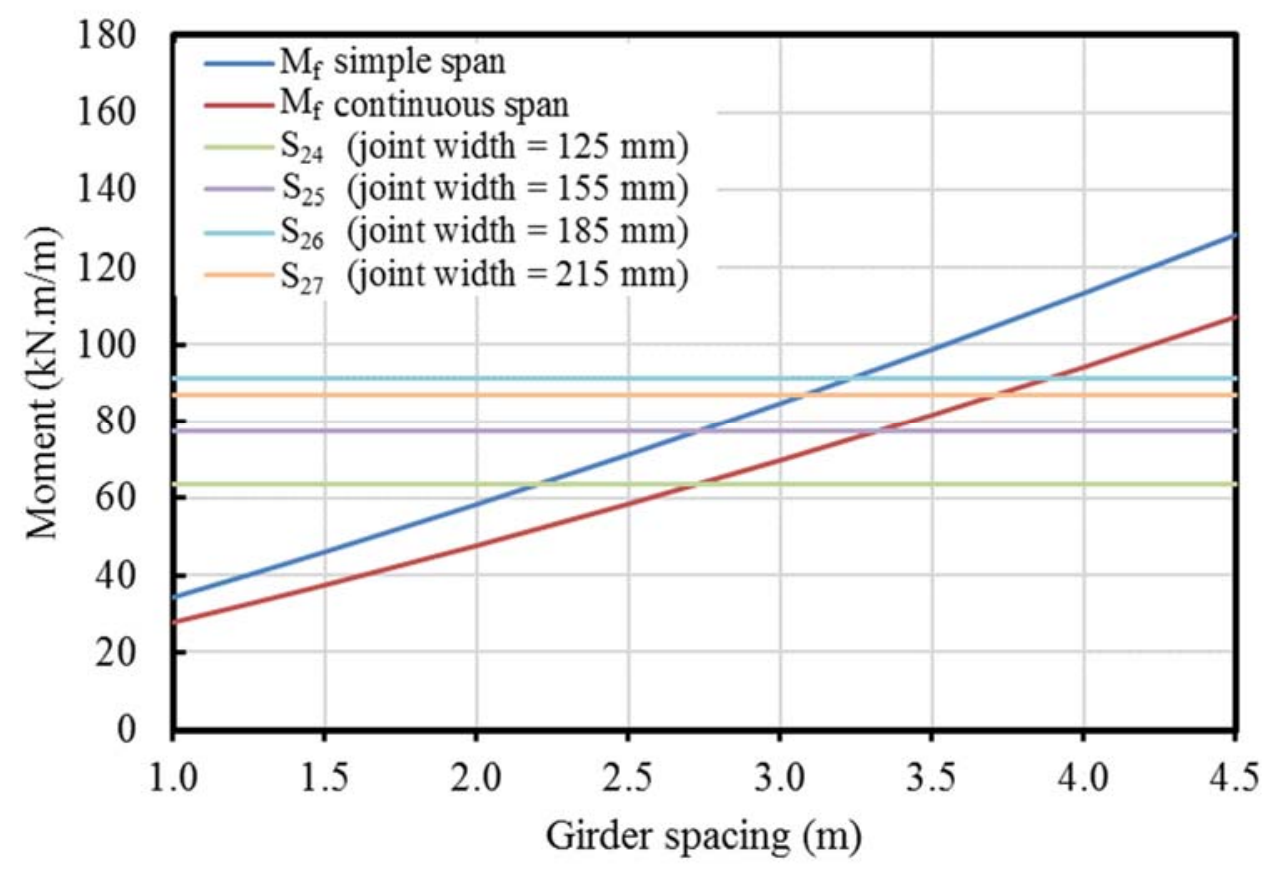

Figure 4.191 Specified maximum spacing between girders for jointed slabs in group G6 with 75 $\mathrm{mm}$ spacing between spliced bars 